UNIVERSIDAD POLITÉCNICA DE MADRID

ESCUELA TÉCNICA SUPERIOR DE ARQUITECTURA DE MADRID

Pikionis, Lewerentz, Venezia y Siza.

La experiencia como narración en ocho itinerarios

Pikionis, Lewerentz, Venezia and Siza.

The narrative experience in eight itineraries.

Tesis Doctoral

ZHANG YINGLE. ARQUITECTO 
Departamento de Proyectos Arquitectónicos

Escuela Técnica Superior de Arquitectura de Madrid

Pikionis, Lewerentz, Venezia y Siza.

La experiencia como narración en ocho itinerarios.

Pikionis, Lewerentz, Venezia and Siza.

The narrative experience in eight itineraries.

Zhang Yingle. Arquitecto

Director: Jesús Ulargui Agurruza. Doctor Arquitecto 


\title{
D.12
}

Tribunal nombrado por el Mgfco. Y Excmo. Sr. Rector de la Universidad Politécnica de Madrid, el día

Presidente D.

Vocal D.

Vocal D.

Vocal D.

Secretario D.

Realizado el acto de defensa y lectura de Tesis el día en la Escuela Técnica Superior de Arquitectura de Madrid

Calificación:

EL PRESIDENTE

LOS VOCALES

\author{
EL SECRETARIO
}


Introduction .

Chapter I.

PAVING TO THE ANCIENT SACREDNESS

Dimitris Pikionis, pathways towards the Acropolis and the Philopappou Hill

I. A SENTIMENTAL LOOK OF “GREEKNESS"

$$
\begin{aligned}
& \text {. "a man of the east" } \\
& \text {. "from the soil of the earth" }
\end{aligned}
$$$$
\text { landscaping the Acropolis }
$$

II. COMPOSE A RITUAL TRANSIT

Through a choreographed order $\S$

$$
\text { presentation of the ruin. }
$$

manifesto of the entry.

pave a "mininature".

$$
\begin{aligned}
& \S \text { Into the constructed landscape } \\
& \text {. configure a straightforward ascent } \\
& \text { approximation to a privileged plot } \\
& \text { the stepped perimeter }
\end{aligned}
$$

\section{A LAYERED APPROACH}

61. Continuity through an intense transit $\S$

$$
\begin{aligned}
& \text { truncation in the experience. } \\
& \text { an ephemeral encounter. } \\
& \text { a manifestation of distance. }
\end{aligned}
$$

$\S$ From architecture to a diverging journey . 62

. "architecture on the road" $\quad .62$ . pave a metaphorical landscape $\quad .68$ the loop that deviates

$\S$ Epilogue -

journey of expectation

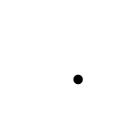

IV. AN UNFOLDING JOURNEY TO THE SACREDNESS

81. The convergence of opposing flows $\S \quad \S$ Through an abandoned trajectory $\quad .82$

$$
\S \text { Epilogue - }
$$

to create another rituality 


\section{Chapter II.}

LANDSCAPE OF REMEMBERANCE

Sigurd Lewerentz, the ceremonial routes in Stockholm and Malmö

\section{LANDSCAPE AS MONUMENT}

135.

$$
\text { the last landscape }
$$

myth in the modern cities

crisis in "the other city"

ii. Sigurd Lewerentz, revive the landscape for commemoration. 104

\section{THE SUBLIME LANDSCAPE}

\begin{tabular}{|c|c|}
\hline Two sets of narrtive actions $\S$ & $\S$ Landscape of the interior \\
\hline The landscape of remoteness. & the descent that detains \\
\hline $\begin{array}{l}\text { the Way of the Cross - . } \\
\text { articulation and deflection }\end{array}$ & an anonym \\
\hline ascent thro & way of reture \\
\hline
\end{tabular}

ascent, descent towath farewell
As, retrace the original reality

Sequential detachment $\$$

$\S$ Sentimental functionality a walk through departure a room of isolation

$\S$ Epilogue -

transit upon distance .
135.

145 .

IV. A WALK TO THE PLACE OF REMEMBERANCE

$\begin{array}{lrlr}\text { 155. } & \text { Towards the Chapel of Resurrection } \S & \S \text { Towards the Twin Chapels } & .156 \\ 155 . & \text { into the woods } & \text {.the parallel journeys } & .156 \\ 161 . & \text { the constructional differences } & \text {.transmit through tectonic approach } & .162\end{array}$

$$
\S \text { Epilogue - }
$$

the paradoxical continuity and material basis for a transit
115. a dialectic unity beyond the boundary. . architecture as monument of burial $\quad .116$ 123. 


\section{Chapter III}

\section{THE ROOTING OF DETACHMENT}

Francesco Venezia, the anomalous monuments in Belice

I. REDEEM FROM EXCLUSION

II. TOWARDS AN AUTHENTIC SITE

\section{From the underground $\S$}

multiple detachment .

into the subterranean.

\section{the construction of cannibalism}

confronting the horizon

$\S$ Epilogue -

excavation as method

III. CRITICAL SUPERIMPOSITION

207. Space for intervention: a work of motage $\S \quad \S$ The inconsistent structure

207.

213

217. where those events converge

the walk provoked by distortion

the will to connect
IV. "IN FORMA ELICOIDALE" : MOVEMENT THROUGH SENSATIONS

231.

231.

235 .

239

\begin{tabular}{|c|c|}
\hline A private journey $\S$ & $\S$ Towards the infinite \\
\hline a round trip. & . exchange of relationships \\
\hline "reposo". & the loop \\
\hline a garden of isolation. & the circulation that withdraws \\
\hline
\end{tabular}

monument for walk: from the solitary to the collective

V. CONCLUSION -

MELACHOLY, RETROSPECTION AND PERMANENCE 
Chapter IV.

THE PROVISIONAL VISUALIZATION

Alvaro Siza, ephemeral images on the paths in Santiago de Compostela and Porto

$\S$ The stratification of representation

303

The conceptual unity $\S$

$\S$ Through the absense

304

the site

architecture

the human figure

the mirror

305.

309.

bringing together the disparate.

the Orchard

the inflected responds

the Grove

the Cemetery

$\S$ Epilogue -

appreciate the accidents

§ Epilogue - A fragile invitation

$\S$ Two works

IV. CONCLUSION - CONDITIONAL UN/CONTINUITY

II. CONFIGURE ANOTHER REALITY 
ACKNOWLEDGEMENT

I have been treasured my identity as a stranger and an outsider in Spain and Europe during the seven years of living, studying and growing in Madrid and in ETSAM. To some extent it obligates me to keep a distance with what I see, hear and learn; and convinces me to accept the truth that I may never understand something what others can, just like I may find something that others can't. This nomadic perception of "I", of the context, of the things I learn and write, is such a foundation, a motivation and support that keep accompanying me to start and to finish this investigation. I write this thesis which in turn portrays me. I think it is the essential meaning of every research work, always ending up with a reflection of ourselves.

After these years, now it is a difficult time to recall all the names I should appreciate. But I have to remember professor José Ignacio Linazasoro, since this work is due in large part to his suggestive seminar on the silent European architects of 20th century.

This course inspired my thesis of Master degree on the pathways around the Acropolis by Dimitris Pikionis, which later serves as the first chapter of the doctoral dissertation. Thanks to my friends and to the professors in Spain and China, who contributed with their advices to the progress of this thesis. Especially to professor José Manuel López Peláez, whose erudition, encouragement and generous help have facilitated the chapter of Sigurd Lewerentz. To professor Luis Martínez Santa-María, his impressive work Tierra Espaciada. El árbol, el camino, el estanque: ante la casa. shows me how to perceive and think, opening the door of this writing. To Jesús Ulargui Agurruza, with his intelligence, passion and kindness sets great examples of an architect who designs, of a professor who teaches, of a tutor who guides, and of a friend whom talk with. To Qirui, thanks to her patience, suggestions, understanding, and above all, her accompany. Finally, I dedicate this book to my parents, their legacy, their endless love and selfless dedication give me the courage to face and enjoy the life. 


\section{RESUMEN}

Este trabajo de investigación recorre ocho obras de cuatro arquitectos europeos, Dimitris Pikionis, Sigurd Lewerentz, Francesco Venezia y Álvaro Siza, estableciendo análisis y reflexiones sobre cómo las herramientas de la arquitectura son capaces de articular la experiencia temporal que acompaña al visitante. Esa experiencia sobre el tiempo no solo incluye la del propio recorrido que acontece en la visita, sino que se amplia en cada uno de los ejemplos elegidos hacia una expresión temporal que relaciona la obra con su significado.

Las herramientas de trabajo de estos arquitectos varían de acuerdo a las ideas que pretenden mostrarnos. En los accesos a la Acropolis y Filipappou, los pavimentos son capaces de narrarnos mediante sus articulaciones la importancia de la historia en la cultura Helénica. En los recorridos de los cementerios de Malmö y Estocolmo existe una intermediación entre el tiempo de despedida a los seres queridos y la propia representación del curso de la vida. En el teatro de Salemi y el museo de Gibellina está presente la memoria de la transformación topográfica producida por la acción de la energía de la tierra. En las obras de Siza, la Escuela de Arquitectura de Oporto y los jardines de Bonaval, los recorridos materializan la propia experiencia perspectiva del arquitecto.

La investigación es también un libro sobre viajes y una reflexión sobre la cultura europea que tiene un deliberado interés en mostrar un amplio panorama geográfico, que incluye al paisaje nórdico, tan bien representado por Lewerentz en sus cementerios la influencia de oriente presente en la obra de Pikionis; la importancia de la tradición Mediterránea en las obras de Venezia y la cultura atlántica presente en la obra de Siza.

En estos ocho recorridos se describe el lenguaje narrativo de estos itinerarios y su carácter monumental, estableciendo una continuidad entre historia y territorio Este trabajo de investigación nos muestra cuánto la narración temporal y su diseño ha impregnado el discurso arquitectónico moderno, mostrándonos algunas de las experiencias arquitectónicas de mayor valor poético de la posguerra.

\section{ABSTRACT}

This investigation retraces eight works by four European architects, Dimitris Pikionis, Sigurd Lewerentz, Francesco Venezia and Álvaro Siza, establishing analysis and reflections on the mechanisms that architects have applied to make architecture capable of articulating temporal experience that accompanies the visitor. This experience of time not only includes that acquired during the promenade of the visit, but also expands in each of the selected projects and constitutes temporary narrative that relates the work to its meaning.

The research tools vary according to the ideas that the works intend to show. In the accesses to the Acropolis and the Philopappou hill, pavements are able to tell the important articulation between Attica landscape and the history of Hellenic culture. In the routes of the cemeteries in Malmö and Stockholm appear an intermediation between the farewell to the loved ones and the representation of the course of life itself. The memory of topographic transformation produced by telluric power inside the earth is presented in the Salemi theater and the Gibellina museum. In the works of Siza, the School of Architecture of Porto and the Bonaval gardens in Santiago de Compostela, the architect's own perspective experience is materialized by the fleeting images on the pathways.

This is also a book of trips and reflection of European culture, which has a deliberate interest in showing a wide geographical panorama, which includes the Nordic landscape, so well represented by Lewerentz in his cemeteries; the influence of the East presented in the work of Pikionis; the importance of the Mediterranean tradition in the works of Venezia and the Atlantic culture demonstrated in the work of Siza.

These eight routes describe the narrative language of these itineraries and their monumental nature, establishing a continuity between history and territory. This investigation shows us how much the temporal narrative and its design has permeated the discourse of modern architectural, presenting some of the most poetic architectural experiences of the postwar period. 


\section{INTRODUCTION}

Within memory

"And I come to the fields and spacious palaces of my memory, where are the treasures of innumerable images, brought into it from things of all sorts perceived by the senses. There is stored up, whatsoever besides we think, either by enlarging or diminishing, or any other way varying those things which the sense hath come to; and whatever else hath been committed and laid up, which forgetfulness hath not yet swallowed up an buried. When I enter there, I require what I will to be brought forth, and something instantly comes; others must be longer sought after, which are fetched, as it were, out of some inner receptacle; others rush out in troops, and while one thing is desired and required, they start forth ... These I drive away with the hand of my heart, from the face of my remembrance; until what I wish for be unveiled, and appear in sight, out of its secret place."

Confession - book X - chapter VIII, Saint Augustine of Hippo, 397 AD - 400 AD

St Augustine's remark about memory not only explains its formation in terms of transformation from immediate perception of real images into stratified deposit in our mind, but also describes reminiscence as a traceable process through going into and out of our interior world. His meditation, which played a fundamental role in the establishment of the concept of temporality in the Christian world seventeen centuries ago, has been taken as a recurrent reference by architects who regard the coexistence of instant and permeance as one of the fundamental qualities in architectural space Augustine's words also suggest how our interior world is structured through a constant and unconscious accumulation of independent "storages", in which fragmentary images of the past are kept. It relates recollecting - the mental pursuit - to a penetrating movement from the exterior into the interior domain, in which one has to find the location of particular images and to extract the specific message which he/she is tracing

\section{for from the rich resource.}

The opposing reflections of "spacious palaces" and "secret place" suggest the duality of the treasures left by the passage of time in our mind. On the one hand, our mind constantly receives fragments from sensorial perceptions although most of them would finally fade to oblivion; on the other hand, the shining episodes, which always respond when they are called, would stand out from the rest, marking the retracing process. The event which had taken place in reality, now deposited in memory, is brought up by a series of mental activities. The whole process is interpreted according to the temporalspatial structure of storytelling, following a communicative aim, which involves spatial character that we perceive from the outside and tangible world, the perception and movement that we apply as instrument, and the introspective landscape formed in ou mind.

Roland Barthes emphasizes that the storytelling/narration exists in a variety of media in the world to "accommodate man's stories". Following his words "the function of narrative is not to 'represent'; it is to put together a scene which still retains a certain enigmatic character for the reader, but does not belong to the mimetic order in any way. The 'reality' of a sequence does not lie in the 'natural' order of actions that make it up, but in the logic that is unfolded, exposed, and finally confirmed, in the midst of sequence" ${ }^{2}$, we understand narrative as not only the story itself but a strategic system

1. Roland Barthes, "Introduction à l'analyse structurale des récits", Communications, 8(1) (1966):1-27, translated as Introduction to the Structural Analysis of Narratives, in: Roland (New York: 1977), 237.

2. Barthes, Introduction to the Structural Analysis of Narratives, 271. 
of composition to determine the sequence of episodes of a story to make it readable. In the same sense, considering the constructed space as medium to present a group of messages of topography, memories and spatial atmosphere, it can verify the fundamental character of narration in architecture. In "Time and Narrative", Paul Ricoeur incorporates temporality and spatiality into architecture through a narrative structure: " $i$ is possible to found an absolutely primitive reason to not abide by the simple realization of difference between storytelling and architectural design, this reason is the fact that neither the time of tale nor the space of architecture are simple portions of universa time or geometrical space". AAnd the importance of composition of sequences in the experience of constructed space is emphasized by Le Corbusier: "Architecture can be classified as dead or living by the degree to which the rule of sequential movement has been ignored or, instead, brilliantly observed".

Therefore, the initial interest of this investigation lies in the memory and narration about time in architecture, as well as the bodily movement that spectators apply as an interactive and psycho-physical tool to participate in and to read the story created by both architect and architecture itself. It is important to note that the study does not focus on the concept of time nor the spatial rhetoric. The objective is to analyze what are the design tools that architects apply and develop to produce narrations of time through itinerary. The work is established on the basis of three questions: first, what is the concept of temporal narration in space; second, how to make the temporal narration readable and perceivable in architectural space; and the third, how do people

3. Paul Ricoeur, Time and Narrative (Chicago, IL: University of Chicago Press, 1984), 9.

4. Le Corbusier, Stanislaus Von. Moos, and Arthur Rüegg. Le Corbusier before Le Corbusier: Applied Arts, Architecture, Painting, Photography, 1907-1922 (New Haven: Yale University

Press, 2002), 41. perceive this temporal narration. The first and the third question respectively refer to the objectivity of constructed space and people as subject in the space. And itinerary wil answer the second question. By arranging a series of images along a designed trajectory, architects work to edit the order according to which evocative elements appear and control the rhythm of people's movement, creating the narration and guiding their perceptions.

The time-consciousness structure created by Edmund Husserl gives an importan guidance of this investigation aimed at elaborating an architectural mechanism to establish relationship between individual perception and the given narration. In his serial study (1904-1935) published in The phenomenology of internal time-consciousness, Bernau Manuscripts and C-Manuscripts, Husserl developed a threefold-structure, describing our consciousness for the present that takes place in a very short duration is composed of "primal impression", "retention" and "protention". This structure defines a process closely attached to people's instant action and provides an inspiring and effective method to alienate the immediate consciousness of the subject from the objective category, in which time and space would lead to a more durable consciousness such as recollection and expectation.

Considering narration as a method to unfold the temporal-spatial quality of architecture, Sophia Psarra's remarks can be seen as another guidance to the study on this term:

"Narrative is often seen as a form of representation bound with sequence, space and time (...)A narrative, therefore, is not only the content of the story that is narrated, or

5. Dan Zahavi, "Inner (Time-)Consciousness," in OnTime-New Contributions to The Husserlian Phenomenology of Time, ed. D. Lohmar, I. Yamaguchi (Dordrecht: Springer,2010), 319-339. 
the way in which it is interpreted by readers, but also the way in which it is structured and presented to an audience by an authorial entity. The relationship between narrative structure, perceptual experience and representation is the aspect of narrative that is most relevant to architecture."

In addition, although this dissertation will not detain us at linguistic analysis, its structure is established with the help of Roland Barthes' three-level stratification of subjects, suggested in his "An introduction to the structural analysis of narrative", which allows to describe a narrative system according to a sequential succession: first, the level of functions (niveau des fonctions), studying the narrative units and their relationships; second, the level of actions (niveau des actions), studying the sphere of actions that the characters participate in; and the third, the level of narration (niveau de la narration), studying the relations between narrator, author and reader.

In determining observer's action and narrative structure, selection of architects and their work in this study is according to a hypothesis on a wide range of time and the various concepts of temporal narration that architecture is able to present. The investigation is structured around four European architects and their eight architectural and landscaping work:

- The pedestrian intervention and landscape reformation around the Acropolis and Philopappou Hill by the Greek architect Dimitris Pikionis;

6. Sophia Psarra, Architecture and Narrative. The Formation of Space and Cultural Meaning (New York: Routledge, 2009), 14
- The Stockholm Woodland Cemetery and Malmö Eastern Cemetery by the Swedish architect Sigurd Lewerentz

- The Museum of Palazzo di Lorenzo in Gibellina Nuova and an Open-air Theatre in Salemi by the Italian architect Francesco Venezia;

- The Faculty of Architecture of Porto University and Santo Domingo de Bonaval Park in Santiago de Compostela by the Portuguese architect Álvaro Siza

Despite of the geological differences and distinct generations of these masters, it is curious to see their intersections in academic researches and professional work. Peter Smithson and Alison Smithson considered Lewerentz, Pikionis and Konstantin Melnikov as the first generation of the "silent architects", by explaining the title: "It is not that the silent architects say nothing, but it is what they do, yet are - by the complexity of invention - unaware of doing and therefore cannot talk about that shifts the tide of architecture."” PProfessor José Ignacio Linazasoro involves the Pikionis and Lewerentz, together with the Dutch Hans van der Laan in the anthology "Otras vías", "se refiere a estos arquitectos menos conocido por inscribirse en vías alternativas a las convencionales de la modernidad [...] Todos ellas constituyen una auténtica familia espiritual". ${ }^{8}$ Not to mention Francesco Venezia and Álvaro Siza have a closer relationship. They worked together in "laboratorio 80 ", a group established to promote

7. Alison Smithson, and Sigurd Lewerentz. Sigurd Lewerentz: 1885-1975: The Dilemma of Classicism. (London: Architectural Association, 1989.), 5.

José Ignacio Linazasoro, Otras Vias: Pikionis, Lewerentz Y Van Der Laan. (Buenos Aires: Nobuko, 2011), 6. 


\section{CHAPTER \#}

MONOGRAPH

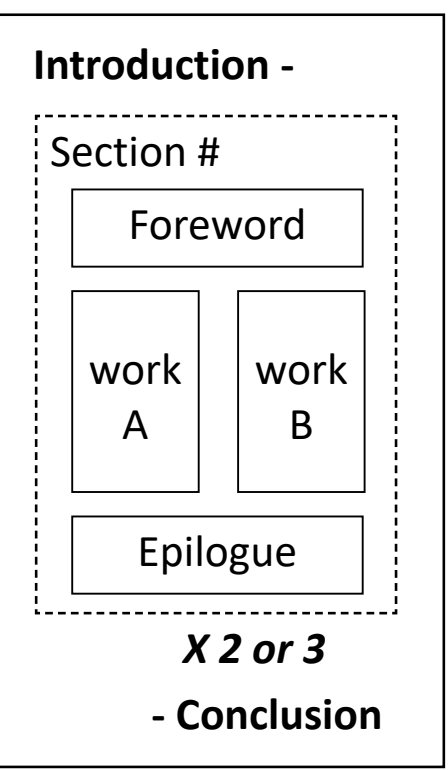

Fig a. Sturcture of one Chapter/Monograph.

the reconstruction of the towns destroyed by the earthquake in 1968 in Belice valley, Sicily. Both of them have realized projects in the same town of Salemi, where Siza reorganized the city streets and renovated the 17th-century Chiesa Madre, and Venezia built an Open-air theatre upon the ruins of an old convent on the margin of the town. Siza also wrote a preface to the monograph on Venezia's works, published by Gustavo Gili in 1988.

Though the dissertation is not to study the pedigree of these architects as they are not bound to each other by any theoretical structure, these connections do provide a way to delve into some common characters in their works which, despite of their cultural and historical differences, can be experienced during the visit. All the projects present progressive way to achieve temporal-spatial narration. It starts from the establishment of relations between topography, landscape and preexisting elements on site, giving rise to a context to evoke memory of the past. Then, space for particular events are created as outstanding points alongside the journey, accommodating visitors into specia atmosphere. Finally, the designed itinerary, the orchestration of all the events, creates bond between walker/reader and space/narration by determining rules of walk.

The configuration of spatial narration in architecture, which is produced by sophisticated transformation and organization according to sequential rules sees a process that interprets Barthes' three levels and accommodates them into the design of a physical environment. In the same sense, this thesis is narratively structured. It consists of four chapters as monographs of the four architects. Apart from the general introduction and conclusion, each chapter contains two or three sections made up of two individual and parallel columns dedicated to the selected works. (Fig.a) (In the case of Pikionis, since the architect applied different strategy to design the bidirectional ascents to the
Acropolis and Philopappou hill, the two pathways are studied as two individual cases) Every column is developed by a series of topics: the "site" is a study of the relation between the project and the ground, as well as the strategy applied by the architect to intervene in the original context; the "constructive strategy" analyzes configuration of particular space to create specific and outstanding episodes along the journey; and the "itinerary" focuses on the design strategy of pathway which determines the order of those episodes, the rhythm of movement, as well as the experience that spectators have acquired during the visit.

The independency of study on each work of the same author is protected in order to avoid cross-reference, meanwhile, then, foreword and epilogue of each section involve the two works into the architect's thought on one topic. This writing structure that imitates a narrative system allows an individual and simultaneous read of the selected work, as if it was reflecting architects' mechanism to develop several projects at the same time. It permits a research structured by eight individual case studies, making it possible to represent any relationship between the projects rather than the architects in a spontaneous way.

The challenge of this investigation, which also would be the most fascinating aspect in the presented book, lies in the organization of a wide range of time and the various concepts of temporal narrations in such a broad geographical panorama, from the north to the south, from the Atlantic to the Mediterranean. Each work in this dissertation involves a static condition of place that tells the permanent quality of architecture, the ephemeral rhythm of movement and perception of individual person according to a linear timeline, and personal memory which has its own structure and is not necessary to be linked with the chronological sequence of time of the real world. According to 
Juhani Pallasmaa's note: "We have a mental need to grasp that we are rooted in the continuity of time, and in the man-made world it is the task of architecture to facilitate this experience", 9 this investigation aims to analyze the role that architecture plays in the process of establishing the continuity of time between the exterior and the interior world.

The four architects work with ruins and topography. They combine new materials with old ones through creative manners, and generate meanings that relates construction and destruction upon or inside the ground. From the discrete images we find a similar character inherent in memory and ruins. They are vestiges from deconstruction of a unity and share a fading quality. Georg Simmel says: "every ruined object infused with our nostalgia." He continued to delve into the nature of architecture, "the ruin strikes us so often as tragic - but not as sad - because destruction here is not something senselessly coming from the outside but rather the realization of a tendency inherent in the deepest layer of existence of the destroyed" ${ }^{10}$ Hence, reorganization of old materials manages to reinforce the identity of a place as well as to assemble the fragments of memories, and in this way, architectures are placed in continuity and polysemy.

Apart from the general approach to evoke memories, or the particular sense of nostalgia the various properties of the preexistences, the different interpretation of those old traces in the projects, and the relations between constructed space and visitors, are the crucial factors for the architects to conceive temporal dimension in specific work.

9. Juhani Pallasmaa, The Eyes of the Skin. Architecture and the Senses (Chichester: Wiley\&Sons Ltd, 2005), 32

0. Simmel, Georg, Two Essays: The Handle, and The Ruin. (New York: Hudson Review. 11:3, 1958: Autumn), 377.
The sacred monuments and the hilly landscape established a grand backdrop of ancient Hellenic glory for Dimitris Pikionis' intervention - a commission follows an urgent need of a new nation to reconstruct its identity. The architect, as eloquent proponent of "Greekness", collected stones from the destroyed Byzantine churches and houses, mingled them with new materials in a creative and metaphysical manner to create two ascents amidst the time of history.

The outstanding mound in front of the forest and the ancient tombs on the ridge in Lewerentz's cemeteries combine burial precincts with the Nordic landscape and funeral tradition. Through rediscovering the relation between human and the nature, and infusing the space with metaphoric meaning of life circle, Lewerentz interpreted the spirit of transcendence by the means of ritual movement towards the farewell from natural environs to the commemorating plot.

Francesco Venezia's buildings see two concepts of time. The museum and theatre deeply rooted into the earth give metaphor of the subterranean world, suggesting the long process of topographical transformation. Meanwhile, the remounted materials of collapsed buildings represent the telluric force in new architecture, recalling the memory of seismic catastrophe.

The tension between new constructions and old ones in Siza's architectures suggests his idea to keep a delicate equilibrium with the original condition of the site. He creates the sequence of movement in relation to his sketches. The changing points of view and enhanced perspective give rise to the perceptions of a series of fleeting images that always accompany the spectator. 
Study of itinerary in these projects focuses on the design strategy that the architects use to define order. This order works, on the one hand, as medium that relates the individuals with the outside world, as Merleau-Ponty pointed out, "It (Time) is the landscape as it rolls by for the moving observer. [...] It arises from my relation to things" ${ }^{\text {"11 }}$; on the other hand, as the key element that mediates between static narrator and observer in motion, showing how the narration is presented.

"Time is not a phenomenon, but the order of phenomenal succession and change Buildings and settlements, however, are static, apart from certain mobile elements of secondary importance. Nonetheless man has succeeded in "building" time, by translating basic temporal structures into spatial properties. Primarily life is "movement", and as such to possesses 'direction', and 'rhythm'. The path is therefore a fundamental existential symbol which concretizes the dimension of time. Sometimes the path leads to a meaningful goal, where the movement is arrested and time becomes permanence., ${ }^{12}$

Norberg-Schulz considers bodily movement as a bridge that connects properties of time and space. This concept is applied by the four architects as a design strategy to lay out itineraries, conforming pathway with topography, natural elements and preexisting things on site. Pikionis uses sophisticated pavement to transform the ascents into metaphysical puzzles meandering the sacred hill. The transcendental atmosphere inherent in Lewerentz's cemeteries is experienced when ascending and descending the Scandinavian landscape. The spiral route that runs through Venezia's architectures

11. Maurice Merleau-Ponty, Phenomenology of Perception an Introduction (London: Routledge, 1962), 478

Christian Norberg-Schulz, Genius Loci: Towards a Phenomenology of Architecture (New York: Rizzoli, 1996), 56 inherits from Giuseppe Terragni and Le Corbusier. It suggests a journey from the subterranean domain to the upper world, or the opposite, giving rise to the dialectic of rooting versus detaching. As for Siza, the bidirectional courtyard that calibrates studio towers of the school, and the zig-zag pathways ascending the civil park, produce an accommodating perception of the continuity of movement and the discontinuity stemmed from spatial composition.

Flora Samuel has noted in her book "Le Corbusier and the Architectural Promenade", that "the promenade would be designed to resensitise people in the process of savoir habiter, knowing how to live". ${ }^{13}$ Indeed, pathways in these projects were organized as internal parameters that determine the way to read the space, and place observers walkers/readers at an intermediate stage between imagination and discipline defined by chronological timeline. These designed itineraries indicate that the spatio-temporal narrative must be read as much by the body as by the eyes, reminding of Le Corbusier's words: "You enter: the architectural spectacle at once offers itself to the eye. You follow an itinerary and the perspectives develop with great variety, developing a play of light on the walls or making pools of shadow". ${ }^{14}$

The main body of the presented dissertation is developed by the analysis on the selected projects on two aspects: the temporal narrative and the itinerary as mechanism to complete the storytelling structure. Apart from this, an order which will structurally

13. Flora Samuel, Le Corbusier and the Architectural Promenade. (Basel: Birkhäuser, 2010), 4.

14. Le Corbusier and Pierre Jeanneret, Oeuvre Complete Volume 1, 1910-1929 (Zurich: Les Editions d'Architecutre, 1995), 60. Originally published in 1937. Translation from T. Benton, The Villas of Le Corbusier 1920-1930 (London: Yale, 1987), 4. 
link the four chapters is established during the writing process. From the approximation to the ruins of sacred monuments, the ascent and descent towards farewell, to the vestiges that evoke the brutal event and the instant rhythm of the individuals, a reducing temporal distance between narrated objects and visitors as subject in the space suggest the trace by which the relationships between the architects and their projects are able to be consolidated within a same context. It hypothesizes that temporal narration and itinerary can be the point of departure of architecture design from which to develop the whole program. By creating spatial monumentality and defining rituality of walk, the deep connection between architecture, ground and collective memory are established. The temporal-spatio narration in these works of those masters present both fixed bond and the continuity between architecture and territory, suggesting a possible mechanism to resist the universal and fragmentary meanings which are constantly growing in today's architecture. 
Chapter I .

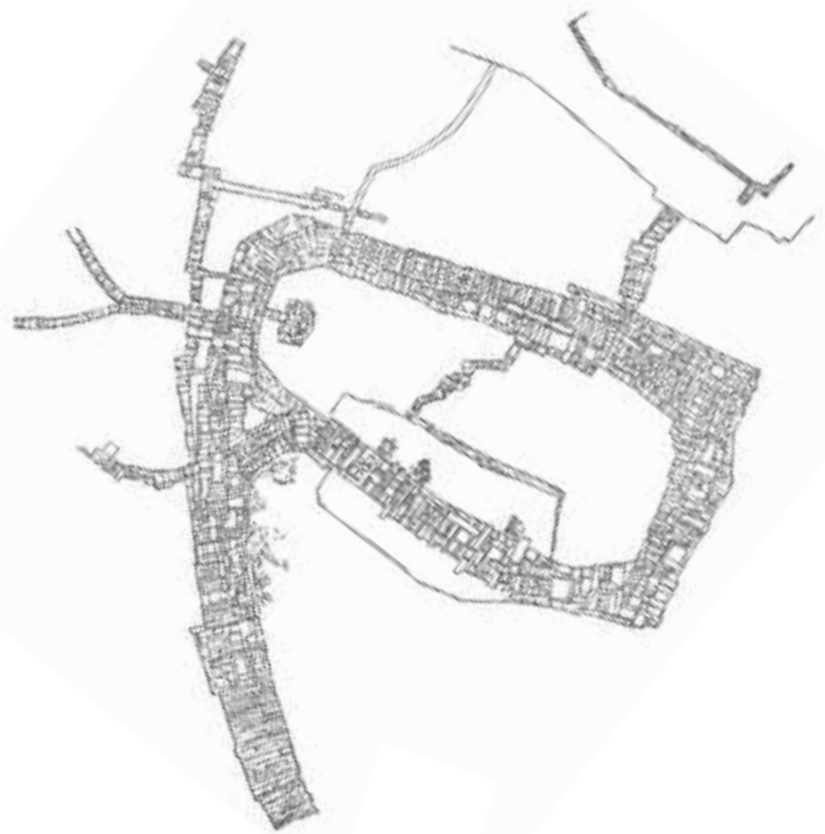

PAVING TO THE ANCIENT SACREDNESS

Dimitris Pikionis, pathways to the Acropolis and the Philopappou Hill 

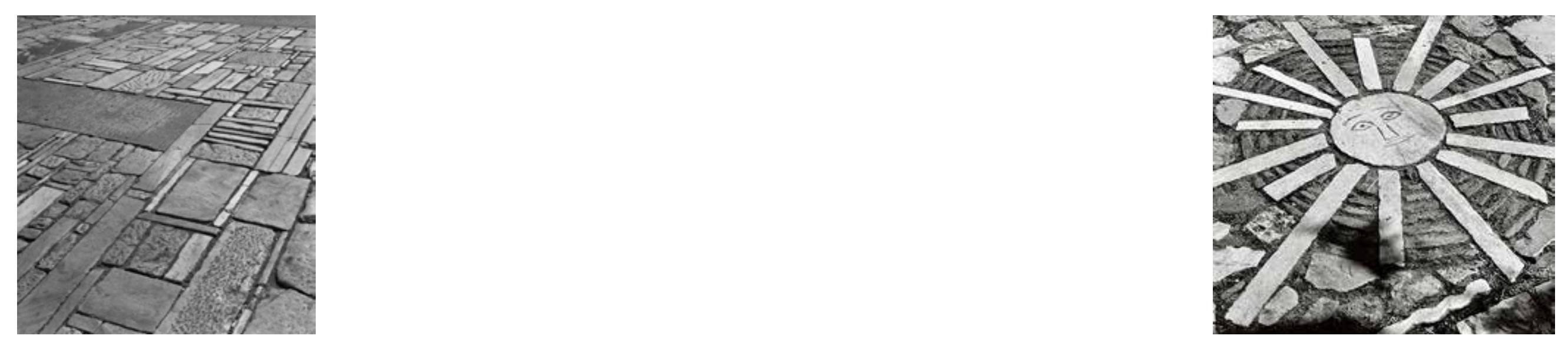


\section{A SENTIMENTAL LOOK OF "GREEKNESS"}

. "a man of the east"

Born in Piraeus, a port city in Greece, Dimitris Pikionis (1887-1968) was of the generation that saw an urgent need of a new nation to reconstruct its identity among the magnificence of Byzantine Empire, the influence of the European Enlightenment and the subsequent trends of nationalism. In the field of architecture, the appeal of national consciousness led to the adoption of Neo-classicism in the early 20th century through evoking the memory and qualities of Hellenism, meanwhile, the vernacular archetypes which had developed under Ottoman rules was abandoned.

However, as an eloquent proponent of "Greekness", Pikionis explored its expanse by turning to the folk traditions for inspiration and bring them to bear on the development of distinctively Greek architecture. Such practice placed himself at an eccentric position that was out of the limit of conventional Modern Movement led by the masters of the same generation, and was deflected from ambitious renaissance which was under way in Greece. It was this marginal way that enabled him to search for the "Greekness" which moved along interconnecting Eastern and Western corridors.

"Between Phrygia and Persia, Caria, between China and India you make out the lurking unity but also the lurking difference. Between East and West, North and South you can tell the difference and the mythical identity. This constant sameness was foundational. Differences were insignificant, deep and internal identity (was) essential.".15

15. Dimitris Pikionis, "Autobiographical Notes." in Dimitris Pikionis, Architect 1887-1968: A Sentimental Topography, (London: Architectural Association, 1989), 34
Professor Alberto Ferlenga points out that it was Pikionis' understanding and encompassing of multiple cultures that gave him a broader horizon which allowed him to search for the authentic spirit of his nation beyond barriers and limits: "Pikionis is attracted by the plurality of traditions that have helped to establish a culture of unusual importance as the Greek one and to shape a common Mediterranean land, that is the cradle and the background of universal myths." ${ }^{16}$

His belief in universal unity, the continuity of time and the convergence of conflicts may suggest the influences from Neoplatonism, since he was friend and reader of philosopher Yannis Theodoracopoulos. The concept was also related to his interests in Greek literature, music, and above all, his lifelong enthusiasm for painting. After graduating from Athens Polytechnic University on civil engineering in 1908, he moved

16. Alberto Ferlenga, "Road of stones, Places of dreams, Two Dimitirs Pikionis' works in 16. Alberto Ferlenga, "Road of stones, Places of dreams, Two Dimitirs Pikionis" works in Athens," in Otras vias: 1 Homenaje a Lewerentz = Other ways: 2 Homage to Lewerents.
José Linazasoro, Ignacio (Colegio Oficial Arquitectos Castilla y León Este, 2005): 28.

Pikionis' meditation on the eastern motif should be read together with the social background during his period. From the beginning of 20th century, Oriental motif and especially the Japanese art and architecture had been introduced to Europe and begun to have a rising influence on the western world. In the field of architecture, among various of publications, Franz Adolf Wilhelm's Das Japanische Haus (1901), Bruno Taut's serial study on the Katsura Imperial Villa, Richard Neutra's Über das Japanische Haus (1931), Tetsuro Yoshida's Japanische Architektur (1952), Walter Gropius' essay about Kenzo Tange, decanted the techniques and metaphorical expression in traditional Japanese architecture and garden, and presented the exploration initiated by those architects of the modern generation. 


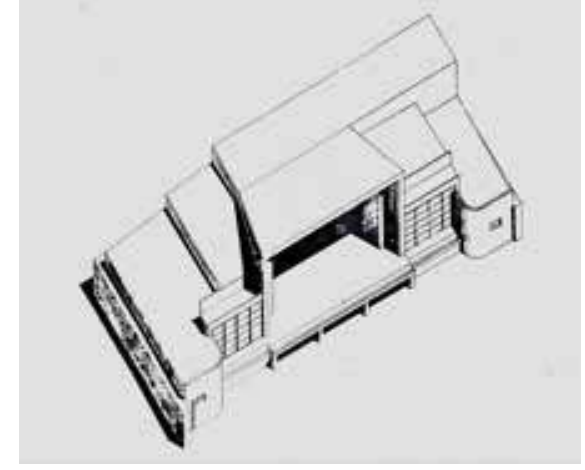

Fig 1.1. Athenian Open-Air Theater design.

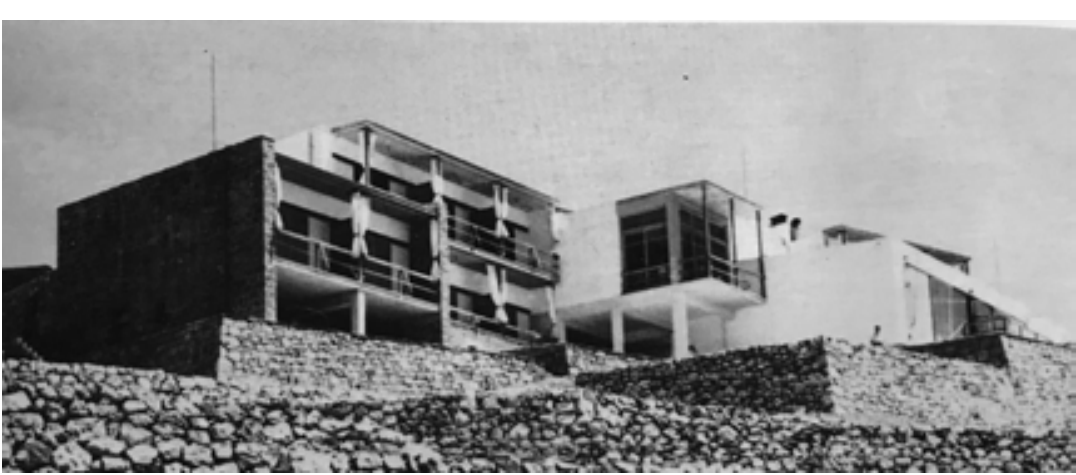

Fig 1.2. Xenia hotel.

to Munich to study painting. On seeing the works by Cézanne, young Pikionis was fascinated by the French artist's knowledge of traditional art of East Asia, especially the Japanese landscape, which took him away from the "ideals of the West".

As a painter prior to an architect, Pikionis depended much on painting to conceive space. His self-training in the techniques of Cézanne, inspiration from East and Byzantium art made him to look for a symbolic idiom excelled in spirituality and its interpretation within the Western context. His remark indicates the intention to achieve a fusion of the two worlds while confirming his own identity:

"Someone said correctly that the trajectory of the Greek nation will depend on our responsible position between East and West. I will add: Also, on the suitable composition of antithetic currents in a new form. I could analyze how this problem is presented in architecture. But suffice it to say here that I am a man of the East."

Pikionis started his architectural training in the atelier of French architect Chifflot during 1909-1921, then he devoted most of his time to architecture because of practical problems such as economic reasons. However, there is no doubt that the Oriental aesthetic had left a fundamental and lasting influence in his design. In fact, an ascent of echoes from the remote world can be traced in his following professional practice: it first rose from the Athenian Open-Air Theater (1933), (Fig1.1) developed in several houses, the Xenia hotel, (Fig1.2) and the restoration of the San Dimitris Loumbardiaris Church on the side of the pathway up to the Philopappou Hill (1954-1958), and came to its crest in his last and less known work, the Children's playground in Filothei built between 1960 and 1965. (Fig1.3)
Pikionis' chase for the combination of the West and the East lends his architectures much of their dialectic: The composition is governed by geometry that conveys a universal manner, but at the same time the spatial unconscious transmitted by unpretentious architectures, resulting from the blurred disciplines between artifacts and natural things, between new constructions and old ruins, reveals a design capable of representing Eastern philosophy.

\section{"from the soil of the earth"}

“He: I don’t know why you attach so much importance to this building.

I: The significance of buildings does not stem from the simplicity or complexity of the solutions they contain. A simple plan is often more difficult than a complicated one.

Once, I saw the two domes of a country chapel rising in a waste place below a line of hills. There could have been nothing simpler in the emptiness of the landscape. But how rich that simplicity was.

I went closer to see it, inside and out. Allow me to assure you that I wanted not more than to be able to build something which was a fraction of that astounding simplicity, so plain and yet so rich in results, lust like the simplicity of the distant line of the hills in the landscape.

I was anxious to build a chapel like that: nothing simpler, and nothing more difficult. How much hidden glory there was in that waste place.

So what I wanted was that everything you see- what you called a stark building, 
and that spoil, and this bare mountainside, and this passing flock of sheep, and the light floating clouds, and the evening sunshine- to look like a single thing. It is this consubstantive nature, the work of God, that humble man must imitate in the inner essence of his work, so as to elevate in to the consubstantive unity of the cosmos. Do you see?

And then there are the words of Aristophanes which you quoted: he talks of the $\gamma \pi \gamma \varepsilon v \varepsilon \zeta \varphi v 0 \pi \mu \alpha$. which means the breath that emerges from the soil of the earth."

Contemplating Pikionis' poetic and sensitive text, we would approach to the root of his ontic thought on matter's specificity which represents the "thingness" and eternity of matters. This cognition is inseparable from his insistence on simplicity on construction and the interdependence of Greek culture and landscape. It represents the essence in most of his works involving the topography, natural elements, ruins and monuments, and pathways throughout the place.

There is no doubt that Pikionis' incessant practice on art helped him to perceive and contemplate the world from artist's eyes and mind. In his "Autobiographica Notes" 19 , the architect recalls his childhood when the routine walk with his sister and grandmother over the rocks along the coast gradually formed an image in mind of the

18. This short text named "In a waste place. An interior dialogue." is extracted from Pikionis notes for the inagut "ech to the Academy of Athens entitled "The Project", which was

as vias: 1 Homenaje a Lewerentz $=$ Other ways: 2 Homage to Lewerents. ed. Jose

Linazasoro, Ignacio (Colegio Oficial Arquitectos Castilla y León Este, 2005): 49.

19. Dimitris Pikionis, "Autobiographical Notes," 34

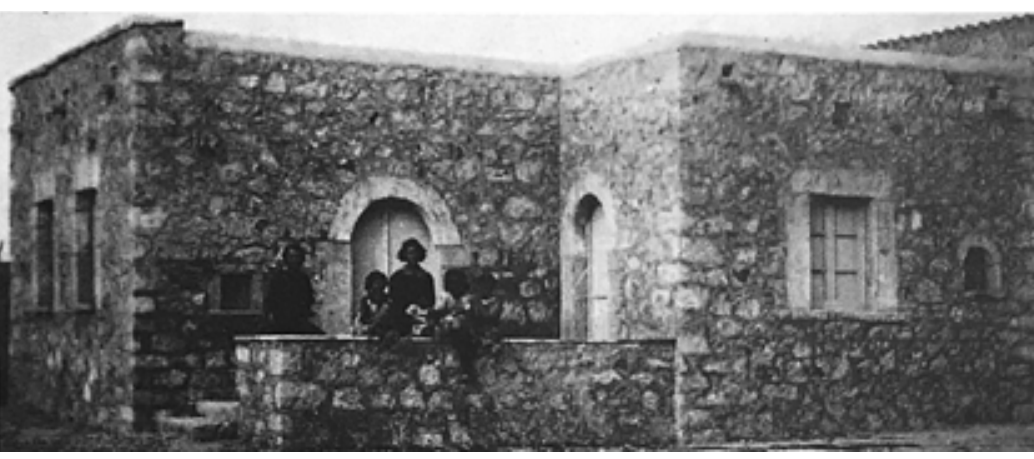

Fig 1.4. Moraiti house, elevation and photo, Pikionis.

spirit and history of the soil from his own land. Later, in "Sentimental Topography", Pikionis explains that nothing is individual but a partial component of a total harmony The silhouette of every stone and leaf, the sound of stream and children's voice at play possess their own position and order under the law of the nature, thereby being indispensable parts of the complete landscape of the universe.

Pikionis ended the essay by saying: "All things are interconnected, for they are al affected and changed by each other. We can apprehend one thing only through the intermediary of everything else. ${ }^{20}$ His cognition of a world where everything is united by undecipherable connections is reflected in Auguste Choisy's discussion in "The Picturesque in Greek Art: Asymmetrical Parties, the Ponderation of Masses" in his Histoire de l'architecture. The architecture historian observed the "Picturesque" quality in the layout of Acropolis, as one of the principles that characterized Greek architectures, where "nothing appears more irregular than this plan; yet it presents a balanced ensemble, where the symmetry of the masses is associated with the most original variety of details." ${ }^{21}$ In his lecture entitled "Changing Times", Alberto Ferlenga also pointed out that, rather than the Romans who built by means of "bulldozing the terrain", the Greeks treasured more the pre-existing elements on the sites and their structure and composition. This preoccupation gave them capacity to cast buildings in the complex environs in order to generate a sensitive relationship with everything around.

20. Dimitris Pikionis, "A Sentimental Topography," in Dimitris Pikionis, Architect 1887-1968: Sentimental Topography, (London: Architectural Association, 1989), 69.

21. Auguste Choisy, Histoire de l'architecture (Paris: Gauthier-Villars, 1899), 144 

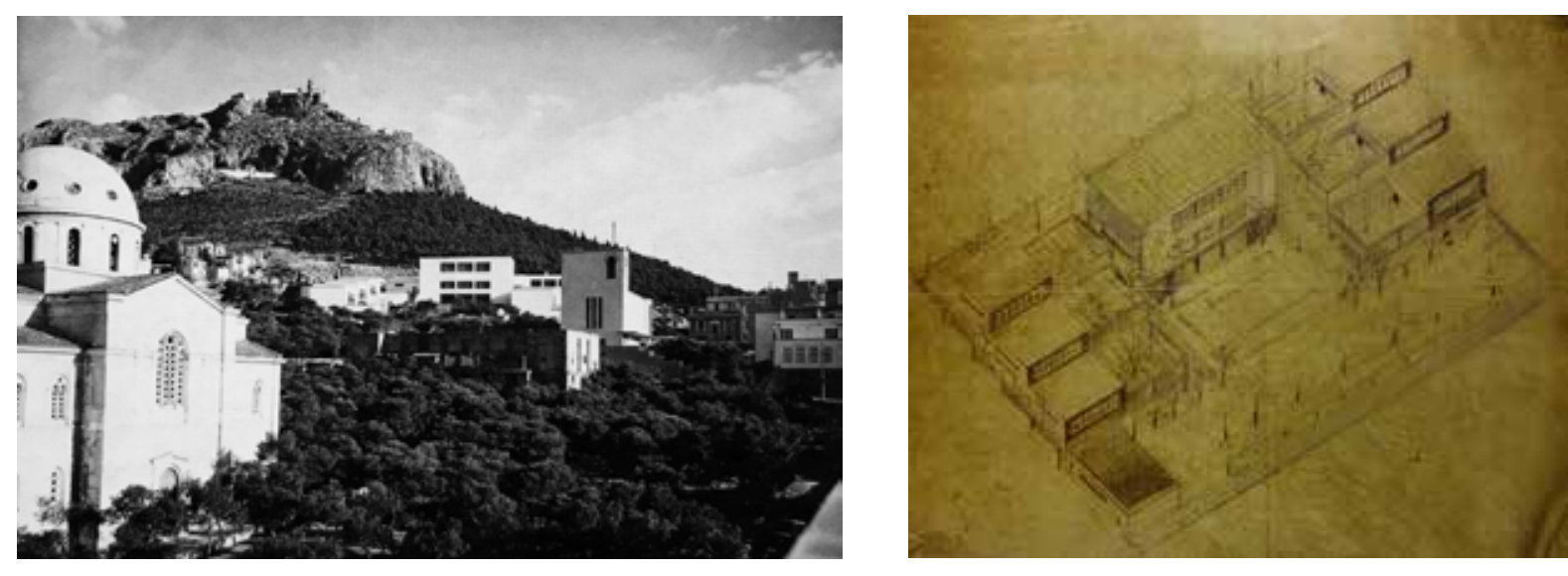

Fig 1.5. Lycabettus Primary School and study sketch.

Following the belief of his ancestors, Pikionis found his own way to develop modern Greek architecture by turning to local materials and techniques, "rather than dedicating himself wholly to the classical rigor of the grid or to the virtues of Western science". ${ }^{22}$ The value of his constant studies on Greek vernacular architectures, which would be much more important when considering the ideological background in Greece and the mainstream in architectural design in Western world from the early $20^{\text {th }}$ century to the 1970's, was firstly reflected in the 1921's design for his first house in Moraiti. (Fig1.4) The subtle rhythm on the facade formulated by the arch and rectangular windows, the intention to find relation between essential elements and the monolithic volume from his Cézanne-like drawings, present synthesis of general characters and traditional construction of popular houses in the island.

Pikionis started to get public commissions since 1930s. Two schools built during this period present a quick shift of the architect who discarded modernist utilitarian purposefulness and started with a research aimed at documenting the survival folk elements in modern architectures.

When Pikionis studied art in Germany, he was inevitably influenced by Bauhaus The principle of functionality, precisely geometric shape of sense of lightness against decorations, as he said, "promised completeness of organic truth, was strict and simple, and was governed by the geometry of a universal pattern capable of expressing our age"23, characterized his 1930's design for the Lycabettus Primary School. By

22. Nicholas Adam. Review of Dimitris Pikionis, 1887-1968, by Alberto Ferlenga. Journal of the Society of Architectural Historians, Vol. 59, No. 1 (March 2000): 126.

23. Dimitris Pikionis, Architect 1887-1968: A Sentimental Topography, 74.
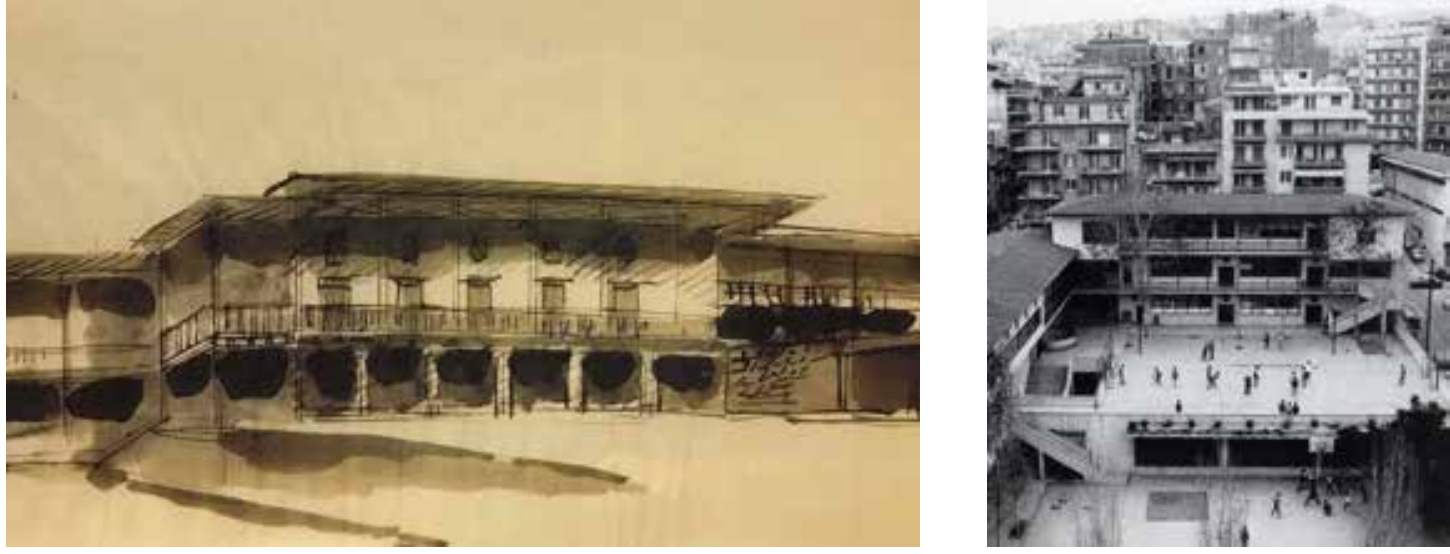

Fig 1.6. Salonica Experimental School and sketch.

symmetrically laying out the buildings on the slope site, he organized classroom and offices in different levels around the central courtyard in order to give rise to the interrelations between them, and to accommodate the building complex into the hilly topography. (Fig1.5) Finally, the school shaped by boxes standing out of the village, with windows that recall Le Corbusier's la fenêtre en bande, seems to be a declaration of the spirit in a new epoch. However, Pikionis was not satisfied with the building when it was finished. He said: "If that is all the Modern movement has to say, well then, I want nothing to do with it", then gave the reason that "the historic memory of the nation" must be conveyed in architecture, and the universal spirit must be "bound up with the spirit of nationality"24. Nevertheless, Lycabettus Primary School remains one of the most important works in the history of Greek modern architecture.

Two years later, Pikionis built an experimental school in a crowded neighborhood in Salonica. The dark colors in his study sketches present the shadow given by the pitched roofs, which were absent in Lycabettus. The timber structure and exposed corridor no only confer an Oriental aesthetic on the building, as the architect described "a slightly Japanese character", but also indicate the application of local materials and technique to promote ventilation and protection from the sunlight. (Fig1.6)

Apart from the inspirations from traditional constructions, the mythical and metaphoric meanings, illustrated in Pikionis' drawings, the notable sketch series of Attica, and stemmed from the pavement and the few but expressive decorative elements in his buildings, deeply root his works into the territory of Greece. (Fig1.7) Besides his profound understanding of Greek literature, especially poems, these symbolic representations in Pikionis' constructed space have much influences from
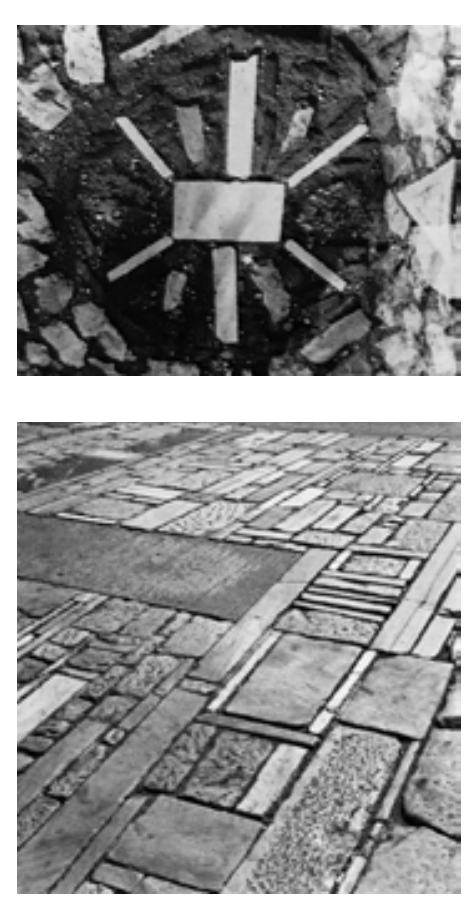

Fig 1.7. Acropolis pathway pavemen 


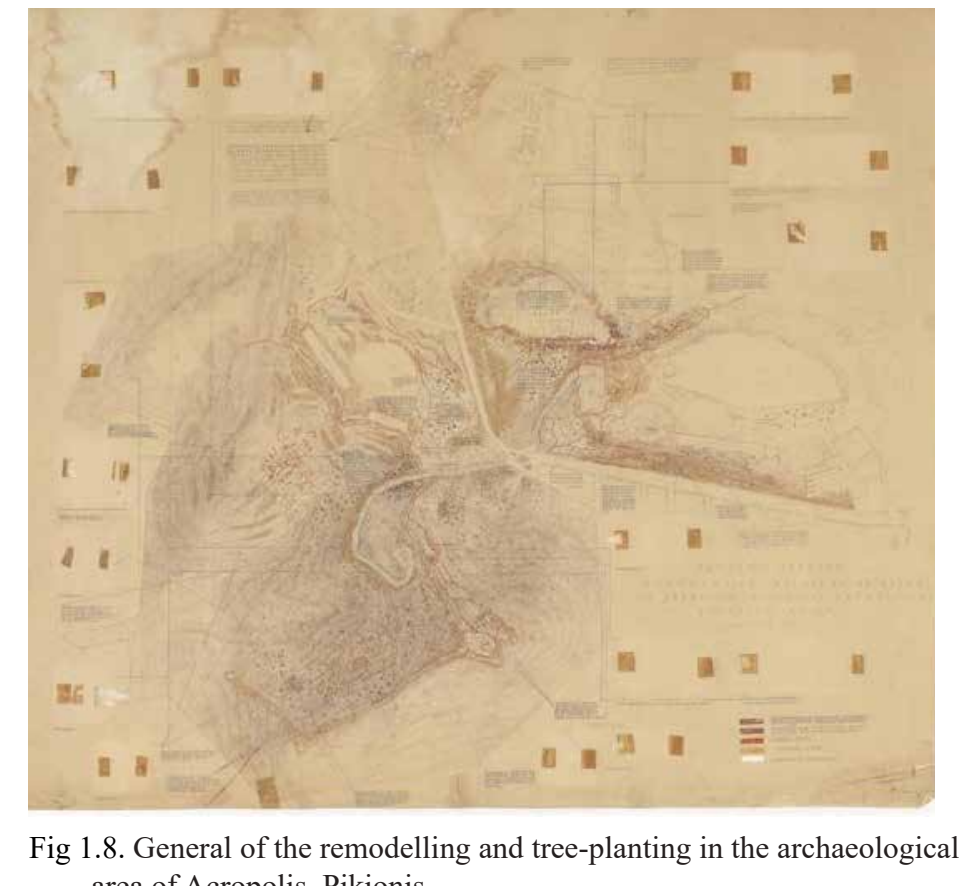

area of Acropolis, Pikionis

European avant-garde, Kandinsky, Klee, and above all, his life-long friendship with the metaphysical artist Giorgio de Chirico started from their studying time in the Polytechnic of Athens. The mystery created by Pikionis is not only capable of evoking the history of the Greek earth, but also of generating the transcendent significance that allows everyone to read the inner narrative of eternality and to find the indivisible identity of the world.

. landscaping the Acropolis

Faith in universal unity, insistence on simple and vernacular construction, and creation of metaphoric representations contribute the basic characteristics in Pikionis' works. Back to the 1950s, when Pikionis, who was already the professor of Interior Design at Athens Polytechnic and had cult status in the field of architecture and art because of the influential magazine To Trito Mati (The Third Eye) he had created with a group of partners from 1935-37, was called upon to reorganize the archeological space of the Acropolis and the south-east Philopappou hill, whose summit was occupied by an ancient Greek mausoleum dedicated to Gaius Julius Antiochus Epiphanes Philopappou (65-116 AD), creating accesses for the two pathways, defining proper limits to protect the original landscape, and giving new order to the two ascents in order to link the places as well as the heritages atop the hills, became the points of departure for the architect to start the work. (Fig1.8)

The Acropolis commission reflected the tumultuous climate in Greece during the firs half of the 20th century. Upon the victory of the Western supported anti-Communis government in the civil war (1946-49), which eventually led to the seven-year military dictatorship (1967-74), the new leaders of the nation interested in Greek classical monuments to retrace the pride of the country and refuel the people. However, rather than by privileging architectural and political value of the Acropolis to serve propaganda as the authority assumed, Pikionis executed the lay-out of the archeological area on the basis of fundamental integrity, that the significance of this important place stem from the position of the heritages and ruins, not only the Acropolis', relative to the surrounding landscape.

A letter written to the client at the beginning of the project shows a quite comprehensive guideline of Pikionis' understanding of the very nature of the extensive work about its landscape and sacredness, as well as his methodological approaches to problem solving:

"1. There can be no doubt that the project cannot be carried out mechanically using conventional construction methodologies whose application is practiced on a daily basis; instead it is an essentially artistic project that requires at the same time a large amount of manual work. It can also be seen that the difficulty of achieving a good outcome is made more difficult by the historical nature of the area in which it operates.

2. The work to be done involves a whole array of specialized jobs which, if they do not obey the aesthetic conception of the whole project, will be able to determine in this defects and contradictions that will reduce its overall quality.

3. All this generates the need for individual buildings to be brought back to those responsible for the project's artistic success. That is to say that this person must receive the appropriate information about the opinions of the artisans (from the constructive point of view) and that, conversely, these will be informed about his aesthetic beliefs. The result will be a close and continuous relationship and a mutual exchange of 


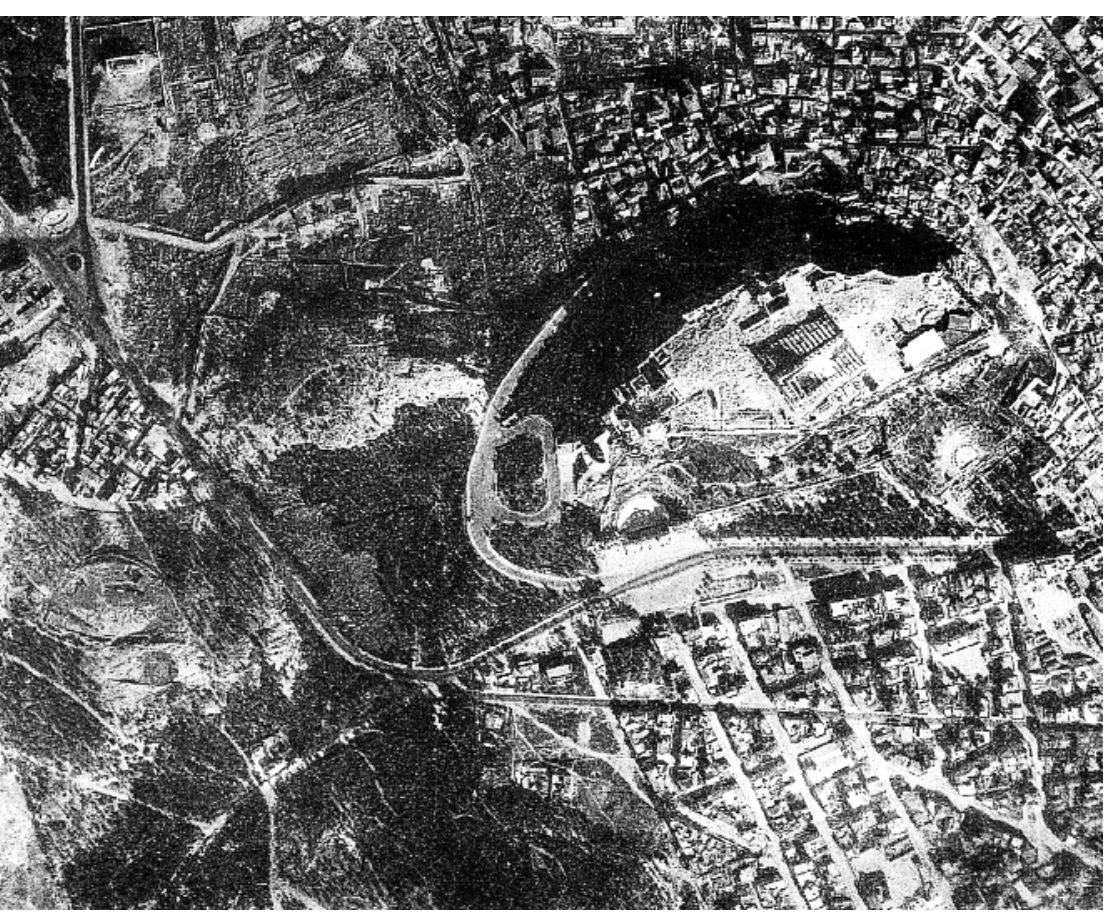

Fig 1.9. Aerial view of the Acropolis area prior Pikionis' work.

information among all those who collaborate on the project. This method is made even more indispensable by the fact that the various drawings necessary for the work will not be completed before its beginning and that the fact that the work is under construction makes difficult to prepare the drawings with ease and in the necessary harmony with the whole project. In these conditions, in fact, the drawings must be prepared in a hurry so as not to delay the execution of the project.

4. It is clear that the architect who will receive the task must be free from other commitments and that his mind must be completely focused on this project.

5. Another fundamental question for the aesthetic success of the operation is that, in addition to the preparation of the drawings, whose conception in formal terms must answer the questions posed by the site, the supervision of the project must be exercised continuously by the same architect. Or, given the multifaceted nature of the assignment and the extension of the work, it must be exercised by experts chosen in their absolute discretion who will be constantly informed of its aesthetic intentions.

6. For how the project is conceived the architectural forms and current popular buildings will not serve: given the importance, from the formal point of view, of the place where the project is located, they are extraneous to it. Up to the last detail the architect construction techniques in use, raising both to a level of absolute validity inspired by ancient art and comparable with it.

7. Hence the construction of the way-stations, pavilions, etc. will require stones of a special texture, shape and colour, as well as large loose boulders and marble lintels from ancient or Neo- Classical buildings. Reliefs and capitals will be ensconced in

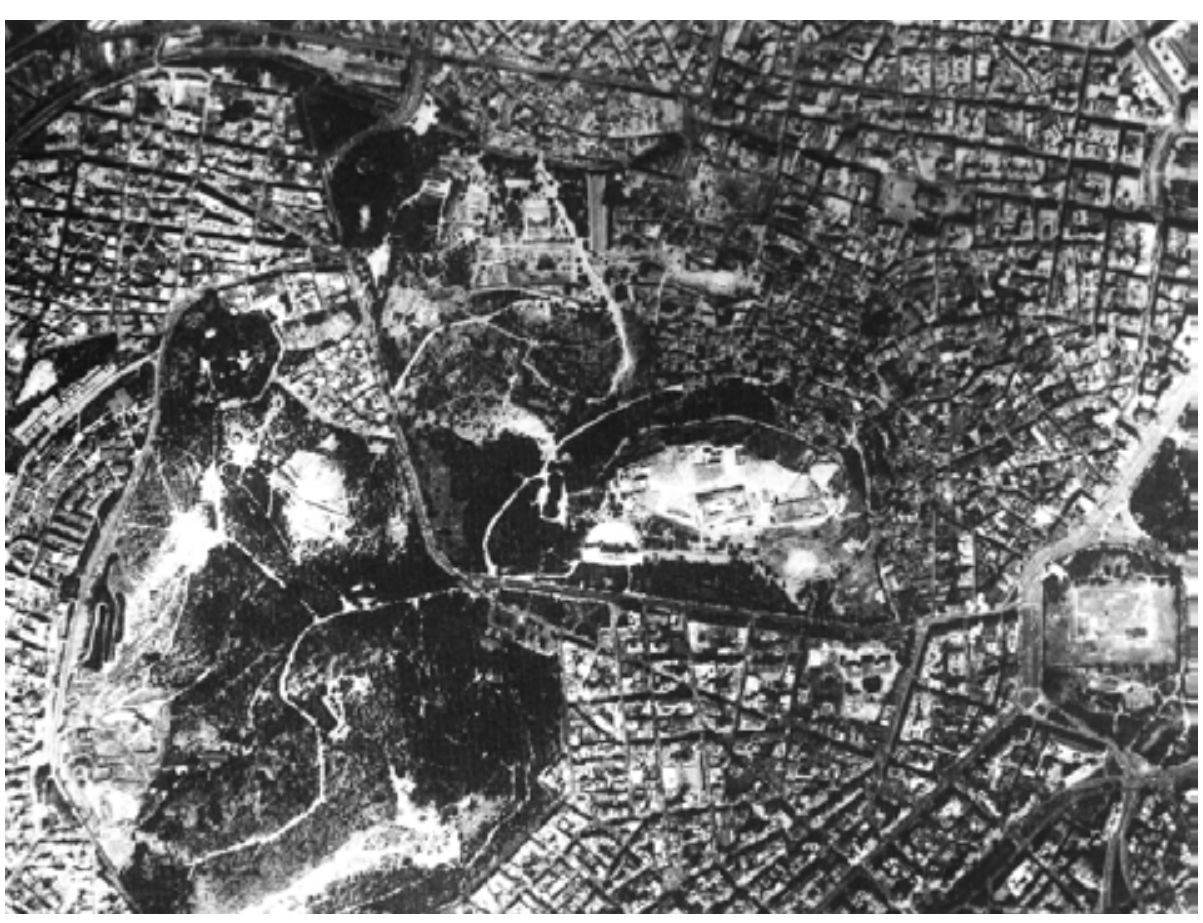

Fig 1.10. Aerial view of the Acropolis after Pikionis' work.

the walls. The alleyways and pathways will be ornamented with antique fragments, such as stone benches and cylindrical shapes belonging to tombs from the period of Dimitris Poliorcetes, which can be found in abundance in the courtyard of the National Archaeological Museum. Several other antique fragments discovered in situ will also be used for this purpose. For the wooden constructions, great care in the selection of timber will be required; the timber will be used either in its unprocessed state, providing this is in keeping with the spirit of the project, or in a processed form, providing an aesthetically valid solution is found the ordinary way will not suffice.

8. This can also be said of stone benches, low walls, etc.

9. As regards the landscaping of the site, the existing number of shrubs will have to be increased and a large amount of olive trees, both wild and cultivated, will have to be planted. The ancient monuments call for the kind of plants that customarily adorned sanctuaries in antiquity: pomegranate, laurel, myrtle. The visual, chromatic, formal and symbolic aspects of the trees and plants on the site, as well as the overall composition, will have to be studied with particular care. This aspect of the project is closely related to the works on Vassilissis Sofias Avenue and at the Theseum, as there, too, the replanting has to be harmoniously integrated with its surroundings from both an esthetic and a symbolic point of view. Non-indigenous trees will have to be removed, as will trees that clash with the general character of the site. Certain other types will have to be reduced in number (such as the cypresses, as their vertical lines lessen the impact of the ancient columns). Naturally the removal of unnecessary or unsuitable trees will be done 


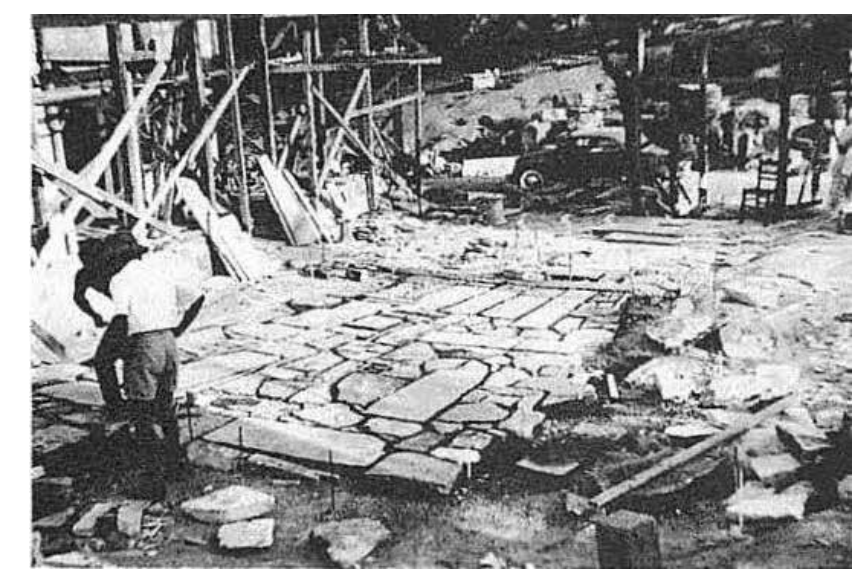

Fig 1.11 Pikionis woking on the site of Dimitris Loumbardiaris Church.
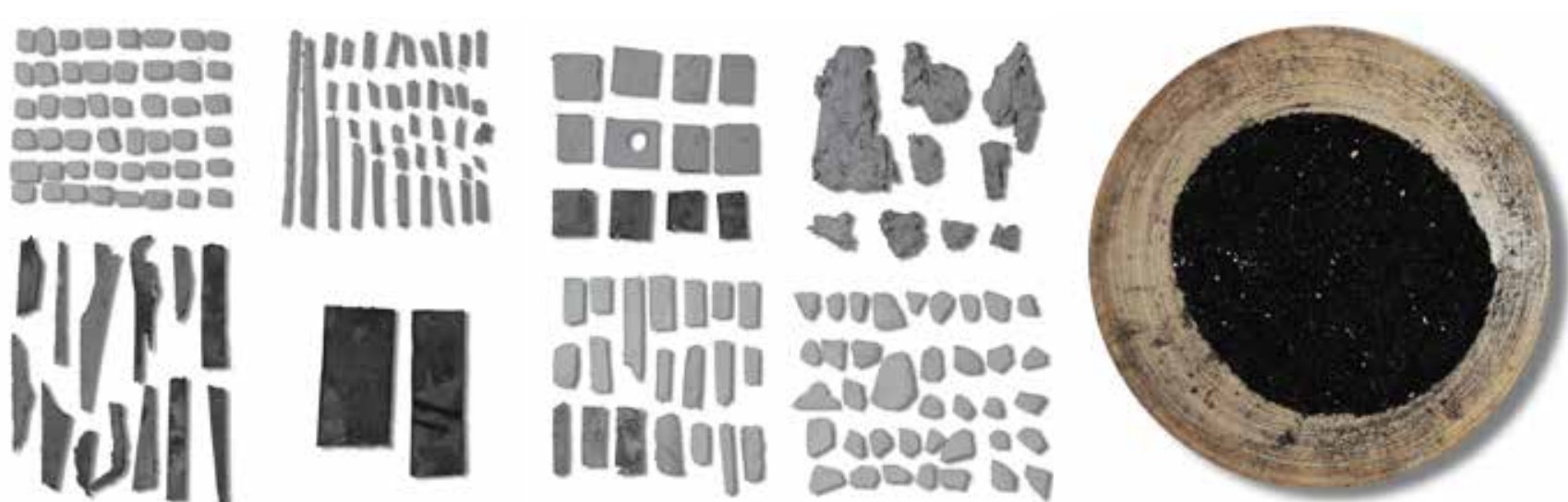

Fig 1.12. Mock-up components. gradually, to allow the new trees and plants enough time to replace them. ${ }^{25}$

In short, this list of details serves to indicate Pikionis' objectives to raise the aesthetic level of the site, and to derive profoundly historical significance from its nature of the place. The area around the Acropolis prior Pikionis' work was in abandoned state. The tarmac pathway to the Parthenon constructed prior World War Two was nothing but a pure functional solution for people to go up the slope, meanwhile, the dense trees on the site, many of them were nonnative plants, reduced order in the space and blocked views to the hills. ${ }^{26}$ Comparing the aerial images before and after the project we can tell significant changes by Pikionis' intervention. (Fig1.9, Fig1.10) Intersection of city streets were transformed as starting point for the two ascents, whose winding itineraries order the whole area through a relatively symmetrical lay-out. Both trajectories are made up of progressive stages: while the main pathways end up with loop routes, narrow trails keep ascending until the monuments atop the two hills. Showing same respect to the different places and by applying similar treatment to reorganize the landscape, Pikionis configured the ascents for respective topics: while the slight slope of 500-meter in length on Philopappou hill allows a casual walk within its hilly environs without putting emphasis on the arrival at the final point, the 700-meter route up to the

25. 1-6 is translated by author from Italian of Professor Alberto Ferlenga's essay.

Alberto Ferlenga, "Sistemazione dell'area archeologica attorno all' Acropoli e al colle di Filopappou Atena 1954-57," in Dimitris Pikionis 1887-1968, ed. Alberto Ferlenge (Milan: Electa, 1999), 226-227.

7-9 in Dimitris Pikionis, 75

26. According to Nicholas Adam, a program to reforest the hilly areas around Acropolis were Queen-Sophia. Over 300,000 trees were planted on the sites from

Adam, Dimitris Pikionis, 127
Acropolis suggests an intense and direct walk to the sacred ruins. By dealing with the internal variation and paving patterns of the two pathways, Pikionis achieved an overal continuity and balance on the archeological site and at the same time keeping their independent qualities.

Pikionis worked on the site. He designed while the project was in construction. $\mathrm{He}$ went to demolished buildings and the courtyard of archeological museums to choose fragments, brought them back and composed the floor together piece by piece together with his students and artisans. (Fig1.11) His beautiful drawings, rather than rigid example to copy in real work, served only for general orientation on particular areas. He encouraged the group members to work with their own knowledge, memory and technique, in this way, the final work is more than an intellectual production, it interprets a collective image of normal people, whose work contributed to sensitive and living forms from which derives the authentic spirit of the nation.

Beauty of the two pathways can be easily captured by photograph and sketches, but they fail to present a panoramic view since it is impossible to have a schematic description of a work highly-integrated with the nature, presenting so much complexity and randomness. Thereby, a series of pavement mock-up made by the author serves as short episodes of a long story, would provide continuous clues to trace the compositional performance along with the pathways. (Fig1.12)

The study focuses on the reorganization of circulation with the help of vegetation, floor pavings and few constructions. The objective is to analyze architect's strategy to produce respective order of the two journeys that departure from the outside world, penetrating into the landscape until arriving at the ancient monuments. Pikionis applied 
this order in a more intense way in the design of Filothei playground. This project is to be studied as reference in parallel with the work around the Acropolis.

In his last works Pikionis showed a religious spirit to trace for and defend the elusive "Greekness", and made the narrative of a long-range time manifest. By combining the reality of the history, the art of vernacular life, and the nature invested with a deep metaphysical significance, Pikionis invested the work made of stones with a deep metaphysical meaning and cosmical unity which become accessible for everyone, reminding of Professor Y. Despotopoulos words in the letter to the architect after visiting the pathways: "I urged several distinguished foreign friends of mine to visit the site, and they, too, 'behaved reverently' the moment they entered this area where you have unified 2500 years of history."27 
1. Dionysiou Areopaitou street

2. Rovertou Galli street 3. Theatre of Odeon of Herodes Atticus.

4. Theatre of Dionysus.

5. Path to the Acropolis.

6. Path to the Philopappou.

7. St. Dimitris Loumbardian

Church and pavilio

8. Viewpoint.

9. Philopappou monument.

10. the Pnyx.

Fig 1.13. Siteplan of Pikionis' project around the Acropolis, drawn by author

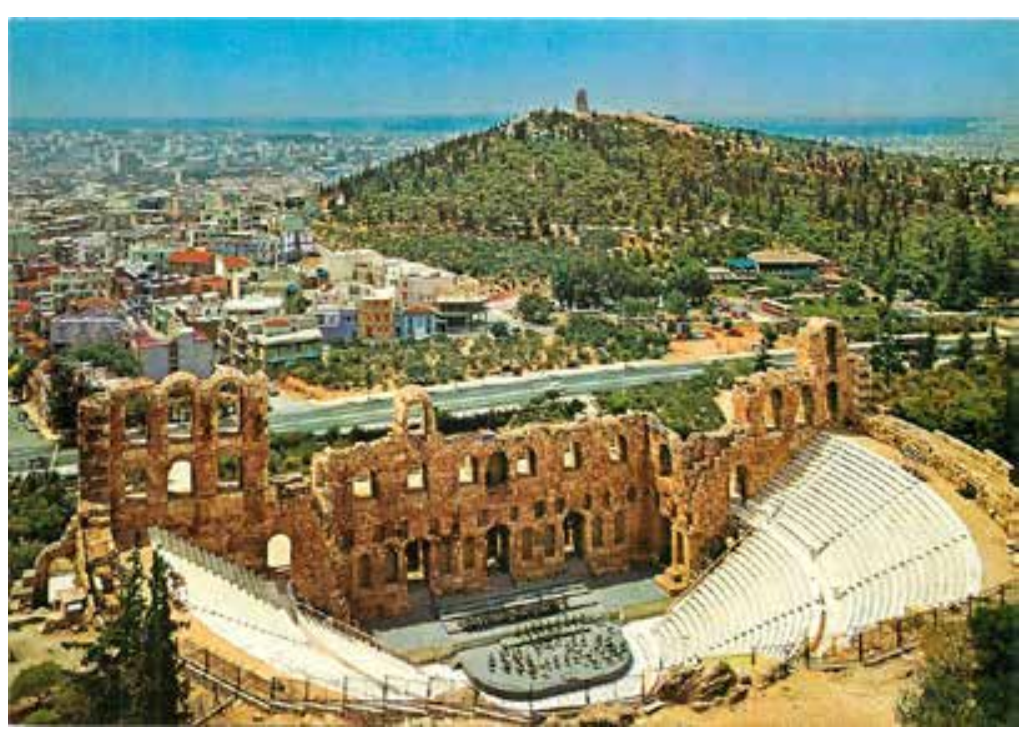

Fig 1.14. The Philopappou monument seen from the Acropolis.

\section{COMPOSE A RITUAL TRANSIT}

The two roads running east-west along the southern edge of the Acropolis site lead to the accesses of the two hills, give visitors very different experience during the approach (Fig1.13.) The Dionysiou Areopagitou street on the north side, connected with Temple of Olympian Zeus, passes by the Theatre of Dionysus, whose opposite side stands the New Acropolis Museum of Bernard Tschumi, and the Odeon of Herodes Atticus under the Acropolis, stands out for a series of traces from the history. On the south side, the Rovertou Galli street that comes from the residential district of Koukaki takes people from the narrow neighborhood to the convergence of city roads, where one can barely see the temples atop the hill. The two streets create an interval between the hills by defining a clear boundary between archeological landscape and urban space of everyday life. Further, the Apostolou Pavlou street turns the way to the old district of Attica on the north side.

The commission by the Minister of Public Works Constantine Karamanlis called for new accesses to the Parthenon and the Philopappou hill whose summit provides great views of the Acropolis and of the city, as well as connections between the various monuments around the site. (Fig1.14.)

Back to 1954, when Pikionis was assigned with the task, his study of the overal composition with particular care established the principle of the work that would last for seven years. Pikionis' first work on the site included eradication of old paths and arbitrary structures that had destroyed the original character and the sacredness of this archeologic area. In addition, in order to integrate the landscape and pavements with the surroundings, he was strict in the species of trees in the two hills and those that were to be planted in the area.
Certain paradox was set as the point of departure for Pikionis to find the spirit of this extensive project from the very nature of the site. On the one hand, Pikionis' search for a harmony integration, engendered in his belief in "the one and the only", would not allow any indifferent component, everything must be at its own position to elaborate a spectrum consists of visual, chromatic and formal qualities; on the other hand, rich variations in the modern city and the permanence of historic heritages, the unchanged topography and traces of previous construction contribute to the diverse characters inherent in the site. Pikionis did not intend to combine the circulations on the two hills as one route, because the an unique order would lead to an intense control and uniformize the area, presenting "something commonplace or mediocre, so depriving the undertaking of its true meaning... ${ }^{28} \mathrm{He}$ made fully use the spatio-temporal qualities and diversity on site to formulate respective narrative of the two paths. At the same time, their profound relationships were developed to give rise to the perceptional correspondence, that is to say, the experience acquired from one pathway would resonate with the feeling when walking through the other one.

Visitors on the Dionysiou Areopagitou street first encounter with Pikionis' work as a series of platforms connected by steps going up to the theatre of Odeon of Herodes Atticus. This intervention, together with the 100 -meter pavement adjacent to the main road, contributes a prelude that helps to form continuity of materials, pavement and tactile felling of the ground. Two smaller accesses are sequentially arranged before the arrival of the Acropolis access, whose open dimension and sprawl of pavings give a welcome gesture

28. Dimitris Pikionis, Architect 1887-1968, 72. 
In Philopappou hill, apart from the new circulation and reorganization of landscape, Pikionis' work includes restoration of a small stone building, the church of St. Dimitris Loumbardiaris, a new pavilion next to it, and improvement to the priest's houses. Contrary to the treatment along the Dionysiou Areopagitou street aiming at stressing the continuity of historical images, the narrow and set back access to the Philopappou is not likely to attract visitors at first sight, as Kenneth Frampton describes his unexpected encounter: "When I first visited the Acropolis in 1959 I found myself walking virtually by accident on the adjacent landscape of Philopappou Hill..29

Different characters of the two accesses indicate Pikionis' idea to make use of their physical separation to produce respective expressions from the beginning of the journey. The two entries also suggest the strategy that the architect applied to lay out the ascents. By composing the pavement to accommodate visitors into evocative trip, and conforming floor development with specific condition characterized by vegetation and topography, Pikionis formulated distinct orders of movement and episodes and made the start-up phases as ritual transit from the outside street into an internal world established on the basis of "the need for quality, for higher aesthetic standards, arises from the very nature of the project, and from the major historical importance of the site. ${ }^{30}$ 
$\S$ Through a choreographed sequence

presentation of the ruin

Old postcards show the original condition that Pikionis was facing when he begun the work at the south slope of the Acropolis. (Fig1.15.) The Odeon's facade standing in three stories high, recalls decoration with white and black marbles and ceramic pieces of the Greek-Roman semi-amphitheater built between 160-174 AD. It guides views up to the hill where the Parthenon seems to be close to the visitors. The already constructed Dionysiou Areopagitou road allows an easy access to the heritage. However, the abandoned forecourt which had been occupied by the stage building, the bare groun between the facade and the street, present the banal and orderless condition at that time.

Pikionis reorganized the surrounding elements to create a new access to the plaza, giving rise to the presentation of the theatre as a ruin rather than a building for theatrica events as it was 1800 years before. Pikionis arranged an upward approach penetrating into the surrounding trees which minimize visuality of the interior space. (Fig 1.16) In this way, a rigid boundary between the exterior street and the interior monument is defined. Pikionis divided the space to produce different observations on the main road: while the distant Parthenon keeps a privilege image over the site, the Odeon is hidden inside, only the top story of the facade suggests its position. Pavement of large slabs stands out from the street floor, marking the theatre's stepped entryway which is perpendicular to the main road. The shady passage framed by trees on either side provides a comfortable place away from the harsh heat in the summertime. On the upward approach, vegetation keeps concealing the view of the ancient building, whose full size is only perceived until arriving at the dramatically expanded forecourt.

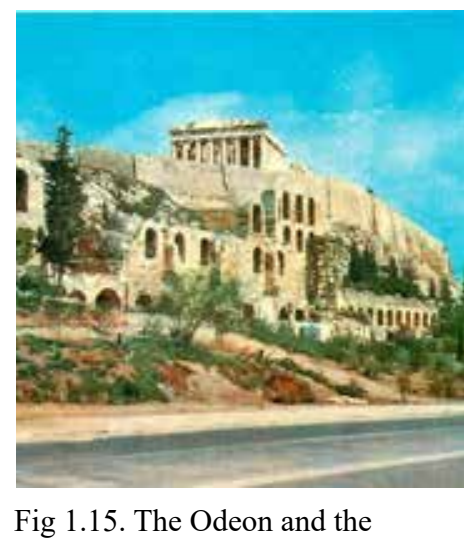

Fig 1.15. The Odeon and the Acropolis

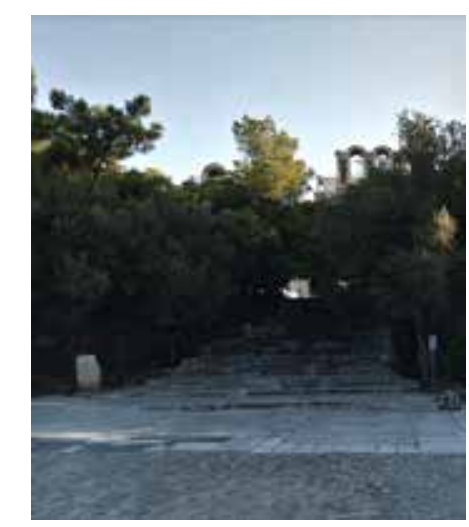

Fig 1.16. Ascent to the of Odeon.

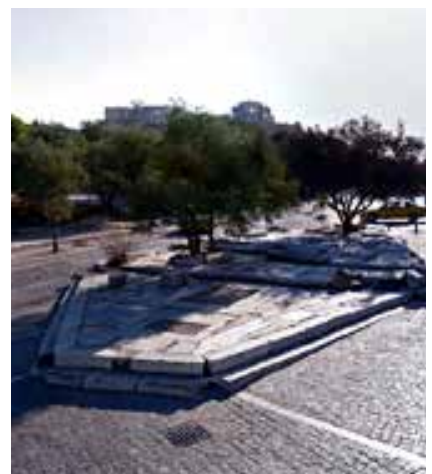

Fig 1.31. Island at the intersectio
$\S$ Into the constructed landscap

. configure a straightforward ascent

Pikionis replaced accesses of the Acropolis and the Philopappou hill to the intersection of city streets in order to produce an intermediate area that on the one hand, highlights the mutual relation between the two sites and their circulations, on the other, incorporates the trajectories towards ancient monuments into the structure of urban space. Three small islands composed of olive trees, rocks and stone floor, reminding of karesansui in Japanese Zen garden, were located by Pikionis as division of the interval area, serving pedestrian and vehicle circulations. (Fig1.31)

Visitors step on the islands, pass through the asphalt motorway and arrive at the access of the Philopappou hill. The straight ascent from the entry to the San Demetrius Loumbardiaris Church on the roadside at the end of the 150-meter long route present the first part of the pathway. Pikionis conceived this short course both for vehicles when ceremonies are held in the church and an accommodating process for pedestrians to walk into the deep landscape.

The pathway shows a composition of longitudinal and horizonal dimensions from the access: while the straightway at the middle part paved with stones facilitates cars to go up, the terraced walkways on the roadsides, where benches create resting places on the lateral side, provide passages exclusively for walkers parallel to the main road. (Fig1.32) Trees alongside the ditches reserved between the main path and stepped walkaways ensure privacy for individual walk, which is facilitated by stone ramps. The trees replanted more than half a century ago now are harmoniously integrated with old species. 


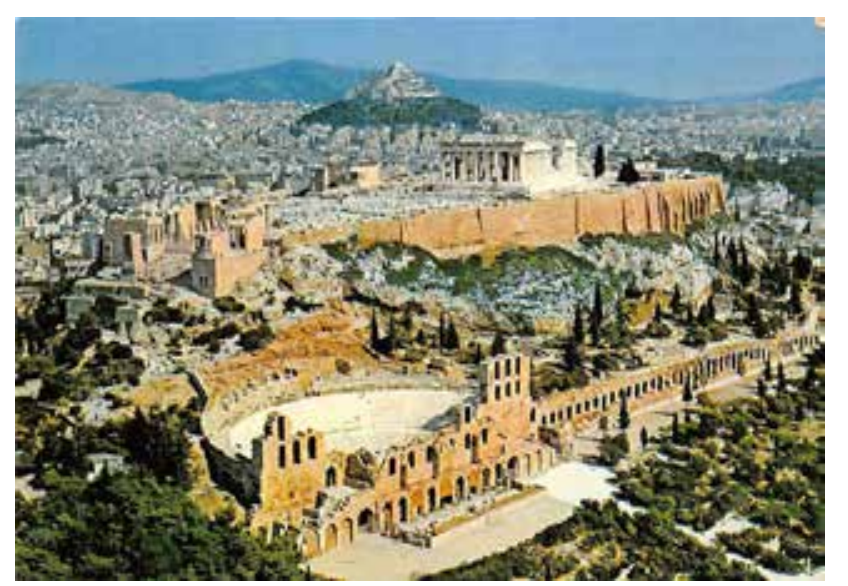

Fig 1.17. Odeon with forecourt and the Acropolis.

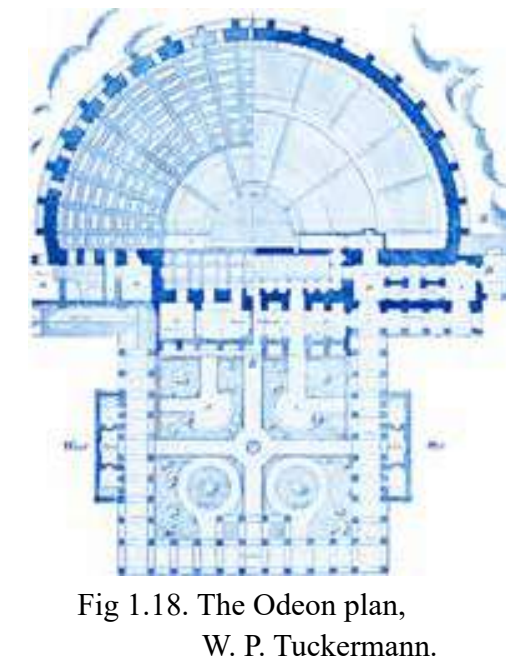

W. P. Tuckermann.
Pikionis deviated the access away from the theatre's axis, arranging it to the east corner as if the approach was calibrated by the Parthenon. (Fig1.17.) In this way, apart from his search for an irregular plan differed from the originally symmetrical composition of the facade, this layout leads to the simultaneous presentation of the theater and temple once visitors arrive at the internal space. An exit at the west corner suggests a diagonal route through the rectangular forecourt to the secondary path to the loop on the upper level.

Contrary to the sense of movement promoted by the access and exit, the rigidly geometrized plaza and pavement help to keep a static character of the building of the theatre. By levelling the front floor, Pikionis reorganized the relation between construction and ground. The open space adjacent to the building recalls the square in W. P. Tuckermann's drawing. (Fig1.18.) By keeping a distance from the natural environs, this wide area provides a symmetrical plaza that ensures the completeness of the site for the building and reinforces the expression of frontality of the facade As regards the pavement, Pikionis used singular composition of larger marble in rectangular and square shapes, whose dimensions correspond with the stones of the theatre, slim pieces are applied to fill the gaps. (Fig1.19.) The pieces evenly distributed on the ground produce a homogenous and directionless quality, promoting a sense of stationary that relates to the expression of the heavy wall made of big stones.

The floor contacts directly with the stage wall that conveys a binary character of the horizontal and the vertical. It seems to reproduce the mechanism that how the Parthenon was placed on the hill by clearing and transforming the summit into a monolithic platform. The slim fissures between the paving pieces emphasis the thinness of a delicate and smooth floor, which deprives the expression of the depth of soil and its connection with the building. As a result, the three-story wall without extra support is

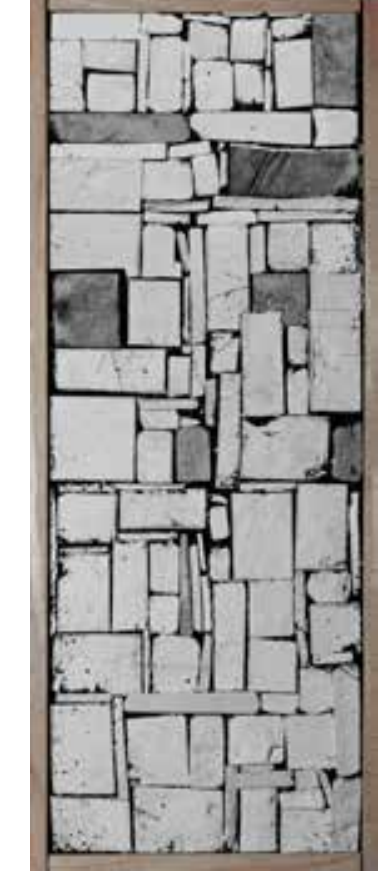

Fig 1.19. Odeon forecout mock-up.

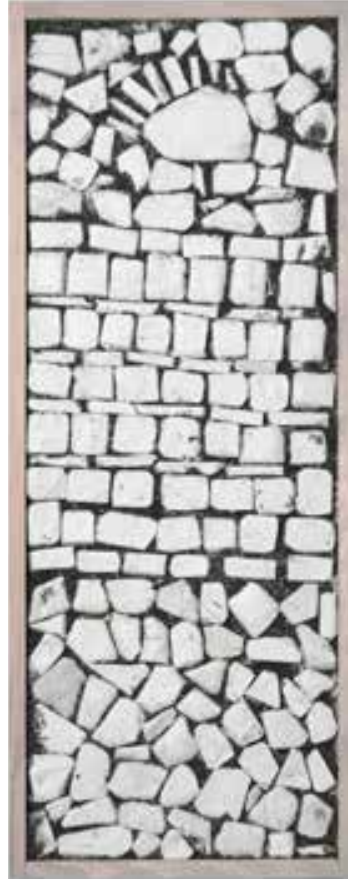

Fig1.34. Philopappou route's entry mock-up.
The vertical screens produced by the sidewalk trees give rise to the exclusiveness of the middle pavement, strengthening the perspective on the road so that enhance perception of spatial depth. But at the same time, through intervals between trunks visitors can look both ways where soft slopes and vegetations present the original landscape of this area. (Fig1.33.)

With the narrowed entry, symmetric composition and control of sunlight, the access of the Philopappou hill suggests a protected and interior itinerary. By establishing a threshold between the external and internal space, a band made of irregular slabs, abruptly ceases when meeting the asphalt motorway, defines the basic patterns at the entry area. The nonuniform pieces in the middle part form the main image of the pavement, those arbitrary lines give the floor natural textures as if they were imitating the cracks of dry land. (Fig1.34.) Smaller slabs in regular forms are used to shape clear boundaries on the both sides, compensating the precariousness of the middle composition. In this way, Pikionis has created a balanced composition on the floor to mediate between regular and irregular pieces. It works together with the overall layout of the pathway to maintain a sensation of equilibrium.

Apart from the small pieces which form homogeneous patterns on the floor from the entry, transverse stripes are applied to mark a succession of groups of pavements. As visitors go deeper, the increasing dimension of horizontal stripes, formed by simple marble pieces or square slabs evenly placed in lines, keep reducing the proportion of the freely-composed features. This constant change that accelerates the rhythm of development on the floor would slow down visitors' speed, anticipating the upcoming event that will adjust the order of space. 

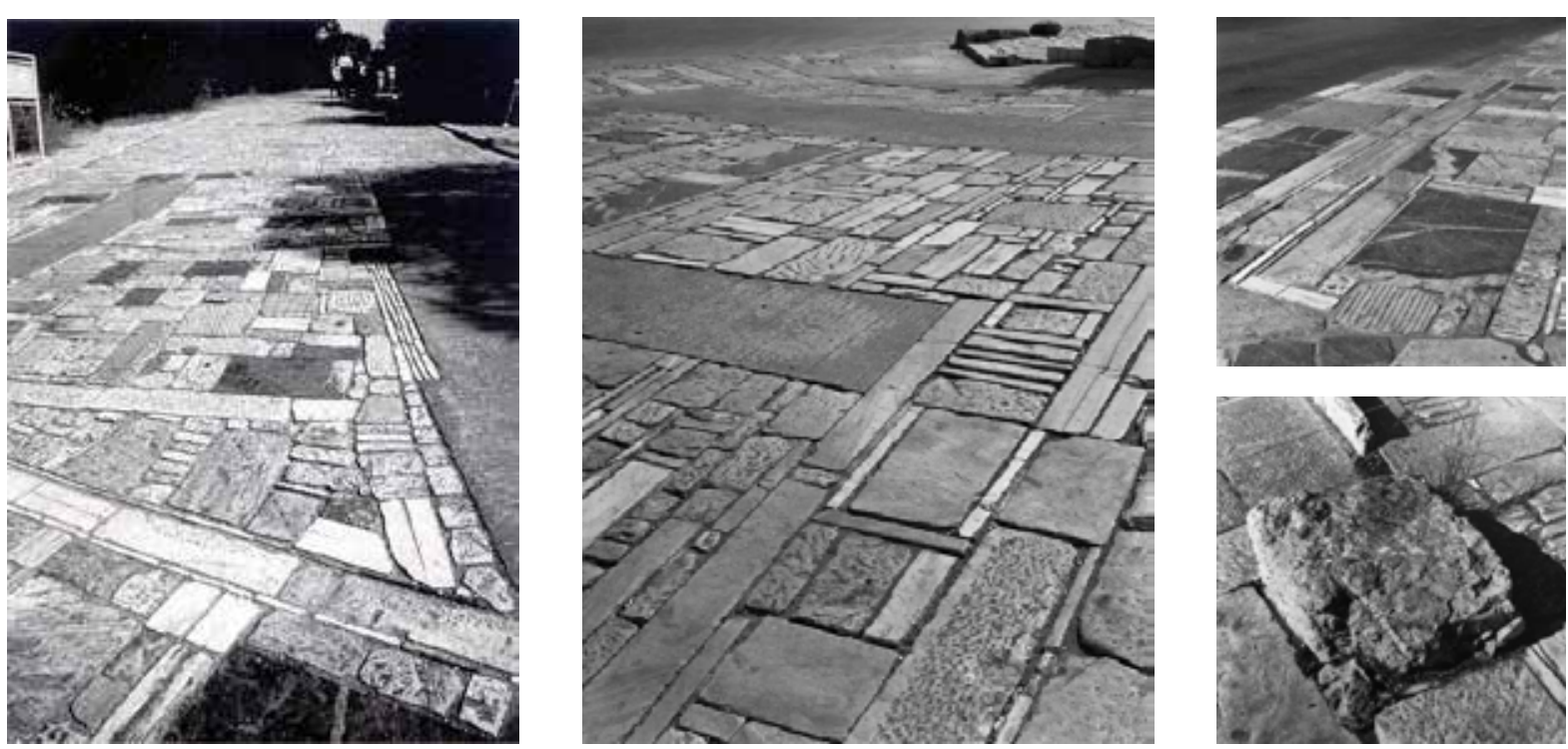

of the Acropolis.

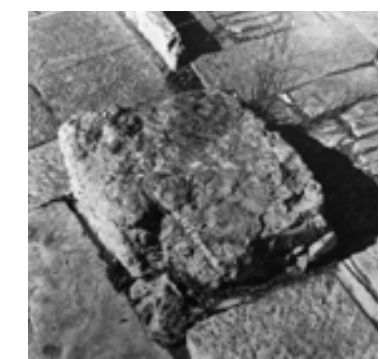

Hig 1.20 . Pave

seen as a free-standing structure put on the ground. The absence of apparent foundation and supports of such a mass structure leads to a great contrast and tense on materiality, showing the fragile surface underneath can barely bear the load of the lithic architecture stand on it.

By involving contradictions of movement and variation of material characters into a united quality of the space, Pikionis arranged the approach to the Odeon and views to the Parthenon in a choreographed sequence, and in this way to reduce the tempora distance between the two monuments and his own work.

. manifesto of the entry

After the spectacular views of the theatre, images of the ancient monuments are gradually concealed by the olive trees alongside the continuous walkway to the east. Narrow ascent and steps are arranged on the right side for visitors to enjoy the shade of trees, yet to break the continuous pathway to the access of the ascent to the Acropolis.

Visitors encounter the access of the Acropolis hill by the sprawl pavement flowing down from the north to the parking on the other side. (Fig1.20.) The extended pattern on the floor made up of a variety of pieces contribute to a carpet made of stone that delimits the boundary of Pikionis' pathway from the street paved by small slabs. The entry area in trapezoid flares out and is further broadened by steps on both sides. Stairs on the right lead to an ascent back into the trees, and reach a seating square adjacent to the central part remains a slope. Following the curvilinear edges visitors are gradually directed to the point opposite the route. Pikionis took landscape and topography qualities into account when as if the access was upward path generated from the earth.

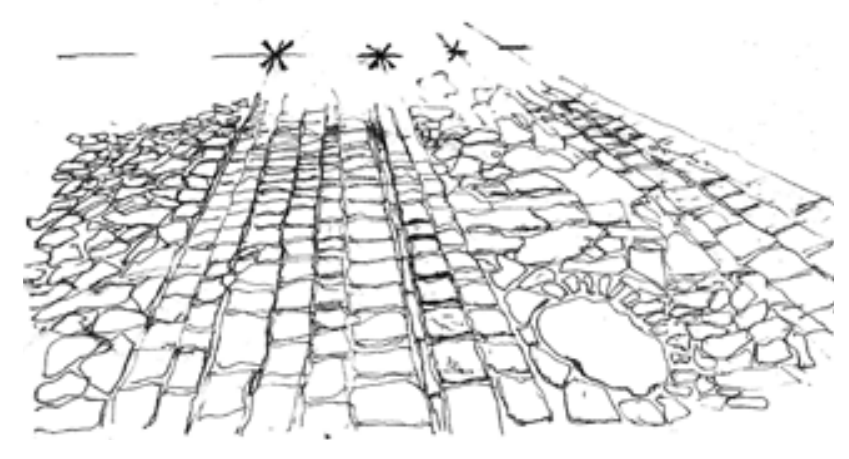

Fig 1.35. Sketch of the entry of the Philopappou route, author.

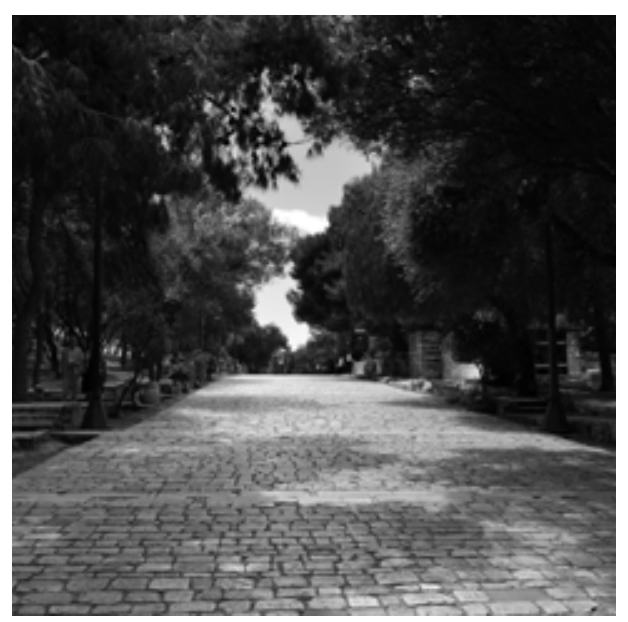

Fig 1.36. Pavement before the church.

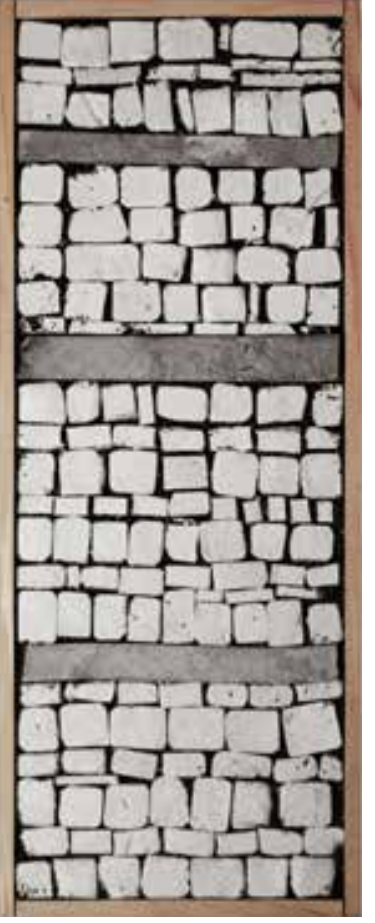

Fig1.37. Philopappou pathway mock-up. approximation to a privileged plot

The relatively arbitrary patterns on the pathway are completely replaced by a singular term of squared pieces when visitors on the halfway to the church. By repeating a section of 3.5 meter in length delimitated by concrete strips, Pikionis reduced the complexity of pavement. It suggests the change of the pathway's objective from promoting an intense transit of space to presenting a static rhythm of movement and the continuum of the itinerary. (Fig1.35, Fig.1.36.) The development of paving patterns leads to the transformation of features from natural realism to homogeneous composition, indicating Pikionis' idea to create a calm and ritual walk towards the privileged position on the top of the first ascending course of the pathway.(Fig1.37.)

The area of San Demetrius Loumbardiaris church ${ }^{33}$, originally occupied by a Byzantine church, is located at the crossroads of the ancient wall of the Diateichisma and the wall of Cimone. (Fig1.38, Fig1.39.) The constructions formed the line of defense and observation points at the end of the 4th B.C to protect the Acropolis from the force coming from Piraeus. In Justinian times, around the 6th A.D, the walls were added with towers. The ruins that currently preserved on the opposite side of the church, the Diplon over the Gates, are fragments of one of the towers and a wall gate. Today, a branch perpendicular to Pikionis' pathway leads to the Pnyx on the south, the site which was used for popular assemblies as early as 507 B.C and became the symbol of the creation of democracy. On the other side, a narrow path leads a shortcut up to the summit of Philopappou hill.

33. The name of church Loumbardiaris ('of the cannon') comes from a miracle. In 1648 the Turks, ensconced on the Acropolis, prepared to fire a cannon on worshippers gathered in the church, but the gunner was killed by lightning, saving the congregation. 


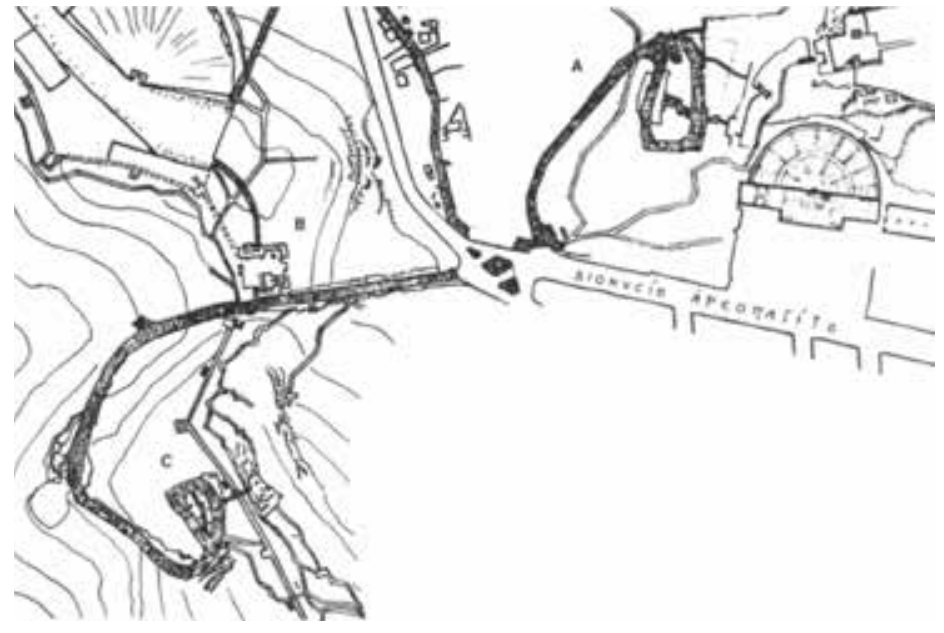

Fig 1.38. Project sketch for the pathways illustrates the traces of the city wall, Pikionis.

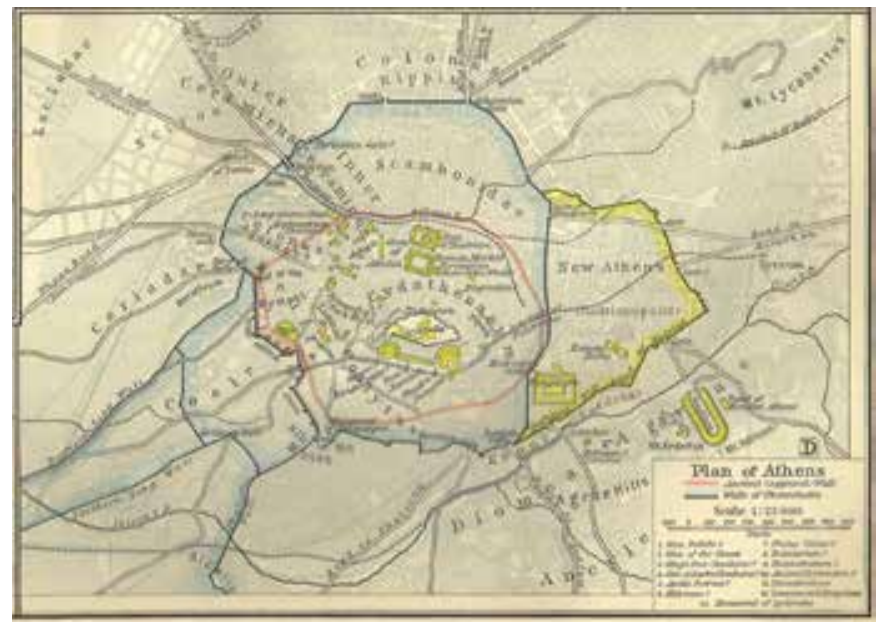

Fig 1.39. Map of ancient Athens shows city walls surrounding the Philopappou monument and the Acropolis.
The paved floor, the stepped seating area, the short walls, and the earth land and trees behind contribute a transit from an open and flat space formed by artificial materials to the space of depth surrounded by natural elements.

Pikionis animated the sequential views, first and foremost, by the means of the variation of pavement. (Fig1.21.) The initial part of the pathway is paved with big square slabs and slim stripes to form clear and accurate geometry of rectangular shapes in differen sizes. The various textures and colors of paving pieces enrich the composition. Natural stones are applied to mark the boundary of steps, and others slabs with cuts on surfaces suggest their origins from collapsed buildings. At the access of the Acropolis pathway, Pikionis presented the charm of pavement that lies in the alliance of the memory of old constructions with natural materials. Dimension of floor patterns reduces at this area as if they were accelerating the movement towards the inner place. This tendency is strengthened by the three bold concrete strips which engulf the delicate rhythm of smaller pieces, giving a powerful sign of straightforward trajectory.

The seating square consists of two terraces. (Fig1.22.) The five benches placed in L shape, and the short walls that manifest the deep soil on the back reveal Pikionis strategy deeply steeped in the combination of constructive language, ancient spirit and natural landscape on site. The walls capped by slabs serves as interval between soil on the top and stone floor on the bottom, representing the excavation of the square. The columns fragments beside the access of the secondary ascent and the benches of refined shape stand out from surrounding landscape, contributing a suggestive narration of the entry, as Kurokawa perceived: "Near the entrance of the Acropolis the road forms a symbolic open space, embracing the a ruin of Doric and Ionic columns." ${ }^{31}$ (Fig1.23.)

31. Dimitris Pikionis, Architect 1887-1968, 76

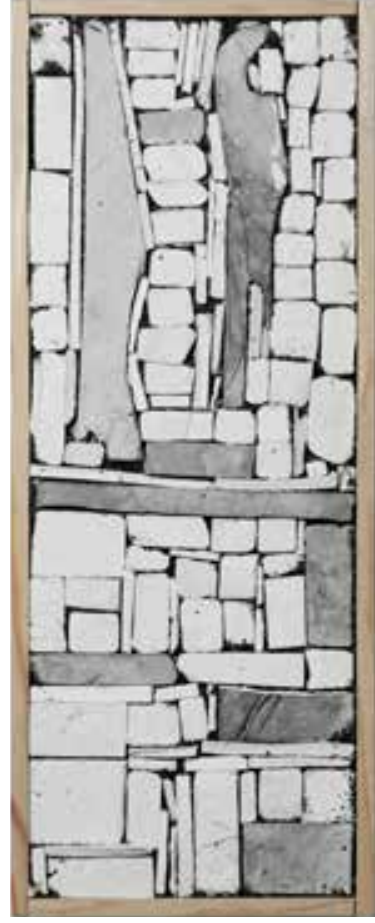

Fig1.21. Acropolis route's

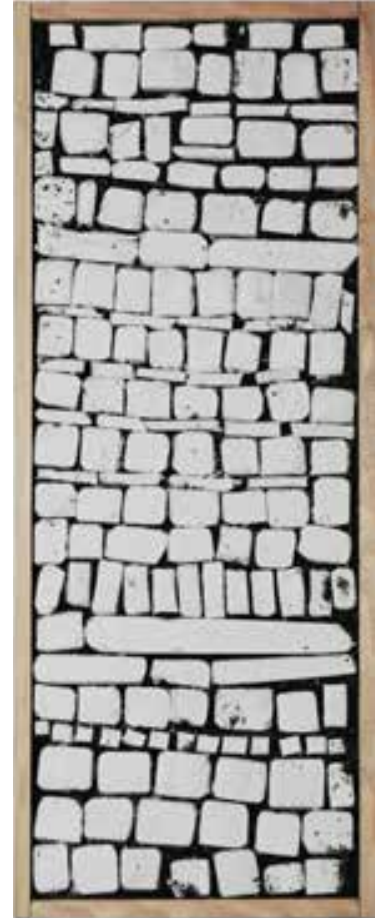

Fig1.40. Philopappou pathway mock-up.
Pikionis set the intermediate point of the itinerary and access to the church on the frontier of ancient city, where ruins and traces of old circulation underline the historical and territorial importance. The typological transformation of the church follows its full adaptation to the slope of the pathway. The service building on the bottom, whose position is aligned with the walkway, presents the delightful piece of stonework on the exterior wall realized by Pikionis. Terraced platforms raise the ground. A giant cypress stands out from the surrounding olive trees and conceals the full size of the church behind. Rocks on the bottom recall a typical topic in traditional Chinese and Japanese wash painting, that cypress and sharp always appear together as representation of the vitality and eternity of the nature.

A horizontal strip consists of two marble slabs is aligned with the steps to the service building and indicates the entry of the church's back yard.(Fig1.40.) Differing from the previous lines made of concrete, the marble lines mark the division of the pavement and, together with the dramatically softened slope, remind visitors of encounter with a new space. Plants and external structures keep concealing the images of the building of the church and its interior patio, stimulating people's expectation along with the approaching process

A frame of limestone and concrete filled by eight squared slabs leave a bold sign on the floor which, on the one hand, marking the end point of the first ascent, on the other hand, arresting visitors' by connecting the remains of the city wall with the wooden portico serves as the entry of the church yard.(Fig1.41, Fig.1.42.)

Symbolic meaning stems from the alliance of the transverse pavement with constructions on the both sides. Since the church sets the destination for many of the 


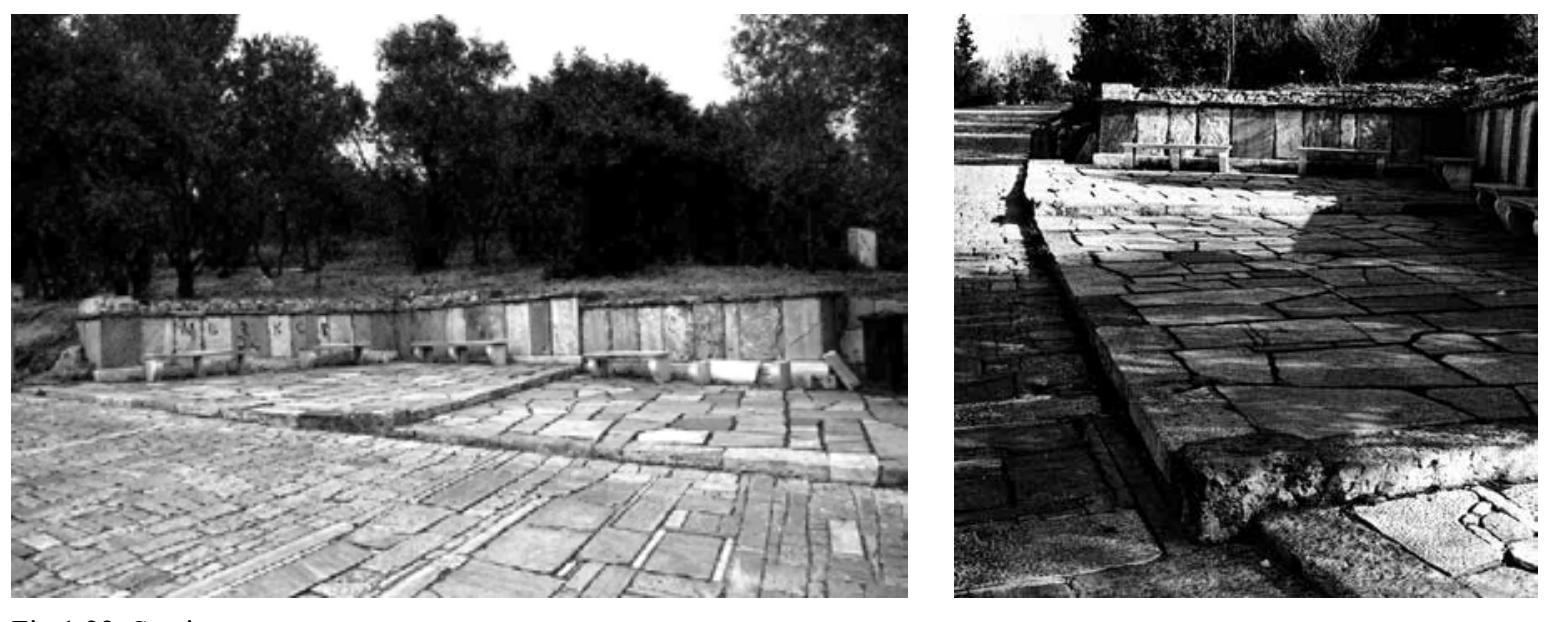

Fig 1.22. Seating square.

Scale of the walls corresponds with the height of people who are seating on the benches The pavement is defined by different uses, the area delimited by the seats is paved with bigger slabs in random shapes, and the interval between the two terraces and thei boundaries are paved by smaller and rectangular pieces.(Fig 1.24.) The smooth surfaces and wider gaps in-between the pieces suggest a slower movement compared with the pathway. This square as a stop point indicates Pikionis' concern about functiona requirement: a wide access is necessary, otherwise the road may be blocked by crowds. Though the Acropolis route was conceived only for pedestrian use, the seating area facilitate vehicles in some occasions.

The various elements arranged by a sequential manner in the entry space sugges Pikionis' capacity to find right solutions and create narratives from the nature of the site. Although the image of the Acropolis is concealed at this moment, an evocative atmosphere derived from Pikionis' artistic work on the floor is already hover over the access attracting people to a journey towards the distant past.

.pave a "mininature"

The rich composition of the access to the Acropolis gives an intense manifesto of Pikionis' methodology to create a transit from the intersection of city streets to a unique passage without indicating its destination. The narration of the Hellenic history and the straightforward route subtlety detach visitors from the city street. Pikionis' sentimental use of materials, paving pieces being bound with surrounding trees and original ground and building fragments resonating with those ancient ruins scattered around the city, helps to create an evocative space, indicating the rituality of the ascending movement only could be derived from both historic realities and natural landscape on site.

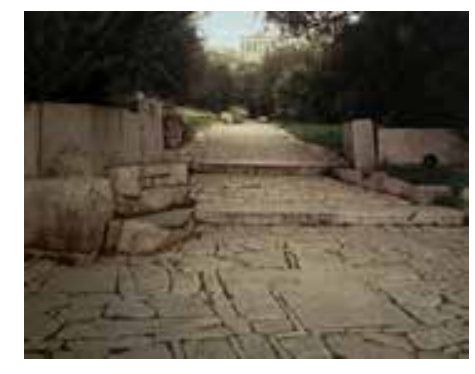

Fig 1.23. Ascent adjacent to the seating square.

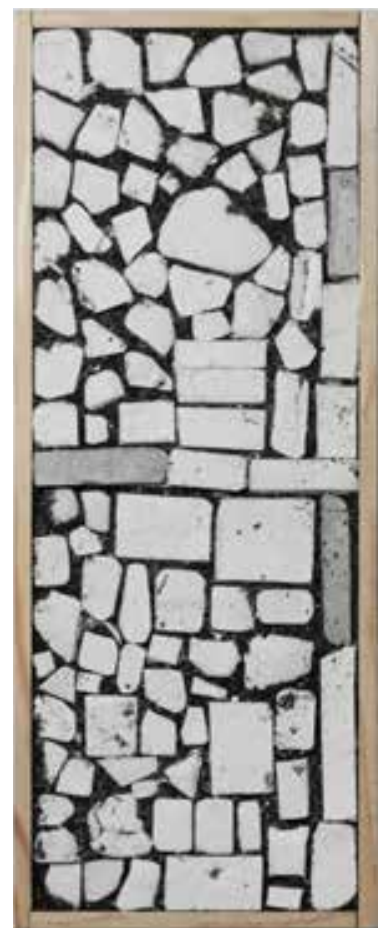

Fig 1.24. Seating square mock-up

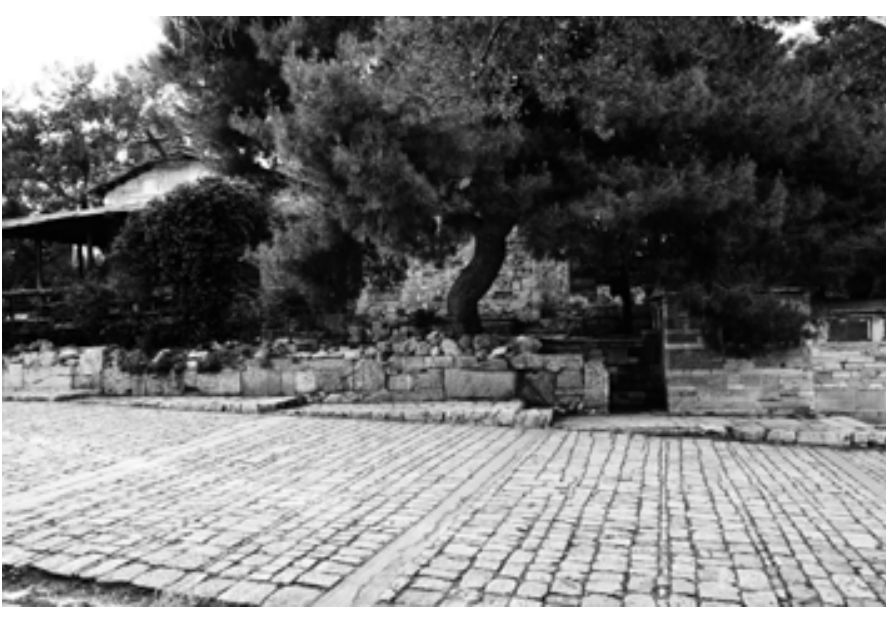

ig 1.42. Paving parallel to the curch.

visitors to the Philopappou hill, this pavement represents a border between the pathway that serves ceremonies and the further promenade towards the monument on the summit. Although the stone band across the pathway does not retrace the exact trajectory of city wall, it gives a sign that recalls the old frontier, creating a virtual partition that calls for effort to pass over it, just like Athens residents in the ancient time had to pass through the wall gate to go in and out of the city.

\section{the stepped perimeter}

From the entry of Philopappou promenade Pikionis made use of bold ditches and trees to draw straight borders of the main road as well as to separate the walkways on both sides from the middle course. (Fig 1.43.) This strategy to create division indicates his idea to compose two individual experience in the first part of the pathway. In fact, rather than presenting a continuous ascent, the terraced walkways constantly interrupt movement and arrest visitors during the walk. Benches of different shapes are placed beside steps, "making alcoves and sometimes forming small enclaves." are ornamented by big rocks and building fragments that on the one hand give a rhythm of movement, and on the other hand, present combination of natural elements and artificial materials, reminding of historic meanings inherent in Attic landscape. (Fig1.44.)

Contrary to the rubbles on the middle pavement to serve vehicles and give strong tactile feelings that help a continuous movement, the walkways on both sides aim to give visitors a tranquil walking experience. The squared slabs of the pavement are aligned with each other, gaps are filled by strips to create solid and smooth surfaces. 20. Dimitris Pikionis, Architect 1887-1968, 76 


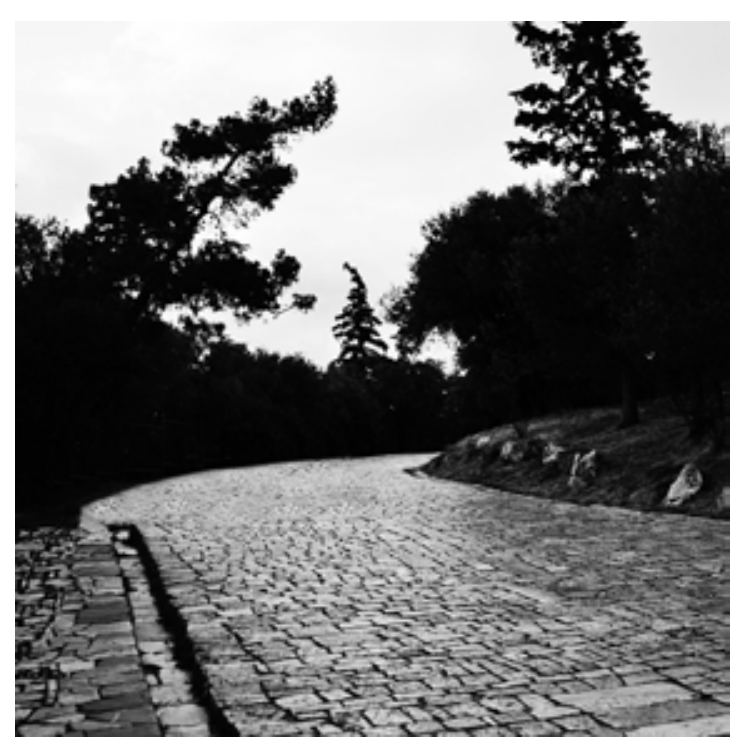

Fig 1.25. Road after the entry.

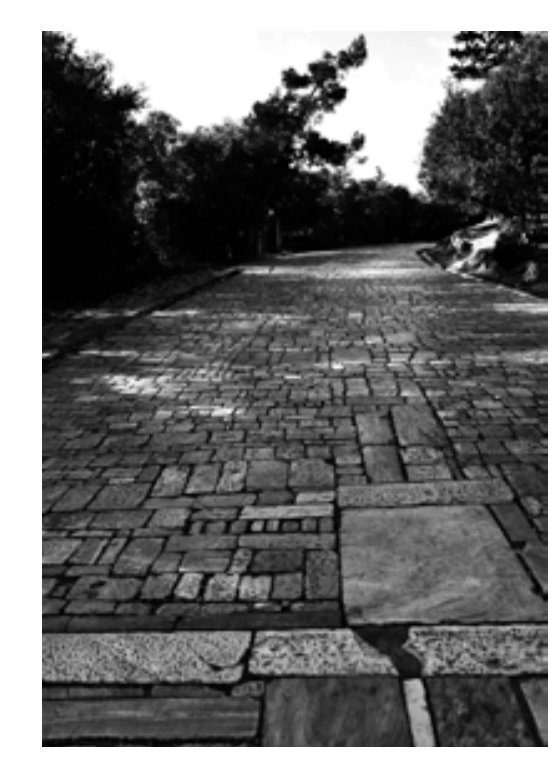

Fig 1.26. The pavement axis.
While the dynamic pavement on the access stresses the intensity of space and animate visitors, the following part of the pathway sees a reduction of variations of spatial configuration. The thirty-meter long way that runs alongside a steeper slope appeal more attention on the walk. The rich floor patterns end up with wide marble stripes and paving pieces become smaller and are arranged in a more regular composition of repetition of slab rows and slim bands. (Fig1.25, Fig1.26.) While the evenly placed pieces help to maintain a constant manifesto pavement and keep visitors' paces, an intermittent axis consists of longer slabs perpendicular to the horizontal patterns can be traced on the floor. It plays the role of a guideline that indicates direction of the journey, dividing the road into two parts as if they served respectively the visitors going up and down the hill. (Fig1.27.)

Development of paving patterns shows Pikionis' strategy to realize a progressive distancing from the outside world,(Fig1.30.) at the same time, the way how the architect creates continuous outlines of the route by controlling its boundaries reflects the importance to keep continuity on the floor, which is one of the fundamental characters of the narrative given by the pathway. As cracks on the ground, two lateral ditches mark bold boundaries of the route from the access, giving a clear manifest of the width of the road.(Fig1.28, Fig1.29.) In addition, Pikionis abandoned extra structures and seating platform on the roadside in order to keep continuous perception and movement, making the pathway receive its shape from constant adaption to the earth.

The straight ditch on the left, 50 centimeters in width and only 26 meters in length, helps to define a solidified streak. It delimits an extended floor of 2 meters in width from the main path. This extra pavement, though loosely composed, inherits from the irregular patterns of the entry floor made up of slabs in various dimensions and shapes, standing out from the regular composition of the pavement on the main road. The

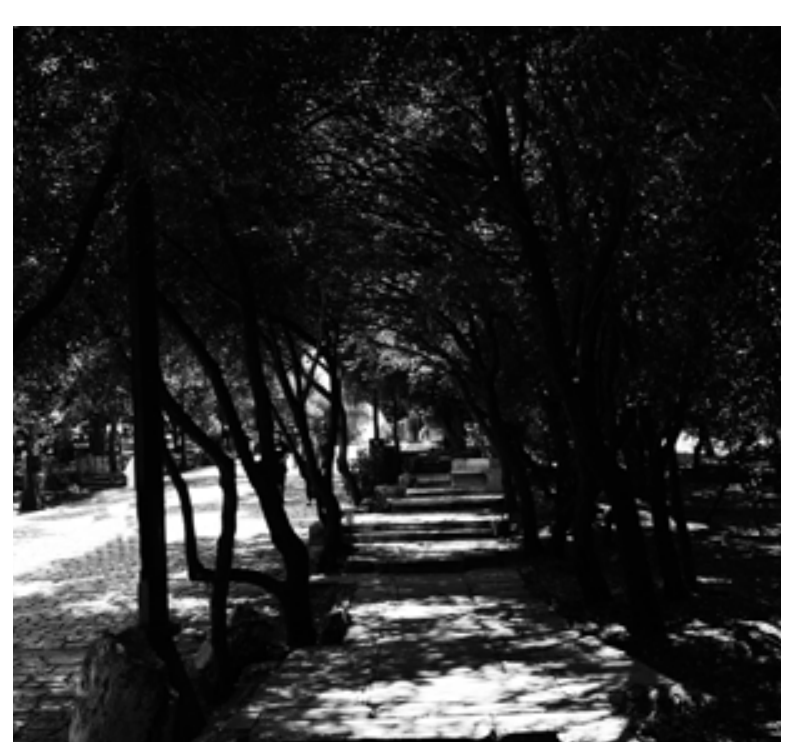

Fig 1.43. The lateral walkway.
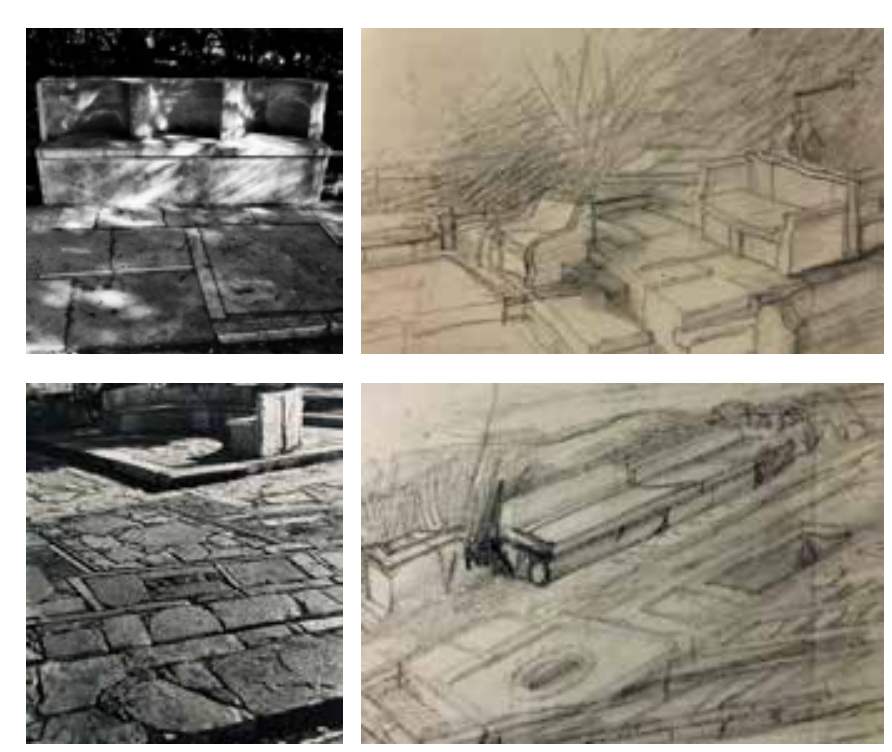

는

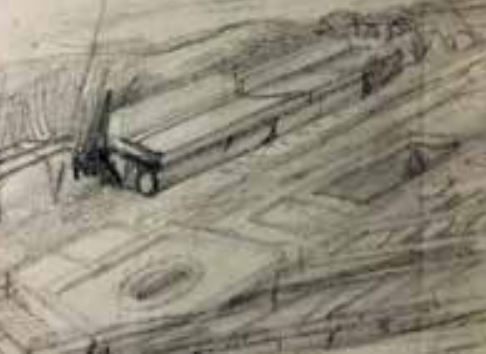

Fig 1.44. Stone benches along the Philopappou route and

Pikionis' study sketches.

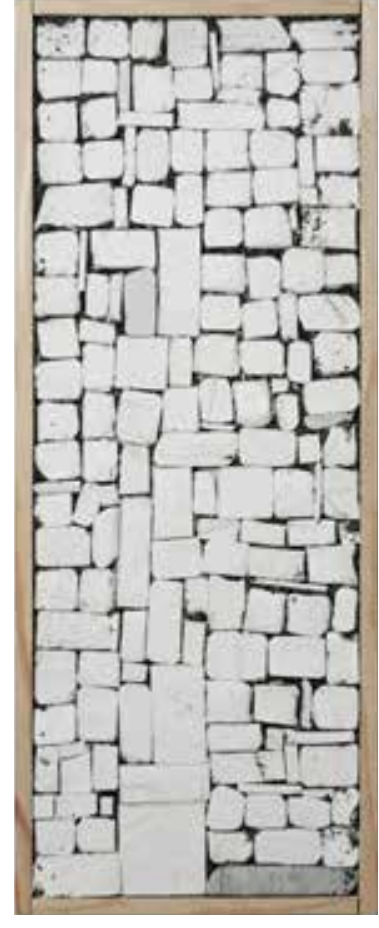

Fig 1.27. Road pavement mock-up.

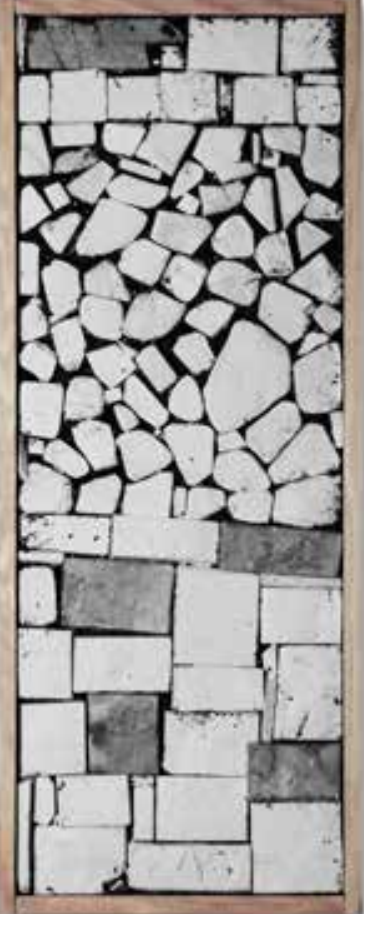

Fig1.45. Lateral walkway
(Fig1.45.) Pikionis created flat surfaces to reduce the feeling of climbing up a slope on the walkways, staircases made of limestone stand out from the plane floors of sandstone and slate, putting emphasis on the change of levels.

Benches varying in scales and shapes provide seating for groups or individual person, Their different positions, some are installed with platforms and placed next to the walkway, others are placed rightly on the route, indicate the duality of the floor as a passage taking the ascent and a series of small squares for rest. Intervention of the benches also break the continuity in the external edge of the walkways. However, the appearance and randomness of the borders present here is actually ordered by the general rules that unite the pavement, the seating squares and benches to the adjacent soil ground and trees, so that they constitute tortuous outlines of the pathway that seemingly weaken the limit between the world of stones and the landscape of Philopappou hill, allowing every passerby to stop and to admire the nature.

The seating terrace on the south walkway that appears beside a path going deep into the forest give an outstanding narrative. The broken terraces accessed by steps was conceived as abandoned settlement. (Fig1.46.) The benches, in rectangular and semicircular forms, are placed one behind the other on the floor respectively paved by rocks and slabs. (Fig1.47.) A cypress breaks the curved seat give a dramatic manifest of conflict between natural power and artificial product. It seems to tell a story that the tree seed germinated after the project, then it grew up and broke the stone bench of stone slab. However, it is not the truth: first, according to the height, the trees are apparently older than the project, second, it is impossible for cypress to break through stones. The hole cut on the ground, reserved for another tree, suggests how the architect treated stone material in favor of growth of vegetation. 


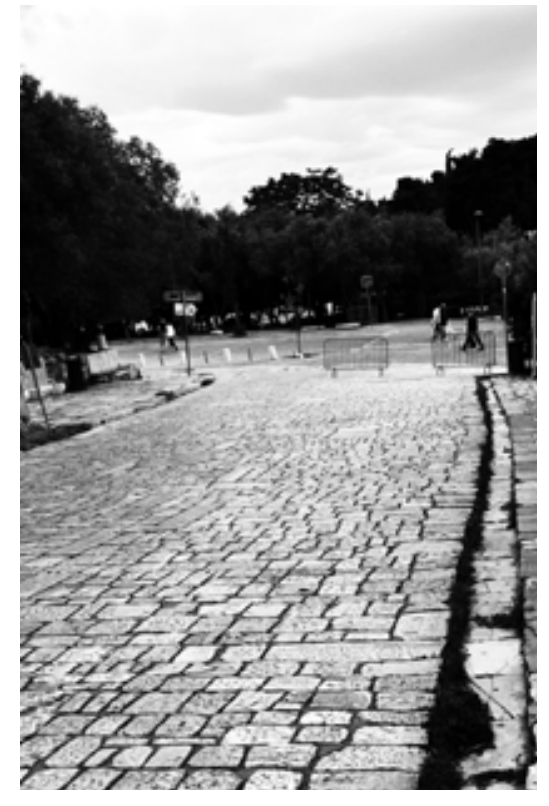

Fig 1.28. The left ditch and extension floor.

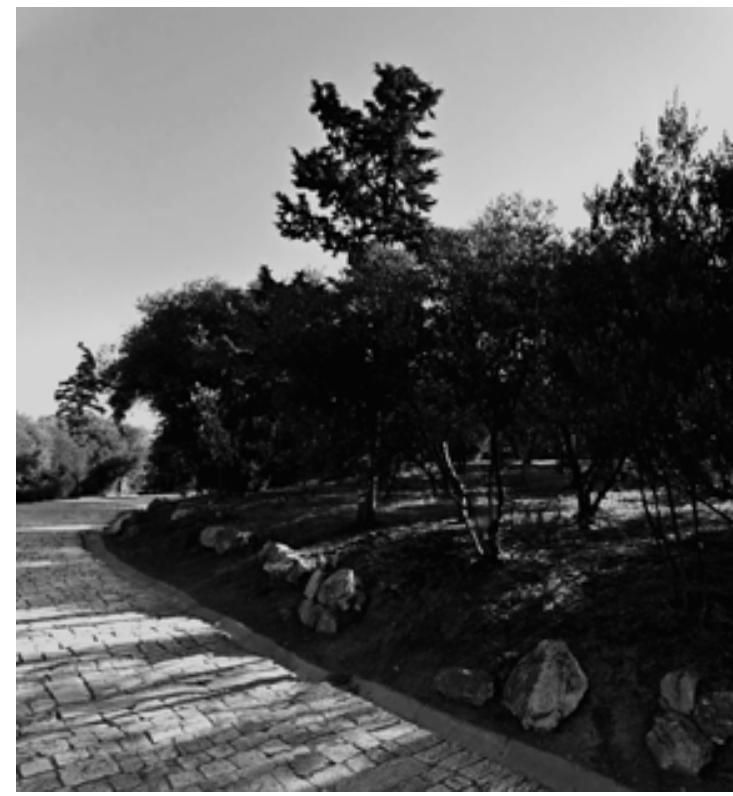

Fig 1.29. The right ditch and adjacent landscape.
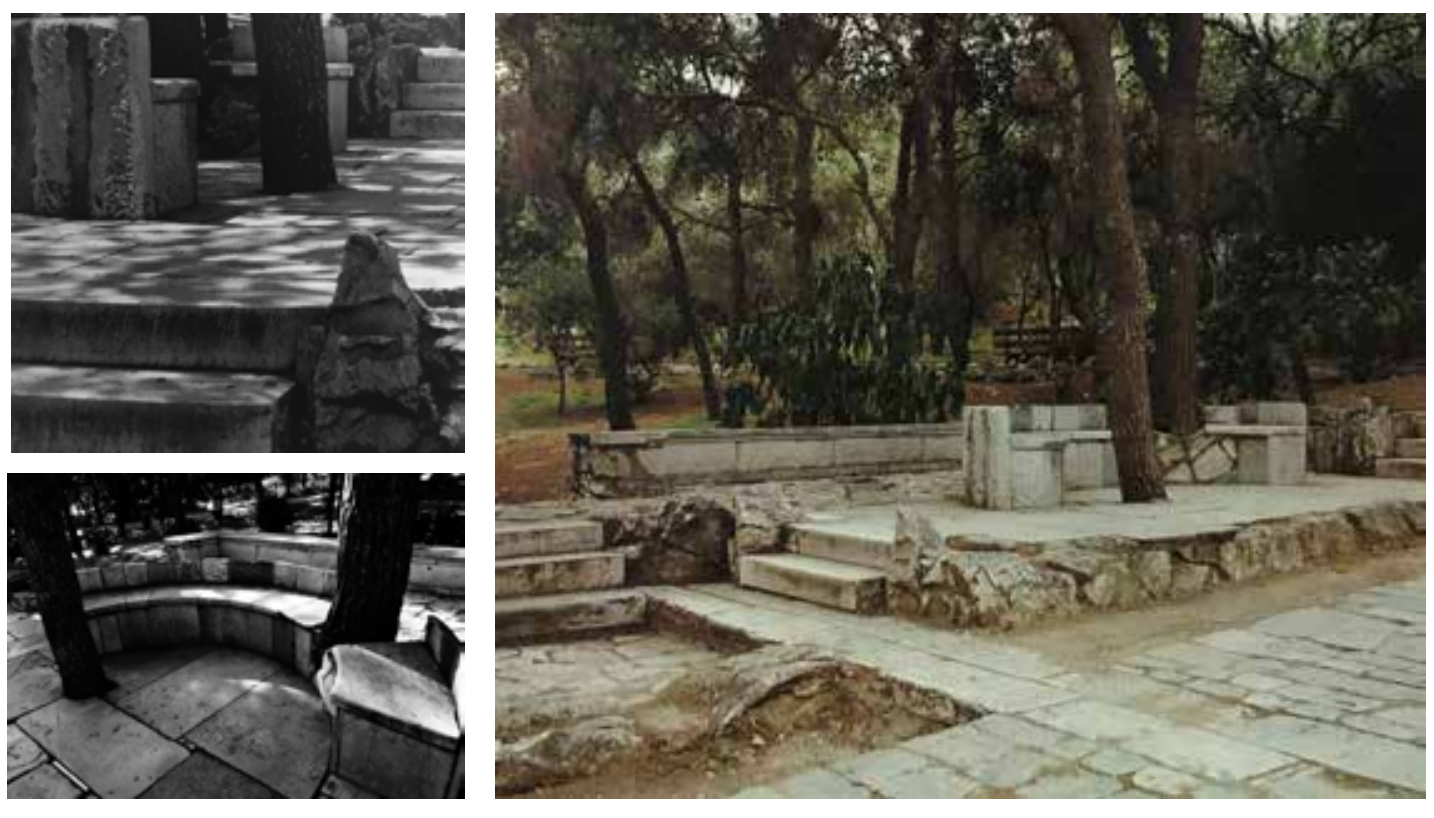

Fig 1.46. Stepped seating area beside the main pathway. extended floor, as if it was indicating a possible route, together with the seating on the opposite side, gives rise to a relative symmetry from the access, in which the central ascent is protected and underlined.

Following the stepped resting square on the right side, a ditch made of bended slabs draws the curved boundary in the distance. Though this fined interval demonstrates a closer relation between the solid pavement on the one side and the earth land on the other, the seamlessness of the precise outline of the raised ground supported by big rocks does not indicate accessibility but accompanies the attentive visitors, reminding them of the archaic nature of this hilly area. This stone channel designed for the outflow of water, together with the adjacent trees, rocks and soil, constitutes a set of elements that Alberto Ferlenga calls "miniature", which "makes the mountains and rivers of the attic landscape reappear" ${ }^{\prime 32}$. This sophisticated combination of artificial and natura materials reminds of the representation of nature with skillful scale in Japanese te gardens, whose designers have been working to transfer aesthetic functions to liturgy of an ingrained landscape religion.

Trees planted alongside the deeper course of the pathway, which are apparently bigger and denser than those at the access, reduce visuality of the city street on the south side. Pikionis subtly oriented the first part of the pathway to the east before gradually turning the way to the west through a soft bend. This curved itinerary leads to a compressed dimension on this short passage which will give visitors a sense of inhibition since their perceptions are limited at close distance. In this initial part of the Acropolis path, the architect altered scales, pavement and structures to promote an intense transit from the outer world into the increasingly narrowed path on which visitors seem to get lost.

32. Alberto Ferlenga, "Sistemazione dell'area archeologica attorno all'Acropoli e al colle di Filopappou Atena, 1954-57," in Dimitris Pikionis 1887-1968, 236.

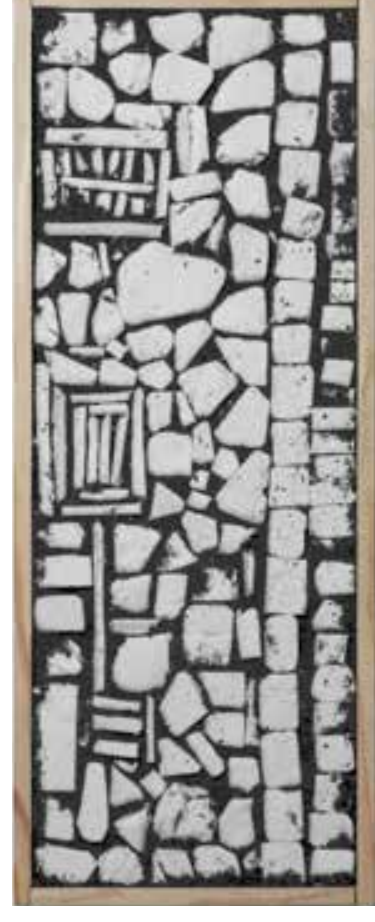

Fig 1.30. Extension pavement mock-up.

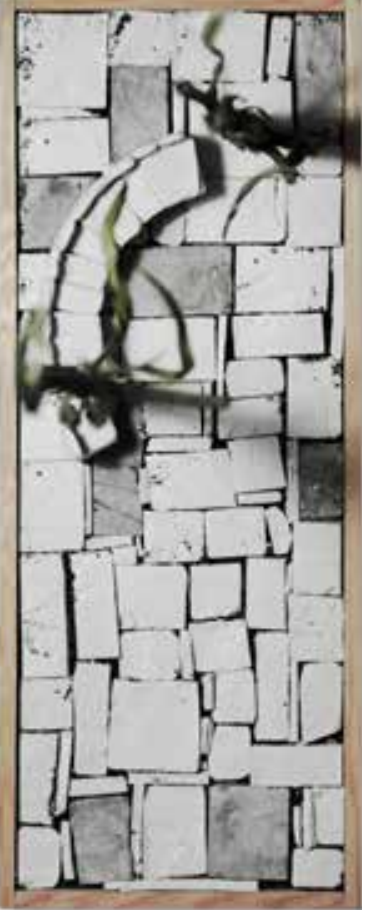

Fig1.47. Seating mock-up.
The illusion created by Pikionis at this particular place reflect general character of his work on the archeological sites: It is impossible to discern a clear organizational logic to separate his intervention from the original quality of the landscape, components of these two groups are mixed as connective elements that manage to achieve a sense of unity by relating artificial products, as the Parthenon or a simple bench, to the life circle of the nature.

"All the forces of nature converge and work together to produce this particular configuration: the refined air, the bright light, the color of the sky, the floating clouds, the slope of the mountains, the boulders scattered around the Temple's stylobate and the grass growing between the cracks."

Pikionis was fascinated by the undecipherable connections between constructional and natural elements. On the Philopappou pathway, the two walkways detach visitors from a penetrating passage whose manifesto of depth keeps stressing a straightforward route. On the contrary, the discontinuous trajectory on the lateral passages deprives the measurement of distance and provides sufficient time for people to admire the natural views. By telling the species of trees, studying traces on the fragments, sitting on the bench and feeling the marble texture, we can apprehend Pikionis' creation of another world on the basis of the entirety of things.

35. Pikionis, "Sentimental topography," 69 


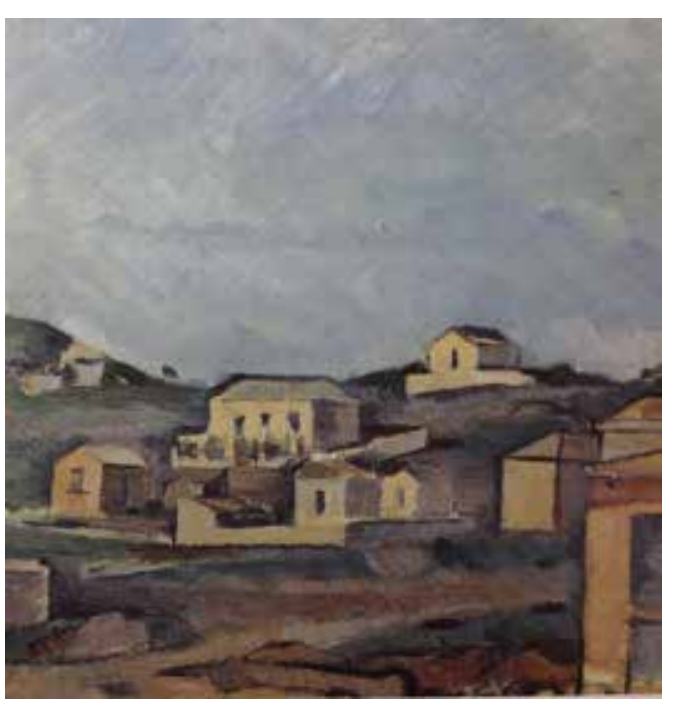

Fig 1.49. Hillside in Provence, Paul Cézanne, 1980-82.

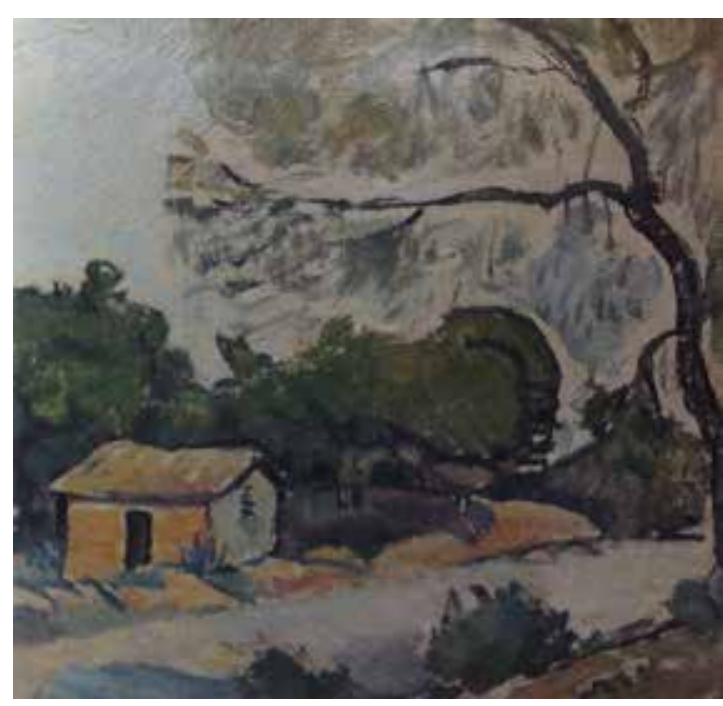

Fig 1.48. The countryside landscape, Pikionis.

$\S$ Epilogue - synthesis of pavement

Though the Acropolis is the protagonist in the narration created by Pikionis, organizations of the initial part in the two itineraries do not mean to make the grand images manifest from the first place. Pikionis composed the floor with discreet characters. Stones, rocks, trees are in constant game at the access, beside steps and around seating points, their relations are mediated by the means of scenography to reproduce analog ruins with solemn characters. Precisely at the intersection of the modern world and paths to the sacred places, Pikionis produced a narrative of a frozen time to introduce the background of a long story to every spectator

The pavement appears simple and refined at the same time. What Pikionis tried to bring forth from the earth was the characteristics inherent in the site, which were captured by his eyes on the attic landscape as fundamental connections between the temples and the pathways created in 20th century, and were mapped on the ground by the architect in the footprints of those Avant-garde masters.

In his drawing of Greek village, Pikionis contoured the vernacular houses, roads and trees with bold lines to emphasize their geometries. (Fig1.48.) This technique, which may come from the advice of his first teacher of drawing, Parthenis, who told him "to trace outline of objects as accurately as possible", is also found in Cézanne's works. (Fig1.49.) Pikionis described that the principle theme in Cézanne's paintings lies in the position between "the eyes and the objects". By precisely following the physical quality of things, the "blunt, pointed, broad, thick, thin, narrow, high, low, hard, soft, dry, wet, hot, cold, light, dark...", the painter will acquire the ability to portray the essence of natural forms without mimetic representational techniques, so he/her can reach their

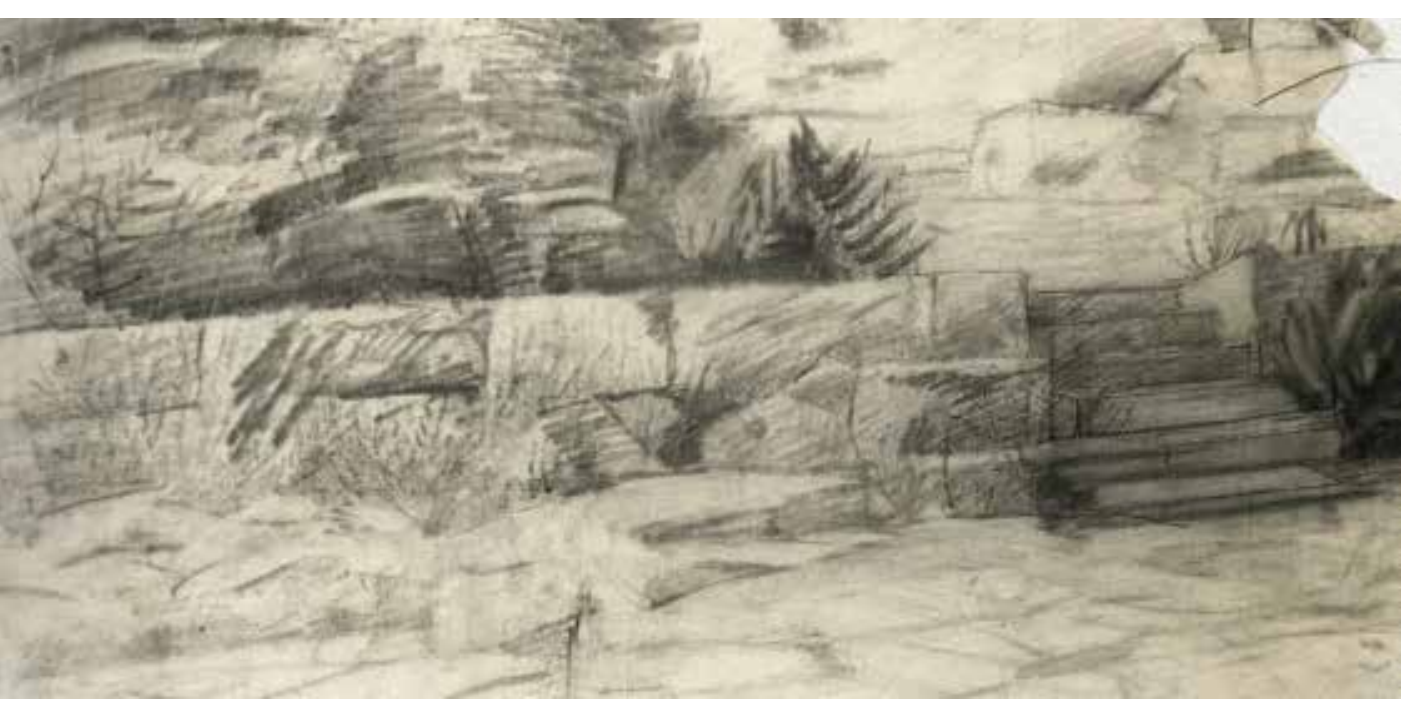

Fig 1.50. Sketch of the Acropolis landscape, Pikionis. internal characters which are "graceful, beautiful, strict, kind, tender, sad, joyful, poetic, dramatic, tragic..."2

Both of the masters pay much attention on the expression of sunlight when illustrating the landscape. The contrast between warm and cold color in their works emphasizes the light and even radiation of heat on the surfaces. Pikionis valued the crucial importance of light in his design. He used to say: "architects ought to realize that architecture involves lighting as well; lighting should not be added later." In those project sketches for the Acropolis landscape, one can tell sun rays filter through bushes, fill the soil, and reflect on the limestone steps, slate floor and marble benches. (Fig1.50.)

Pikionis said: "The sensitivity of nature penetrates into the work of art through the sensitivity of the spirit. ${ }^{36}$ His capacity to translate observed things to drawings, and then to constructions was inherent in his sentimental understanding of the nature of materials, especially the stone. He wrote in A sentimental Topography: "I stoop and pick up a stone. I caress it with my eyes, with my fingers. It is a piece of grey limestone. Fire moulded its divine shape, water sculpted it and endowed it with this fine covering of clay that has alternating patches of white and rust, with a yellow tinge. I turn it around in my hands. I study the harmony of its contours. I delight in the way hollows and protrusions, light and shadows, balance each other on its surface. I rejoice in the way, the universal laws are embodied and fulfilled in this stone.. ${ }^{37}$ The belief in each paving

36. Ibid.

37. Pikionis, "A sentimental topography," 68 


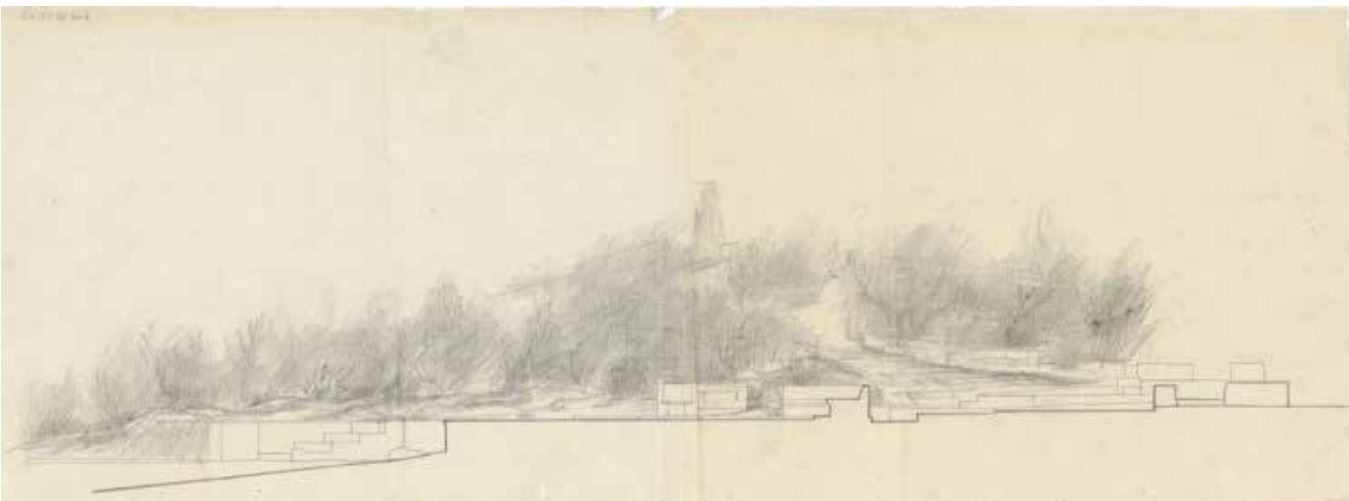

Fig 1.51. Section of the Philopappou road.

piece contains the law of the universe set a rule for him to carefully select and arrange of the stones, with the aim of involving the pathways into the harmony of the whole around the spirit in situ of the Acropolis and the Philopappou hill.

The initial course of the two pathways indicate one of the mechanisms of Pikionis to compose the pavement. The overall trajectory is divided into several stages with respective themes, whose meaning from their position and relation with the surroundings: the distance to the buildings and monuments, the adjacent topography, as well as the density and species of plants on the roadsides.(Fig1.51.) As for each stage, its composition is made of repetition of a motif - a particular combination of regular and irregular stones, in square or circular shapes. Rather than completely copying the term, variation of materials and paving scales were applied to form rhythms in the process of duplication. In this way, though individual pieces seem to be placed in a random way, a compositional order was kept to ensure a stable and continuous process, capable of showing the significance of one theme, as well as to anticipate the following stage

Therefore, apart from the development of landscape, the ancient fragments scatter on the roadsides and structures added by Pikionis that manage to unite of sacredness and the natural quality in the site, the aesthetic solutions on the pavements make the two paths experienced as a series of episodes drawn by "the abstractness and at the same time the extreme 'topographical' realism of the figures" ${ }^{\prime 38}$. The floor is transformed into a labyrinth, whose variations and complexity alter the walking speed, vibrate perceptions between the ground and the surrounding elements, between the nearness and the farness.(Fig1.52.)

38. Alberto Ferlenga, "Sistemazione dell'area archeologica," 232.

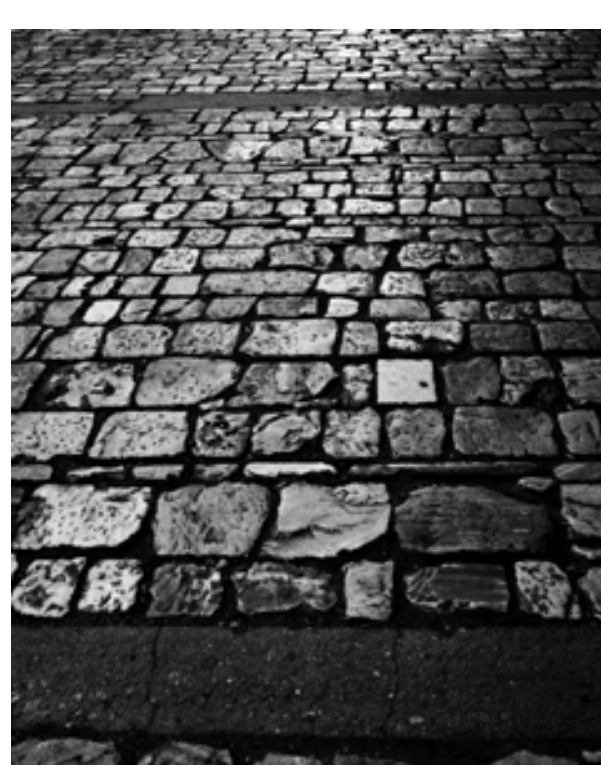

Fig 1.52. Pavement on the Philopappou road.

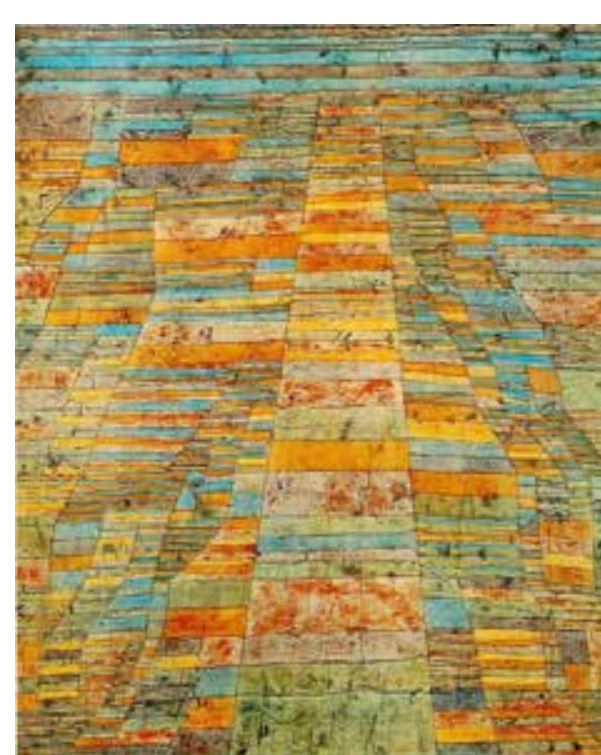

Fig 1.53. Main road, side road, Paul Klee, 1929.
Paul Klee said: "Art does not reproduce the visible but makes visible." Under this interpretation, his painting and Pikionis' pathway can be said to perform as an engine to produce a way of looking. In the pavement, there is Klee's compositional mechanism in his Main road, Side roads (1929): a balanced structure is barely visible from the constant alternation of an interest in axiality and symmetry, and the abandonment of it in favor of a more fluid mediation of the boundaries. (Fig 1.53.)

Paul Valéry described "synthesis" as "an artificial invention which attempts to give order to a primitive chaos of feelings and natural evolution. It involves intentional and contemplative actions that discipline the impulsiveness of a natural production according to a particular conception. ${ }^{39}$ On the foot of natural and artificial monuments, Pikionis created a world of randomness and primitiveness inherent in the attic landscape, and controlled the variation of those components to make them readable, and more important, walkable, to serve a journey towards the remoteness. 


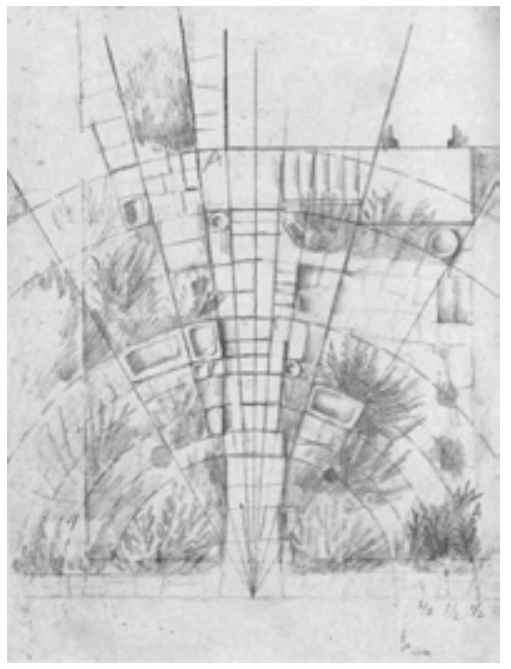

Fig 1.54. Study on visual segment of the

Philopappou pan

\section{A LAYERED APPROACH}

In the letter he wrote to the client to ask for extension of time for the construction, Pikionis said: "Plans and instructions are insufficient here, for the plan is not applicable as it stands, but serves only as a model representing a general idea which requires constant interpretation... What should be kept in mind is the ancient Greek motto, 'Make haste slowly'., ${ }^{, 40}$ Though Pikionis would not like to produce detailed plan of the project, a number of sketches he did during the work served as guidelines to conceive specific space. Apart from the sketches that represent harmony coexistence of trees, the hilly site, new and old stones from the artistic eyes of the architect, the layout of the siteplan organized by the means of scientific study on geometry to relate sight lines with the position of objects can be regarded as formal strategies more about the way the architect was thinking and experimenting in the space than the same result he tended to achieve. (Fig1.54.) Established on the basis of a sequence of views and angles of sight, the schematic composition gives the site an overall measurement. Sight lines were applied to create rules to calibrate the location of objects and to direct movement of visitors from the outside to the innermost place. Thereby, the plan drawings represent walking experience and chronological quality, a series of critical points elucidate the events and objectives at each moment during the journey throughout the landscape.

This method was developed from the innovative interpretation created by his old student Constantinos Apostolou Doxiadis (1913-1975). After graduating from Polytechnic University of Athens in 1935, Doxiadis followed Pikionis' advice, went to Berlin for doctoral research. In the next two years while Pikionis was working on the magazine The Third Eye, Doxiadis developed an innovative method over the interpretation of spatial composition of ancient Greek temples. Contrary to those mostly accepted

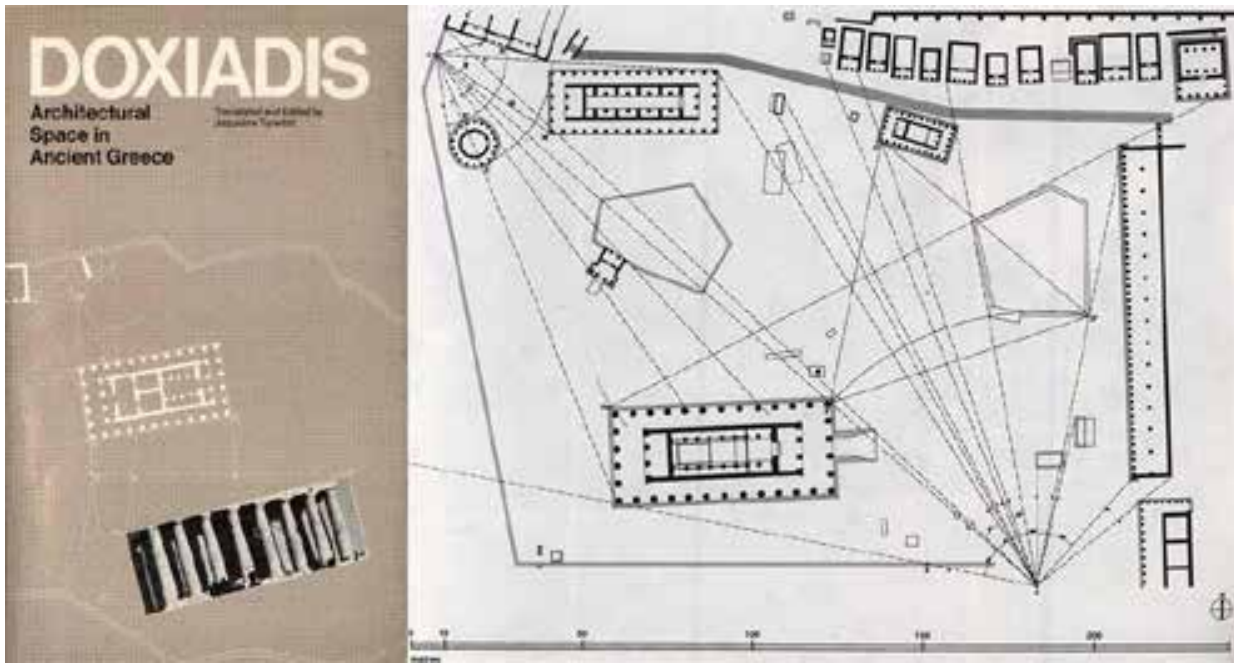

Fig 1.55. Doxiadis' doctoral dissertation Architectural Space in Ancient Greece.

views, as Choisy's theory of picturesque, regarding the plan of the sacred sites as aesthetic production, Doxiadis investigated the classic composition by the means of a mathematical method based on golden section, that unite all the buildings in a general layout. (Fig1.55.) In his doctoral dissertation entitled "Raumordnung im griechischen Stadtebau (Architectural space in Ancient Greece)", translated into English and published by 1972, Doxiadis wrote:

"It is not always easy to remember that these complexes were built by the ancient Greeks not as isolated objects, as we see them today, but as parts of a dynamic urban environment. As elements of a city they were subject to contemporary conditions of growth and change. They were not designed to satisfy the aesthetic demands of modern man fir an ideal layout, an ideal city, unrelated to an actual time or place."

He continued to draw up the compositional principle in these ancient scared places:

"1. The position of the buildings was determined not only by the angle of vision but also by their distance from the viewpoint.

2. These distances were based on simple geometric ratios deriving from the angles of vision.

3. One angle, frequently in the center of the field of vision was left free of buildings and opened directly to the surrounding countryside. This represented the direction to be followed by the person approaching the site: it is the "sacred way"

4. The buildings were often disposed so as to incorporate or accentuate features of the

41. Constantinos A. Doxiadis, "Architectural Space in Ancient Greece, (The MIT Press, 1977), 


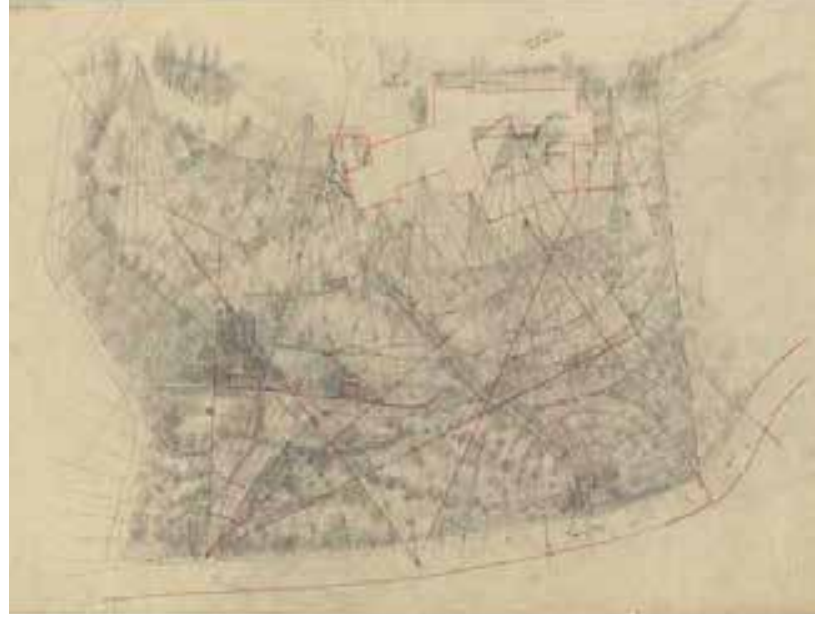

Fig 1.56. Sketch of the Xenia Hotel, Dimitris Pikionis, 1951-54

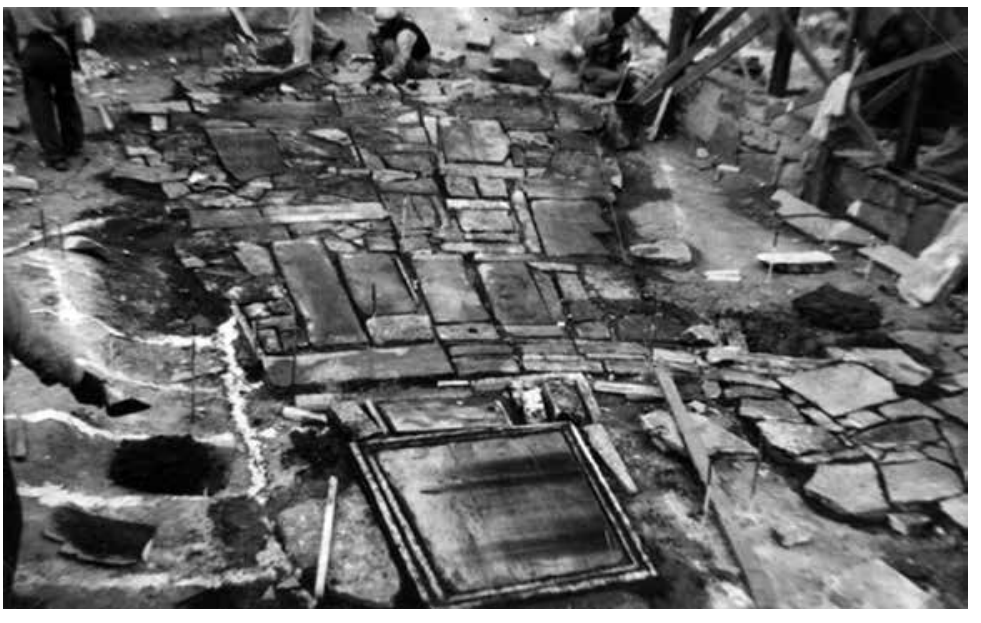

Fig 1.57. Paving work of the San Dimitris Loumbardiaris church. existing landscape and thus create a unified composition., ${ }^{42}$

Doxiadis' controversial perspective, which, regarding the observer, the man, as the center of the place, and gave rise to a polemic with those who saw the temples were built only to serve the gods, recalls Protagoras' words quoted in Plato's Theaetetus: "Man is the measure of all things, of the existence of the things that are and the nonexistence if things that are not." His work fascinated many architects and scholars. Among them, Pikionis, the man who learned from the ancient Greek architectures throughout his life, thought highly of the concept and applied it in the arrangement of normal objects: "I tried to place five objects on the table: a vase, a glass, an ashtray, a box of cigarettes and a matchbox ... It was not at all easy. It lacked geometry, frame. There was an absence of order. Then I tried to implement the "Doxiadis" laying-out method and the subdivision of distances according to the analogies of the Golden Section. The result was much more solid, the picture much more precise, the reference more visible." ${ }^{33}$

Prior to the Acropolis project and the playground in Filothei, Pikionis used "Doxiadis method" in the design of the Hotel Xenia (1951-54), situated at the west part of the ancient city of Delphi. The hilly topography provides opportunities for the architect to create a dynamic landscape in order to animate views. The siteplan that he has made illustrates the relationship between the building and the multiplicity of elements in the garden in front of the hotel. (Fig1.56.) There are two groups of sight lines, one from the garden to the building, and the other from the building alongside its winding outline They interact with each other and establish a microcosm that involves buildings, trees,

42. Ibid, 5 .

43. Dimitris Pikionis, Architect 1887-1968, 74 paths and rocks. Those angles, defined by sightlines, are the verification of every possible relationship between the hotel and the landscape, indicting Pikionis' attention on every potential area in the site that might be observed.

As for the Acropolis intervention, working sketches show that Pikionis did not apply the method for general control but used it to structure the most important plots.(Fig1.57.) In the second part of the routes which end up with loops, turnings, variation of landscape and pavement, and more important, the distant images of the Parthenon and the Philopappou monument gradually replace the expression of straightforward paths in the first half of the trajectories, structuring a net of visual points that constantly guides visitors' perceptions. The use of radial systems and foci coinciding with viewpoints of the viewer, which works fundamentally at certain intersections of the roads and in the layout of San Dimitris Loumbardiaris church, contributing to layered the promenade in these areas. Thereby, Pikionis identifies landscape features with the potential to frame or direct individual's eyes, and creates itineraries based on the sequence of provisiona views that keep building anticipation and promoting a penetrating movement through a succession of phases towards the further space. 


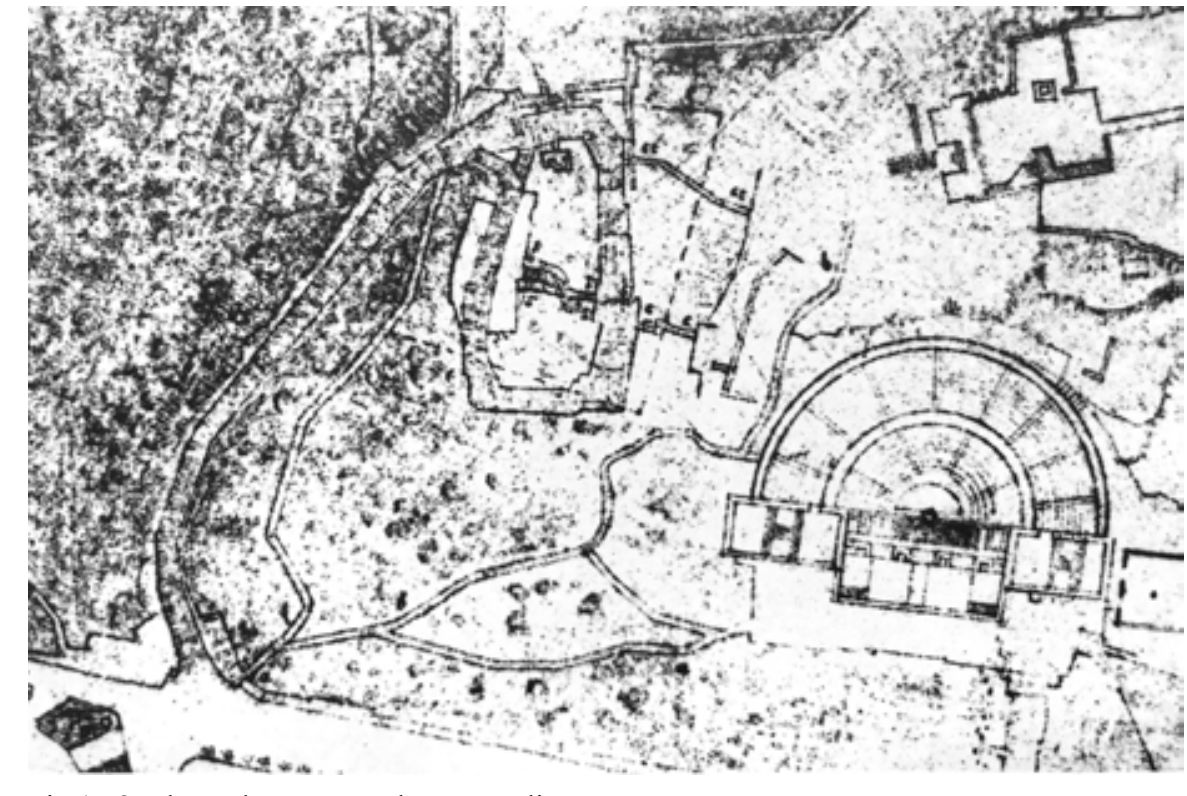

Fig 1.58. The pathway up to the Acropolis.

$\S$ Continuity through an intense transit

truncation in the experience

Beyond the entry which stands out for its rich composition and the following shor course that sees reduction of the variety of pavings and materials, the pathway up to the Acropolis is continued by a bend that turns the way to a straight course that runs to the north-west direction. (Fig1.58.) As the overall aim of this itinerary is to produce a direct ascent to the sacred rocks and to give visitors a continuous experience, one of the challenges lies in the establishment of a particular order of movement and views which must isolate visitors from the outside world and to provide them an exclusive approach in a short time and distance, because the 200-meter trajectory does not allow a slow transit. This intention may suggest the reason why Pikionis decided to relocate the path By moving the access to the east about 140 meters away from its original location under the Odeon, a systemic approach is created on the pathway which acquires sufficient space to turn back through a curved route.

The soft bend releases tension between the previous and the following straight trajectory by stretching the middle course. The lengthened turning leads to a gradual process which on the one hand, reduces the intensity of movement so that allow people to keep a steady speed while climbing the ramp, and on the other hand, divides the overall itinerary into two parts: the first one, whose variations manage to define a new space ye to detach itself from the images of the intersection of city streets, and the second one, whose simplified composition and gradually reduced visual connections with the streets manage to enhance its independency.

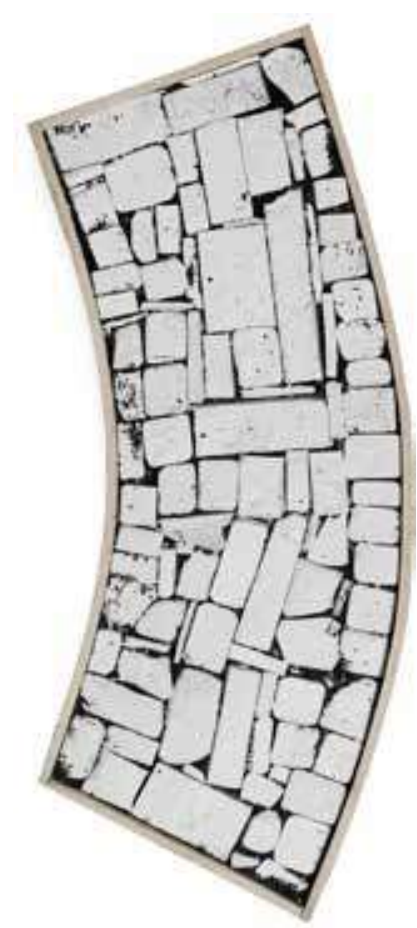

Fig1.60. The bend mock-up.

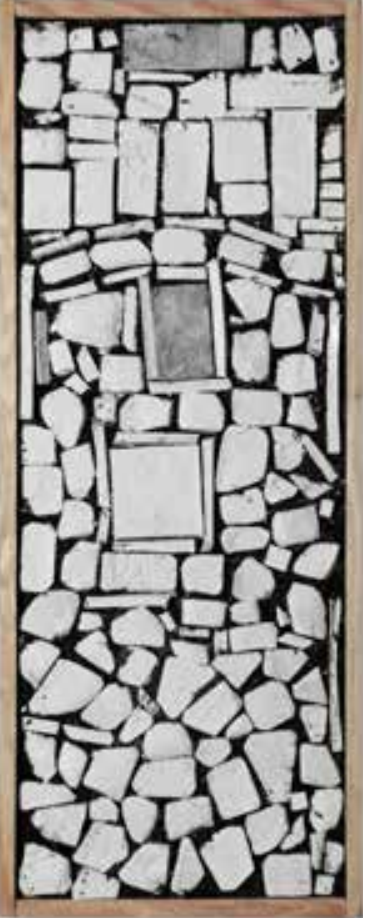

Fig1.73. Church courtyard mock-up.

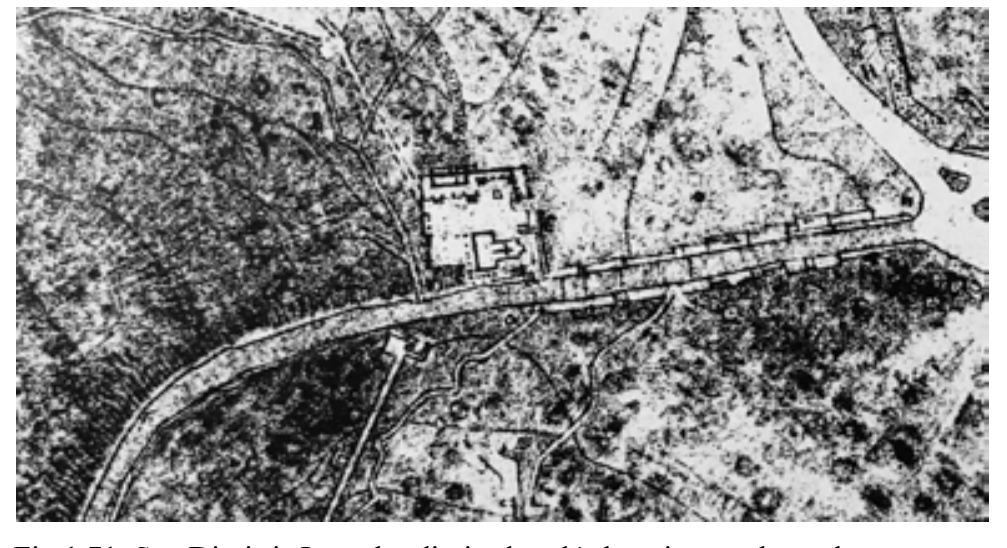

Fig 1.71. San Dimitris Loumbardiaris church's location on the pathway.

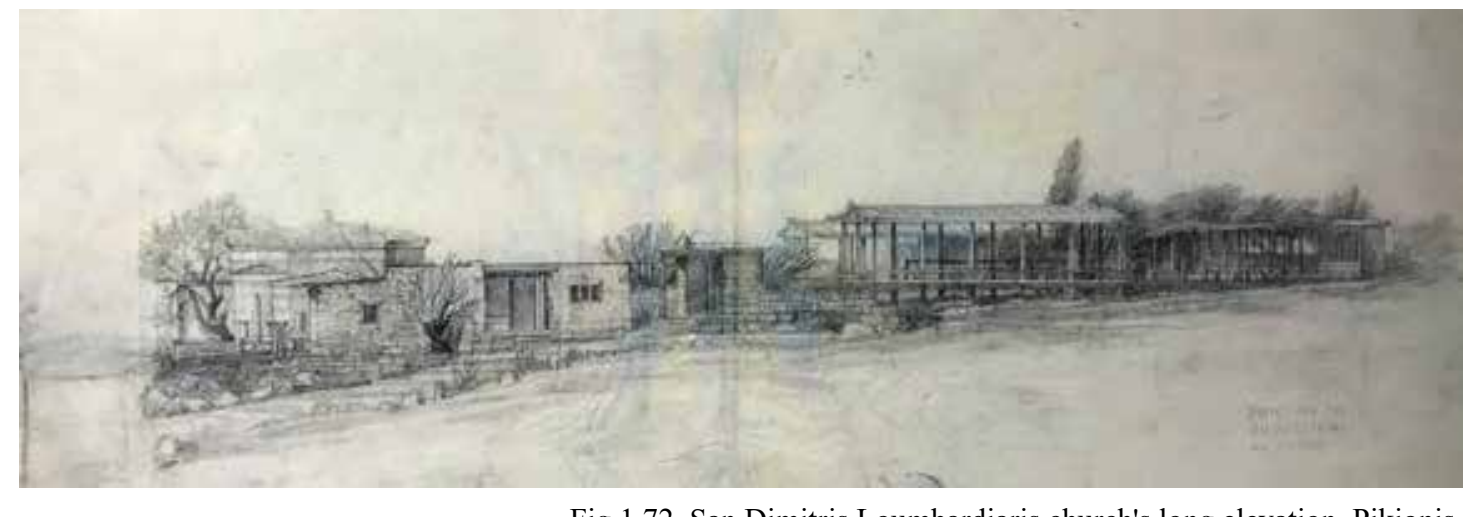

Fig 1.72. San Dimitris Loumbardiaris church's long elevation, Pikionis.

$\S$ From architecture to a diverging journey

"architecture on the road"

The small enclosure of San Dimitris Loumbardiaris Church in the middle stage of the Philopappou pathway provides a religious and public space that arrest visitors. It gives a bold separator between the first and the second half of the ascent. (Fig1.71.) By adding a narthex to the church, Pikionis transformed the old Byzantine church into a small basilica. The additional pavilion behind the building accommodates the complex to the slope ground and amplifies the geographical qualities in situ. (Fig1.72.) The church's layout consists of two sets of constructions and yards perpendicular to each other is able to dialogue with the surroundings. (Fig1.73.) It also leads to an internal division of space and events: while the church and its foreground are used for public ceremonies and sees a narrow route across the main road up to the Philopappou hill, the pavilion and the adjacent court produce a contemplating space from which people will have a calm view to the ancient monuments.

Pikionis restored the building of the church and added affiliated structures in temporary forms. (Fig1.74.) The simple tectonic presentation and authentic manifestation of materials of the complex contribute to a synthesis of rural, natural and historic values that make the enclosure manages to "avoid the risk of anachronism and the picturesque and gives rise to a timeless construction." ${ }^{, 48}$ Apart from the formal evocation stemmed from the constructions, the siteplan with sight lines indicates the influence from

48. Alberto Ferlenga, "Centro di accoglienza turistica di San Dimitris Loumbardiaris Parco dell'Acropoli, Atene, 1954-58," in Dimitris Pikionis 1887-1968, ed. Alberto Ferlenga (Milan: Electa, 1999), 274 


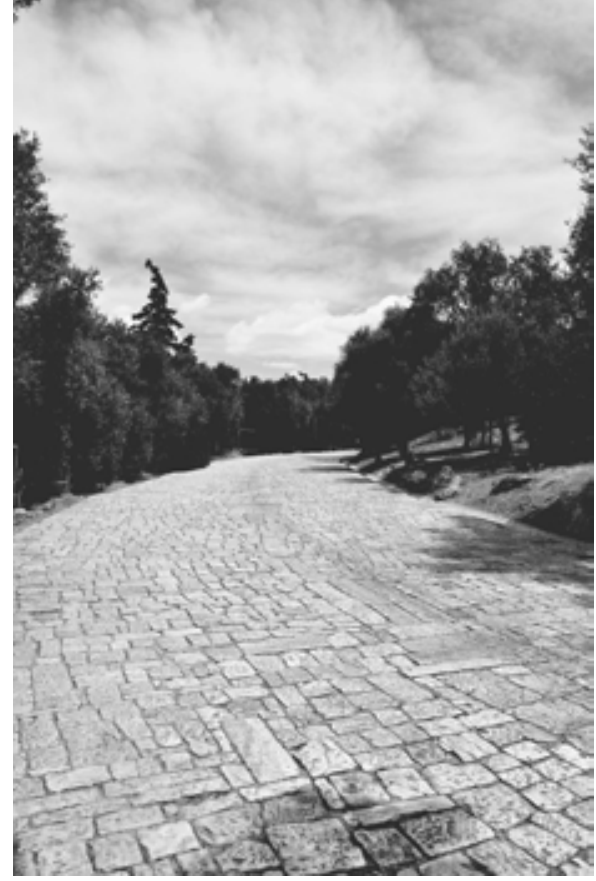

Fig 1.59. Bend after the entryway.

Removal of rest points and seating areas promotes a non-stop journey, whose directionality is further emphasized by the vegetation on the roadsides. Trees on the left side, much denser than the those on the right side, create a continuous screen on the site's periphery that wraps the space. (Fig1.59.) The natural boundary directs views to the other side, where a set of trees, bushes and rocks on the raised ground recall the original condition of the hill. The sparse vegetation permit people to see through the landscape though images of the ancient temples are completely hidden. Believing in the site's potential to imply the location of the Acropolis at any single point, Pikionis postponed the appearance of the monuments, leaving them as a constant and imagined presence that psychologically orients the visitors by the means of keeping its historical narration quiet until the last moment.

Alongside the route to the Acropolis, Pikionis gave rise to a monomateriality condition as a way to establish a unitary language of design. Pavement do not change much on the bend. Since the terrain is not particularly steep and the gentle slope was not used much by vehicles, Pikionis did not use cement or concrete to reinforce the floor but paved the ascent with fragments of marble and stone. While small and squared slabs compose homogeneous patterns that coordinate with the monotonous composition in the space, irregular pieces were used on the road edges to fit with the curved outlines. (Fig1.60.) The limited use of materials also gives a good indication of how Pikionis defended the consistency of the individual expression of the itinerary, whose accurate and clear meaning is easy to reach a consensus in order to eliminate ambiguity in physical and metaphorical narratives. In addition, the monotony of floor patterns would ask visitors to pay much more attention on the forward movement than on the floor

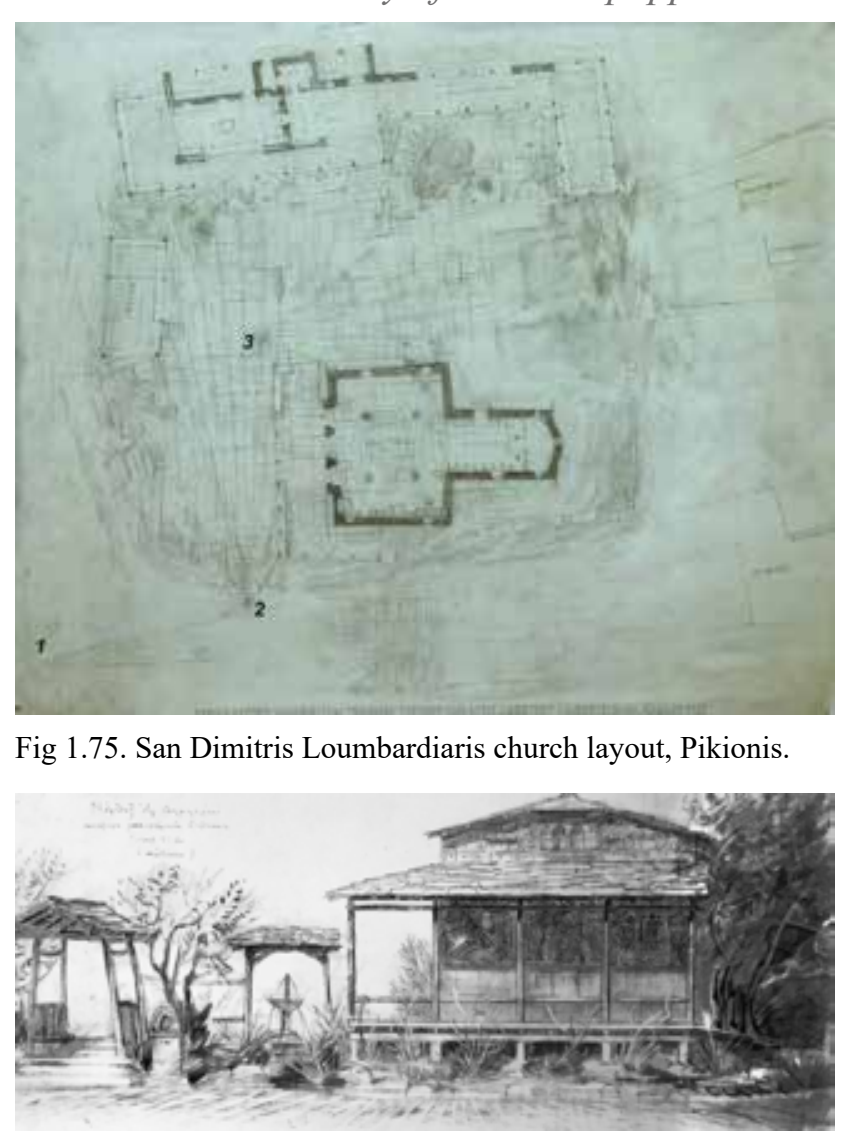

Fig 1.74. Sketch of the church entryway, Pikionis.

Doxiadis. An early sketch shows how the architect structure the space according to precise measurement. (Fig1.75.) The distance between the observer on the pathway and the cypress next to the church entry is divided according to golden section into 3:5 and 8:13. Standing point of observer is set as center to generate a gridded viewing segment of thirty degrees. Rocks and objects are placed at the points of intersections, which also control the width of the road. The dimension of the church entry is determined by another viewing segment from point 2, which turns the direction to the interior of the enclosure. Since the final work does not intend to show the Acropolis from the main pathway, we may assume that this sketch did not illustrate the idea which has been realized. But it definitely explains the strategy that Pikionis applied to discover what the particularities of each location and structure the space according to a series of overlaid grids. As for the plan drawing of the church, three points respectively marked on the pathway, at the entry of the enclosure and by the edge of the inner court indicate a sequential movement led by a series of critical objects. (Fig 1.76.) The facade of the church, repaired by Pikionis by mixing Byzantine and popular fragments, resonates with the pavement. The use of ancient pieces to form a motif on the facade recalls his renovation of the House Garis in Athens, between 1960-1964. The stone walls of the church are partially framed by the external elements of shrub, rocks and the added wooden porch, which serve as a bold interval between the raised architecture and the main road.

Pikionis took advantage of the elevated ground of the church to create an ascent into the patio. The stony stairs from the entry porch gives a straight access. It passes over the forecourt of the church and reaches the steps which lead up to the pavilion located as a temporary backdrop. On the opposite side across the pathway, the remains of city wall and the trial meandering up the hill are framed by the wooden door, seemingly expand 


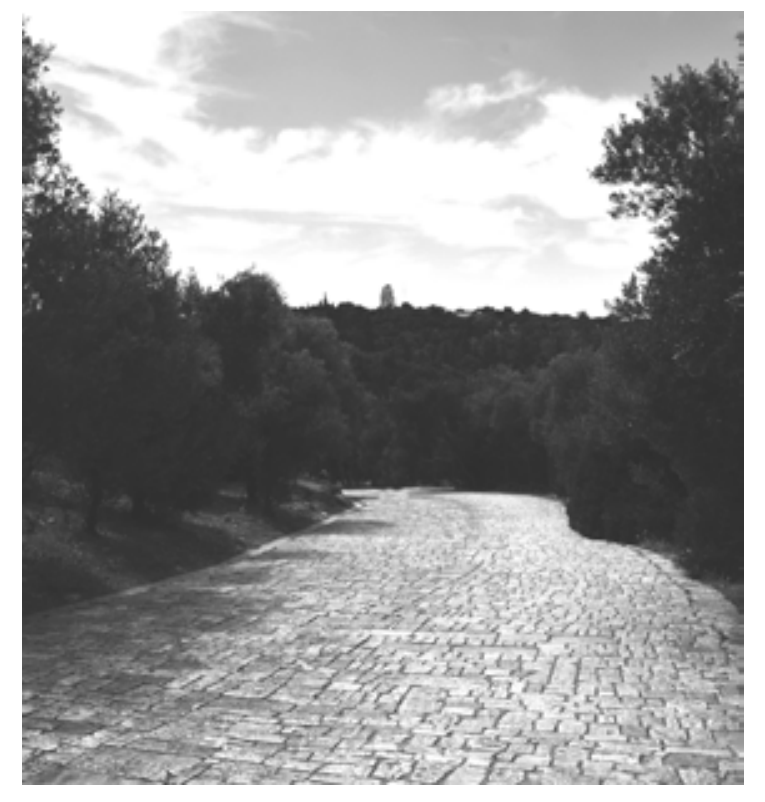

Fig 1.61. Philopappou monument seen from the Acropolis road.

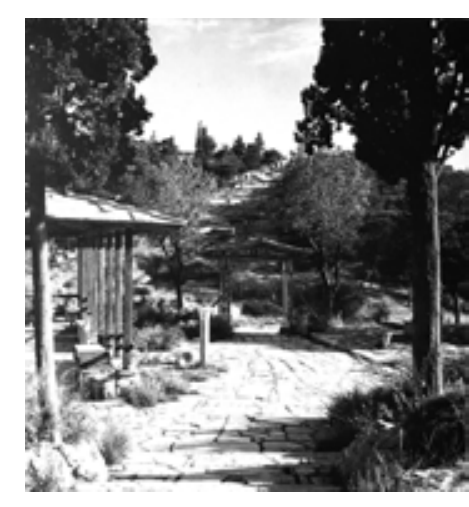

Fig 1.77 Route up to the Philopappou.

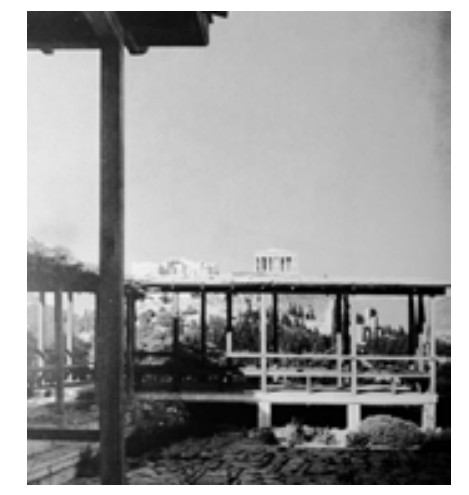
Fig 1.78. The Acropolis seen from
the church's inner courtyard

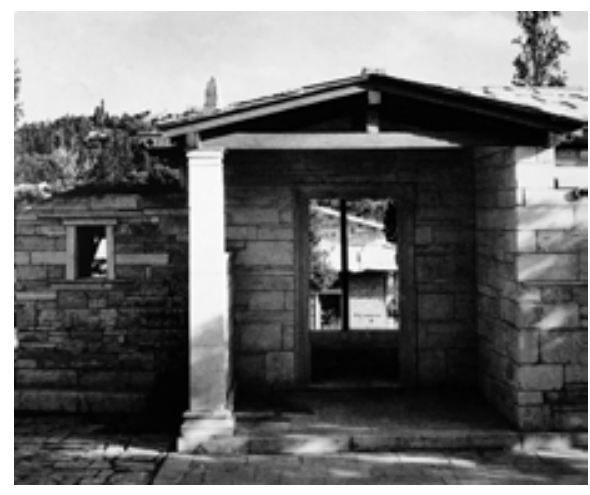

ig 1.80. The Philopappou monument seen from the pavilion's perimeter.
The bend plays a critical role in the overall itinerary by providing a process that isolates visitors from the outside street and gradually unfolds the images ahead. It was developed according to the changes of perception from a short range to the observation of spatial depth in a long distance. The following course, a straight route which only lasts 26 meters, is too short to draw one's attention during the ascending process. (Fig1.62) This short course is precisely aligned with the Philopappou hill (this could be another reason to relocate the entry of the pathway) to provide an important view to the monument on the summit in the distance. (Fig1.61) Pikionis presented this correspondence of images of the two hills as unexpected encounter for visitors who are going back down from the Acropolis.

The short course effectively concludes the landscaped sequence by the means of a succession of visual points alongside a round trip. It was produced on the basis of Pikionis' intention to relate the archeological sites and their monuments with each other, and to place visitors' experience within the constant dialogue between those preexisting elements. Despite of the aim to present a direct transit to the Acropolis, Pikionis played with the relation between the invisible and the visible, between the objects in the near and far field to incorporate opposing narrations on the ascending and descending trajectories on a single route. Emile Chlimintzas indicates that the unity of paradoxical factors is one fundamental character inherent in his works:

"Pikionis liked working with complementary contrasts: open and closed, inside and outside, light and shade, solid and transparent, linear and concentric, unity and diversity, past and present...His work is multivalent; he endeavored to bring about a synthesis of these contrasts.." ${ }^{44}$

44. Dimitris Pikionis, Architect 1887-1968, 60

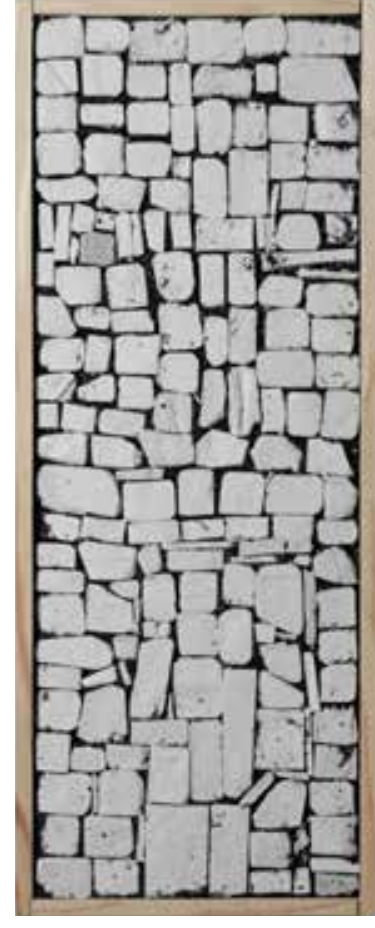

Fig1.62. The short course mock-up.

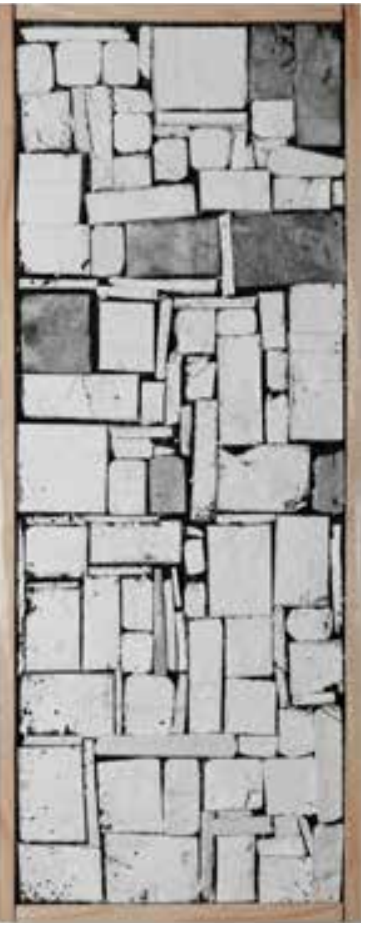

Fig1.79. Pavilion floor and mirror the itinerary inside the church. (Fig1.77.) This unexpected encounter with the alignment of promenades of different epochs is stemmed from Pikionis attentive study on visual relationships and the original order, presenting how the intervention of a revived site was strongly rooted into the place and its history.

The third point next to the northern corner of the portico reorients the circulation to the east. A short slope narrowed by trees on the both sides, together with the continuous border formed by the pavilion in $\mathrm{L}$ shape contribute to a space of interiority, which is independent from the first court and from the views of the Philopappou landscape. (Fig.) Everything in this inner yard is arranged according to an orthogonal composition. The pavilion floor paved by precisely cut marbles presents a mythical narrative and interrupts the flow composed of larger slabs and natural stones from the first yard. (Fig1.79, Fig1.81.) The pavilion's short wing, arranged in parallel to the Acropolis, sets the backdrop of the whole enclosure. For the first time, the Parthenon appears from the horizon of its roof, whose slope is reduced in favor of presentation of the distant temples. (Fig1.78.)

Pikionis incorporated the architectures into the overall itinerary. The impending structures and vegetation have been conceived as a series of points of observation, the sum of real and metaphorical views on topography and history, which were used to measure visitors' paces and direct to the encounter with an exclusive space where sacred images are to be perceived.As Kurokawa used to say: "If this road can be called an 'architecture for human movement' the little church should be called an 'architecture of the road'., .49

49. Dimitris Pikionis, Architect 1887-1968, 76. 


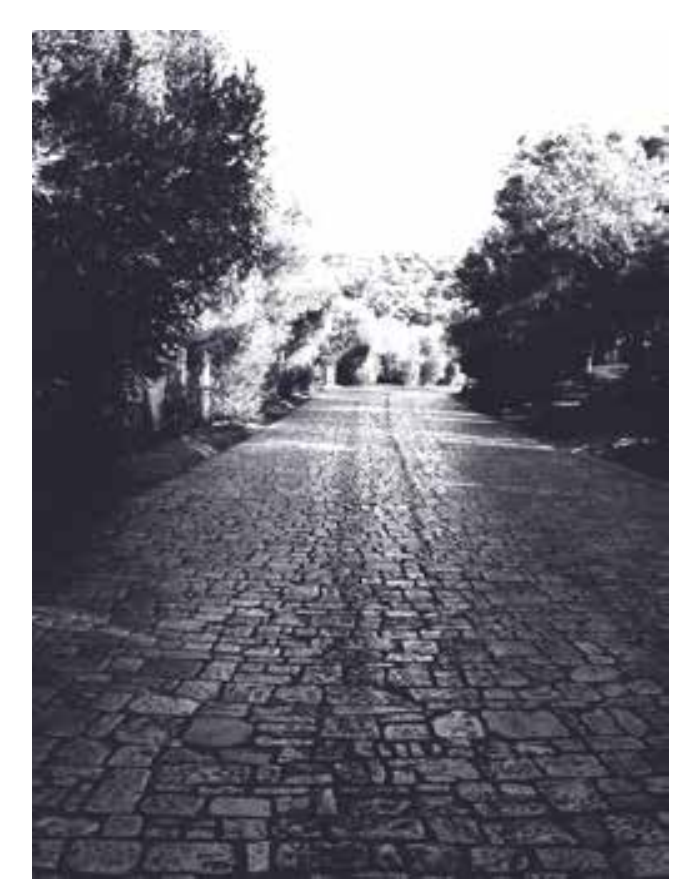

Fig 1.63. The straight course on the Acropolis road.
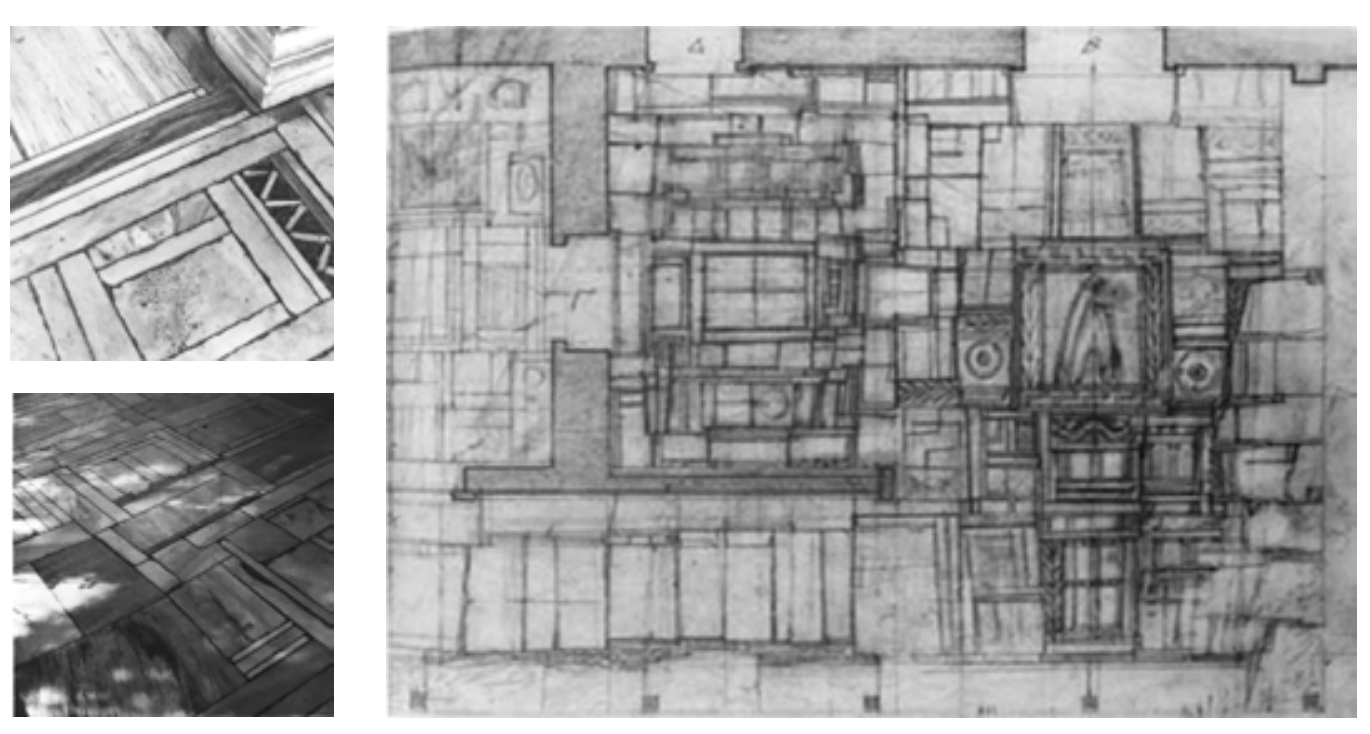

Fig 1.81. Pavement and sketch of the pavilion's floor, Pikionis.

Another drawing shows Pikionis' study about planimetry on the pavilion floor. Visual points are marked on every corner, from which views are directed to the doors and particular pavings or stretch out of the building. (Fig1.80.) These overlaid grids promote the feeling of being at the center of an endless network of evocations. Among all the accesses, one door on the north side leads to an exceptional place. When visitors go out of the pavilion and climb up a small mound on the back, the distant images of the Acropolis and Philopappou mausoleum are presented simultaneously in a choreographed sequence that collapses distance between the two monuments.

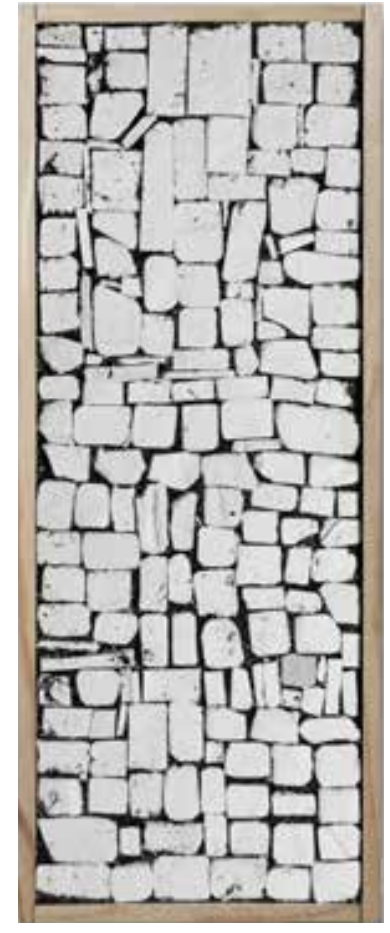

Fig1.64. The long straigh course mock-up

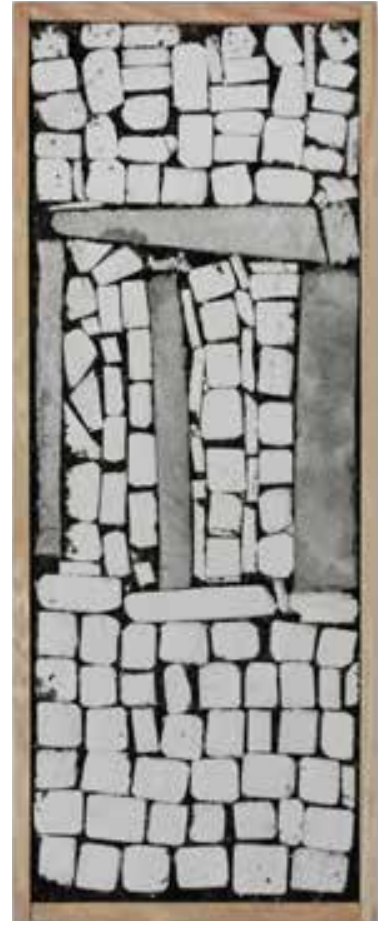

Fig1.82. Philopappou road pave a metaphorical landscape

If the first part of the ascent on Philopappou hill represents Pikionis' concept to create an exclusive system, in which plants, pavement, the pathway and lateral passages were arranged together to serve a calm transit from city streets to the internal environs, then, the second part of the itinerary, a 300-meter long route which is delimited from the first one by the church and runs until to the loop, indicates the architect's strategy to make original characters and metaphorical interpretation of the landscape.

Contrary to the straightforward course to the west of the first part, turnings prevail in the following trajectory that gradually orients the way to the south-east direction. From the church access, the pathway first descents before it rises up. Natural ground and rocks on the roadsides reduce the accessibility. Though the removal of lateral walkways provokes a direct relationship between the visitors and the surrounding elements, the road boundaries are never sharp and irrevocable. Paving slabs, in this case smaller pieces were preferred, rocks and vegetations are interwoven at road turning and intersections. They reduce clean edges and give rise to a continuous fraying, indicating the precariousness of the intervention of the pathway. use of intervention of the nature to produce a powerful trajectory that combines the 


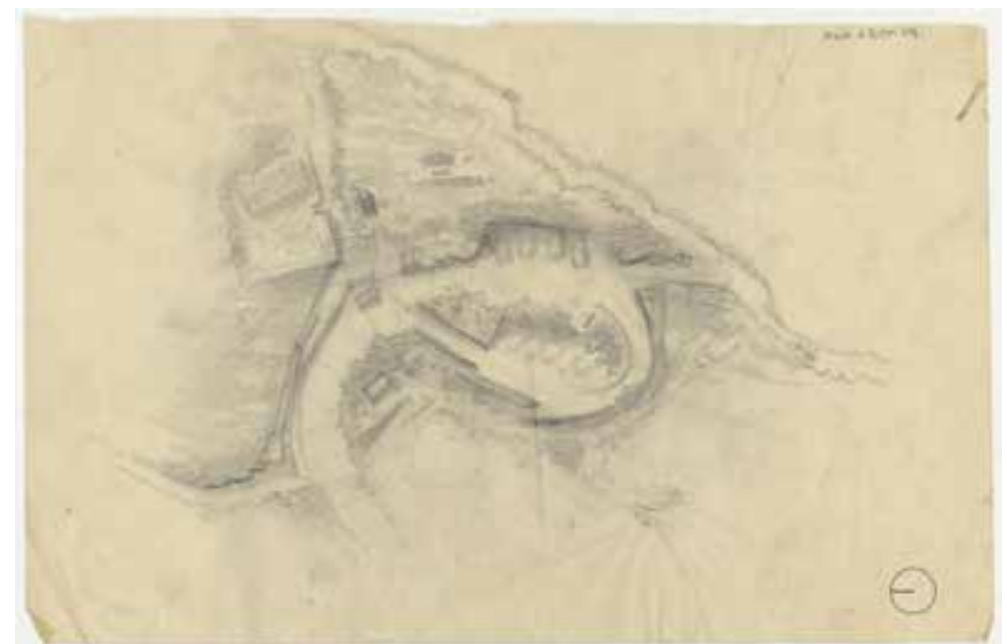

Fig 1.65. Preliminary drawing for the loop under the Acropolis, Pikionis.

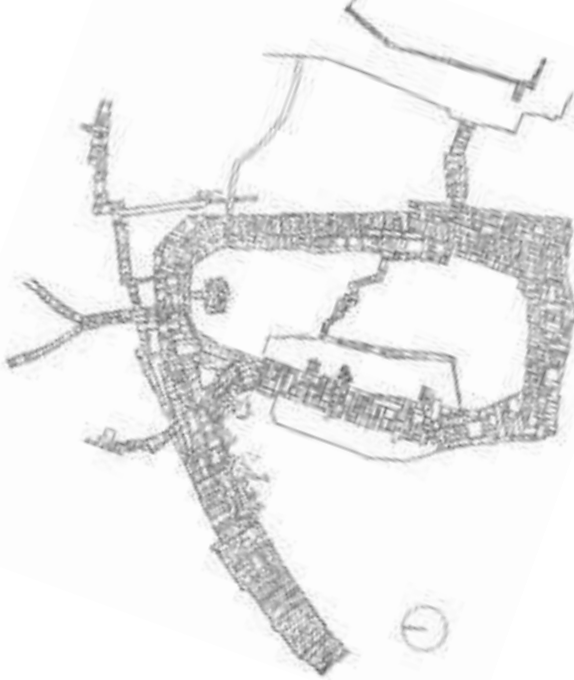

Fig. 1.66. Final layout of the loop, Pikionis. office and small shops located on the roadsides, serves as an intersection that plays a critical role in resolving multi-circulations. While a winding route derived from the west wing passes by the Areopagus and further leads a soft descent to the district on the north side of the hill, the south wing of the loop connects the narrow trail comes up from the Odeon with a stony slope runs to the east away from the loop and starts a circuitous route up to the Propylaea.

Contrary to its expanded dimension that increases the capacity at the final point of the main road, the loop establishes an unusual sequence according to which images of the sacred temples are gradually presented. The straight pathway ends up with three branches towards different directions, contributing a clear division on the itinerary. The middle one that extends the main course provides a partial view to the Propylaea However, this sudden encounter with journey destination does not last long. When visitors either move forward or turn right to west wing, trees on the periphery and in the central plot immediately hide the ancient gateway and thereby reproduce an introverted condition. In this way, the road junctions acquire an ephemeral quality by presenting itself to the visitors as a reminder, a brief introduction of the upcoming episode.

The partially demonstrated image of the sacred rocks reflects Pikionis' intention to achieve balance between the most important figure and the pathway itself. On the one hand, visitors are animated by the presentation of the monument, on the other hand, the momentary encounter with the sacred temples only shows an imagined position, so that its visual and positional privilege is relatively reduced. Pikionis organized the route to strengthen people's inner impulse, which in turn promote further development of the pathway. The mutual relation explains how he proceeded while working on the project, as he said "your instinct proved the most trustworthy guide; it enabled you to read into
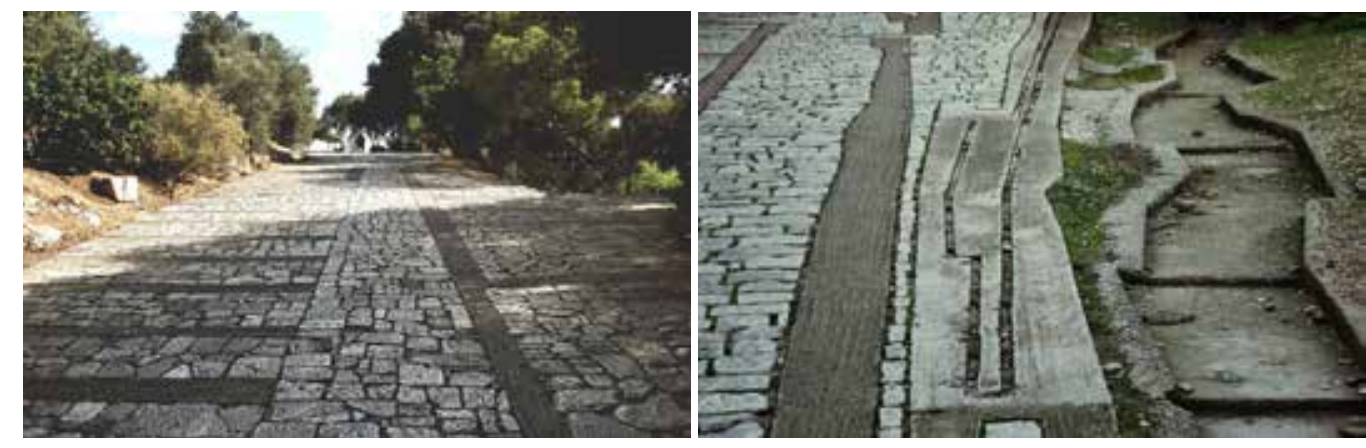

Fig 1.83. The ascent after the church.

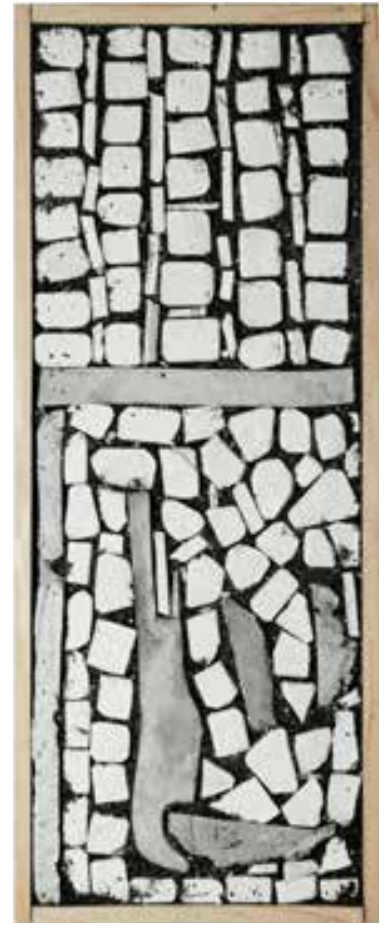

Fig1.85. Philopappou road pavement mock-up
Cement bands are added in the pavement to consolidate the steepest part of the route. (Fig1.83.) Where natural rocks occur beside the road, the concrete and cement lines stretch out to engulf them. By beating with iron rods on the cement surface when it was still wet, the craftsmen and artisans produced rough textures on these spreading strips to highlight their gravelly components, making them less distant from stone slabs.

The cement lines freely running through the pavement remind of the abstract composition of Kandinsky when he was in Der Blaue Reiter. (Fig1.84, Fig.1.85) But their articulated forms also take up, in a small way, the overall course trend or "become calligraphy turning into the deformed ideograms of a vaguely oriental alphabet." ${ }^{, 50}$ If the overlapping of meanings is part of the representation put in place by Pikionis, the use of some solutions ensures continuity of the story. In particular, the way of developing cement lines is strictly based on the orientation of the road. Lineal lines and shorter transverse pieces emphasis the directionality in straight courses which always end up in bold cement slabs. The cement stripes become disorderly and unsystematic at turnings as if they were lava flow spreading over the ground. By indicating the development of the itinerary's development through the change of pavement, Pikionis promoted immediate dialogues between the pathway and the individual's movement.

The rich variation on pavement and surrounding elements contribute to promoting a promenade of pleasure and discoveries. It always has stimulated visitors' curiosity to trace the figures marked on the ground, and has led to oblivion of their expectations of the arrival at the monument on the summit. (Fig1.86, Fig1.88.) By the means of a series of turnings, Pikionis aligned the final route to the ancient mausoleum so that visitors only perceive its presence upon arriving at the last straight route before reach the loop. Here, the softened slope facilitates walk. Though trees and bushes on the roadsides 50. Ferlenga, "Sistemazione dell'area archeologica," 234. 


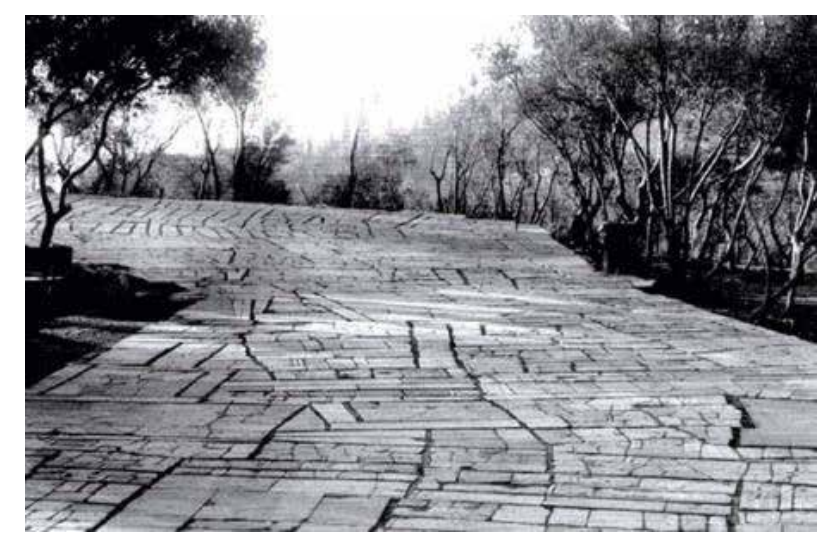

Fig 1.67. The loop pavement.

the souls of simple people and appreciate their unerring judgement. ${ }^{, 46}$

The loop presents an important feature in the disposition of the monuments in relation to the landscape. The oval yard at the center perfectly adapts the ground slope. A stony stairway divided into two ascents by a tree in the middle, meandering through the slope in a seemingly random manner, provides a transverse passage that crosses the paving loop throughout the natural plot. The ascent's boundaries consist of fragments of marble and stone are effortlessly absorbed by soil and dissolve into the mini-landscape. (Fig1.67.) Its ambiguous outlines help to give visitors a sense as if they were immersing into a grove. This secondary route that breaks the circular movement would indicate Pikionis' idea to compose a system which involves continuity and discontinuity at the same time. Such strategy is also seen from the displacement between the transverse path and the entryway of the Acropolis. It presents a certain manner to articulate the loop and the further route to the Propylaea. While the circular path presents an infinite route that terminates the previous journey, the other one breaks away from the main itinerary and starts a new way to the destination on the top of the hill.

\section{a manifestation of distance}

Though no sketch shows that Doxiadis' method was applied by Pikionis in the design of the pathway to the Acropolis, the route presents a series of critical junctures that establish relations between views and locations of architecture and other elements on site, in order to create a progressive approximation to the final point. Pikionis valued the historic and systemic significance of the loop. By adding trees and organizing a sequential circulation, he reinterpreted the significance of the junction and produced the meaning of an interval of both space and time, derived from the physical distance to the monuments on the top of the hill, and from the temporal distance between immediate actions and ancient monuments.

46. Dimitris Pikionis, Architect 1887-1968, 76.

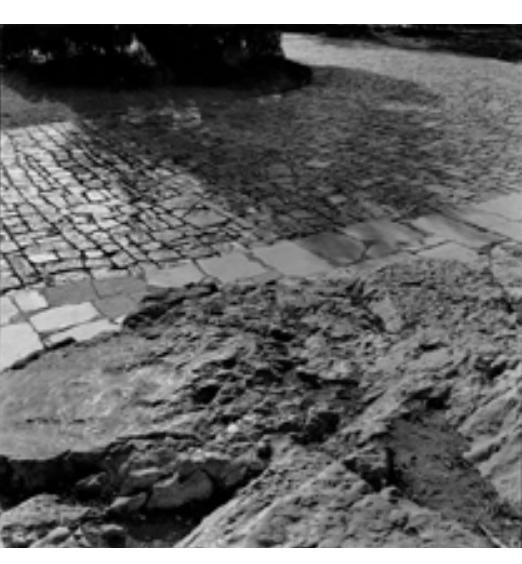

ig 1.86. Natrual topography next to the pathway.

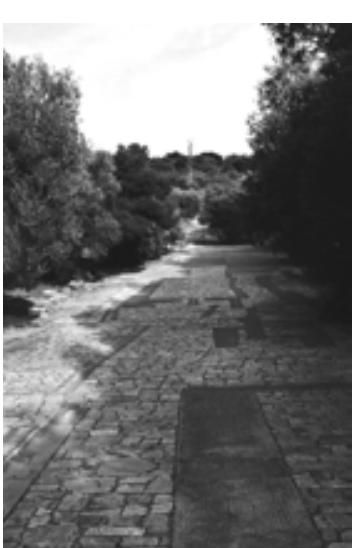

Fig 1.87. The Philopappou become denser than those on the previous journey, the absence of rocks weakens the expression of natural force. Broader strips and cement lines form continuous frames which give the floor a sort of architectonic language. They run alongside the road and emphasize the forward trend towards the monument which is emerging from the tree top. (Fig1.87.)

\section{the loop that deviates}

The final part of the main pathway of Philopappou hill presents itself as a circular route. A 35-meters long bend leads visitors from the straightforward road to an intense turn towards the north. This reorientation delays the appearance of the loop. Rocks on the periphery envelop the final passage and create a solid boundary which on the one hand, gives the sense that this end course was being excavated from the ground, and on the other hand, presents the conflict between natural rocks and paving pieces. Plants on both sides further compress the dimension of this short route and reduce angle of sight. Contrary to the experience on the straight route where the monument has indicated its position and stimulates visitors' expectation, the intense reorientation confuses them since the disappearance of objective and the route which is away from its location. From this point of view, the sharp turn cuts all the connections with the preceding experience and implies the arrival of a new space.

Variation on the pavement of the loop gives visitors different observation and experience. Slabs in small sizes and regular shapes, cement pieces, lineal, curved, semicircular, rectangular, triangular, were placed at the intersection as if to dam up the stream of cars, and then suddenly flow towards the two wings tore apart by the terraced garden in the center, which consists of a lower and a higher platforms. (Fig1.89.) The floor composition, bold cement stripes on the descent of the west wing and slender lines on the ascent of the east wing, seems to draw the flow of water affected by gravity. (Fig1.90.) Division is also seen from the two wings' edges, while the net outline of the 

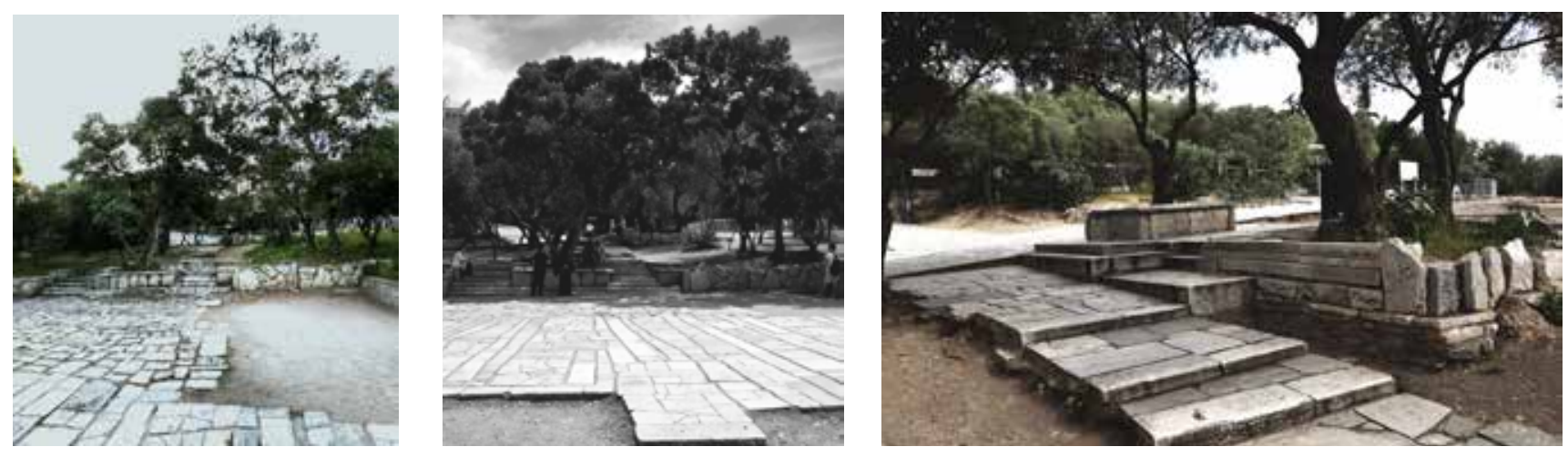

Fig 1.68. The east wing and the stony stairs.

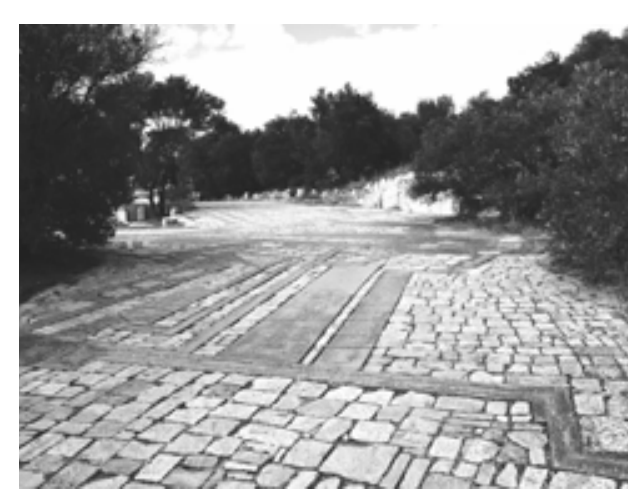

Fig 1.89. Pavement that predicts to the loop.

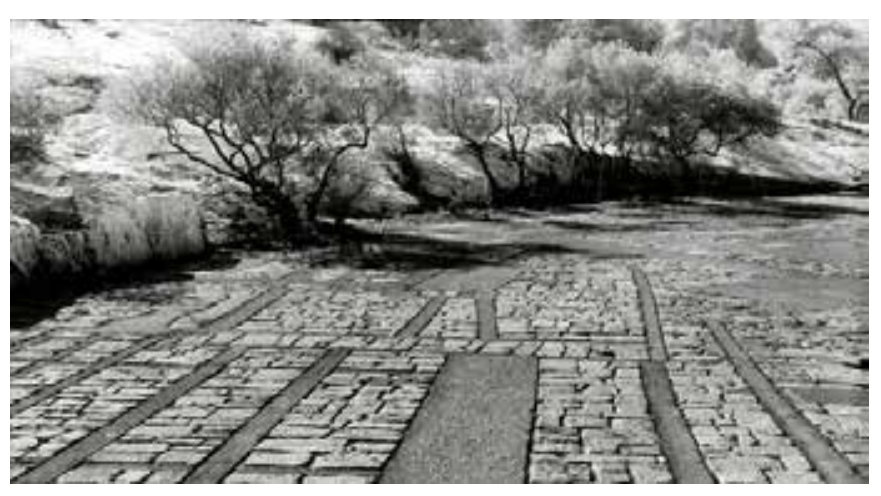

Fig 1.91. Pavement of the loop's east wing.
When people enter the loop, the disappearance of the ancient images leads to the absence of an absolute reference. This change in observation may interrupt or shut down the mechanism which we have applied to relate the objects we are looking at with its imagined location in our mind. A stronger feeling, a great upsurge of hope are eviden when the temples reappear once people walk out from the stepped route and reach the point connected to the narrow entryway up to the summit, despite of the vertica distance to the Propylaea indicates an arduous climb and conveys the difficulty to get over the border in order to reach the ancient sacredness.(Fig1.68.)

The paving patterns become much more diverse and it is on the final part of the main climb that some of the most fascinating features of the path become apparent. The blank triangle in the sketch at the intersection is filled by regular slabs. (Fig1.69.) This exceptional composition stands out from the vivid patterns around, and server to provide a guidance of the following trip by highlighting the outlines of different route and depriving the dominant directionality from the axial path which continues the main road. In a same way, different pavements are applied to present a clear division and individual expression of the two wings of the loop.(Fig1.70.) Irregular pieces and the bold gaps on the west wing compose a loose structure that seems to simulate or coordinate with distortions due to the landscape changing over time. The broadened parts on the both sides in the middle course emphasis the confrontation between the pavement and the raised natural ground, and at the same time provide rest points for visitors. As for the pavement of the two short wings, the increasing number of marbles and architecture fragments that lie in the way of the ascents are left untouched, so that they momentarily syncopate the rhythm of the pavings. (Fig.) This synthetic character makes visitors to assume that the path dates to antiquity, as Lewis Mumford wrote in The City in History that the project "reveals a contemporary mind deeply steeped in the ancient culture, but free from any temptation to imitate the inimitable. This group mingles the sacred and the secular, as in the ancient Agora...."

47. Lewis Mumford, The City in History. in Dimitris Pikionis, Architect 1887-1968, 76
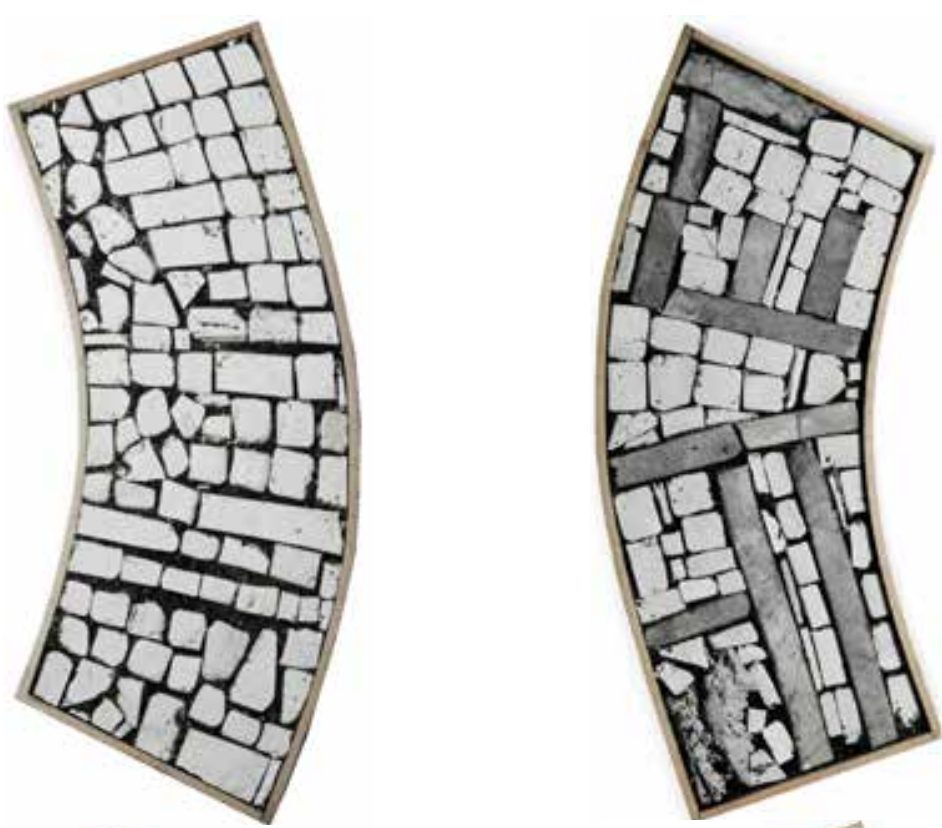

left wing implies an easy accessibility to the garden, the broken borders on the right wing stimulates a sense of detachment as if the pieces were broken away from the ground.

Divisions that appear in this route with respect to pavement, relations with the ground, movement and time present internal contradictions.(Fig1.91.) It emphasizes the autonomy of the loop by promoting an individual and closed circulation. Pikionis designed an itinerary deviated from the location of the monument. Therefore, at the endpoint, the Philopappou pathway becomes paradoxical. A visitor gradually loses visual connection with the ancient symbol and instead begins to walk on an infinite journey.

"Infinity is not a focused collection of distant points, but exits somewhere outside of a series of concentric spheres, varying in atmosphere and content, their boundaries never very well defined, their range to be taken in at one's won speed, according to one's own inclination. ${ }^{51}$

William Alex's description on the concept infinity would explain the metaphorical significances of Pikionis' layout. At the endpoint of the main road, Pikionis did not intend to direct walkers towards a particular place characterized by the image of an ancient ruin, to get them away from the historic atmosphere. What he has created is an exceptional area, in which visitors become outsiders who are isolated from the dominant narrative and center on their own mind. In addition, the loop implies a new possibility: in order to get to the ancient ruins on the summit, one has to make up his/her mind to get out of the current circular route in order to enter the further place.

51. Dimitris Pikionis, Architect 1887-1968, 79. 


\section{$\S$ Epilogue - Journey of expectation}

Pikionis syncopated the itinerary with the help of visual segments as both a general control of the overall trajectory and the manner to realize specific configuration in short distance. In addition, his ability to create the layered structure of the two journeys is due in large part to the play between the apparently purposeful disappearance and more accidental appearance of the monuments on the top of the hills, which creates an ambiguous condition. The relation between the ancient heritages and the pathway has developed the promenade which is led by the images in mind rather than the visible things, presenting a mechanism in some way might be analogous to the process of recollection. The imagined location of objectives and hierarchical trajectories psychologically expand the approach. The sense of uncertainty and expectation would coordinate with the visitors' experience of temporal distance, as Pikionis promoted, that contributes the "major historical importance of the site" and "the very nature of the project". ${ }^{2}$

In Building, Dwelling, Thinking Martin Heidegger talks about how expectation can be the guidance of virtual movement:

"We do not represent distant things merely in our mind-as the textbooks have it-so that only mental representations of distant things run through our minds and heads as substitutes for the things. If all of us now think, from where we are right here, of the old bridge in Heidelberg, this thinking toward that location is not a mere experience inside the persons present here; rather, it belongs to the nature of our thinking of that bridge that in itself thinking gets through, persists through, the distance to that location.

52. Dimitris Pikionis, Architect 1887-1968, 75.
From this spot right here, we are there at the bridge-we are by no means at some representational content in our consciousness." ${ }^{53}$

Roland Barthes indicates that it is empathy that plays the key role in the establishment of the relation between subject and the imagined object and its location.

"In transference, one always waits...so that one might say that wherever there is shared and requires time to be bestowed - as if it were a question of lowering my desire, lessening my need. To make someone wait: the constant prerogative of all power, 'ageold' pastime of humanity." ${ }^{54}$

These discourses that relate memory with expectations provide a new perspective to read the layered structure of Pikionis' intervention around the Acropolis. In fact, Pikionis did not tend to establish apparent articulation between the pathway and the ancient monuments. The ambiguous messages, conveyed by the variation of pavings an the relation between the pathway and surroundings, lead to hesitation and distraction on one's perception and movement. The independent configuration of each segment of the itinerary, as well as the loops at the end effectively present the main paths as indivisible totality. Though old fragments were applied in the pavement, Pikionis carefully controlled their evocative quality by composing them as an analogue landscape through

53. Martin Heidegger, "Building dwelling thinking," in Poetry, Language, Thought, trans. Albert Hofstadter (New York: Harper Colophon Books, 1971)

54. Roland Barthes, A lover's discourse. Fragments. translated by Richard Howard. New York: Hill and Wang. 1978, 40 


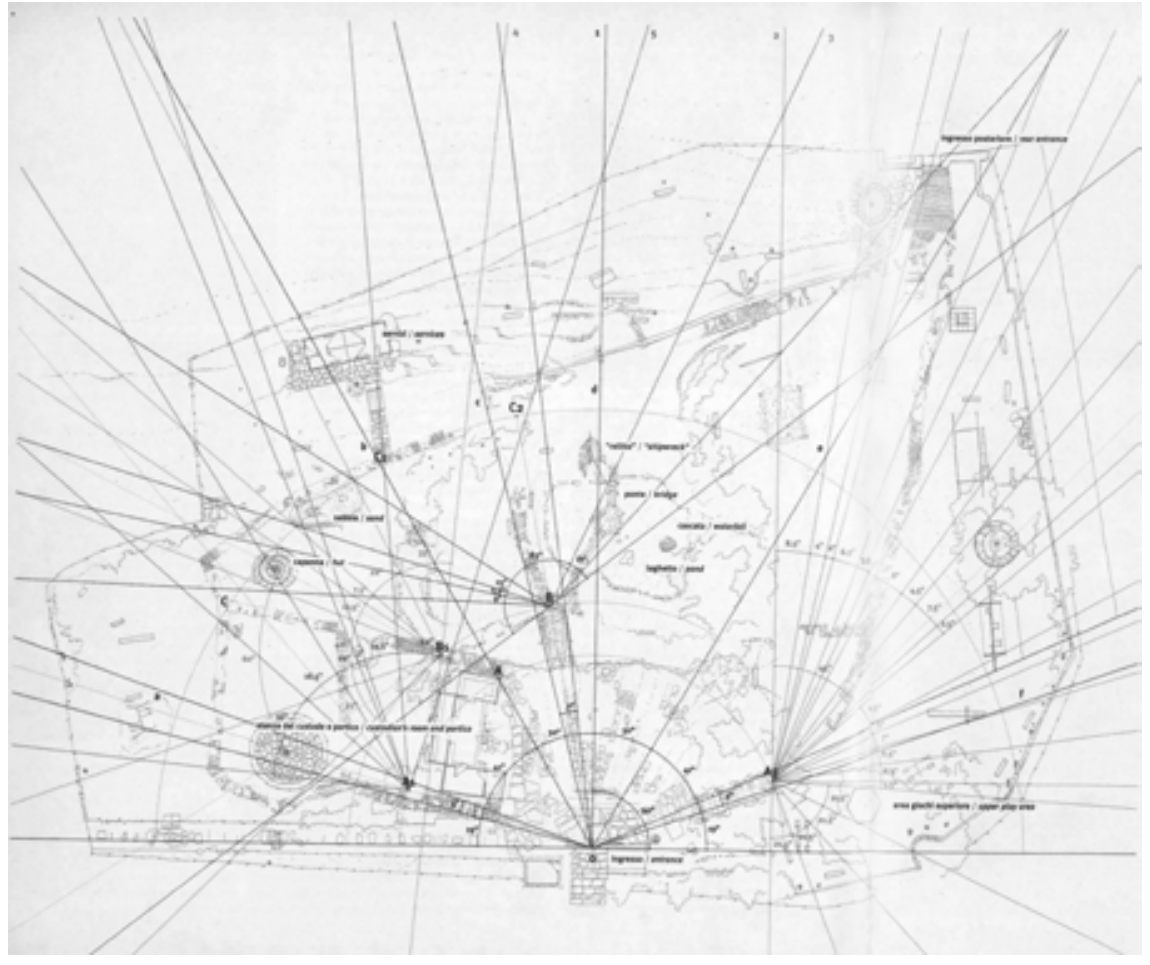

Fig 1.92. Layout and visual study of the playground.

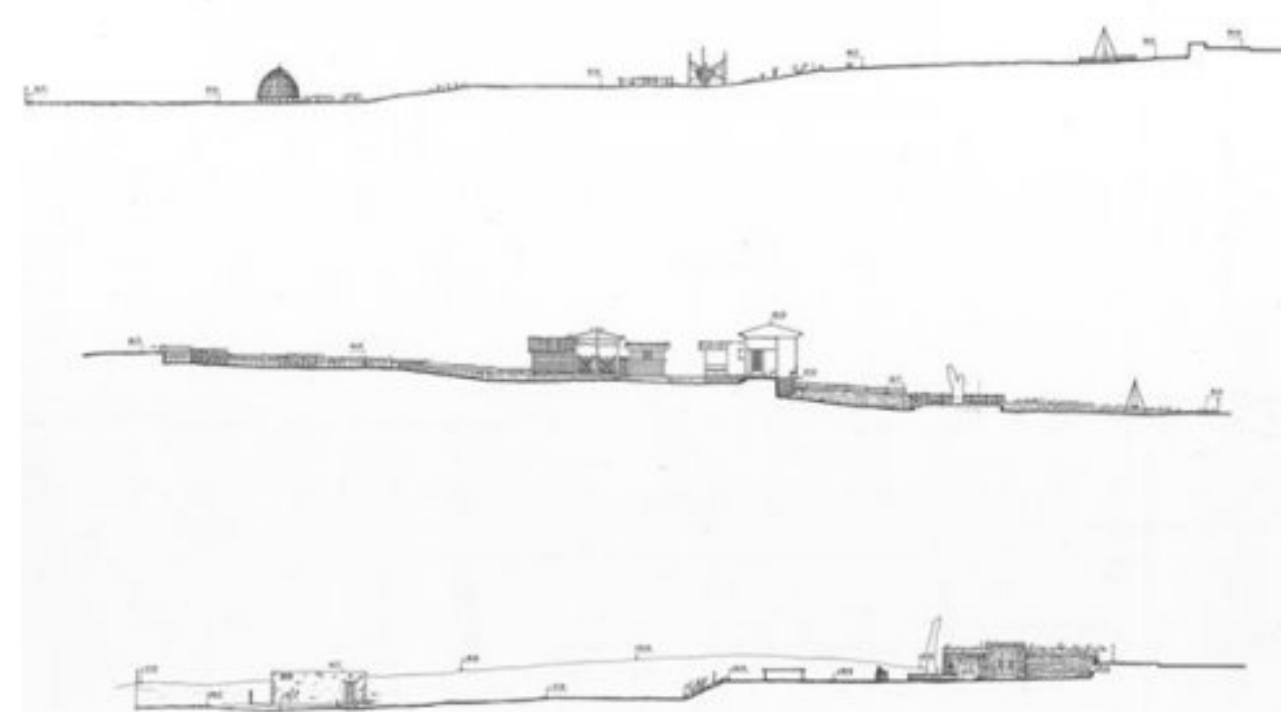

Fig1.93. The playground section, Pikionis.

state, providing this is in keeping with the spirit of the project, or in a processed form, providing an aesthetically valid solution is found - the ordinary way will not sufficient" ${ }^{\prime 56}$ While its simplicity reflects the influence from the oriental technique, this entryway establishes the first threshold that detaches the playground from the outer space and gives a certain rituality of movement.

A small plaza in fan shape welcomes visitors from the street. It forms the outmost layer of the overall space. Being introverted by the boundary made of bushes and wooden pavilions, this open space paved by loose slabs provides a rest point. Pikionis creates the enclosure that effectively separates people from the content of the inner space. The pathways that penetrate into the plant screen partially shows the pond and shipwreck a the center, as if it was inviting people to a hide-and-seek game. It conveys the hidden message and serves as a bridge that allows people to follow their expectation, just like the magical passage in fairy tales that one has to cross it to arrive the dream world.

The progressive approach and the delimitation that asks for transcendence in the itinerary around the Acropolis and Filothei lead to the hierarchical quality in Pikionis projects. The specious images and imagined locations guide visitors to a constant play between the presence and absence, making expectation govern the system as a whole and make understandable the unity of space as well as the individual parts. Thereby, from the phenomenological point of view, the works acquire the ability to interpre the attempt to project our "internal time", as E.Edmund Husserl called it, over the active landscape and the "objective time" which corresponds to the physical space and distance.

56. Dimitris Pikionis, Architect 1887-1968, 75.

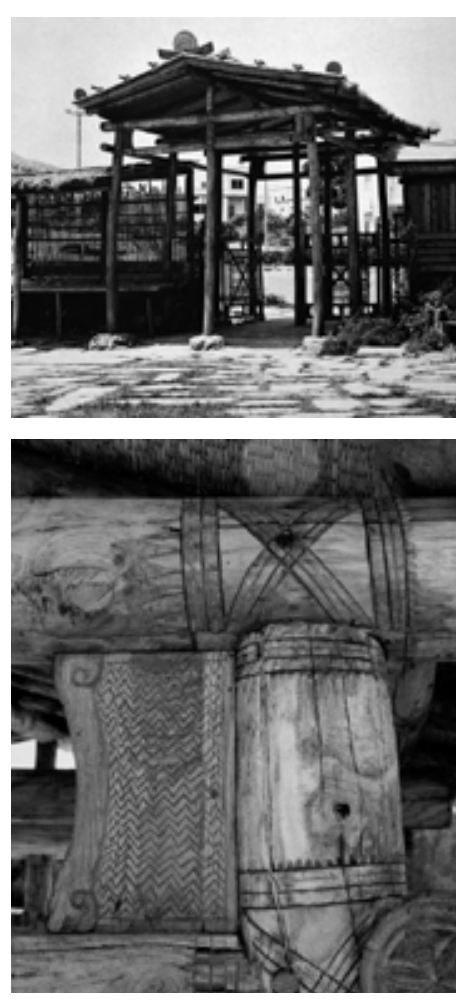

Fig.1.94. Wooden gate and joints.

(Fig1.93.) The fence surrounds the trapezoidal plot serves to give the interior privacy. A simple gate of wooden structure and straw roof (Fig1.94.) recalls the St. Dimitris Loumbardiaris Church. Pikionis was keen to present the essential character of construction and materials. He said: "For the wooden constructions, great care in the selection of timber will be required; the timber will be used either in its unprocessed

55. Alberto Ferlenga, "Sistemazione dell'sarea archeologica attorno all'Acropoli e al colle di

Filopappou Atena, 1954-57," in Dimitris Pikionis 1887-1968, 232. 


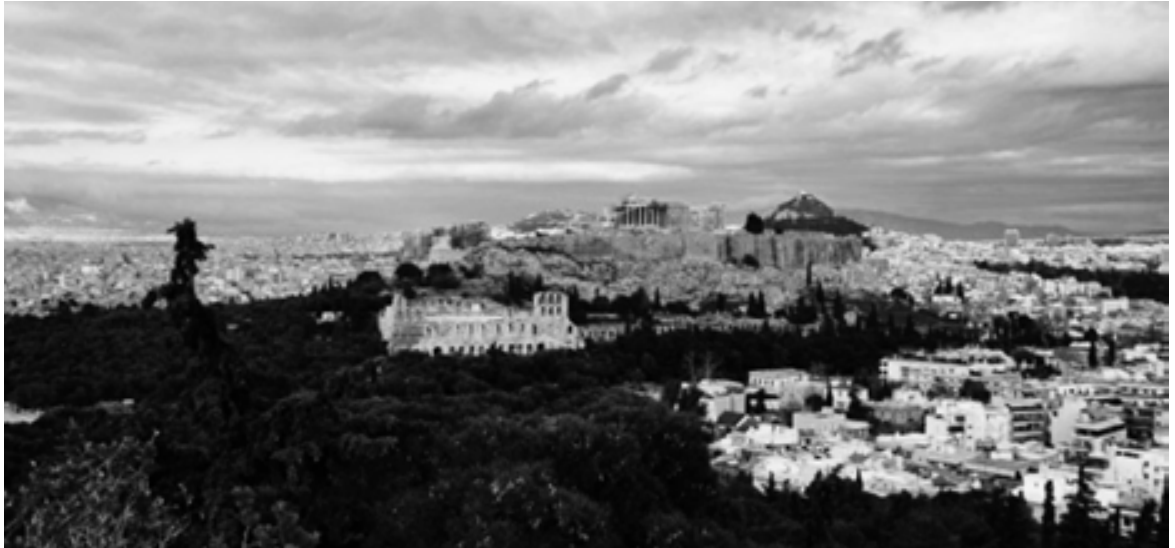

Fig1.95. The Acropolis and the Odeon viewd from the Philopappou summit.

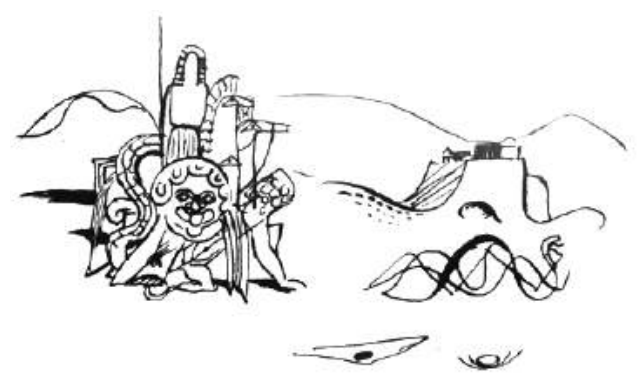

$\Longrightarrow$

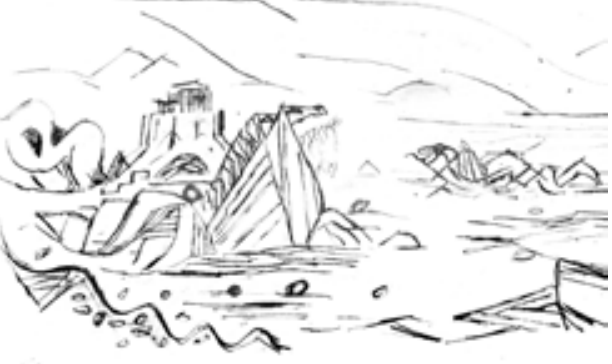

U/,

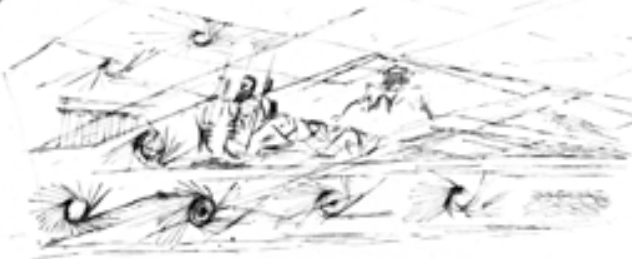

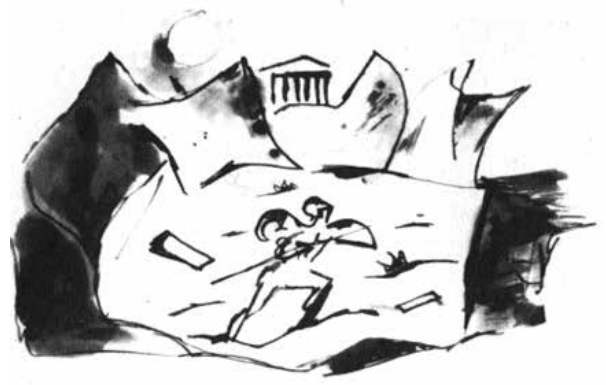

-

Fig 1.96. Attica, Pikionis.

\section{AN UNFOLDING JOURNEY TO THE SACREDNESS}

Both of the loops that terminate the main course up to the Acropolis and the Philopappou hill contribute a duality on movement and on the overall itinerary at the archeological site. The two passages present themselves as metaphoric journeys that give an expression between finity and infinity, and meanwhile, they make visitors to make choice to go down the hill or follow the new routes to reach the summit where ancient monuments are located. (Fig1.95.)

Pikionis reestablished the physical configuration of the paths to present a great division of spatial quality. It works to delimit the expression of the ascents to the sacredness from the experience that visitors have acquired from the previous walk. This change of perception and felling is obtained from the limited capacity of the greatly narrowed road that indicates the exclusiveness of the passage to the sacred monuments; from the less compact and more symbolic pavement which tells spiritual meaning in a humble way; and from the rest station and stop point in the middle of the routes that greatly expand views to the grand background consists of the monuments, the original topography and the reformed landscape.

All these paradoxical factors indicate Pikionis' strategies of how to create a balanced condition and give rise to rituality in the walking process. The specious relations between components would avoid an overwhelming expression of the historic evidences, meanwhile, provide a subtle guidance of movement and keep a sense of orientation in people's mind. From this perspective, Pikionis created a unity that accommodate elements of different categories and from distinct epoch through a way that seems to relate to a process of assimilation. As Professor José Ignacio Linazasoro indicates the quality of equilibrium in this constructed system: "There would be, in all those things, in conclusion, a return to the primitive balance between people and Nature; between Architecture and landscape; to that statu quo, called up and idealized by the

ancient Greeks themselves." 57

The origin of Pikionis' combination of the natural and the spiritual can be traced from his paintings, especially the series "Attica" that represent the space around the Acropolis. In those ink sketches, Greek mythology are illustrated according to an abstract composition of the gods and hilly land depicted in sharp forms. The Parthenon as a recurrent element plays a critical role in the composition and metaphoric narration of the image. (Fig1.96.) One drawing shows Athena grips her lance, with her "gorgon's head" and a horse. On one side, the snake creeping on the ground, symbol of Erichthonius, stands for the eternal regeneration from the earth. Its arched body echoes the hilly terrain as backdrop, which is topped by the sacred temple. By arranging the sacred and secular world according to the spatial depth, Pikionis produced a surrealistic scene of spiritual transcendence that directs to the antiquity. They contribute an artistic manifestation of Pikionis' deep and sentimental understanding of the "oneness" of Hellenic spirit made of cultural and topographical facts.

In his project of the playground Pikionis has made a more intense and direct itinerary towards the place of sacredness. The central plot was conceived as a stage of Hellenic civilization. The symbolic elements, small pound and vegetation form a schematic narration which is "far from real time in centuries, but near to the analogue play that rules and continuity and the forms and the ideas of the history."${ }^{, 58}$

57. José Ignacio Linazasoro, "Stone Talk. Round Dimitris Pikionis," in Otras vías: 1 Homenaje Lewerentz = Other ways: 2 Homage to Lewerents. ed. José Linazasoro, Ignacio ( Colegio Oficia Arquitectos Castilla y León Este, 2005): 15.

58. Alberto Ferlenga, "Road of stones," 28 

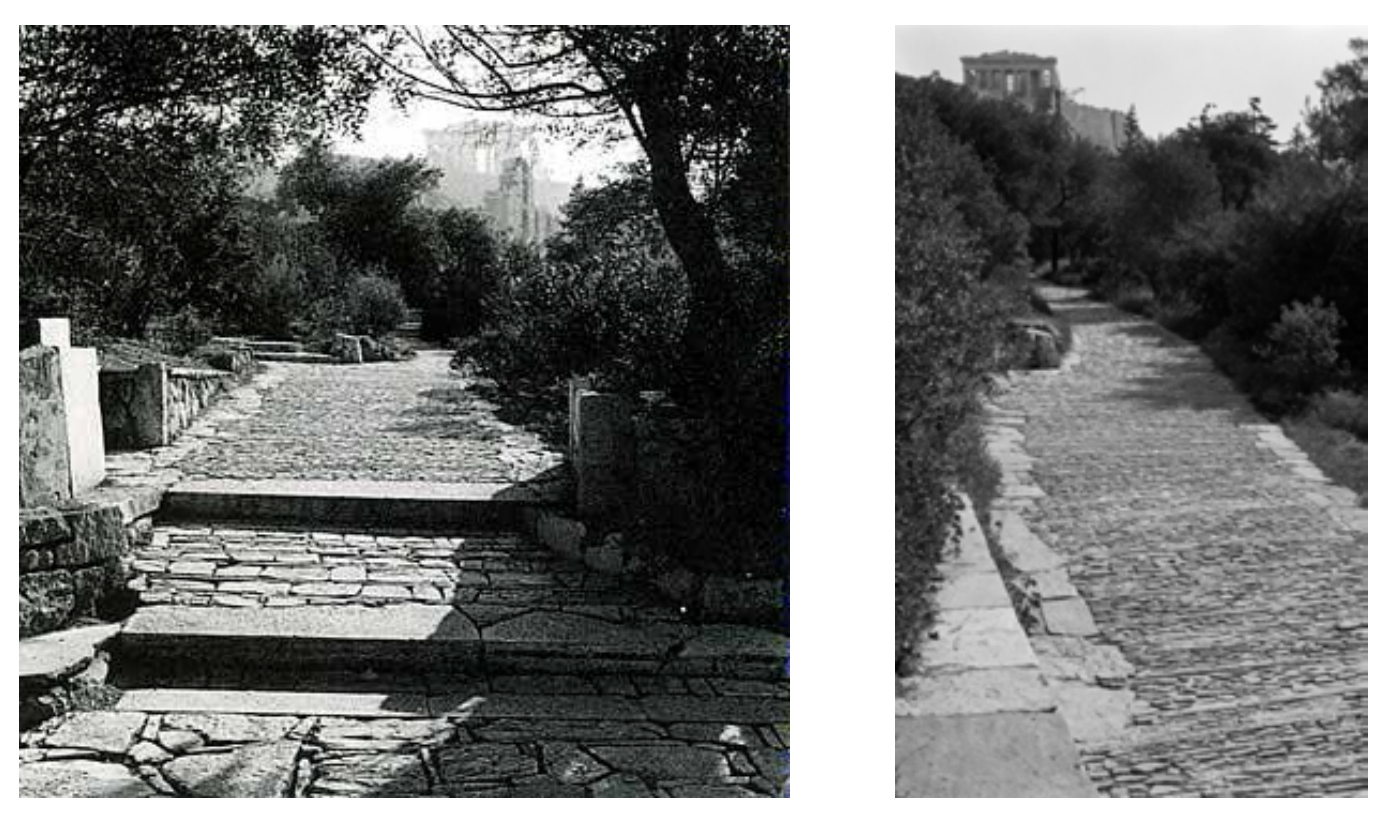

Fig 1.97. Steps to the secondary route.

Fig 1.98. Secondary route pavement.

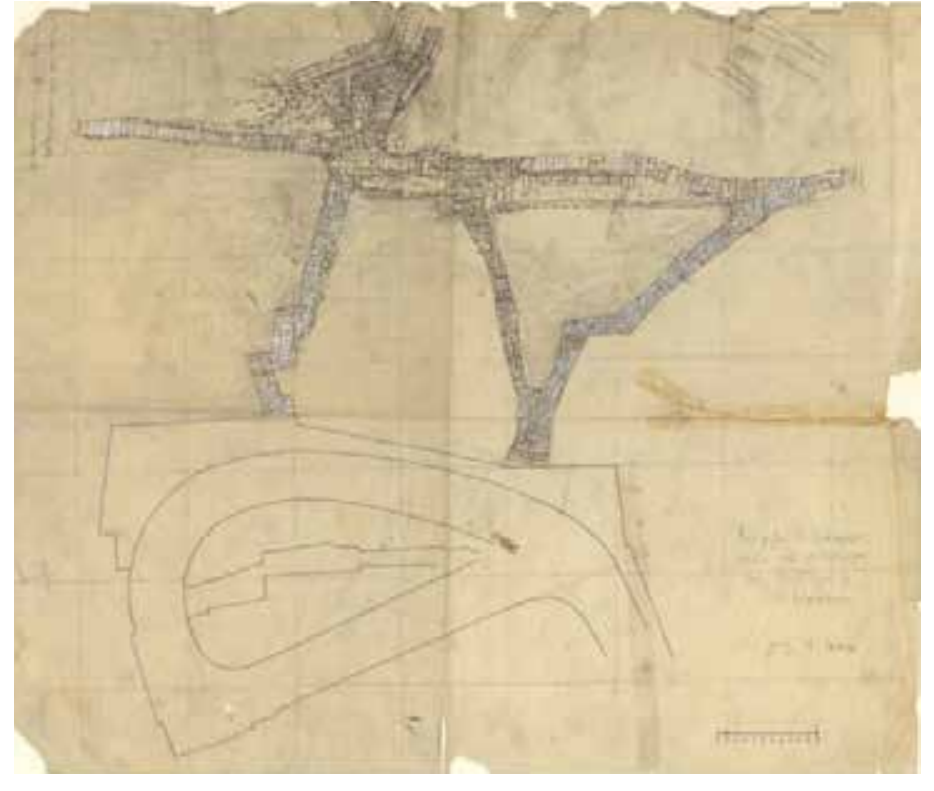

Fig 1.104. Connection between the loop and Anderon, Pikionis.

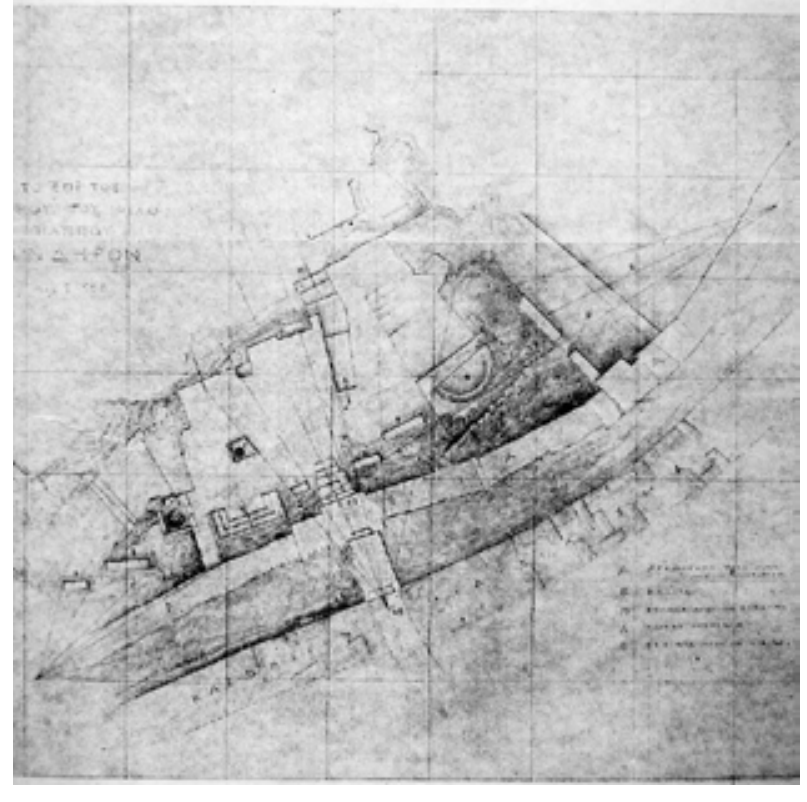

Fig 1.105. Plan of Anderon, Pikionis.
$\S$ The convergence of opposing flows

Apart from the main road towards the Acropolis, Pikionis created a more private route that brings people up to the loop. This secondary itinerary consists of narrow branches serves as a system of casual paths between the main passage and the Odeon Theatre Its limited dimension helps to promote a close relationship between walkers and the surrounding landscape, providing a less ritual trajectory that emphasis the original condition of the site.

Contrary to the main road that keeps concealing the sacred image until the last moment so that the pavement becomes an important factor in walking experience, the Parthenon presents itself as the objective of the narrow path from the first steps of this secondary circulation. (Fig1.97.) The floor paved by slim stones and composed in natural patterns reduces metaphoric meanings. This fine and even texture on the ground helps with tactile feel on the foot as well as produce an analogue of a stream trickles into the deep. (Fig1.98, Fig1.99.) It corresponds with the grand guidance on the top of the hill, contributing an illusion of a direct route towards the ancient temples which seem to be more accessible and much closer to the visitors.

The alternate itinerary produced by Pikionis presents an opposing perception of distance and objective of the journey. As the route goes deeper, the increasingly irregular paving pieces show the influence from the surrounding natural elements. Though the temples preset the destination, Pikionis did not conceive the secondary pathway as a powerful route towards a unique direction. The recurrent branches lead people away from the sacred image, guiding them to the ancient theatre, into the woods, or back to the city street. The flexible relation of visitors and the site place people in a balance of experience between the call from the past and the will to stroll around the parklike place. Pikionis deprived archeological indication from the pavement, making the

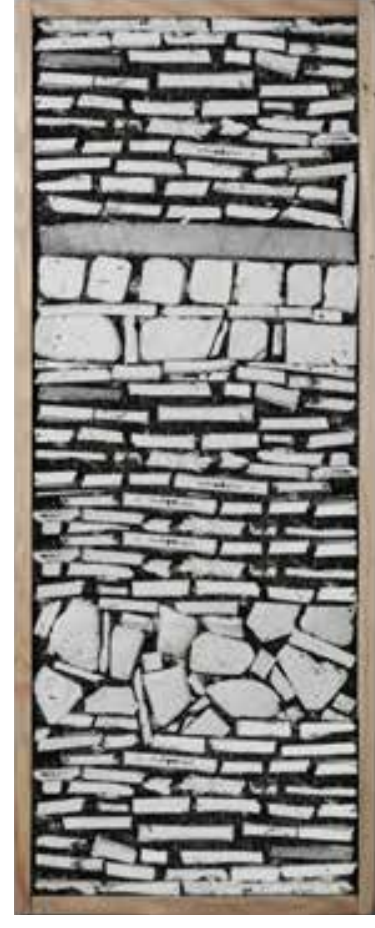

Fig1.99. Secondary path mock-up.

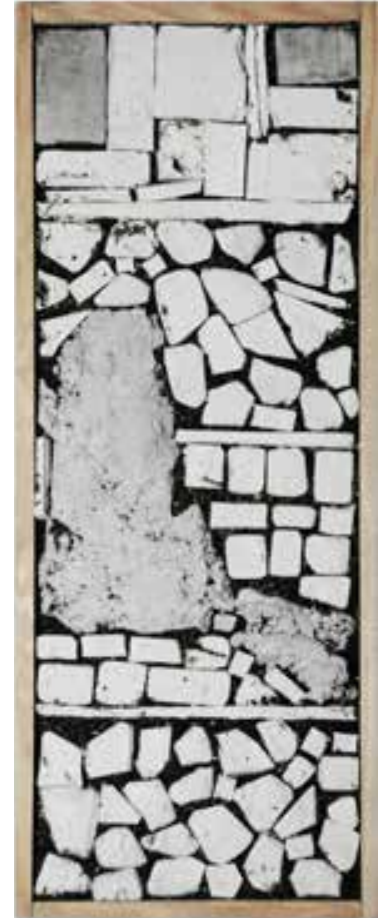

Fig1.106. Anderon paving
$\S$ Through an abandoned trajectory

The stony stairs generated from the circular route at the Philopappou hill leads people away from the loop and guides them to a journey of adventure. (Fig1.104.) The dense vegetation and stepped pathway that meanders through trees in a seemingly random manner produce a transit that tends to cuts all the connections with the previous trip. The limited views from the narrow route prompts the uncertainty about the front prospect at the first moment, meanwhile, fragments scattered around the road present an analogue of ruins. These facts give a gesture of departure which, once again, invites visitors to set foot on a passage towards the deeper space.

This narrow entryway is connected with the Anderon, an open platform which provides the best view to the monuments of the Acropolis. Pikionis isolated the short route and conceived it as an interval between two worlds. Through an intense ascent those adventurers are transcendently transmitted from an introverted loop to the great manifestation of the Sacred Rocks. Delimited by short walls, the "belvedere" conceived as an abandoned settlement was framed by natural rocks and marble seats in different shapes.(Fig1.105.)The main installations at the viewpoint -several semicircular and triangular benches located side by side- seem to emerge from the rock and simulate archaeological remains. Their particular geometries lead to two separated compositions on the plan. (Fig1.106.) Steps aligned with the platform's broken edges subdivide the floor into small sections. Pikionis integrated the remains of the ancient habitations which were revealed on the site, he drew the platform according to linear compositions and presented it as an analogue of building plan. The slightly stepped terrace, perfectly adapted to the terrain, permits people to observe a direct image of the Parthenon from a privileged position, where subtle fluctuation on the floor enrich the experience. While splendid views are enjoyed from the "belvedere", all the components inserted and arranged on the broken platform, on the one hand, give rise to a quality of randomness, 
sacred rocks as the one and the only image to tell historical significance.(Fig1.100.) The inconsistency between the itinerary and its objective contributes the ambiguous quality that demonstrates this secondary route as a labyrinth which stands out for its arbitrary orientation and the casual movement.

Pikionis' circulation around the Acropolis constitutes a background into which the pathways might be thought of as inserting, integrating, or diffusing themselves. They reflect respective strategies that Pikionis' applied to produce different narratives. The main road presents a powerful and unique way to an outstanding object which is not observed during the approach. In addition, the presentation of spatial depth keeps stimulating an individual's expectation and motivating the movement. Meanwhile, the secondary passages show how the slim and winding trails, under the clear sign of the destination, compose a capillaries-like circulation being lack of clear directionality The sense of uncertainty since the passages are being completely interwoven with the landscape emphasis the depth of the terrain, and only at the moment of arriving at the loop, the image of the sacred rocks would compensate those visitors who have found the way by themselves.

The ramp goes towards the Propylaea converges flows from the main road and the secondary routes. By laying out the zig-zag route, Pikionis created an itinerary that slowly meanders up the hill that allows people to observe archeological monuments located around the site: The Odeon Theatre serves as a critical point that leads the short path to the east above its perimeter. During the walk alongside final passage, visitors are able to overlook the interior stage of the theatre which has been hidden by the facade from the plaza. Meanwhile, the monument atop the Philopappou hill in the distance echoes the Acropolis on the upper position, reflecting the architect's initial idea to reconnect the archeological sites and to create an overall narrative about the history.
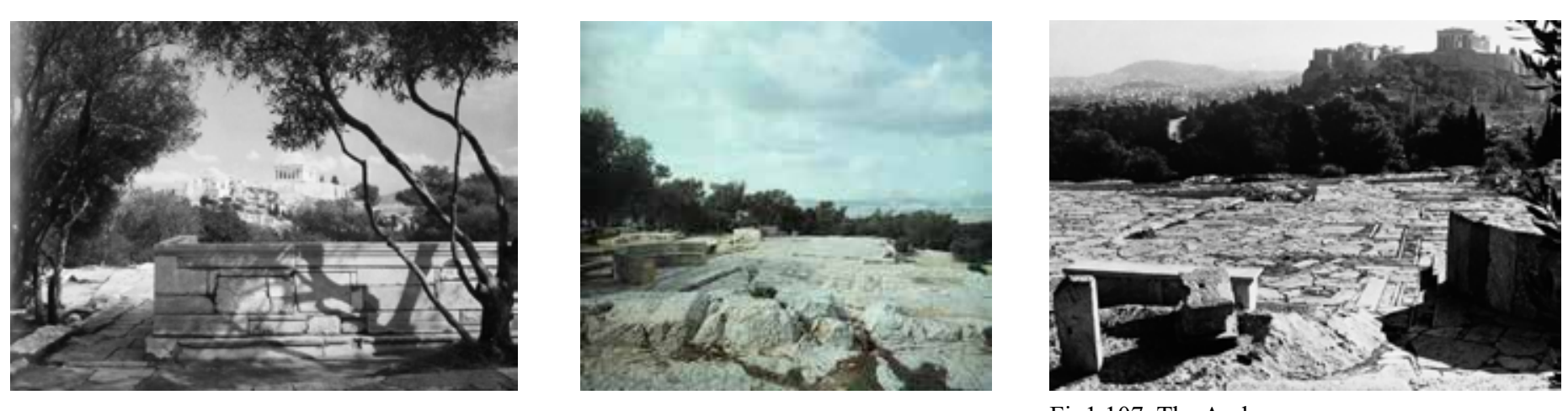

Fig1.107. The Anderon.

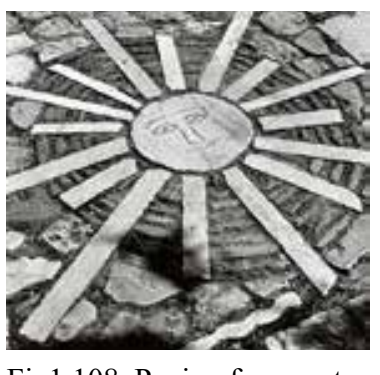

ig1.108. Paving fragments on the ascent.

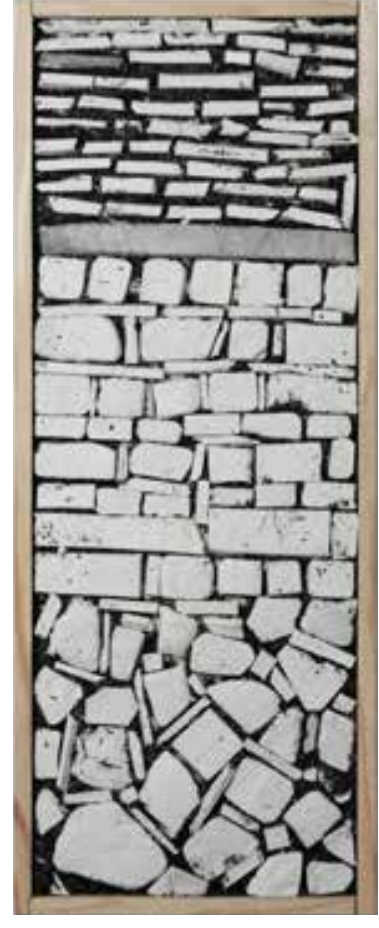

Fig1.100. Paving variatio mock-up

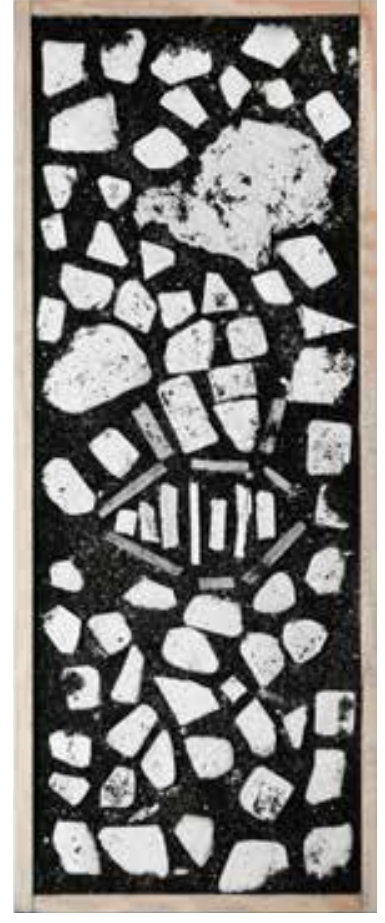

Fig1.109. Narrow ascent and on the other hand, present an unfolding sequence according to which visions are directed, step by step, from the nearest bench to the temples in the distance. (Fig1.107.) Alberto Ferlenga finds that the Anderon's composition is based on the same rule that unites the pavilions of San Dimitris Loumbardiaris church to the Acropolis. It is Pikionis' strategy to turn constructions into the medium that articulates the individual with the sacred monument, and promotes metaphoric observations "towards the external, the real landscape, and towards the internal enclosed in the soul of every passerby that stops here. ${ }^{\prime 60}$

Pikionis applied a sophisticate structure of visual system to promote narrative and individual meditation of the history, making the platform experienced as a machine of vision. In Anderon the "Doxiadis method" reaches its peak. The space is structured by fan-shaped lines organized from three focuses, one on the center and two on the lateral sides. Virtual sight lines are replaced by the visible lines of edges, steps and pieces of pavement

"Pikionis located the seating areas where there was an opening in the foliage to catch the sun's rays as well as a view of the Acropolis. The belvedere on Philopappou hill ensures an angle of vision towards the Parthenon of approximately thirty degrees. A secondary path leading to the belvedere reveals the ancient wall or 'Diatichisma' hidden amongst the dense growth of trees." ${ }^{, 1}$

Alexandra Papageorgiou observes the specific geometrical matrix was used to relate people's experience to the movement of the nature, Pikionis provided visitors a excusive

60. Alberto Ferlenga, "Sistemazione dell'area archeologica," 232

61. Dimitris Pikionis, Architect 1887-1968, 82 


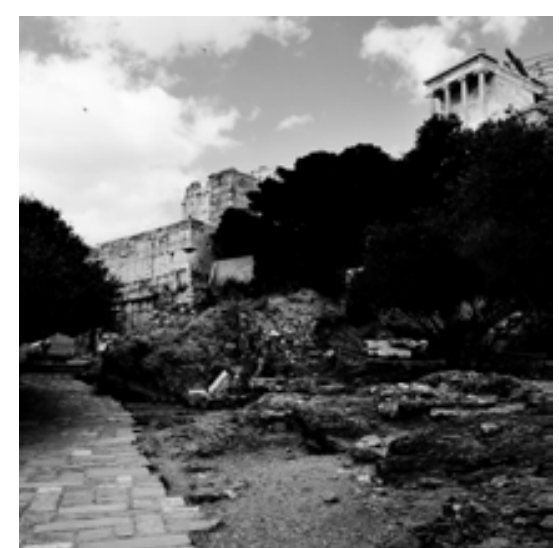

Fig 1.101. Route towards the Propylaea.

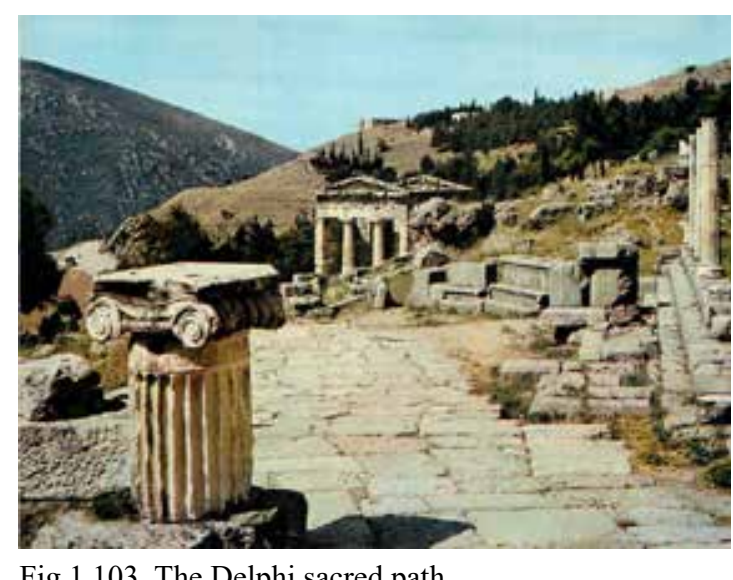

Fig 1.103. The Delphi sacred path.
Pikionis composed the final route towards the Propylaea in a humble and quiet way Big slabs in regular shapes are carefully combined as a sophisticated transition between terrain and paved passage. Rocks and vegetations invade the road and contribute a manifestation of artificial products affected by the transformation of natural landscape. (Fig1.101.) The rich expression of evocative and symbolic figures in the pavement is reduced by limited variation of materials and colors in order to minimize distractions in favor of a continuous movement.(Fig1.102.) The architect used antique technique to cut and place stones, and the powerful composition of those squared pieces gives an analogue of the sacred path towards the Temple of Apollo in Delphi. (Fig1.103.) He removed cypress alongside the path in order to give sufficient space to the monuments for the narrative of rhythm and verticality of the columns.

Accumulation, reiteration, disconnection, and difference are some of the substantives most frequently repeated in Pikionis' organization of the path towards the Acropolis. The short course presents itself as a permanent approximation, and as a result, the experience has extend the resources of our relationships with both the present and ancient world, which "reminds us the relationship between present and past and is able to keep away immediate conditions in order to observe them in a perspective where tradition and history are connected with a logic discourse., ${ }^{59}$

59. Carlos Jiménez Pose, "Introduction," in Otras vias: 1 Homenaje a Lewerentz = Other ways 2 Homage to Lewerents, 10.
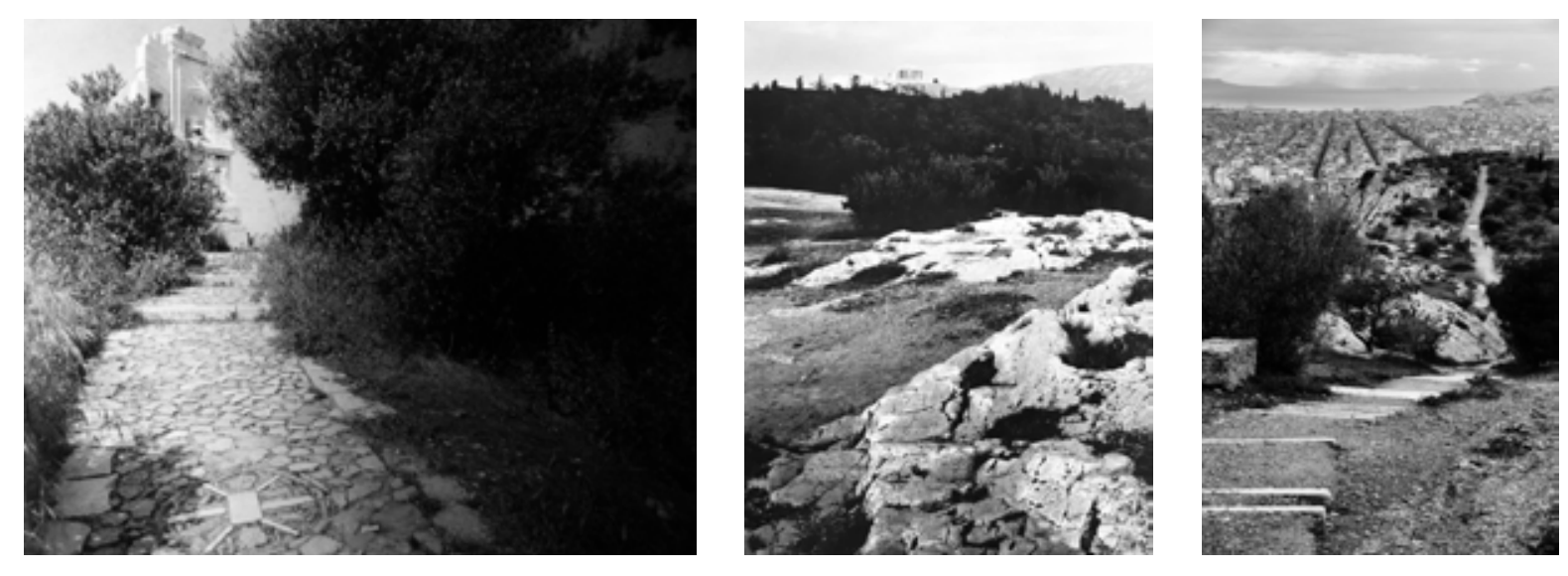

Fig1.120. Route towards the Philopappou monument. Fig 1.122. Views to the Acropolis and the city

space for them to contemplate the time of Hellenic history while observing the majestic architectural landscape.

A transverse route draws the western border of the platform takes the direction of an increasingly narrowed ascent to the Philopappou monument. From this point pavement becomes "clay inclusions". Fragments of building such as roofing and wall decorations grouped and composed in childish figures - fishes, insects - that contribute soft traces that barely serve as a guidance for the visitor.(Fig1.108.) These paving fragments that show particular aesthetic present a series of symbols that express both remoteness and primitiveness, evoking the image of a civilization of distant past. (Fig1.109.)Alberto Ferlenga regard the fragments as Crumbs of Pollicino since they simply invite you to lower your gaze to the land. During the climbing, visitors can only see the partial image of the Acropolis from the occasional openings on the shrubs on the roadside. The increasingly loose floor paving and limited views emphasize the abandoned quality that contributes a path that gradually gets lost. The reduction of the route's formal importance grows along with the ascent and reaches to its peak when visitors encounter with the ancient mausoleum on the summit.(Fig1.120.) Rocks and soil on the ground erase any trace of paving pieces, therefore, the elevated monument becomes the only symbol of the history of human beings.(Fig1.121.) Pikionis conceived the final plot as an abandoned place from which derives the authentic meaning of ruins. Moreover, it remains the original relation between the two monuments that echo each other over a distance for thousands of years. In addition, the weakened rituality at the end of the pathway manages to reduce the independency of the monument, making the destination of a long ascent on the Philopappou hill play a critical role to draw an image of physical and temporal continuity of the Athenian landscape. On the one side, the sacred temples permanently rooted in the terrain are showing a static mark of the glory of Classical times, on the other side, at the foot of the hill, the modern city presents a constant expansion towards the ocean. (Fig1.122.) 


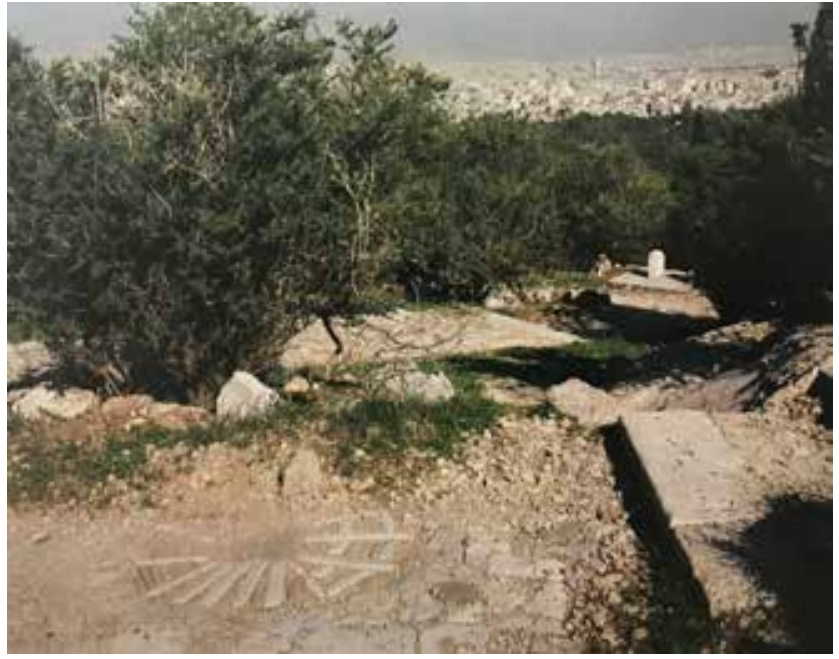

Fig 1.123. Summit of the Philopappou hill.

$\S$ Epilogue - To create another rituality

The final part of the pedestrian intervention on the archeological sites, not very formally emphasized and less documented than the main trajectory, is actually essential to understand Pikionis' design method and the narratives that have been created. It was conceived to allow new paths to flow in an environment that determines the effects and completes the arrival to the sacredness, manifestation of the monumental ruins, and transition to the past reality. However, contrary to the clear aim towards antiquity and specific position, the architect conceived the approximation as an uncertain promenade along with which the sense of return to the nature is gradually generated from the route's simple composition and the feeling of being immersed in the natural environs. In this way, during the journey's final stage, Pikionis purposely reduced direct connection between visitors and the monuments on the top of the hills, trying to create a bridge whose narration seems not to be in accordance with the historical significance of the site and the heritages. (Fig1.123.)

The reduction of sophisticated treatment and the lack of sequential development of the final paths lead to dual effects of the interval and articulation of two worlds: on the main roads, the paving patterns, orientations and slopes are developed based on a lineal sequence, which pre-edits an order of movement that helps to stimulate people immediate perception and the awareness of the flow of time; and the plots where ancient ruins are located, on the other hand, present a stationary reality of frozen time. Pikionis' abandonment of clear guidance postpones the arrival at the summits as well as underlines the temporal distance between the ruins and spectators. Divisions on road plays with visitors' anticipation and recollection. There is an undecipherable connection between these stories, the arranged stones, the distance to the ruins, kinds of paving pieces and fragments scattered around, all this mystery that appears to be composed of irreconcilable opposites are made one in the equation of an anomalous rituality -that guides spectators into deep passages and then make them get lost- on the walk to the sacred place.

Pikionis put his own recollection in the intervention. Professor Darío Alvarez indicates that in the project, "Pikionis' memory and the intensive and inexhaustible memory of the Acropolis' landscape superposed." ${ }^{, 62}$ The last stage of the journey sees a great change of the pathways' role from the protagonist of the space to humble trajectories, as if the reduction of their importance was to compensate the ancient ground. The architect is guided by historical horizon and direct actions; it can be said that by restoring the landscape and circulations system of the Acropolis he also reproduced the landscape of his cultural formation and his youthful walks. By making use of "lens of the naturalist and of the poet's memory" ${ }^{13}$, Pikionis is able to let himself go above all to listen to the "secret inner voices" and to that child's gaze that allows him to detect every trace.

62. Darí Alvarez, "Stone, Landscape and Memory," in Otras vias: 1 Homenaje a Lewerentz Other ways: 2 Homage to Lewerents, 41.

63. Alberto Ferlenga, "Sistemazione dell'area archeologica," 230 


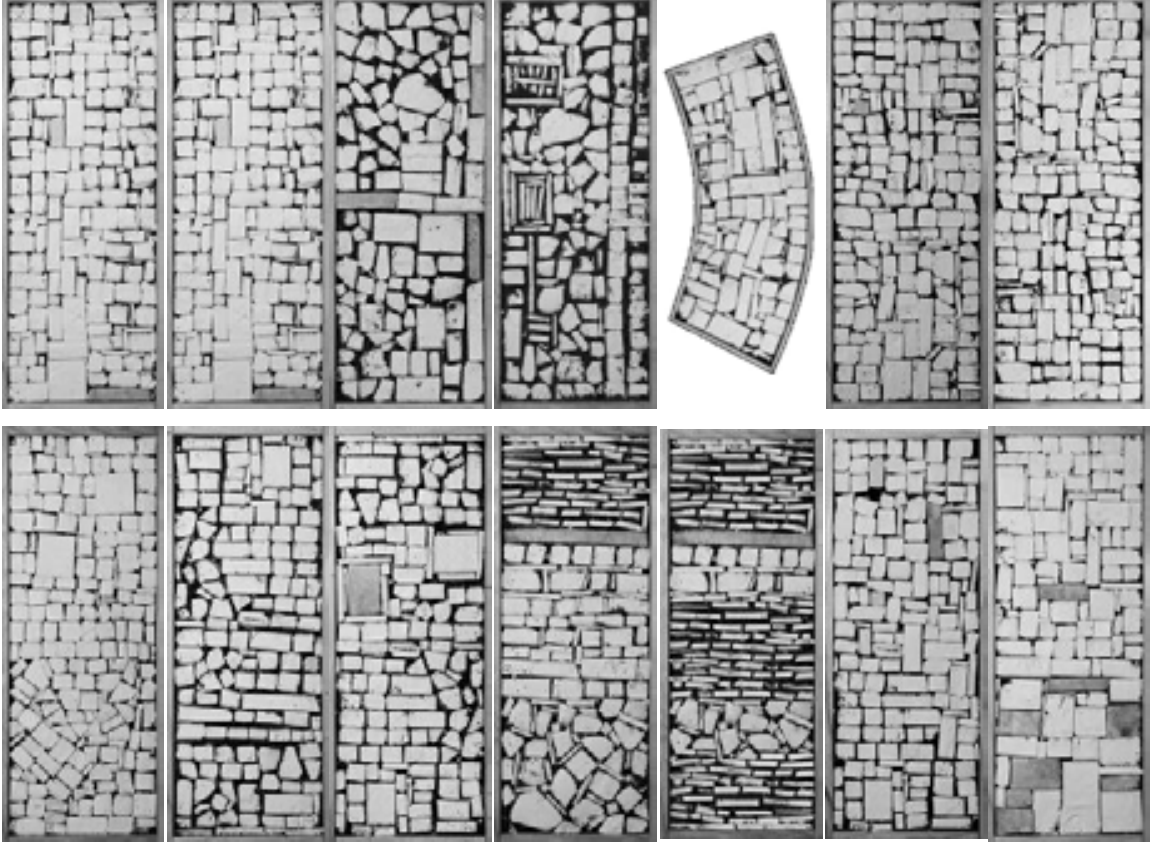

Fig 1.124. The Acropolis hill pavement mock-up.

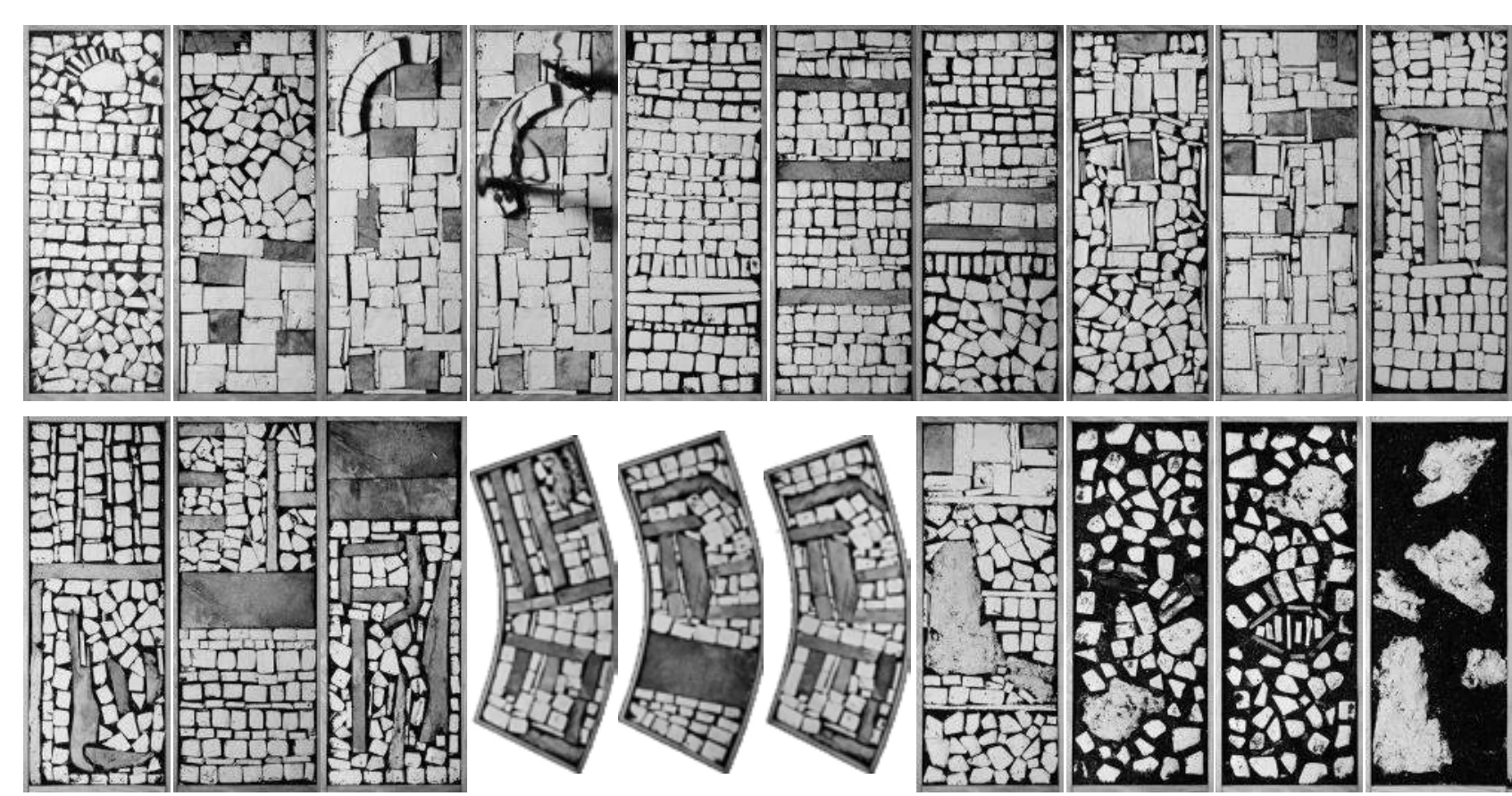

Fig1.125. The Philopappou hill pavement mock-up.

\section{CONCLUSION- THE DEVOTATED ANACHRONISM}

"The simplicity of the total composition, the accurate exploration of the view, the use of materials, the integration of built-up elements with the plant life, and finally the treatment of every detail make it unique. The viewer may also be captivated by the endless sequence of the designs in the walls of the church of St Dimitris. There again the same spirit prevails: poems with stones through the language of symbols and metaphysics. ${ }^{, 64}$

Anthony C. Antoniades indicates Pikionis' strategy to integrate hilly landscape and constructions aimed at serving an overall expression. Apart from compositional capacity, the storytelling of a long-range civilization told by the restoration work around the Acropolis gives it a critical edge which was so precious in that period.

Pikionis embedded pathways paved by Greek neo-classical pieces in the fabric of modern Athens, laying out passages towards monuments which stand for the glories of the city's classical past that his work was intended to serve. This panorama of realities of different times juxtaposes the city heritages and urban impulsive growth, contributing a disturbing and poetic system which is polemicized by fragmental manifestation, which dedicates to a work of anachronism in the 20th century. The arbitrarily located stones seem come from personal whim and immediate decision. Those normal pieces which can only be shown indirectly through images that can never reveal a complete picture compose a homogeneous floor and indivisible trajectory, and in a certain way may reflect Henri Bergson's dureé that time is "incomplete and continuously growing". Meanwhile, those figurative patterns present evocative gesture, leading to a sense of truncation in the experience. (Fig1.124, Fig1.125.)

64. Dimitris Pikionis, Architect 1887-1968, 86.
The two routes are at the same time empathetic and abstract, old and new, natural and cultural. Oppositions derived from compositional hybridity lead to ambiguity in meaning, imbuing the restoration of landscape and pedestrian system with great spatio-temporal capacity that serves to articulate space and constructions of different times. Nicholas Kehagias elaborates the internal movement in Pikionis' project that "similar images are created by the embedded fragments, but can appear to be somewhat contrived, unconvincingly straddling the line between superficial sentimentality and evocative polemics. ${ }^{365}$ Topographical and archeological qualities that prevail at the same time in the Pikionis' intervention lead to the work's polysemy and constant changes in spectators' perceptions, making it difficult to read the work through a same manner. Their experience is constantly disturbed by facts and events of different categories. Therefore, the resulting elusive quality eventually estranges visitors from the passage through which they are walking. Sense of alienation derived from this distancing effect becomes the most fascinating feature in the work conceived as a progressive legitimization of the final manifestation of the long past.

Both of Pikionis' Acropolis project and the playground are characterized by a primitive balance between people and nature. From this fundamental character originated from a series of signs that indicate ancient techniques developed from the root of Hellenic culture, Professor José Ignacio Linazasoro sees the anthropological significance inherent in the architect' works:

"Architectures, that is derived from the Protodoric principles; woody, and jointed with the difficulty and the originating roughness; belonging to a world of primitive objects,

65. Nicholas Kehagias, "Paving a Greek Path to a Western Monument," accessed May 1, 2015, http://www.nicholaskehagias.com/the-acropolis-pavement. 
as the Homeric Odysseus' bed in Ithaca; inhering in the Golden Age, when the objects themselves, as the Nature's forces, that incarnate the ancient gods, talk to human beings.

The ambiguous condition that Pikionis created in the two pathways succeeds in avoiding a narration of specific temporality. It becomes an essential part of its composition and is critical in the creation of a truly immersive experience, which works fundamentally to reduce the intangibility of ancient heritages and help to accommodate visitors into the space governed by the reality far from the present. As Pikionis himself explains, "more than the purity of rationality, darkness and the incomprehensible create an atmosphere of initiation for those who have inwardly the capacities of to perceive and to understand", on the passages towards ancient and sacred monuments he put end to realism, paving an infinite piety of the eternal nature of this sentimental topography. (Fig.)

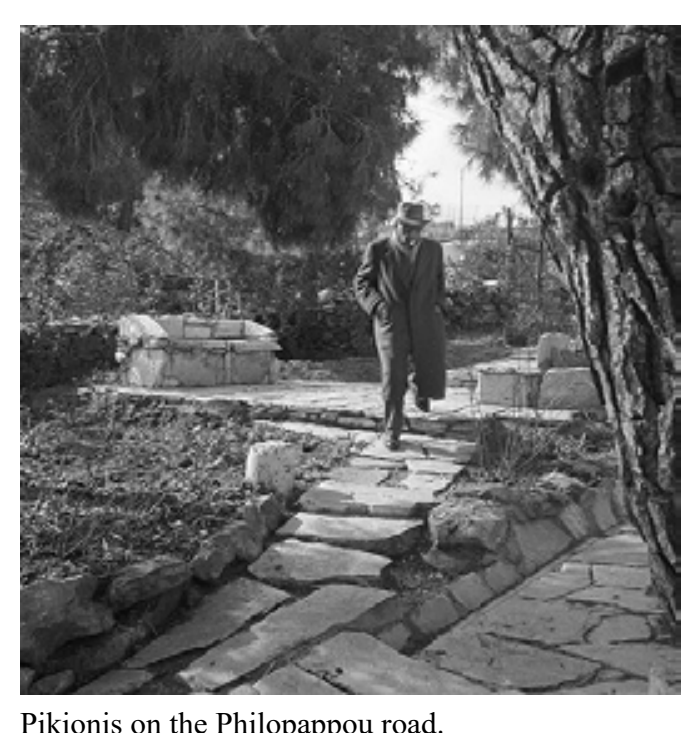

Pikionis on the Philopappou road. 
Chapter II .

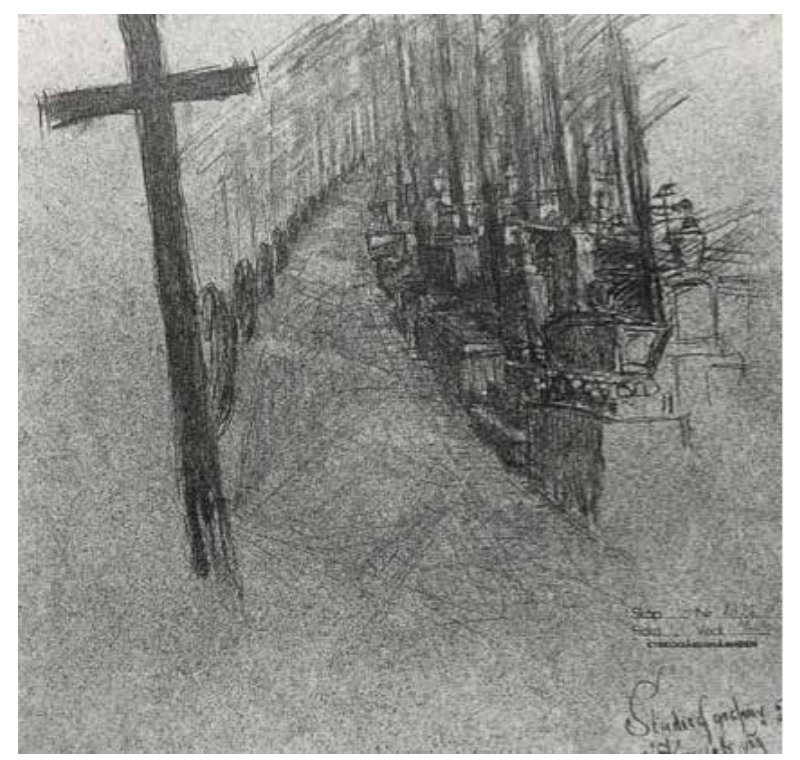

LANDSCAPE OF REMEMBERANCE

Sigurd Lewerentz, the ceremonial routes in Stockholm and Malmö 

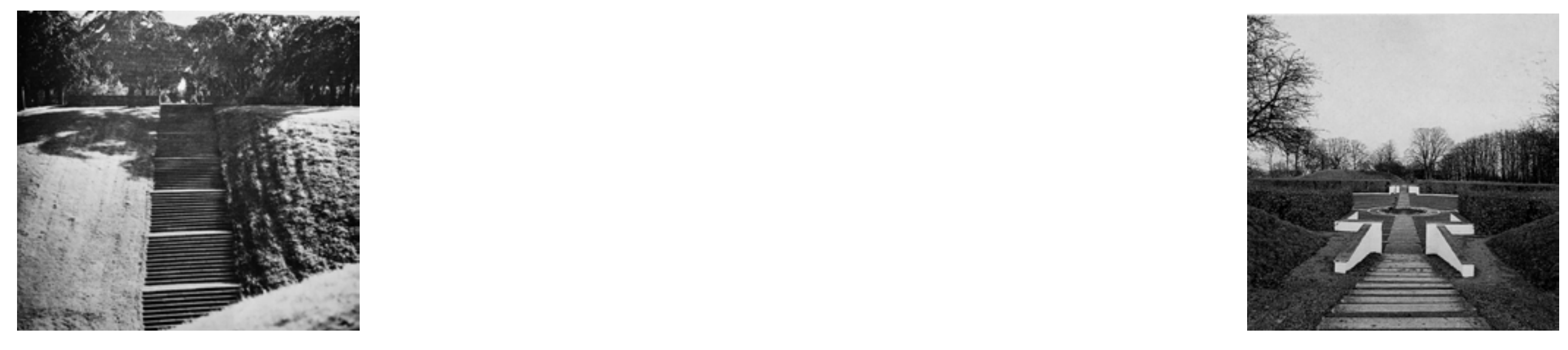


\section{AGAINST THE CRISIS OF THANATOLOGY}

O man! while in thy early years,

How prodigal of time!

Mis-spending all thy precious hours-

Thy glorious, youthful prime!

Alternate follies take the sway;

Licentious passions burn

Which tenfold force gives Nature's law.

That man was made to mourn.

Robert Burns, Man was made to mourn: A Dirge. 1784

i. The displacement of the cemetery, from interpretation to illusion

the last landscape

A place destined to the memory of our ancestors always has the capacity to reach our deepest emotions. By placing ourselves in front of a tomb we connect deeply with the being that has disappeared. It is a feeling rooted in the relationship between the death of the other and our own existence as mortals. As the work "Et in Arcadia ego" of Nicolás Poussin says "Memento mori”, death unites us all.

We call cemetery the last landscape because it is the final place of everyone. The place of death is created from burying actions. Death cannot physically represent itself, it needs a substitute, a mask to cover the crucial facts meanwhile keeps communicating with the world. In this sense, inhumation is regarded as the ritual process to dematerialize death, freeing it from the presence of the body, and locates the death by creating semiotic significance on a plot of earth. Mound, tombstone, status become the new medium that reinterprets the body of the deceased. Cremation is another practice but carries the similar mechanism of locating the death according to the place where ashes was disposed.

The practice of removing bodies stood for the very original displacement of death. It is such an effective manner that has substituted the subject of death, which transmits its biology meaning, from organic decay, into a spatial presence and formation of symbols. By sanctifying place and natural elements, specific commemoration becomes feasible.

In the same sense, burial and ashes disposal have conferred geographic meaning on the death. Graves articulate the identification of the dead with the ground, the plot of earth and surroundings space. Since then, death had been converted from a biological term to a spatial matter that stresses the meaning of place, it could be gathered and generalized in a communal place. Within the place, individual's death, same as the alive people, has been endowed with a collective identity so to participate into the group's history. ${ }^{67}$

Cemetery was once close to the living realm. Corpse were buried underneath houses in many prehistoric cultures, and Ancient Roman cities were adjacent to the Vía sepulchra lined by mausoleums; even to the late 18 th century, as Foucault observed, "the cemetery

67. Spatial identification in burial is used as punishment in most culture, for those unworthy descendants who are banned from the family grave. 
was placed at the heart of the city, next to the church." ${ }^{68}$

In a section view of these old cities, we would see gaps consisted of tombs were orchestrated into the living lines, houses were built along street while the graves accumulated in the cemetery. It proved the facts that death once stayed parallel to the life, people lived simultaneously with their ancestors within the same space, a spatial and temporal co-existence was a basic relationship between death and life then.

Temporal continuity was another remarkable factor. The old were buried and the new were born in the same land where traces of the group were recorded and renewed. Juxtaposition of death and life enlarged the dimension in space and time, it gave people's existential experience a strengthened coherence that stayed in the heart of the collective memory. As the sacred place in the city, cemetery balanced the real world, its closeness to the secular lives had always reinforced the acknowledgement of death as an inevitable image in the everyday scene, it reminded the living ones of the weakness and ephemeral in lifetime, and always preserved their identities as mourners.

myths in the modern cities

The coexistence lasted until recent time, when the second displacement of death took place under the sanitary concerns and land crisis. The modern history of cemetery was actually a competition with urban space. The result is apparent: place for the alive won the battel, and place for the dead was exiled.

68. Michel Foucault, trans. Jay Miskowiec, "Of Other Spaces: Utopias and Heterotopias," from Architecture $/ \mathrm{M}$ "during the nineteenth century, the shift of cemeteries toward the suburbs was initiated. The cemeteries then came to constitute, no longer the sacred and immortal heart of the city, but the other city, where each family possesses its dark resting place. ${ }^{69}$

Relocation of cemetery also reflected the change in social ideology that regards death as taboo to be removed from urban space. Cemeteries were placed in the peripheral areas in the masterplan of modern cities, with walls erected to keep the death place from public sight. Instead of being a crucial component, modern cemetery is restricted with particular objects - it only accepts dead bodies and mourners.

Physical separation and communal resistance to the death scene lead to interruption in temporal continuity of the city, where the circular of life and death once played an importantly role in the representation of spatial complexity. This interruption has bidirectional effects that lead the simplification and discord on the temporality both on the city and the cemetery, which end up running towards the opposite direction - the eternal and the forgotten.

The anti-cemetery notion would lead to the collective oblivion of death in the modern city, decease happens as an individual or a family's incident, it is treated immediately and exported from the city to "the other city". This removal is what the modern city would like to see, economy substitutes for ethnic connection to form social structure. Cemetery, once the heart of memory, now is a potential threat, standing for the declined and the negative. It exists like a myth far away, the exile means to minimize the awareness of death, as well as the collective and historic sense. 
Time in the city is now urged in a way all about moving forward, about producing and consuming. Death becomes invisible in our living space. It is a great victory of life, so is it for the modern urbanization. The new sacred city of immortality has been built upon the ruins of old and scared cemeteries. City becomes a dreamscape, with its irresistible slogan of the long live, that attracts more and more migration. For the first time, people are freed from their identities as mourners and become worshipers of this everlasting power.

crisis in "the other city"

On the contrary to the eternal character in the modern cities, importance of those cemeteries on the city margins are fading in the temporal-spatial dilemma.

Under the appellation of "the other city" or "the city of the dead", modern cemetery configured by the imitation to its referent, the inhabitable place of city - it purports to dwell the dead. However, it ends up as a city's enclave, connected by a one-way road.

Walking through a cemetery of modern design is hardly to be an experience of meditation. Those densely laid tombstones and closely stacked urns tell the shortage in space, paths divide the ground and lead to the specific point in the most efficient and direct way. It's hard to imagine so many people, if they were alive, stay within such a crowded place. The dimension of life, or post-life, in this "city", is extremely compressed.

The spatial crisis represents not only in physical format, but also in the ideological dilemma behind - a lack of spatial spirit in the cemetery. It primarily results from the loss of context. In the time of primitive belief of the immortality of the soul, the affinities of cemeteries with the living realm may be seen as an attempt to recover the life aura of the dead by anchoring the relation of graves, the surrogate objects of the deceased, with the meaningful place. Once a man dead, his identity is eliminated from the living place. In this sense, modern cemetery might be seen as a deprivation of spatial meanings. The homogeneous and crowded look turns it as a bored and passive space, with nothing to generate its own spirit but merely accumulating death. Finally, the dead body is buried in an anonymous place.

In contrast with the high-speed development of the modern city, cemetery runs much slowly. Graves keep occupying the space but its character is left in a stagnant course, since its barren body and suspended condition cannot afford any renovation for the progress

"for the individual, the cemetery begins with this strange heterochrony, the loss of life, and with this quasi-eternity in which her permanent lot is dissolution and disappearance. ${ }^{.70}$

Death is never an isolated fact, it completes the notion of life. In the same way, a cemetery cannot be suspended from the real world. Both the city and cemetery have to be inclusive, being capable to reaffirm the collective identities, so to connect people with their ancestors, to regain their identity as mourners, and to relate themselves with the death. A cemetery should play a critical role in keeping the memory by the means of commemoration.

Since the physical division between death space and urbanscape cannot be fixed, 


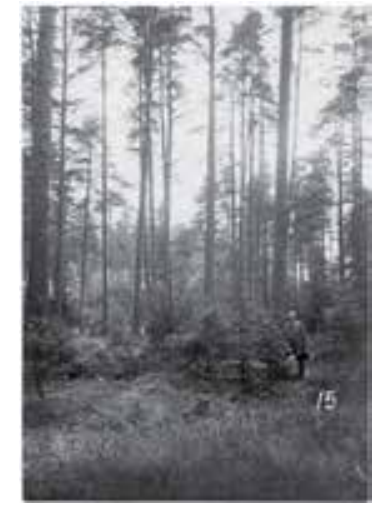

Fig 2.1. Original condition of Woodland cemetery in Stockholm

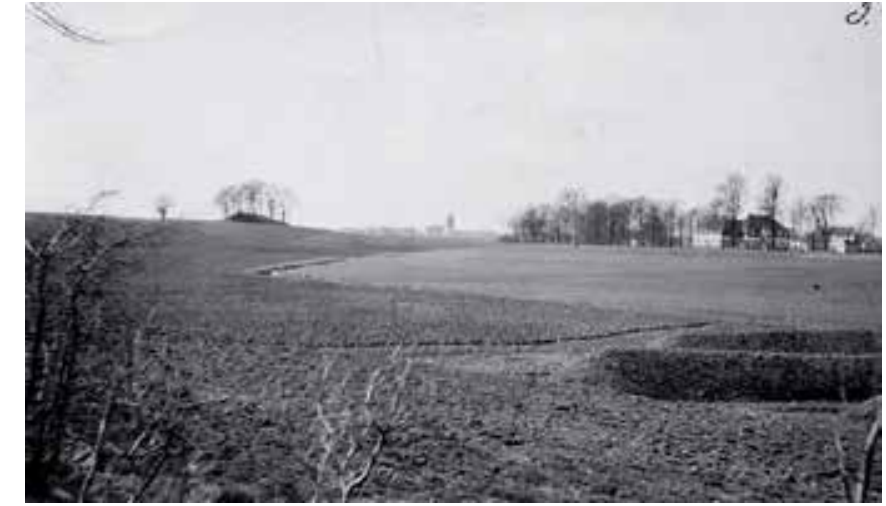

Fig 2.2. Original site of East cemetery in Malmö

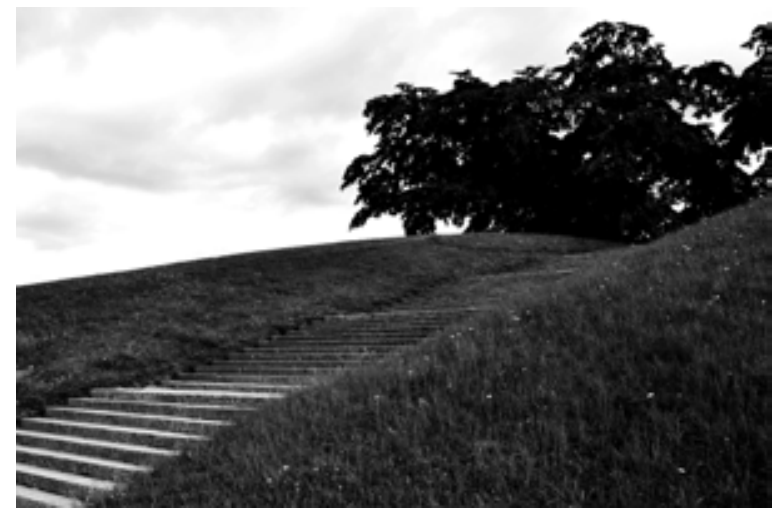

Fig 2.3. Meditation Grove, Stockholm.

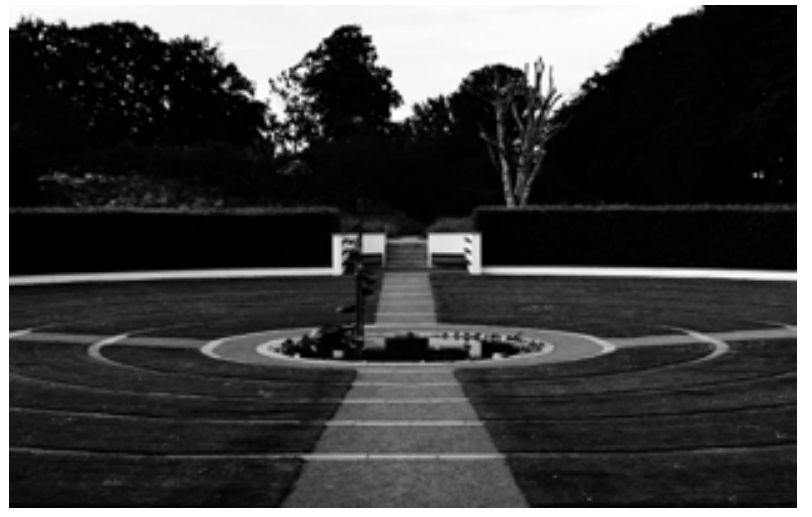

Fig 2.4. Ceremonial Plaza, Malmö. rebuilding the spatial spirit in cemetery become the critical point in order to reconcile their conflicts. For the cemetery, its Genius loci stems not only from the position as a proper border that keeps a balance, "like the frame of a painting, it demarcates a limi between the work and what lies beyond" ${ }^{71}$, but also from an equal representation of death and life. It must convey the communal values in order to overcome the physical distance and to repair the ideologic gap, through the way of binding up, again, the two phases of life circle, debunking the immortal myth and reproducing the contemplation of death.

Only in this way can the last landscape be involved into the real time, and can we live the life as mortals.
71. Christian Francois Hubert, "The Ruins of Representation," Idea as Model, Rizzoli, 1982 Republished, with a new postscript, Oase 84, Rotterdam, 2011. http://www.christianhubert.com/ writings/ruins

\section{ii. Sigurd Lewerentz, revive the landscape for commemoration}

From the early twentieth century until the last period of his life, Sigurd Lewerentz (1885-1975) worked simultaneously on the development of two cemeteries: the Stockholm Woodland Cemetery (1915-1961), collaborated with Erik Gunnar Asplund $(1885-1940)^{72}$, and the East Cemetery of Malmö ${ }^{73}$ (1916-1956, 1968-1969). The landscaping emerged from the original conditions of the places. The dense forest (Fig2.1. and the earth crest (Fig2.2.) were the basis that allowed to incorporate episodes into the plastic images of the ground, to generate the spiritual value in each burial place, and to promote meditation of life and death along the journey. 72. Among the design of the woodland cemetery, Lewerentz was mainly dedicated to the work the Resurrection Chapel, meanwhile, Asplund was commissioned of the rest buildings and the surrounding of the Holy Cross Chapel. It was precisely because of this division of work and the in their final rupture in 1935 after collaborating for more tha a decade. Asplund died in 1940 and was buried next to the crematorium of his design, Lewerentz returned to the project ind landscape.

73. According to Ingrid Campo-Ruiz's investigation, another key figure in the landscape developments in Malmö Eastern Cemetery was Gustaf Valfrid Wahlberg, who worked at the cemetery from 1925 to 1956 . "according to existing documentation, it is difficult to determine the exact degree of Wahlberg's influence on the landscape design. Wahlberg's documents usually specify plant species, whereas many of his plans are tagged with his explanation 'according to Lewerentz plans'."

Ingrid Campo Ruiz, "Malmö Eastern Cemetery and Lewerentz's critical approach to monume (2015): 335 
When we stop before the embedded stairs of the Meditation Grove in Stockholm, and look up to its top covered by trees (Fig2.3.), or we approach the small vestibule that opens to the sunken Ceremonial Plaza in Malmö, and observe the ground that descends towards the central fountain. (Fig2.4.) Something unusual emerge in our mind. The ai of serenity, the imbalance between human figure and the scale of the landscape, and the order of the itinerary determine the route. All these factors are located around the site and make up a space in front of the present world, a place of farewell that stops us.

The two cemeteries, whose spatial composition were conceived conceived on the basis of Scandinavian territory and Nordic funeral ritual, possess deep narratives that stem from the authors' concerns about thanatology, which could be regarded as their response to the need of public consciousness when modern cremation became a legitimate form in Sweden. Lewerentz started to develop his idea about narrative of commemorative project and landscape as a continuous theme, through a progressive "rite of passage" in his never built project for Helsingborg crematorium in 1914. Water in the site is channeled into the vault of the building, representing the metaphor of Styx. Entry into the first floor of dimly lit funeral chamber for coffin deposit is followed by climb to the Hall of life amidst sunlight from the high windows and choir sings. Passing by the following urn cloister and the pavilion of memory, mourners then go out into the Grove of Remembrance. In this early work, Lewerentz created rite by incorporating the sacred and the funerary into building and landscaping form, it raised the motif of his later works of cemeteries: "the necessary acceptance of death, the decent rituals of mourning, ${ }^{74}$.

As for the general plan of the cemeteries in Stockholm and Malmö, Lewerentz got rid of the existing structures of European or Islamic cemeteries prototypes - the city of dead or

74. Colin St John Wilson, "Sigurd Lewerentz The Sacred Buildings and the Sacred Sites," in Sigurd Lewerentz 1885-1975, ed. Flora, Giardiello and Postiglione, (Milan: Electa architecture, 2006.), 13. paradise garden. Proper interconnections between the sentimental space and the outside world establish new relation and reconcile their conflicts. Introspective organization of the interior space ensures an independent ambient to protect the felling of bereavement, while the accommodation of religious buildings into topography represents symbol of resurrection, and other facilities respond to the need of functionality for modern funeral. Under the spiritual air and practical requirements, the archeological references were used as crucial elements to configure monumental landscape. With all the natural and artificial elements, the architects tended to achieve an equal view of life and death, conveying the narration that binds us together as mortals.

Lewerentz has worked on more than 28 cemetery projects, only one third of them were realized. Among these sepulchral projects, pathway no longer serve merely dividing and orientating. Being subordinated to the entire landscape, itineraries in his cemeteries are delineated as artificial mediator. On the one hand, it defines and protects the scale of the individual, stressing the coexistence of an individual person with the grand Scandinavian topography; and on the other hand, it converts ground unevenness into a series of ascending and descending pathways, inscribing the attention to the perceptive experience, activated by the changes of rhythms of movement, in the concrete definition of the ceremonial space as well as in the field that it is capable of determining. By delicately unfolding and thinning out on the ground, these pathways put emphasis on their narrative character. They find a way to promote the space-time experience, replacing the indifference of the habitual vision by the rediscovery the ritual of farewell and the reality of the consistence of death and life.

Therefore, according to the sequenced flow of the itinerary that makes us fall back on it, in this chapter of Lewerentz, research on the Stockholm Woodland Cemetery and the East Cemetery of Malmö is structured by three parts. 
The first part focuses on the initial routes of the two cemeteries, which will reflect the mechanism that Lewerentz has applied for to transform the landscape and introduce ceremonial narrative, as well as his consideration to accommodate such expression into the existing structures. The definition of the foreground plaza and entry pathway of the Woodland cemetery encourages and stimulates physical and psychological transit that supposes for the spectator a detachment and rediscovery of the sequential storytelling along with its longitudinal site, and in Malmö, the middle avenue that runs through the cemetery presents the parallel and bidirectional circulation, its connections with ceremonial buildings, the crest and burial plots manifest an itinerary representing the balance between spirituality and functionality.

The second section studies two particular spaces, the Meditation grove raised in the middle ground in Stockholm and the Ceremonial Plaza embedded in the crest in Malmö. As outstanding episodes of the overall narrative given by the cemeteries, they promote spatial monumentality which can be perceived by the ascent and descent that relate the individual to the topography. Both of visual perception and movement compose a certain rhythm that is based on the encounter with rituals whose depth surpasses the daily senses, and connects with the meaning of the cemeteries: the commemoration of the farewell.

The last part focuses on the objective on the itinerary towards architecture. The Way of seven wells penetrating into the woodland defines a powerful itinerary that orients the way to the Resurrection chapel at the end of the journey. The branches and small plaza generated from the main avenue in the cemetery of Malmö, direct visitors to the twin chapel of St. Knut and St. Gertrud, and the chapel of St Birgitta. While the buildings in these two cemeteries show embodiment of the stylistic transition from Nordic classicism to modernism during the first decade of the twentieth century, the routes connected with these buildings for commemoration organize the shift from natural place to constructed space, indicating phenomenological change of the narrative of ceremonial landscape. The sensibility of the architect has presented, through his constructive language, that the time life has come to a stop in the hall of ceremony, the end point of the journey towards farewell, provokes an introspective wonder at our own existence in the space devoted to both of life and death.
1915 1915-19: Winner proposal of "Tallum"

First period of the project revisions Woodland Church. (Asplund) 921-25: The Resurrection Chapel. (Lewerentz) 1920-23 Site development. 1922-24:

Service building. (Asplund) 1923-25: Resurrection chapel. (final solution of, Lewerentz ) 1923-32:

Fieldstone boundary walls. 1924-31:

The main entrance.

1928 Final revision of Meditation Mound. (Lewerentz) 930-33

The Crematorium chapel. (Asplund)

1935-40:

The Crematorium and the Way of the Cross. (Asplund) 935-40 Landscape refinement.

1951-56 1952-61:

Pedestrians entry gate. (Lewerentz) Service buildings of Resurrection chapel. (Lewerentz) 1958-61:

Memorial Mound. (Lewerentz)
1916

Winner proposal of "Ås".

1918-20: 920-23: Realization of the service buildings. 1923: Development of the general layout. 1922-23: Realization of the open-air ceremonial area 1923-26: Realization of the waiting room 1923-24: Elaboration of the project for the main chapel. 1923-25:

First project for the crematorium.

Realization of the funeral chapel (St. Birgitta) 1928-29:

1931-3

Realization of the crematorium (final version) 1935-43:

Project for the bell tower, and twin chapel of St. Gertrud and S. Knut.
1968-69: 1969-71: ower kiosco. Custodian's house. 


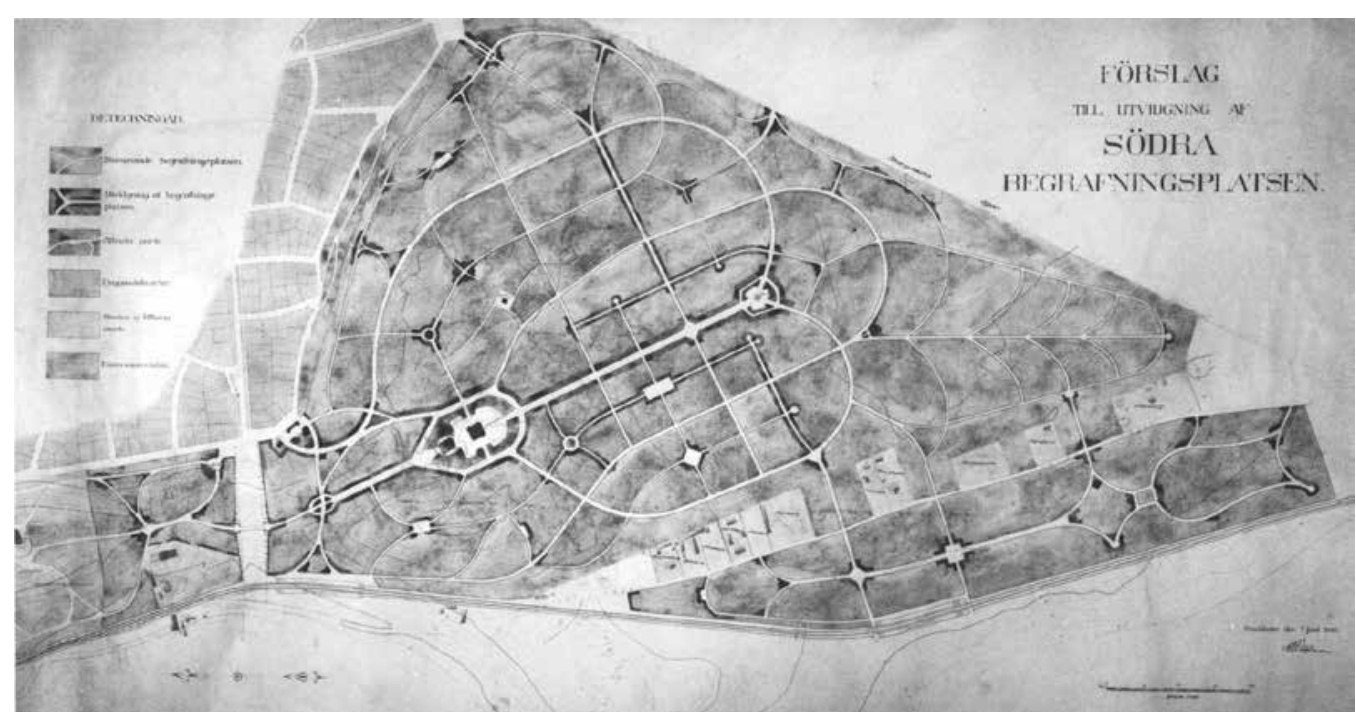

Fig 2.5. A.E. Påhlman, Stockholm Woodland Cemetery plan, 1910.

\section{THE SUBLIME LANDSCAPE}

Both of the Stockholm Woodland Cemetery and the East Cemetery of Malmö manifest the architects' capability of incorporating spatial sequence and ritual ambient into the sites of topographic and historic complexity. Their particular narrations of life and death in the same place is archived by the sublime landscape based on a sophisticated balance between the artificial and the nature. Therefore, the theme of cemetery, lies in "the associations of death and rebirth in a landscape of spiritual dimension" ${ }^{75}$, is experienced through a succession of temporal storytelling based on the increasing dimensions from the instantaneity of individual activity, to the implication of the cycle of life, finally, to the symbols of eternity derived from the archeologic and topographic elements.

From this point of view, despite of the constant alterations during the long development of the two projects, it is important to go back to the early proposals to trace for the architects' initial ideas with regard to the transformation of the original sites and to the mechanism of introduction of the sentimental landscape.

Tallum, a new burial place

In order to resolve the issue of overcrowded space in the Sandsborg cemetery in south Stockholm, plan for a new cemetery adjacent to the souths side of the old one was raised in 1905. In 1910, Sockenvägen avenue which traverses through the area was built, breaking the place into two parts. This separation weakened the continuity of the original discipline and conferred independent character on the site reserved for the new

75. Caroline Constant, The Woodland Cemetery: Toward a Spiritual Landscape: Erik Gunnar Asplund and Sigurd Lewerentz, 1915-61 (Stockholm: Byggförlaget, 1994), 1. cemetery. The design work was firstly commissioned personally to the city engineer August Emanuel Pålman, however, his plan was rejected by the Cemetery Authority since the lack in participation in the site character. (Fig2.5.) In 1914, an international competition was called and attracted domestic architects and foreign architects, most from Germany. By the next year, fifty-three proposals were sent to the committee.

The competition brief described the original condition of the site: the land for the new cemetery, first planned with 50 hectares, then enlarged to 75 hectares, was covered by dense forests, the majority were pines and spruces interweaved by others species of vegetations, rocky ground paved of sand and gravels with grave pits and footpaths scattered around.

"The site shall be arranged, without scarifying an artistic viewpoint and without extensively altering the terrain or corrupting the landscape character $[\ldots]$ so that the entire site is used for the best possible total effect." ${ }^{376}$

With this clear principle announced by the committee, the new Stockholm Cemetery competition was set up to preserve the authentic character of the site and to seek profound values from the typical Nordic beauty deep inside the woods.

The rejected plan of Påhlman demonstrated an apparently attempt of an axial road to treat the site with symmetric composition. It revealed a coherent manipulation of powerful landscaping in Europe at that time. However, explorations of the site's 76. Ibid, 32. 


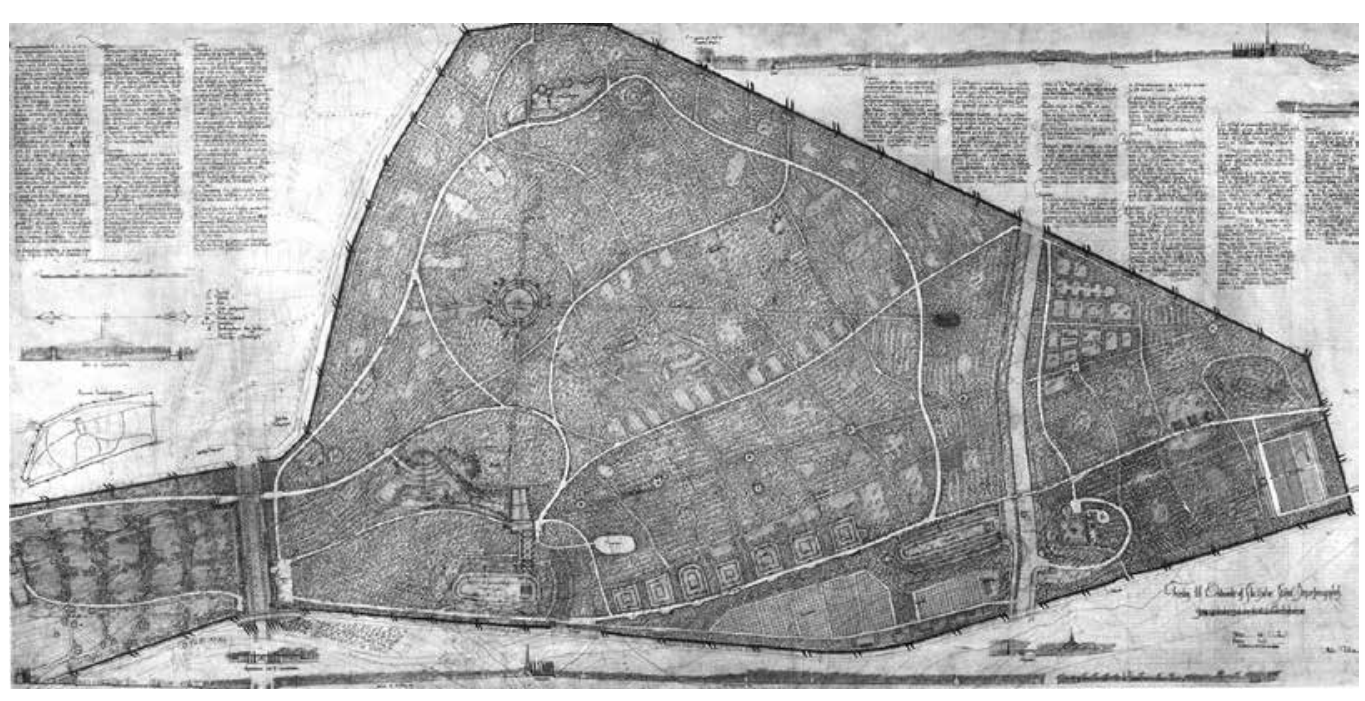

Fig 2.6. Entry Proposal “Tallum” for Stockholm Woodland cemetery, Sigurd Lewerentz, Gunnar Asplund, 1915

potentials in his program had indeed inspired the future projects of other designers, including the winners, Sigurd Lewerentz and Gunnar Asplund, and their entry proposal "Tallum"- which means pine trees in Swedish. (Fig 2.6.)

In this early project, the two young architects carefully retained the wooded character in site. Their main idea of incorporating forest into a cemetery design reminds of the Munich Waldfriedhof by Hans Grässel, opened in 1907, which was believed as key reference of the partners. ${ }^{77}$ Like Påhlman's concept, the entry proposal of Lewerentz and Asplund also involved the consideration to remain the affinity of new cemetery with the old one. The existing itinerary system was depicted in smaller scale on the first plan, suggesting the architects' intention to overcome the separation caused by the city road by fixing the relation between the two funeral places. Two entrance were provided based on this consideration, one with an internal plaza and the other was coordinated with the main route of Sandsborg cemetery, emphasizing the inheritance and facilitating the access. Påhlman's bold axis was taken place by the mild division consists of four entryways which, connected by secondary footpaths, create subdivisions of the site without affecting forests' profile. In their monotone sketches, Lewerentz and Asplund conceived a melancholic and mysterious ambience, wherein mourners were led by narrow pathways to walk through deep forest. This initial conception based on the respect for existing environs of vegetation and topography was kept as a fundamental idea and had been developed in the following decades.

77. Caroline Constant assumed that Asplund may once visited this cemetery in 1910, while Lewerentz was surly familiar with it due to his stay in Munich between 1909-1910.

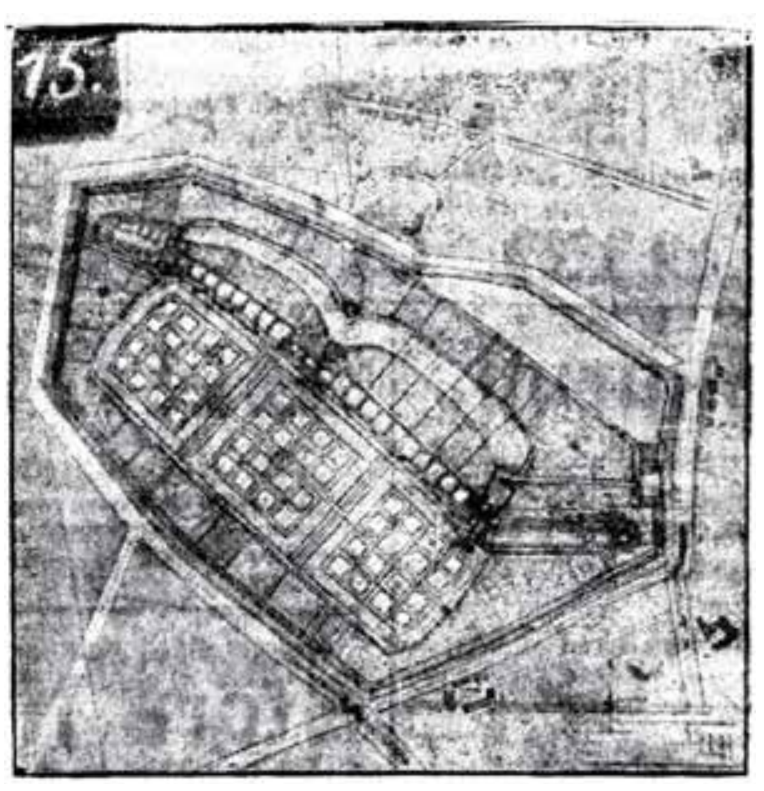

Fig 2.7. Entry Proposal “ $\& s$ " for Malmö Eastern cemetery, Sigurd Lewerentz, 1916.

\section{As, retrace the original reality}

In 1916, in Malmö, the Sweden's third largest city, another competition for a new cemetery was called. The selected site is an abandoned farmland of 32 hectares with ancient graves stretching on the east suburb. Among all the existing elements as mixture of historic and cultural traces, a ridge that runs through the area is the most outstanding element. By evoking the land's original conditions, it forms a powerful boundary that separates the area into the northern and the southern parts.

By acknowledging the importance to preserve the inherent character of the landscape - "It is first and foremost a requirement that the ridge's natural monumentality be exploited and reinforced, and that it be used as a basis for orientation in the design",78 the competition jury consists of pastors, architects and cemetery experts had reached a consensus of the design principle, which was neither to pursuit a prototype of woodland cemetery, nor to over-rely on geometrical treatment.

Sigurd Lewerentz, who already had the reputation of cemetery design for his work in Stockholm and other cemetery projects, won the competition with his proposal under the motto "Ås", which means ridge in Swedish. (Fig2.7.) In this design, Lewerentz had structurally and programmatically conceived the space round the topographic feature. As he indicated the initial idea of design, "Changes made to the terrain are intended to produce a large landscaped monumental cemetery south of the slope, and to increase

78. Constant, "The Woodland Cemetery," 116 
the effect of the altitude and length of the ridge, ${ }^{\text {,79 }}$, three parts have been defined inside the perimeter of trees: the central distribution of ceremonial spaces along the ridge, and burial fields on the south and north part of the cemetery.

From the early proposals for the two cemeteries we see a continuous design strategy of the authors to put emphasis on the affinity with the site itself. (Fig2.8.) By reaffirming the primitivty of the terrain, Lewerentz and his colleague managed to convert woods and agricultural field into sublime landscape in order to to create narrative of transcendence in cemeteries. Apart from the respective manners of transformation of the existing facts, the different organization of the entry routes of the two cemeteries - in Stockholm, the sequential itinerary made of a succession of episodes with doctrine meanings, an in Malmö, the significance of the middle avenue stems from the fusion of functionality of funeral and its interrelationships with other spaces - imply the architects' design strategy to create limits and transit, as well as their distinct mechanisms to create an accommodating space for the mourners and to anticipate storytelling of the subsequent space.

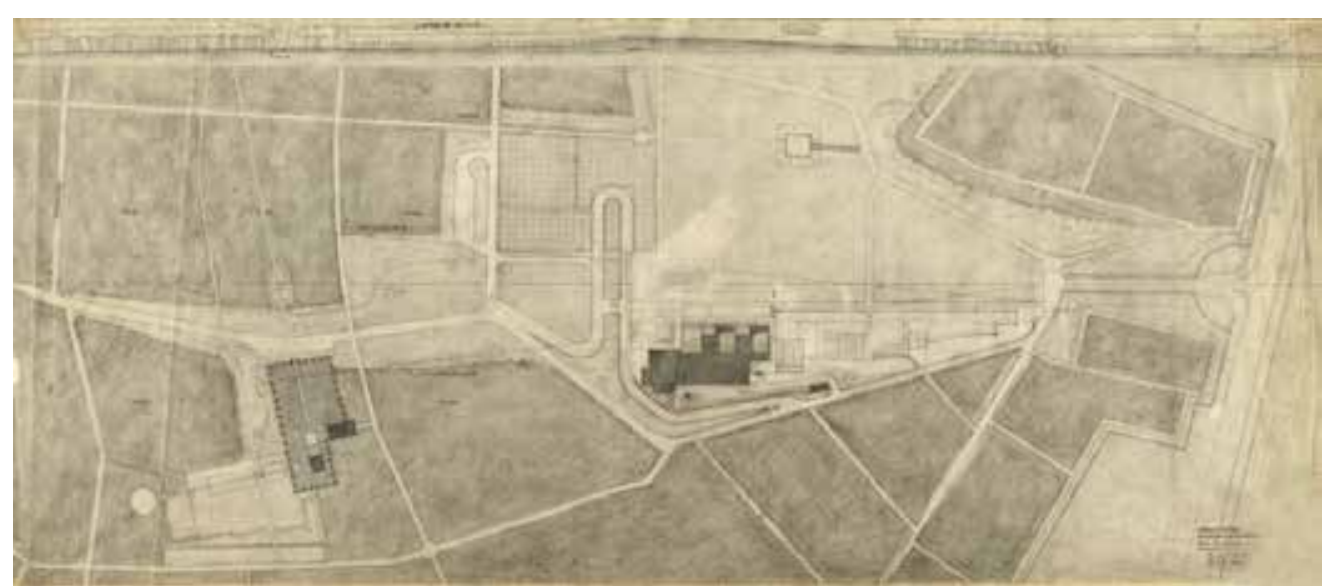

Fig 2.8. Woodland Cemetery siteplan, Asplund, 1924

79. Sigurd Lewerentz, Malmö Stads nya Begrafningsplats vid Hohög, typescript, Stockholm, 3 June, 1918. In Ingrid Campo-Ruiz, "Malmö Eastern Cemetery and Lewerentz's critical approach to monumentality" (Ph.D diss., Universidad Politecnica de madrid, 2015), 330. 


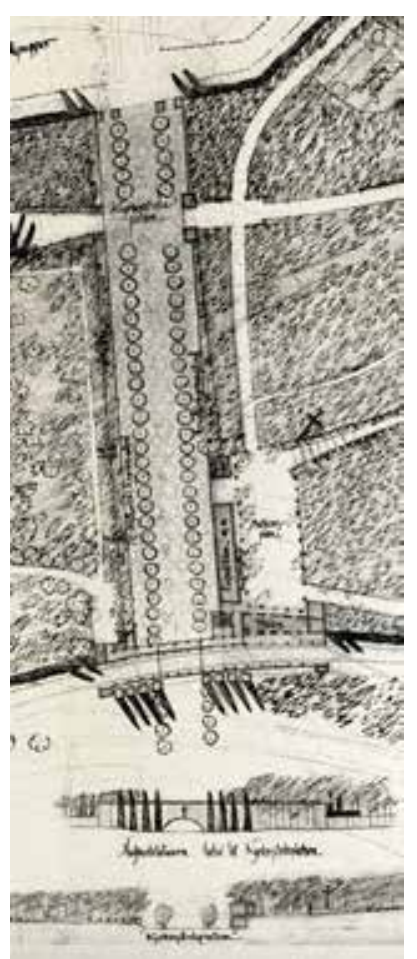
Fig 2.8. Entry proposal for the

\section{$\S$ Sequential detachmen}

. a dialectic unity beyond the boundary

The Sockenvägen street that breaks the continuity of the old site and the Woodland cemetery has brought a dual challenge for the architects. On the one hand, new route must be created to orient the way to the access of the new cemetery, on the other hand, particular strategy should be used in order to evoke the relation between the two places. With the sidewalks beyond the cemetery border and the entry plaza, the architects tended to resolve the conflicts xby reproducing a conceptual unity, as well as emphasizing the exclusive experience of approximation to the woodland.

A series of proposals show the continuous exploration of authors in composing the itinerary round the initial place. In the entry plan, the north boundary of the new cemetery and the south edge of the old one were adjacent to one line of trees, which created a simple division between the street for vehicles and sidewalks for pedestrians. (Fig2.8.) From Lewerentz's plan in 1917,(Fig2.9.) another tree line has been added that converts the walkways into boulevards to receive visitors from tram station. By softening the borders of the old and new cemeteries and converting their peripheries into protected space of passages, the vegetations reduce the impact of the spatial separation between the two areas, and derive particular experience during the approximation to the cemetery.

Besides making up the split, the entry plaza's development demonstrates the architects' intention to create independent quality for the new cemetery from the first place. The two entries in "Tallum" may ascribe to the designers' idea about the necessity to

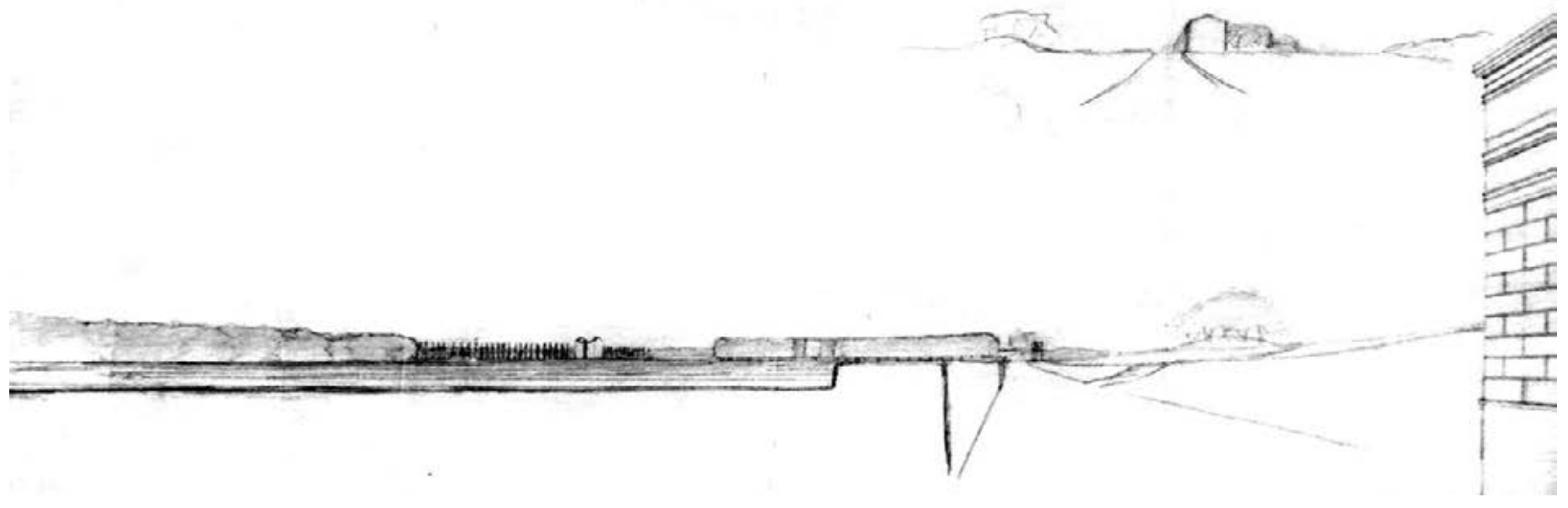

Fig 2.22. Avenue persepctive, Lewerentz, 1939 .

$\S$ Sentimental functionality

architecture as monument of burial

From the first proposals for Malmö Eastern cemetery Lewerentz showed a meticulous approach to the internal circulation within the sepulchral landscape. (Fig.2.22.) Two routes that run side by side through the longitude were delineated as axis of the site and were given with very different characters for their respective purpose. The slim pathway on the ridge, whose edges was straightened in the late 1920s, marked by ceremonial spaces was made for an individual's contemplating walk. Meanwhile, on the southern foot of the ridge, a broader avenue used by both pedestrians and vehicles, connects the eastern and western entrances and shows functionality as a basis for orientation in the design. Along this broader road we see a set of buildings, resting areas and branch paths lead to the burial fields. All of these elements are located in their own position to compose the process of funeral ceremony.

However, Lewerentz would never let spiritual narrative give its way to functions. The avenue offers an outer position to read the ridge as a topographic and cultural entity which accompanies the mourners from the chapel to the burial areas. His sentimental perspective to this itinerary is seen from the methodical orchestration of those functional points, so to achieve a succession of different episodes according to the sequence of storytelling. Entering from the eastern gate, people will not sense the quality of cemetery space until after the bending on the road, the ceremonial area consists of St. Birgitta chapel and its semi-circular plaza become visible. From early proposals to the final plan we observe a reduction of outstanding narrations along the road. The funeral chapel, the small waiting room nearby and the evenly located seating areas, all in simple forms, as 


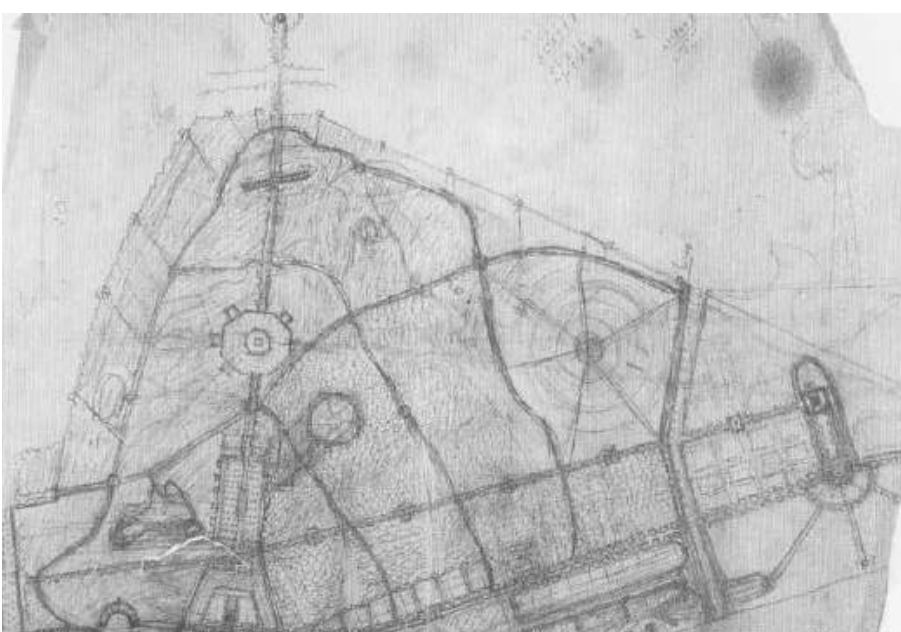

Fig 2.10. Proposal for the cemetery, 1914, Lewerentz.

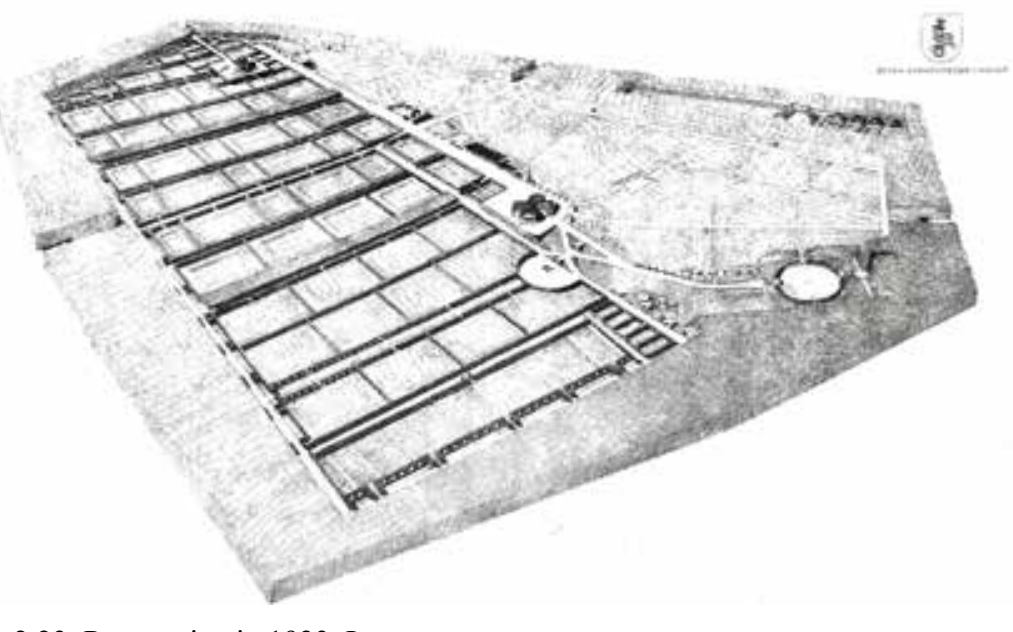

Fig 2.23. Perspective in 1923, Lewerentz.

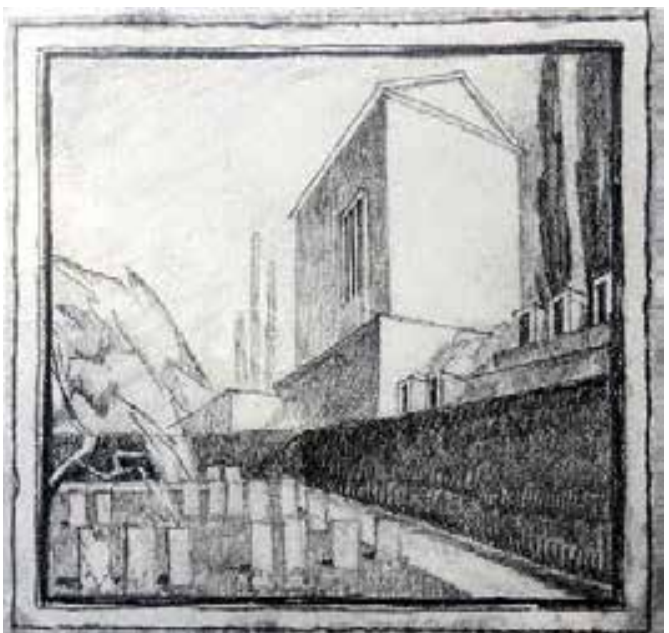

Fig 2.24. Main chapel sketch, Lewerentz, 1920. inherent the characters from the old site. The west entrance was set up with an inner rectangular plaza, from which pathways into the deep space are defined. Changes appear in Lewerentz's sketch in the next year. By removing the east entry, the new work was freed from the old one's circulation and outline. Actually, in his study by 1914 before the collaborated proposal with Asplund, Lewerentz had raised the concep of a unique entrance with axial trajectory, which anticipated the final layout. (Fig2.10) Another plan by the end of 1916 apparently shows Lewerentz's intention to establish particular form of the entry. The entry plaza was placed open to the city street, creating a clearing on the bold boundary of the new cemetery, and facing the Sandsborg's square "Seven gardens". From 1917 to 1918, the rectangular plaza had been radically changed into semicircular form. (Fig2.11.) As Rudolf Arnheim ${ }^{80}$ has argued in Art and Visua Perception, rectangular space tends to direct perception to the corners at the distal side, whereas circular perimeter has the potential capacity to concentrate views on axial direction, (Fig2.12.) the plaza of semi-circular shape emphasizes its axis where entryway is placed. Around 1920, the architects' focus turned to introduce severa functional installations to the plaza to enrich its relation with the street. However, by 1937, all facilities were removed to achieve a simple and open space.

The final configuration of the entry area of the Woodland cemetery consists of three main parts: the walkways of boulevard that starts the journey beyond the northern boundary, the semi-circular entry plaza and the straight gateway runs into the space. Their respective character as well as the resulting progressive narration are experienced through a sequential movement, which contributes to a metaphoric detachment from the outside world.

80. Rudolf Arnheim, Art and Visual Perception: A Psychology of the Creative Eye (University of California Press; Second Edition, 2004).

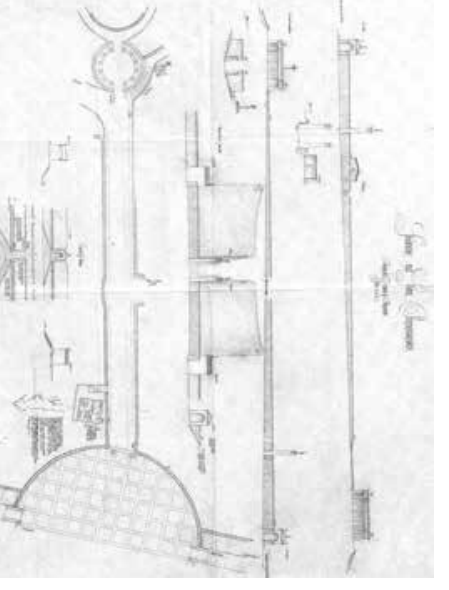

Fig2.11. Entry details, 1918, Lewerentz
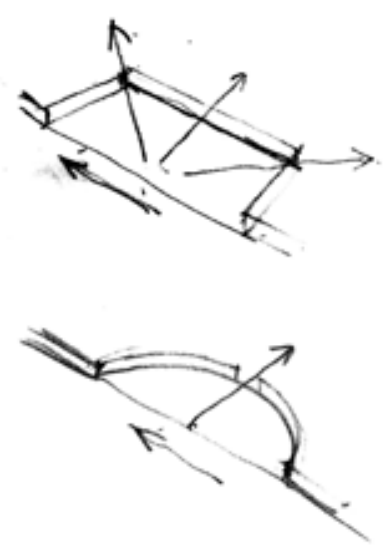

ig2.12. Analysis of spatial shape and visual perception.
drawn by author. pauses, interrupt a continuous transit to the northern part of the cemetery, where the twin chapels and the crematorium are located. These stopping points placed by the method of distancing contribute to the space of protection, wherein mourners are isolated from the funeral procession. The rhythmic movement along the avenue reveals Lewerentz's idea to compose a peaceful walk with great care of the feelings. Therefore, this avenue that connects funeral facilities plays the role of an articulation, which provides sufficient time for mourners to be on the way to the places where the ceremony of farewell will be held.

The aerial perspective in 1923 mand by Lewerentz shows the architect's initial idea to compose an avenue with neoclassical language to put emphasis on architectural monumentality. (Fig2.23.) At the area nearest to the east main entry after the ceremonial plaza, the main chapel with porticos on four sides possesses a Palladian tone of Villa La Rotonda, meanwhile, at the other end of the road, a circular temple recalls Bramante's Tempietto, or its precedent the Temple of Vesta at Tivoli. Behind the stylistic fascination which was to be simplified in the following projects, Lewerentz's idea of combining the narration of a cemetery with the particular topography in the site by the means of architecture has always been the basis for orientation of the design.

The sketch of the main chapel drawn by 1920 (Fig2.24.) clearly demonstrates this intention, first and foremost, through constructive hierarchy in the space. Meanwhile the chapel on the top and burial land at the bottom present an intense confrontation of different storytelling, the ridge that separates the two places is given a dual meaning. On the one hand, it manifests the depth of earth and the sunken ground where tombstones are placed, the excavation of soil is used as the way to interpret burial and the descent of life; on the other hand, it provides a powerful base to support the chapel above, 


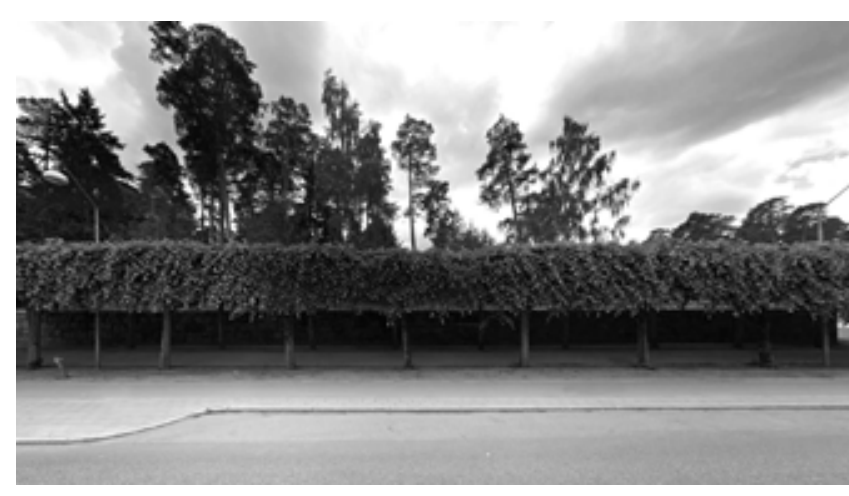

Fig 2.13. Boulevard adjacent to the cemetery north boundary.

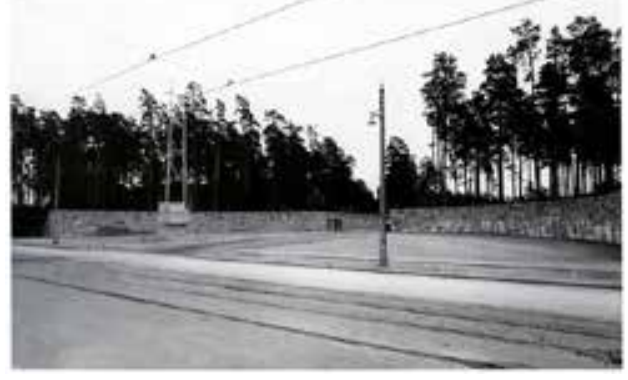

Fig 2.14. Early condition of the plaza.
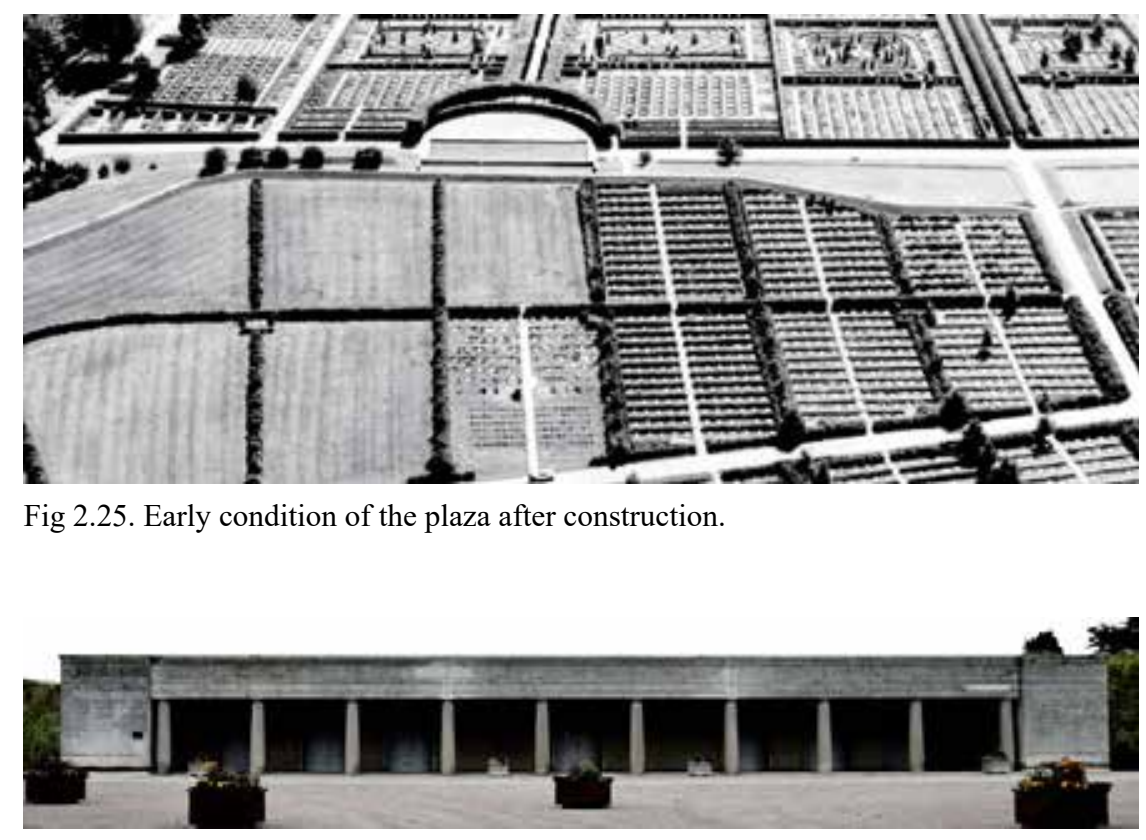

Fig 2.26. St. Birgitta chapel facade.
On the both sides of the street, boulevards with short and dense treetop cropped in cubic shapes, demonstrate a language of unity that implies the connection between the two cemeteries. This link is also implied by the trees of natural forms behind masonry walls, evoking the original woods in this site. (Fig2.13.) The route of three meters in width derives a gesture of protection. The branches and leaves have formed a continuous volume floating as a heavy canopy that keeps filtering sunlight into the passage facing to the north. The dramatic reduction of light and dimension enhances an introspective ambient along with this first trajectory, along which one would have a feeling of a precise point of domestic and ritual condition at the same time. This route minimizes communication with the outside and so to promote a particular feeling of being at the interior space, achieving the balance of perceptions between its two sides of opposing characters - it partially opens on the one side to the street, and closes on the other side with heavy wall made of ashlars. The lack of interrelations along the passage with the outside can be understood as affirmation of the independence of actions within a tunnel. While passing through the shady and narrow trial, everything seems to stand still, with only the alternation of trunks implying the movement and highlighting the orientation of the trajectory. People are moving through a protected space in a sense of security, there is nothing to see in relation with funeral or ceremonial activities. In this case, the architects have incorporated vegetations, masonry and light to contribute to a stabilized space, from which stems the solemn ambient dedicated to a pure rituality of walking, to remind the walkers of an approximation to a special place.

As the boulevard walkway terminates all of a sudden with sunlight streams down, pedestrians are pulled out from the dim pathway and are exposed unexpectedly in an open plaza, where communication with the exterior space is regained. (Fig2.14.) This dramatic change of spatial quality, from a dark and enclosed passage to the open and

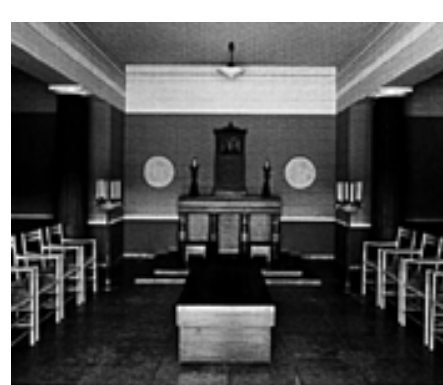

Fig 2.27. Chapel interior, author. whose austere surfaces generate the sense of anti-gravity, and the slim window that filters sunlight into the nave, achieving a form of sacralization with the meaning of transcendence, as the case of the Chapel of resurrection in Stockholm Woodland cemetery.

Lewerentz valued the importance of the ridge not only as topographic entity, but also as the basic element to derive narratives of earth and burial, of separation and connection of the rising and falling worlds, which are fundamental for cemetery space. In this sense, the development from the outstanding form of the main chapel to the constructed St. Birgitta chapel, achieved through simplification of forms around the ridge, can be seen as gradual transmutation rather than an intense rupture.

Lewerentz oriented the architecture ${ }^{84}$ opening directly to the burial ground and submerged the complex of urn chapel and mortuary within the ridge. (Fig2.25.) This treatment of insertion of volume, or excavation of cavity, demonstrates a deep relation of building with the territory. In addition, it produces the sense of "the other place", which stands opposite to the everyday world.(Fig2.26.) By removing the portal, Lewerentz set the portico back to the avenue, in this way, the building is visible only on the approach. Unlike his other chapels with high windows to create the sense of lightness in the interior space, as suggestion of resurrection, the deep loggia and small window of St. Birgitta chapel produce dark ambient inside the small nave. (Fig2.27.) Therefore, our perception of entering in the chapel is activated by the reduction of light, and is prolonged and enhanced, in terms of movement, by the semi-circular plaza on the other side of the avenue. Confrontation of the architecture and its forecourt establishes

84. Caroline Constant points out that Lewerentz aligned the building's longitudinal form with the edge of the ridge in order to conform with the path of the sun. 


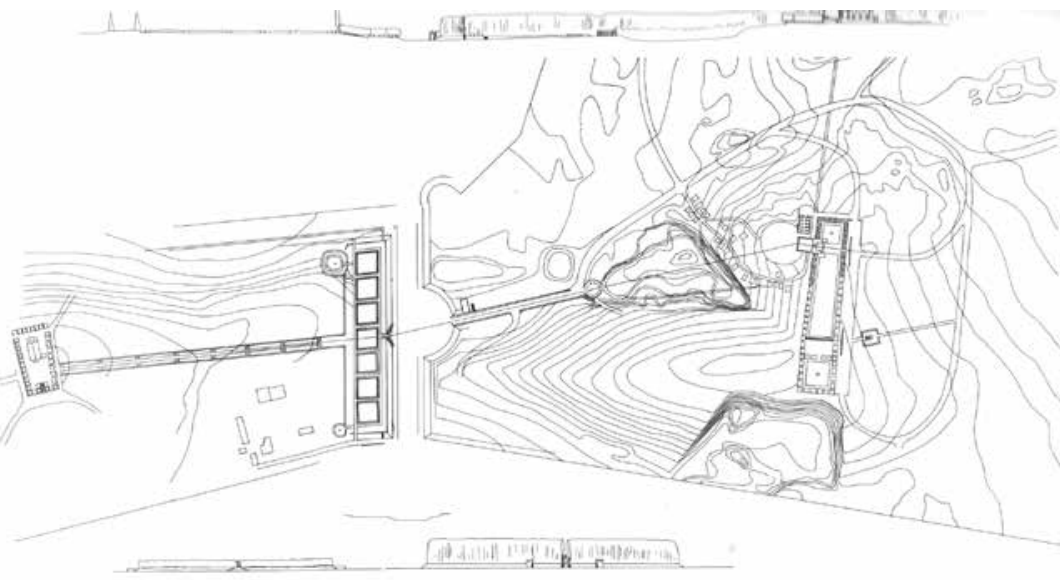

Fig 2.15. Lewerentz's proposal for the cemetery by 1918 shows correspondence between the two cemeteries' routes.

illuminated space, has incorporated the feeling of returning to the world of things wit physical transit to the cemetery entrance. This experience reminds of José Ortega y Gasset's words about the potential narrtive of visual perception, "la invisibilidad, el hallarse oculto, no es un carácter meramente negative, sino una cualidad positive que, al verterse sobre una cosa, la transforma, hace de ella una cosa nueva." ${ }^{\$ 1}$

Though the plaza is located in confrontation with the small entry of Sandsborg cemetery, this relation has been weakened to confer autonomy on the new space. (Fig2.15.) The plaza was conceived as a place to demonstrate, in a modest way, the contradictions of dimension and materials. While its centralized geometry defines stopping point after an intense walk, the entryway that runs towards the deep space puts emphasis on the powerful trajectory which penetrates through the thick boundary. Despite of the subtle oblique of the entryway, the identical treatment of the plaza's two wings helps to maintain a sense of symmetry and to enhance a dual perception of closeness and profoundness. By observing the entry plaza, it is evident to observe the intention of the architect who created this environment in his ability to produce a public place, with the capacity to balance the narrations between artificial and natural elements. This idea is conveyed first and foremost by the combination of the horizontal dimension of the ashlar parapet and the vertical of those trees behind the walls. With this clear delimitation and the absolute absence any decorative elements, the entry plaza achieves the expression based on rational and abstract language, as if to avoid any tendency of empathy. It clarifies the narrations of the initial space of the cemetery in a manner that postpones its thematic basis as ritualized landscape of remembrance.

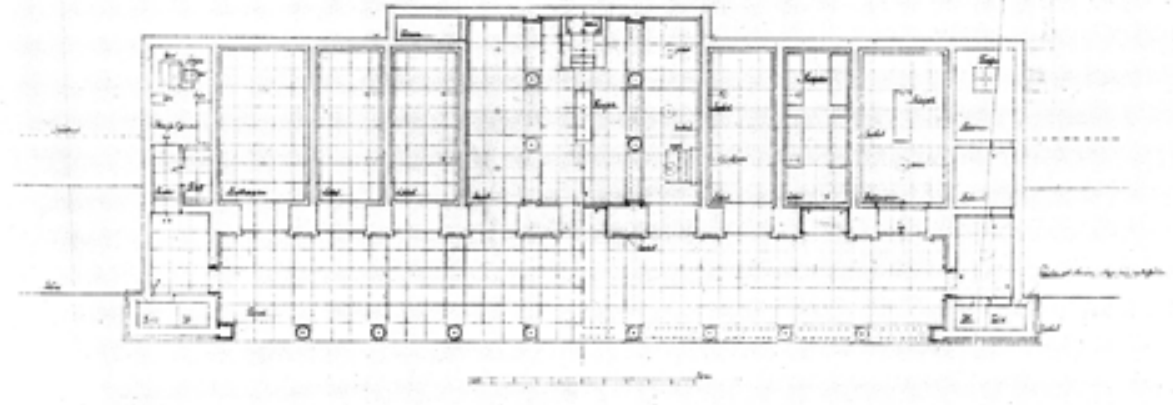

Fig 2.28. Floor plan of funeral chapel and mortuary.

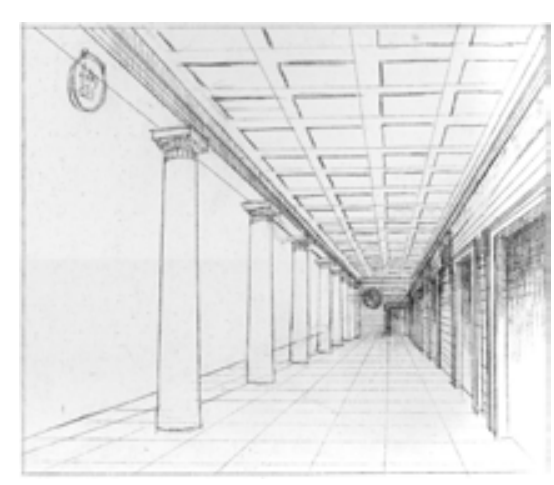

Fig 2.29. Portico perspective.

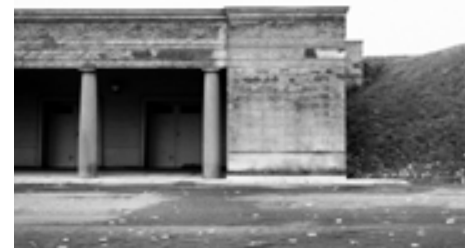

Fig 2.30. Chapel and the ridge. short route runs perpendicularly to the avenue and breaks the continuous transit on it. The ground has been treated to permit the mourners to walk on a slow descent before ascending to the portico. (Fig2.28, Fig2.29.) Despite of the traverse road and different pavement, the perimeter of trees of the plaza establishes relation with the chapel portico, meanwhile, its semicircular outline and the constructive volume produce a geometrical unity, which unites the two separated spaces. Therefore, the symmetric and centralized composition guide people who are standing on the plaza to look at the deep loggia, suggesting a trajectory towards a physical and spiritual space beyond.

Lewerentz conceived of the Chapel of St. Birgitta, connecting topographic and spiritual facts, as monument with profound narrative of termporality, recalling the prototype of ancient tombs. ${ }^{85}$ Its submerged form inside the earth riases the tension between natrual power and the time of an architecture's life, giving a gestrue of portection and an expression of dread, (Fig2.30) meanwhile, the short route possesses intense changes, from the open and birght plaza to the interior space of the ceremonial room, seems to interpretate the process of one man's life through an approach to the subterranean world. In the opposite direction, the plaza plays as an intermediate space that shows a direct way from the chapel and mortuary to the burial plots, which completes the procedure of funeral ceremony.

85. In his article, Wilfried Wang juxtaposes an old photograph of Jacob's tomb in Kidron Valley and Lewerentz's drawing of the colonnade fountain in Stockholm Woodland cemetery to imply possible reference. Besides the similarity in forms, the ancient grave dug from rocky mountain by ancient Jewish much likely inspired the Swedish architect to value the relation between ecavated condition and burial narratives. 


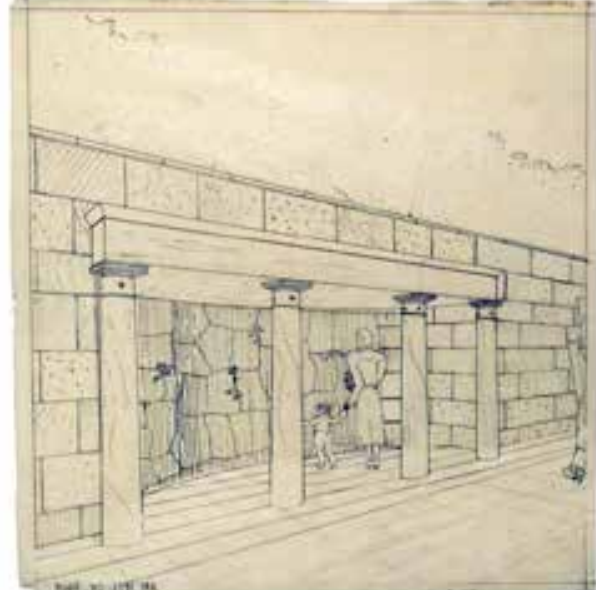

Fig 2.16. Early proposal for the fountain, Lewerentz,
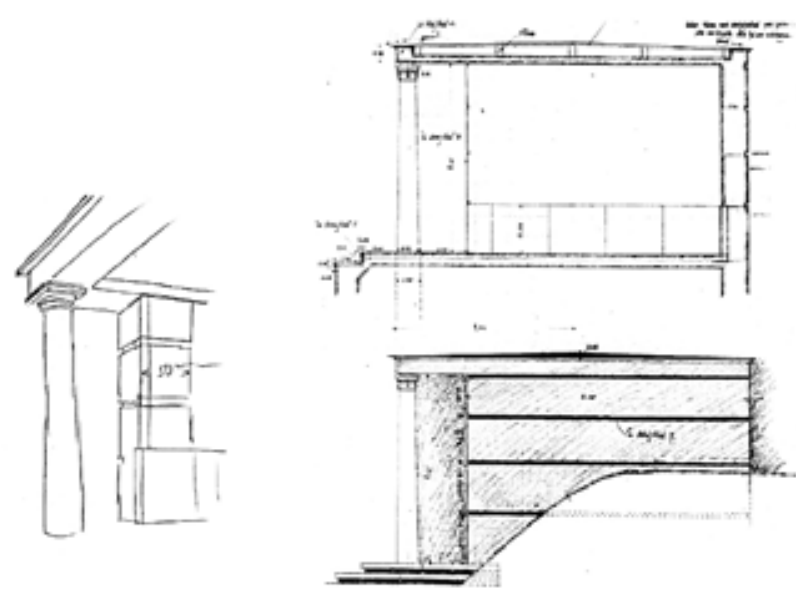

Fig 2.30. Waiting room section, Lewerentz, 1923 .

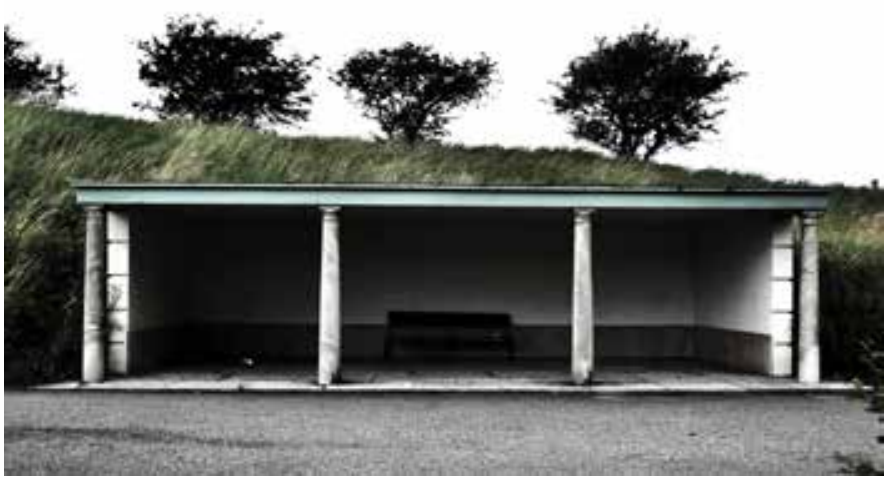

Fig 2.31. Waiting room interior

\section{transit upon distance}

While the treatment of the space beyond the boundary works to restrain emotions in order to make visitors have physical and psychological preparation, the subsequen trajectory runs into the cemetery resonates with our sensibility. It is firstly activated by the colonnade fountain located at the beginning point, and is augmented by the expectation of the inner landscape along with the ascent of the gateway.

Lewerentz's proposal by 1932 (Fig2.16.) shows his idea about an accessible fountain to fit the niche on the wall, which had been conceived as an exedra installed with a curved bench in it. Since the reduction of its capacity for a family group to a shallow space only for just one person, the fountain diminished in importance as resting space, but retained its metaphoric narrative based on the initial composition of different elements and the sequential reading.

Being the outmost layer of the fountain, the colonnade of four Doric columns stands out as a mural relief to mark the northern end of the access corridor, as well as to respond to the portico of Asplund's main church in the deep place. (Fig2.17.) Its protruded volume leads to a slight invasion to the walkway, that slightly change the rhythm of movement, affirms a threshold in this entry area.(Fig2.18.) The refined treatment of the columns contrasts with the brutal look of the cavity as statement of ground. The edges of the adjacent walls to the sunken plane of greater radius of curvature implies an excavation of the ashlar surface until to the rocks at the bottom in irregular forms, which compose the image of subterranean domain. And it is the water, the key element of this "weeping monument", seemingly seeps out of the cracks of the rocks and trickles down, plays as essential psychological symbols of sadness, hope and the flow of time. Gaston

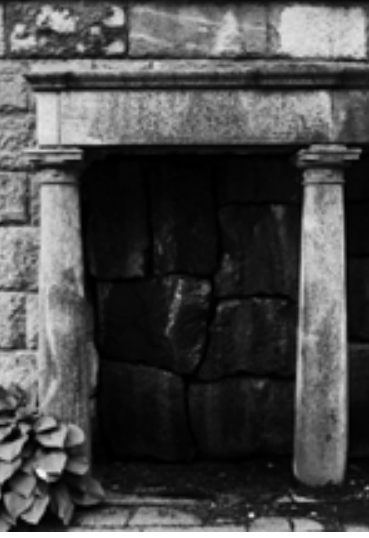

Fig 2.18. Fountain details. a room of isolation

Next to the funeral chapel, a small waiting pavilion half-buried in the ridge serves as an introduction of the subsequent ceremonial place, and as a stopping point on the way from the eastern entry. Although both of the architectures are characterized by simple volume with colonnade, their inserted volumes and positions according to the outline of the ridge suggest their individual relation with the cemetery landscape stronger than the connection between them. Built in 1926, the two buildings define the place round the bending as the first nuclear of the cemetery. They also reveal Lewerentz's shift from his initial idea of highlighting architectures on the main road to accommodate them into a less rigid plan.

Unlike the ritual entryway of the funeral chapel and the architectural monumentality, in this small pavilion, Lewerentz tended to give rise to the sense of transparency to emphasis the gesture of reception. The colonnade, copper roof and stucco walls in thinner dimensions illustrate a light structure, creating a formal contrast that emphasizes the sense of its interior capacity as the result of excavation from the ridge on the back. (Fig2.30) The portico slightly separated from the interior space remains a classical tone of entryway but has nothing to do with a rigid order. While the frontal opening indicates an easy accessibility, the symmetrical composition of the waiting room and its limited visual connection of the interior with the exterior are engaged in the architect's sentimental view of the site, and of a separated space of stability and tranquility. (Fig2.31.) The bench set back to the bottom indicates a space to stay. The deep and shady hall provides a private, even secrete space in which the mourners are isolated from the outer world. Sitting inside the pavilion, what they can see is nothing more than a narrow pathway penetrating through the burial ground. The deep scene lets 


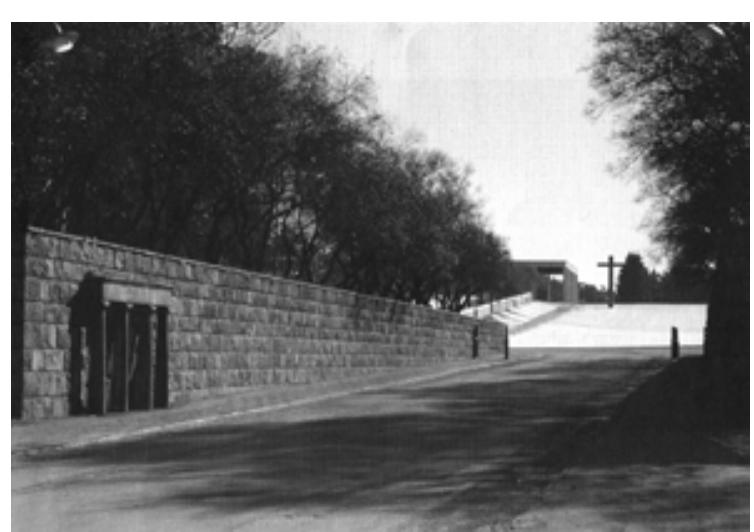

Fig 2.17. Entry way and interior landscape.

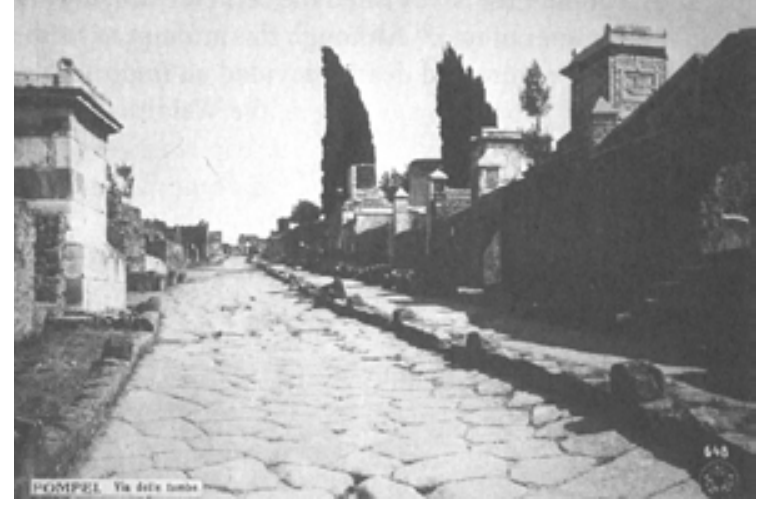

Fig 2.19. Via delle Tombe, Pompeii. Postcard

from Asplund collection.

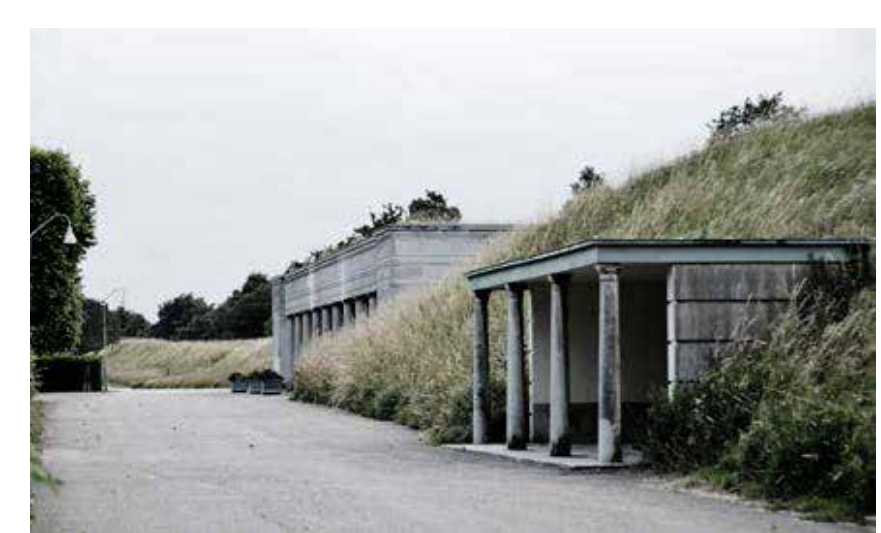

Fig 2.32. Funeral chapel and waiting room along the avenue.
Bachelard indicates the symbolic meaning of water, "Water always flows, always falls, always ends in horizontal death. In innumerable examples, we shall see that for the materializing imagination, death associated with water is more dream-like than death associated with earth: the pain of water is infinite. ${ }^{.82}$

Therefore, by combining constructive elements and water, the "material imagination" with regard of spatio-temporal narrative about life and death is provided. Lewerentz converted the fountain into a contemplating point which interrupts the continuity of the transit.

The architects defined the transit from a demonstration of horizon in the plaza to the deep access through a study of scale and distance. From the fountain, the entryway in slight ascension starts an almost ritual way towards the cemetery interior. Its rigid masonry profiles emphasize the constructive character, as well as the floor divided in three rows, have classical origin, evoking the grave-lined paths of Pompeii's Via delle Tombe from Asplund's postcard during his gran tour to Italy and Greece. (Fig2.19.) Walls and trees on both sides partially frame and unfold, along with the approaching process, the internal scene consists of architectures and the expanding and plastic grassland. The slight ascension lead to an illusion that the elements in the interio space seem to be much smaller and farer away from the spectators. Here, the sensation of distance is clear, which at first could have been intuited, between the straigh trajectory and the expanding dimension of the deep place, between the arrival at the end of the route and being involved into ceremonial landscape which is associated with commemoration. (Fig2.20.)

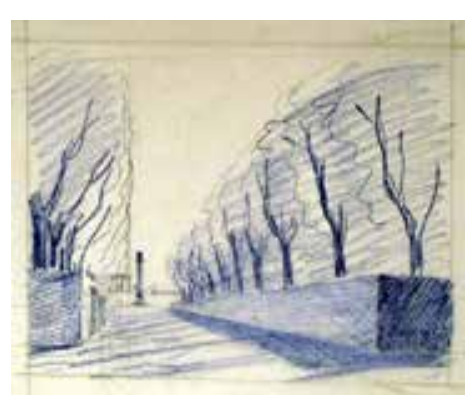

Entry way perspective,
Asplund and Lewerent

the person sitting inside the small room to expand their views until the bottom of the cemetery, allowing an individual contemplation before the funeral ceremony. Amidst the introspective and serene air, the inner place of the waiting room (contrasts with its outside form which is engaged with the spatial sequence on the main avenue and its affinity with the ridge) and people inside are suspended from the narrative of the cemetery, and therefore, their independence is assigned.

Lewerentz sought to give the funeral chapel and the waiting room a sense of identity by placing them at precise location yet making them stand on their own. (Fig2.32.) The concentrated space of both buildings accentuates a particular order of movement and episodes out of the overwhelming discipline defined by the avenue. The events composed by them inform one's overall impression of this area, both evoking the spirit of the design: the idea of descent, of excavation and of protection. Being regarded as "testimony to the period in which Lewerentz interpreted the Neoclassical tradition in architecture in an independent and critical manner ${ }^{\circ 6}$, the two ceremonial buildings are less about strictly adhering to a known architectural language than about exploring the making of a place for a ritual and burial demanding respect as well as consolation for the mourners.

After the nuclear space made for funeral services, five seats whose locations are coordinated with the subdivision of the burial precincts offer a succession of open-air resting areas, contributing a rhythmic walk of the following trajectory from the funeral chapel to the cemetery western entrance. Located on the foot of the ridge, the small plot paved in gravel, separated from the avenue and adjacent grassland, stresses the tone of

86. Nicola Flora, Paolo Giardiello, and Gennaro Postiglione, Sigurd Lewerentz: 1885-1975, (Milan: Electa architecture,2006), 160. 


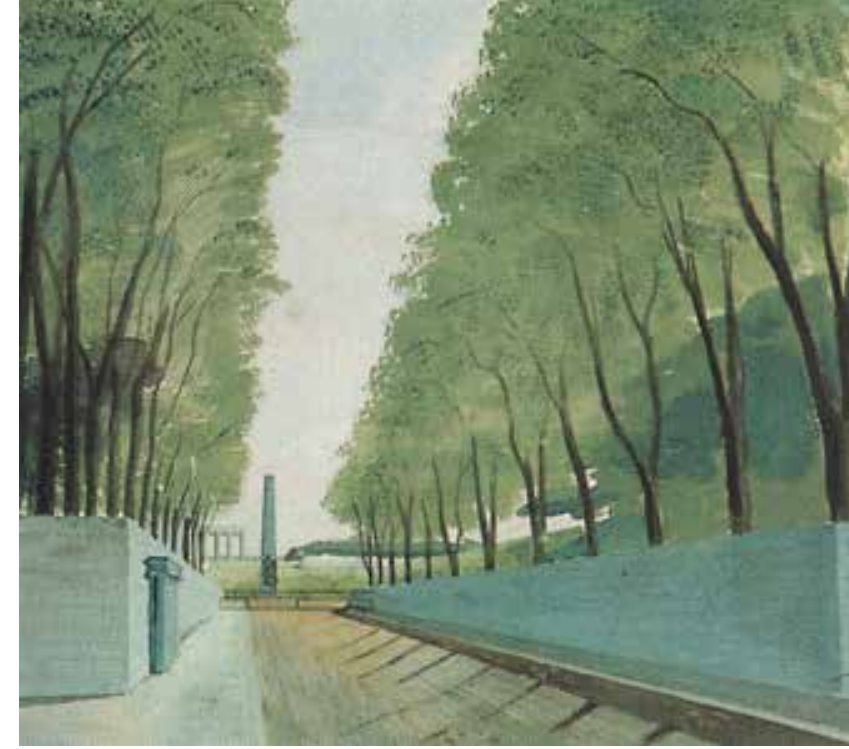

Fig 2.21. Entrance with obelisk inside the landscape, 1932.

While visual perception is led by the views composed of spiritual signs and natural elements, the ashlar walls that establish solid screens, by which visitors are passing, promote tactile experience because of the closeness to the materials. Bachelard further emphasis tactility's importance in the formation of cognition of matters since "The eye assigns them (forms) name, but only the hand truly knows them". Rough surfaces attract people to touch, the precisely composed masonry pieces of same size create a steady rhythm of movement that resonates with our feeling, and therefore, achieving an equilibrium in our sensibility with the expectation of further space. The continuous volume and flat profile of the walls mark the rising floor whose slope is too subtle to be visually noticed during the walk

As professor José Manuel López-Peláez observes, "la entradad se realiza a lo largo de un espacio profundo con entidad en sí mismo." ${ }^{\prime 3}$, the entryway of the Woodland cemetery was conceived to provide sufficient time for accommodating. Lewerentz and Asplund prolonged the access in a walk that unites two open spaces of very different quality. From this point of view, the solemn ascent derived from the outer plaza upon an embracing gesture, suggests a physical and psychological detachment from secular world and archives the transit to the contemplating landscape open to the interior. (Fig2.21)

83. José Manuel Lopéz-Peláez, La arquitectura de Gunar Asplund, (Barcelona: Fundación Caja de Arquitectura, 2002), 135 .

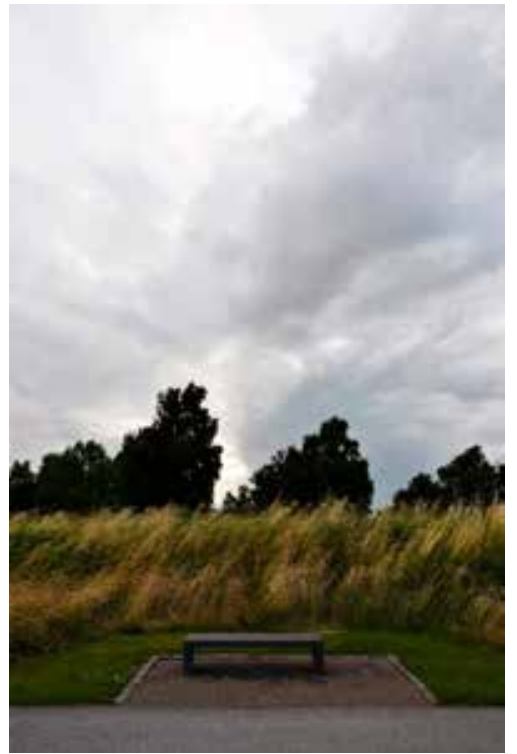

Fig 2.33. Seating area.

privacy, as well as evokes the composition of ritual area of "minneslund" ${ }^{87}$ (Fig2.33.) Unlike the "memorial benches" of these seating areas is more characteristic of Lewerentz's underlying concern for representing the communal remembrance. One may perceive a particular thoroughness in how funeral and natural elements are articulated to convey spiritual narrative round the seat. The ascent led by the deep route on the opposite side, from the burial ground up to the sky, reflects a metaphor of resurrection, whereas the rising ridge on the back, covered by wheat, represent the course of life itself. 87. As the particular funeral space in Sweden, minneslund "is anonymous burial place, where present. " and "Names of those whose ashes have been buried or cattered... are not displayed, but there is a communal orea for decoration where cut flowers and candles/.. anterns can be placed," About funerals, burials and cremations. Stockholm 2013. Translated in December 2013. $2^{\text {nd }}$ edition. Original title "Om begravning". About funerals, burials and cremations

88. Memorial Bench is made for specific space of remembrance, "there is the subtext of their form and location; the explicit, if brief, text found on plaques 'storying the deceased'... where Maddrell, Avril, and James D. Sidaway, Deuthscapes: Spaces for death, dying mourning and 

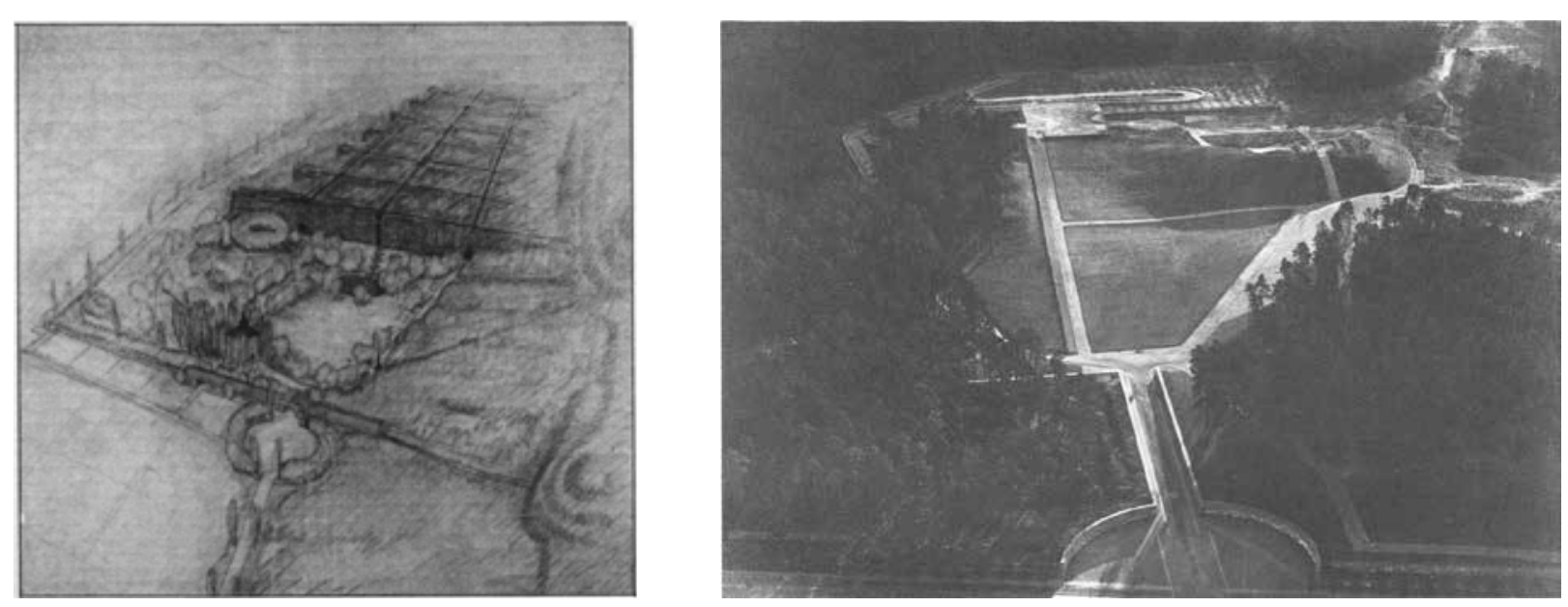

Fig 2.34. Proposal for Rud cemetery, 1916, Lewerentz. Fig 2.35. Aerial view of Stockholm Woodland Cemetery entry.

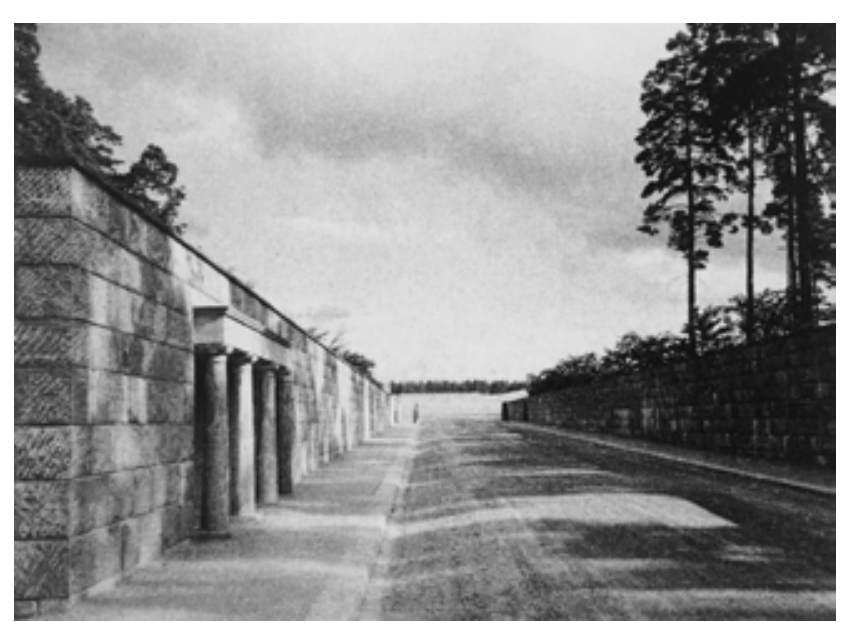

Fig 2.36. Entry route of Woodland Cemetery.

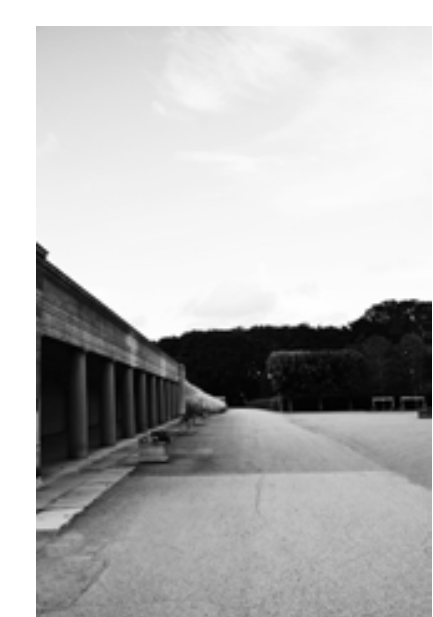

Fig 2.37. Funeral church entry in Malmö.

§ Epilogue - a walk through departure

The architects elaborated the cemeteries' entryways by building upon the intrinsic qualities of the sites and their ceremonial quality.(Fig2.35.) Despite of the differen structural relations between accesses and the cemeteries, the approaches to the two sepulchral spaces suppose, in an invariant way, to define the internal mood and capable of connecting with the broader landscape in the further place. By emphasizing the action of detaching from daily environs, the Woodland cemetery's entryway that focuses on a spiritual transit and the Malmö cemetery's avenue that serves multiple purposes establish the way of departure, denoting the constructive elements' potential interaction with natural things.

Design of the routes includes study of typical boundary condition. Since the grassland and the ridge are kept away from the visitors who are approaching the place, each road subject to prolonged exploration, in tandem with psychological accommodation. This idea can be seen from the removal of the obelisk from the entrance in Stockholm to avoid a dramatic profile, and the continual simplification of architectures in Malmö. In addition, application of space in circular perimeter in these works, by using its potential meaning of encounter and stop, to define a particular point as well as a specific moment in the early phase, recalls Lewerentz's proposal for Forsbacka cemetery and Rud cemetery. (Fig2.34.) Completed in 1916, the latter plan may reveal an ideal manner of architect to incorporate cemetery space into natural environs through the development of geometries. The round plaza that terminates narrow route defines the beginning of a new place. Upon entering the gate, a big oval pound, whose perimeter is paved as two slight ascents, is used to structure circulation on the slopes, as well as to draw a transit from open landscape to the deep burial precincts contoured by tall trees. In the same

sense, by giving the idea of programmatic import, in Stockholm and Malmö, the semicircular plazas with enhanced orientation take the role to receive and to start again on a journey to the sublime landscape.

Another character of the entryways is derived from the organization of ascent and descent. In the two cemeteries, departure from the outer space were achieved through physical treatment of floor as well as the edition of spatial quality, with the help of control of light and historic images on the approach. (Fig2.36, Fig2.37.) The ascent from shady walkway to the interior landscape in the Woodland cemetery, and the route towards the funeral chapel in Malmö amidst darkness, formulate the concept to fulfill ritual and symbolic aims of descension of life and ascension of spirit, recalling the rite of passage in his project for Helsingborg crematorium.

Through geometric, topographic and historic approaches, the architects composed the two entryways in response to two pragmatic considerations: separation from the outer world and accommodation into the funeral narrative, both of which imposed a rectilinear order on the initial stage without sacrificing the natural attribute in the further space. The access routes serve as introduction and preparation in a manner that also anticipate the thematic basis of the two works as ritualized landscape of remembrance. 


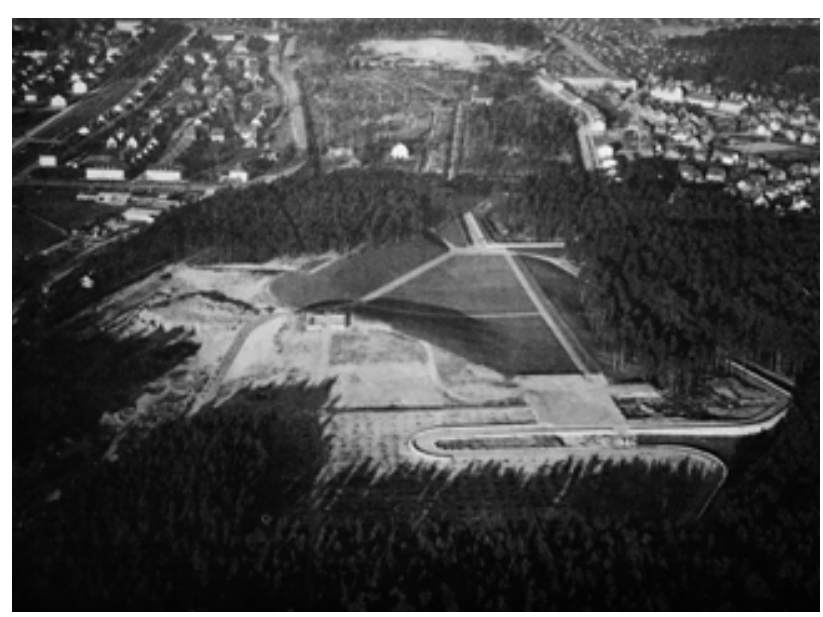

Fig 2.38. Middle landscape of Woodland Cemetery in construction.

\section{LANDSCAPE AS MONUMEN}

"From the early cemetery projects for Helsingborg, Malmo and Karlstad he projected prodigious inventions on the theme of the Northern Landscape and in the execution of the Woodland Cemetery at Enskede his was the guiding hand in the creation of one of the great epic landscapes of all time. In its primal elements, - forest, cropped mound, unruffled water, low sun in a huge sky - it is the very embodiment of the North to rival the horned mountain, rock and blazing sky of the ancient temple site of Greece.,

Colin St. John Wilson's comments on Lewerentz's cemeteries highlight his capacity of generating emotions from landscape by organizing and composing natural elements, and enabling the funeral spaces to resonate with architectural monuments. The particular quality comes from Lewerentz's appeal for proper constructions and storytelling in the last landscape. In his never published article Modern Cemeteries: Notes on the landscape written in 1939, the architect raised the question of cemetery design: "There is sense in erecting a monument to commemorate an important event or an outstanding deed, but we seem to have lost our sense of proportion when we build monuments for those who die... ${ }^{, 90}$ In Stockholm Woodland Cemetery and Malmö Eastern Cemetery, Lewerentz and colleagues worked to configure place that keeps stimulating visitors' experience of monumentality. Archaeologist James F. Osborne explains monumentality as "an ongoing, constantly renegotiated relationship between the monument and the

89. Colin St. John Wilson, "Twelve notes toward a portrait," in Otras vias: 2 Homenaje a Lewerentz $=$ Other ways: 2 Homage to Lewerents, ed. José Ignacio Linazasoro (Colegio Oficial Arquitectos Castilla y León Este, 2005), 19.

90. Sigurd Lewerentz "Modern Cemeteries: Notes on the Landscape," in Sigurd Lewerentz 1885-1975, ed. Flora, Giardiello and Postiglione, (Milan: Electa architecture, 2006.), 45. person experiencing the monument"91 , The Meditation Mound and the agricultural ridge in the two cemeteries, which combine topography and burial form so to evoke collective memory and accommodate individual contemplation, are capable of deriving monumentality from their deep psychological bond with mourners. By dealing with qualities of visibility and durability, the two landscape compose the "a monument suitable for a burial ground",92, and further obtain the capacity of prompting empathy, as Georges Didi-Huberman indicates in his "Lo que vemos, lo que nos mira":

"He aquí por qué la tumba, cuando la veo, me mira hasta lo más recóndito - y en ese título, por otra parte, viene a trastornar mi capacidad de verla simple, serenamente-, en la medida misma en que me muestra que he perdido ese cuerpo que recoge en su fondo. También me mira, desde luego, porque impone en mí la imagen imposible de ver de lo que me hará el igual y el semejante de ese cuerpo en mi propio destino futuro de uerpo vaciándose, yaciendo y desapareciendo rapidamente en un volunmen más o menos parecido. Así, ante la tumba yo mismo me tumbo...."93

Juhani Pallasmaa insists that "qualities of matter, space and scale are measured by the eye, ear, nose, skin, tongue, skeleton and muscle." In Stockholm, the plastic quality

91. James F. Osborne, 'Monuments and Monumentality', in Approaching Monumentality in Archaeology, ed. James Osborne (Albany: State University of New York Press, 2014), 1-22.

92 Lewerentz, "Modern Cemeteries," 44.

93. Georges Didi-Huberman, Lo que vemos, lo que nos mira (Buenos Aires: Manantial, 1997), 


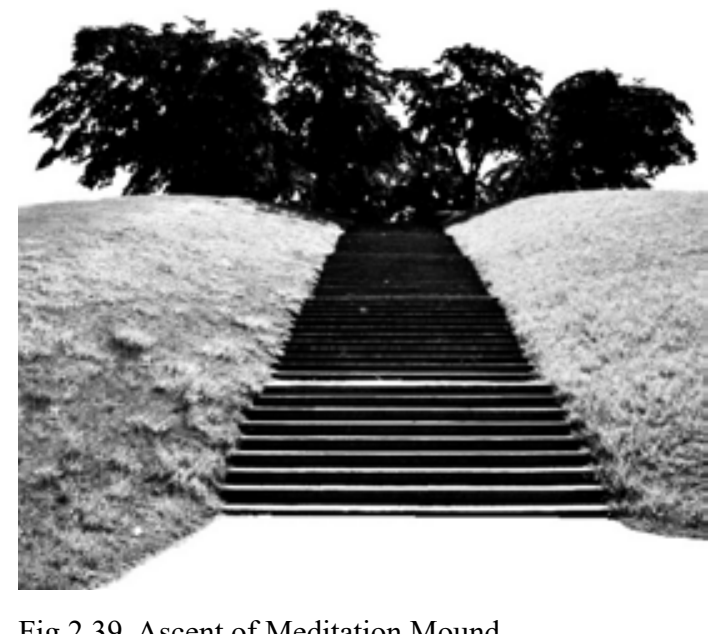

Fig 2.39. Ascent of Meditation Mound.

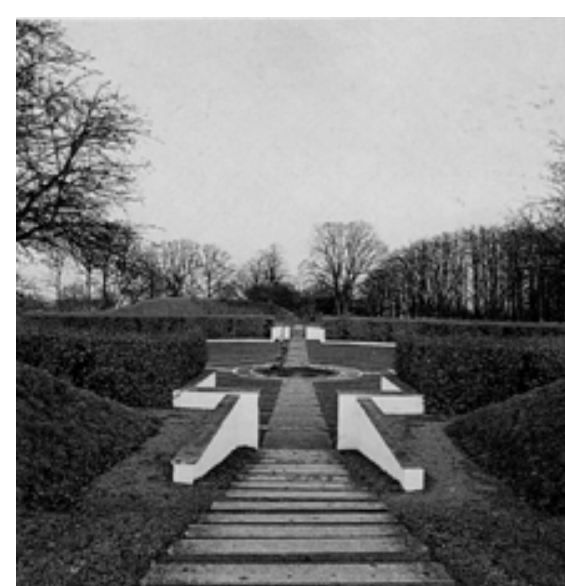

Fig 2.40. Descent of Ceremonial Plaza.

of the open landscape consists of the expanded grassland and uprising mound seems to put everything in a subtle movement, which keeps stimulating visitors' multiple perceptions. (Fig2.38.) While in Malmö, the ridge represents a sense that completely opposes openness. The privileged space and its passage hidden from the outside stress a quality of interiority, permitting individual person to immerse himself/herself into a world of serenity.

Interpretation of commemoration in the two places have their essence of anthropology, as Professor José Ignacio Linazasoro indicates the quality in Lewerentz's works: "Para todo aquél que espera de ellos una trasmisión de sensaciones y antiguos saberes casi connaturales a la naturaleza human." ${ }^{94}$ The plateau and ridge declare the topographical roots of burial. People's instinctive need about being properly oriented in space satisfied by the ritual movement towards the sacred areas of the top square and the sunken ceremonial plaza. Along with the ascent and descent, (Fig2.39, Fig2.40.) narrative of time of the farewell to the loved ones and of the course of life itself told by the change of individual identity from a visitor who observes from the outside to the mourner who enters into the heart place of commemoration.

94. José Ignacio Linazasoro, "En torno a Lewerentz," in Otras vias: 2 Homenaje a Lewerentz = Other ways: 2 Homage to Lewerents, ed. José Ignacio Linazasoro (Colegio Oficial Arquitectos Castilla y León Este, 2005), 13. 

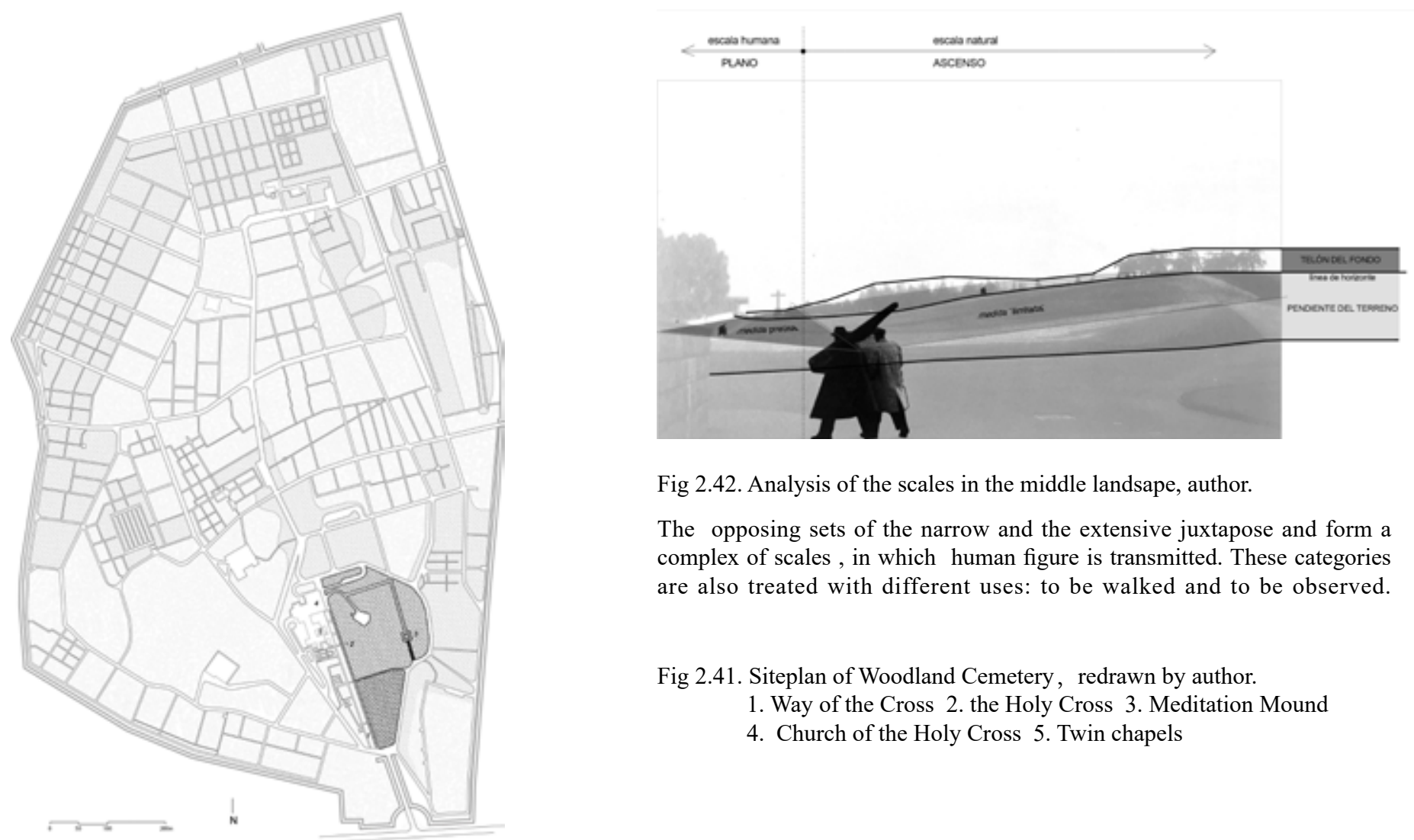

Fig 2.42. Analysis of the scales in the middle landsape, author

The opposing sets of the narrow and the extensive juxtapose and form a complex of scales, in which human figure is transmitted. These categories with different uses: to be walked and to be observed.

Fig 2.41. Siteplan of Woodland Cemetery, redrawn by author. 1. Way of the Cross 2. the Holy Cross 3. Meditation Mou 4. Church of the Holy Cross 5. Twin chapel

$\S$ Two sets of narrtive actions

. the landscape of remoteness

Upon entering the interior landscape of the Woodland Cemetery by the iron gate, designed by Lewerentz, one will perceive different scales and narratives. (Fig2.41, Fig2.42.) Buildings on the left side designed by Gunnar Asplund were arranged along with the course of Way of the Cross. The gentle ascent, three meters in width, leads a penetrating route that passes by a succession of constructions: the parapet of two meters in height forms a continuous screen to protect the burial garden behind, the twin chapels of Faith and Hope for preparation and small ceremony, and the portico of the main building at the end, the Chapel of Holy Cross. Across the pathway, the giant Cross, clad in dark marble, confronting the religious architectures and giving clear guidance of journey, interprets the sacred ambient around the space. Asplund worked to control the development of scales in this complex of structures and buildings. And by giving variation of episodes and speed on the route, organization in this part has reached a balance with the scale of man's body. An opposing character is perceived on the rightside space which was organized by Lewerentz. The undulating ground and the plateau crowned by elms grove show a primitive sentiment of nature that lies in evocation of Scandinavian landscape of mountain and forest. By giving great effort to transform topography, the architect conferred an expanding dimension on the middle space of the cemetery, as if provoking its relation with the refined order of Asplund's works as well as with visitors in front of it.

The narrow path as connection of the two sets placed in the middle course is hidden from views, therefore, visitors have to choose which way to go from the initial point. Variation of scales between the architectures and natural landscape not only addressed

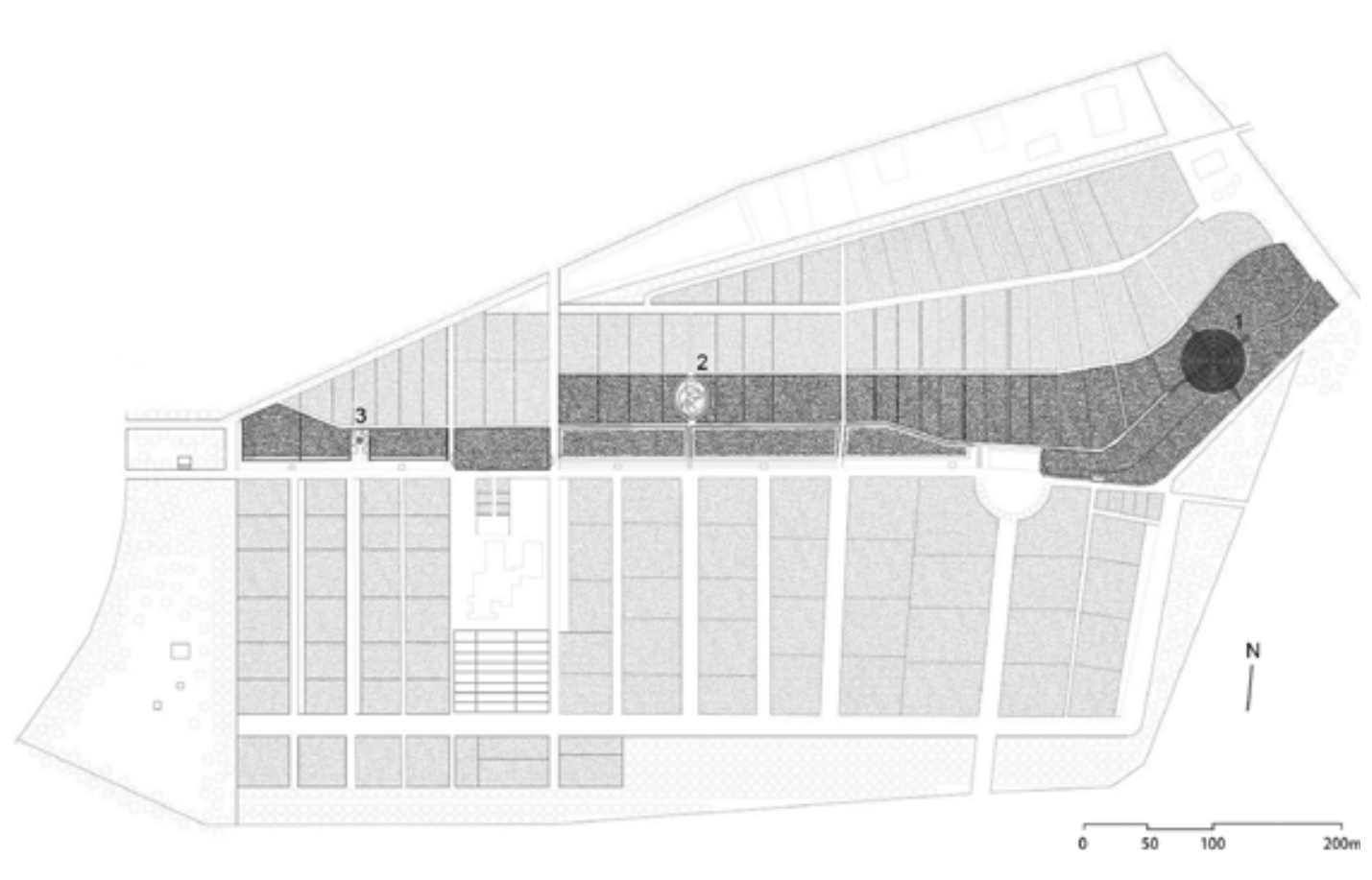

Fig 2.62. Siteplan of Eastern Malmö Cemetery, redrawn by author 1. Ceremonial Plaza 2. the ancient tomb 3. the belfry.

$\S$ Interior landscape

the descent that detains

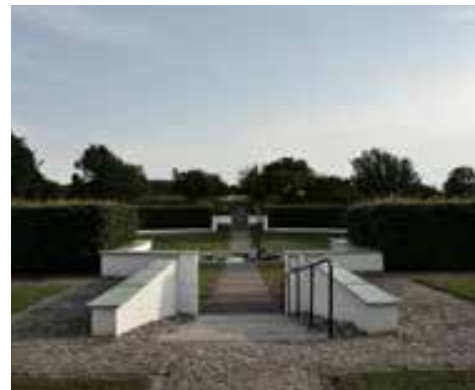

Fig2.63. The plaza entry.
The ceremonial in Eastern Malmö Cemetery first appeared in Lewerentz's proposals by 1923. Although site plan shows no preference, locations of the Ceremonial Plaza and funeral chapel definitely gave more importance to the area near the eastern access. Rather than privileging the sacred place through good visibility, Lewerentz made use of the ridge to alienated it, giving rise to the monumentality of the sunken plaza by means of creating and enhancing the quality of interiority.

The terrain bulge that divides the cemetery plays the main role in developing orientation. (Fig2.62.) Along the ridge, a continuous route drives a sequential chain of movement through a series of events, from the ceremonial plaza, to the old tumulus in the middle course and the belfry located at the west rear end. The elevated ground is populated by trees and wheat fields that seem to allude to the idyllic image of the past and, at the same time, define an extensive and isolated island from the outer space. By preserving the pre-existing topography, Lewerentz emphasized the importance of emotions and memory: the shape of the terrain is used to generate a sensitivity to the nature that permits the narrative of farewell.

The journey is characterized by a rite of movement. Visitors have to climb the ridge, follow the route to arrive at the place of excavation. Arranged as a courtyard, the Ceremonial Plaza which sinks into the ground until it becomes a reality of the "interior". (Fig2.63.) While the round perimeter defines a refined geometry of the sacred place, its components of the retaining walls in white plaster and capped by copper panels, the route penetrates the rings made of grass and sand, make up a solemn landscape that arrests visitors. 


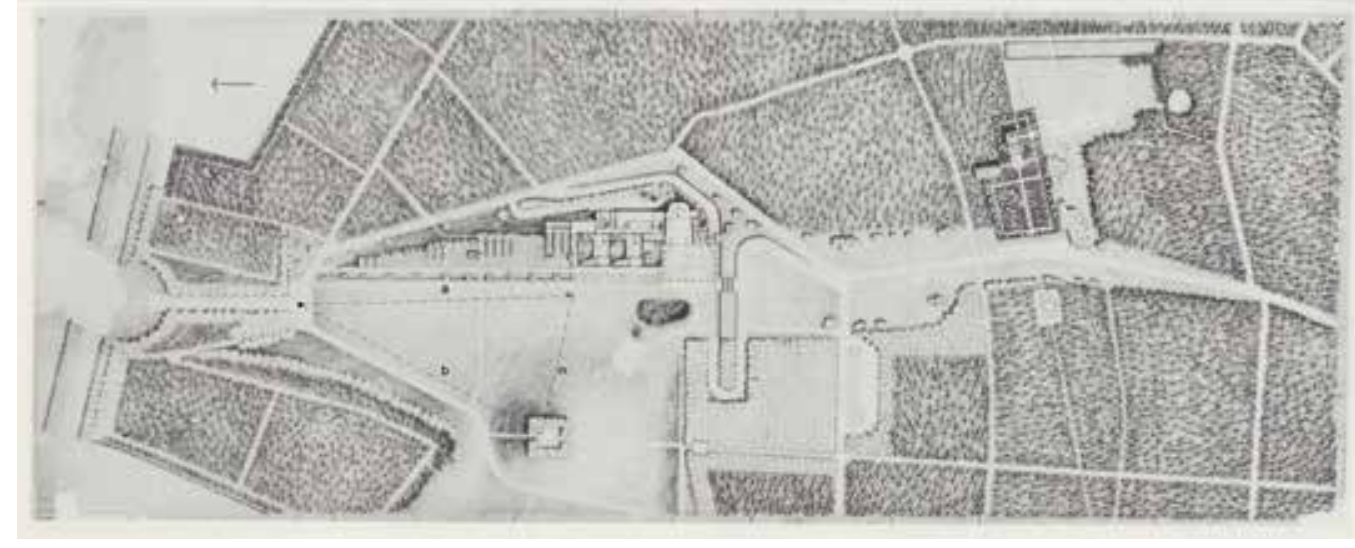

Fig 2.43. Dimension of the middle landscape. ( $\mathrm{a}=211 \mathrm{~m}, \mathrm{~b}=215 \mathrm{~m}, \mathrm{c}=100 \mathrm{~m}$ ) The game of scales in the middle landscape seems to push the Meditation Mound despite the fact that the cross and the hill are located at the same distance from the entrance.

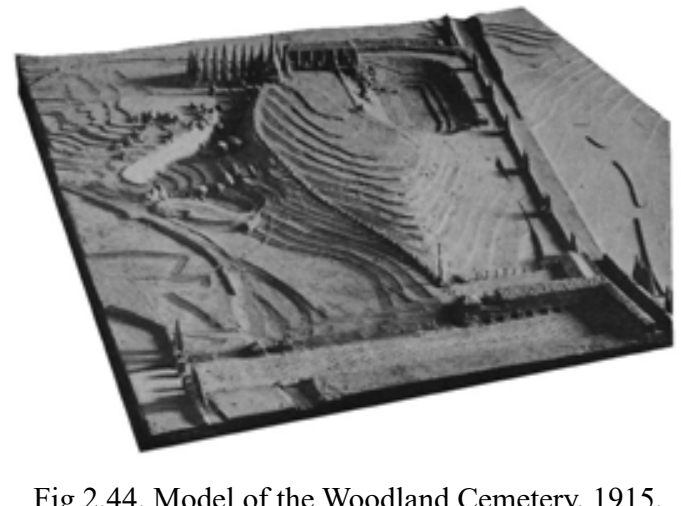

Fig 2.44. Model of the Woodland Cemetery, 1915

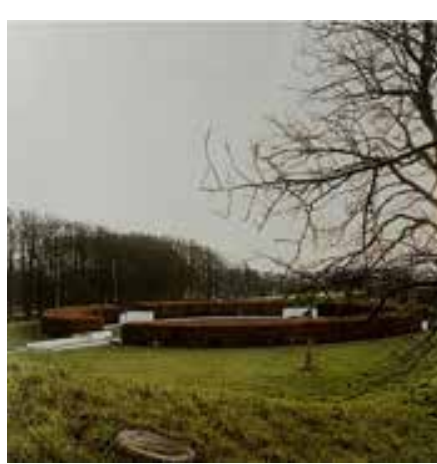

Fig 2.66. The plaza perimeter

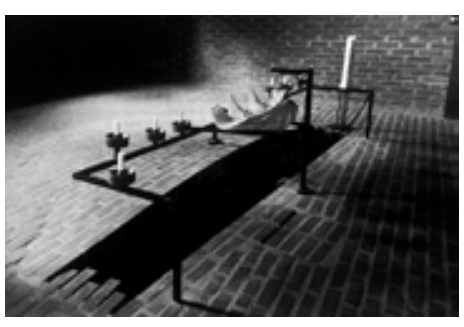

Fig 2.67. St. Peter's church floor functional aspects but also aided individual visitors in deciding how to relate to this commemorative landscape. Being the only apparent route, the Way of the Cros indicates the accessibility of the open space from the side, thereby leaving the rest par -the one based on refined order and the other without precise measurement- will lead to a confusion on people's perception of distance: the Meditation Mound seems to be fare entrance. (Fig2.43.)

The meadow ascending from the pathway to the mound top characterizes the landscape with an upbringing form. The horizon that rises offers a certain revelation on the topography. Without indicating a route, the slope ground reveals the difficulty of approaching the Meditation Grove, and gives the entire landscape a quality of movement without respecting the vertical or horizontal. The mound's summit condenses in the somber tone. Therefore, the contrast between this outstanding point of topography and the Way of the Cross, the path to be walked, creates an enigmatic image that draws an inaccessible site. (Fig2.44.)

Perception of distance in this space is also stimulated by the sense of anticipation. Being the vertex of respective set, the Chapel of the Holy Cross and Meditation Mound seemingly contribute a virtual boundary that terminates the development of space. It tends to stop our observation, yet to become a full rejection of the place beyond. A continuous line of the forest top stands out from the backdrop, giving a reminder of further space as well as suggesting an experience of a new journey which would be totally different to the present one.

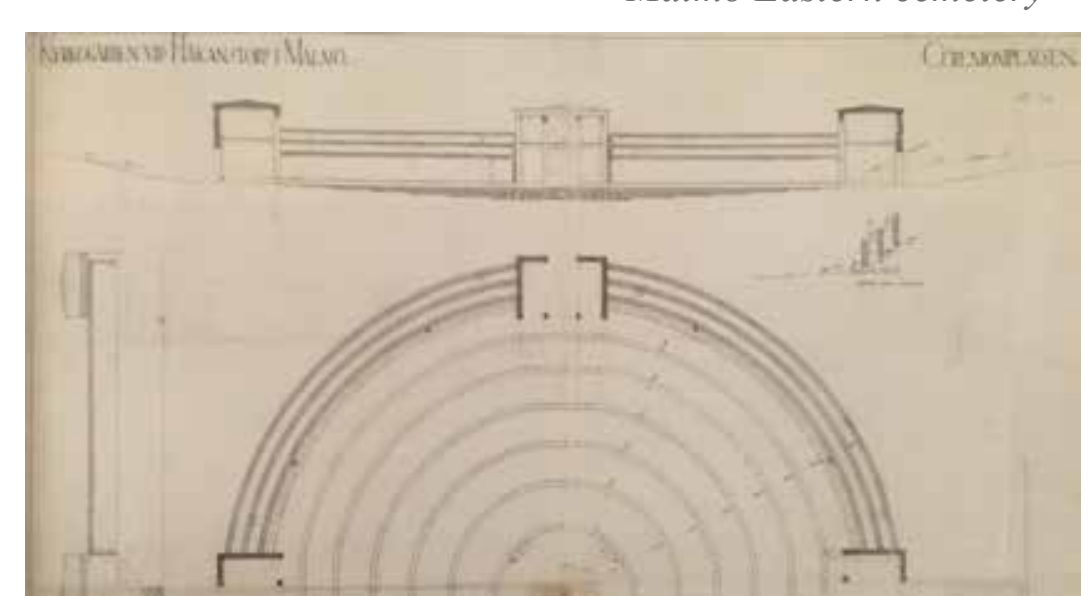

Fig 2.64. Proposal for the Ceremonial Plaza, 1922, Lewerentz.

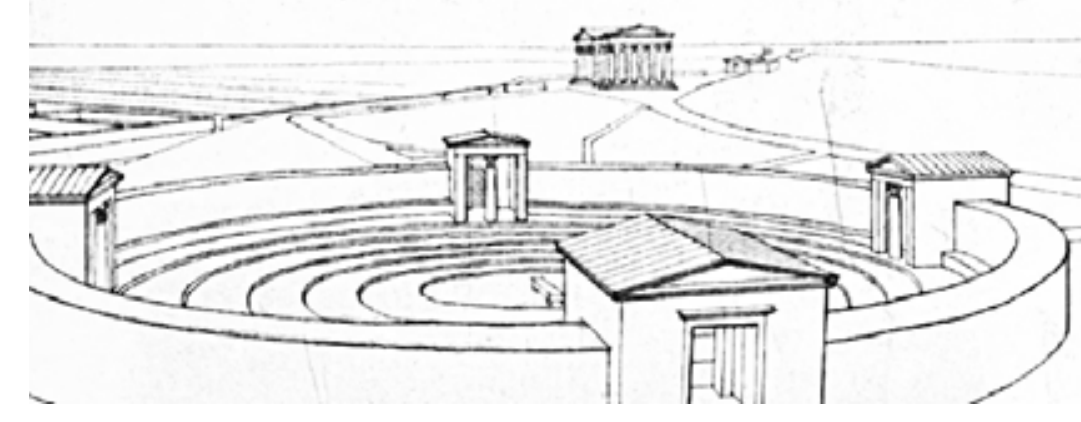

Fig 2.65. Proposal for the Ceremonial Plaza, 1923, Lewerentz.

As reminder of the depth of ground, the plaza's access in descent reproduces the entrance towards underground world, emphasizing relation between visitor and the earth. (Fig. ) Its interior composition based on a concentric itinerary, gently moves to the fountain at the center, elaborates an action of penetration to the bottom, meanwhile this downward tendency is somehow compensated by the repetition on the floor as layers of ripples spreading from the pond.

Rituality in a continuous movement of climbing and going down recalls Lewerentz's St. Peter's Pedro church in Klippan (1963-1966). A bold crack made for receiving water from the shell stoup cuts through the floor vertex, telling an enigma of duality in space and time. (Fig2.66, Fig2.67.) In the same sense, the Ceremonial Plaza descends and creates a sunken space destined to encounter and preservation.

By applying elements of very different qualities, Lewerentz made effort to configure the itinerary of the square according to their relations with those limits and the resulting variations of rhythm in movement. The series of physical and virtual boundaries plays an important role in the provision of layers that work against a continuous descent towards the plaza's interior. Early proposal for the commemorative place shows the plaza frontier made of a succession of three low walls placed on a slope, presenting a solid boundary as representation of firmness. (Fig2.64, Fig2.65.) This set of limits, whose constructive quality is minimized in the built project, has been replaced by a perimeter of shrubs upon the base to give the plaza a softer bound that corresponds to the natural environment.

Four entries are symmetrically placed in alignment with the crossed routes inside the plaza. (Fig2.68.) The manner to accommodate lineal routes into a circular space remind 


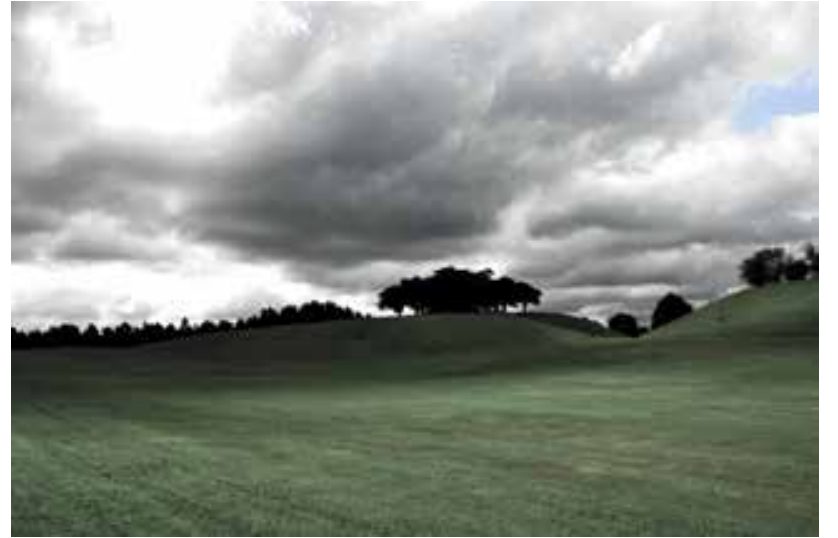

Fig. Meditation Mound.

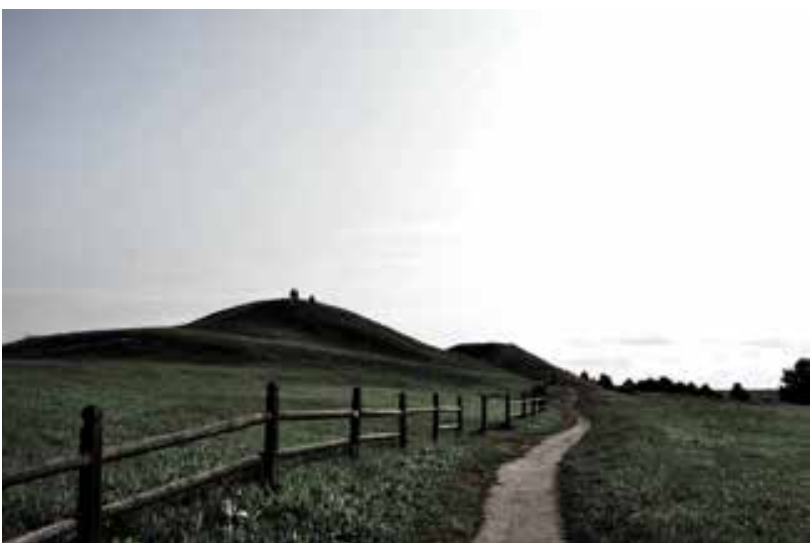

Fig. Real Mounds, Gamla Uppsala. classic origin. There is no doubt that the Royal Mounds of Uppsala had a great influence on the young architect. Located on the vast plain of the suburb near Stockholm, the three tumulus of early Middle Ages play the role as central points on the land and constitute an important symbol of combination of Nordic burial and landscape. (Fig2.45, Fig2.46.). Rather than declaring an easy accessibility, the sense of remoteness derived from these mounds that preserve the human figure implies the description of Norberg Schulz on the mountains as "places within the comprehensive landscape, places which make the structure of being manifest." ${ }^{\text {95 }}$ Being, according to Heidegger's interpretation, refers to the space of action of "mortals", and Adolf Loos combines the two concepts in his idea of monumentality in architecture.

'If we found a mound in a forest, 6 feet long and 3 wide, piled up in a pyramidal shape, we will get serious and in our interior something will tell us: Here is someone buried. This is architecture.".96

Representing the land of their ancestors buried in gigantic mounds, the Meditation Mound establishes a topographical and archaeological base that evokes the memory of ground, thereby relating ceremony of farewell to a certain sense of nostalgia. Lewerentz weakened the limit between artificial form and natural shape, and in this way, has configured a symbolic place that unites us all.

Juan Gelman said that poetry is a form of resistance. Poets are extreme when developing

95. Christian Norberg-Schulz, Genius Loci: Towards a Phenomenology of Architecture (New Jersey: John Wiley \& Sons Ltd, 1980), 22.

96. Adolf Loos, "Architektur," in Ornamento y delito y otros escritos, 1910. trad. Lourdes Cirlo y Pau Pérez (Barcelona: Gustavo Gili, 2.a edición, 1980), 230.

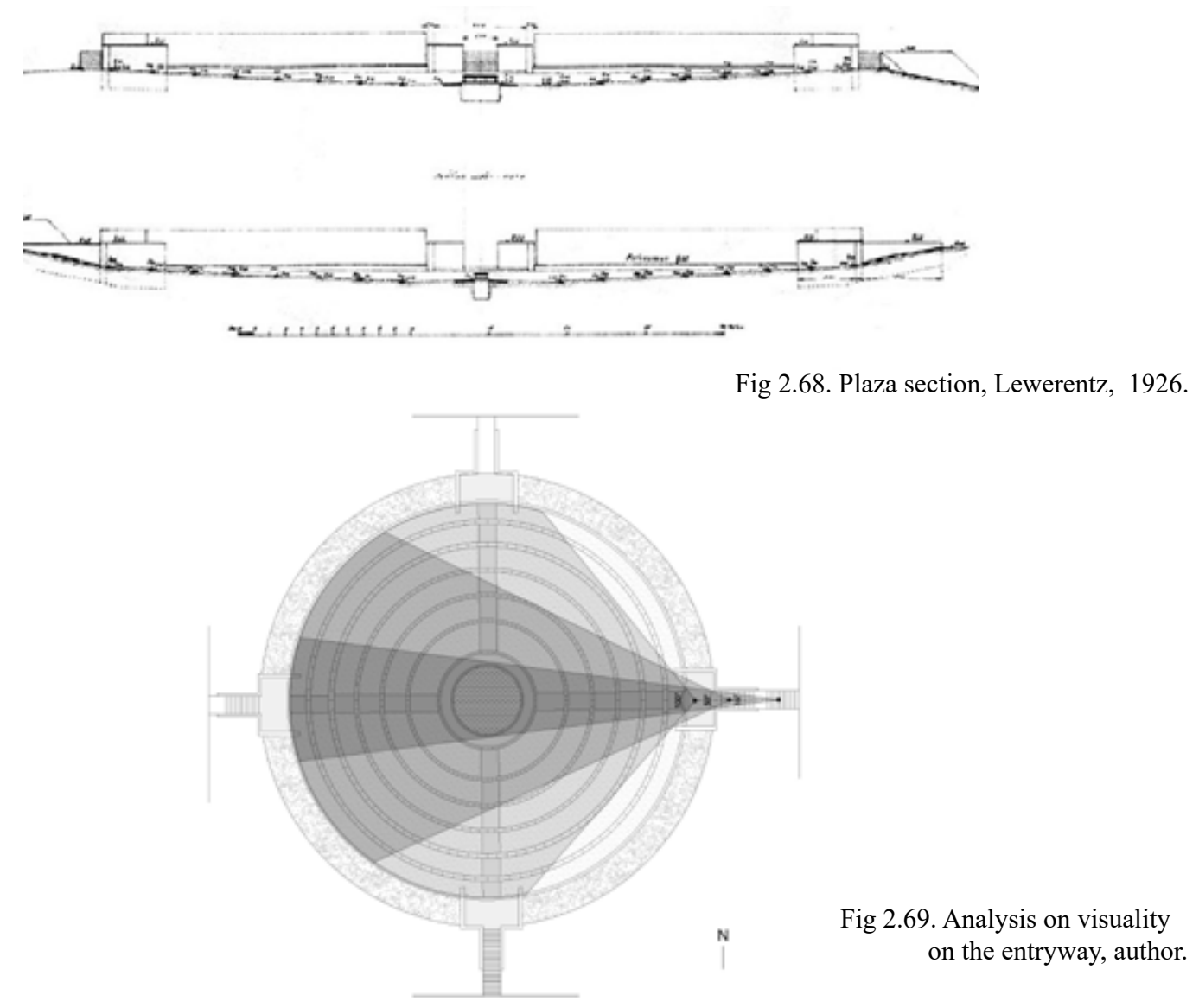

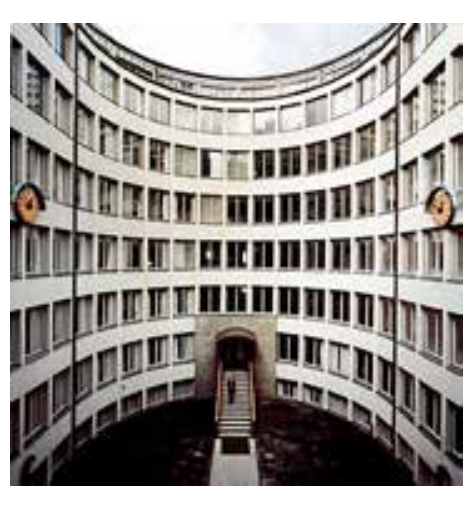

Fig 2.70. Office building for the national insurance.

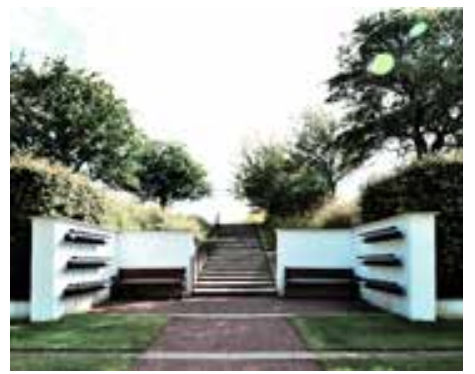

Fig 2.71. Ceremonial plaza vestibule.
Us of his office building for the national insurance board in Stockholm (1928-1932), whose oval courtyard is connected via a straight pathway from the stairs descend from the second floor to the main entrance of the building. (Fig2.70, Fig2.71.) The salient figures of the plaza's accesses come out of the perimeter, on the one hand, hide the interior and only show the axial routes move along with the courtyard slope, and on the other hand, enlengthen the entryway through establishing a threshold between the ridge and the courtyard. The fine materials and rigid sequence perceived over the accesses give rise to a metaphoric image of the entries, representing boundaries between the inner space constructed based on refined order and the outside world within natural environs.

Both of the effects on visibility and movement around the plaza make the action of entering the circular yard as an exploring process of its interior capacity. (Fig2.69.) Lewerentz combined the staircase and the inclined floor to define a progressive descent from the exterior space to the interior. Upon going down the stairs, visitors arrive at flat square of larger dimension before entering the expanded plaza. By altering the number of steps, Lewerentz accommodated the four vestibules into the same level. The progressive amplification of space is marked by the development of enclosures. Descent of stairs gives a growing gesture to the entry parapets, which seem to rise from the ground and become walls of the vestibule, before dramatically reduce to the base that configure the interior perimeter of the plaza. The variations of walls' height place visitors into unstable relationships with the surrounding elements. The plaza creates a walled space and assumes an intermediate space which terminates the descent of the staircase and starts the ritual movement within the square. In this sense, the vestibule between the slopes and the interior places has become an intermediate place, wherein the changes of movement and spatial character are likely to detain visitors, resulting a 


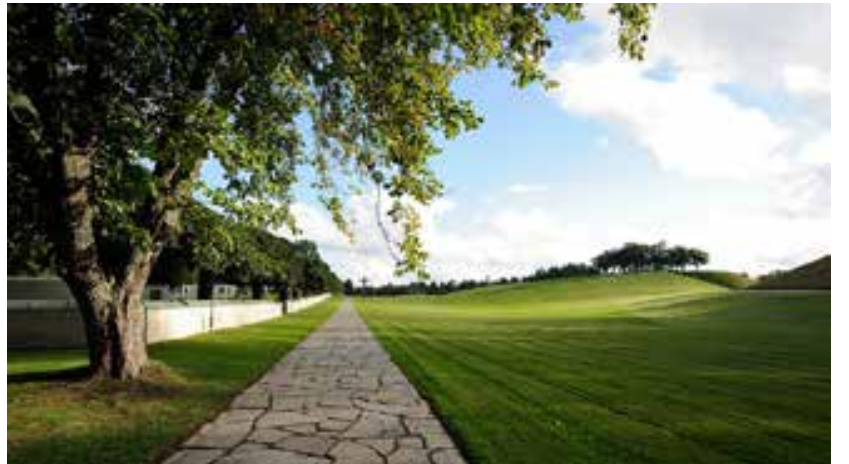

Fig 2.47. Way of Cross.

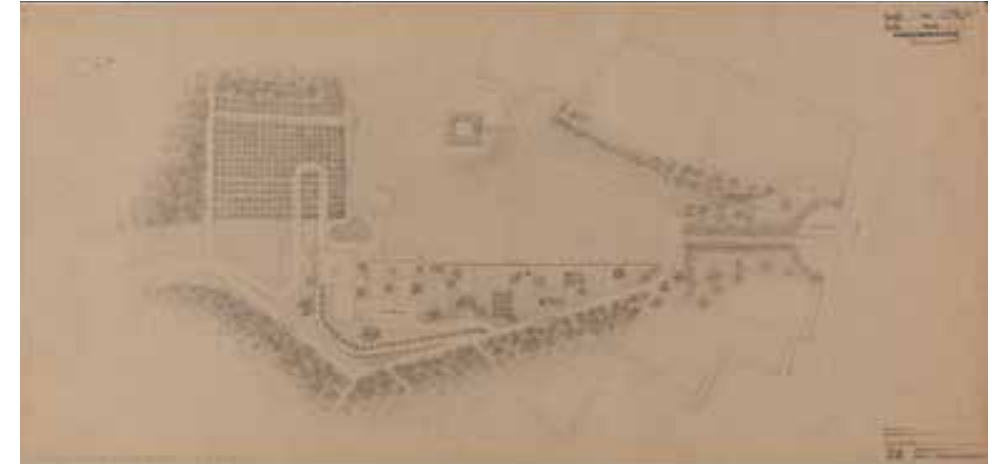

Fig 2.48. Opposition between the Way of Cross complex and Meditation Mound, drawing of Asplund.

syntax in order to avoid obvious interpretations. In Stockholm, we perceive this literal ambiguity from the quality of remoteness of the landscape which comes from physica and temporal distance. The parallel itineraries of the Way of the Cross which makes the varying scales of a succession of matters manifest, and the staircases embedded into the earth of Meditation Mound, elaborate the expression of humanism through trajectory towards farewell and transcendence.

\section{. the Way of the Cross, articulation and deflection}

The journey of the Way of the Cross presents Asplund's idea of clearly established directionality and continuity. It ensures an individual walk and at the same time establishes relation with the topography, the religious symbol and architectures. The loose pavement of the pathway and lateral parapet contribute the discipline of movement, as well as define a proper dimension close to man's body, as if the ascent was giving a gesture of protection that introduces mourners to get into the landscape.

Between the two sets of elements, the monumental figure of the Holy Cross plays a key role to balance the opposing characters and to lead the deep road. (Fig2.47.) Though the cross was placed by Asplund, the theme of laterality that it shows through its position set aside the route instead of aligning to it, discussed by Tomás Carranza ${ }^{97}$, and the pantheistic metaphor which refers "simultaneously pagan and biblical, Nordic and classical" ${ }^{198}$, were premiered by the obliquely free-standing cross, which had been

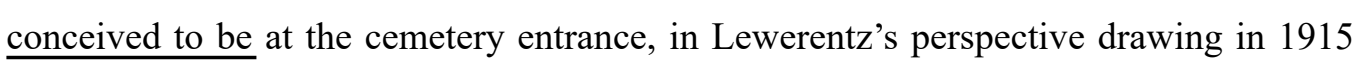

97. Tomás Carranza, "Cruces," in Otras vías. Pikionis, Lewerentz y Van der Laan, ed. José Ignacio

Linazasoro (Colegio Oficial Arquitectos Castilla y León Este, 2005), 75 .

98. Constant, "The Woodland Cemetery," 40

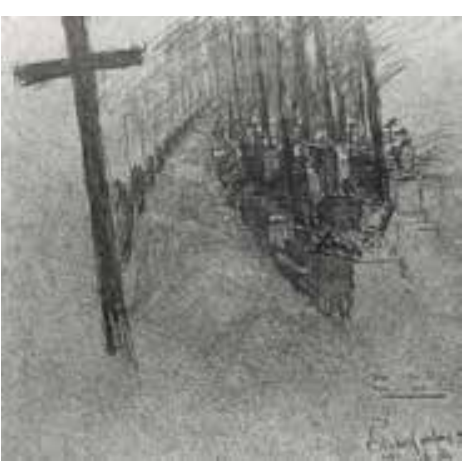

Fig 2.49. Sketch of the Cross in the first proposals, Lewerentz. short pause that interrupts the continuous movement.

The fountain, the Minneslund of water, delineates a limit in the center and marks the hearthplace of this ceremonial site. (Fig2.72.) It establishes a contemplating plot which is not the end point of the trajectory. Lewerentz did not indicate a specific end of the Ceremonial Plaza itinerary. On the contrary, the symmetrical composition repeats the path on the other side of the fountain. Through the gentle ascent visitors return to the ridge. (Fig2.73.) From this point of view, despite its independence, the sunken plaza appears as a place set on an extended road. However, the fountain, stands on its own character, denies that continuity: its lower position not only indicates a fluctuating movement, but also marks the circle center as a spiritual point for the ceremony of farewell.

Itinerary of the Ceremonial Plaza requires a slow transit. The change from the ridge to a refined space; the interruption imposed on the movement, and the contradiction between the approximation and departure destabilize the mourners. The ambiguity of the routes forces a certain commitment that transforms the walk from an unconscious action into a ritual reality

\section{an anonymous monument}

The route after the Ceremonial Plaza allows visitors to immerse themselves into the natural environment again. A soft turning that redirects the way blocks the front view. Lewerentz made use of ridge's geometry to divide the itinerary into two sections of different characters and functions - the shorter one that links the east gate to the plaza was created under the control of dimension and quality of vegetation to create a ritual 


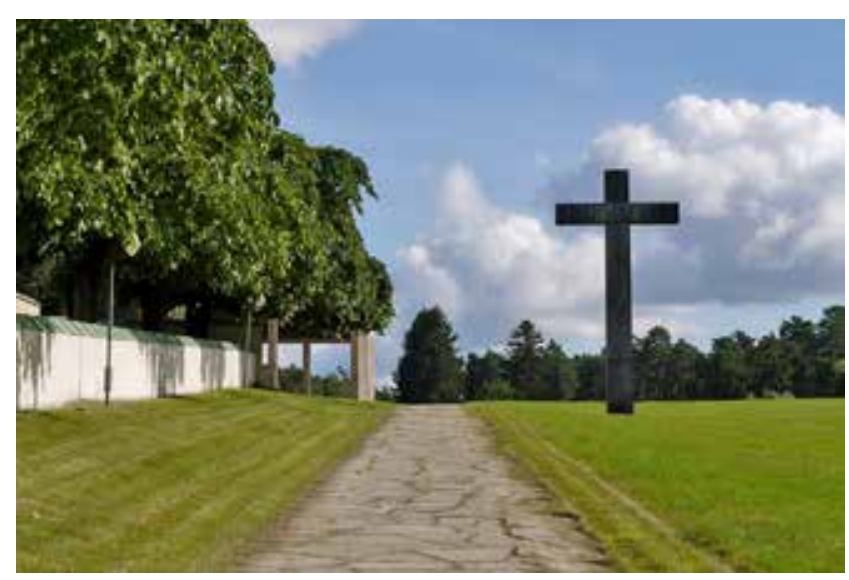

Fig 2.50. The Way of the Cross goes between the Main church and the cross.

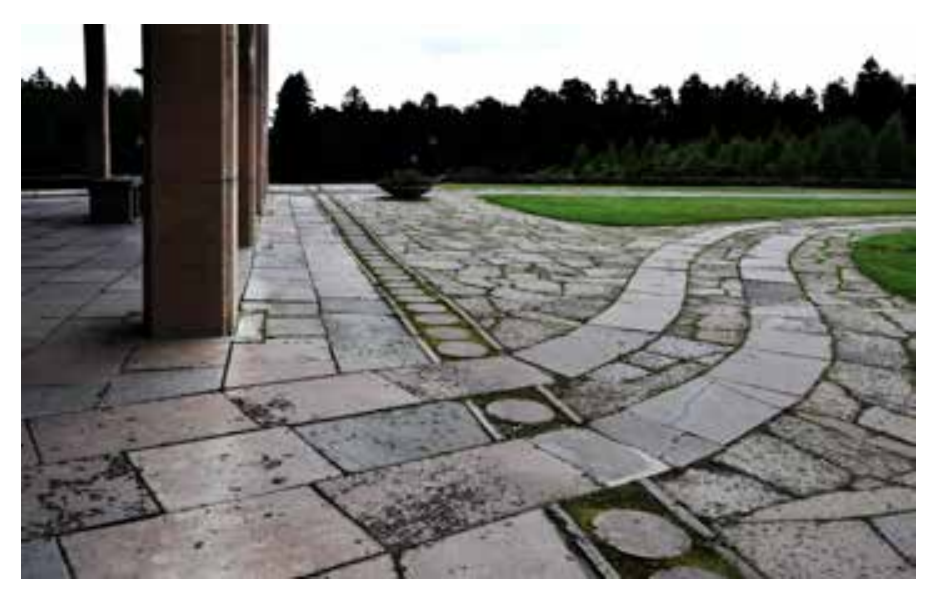

Fig 2.51. Crossed circulation from the portico

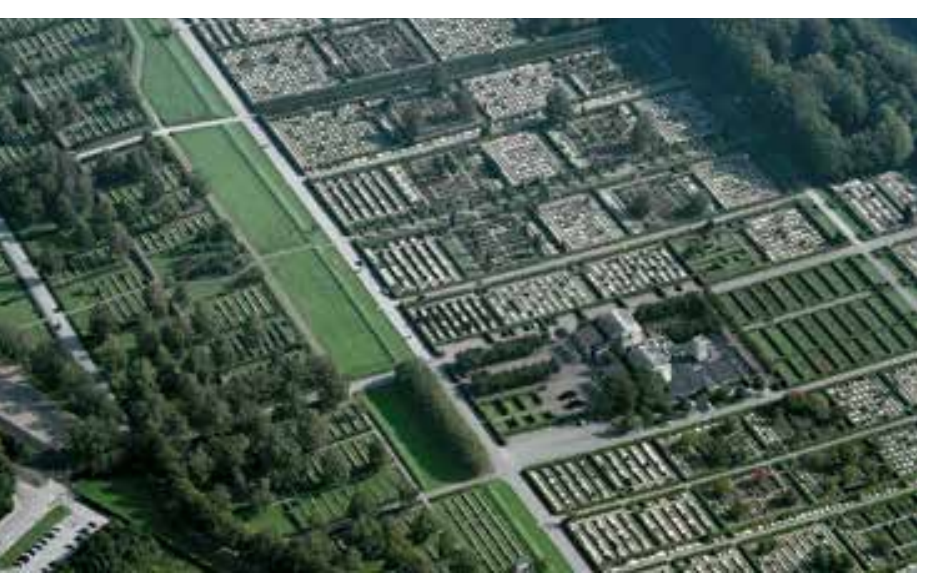

Fig 2.74. Aerial view of space around the tumulus.

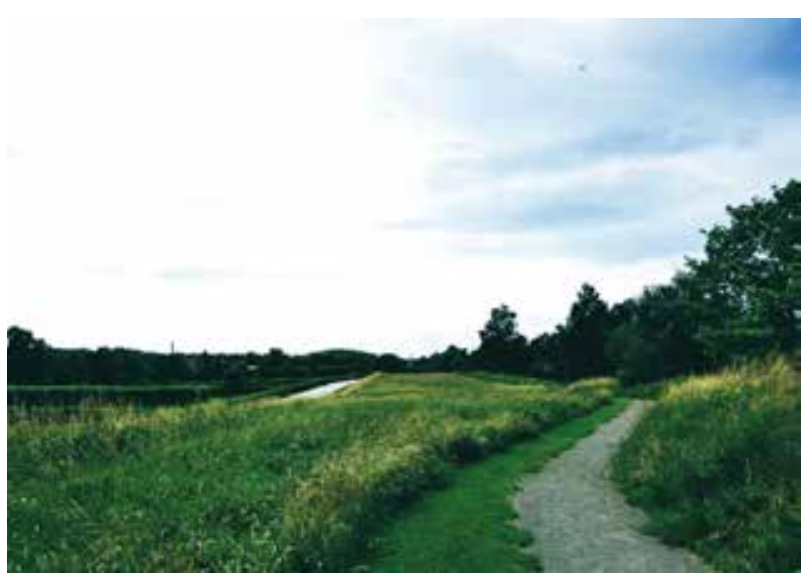

Fig 2.75. Turning on the ridge route.
(Fig2.49.) The following changes of location to move the it back into the middle space implied the architects' idea to make the cross, the most representative symbol of Christianity, adopt a secondary role that "renounces its domination of the space in an obsessively protagonistic role. ${ }^{199}$

The unorthodox location of the Holy Cross (Fig2.50.) recalls the cruciate structure that characterizes the interior of the Church of St Peter in Klippan through perfect incorporation of symbolic meaning and constructive language. The two crosses in sacred architecture and sacred site, displaced from central position, seem to destabilize the space. By reinforcing the images which stand on their own, they declare the importance to establish an exclusive bond between people and the spiritual symbol.

Understanding the need for sufficient time for mourners to arrive at the chapel, Asplund stressed perception of depth on the pathway through the soft ascent and invisibility of the main chapel's entrance. As Merleau Ponty describes depth as dimension that "announces a certain indissoluble link between things and myself by which I am placed in front of them" 100 , and contributes the "individual perspective", depth on this sacree road interprets a spiritual meaning that lies in the essence to invite people to enter a new world.

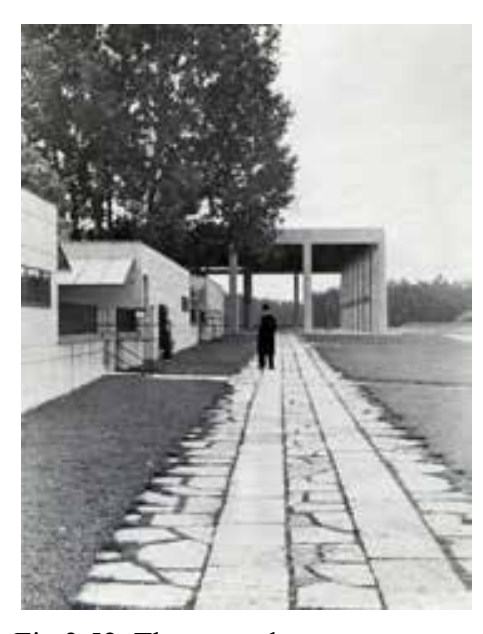

Fig 2.52. The secondary route.
While the Way of Cross serves a ritual walk that passes by the building complex, a secondary route that goes throughout the burial garden connects the twin chapels'

99. Tomás Carranza, “Cruces,” 66

100. Maurice Merleau-Ponty, Phenomenology of perception (Motilal Banarsidass Publishe, 1996), 297

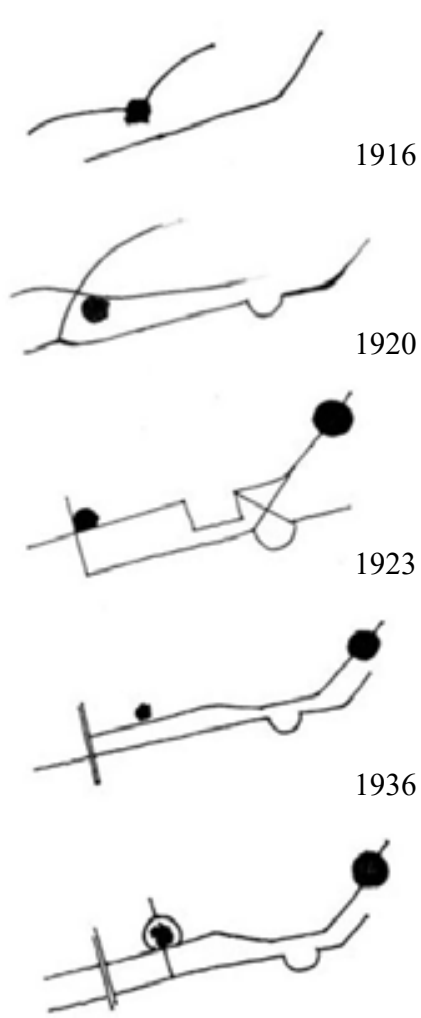

1940

ig 2.76. Development of relation by author based on Lewerentz's proposals. sequence; the longer one, on the contrary, advocates to enhance the expression of natural landscape.

After the turning, wheats replace trees on the left side so that views are intensely expanded. It makes reference to farmland in order to evoke the idyllic image in this old agricultural field, and more importantly, to give implication of the cycle of life. (Fig2.75.) A series of plans shows Lewerentz's intention to move the ridge path to the north, in order to avoid visual connection with the adjacent avenue and the burial precincts at farer place. This set-back strategy manages to separate the contemplating walk from funeral procession. In addition, trees across the pathway block the mombtones scattered on the north slope, ensuring an independent and tranquil character on the road by keeping the pathway from the dominance of burial images.

Lewerentz had made several proposals to study the approach to the ancient tumulus located in the middle of the path. In those plan drawings, this archeological heritage had always been treated as the crucial factor that guides the ridge walkway, from the early curved route to the realized course in lineal way. (Fig2.74, Fig2.76.) However, instead of privileging its position, Lewerentz did not put emphasis on the making of an outstanding element. Therefore, a paradox appears between its anonymous figure and the expression of monumentality. As Lewerentz insisted, "as far as the funeral monuments are concerned, the best ones are those do not disturb the lie of land, but are integrated with it ${ }^{\prime 104}$, he did not conceive the ridge as a stage to present. Thanks to the configuration of the pathway without special treatment to anticipate the ancient tomb, the unity of the two preexistent elements remain untouched. A circular route around

104. Lewerentz, "Modern Cemeteries," 44 


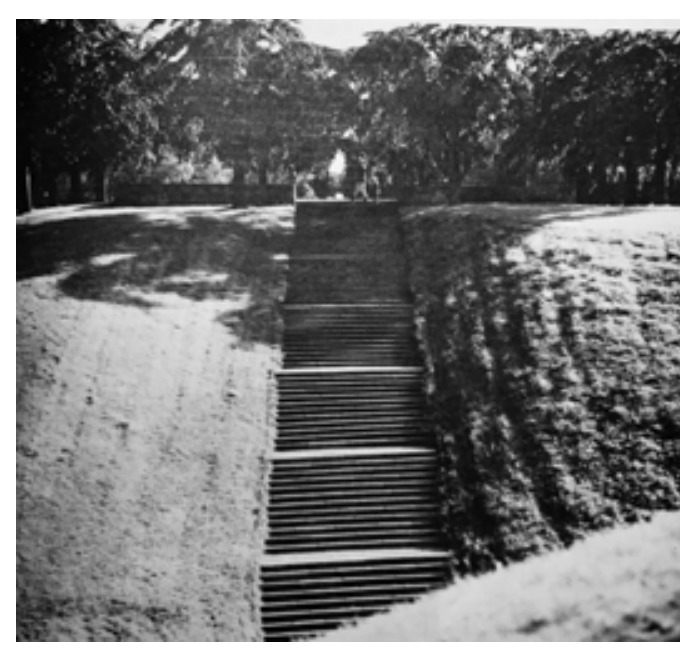

Fig 2.53 Staircase of the Meditation Mound.

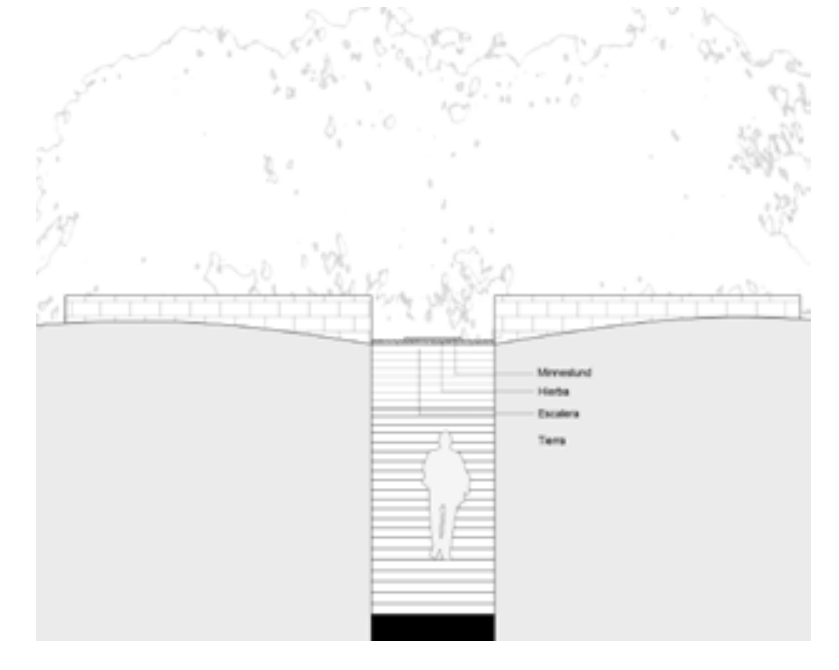

Fig 2.54. Meditation Mound, section, drawn by author

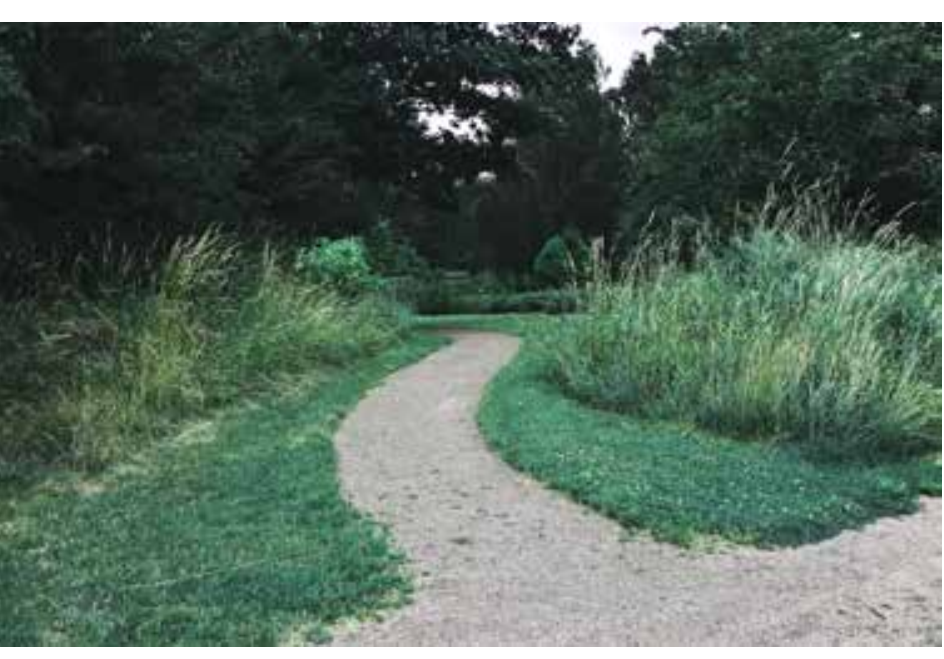

Fig 2.77. The circular route of the tumulus.

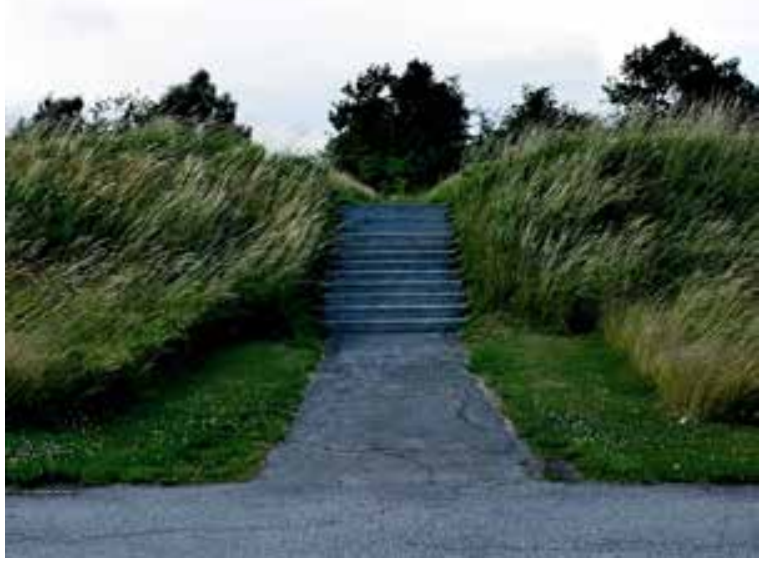

Fig 2.78. Stairs towards the tumulus.

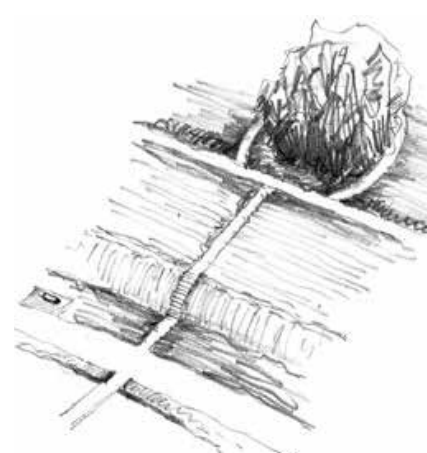

Fig 2.79. Circulation around the tumulus, author
As the Way of the Cross presents an itinerary of profoundness that runs to reach the horizon, the staircase up to the Meditation Mound configures an ascent that leads to the highest point of the cemetery space. Its recessed form achieved by excavation of the hil manifests the accommodation of stone steps into the soil, declaring the architect's idea to integrate natural and artificial materials. In this way, the ascent's visibility is hidden from the distance to maintain a solid and complete volume of the mound, while from a nearby perspective, it appears as a wound cut through the land. (Fig2.53, Fig2.54.)

By questioning the way to create a ritual order from the open landscape towards a private space for commemoration, Lewerentz reduced manifestation of virtuosity of a the elements to their simplest expression, in order to make the movement clear and fully manifested. It is a combination of construction and natural phenomena.

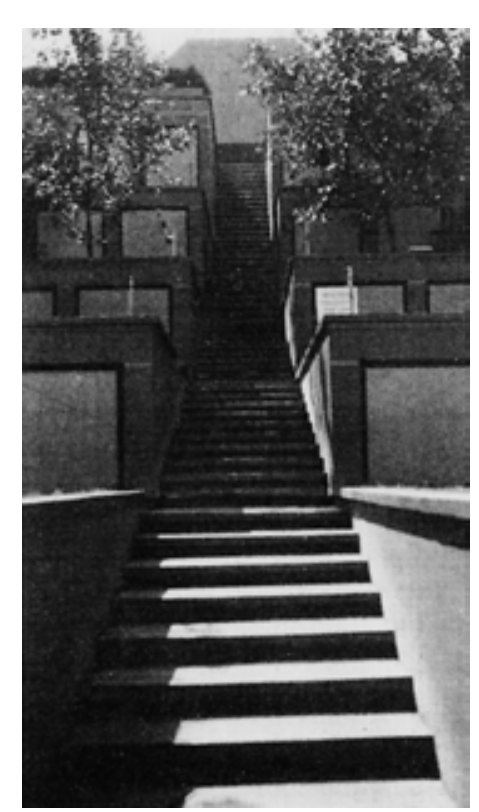

Fig 2.55. Swedish Cremation Society exposition, 1923 the tumulus provides an exclusive itinerary that deviates visitors from the main path. (Fig2.77.) By the means of redirection, this diversion suggests penetration into a deeper place that reinforces the quality interiority of the ridge. Across the road, a staircase that connects the ridge with the middle avenue extends the pathway comes from the south burial, marking the tumulus as articulation of a crossed circulation which combines the serval parts of the cemetery.(Fig2.79, Fig2.79.) However, instead of reproducing a ritual ascent as it is in Stockholm, Lewerentz created an interval between the stairs and the small mound to avoid the archeological vestige from being an outstanding place. By reducing its visibility and accessibility from the avenue, Lewerentz promoted the tumulus' anonymous character to stress its subordination to the ridge.

\section{the way of return}

The last course of the ridge path presents a long and soft decline to the ground level. If ascending the ridge tells an analogy of departure, then, this descent would speak about journey of regression through a slow detachment from the introspective ambient. Though chapels and burial precincts across the avenue are still partially hidden, trees were cleaned from the both sides of the road where tombstones laid on the ground unfold the images of the cemetery space, meanwhile, the inclined floor reminds walkers of a movement down to the earth, as if it was telling a metaphor of being accepted again by the real world.

A belfry, the only vertical element and reminder of time on the ridge from east rear, shows a reversed gesture of the sunken plaza at the other end and is intended to lend a monumental and commemorative character to the walk. However, rather than a bold presence to guide the way of the journey on the ridge, its simplicity of form contributes

wich the relationship between visitors and the terrain is evoked. The earth reminds of the material of burials. We climb a path to the grove on the top, and at the same time, the sunken steps put emphasis on the sense of immersion and make us feel that we are descending towards the bottom of a hill, of a tumulus. 
Fig 2.56. Meditation Mound details, redrawn by author. The staircase composed of six successive courses. Along the asc

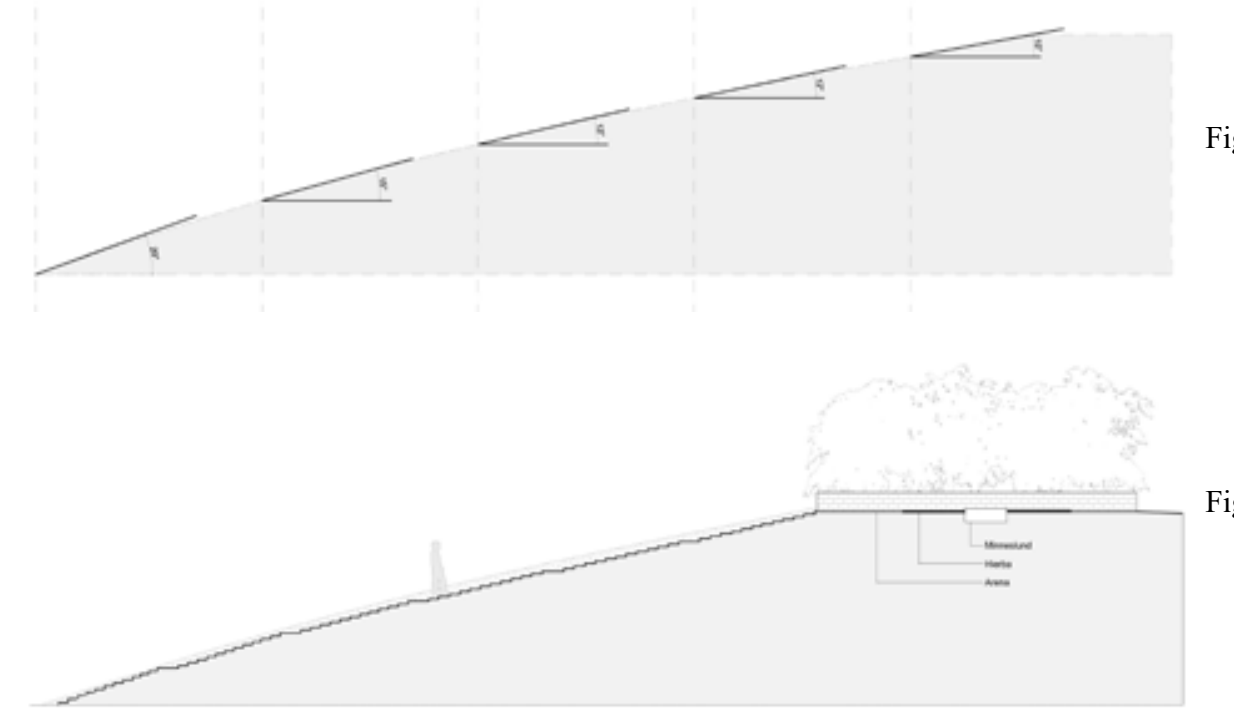

Fig 2.57. Slope of the mound, drawn by author. Through the changes of the staircase, slope of the hill gently curves to facilitate the arrival of visitors.

This embedded route reminds us of another up way designed by Lewerentz - the staircase of truly imposing height in the Exposition of the Swedish Cremation Society by 1923 (Fig2.55). Inlaid between grave terraces, it becomes steeper as it rose, emphasizing a rising gesture. Contrary to this growth, in Stockholm the slope of the hil gently curves to turn the staircase into a reflection on the arrival, which will compensate the effort of visitor's climbing. (Fig2.56, Fig2.57, Fig2.58.) Such gradual relaxation adjusts the rhythm of steps, as Professor José Manuel Lopéz-Peláez observes, "que introduce un tempo más lento en la subida."

During the ascending route it is possible to perceive the architect's searches of ritua effects of height and luminosity. The trees contribute the boundary of the enclosure of the summit, which terminates the ascent and refers to the transit from the exterior space to the interior. Therefore, the climb becomes a rite to enter an exclusive place. Early indicated as a clearing and now as an enclosure, the space on the top is inscribed, although not enclosed, in a frame of a gray parapet of stone as base and twelve elms as columns. The wooded space surrounds us and makes us look at the ground and its specular relationship with the sky.

The well of ashes, the Minneslund, is located at the center and characterizes the whole square as place for commemoration. It penetrates into the earth as if it reached the darkness under which the kings of ancient periods were buried. (Fig2.60, Fig2.61.) The path of the Meditation Mound has become an itinerary through which we climb up to the place where we immerse ourselves into the earth again.

This contemplating space and its ceremonial ambient is created and enhanced by the intimate distance of close phase in this square. Lewerentz has studied about dimension 101. Lopéz-Peláez, "La arquitectura de Gunar Asplund," 147.

A A ual transit, through which visitors enter an erior space for ceremonial use from the r space
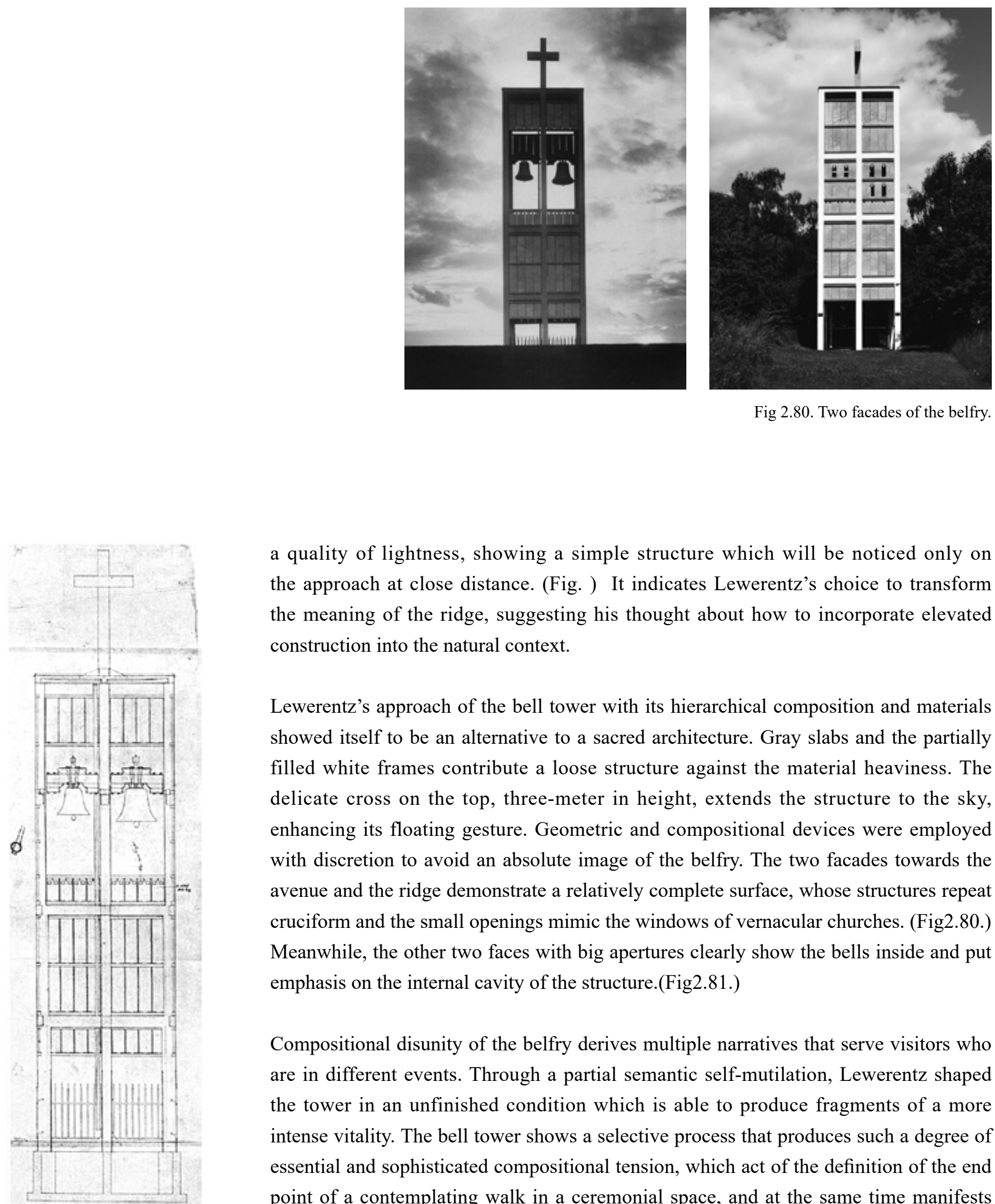

a quality of lightness, showing a simple structure which will be noticed only on the approach at close distance. (Fig. ) It indicates Lewerentz's choice to transform the meaning of the ridge, suggesting his thought about how to incorporate elevated construction into the natural context.

Lewerentz's approach of the bell tower with its hierarchical composition and materials showed itself to be an alternative to a sacred architecture. Gray slabs and the partially filled white frames contribute a loose structure against the material heaviness. The delicate cross on the top, three-meter in height, extends the structure to the sky, enhancing its floating gesture. Geometric and compositional devices were employed with discretion to avoid an absolute image of the belfry. The two facades towards the avenue and the ridge demonstrate a relatively complete surface, whose structures repeat cruciform and the small openings mimic the windows of vernacular churches. (Fig2.80.) Meanwhile, the other two faces with big apertures clearly show the bells inside and put emphasis on the internal cavity of the structure.(Fig2.81.)

Compositional disunity of the belfry derives multiple narratives that serve visitors who are in different events. Through a partial semantic self-mutilation, Lewerentz shaped the tower in an unfinished condition which is able to produce fragments of a more intense vitality. The bell tower shows a selective process that produces such a degree of essential and sophisticated compositional tension, which act of the definition of the end point of a contemplating walk in a ceremonial space, and at the same time manifests

Fig 2.81. Belfry elevation, Lewerentz. Lewerentz's capacity of creating profound qualities and metaphors from simple forms, as Adriano Cornoldi observes: "The less spatially complacent Lewerentz's buildings are, the stronger the sense of 'suspense' charged with a mystery and fascination, such as 

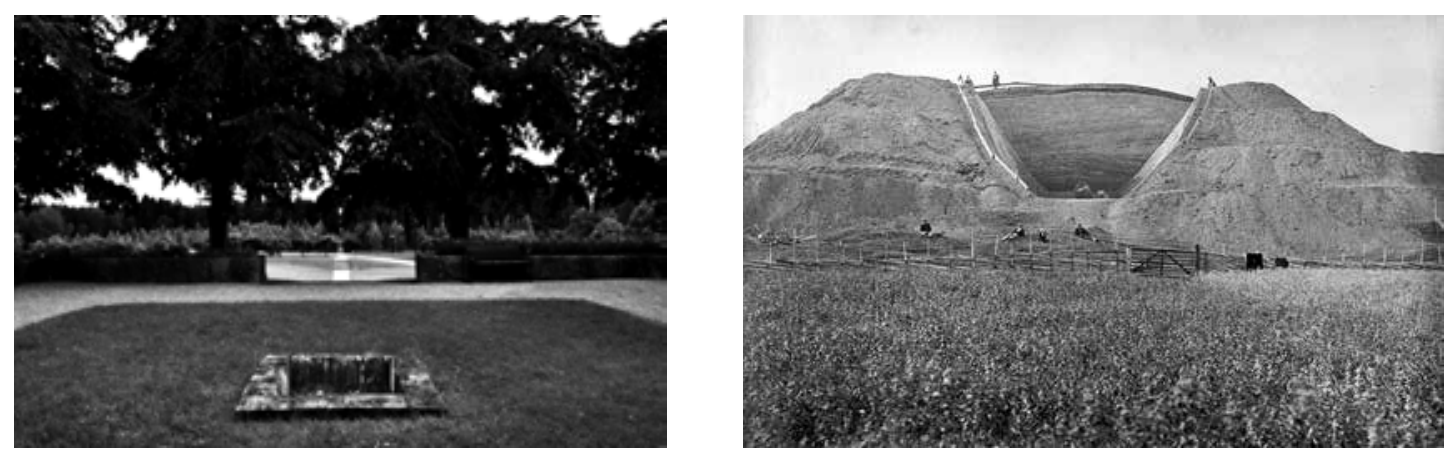

Fig 2.60. Minneslund on the top of Meditation Mound. Fig 2.61. Archeological excavation of Uppsala Mounds,

of the boundary, its relation with the plot that it delineates, and the circular route that passes through this small plaza. The final composition reinforces an introspective quality that lies in a feeling of closeness. In "The hidden dimension", Edward Twitchell Hall indicates the importance of close distance with other people to sense the presence of life.

"At intimate distance, the presence of the other person is unmistakable and may at times be overwhelming because of the greatly stepped-up sensory inputs. Sight (often distorted), olfaction, heat from the other person's body, sound, smell, and feel of the breath all combine to signal unmistakable involvement with another body.",102

It is such intimate dimension in the top square of Meditation Mound that emphasizes our awareness of the absence of the body heat, the sound and the feel of breath, so to remind us of the descent of life affirmed by the central void on the ground. Here, contradiction between material intensity and emptiness of the space enhances the sense of monumentality, recalling the words of professor Luis Martínez Santa-María: "La construcción de un lugar dedicado a la remembranza consiste en conseguir un punto sobrecargado de sentido ante una naturaleza incierta y a veces indiferente." ${ }^{103}$

In the ritual walk of Meditation Mound we find three events: the plateau, the staircase and the Minneslund. They share the same meaning of burial and help to build the form. The corresponded acts of accumulation, excavation and penetration compose an order which guides mourners to participate, through an ascending movement, into the memorial place, meanwhile, the narrative of the farewell is gradually revealed.

102. Edward T. Hall, The hidden dimension (New York: Anchor Books Eds, 1969, 1990), 117.

103. Luis Martínez Santa-María, "El árbol, el camino, el estanque, ante la casa" (PhD diss. Universitad Politécnica de Madrid, 2004), 14

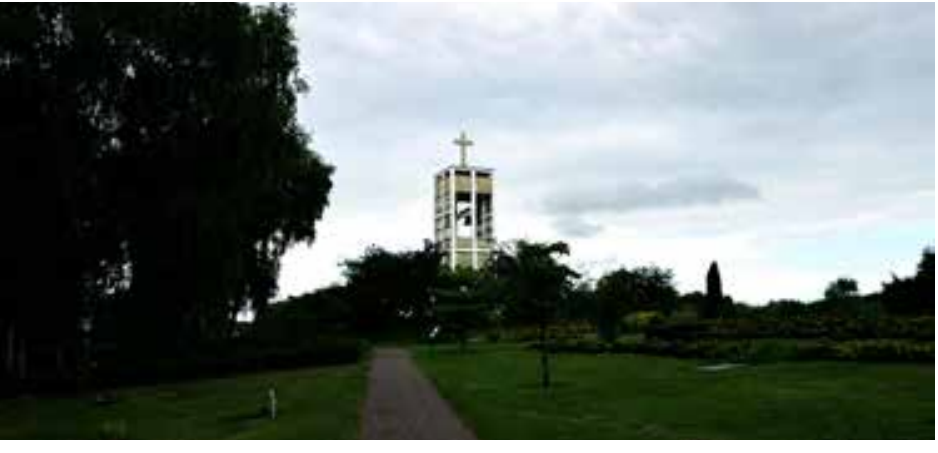

Fig 2.82. Belfry and route on the ridge.

that which ruins often provoke." ${ }^{10}$

Promenade on the ridge is a slow revelation. It gives a perfect manifestation of "another space" which is keeping a dialectic relationship with the ambience over the cemetery. With the help of elevated structure and sunken place at the ends, Lewerentz treated the ridge as a pure thing to develop a self-referential itinerary under the notion of "geographical cure". (Fig2.82.) It gives this journey the characters of independency and flexibility, allowing pedestrians to relate themselves to the rituality of commemorative ceremony, to the nostalgia to the ancient tumulus, or to the peaceful scenery of the idyllic landscape.

105. Adriano Cornoldi, "Architetture dell'interiorità/Interior architecture" in Otras vías: 2 Homenaje a Lewerentz = Other ways: 2 Homage to Lewerents, ed. José Ignacio Linazasoro (Colegio Oficial Arquitectos Castilla y León Este, 2005), 56. 
$\S$ Epilogue - ascent, descent towards farewell

"Just in case you thought experience and the representation of experience melted into each other, death provides a structural principle." 106

Lewerentz's approach of the important places in the two cemeteries showed his manners to create the narrative of remembrance by configuring landscape as monument. In the middle space of the Woodland Cemetery, the felling of monumentality is conveyed, first and foremost, through the sense of remoteness and resistance from the over-size of the Meditation Mound; in Malmö, the sense is derived from the privileged position and immersion into an interior world of the ridge. The experience of the rite of farewell is allied with of fluctuating movement of ascent and descent, through which mourners walk from the landscape that shows vitality of the nature to the sacred place, extracted from earth and amidst serenity, to commemorate the loved ones. Lewerentz talked about the most important thing in the cemetery is to achieve "an atmosphere of peace and quiet that the surroundings must emit, allowing the visitors to spend a few moments in tranquil silence at the graveside". ${ }^{107}$

In the two cemeteries, landscape as monuments that were created or preserved enhances the sense of immersion. They make mourners contemplate the relationship between loneliness and anticipation, to think of the times in which we become alienated from the ever-changing nature of our world. Rather than an absolute discipline, the architect used freer strategies to create and underly spatial aesthetics based on site condition, as Caroline Constant observes:erentz derived their general aim of creating an art that was both nonconventional and intelligible, personal and objective, in which forms of nature 106. Sarah Webster Goodwin and Elisabeth Bronfen, ed., Death and Representation (Maryland: Johns Hopkins University Press, 1993)

107. Lewerentz, "Modern Cemeteries," 44 could express ideas and sentiments without the mediation of history." ${ }^{108}$

Both of the mound and the ridge change the ground surface and become mediators between human and nature, between the present and the past, and, through reflection of tumulus, articulate the spaces of life and death. Excavation is the key manner for Lewerentz to achieve the representation of funeral rite. By rooting excavated conditions into their protruding volumes, both of the mound and ridge manifest the entry into the earth and materializes the ritual of farewell. These empathetic scenes stimulate our imagination: under the soil, we know there is a hollow space made exclusively for the deceased, though we cannot see it, a vague and dark space in mind let us touch the cavity. The motivation of this imagination is likely derived from our identities as "mortals". When we see a grave, we actually see the final place of ourselves, we are not there, but finally we will be there. We mourn ourselves when we are mourning in front of other's tomb. The resulting dialectic of "presence/absence", which is indicated by Foucault about mirror in "Heterotopia":"in the mirror, I see myself there where I am not, in an unreal, virtual space that opens up behind the surface; I am over there, there where I am not, a sort of shadow that gives my own visibility to myself, that enables me to see myself there where I am absent."

Lewerentz made his appeal to the interior life, to the search for the spiritual possibility of space. The Meditation Mound and Ceremonial Plaza materialize a mirrored condition of life and death, meanwhile, their itineraries are interpreted as the means of transit, which elaborate the ritual of our movements and our relationship with the ground.

108. Constant, “The Woodland Cemetery," 132. 


\section{A WALK TO THE PLACE OF REMEMBERANCE}

To understand the narrative of itineraries in Stockholm and Malmö cemeteries which present journey towards farewell, it is necessary to penetrate the protective screen of landscape of the North to the sacred place where funeral ceremony is held. Both of the Chapel of Resurrection located at the end of a sequential movement and the twin chapels of St. Knut's and St. Gertrud's placed away from the main circulation define stopping points at a precise moment on the ritual procession. In addition, these sacred architectures represent the gesture of protection and hope of the interior space, achieving counterbalance to the outer world so to complete a cemetery place where, as Lewerentz put in, "contact with death is not in any way disturbing, on the contrary, one feels imbued with a feeling of peace emanating from eternity."

As to the interpretation of the chapels Lewerentz took different strategies to accommodate the sacred architectures into the pre-existing matters of the nature, and to compose the order of a transit from the exterior space to the interior. The Way of Seven Wells that cuts through the dense forest and reaches the Chapel of Resurrection at the southern sector of the woodland plays an important role to resemble the landscape of different qualities, as well as to maintain a continuous movement to keep mourner's sentiment of immersion into forest, wherein the solemn ambient and consistent walk explain the motto Tallum. The building at the end raises a symbol of hope to convert the long procession into a pilgrimage. Contradiction appears from the relation between the forest route of clearly established directionality and deflection of the chapel itself. The lateral plaza, the free-standing portico and the building's interior circulation contribute a series of reorientation that forms the rite of movement for the funeral. Thereby, Lewerentz achieved a balance between the steady trip throughout the landscape of plateau and deep woods, and an intense approach to the chapel's hall amidst metaphor of resurrection.

A decade later, the twin chapels in Malmö show Lewerentz's critical thought about the relation between collective commemoration and individual meditation. While the precinct outline allows the chapels to get away from the dominant character of the ridge and other pre-existing elements, the differently structured entryways represent two individual programs opposing the tendency of cross-reference. So what is at issue here is not the adequacy of the primitive and natural force to deal with funeral procession, but rather the exhaustion of this power to lay out exclusive route towards each architecture. Colin St. John Wilson regards architecture of the twin chapels as fundamental shift of the Lewerentz's design. In fact, the constructive paradox and materials intensity we confront with in this work foresee his later sacred architectures, notably in the churches of St Mark's and St Peter's, "of great authority, propriety and emotional impact."

Following the sequence of movement from landscape into architecture, study in this section is developed in two parts. By analyzing the process of arriving at the chapels in the two cemeteries, the first part focuses on Lewerentz's strategy of transiting people from outer and natural environs to the architectural space; and the objective of the second part lies in the sacred buildings' gateway, to verify if the continuity of movement and space from the exterior space to the interior is applied by the architect to elaborate an overall narrative about farewell.

110. Colin St John Wilson, "Sigurd Lewerentz The Sacred Buildings and the Sacred Sites," in Sigurd Lewerentz 1885-1975, ed. Flora, Giardiello and Postiglione, (Milan: Electa architecture, 2006.), 11. 


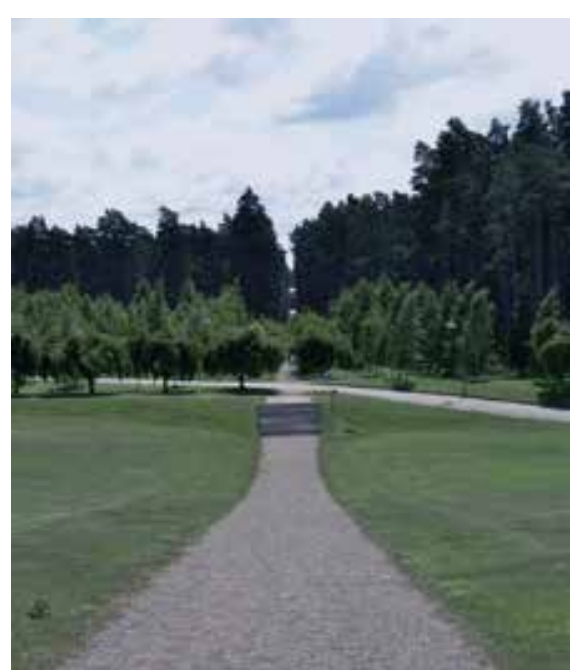

Fig 2.83. Descent from Meditation Mound.

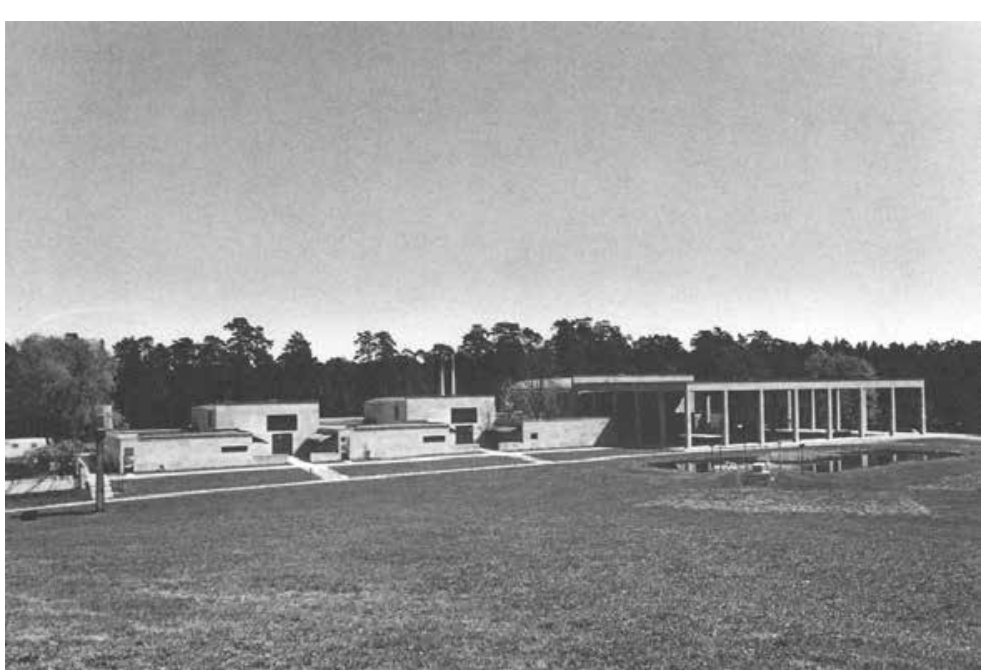

Fig 2.84. Building complex around Way of the Cross.

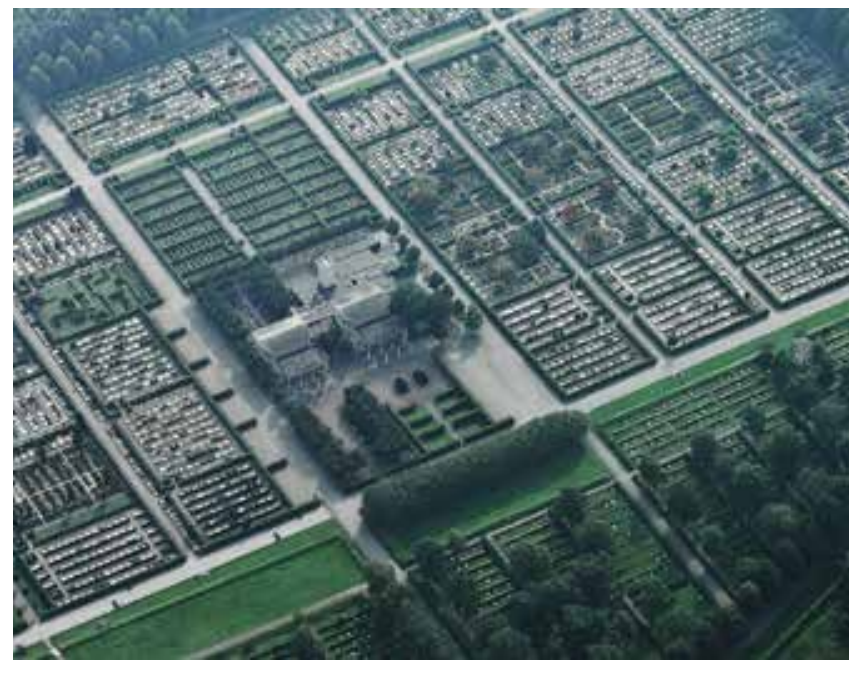

Fig 2.97 Layout of twin chapels in Eastern Malmö Cemetery.

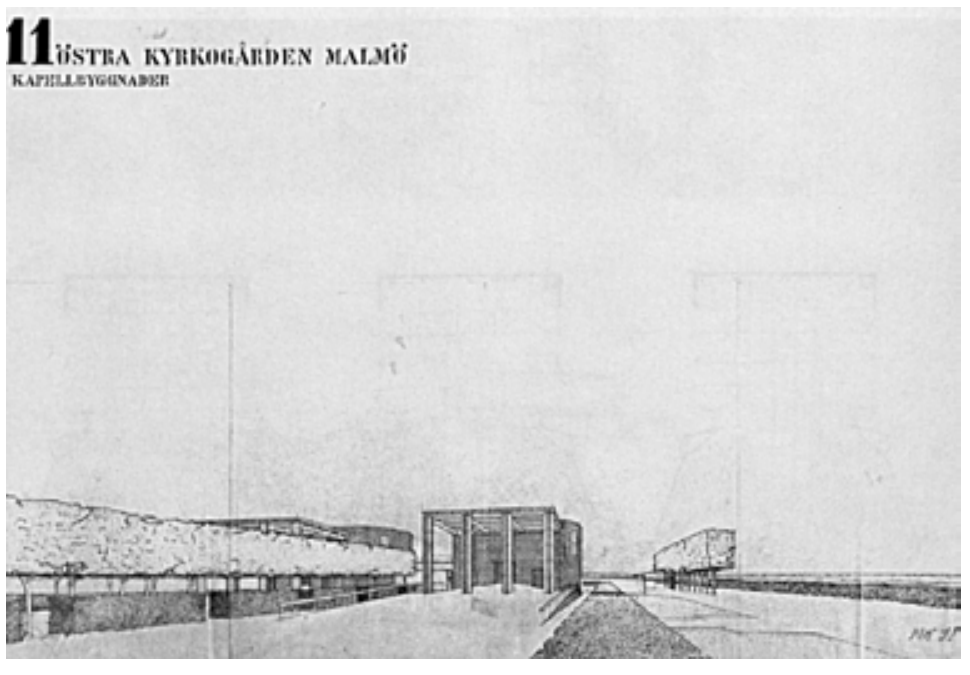

Fig 2.98. Perspective St. Knut Chapel.

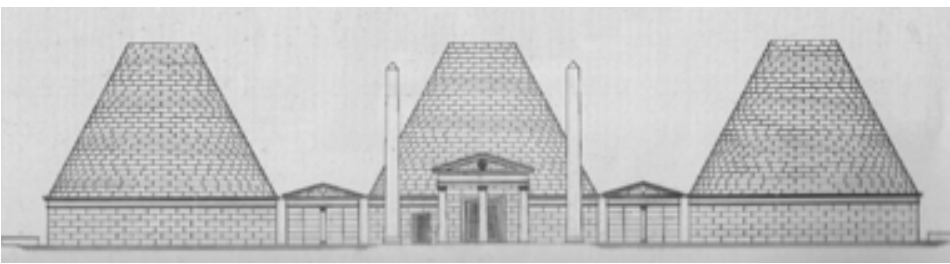

Fig 2.99. Crematorium study, 1923.

$\S$ Towards the Twin Chapels
. into the woods

$\S$ Towards the Chapel of Resurrection

The Way of Seven Wells gives people a great impression before they walking into the woods. The mourning people on the top of Meditation Mound are facing a pathway penetrates into the forest (Fig2.83) A slow descent takes them out of the gloomy Minneslund to the open space. Contrary to the intense ascent, this downward trip does not force people to focus on the floor. The empty route allows people to look around, on the left side, a panorama of Asplund's organization of the chapels, the cross and the lily pond along the Way of the Cross. The gentle slope of the descending route and a proper distance in-between the two pathways slow down the walkers, giving sufficient time and providing a peaceful experience for the mourners to recover from sadness. (Fig2.84.)

The forest path disappears from the horizon on the bottom of the descent, where a short staircase takes people back to a place of intersection.(Fig2.85.) The pathway from the plateau, the paved route from the main chapel and the loop road that encircles the cemetery meet at this point, showing a harmonious encounter of the two architects' works. This crossed trajectory marks the frontier of the middle space, by dividing an itinerary of established directionality from the mound to the forest ahead, it starts a oneway trip after a short pause.

In his book "Nordic Space", Christoffer Harlang indicates that in the culture of the north forest has always been regarded as a "sacred place" because of its deep aura and representation of life cycle. The development of the cemetery design, from the first decision to keep the woods all over the site to the following proposals to clean trees in the entry landscape and elaborate particular definition upon the woodland at the south section, showed the traditional root as fundamental strategy for the two architects to the parallel journeys

In 1943, Lewerentz finished the twin chapels at the western sector of the Malmö Eastern cemetery. Set back from the main avenue, the two architectures standing side by side provide a 40x $50 \mathrm{~m}$ front court and leave the rectangular plot behind St. Gertrud on the east to an urn garden, and the place behind St. Knut on the west is occupied by a crematorium of modern style, constructed in 1936. The symmetrically placed buildings of similar forms may come from Lewerentz's early proposal of a three-cone crematorium characterized by evocative antiquity and balanced composition, (Fig2.99.) and also elaborate an egalitarian and democratic vision of funeral services to deliver simultaneous ceremonies.

Both of the chapels are accessed through passages lined by vegetation. The parallel routes divert mourners from the longitudinal trajectory of the cemetery and create an exclusive procession whose quality is so different from the broad dimension that characterizes the avenue, and from the intimate experience on the ridge walk. Across the road, Trees aligned with the ridge cut off visual connection between the ridge and the architecture complex, meanwhile, the roads on the both sides delimit a south-north precinct in same width. (Fig2.97, Fig.2.98.) In order to reorient circulation towards the chapels, the architect applied hedgerows to configure parallel entryways with various subdivisions, as well as to control the chapels' visuality on the approach

Some important alternations are seen between original drawing and the realized layout. (Fig2.100.) Four bush beds close to the St Knut's chapel are reduced to two, hedgerow which was conceived as continuous boundary of St. Gertrud's entry finally terminates in front of the portico. However, by alienating the chapels from the outside world and 


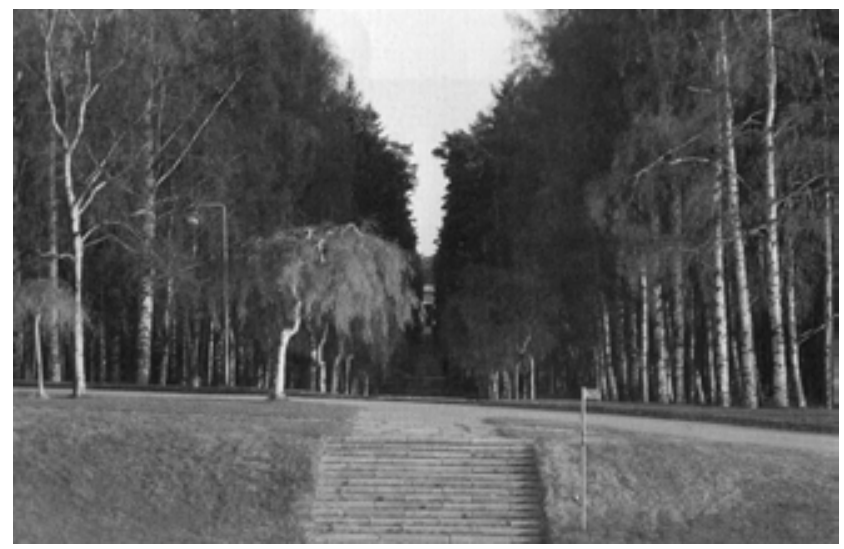

Fig 2.85. The short ascent and deciduous grove.

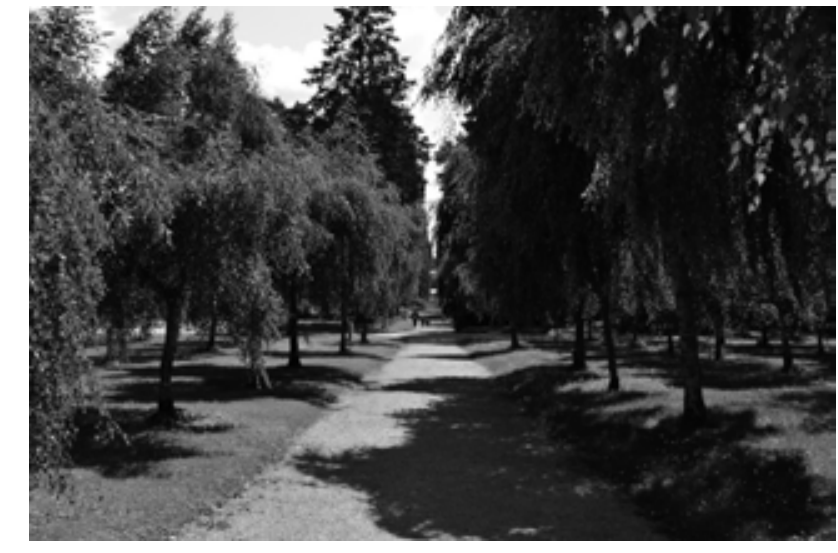

Fig 2.86. Way of Seven Wells from the deciduous grove.

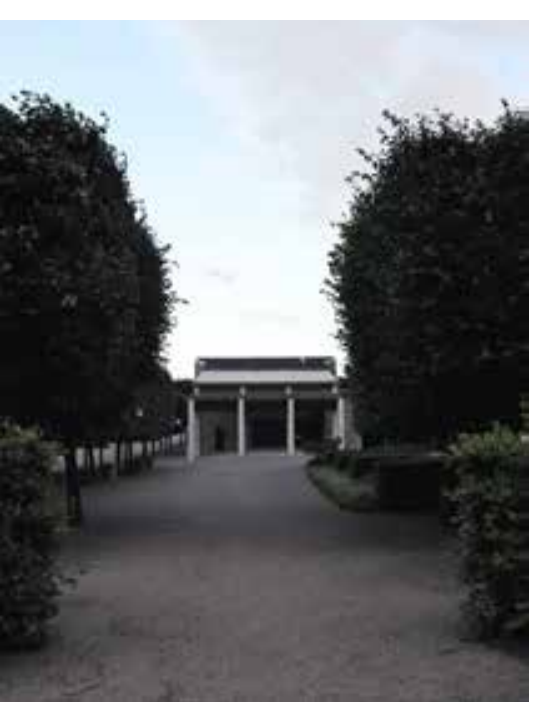

Fig 2.101. Entryways of St. Knut and St. Gerturd Chpels.

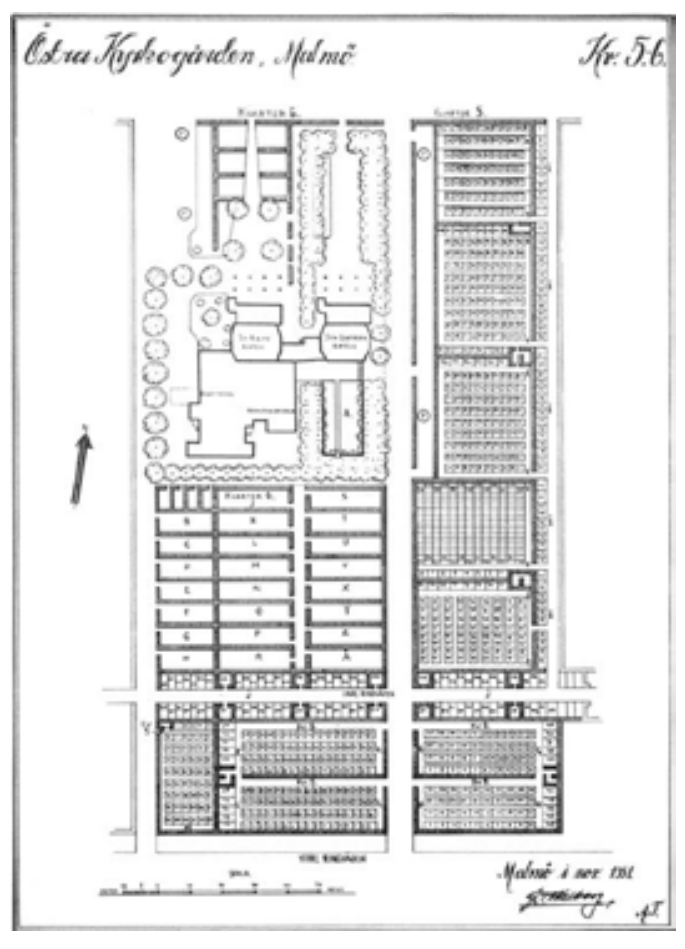

Fig 2.100. Plan around the twin chapels

drawn by Gustaf Valfrid Wablberg, 1951 incorporate the atmosphere of commemoration into the woodland, not only relying on its natural essence to generate a grim ambient, but also from seeking to create a rite of walk throughout the dense space. Lewerentz once said, "When designing a cemetery, it is necessary, first of all, to provide the shade serving to facilitate orientation." ${ }^{111}$ It is evident that the cemetery and its narrative are largely structured by the alternation of light and shadow, and the well-established directionality, which are achieved by the variations of distribution of trees. From the boulevard outside the boundary, to the elms atop the knoll and the forest as the backdrop, trees play a significant role that characterizes each space and marks the transit between different episodes

A small grove of deciduous trees starts the forest path. It lines the upright pines behind and establishes a threshold between the open place and the woodland, qualifying the sense of extension that contributes to the spatial layering, as well as to "ease the resulting sense of immersion in the wooded burial ground."112 (Fig2.86.) Following its path, visitors are gradually conducted into an exclusive realm whose burial character is told by the scattered tombstones. The narrow pathway ahead penetrates into the pine woods was illustrated in Lewerentz's proposal for Valdemarsvik Cemetery gateway (1915-23), (Fig2.87.) giving a clear message of "going into the nature" - a profound notion in the North according to Norberg-Schulz. ${ }^{113}$

The competition entry proposal showed that the south section of the cemetery was divided into grids by a longitudinal road and seven transverse trails, wells are placed in each interval.(Fig2.88.) Though the remaining wells have not been realized, Lewerentz's treatment of the path, subtly divide the trajectory, reveals his idea to create the forest

111. Lewerentz, "Modern Cemeteries," 45.

112. Constant, "The Woodland Cemetery," 105

113. Norberg-Schulz,“Genius Loci”.

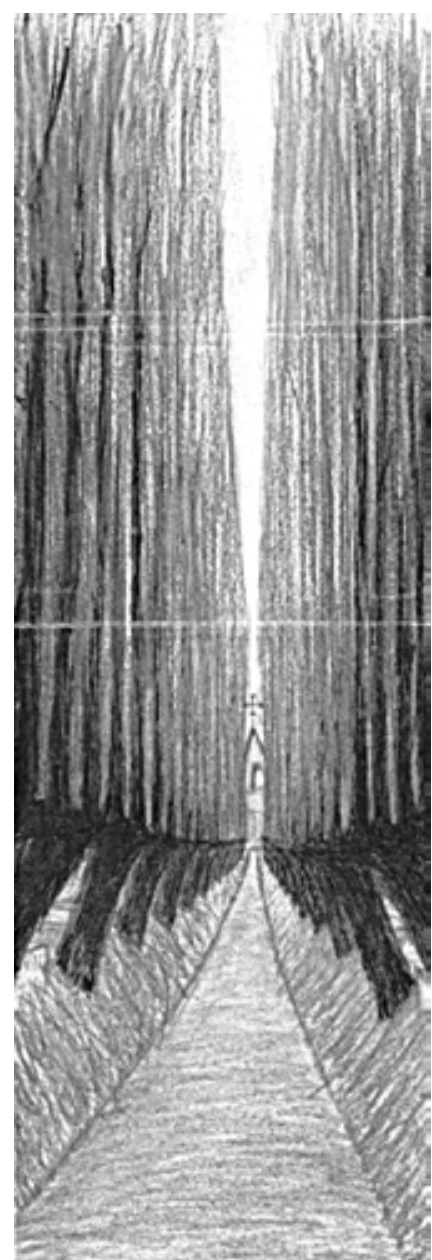

Fig 2.87. Valdemarsvik Cemetery gateway, Lewerentz.

giving the two simultaneous paths individual expressions, the architect's principle ideas about creating two exclusive routes to the buildings were archived.

The continuous border of bush along the avenue and the two narrow openings, set as points of departure, suggest exclusive and parallel trajectories. The exterior simplicity hides the depth and richness of the entryways from the outer space, so to start the approaches with a sudden change of spatial character. Separated by their own bounds, the two passages show their respective development based on symmetrical composition and progressive expansion. The subtly opened route of St. Knut's Chapel, which counterbalances the perspective of the narrow pathway, and the broader boulevard of St. Gertrud's Chapel work to accommodate visitors into the new order of their interior capacity as well as the duality of passages and burial plots. (Fig2.101.)

Under a general control of dimension and directionality, particular configurations of the two passages lead to respective expressions about sequence of space, rhythm of movement and people's relation with the chapels. Lewerentz used hedgerow to alienate the St Knut's Chapel from the views of the western side, where a road for vehicles leads to the entrance of the crematorium. Seen from the route access, clear boundaries of the gravel floor and bushes at the end seem to enhance a straightforward itinerary. However, lines were used to subdivide lateral space into a series of burial squares which are evenly located on the both sides of the twenty-meter long pathway. As a consequence, the crossed-directions between the individual squares and the main route greatly reduce the continuity of movement. These private space make people wonder what is hidden behind the partitions. By creating a series of stopping points that interrupts the approach with a steady rhythm, these cells permit visitors to get away from the chapel's guidance for a moment, and to immerse themselves in personal meditation. The architect's idea of an irresolute movement is also shown at the rear of the entryway. In the original drawing, four bushes formulate an intermediate stage of a centralized space which 


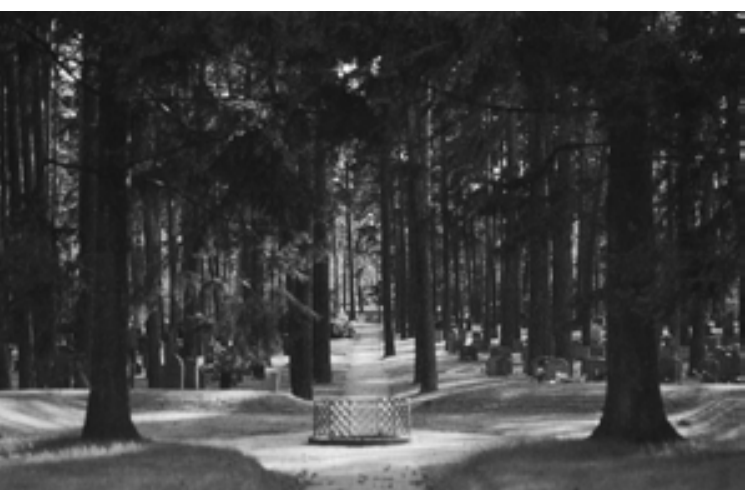

Fig 2.88. The excavated well.

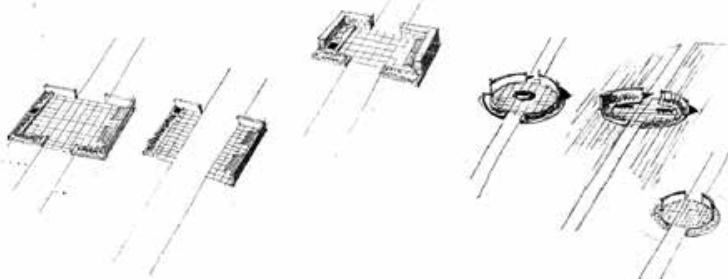

Fig 2.89. Studies of the wells, Lewerentz, 1923-33.

journey with particular rhythm in order to connect with the next episode. Sketches made by him around 1923 shows his study on the variations of the area of wells to compose it as resting places with benches and short walls. (Fig2.89.) Asymmetrically disposed with reducing intervals, these points measure the distance on the route and accelerate visitors' speed, composing a series of signs to suggest the approximation of the chapel.

By thinning the forest and replacing tree species, Lewerentz enhanced visual continuity inside the forest to avoid an ominous tone of an over-gloomy ambient. The uninterrupted expanse of the forest is enhanced by the grassland dotted with grave markers, and the gradually reduced distance between trees achieves a similar effect as the succession of wells would provide. The increasing number of spruce trees in the pine forest results in a gradual change of density of space and quality of light, stratifying the landscape and giving more privacy to the mourners. The pathway was conceived as an undulating procession of a long descent into forest floor and a short way reemerges near the chapel. The resulting sense of immersion and solemnity is evocative of Caroline Constant's definition of the path "as both a gesture of protection and an expression of dread. ${ }^{\prime 114}$

Though the final pathway differs from the initial concept, it remains the original theme of a ritual journey, in which one's feeling is subject to tranquility and loneliness. Pallasmaa includes "silence, time and solitude" in the senses of architecture. The set of feeling is interpreted in the forest as a rite of purification that focuses on "one's very existence" and provokes the awareness of "fundamental solitude". As Gaston Bachelard describes the feeling of being lost in the forest, "we do not have to be long in the woods to experience the rather anxious impression of 'going deeper and deeper' into a limitles 114. Constant, "The Woodland Cemetery," 105.

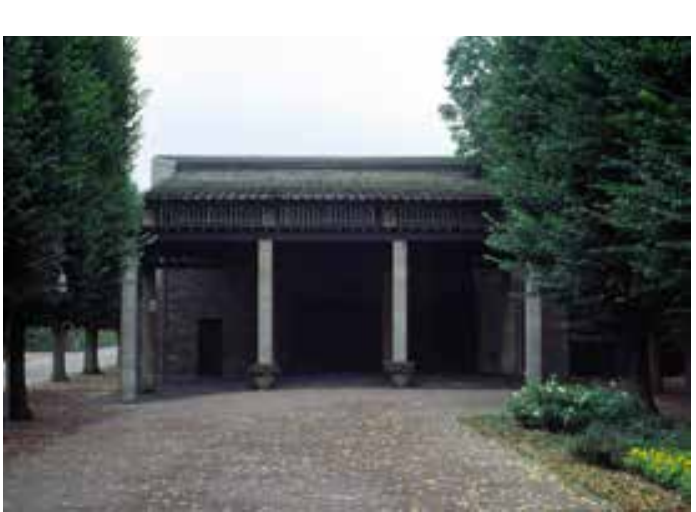

Fig 2.102. Passage next to Chapel of Gertrud.

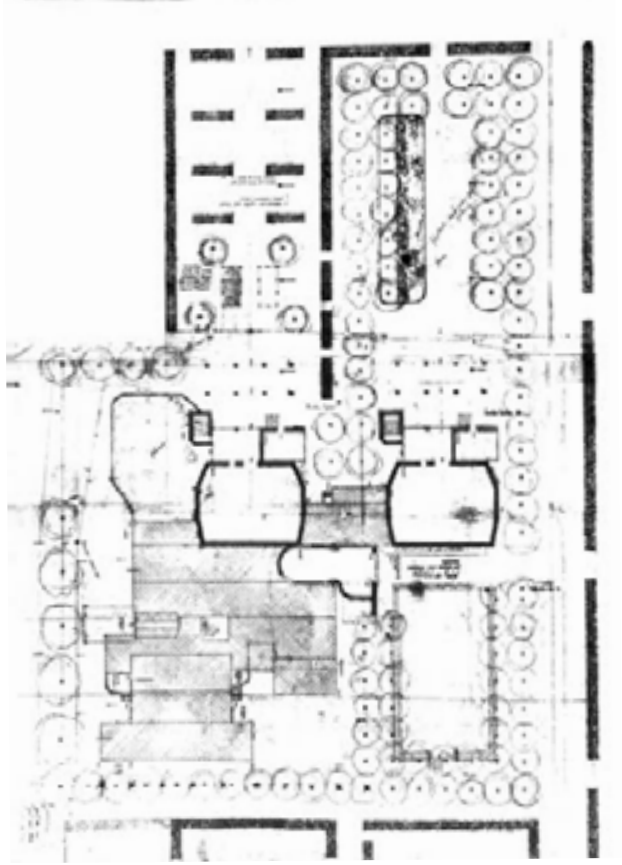

Fig 2.103. Plan around the twin chapels, 1941

serves to suspend walk in front of the portico. With the intervention of squares and grid of bushes, Lewerentz not only reduced the dominance of the building over the entry space but also achieved an indeterminacy of directionality to weaken the connection between visitors and the itinerary. Both strategies would work to postpone the arrival to the accesses of the chape.

Contrary to the distracted movement to the St Knut's Chapel, the open entryway lined by trees presents itself as a rectangular garden, showing the volume of the building of St. Gertrud's Chapel. It affirms a direct connection between walkers and their destination. However, compared with the impression of a straightforward route towards St Knut's Chapel, the gravel floor and simple composition of St. Gertrud's entry tend to give homogeneous character to the space by weakening the concept of a pathway. Trees are the key element to create solemn procession before the funeral: while the trunks form a continuity with the portico pillars, the tree top directs people's observation to the sky.

Rather than to promote an intimate relation with things at close distance on the adjacent trajectory, Lewerentz enhanced an expression of space of a larger scale on the approach to St. Gertrud's. Trees on the both sides correspond to the trees across the avenue. By placing the grass plot on the right side, he effected an impression of asymmetric composition on the walkway that drives walkers' attention to the left side, where a arrow passage next to the building suggests further space. (Fig2.102, Fig2.103.) One can imagine the tree line becoming a continuous gesture of protection that wraps the building, the front court and the back yard within a united layout. 

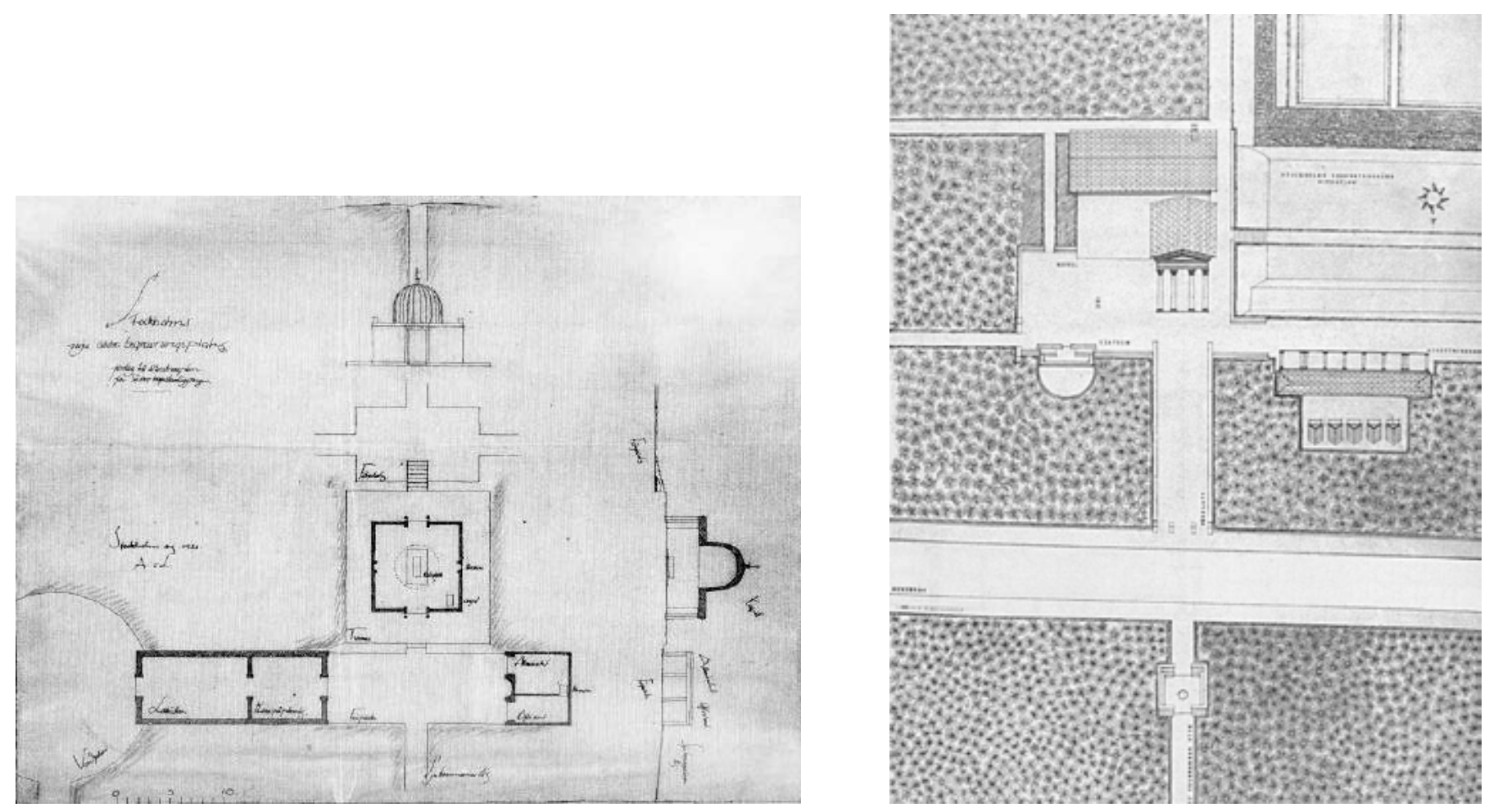

Fig 2.90. "Chapel of passage", Lewerentz, 1921.
Fig 2.91. Siteplan of Resurrection Chapel, Lewerentz, 1923-25. world. Soon, if we do not know where we are going, we no longer know where we are" ${ }^{\text {"115 }}$, the lit chapel standing out from the end firmly marks the exit and the symbol of hope

\section{the constructional differences}

From 1916 when the Cemetery Authority clarified the location to 1925 when the architectural process finished, the Chapel of Resurrection had undergone several changes to reach the final solution. Besides Lewerentz's examination of stylistic issues, studies on the variations of the axis, the relations between portico and nave, and the entrance and exit positions showed his concerns to accommodate an elaborate architectural program as the key element and end point to integrate the journey in the cemetery with the pre-existing conditions of the forest pathway and the graveyard lying immediately to the southwest. (Fig2.91.)

In the early proposal named "chapel of passage" submitted on August, 1921, Lewerentz's unorthodox treatment on a continuous sequence of movement from the chapel entrance to the exit on the opposite side precipitated the question of theological interest. (Fig2.90.) This order based on his concept of a ritual walk to farewell that mourners should not turn back upon the same path, had be realized in his proposal for Helsingborg crematorium, however, was rejected because of the resulting conflict with location of the alter. In the final plan, Lewerentz resolved the problem through an unusual composition. By deflecting the portico from the nave axis and placing the exit on the short side close to the graveyard, the circulation for ceremony is isolated from the trajectory of entering and going out of the chapel. It leads to a division of the

115. Gaston Bachelard, The poetics of space. trans. Maria Jolas. (Boston: Beacon Press. 1994),

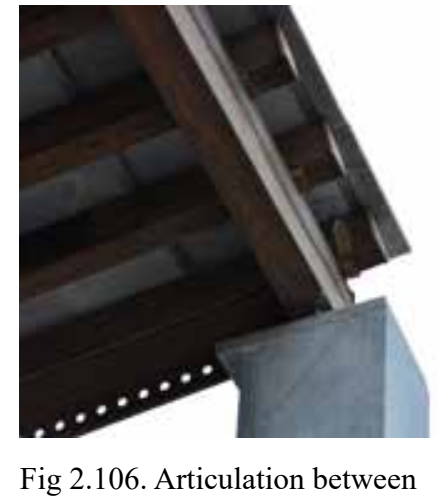

Fig 2.106. Articulation betwe
pillar and roof.

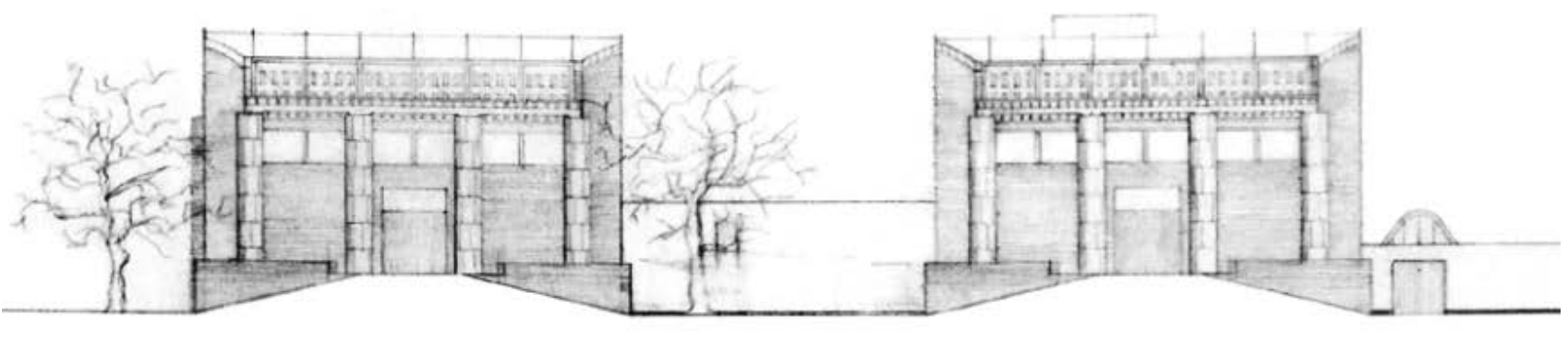

Fig 2.105. Frontal facades of the twin chapels.

transmit through tectonic approach

The final layout of the ceremonial area sees a connected space in front of the two chapels. However, correspondence of the approaching route and the gateway of each building declares their autonomy and independency. The ascent of the gravel pathway reaches to the peak at the raised floor of the portico, highlighting the position of the chapel. (Fig2.105.) In addition, the symmetrical facade reinforces frontality of the building, enhancing a straightforward perception of depth until to the iron gate which marks the destination of the approach. Material and constructive factors were used by Lewerentz as narrative elements to tell the metaphor of a ritual procession.

A pair of wooden roofs at upper and lower position, connected by lattice, gives the portico opposing forms. (Fig.2.104.) This foliage structure and four pillars divide the room underneath in two phases. The downing roof on the lower level receives mourners in a somber place. It works together with the ascending floor to reduce the scale and lower views to force visitors to face the front wall and the horizontal gate. This feeling of inhibition will be relived soon when the rising roof permits sunlight to enter through the gap between the wooden structure and the solid wall. Joints of all the constructive elements are reduced and clearly demonstrated to achieve a lightweight quality. The simple marble-cladded pillars are directly set into the holes on the concrete floor. Marble panels, wooden beams and rafters are overlaid on the small wood block upon the cap of the pillar. Seen from the distance, it seems that the roof structure is placed directly on the pillars. Lewerentz's delicate use of materials and sophisticated joints to show structural simplicity are reminiscent of traditional Japanese construction. Besides this far resonance, the straight lines, slim and light property in each part of the portico lead a taut structure, as if the deeply rooted pillars were pulling the flying tops. The metal downspouts, delicate and shinning, outline the structure and further reinforce this 

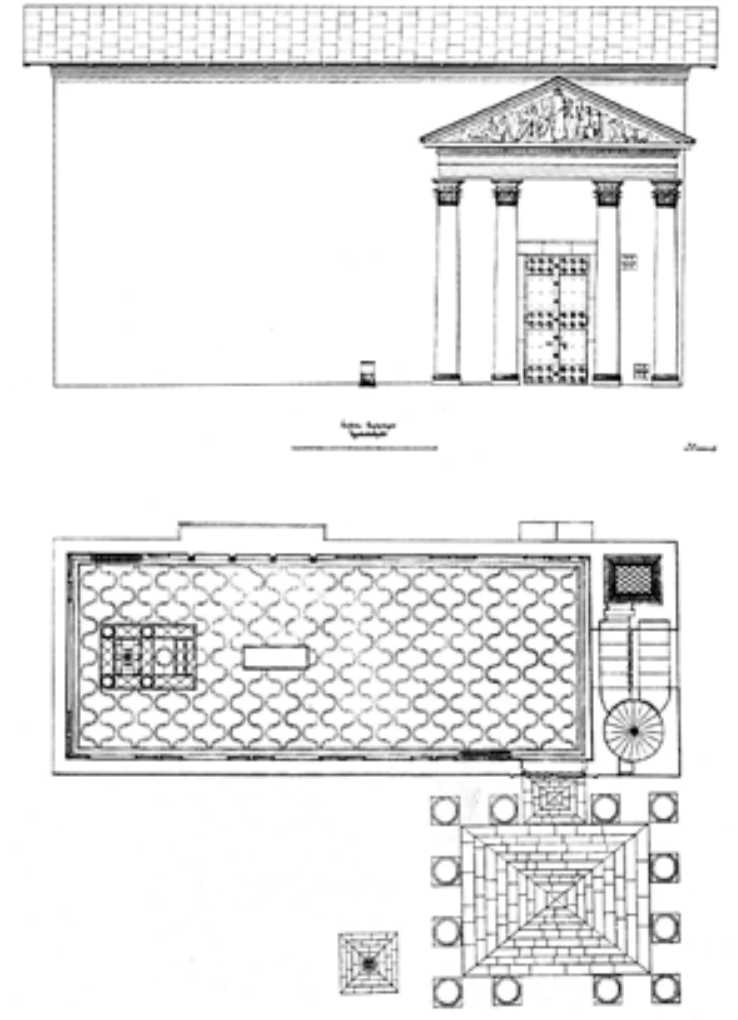

Fig 2.92. Resurrection Chapel, elevation and plan, Lewerentz.
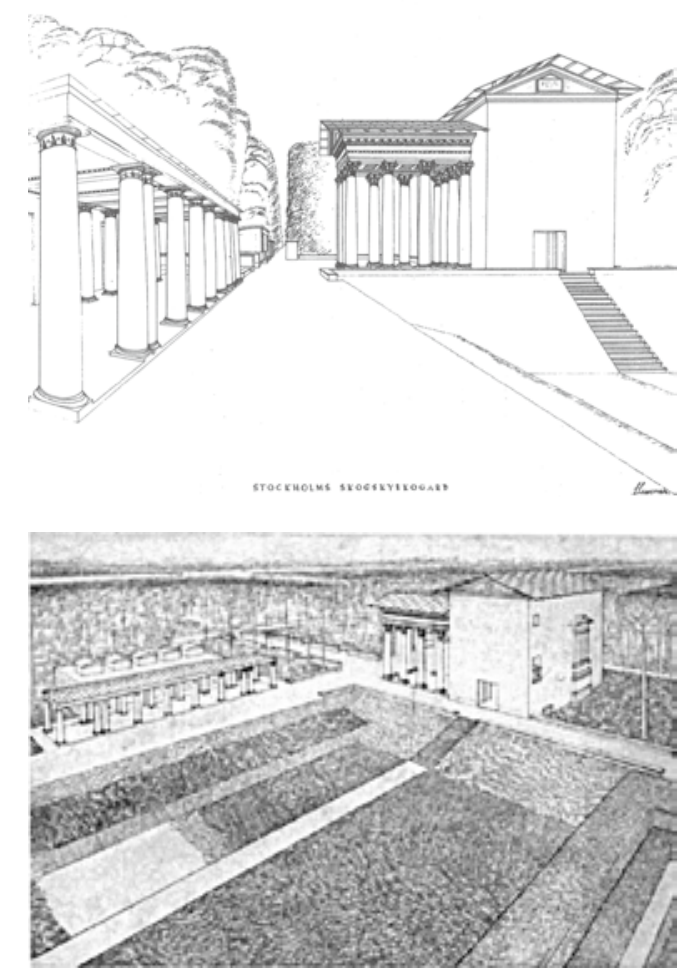

Fig 2.93. Resurrection Chapel perspectives, Lewerentz.

interior space: a full-height hall defines an exclusive place for funeral ceremony, and a small room for the officiating priest is placed at the rear above the exit. (Fig2.92.)

The building sees a quite combination of classicized elements of baroque attitude in a simple volume. Lewerentz organized the entry to accommodate it into the natural context. The chapel is accessed through a walled corridor which remains the dimension and orientation of the forest path, creating a continuous transit from nature to constructive and geometric language. Two paved stripes symmetrically divide the floor into a central way and secondary paths on both sides, which correspond with the three-bay portico. In this way, architectural order is incorporated into the approaching experience. While the entry puts emphasis on the affinity with the chapel, its ancillary constructions, however, present a subtle detachment from their own positions. The rectangular plaza on the left side diverts visitors from the columns of Roman antiquity and the gable inscribed with thematic relief, and guides them to the semicircular waiting pavilion facing the blank wall, mute and somber; on the other side of the entry, a stoalike building serves the sunken burial ground. (Fig2.93.)

This strategy of separation is also seen in the architecture of the chapel, and above all, in the relation between the portico and the nave. Set in a slight angle to the body of the building, the portico is detached from the nave in a silent manner: one can barely see the gap in-between the two, but it can be speculated from the light filtered in the portico and its inconsistent position with the main building. (Fig2.94, Fig2.95.) Janne Ahlin finds the structural duality here: "The portico can thus be said to be both a freestanding building as well as bound to the chapel structure, the architectonic forms of which it mediates. The chapel demonstrates a similar ambiguity in its closedness and in its compound relationships to surround elements of the composition."116 The portico's

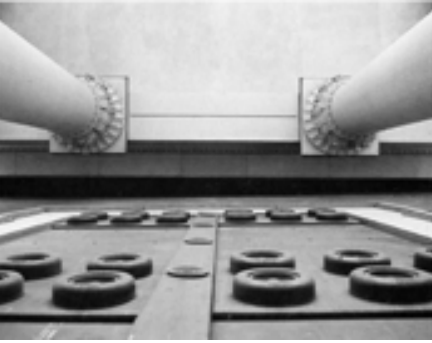

ig 2.94. Gap between portico and the chapel.

116. Janne Ahlin, Sigurd Lewerentz, Architect: 1885-1975 (Stockholm: Byggförlaget,1987), 185.
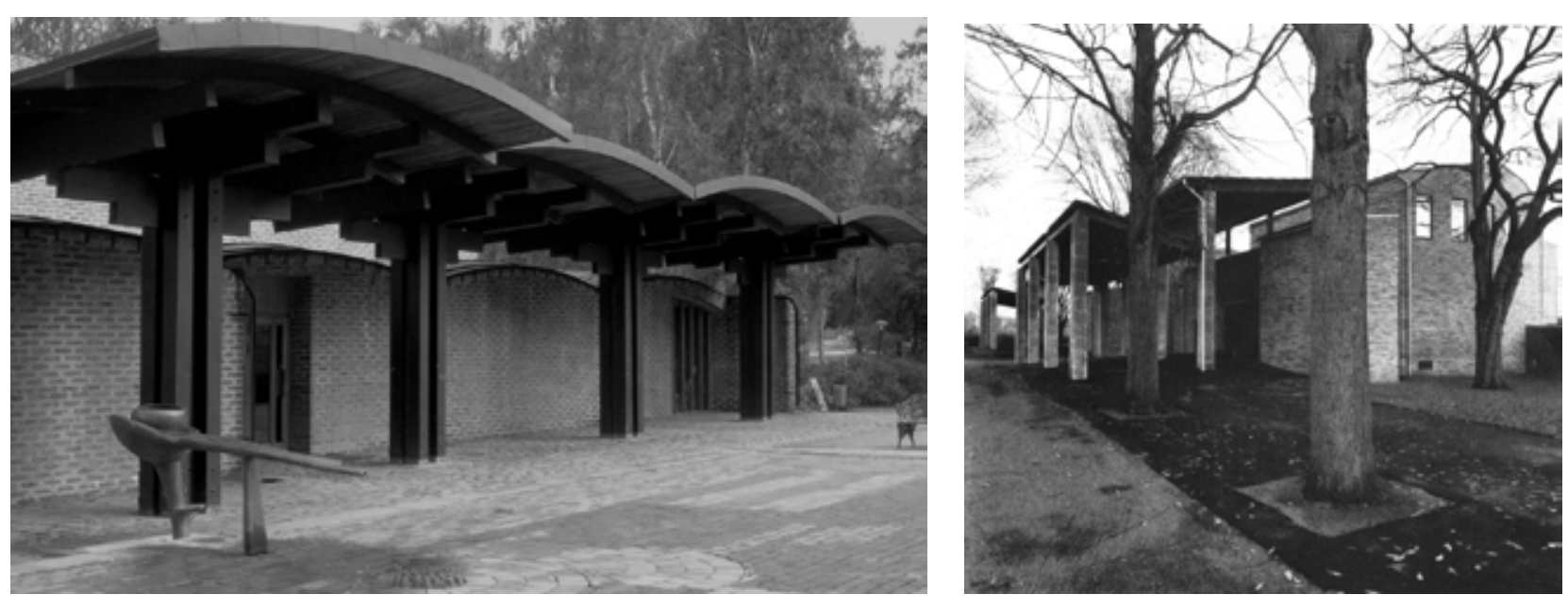

Fig 2.108. St. Mark's church canopy.

tense effect. ${ }^{118}$ As Colin St. John Wilson describes Lewerentz sacred architectures, that "We are confronted as much with a new interpretation of ritual and symbolic form as with the manner of its making" "119, Lewerentz's choice of reversing the expression of the load-carrying structure and the clear demonstration of constructional logic gave a testimony of his turn from Schinkel classicism to the language of modernism.

Rather than an irreconcilable problem, Lewerentz followed the nature of material to create different geometries, in order to emphasis the respective expression of the light and uprising portico, and the heavy and compact building of brick walls. The bold interval between the two parts, with minimal connections, clearly demonstrates the separation by emphasizing their identities as two individual systems. ${ }^{120}$ (Fig2.107.) Like the disjoined canopy and building of St. Mark's church, (Fig2.108.) by incorporating structures which are uncorrelated with each other, Lewerentz showed an integration of making and thought in the twin chapels through a tectonic language, based on which to elaborate the ritual transit of space and narrative.

The chapel's terraced volume composed of the lower front hall and the higher nave

118. The achievements in the portico construction were surly attributed to Lewerentz's sophistication in manufacturing work. The architect started to work with engineering firms from 1930s and opened his own manufacture business of window and door assemblies from 1940 , the long professional work absolutely had a great help of deepening his insight in constructional details.

119. Colin St John Wilson, "Sigurd Lewerentz The Sacred Buildings and the Sacred Sites," in Sigurd Lewerentz 1885-1975, ed. Flora, Giardiello and Postiglione, (Milan: Electa architecture, 2006.), 11 .

120. Subtle relations between the two structures can be found from the roof levels. While the nave keeps the growth of the portico's rising roof, top of its downing roof is aligned with bottom edge of the protruded service room. 

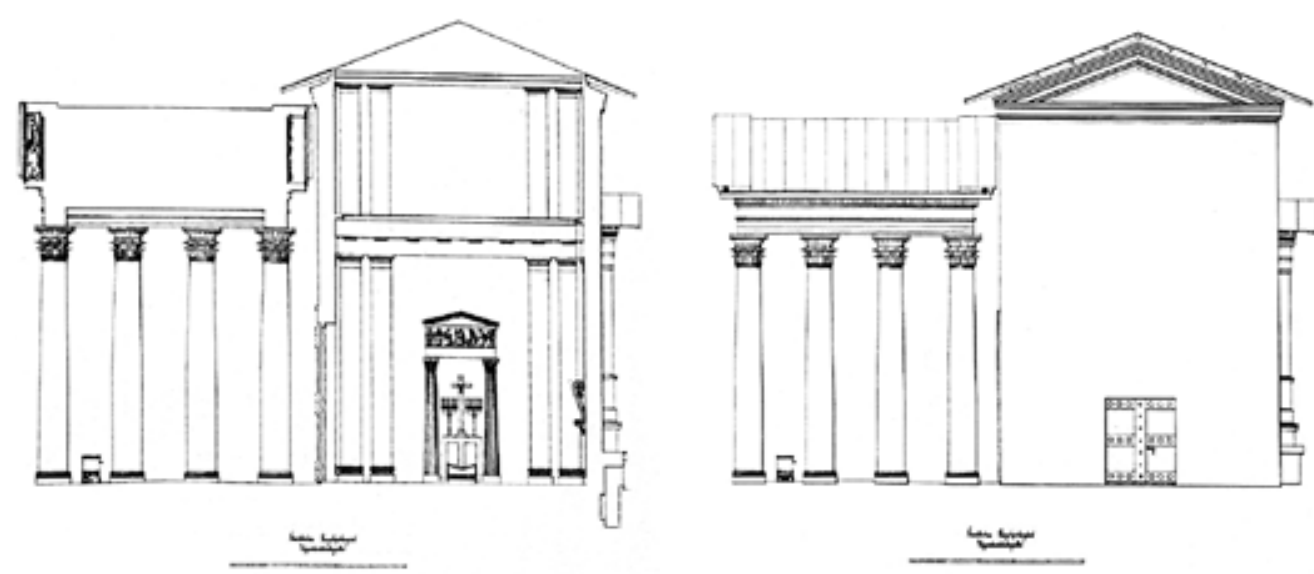

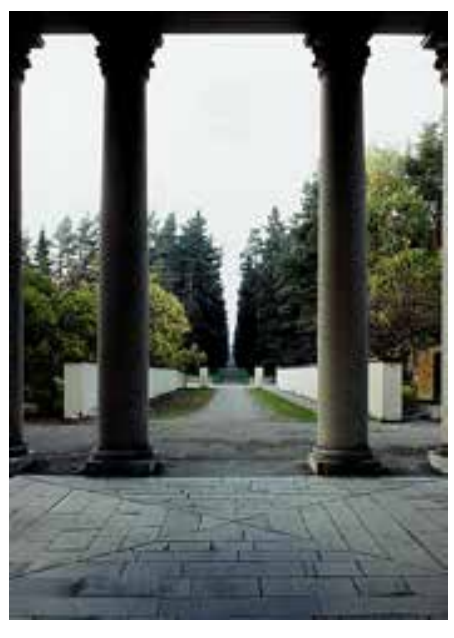

Fig 2.96. Way of Seven wells from the portico.

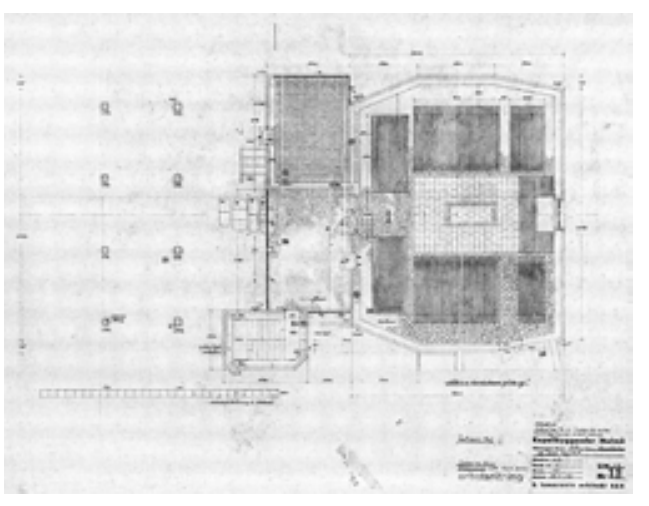

$-2$

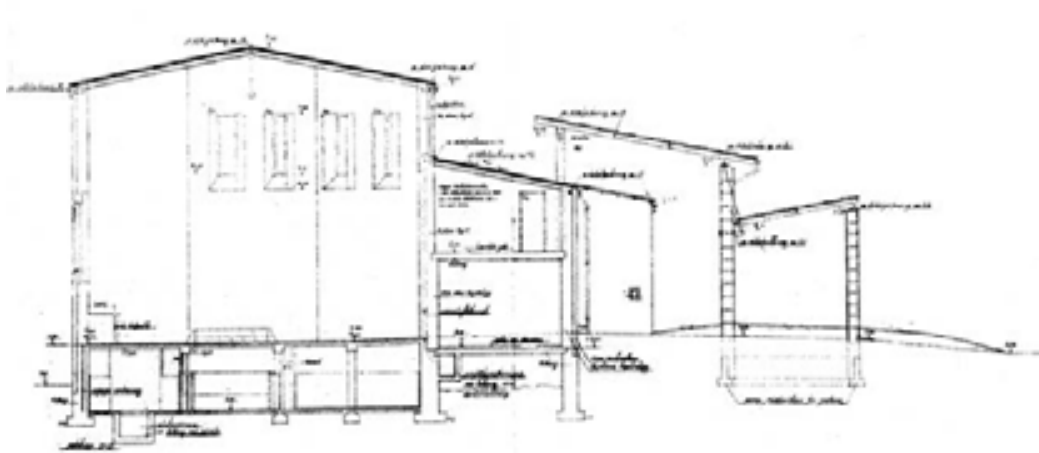

Fig2.109. Plan and cross section of Chapel of St. Gertrud.

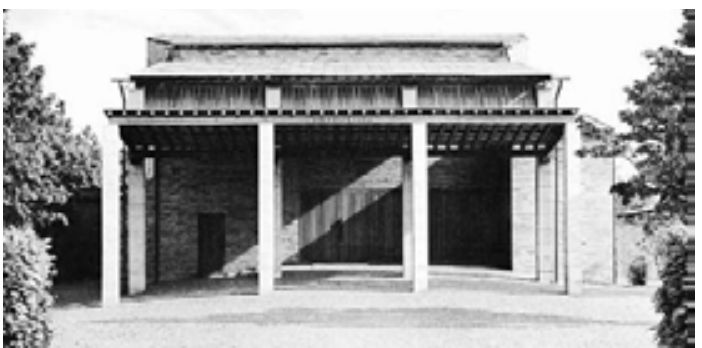

Fig 2.110. Light within the portico. independency is also indicated by its pyramid-shape floor. (Fig2.96.) Meanwhile the centralized pavement emphasizes an autonomic role, its vertex assumes an end point of the ascent from the forest and the corridor. Luis Moreno Mansilla suggests an iconographic cycle in this front structure, "the portico is an architecture of the past, just as at this moment life has passed, but it is also relevant to the present, as it has been resuscitated from classicism, it announces the refuge of the gods and the passing of that threshold[...]".

By establishing multiple relations between visitors and the architecture, the portico leads to the interior inconsistency of the hall. The north wall shows a solid surface to stop people from looking to the direction that they came from, thereby driving their attention to the high windows on the south wall and thin pilasters around the hall, whose uprising gesture emphasizes the interpretation of rebirth.

Through the manner of separating and twisting to produce differences within one architecture, Lewerentz set the Chapel of Resurrection in an unfinished condition, which somehow relates to the imperfect nature of life. As John Ruskin says, "[...] imperfection is in some way essential to all that we know of life. It is the sign of life in a mortal body, that is to say, of a state of process and change. Nothing that lives is, or can be, rigidly perfect, part of it is decaying, part nascent [...] And in all things that lives there are certain irregularities and deficiencies, which are not only signs of life but sources of beauty" ${ }^{\prime 117}$, the ambiguity in the construction of the chapel and people's experience of being away from everyday life become particular invocation of the psychological dimension of funeral ceremony, telling the essential narrative of a cemetery about farewell to the loved ones.

117. Joan Evans, ed., The lamp of beauty: writings on art by John Ruskin (London: Phaidon Publishers, 1959), 238 behind creates a defensive appearance. (Fig2.109.) Amidst the shadow, the dark gate as entrance to a deep cave, open only for funerals, declares exclusiveness and protection of the interior space. The severely reduced palette of materials of the building suggests a silent and introversive place inside, indicating the austere and uncompromising treatment in Lewerentz's late sacred architectures.

Floor descends from the middle pillars of portico and drives the way towards the gate, light penetrating from the upper gap leads views up to the sky. (Fig2.110.) Upon entering the building, the shortened and less illuminated vestibule will impress the visitor with great contradiction with the outside experience. The floor paved with the same bricks of the walls keeps descending to the nave interior, where the catafalque is placed in the center. The abruptly heightened space in the main hall and eight high windows strengthen a floating sense. It reduces the expression of the brick wall's heaviness, creating an expression of lightness that opposes the appearance from the exterior.

With the help of tectonic language, Lewerentz established a refined order based on the changes of scales, materials and quality of light. The gateways of the twin chapels represents the potential of a phenomenological approach with psychological cares to bring mourners from the natural environs into a protected space. 
$\S$ Epilogue - the paradoxical continuity and material basis for a transit

Pathways towards chapels in the two cemeteries show Lewerentz's understanding of "funeral procession" as a continuous itinerary from landscape into architecture. Reorientation in the Chapel of Resurrection not only provides a non-repeating circulation inside the building, it also implies the end of the ceremony; in Malmö, the parallel entryways of the twin chapels, on the one hand, suggest his design strategy to separate the building precinct from the ridge, on the other hand, define independent routes that respectively respond to the tectonic character of the two buildings.

By interweaving the interior journey with the exterior one, Lewerentz created a continuity on the approach to the chapels based on the strategy to treat landscape and construction as a joint system, that the order inside architecture is experienced as an extension of the outer sequence, and vice versa. Portico is the key element to achieve this effect. By making use of its synthetic quality and playing with its relation with the building body, Lewerentz conceived the frontal structure as intermediate stage in the two trajectories to link the exterior and interior space. In Stockholm, the invisible gap between the Chapel of Resurrection and its porch hides the fact of a building consists of two separated units. Therefore, though the entryway is structurally broken, a continuous experience of entering the chapel is ensured by the "produced" unity of the building form, which is further strengthened by the portico's subordination to the nave because of the consistent language of classicism. A decade later, the twin chapels in Malmö see a reversed strategy. The portico and building behind are technically connected by timbers, however, the architect did not put emphasis on any attempt to assimilate the two systems. Opposition in materials and tectonic give rise to perception of the separation, making the portico as a structure standing on its own. Here, continuity is not an experience a priori, it will be gained only by entering the building, reading the hidden relation of the roofs and relating the lightness of the nave interior to the portico's flying gesture. Lewerentz also used floor relief to create an interweaved relation of the architecture and the outer space. By marking the trajectory's vertex at the middle point of the portico's ground, he tended to break the correspondence between the sequence of movement and the order of construction, leading an invasion of exterior itinerary in architectural space.

Paradox between expressions of separation and unity in the two architectural projects suggests Lewerentz's design mechanism against a unique language. More importantly, it brings unexpected and small incidents that contribute to contingencies that work simultaneously with the general manifest of continuity and enrich the narrative of a ritual procession. The Austrian neurologist Viktor Frankl have pointed out that it is the limited lifetime gives us pressure to treasure every small thing:

"If we were immortal, we could legitimately postpone every action forever. It would be of no consequence whether or not we did a thing now (...) But in the face of death as absolute finish to our future and boundary to our possibilities, we are under the imperative of utilizing our lifetimes to the utmost, not letting the singular opportunities (...) pass by unused." ${ }^{121}$

In Lewerentz's sacred architectures, light filtered through gaps, the soft fluctuation on the floor, the tensed structure and conflicts of materials represent the randomness of the world. These incidents appear at specific moment keep stimulating out instinct, urging

121. Frankl, Viktor, The Doctor and the Soul. trans. Richard and Clara Winston (New York: Vintage Books, 1986), quoted in: Brooke Alan Trisel, "Does Death Give Meaning to Life?" Journal of Philosophy of Life Vol.5, No.2 (August 2015): 63. 


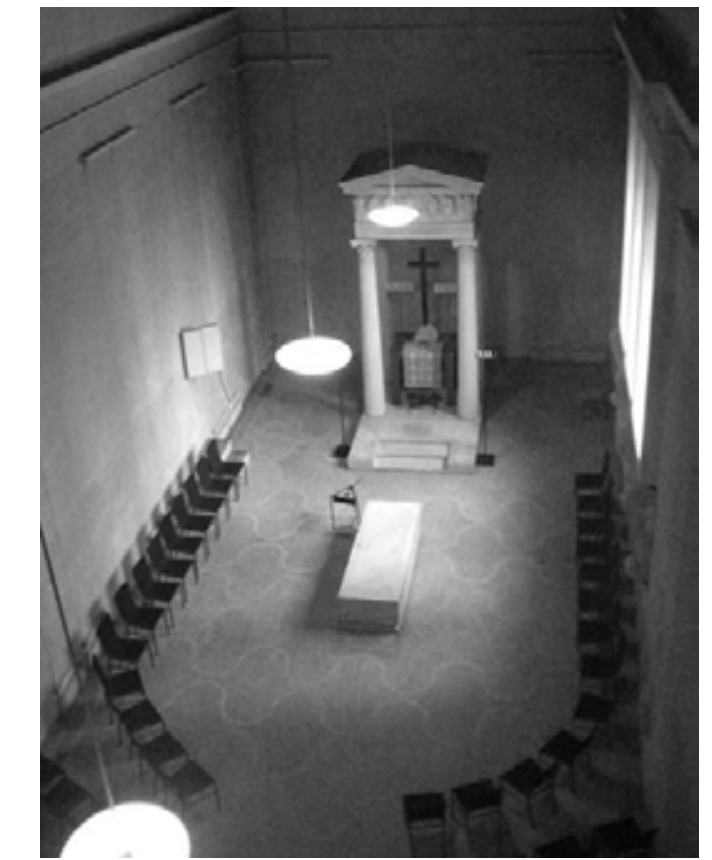

Fig 2.111. Chapel of Resurrection interior.

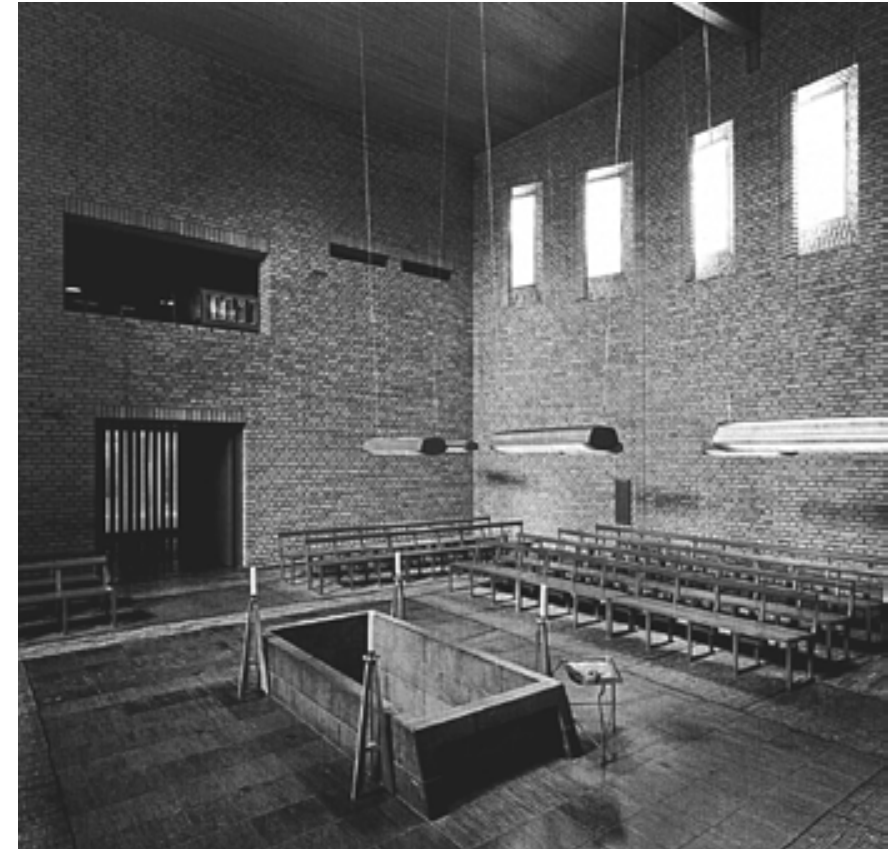

Fig 2.112. Chapel of St. Gertrud interior.

us to capture the fleeting images. And in this way, the route of farewell becomes a journey that indicates the meaning of life.

The same quality of an equilibrium between a reminder of human mortality and subliminal evocation of hope also characters his architectural space. Colin St John Wilson highlights Lewerentz's ability to invent metaphors: "His unflinching acceptance of the tragic view of life was embodied in an architecture whose aura embraced the physical fact and the metaphysical credo with assuring profundity." ${ }^{122}$ Material intensity of the two chapels' main hall provides another perspective to read the deep psychological roots and spirit of humanism in his design. The water-pattern pavement in the Chapel of Resurrection and divisions of different paving materials in the twin chapel highlight the position of the alter and the coffin, and at the same time provide particular things to focus on. (Fig2.111, Fig2.112.) It is as though Lewerentz is compelling mourners to confront the death, meanwhile allowing them to detach themselves from bereavement. When looking at the floor, gazing at the timber roof structure or looking out to sky through the high windows, those who are suffering from bereavement would have a short moment to confront the condition of their own existence. 


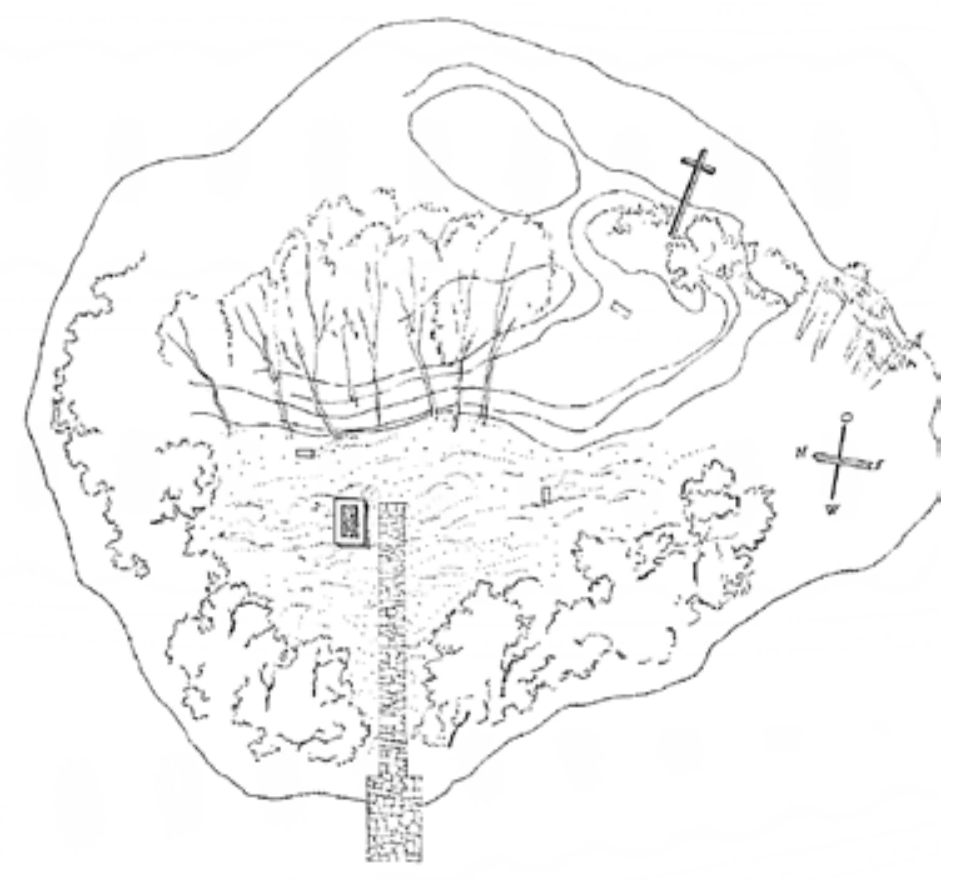

Fig2.113. Plan of the island, redrawn by Lewerentz 1963.

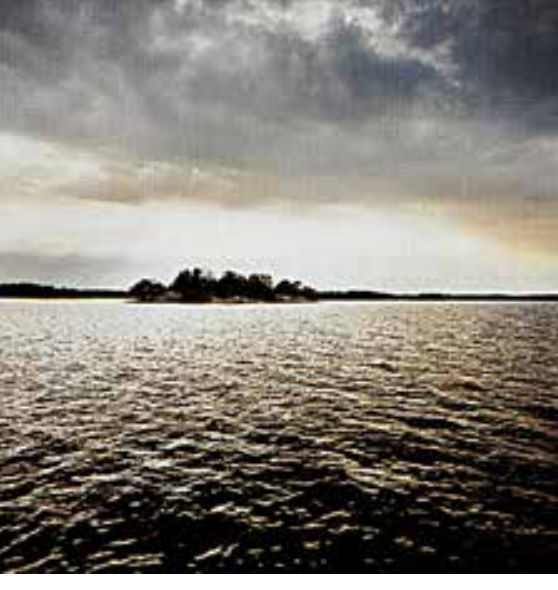

Fig 2.114. Utterö island.

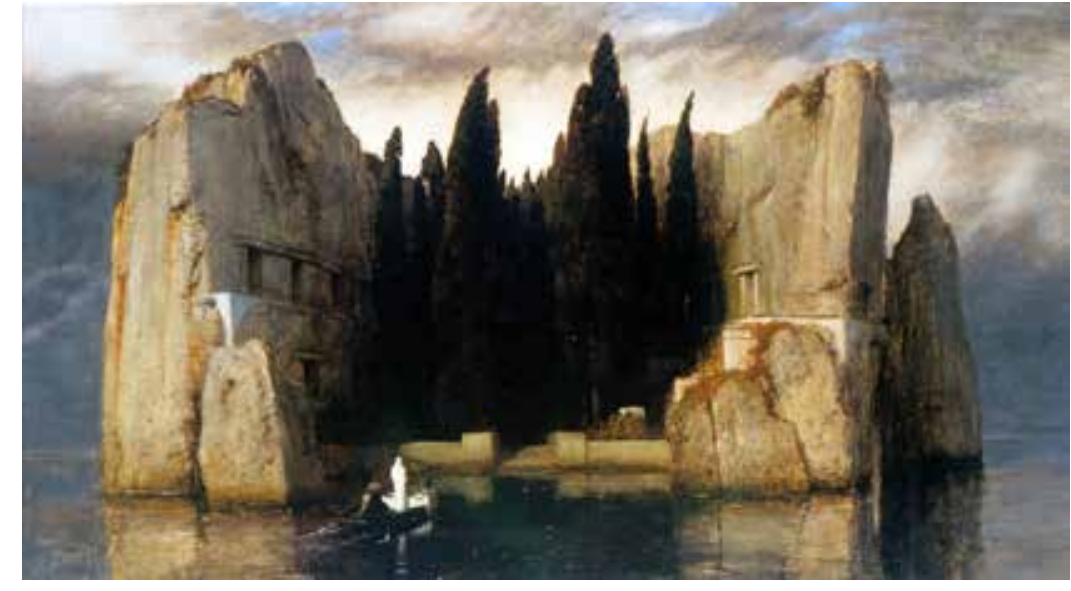

Fig 2.115. Isle of the Dead, Arnold Böcklin,1883

\section{CONCLUTION - A PROGRESSIVE APPROXIMATION}

In the 1914's Baltic Exhibition, the town commissioner of Helsingborg Gustav Schlyter devised the motto, "To death - To life", which raised the duality in the design of funeral architectures and cemeteries upon the call of the movement of burial reform in Sweden. Lewerentz declared his ideas in the never published article "Modern Cemeteries: Notes on the landscape", by indicating the most important character in a burial place space as "an atmosphere of peace and quiet that the surroundings must emit, allowing the visitor to spend a few moments in tranquil silence at the graveside."

In Lewerentz's long career, while his architecture designs have been through grea changes in styles, materials, compositional and constructional strategies, character in his cemetery space has stayed permanent. In the last landscape and on the itinerary organized by the architect, one would soon have an impression of loneliness which derives from, first and foremost, a direct encounter with the grand view of the nature. In a manner reminiscent of the painting of Caspar David Friedrich, Lewerentz reproduced a set of natural figures and kept interval between them to stress their individual significance, allowing the possibility to generate multiple narratives according to the respective bond with the mourner. This opposition that augments the relation between visitors and the grand landscape is established and further developed by Lewerentz's capacity of controlling the distance between people and the scenes with which they are facing. A sense of remoteness that we acquire from the first moment in his cemeteries may come from the elements that are much different in scales, as well as the intense changes between open and closed space. All these elements create an atmosphere both solemn and sublime, which, on the one hand, causes alienation from the experience of everyday life, and on the other hand, suggests the varying episodes that will constitute

123. Lewerentz, "Modern Cemeteries," 45 the experience during the approximation to the buildings and place of remembrance. Obeying the topography, Lewerentz laid out itineraries to show the manner of transit as penetration through variation of dimensions. This process deepens visitors' perceptions, from the general landscape to the very detailed conditions, corresponding to the switch of their identity from a bystander to an inhabitant in the sentimental space, thereby movement becomes crucial factor in the rite of farewell.

Among all the executed ceremonial works of Lewerentz, the 1929's design, the private burial site for Teodor Bergen's family in a small island Utterö in the Stockholm archipelago, explicates in a modes way his strategy to achieve the rituality. (Fig2.113.) Lewerentz reorganized the isle to make it as a sacred place with minimum things, a stone pier and a short pathway contribute a short route to the central part where the grave slab is laid on a low platform, a wooden cross close to the sea against the distant horizon.(Fig2.114.) Lewerentz composed a progressive itinerary through a program involving different distance. The island's calm horizontals and verticals evoke a sense of stillness and other-worldliness from Arnold Böcklin's "Isle of the Dead". (Fig2.115.) The sailing mourners' gaze is led over the water to the monumental terrain but can penetrate no further into the darkness, that stimulates their expectations along this lasting approximation.

Contrary to the long wait for arrival, the short route after climbing up the dock, which professor Luis Martínez Santa-María regards as a transit beyond expectation, provides an intense walk: "Su objeto, que parecía con toda evidencia ser la tumba parece cambia en el último momento, el camino para en seco, ha llegado a su sitio y reconoce en ese no saber seguir su más profimdo sentido: en cortarse de repente. ${ }^{124}$ The horizontal

124. Santa-María, "El árbol, el camino, el estanque," 79. 

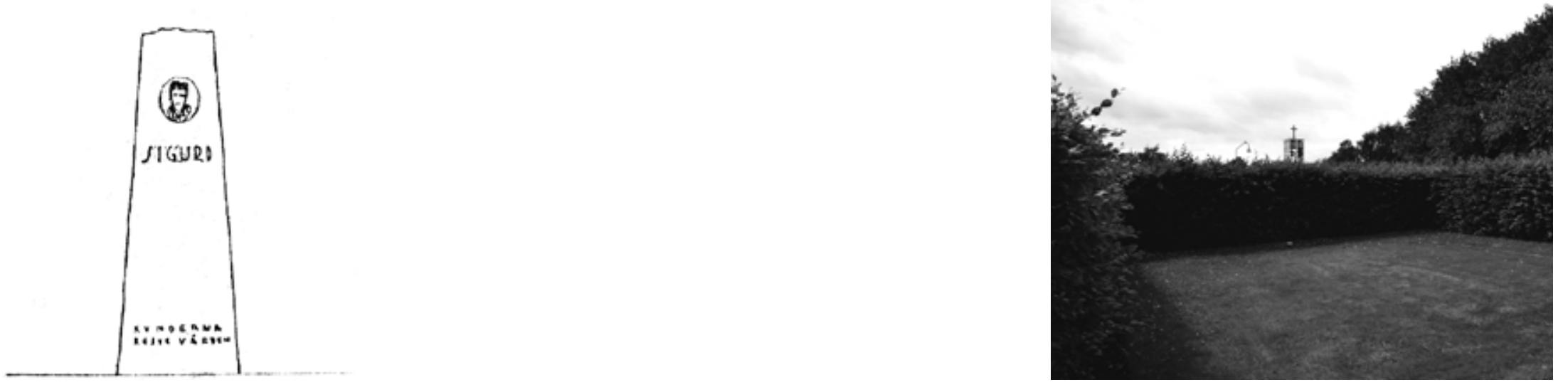

Fig 2.117. Lewerentz's design of his own gravestone.

Fig 2.118. The plot where Lewerentz's ashes were thrown

slab set aside the pavement deflects visitors to the soil, making them standing on the same earth that was used to construct the tomb. (Fig2.116.) In this directionless place, everything is placed at close distance to present a compact spatiality for contemplation and commemoration. This introspective felling ends when people look up to the break in the encircling fir trees. Though without route, the cross on the top indicates an ascent that penetrates the enclosure to the shore, leaning people's gaze again to the sky.

The Bergen's grave presents a particular route of going towards, even in a deflected way, an isolated and suspended precinct. It shares a similar configuration with itineraries in Lewerentz's other cemeteries, above all, the most representative works, Stockholm Woodland Cemetery and Eastern Cemetery in Malmö. By incorporating the Scandinavia plateau, forest and sea with a sentimental itinerary, the architect searched for the narrative of the landscape of remembrance, attempting to establish the relationship of life in the vivid world and death in the tranquil place.

"Out here in the archipelago's hideaway

in the lily of the valley's house

together we wish to dream

and slumber to the murmur of the sea wind."

The inscription on the grave slab of Teodor Anton Bergen describes the ideality of everyone's last place. Lewerentz designed the gravestone inscribed with his wife's name and and his. However, it was not executed. His ashes were thrown, in an anonymous way, on the grass plot in front of the St. Knut's Chapel. (Fig2.117, Fig2.118.)

125. Claes Dymling and Wilfried Wang, Architect Sigurd Lewerentz Vol.I Photographs of the

work. (Stockholm: Byggförlaget, 1997), 110. The original inscription was in Swedish. 
Chapter III .

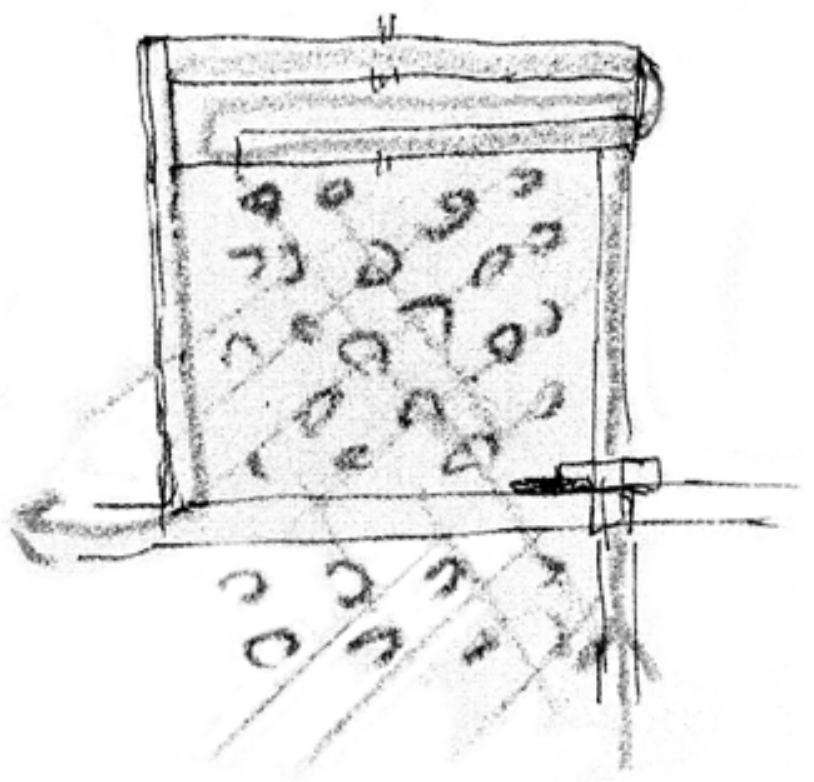

THE ROOTING OF DETACHMENT

Francesco Venezia, the anomalous monuments of in Belice 

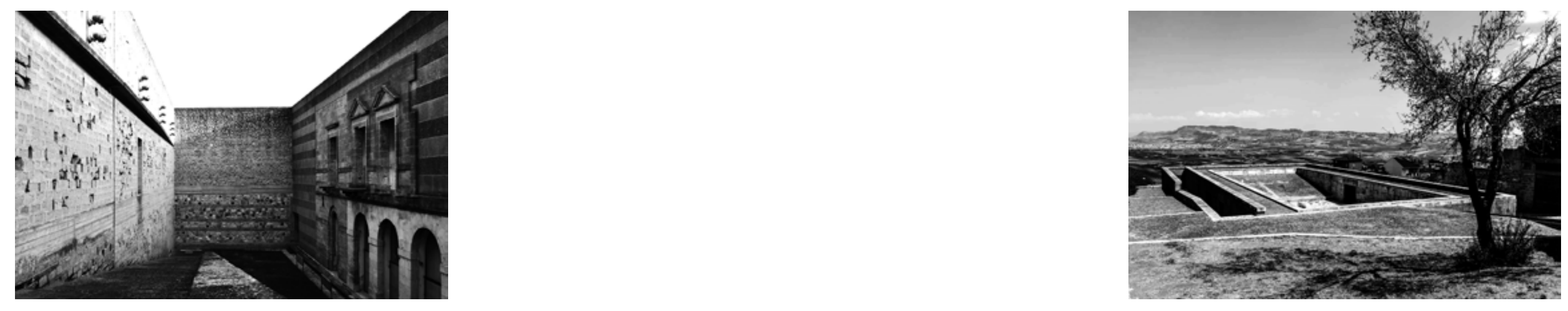


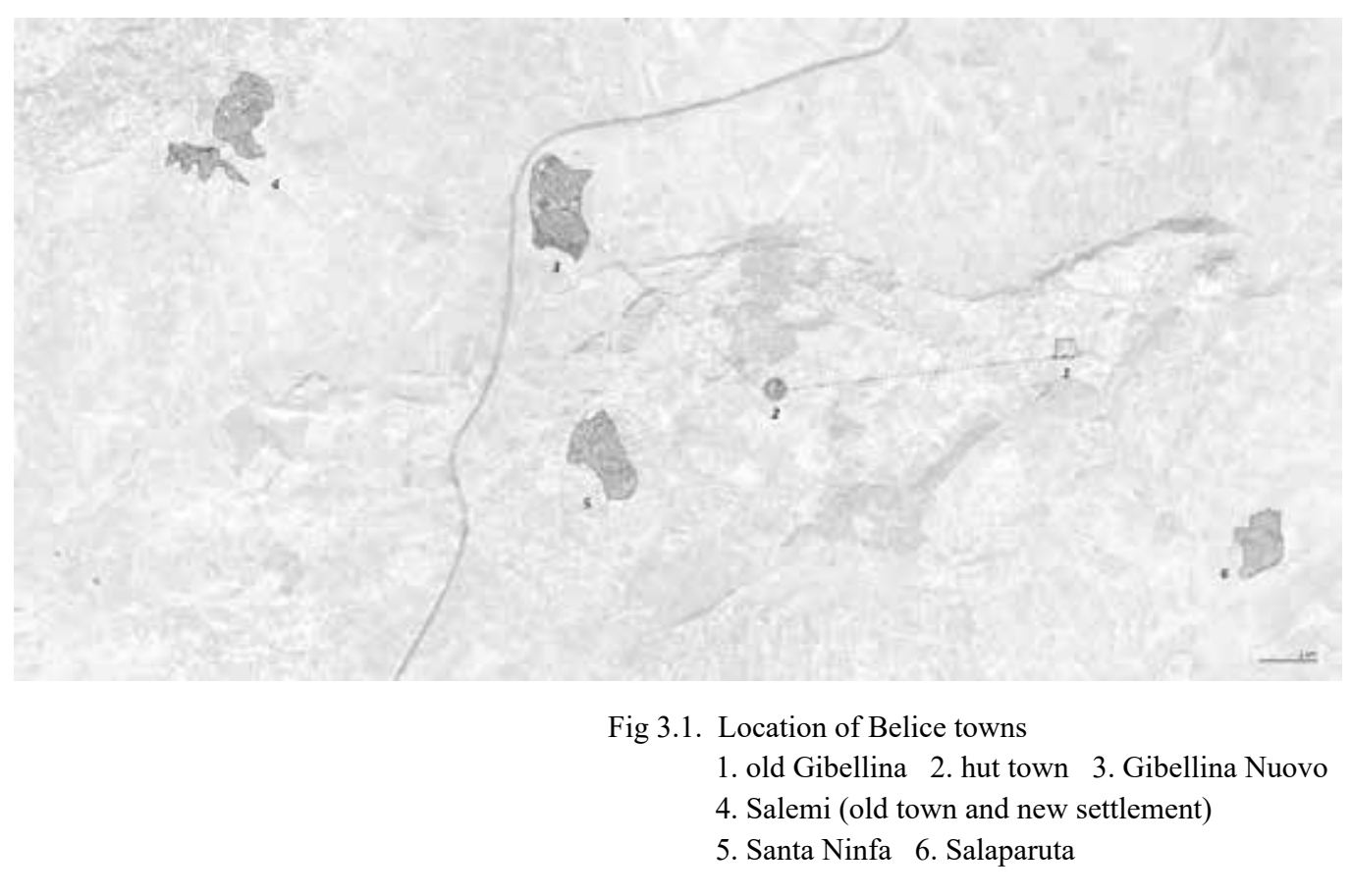

\section{REDEEM FROM EXCLUSION}

"Go out to the roads and country lanes and compel them to come in, so that my house will be full."

In his book Madness and civilization ${ }^{126}$, Michel Foucault points out that with the advent of modernity, the "rule of exclusion" has been established to form the social discipline to defend the dominant paradigm. Its meaning is to grasp from the great division fixed between the irreconcilable parts: the normality and the madness, the group and the individual, the center and the frontier. Thinking about this power cultivated from a centralized environment and its exercising through "marginalization", we will be inclined to change this quote:

“... compel them to disappear..."

Half a century after the earthquake struck the Belice Valley, western Sicily, in 1968, and almost thirty years since the reconstruction work left in unfinished, the transformation which was conceived to establish a paradigm of town planning, of new life and new order, is proved to be a failure today. What we see, as the shipwreck of modern design, is in a certain sense the outcome of a program on the basis of exclusion. Physical distance from the abandoned towns to the new settlements elsewhere (Gibellina Nuova, Calatafimi) breaks connection of the inhabitants with their emotional home; meanwhile

126. Michel Foucault, trans. Richard Howard, Madness and civilization: A history of insanity in the age of reason (New York: Vintage, 1988). the absence of proper articulation between the old centers and the new sites at close distance (Salemi, Partanna, Salaparuta, etc) yet isolates the contemporary patterns from the traditional structure. (Fig.3.1.)

Meanwhile the compulsory mobility stresses "the uncertainties of people who no longer fell secure on the earth" ${ }^{, 127}$ as territorial continuity is excluded from the new reality under a constructive fever, the analytical configuration, embodied in its functionalist basis, underlines the accentuated reduction of temporal narrative of the settled communities. In those new towns, space divided in functional zones supplants the old scheme of high density and mixed functions that formally represent the original social complex. Hierarchy between center and countryside is flattened that reduce the boundaries to unlimited expansion or sharp intervention of infrastructure. Excessive complexity in the new settlements gives rise to the ignorance of nostalgia and memory. Just like those art works of minimalist and abstraction being placed around the neighborhoods yet finding difficulty to accommodate themselves into the local communities mainly made up of peasants, the ephemeral, less inhabitable character of the reconstructed towns denies any reference from the old time for oblivion is recognized ${ }^{128}$.

127. Pierluigi Nicolin, "Gibellina: un centro storico per la città nuova," Dopo il terremoto/After the earthquake. Quaderni di Lotus 2.(1983): 10, Milano: Electa.

128. By excluding vestiges from the disaster, modern urban appearance is imposed on this agricultural terrain to respond to the "geographical restlessness", because "from no longer we were to believe that they had never existed, and from never having existed to concluding that they cannot exist here." Nicolin, "Gibellina," 11. 


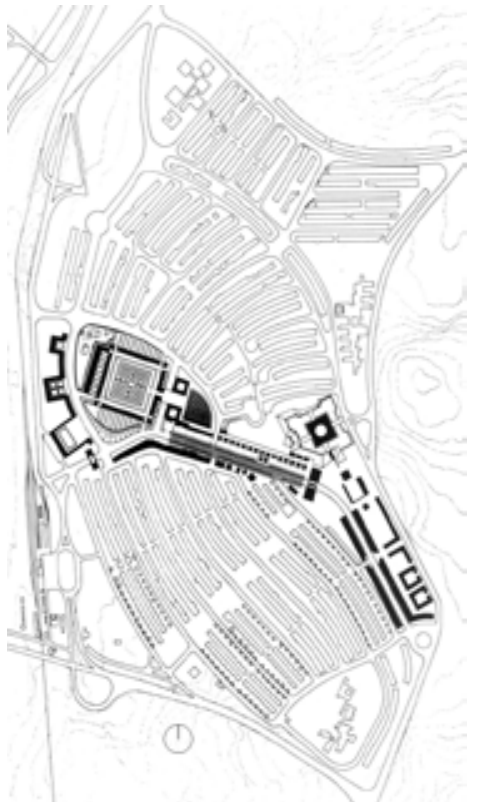

Fig 3.2. Old Gibellina and Gibellina Nuovo.

Parallel to the general planning ${ }^{129}$ based on modern functionalism, oppositions are seen from the field of architecture. Ambitious works of masters as Ludovico Quaroni, Franco Purini, Vittorio Gregotti, O.M. Ungers gave rise to the critique on the standardized buildings yet drove architectural narrative to introverted issues, showing the link between the ideology of architectural design and the blossom of postmodernism since the late $60{ }^{130}{ }^{130}$. The curvilinear theatre and the mega star-shape sculpture "Stella" by the artist Pietro Consagra in Gibellina Nuova ${ }^{131}$ show the common obsession shared in these constructions: typology and syntax. The experimental ideas are taken as primary value beyond history and territory to formulate a purely intellectual language of architecture that "divides the experience of the architecture in independent levels" 132 , offering a certain contribution to the heroic and senseless scenario to the town with no roots.

In this bizarre collage of architectural ambition and more or less spontaneous 129. Among all the stricken towns in the Belice Valley, scenario of the reconstruction paradigm
is more clearly to see in the case of Gibellina Nuova since the new built town has no restriction from the old Another new settlement, Calatafimi, planned as a "Spa town", has been lying there uncompleted and unused.

130. The recovery of Belice Valley was soon accompanied by the blossom of Postmodernism in Europe, just think about the intense publications on the critique of modern architecture since the latter half of the 1970s: Charles Jencks' The language of Post-Modern Architecture (1977); the 2nd edition of Robert Venturi's Complexity and Contradiction in Architecture (1977) and Learning from Las Vegas (1972), collaborating with Denis Scott Brown and Steven Izenour;
Rem Koolhaas' Delirious New York (1978); Colin Rowe and Fred Koetter's Collage City (1978); Rem Koolhaas' Delirious New York (1978); Colin Rowe and
Paolo Portoghesi's After Modern Architecture (1980), etc.

Paolo Portoghesi's After Modern Architecture (1980), etc. 131. Some of the most compelling works in Gibellina Nuova are Ludovico Quaroni's Chiesa Sistema delle Piazze and private house Casa del Farmacista (1980) of Franco Purini and Laura Thermes, Piazza del Comune (around 1971) of Vittorio Gregotti and Giuseppe Samonà, Torre Civica (1988) of Alessandro Mendini.

132. Nicolin, "Gibellina," 10

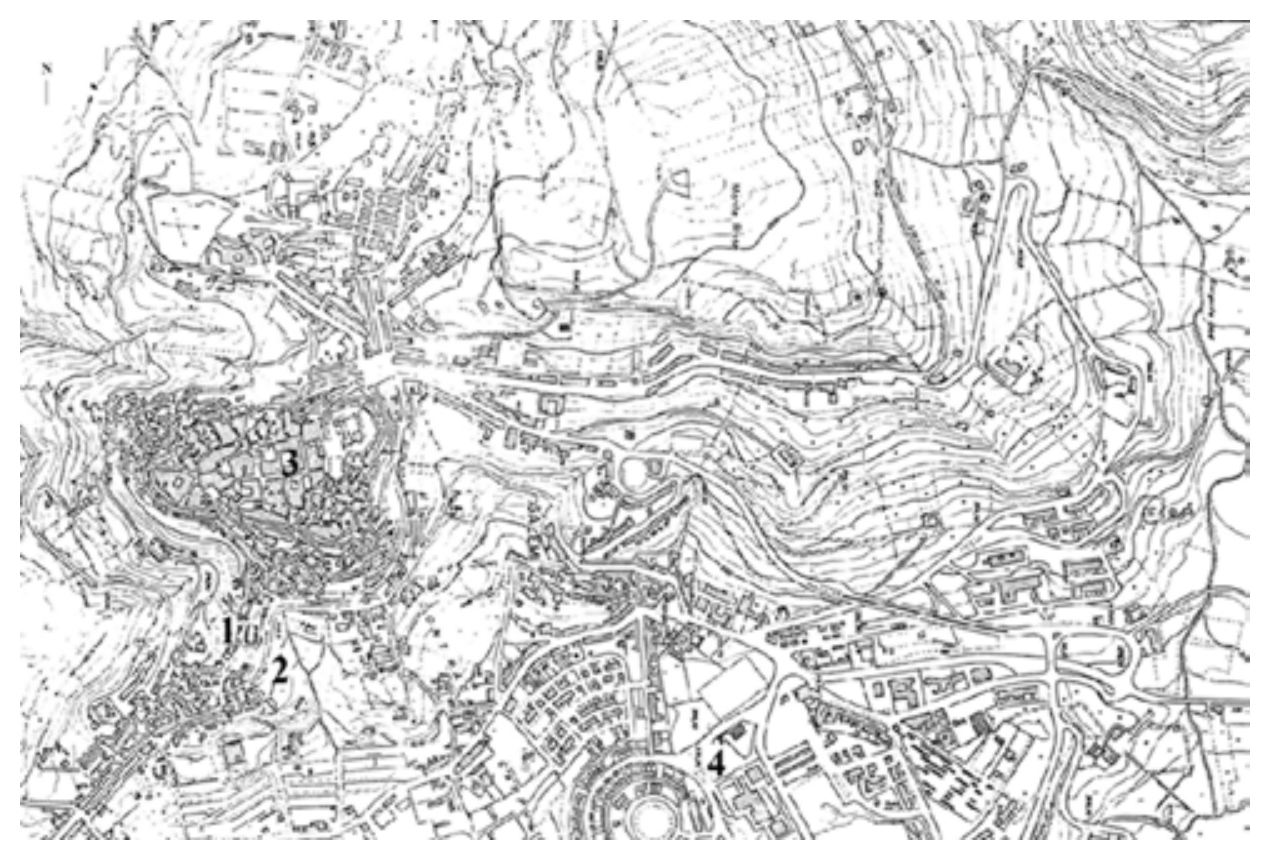

Fig 3.3. Plan of restoration of Salemi. 1. the open air theatre. 2. space for public garde 3. Madre Salemi church. 4. new settlement

construction through exclusion, those works designed by the Neapolitan architect Francesco Venezia in the neighbor towns seem to be exceptional, even strange productions: in Gibellina Nuova, a walled Museum (1981-87) whose courtyard is installed with a remounted facade of the demolished Palazzo di Lorenzo from the old town, a small garden (1985-88) and a pavilion(1986-91) ${ }^{133}$;(Fig.3.2.) and in Salemi, an Open-air Theatre (1983-86) built upon the ruins of the old convent overlooking the landscape.(Fig.3.3.) As a member of Laboratorio $80^{134}$ called on the late 70 's, Venezia revalued those fragments left by the catastrophe and conceptualized projects for the territory to be compensated. His work is distinguished not only by the meditation on the past, but also by the implementation as an excavation that relates architectures to the subterranean world.

"Digamos que en Sicilia son trabajos ... que tienen como objetivo aquello de probar una idea... Esto es verdad porque lo que llamamos teatro no es el teatro, el museo no es el museo, es necesario darle un nombre burocrático ... Son edificios que no son identificables de este punto de vista.En este sentido son edificios anómalos." ${ }^{135}$

Both of the buildings are located in the outmost area of each town: the museum

133. Besides the three famous works, Venezia also made a less known rehabilitation of a concrete structure to a commercial building at Gibellina Nuova, which was finished in 1987. 134. While the responsibility of continuing the reconstruction had been given to municipal authorities, the workshop Laboratorio 80 is called to gather prestigious architects and scholars around Europe to Belice aiming at "modifying the criteria that had previously guided the reconstruction of the stricken towns."

135. Aldo Hidalgo, "Francesco Venezia: temas de arquitecturas," Arteoficio, no 4(2005):47-51, Santiago: Editorial Universidad de Santiago de Chile. http://www.revistas.usach.cl/ojs/index. php/arteoficio/article/viewFile/842/794\#. 


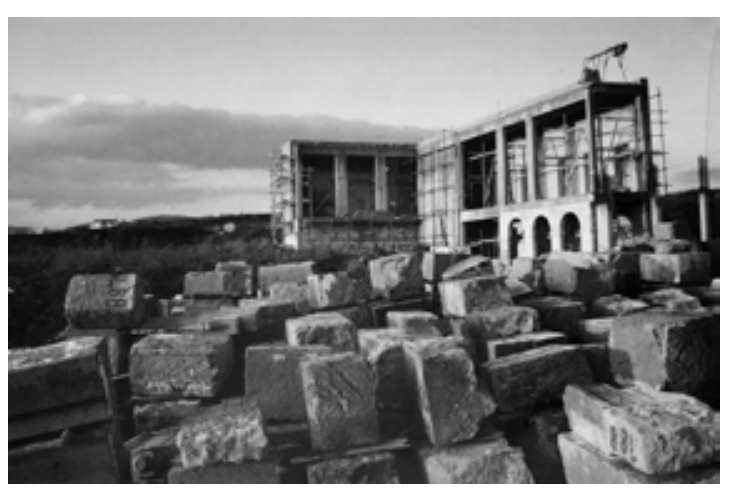

Fig 3.4. Gibellina museum in construction.

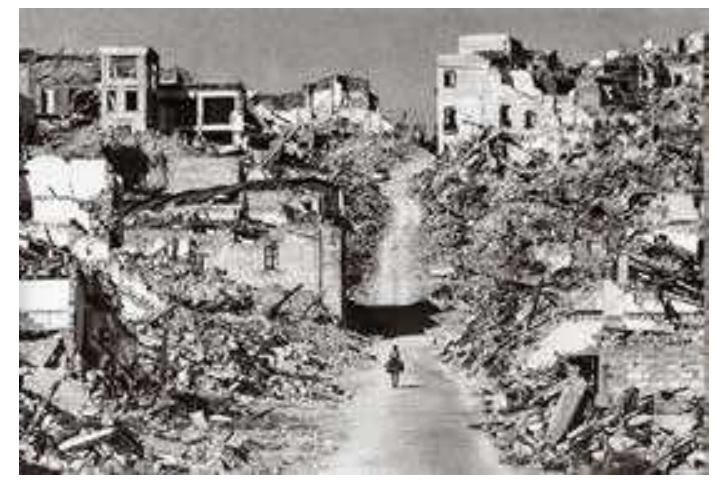

Fig 3.5. Gibellina after the earthquake.

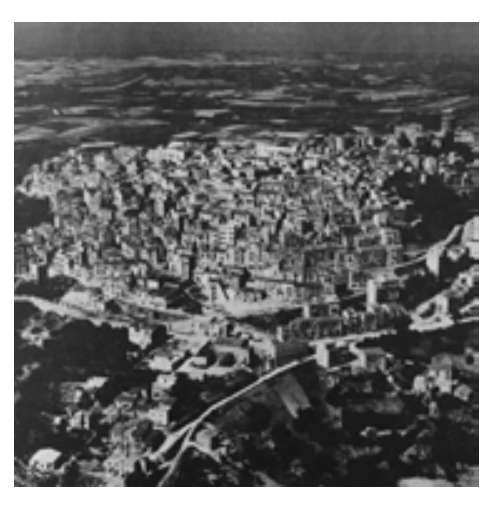

Fig 3.6. Salemi before the earthquake.

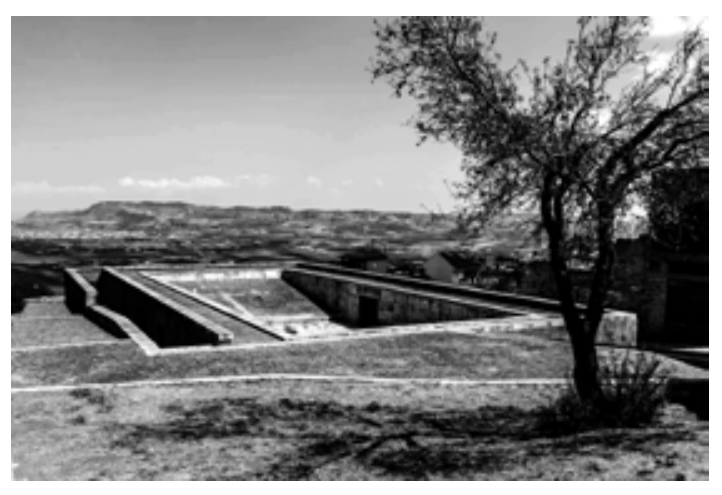

Fig 3.7. Open air theatre.

delimits the boundary of the new town and the vineyard to the countryside;(Fig.3.4.) and the sunken theater separates an order from the old Salemi center on the upper side to the field opening underneath. (Fig.3.6, Fig.3.7.)Austere appearance, frontier location and close relation with ruins give the two buildings a particular quality of detachment to "avoid the disadvantages of comparison with the new town." ${ }^{, 136}$ Instead of accommodating the buildings into the hospitality derived from the "bureaucratic titles" of "museum" and "theatre", Venezia created their own events, addressing them as monuments that provide rare opportunities to commemorate those realities behind the modern Belice - the telluric eruption, the destroyed and abandoned places, the trembling instant and following process of recovery.

Venezia insists that the formation of settlement is truly understood as production from its own territory. In the Belice region where such nexus had been disturbed and further flattened, The priority of Venezia's work lies on the recognition of the relationship between the building and the site, in order to revive the continuity of the memory and the territory.

The mechanism of detachment applied by Venezia in his buildings does not only come from the physical location on the marginal area, but also from an internal tension and vulnerable equilibrium resulted from the distortions and irregularities realized by construction and architectural itinerary, giving rise to an experience of a dialectical connection between architecture as monument and the place where it is located. An inclination of dysfunction can be found in the splits, the displacement and transgression that keep provoking people's perception in the museum and the small theatre. These ambiguous and contradictory qualities is not the production of ontological discourse on

136. Francesco Venezia, Francesco Venezia (Barcelona: Editorial Gustavo Gili , S. A.,1988), 42.

architecture, but is deeply rooted into the history of the territory. The monumentality of the museum and theatre is interpreted by the wholeness of architectural process, by the program as well as their articulation with the place and surrounding landscape.

Recalling the past reality is not a taboo for Venezia. As Paul Ricoeur raised the responsibility of time, "La carga del pasado que recae en el futuro insta a incorporar la noción de deuda, que ya no es pura carga, sino recurso, necesidad de relato." ${ }^{137}$, in Belice, the sense of estrangement from Venezia's monuments manages to redeem history and territory from complacency and ignorance, in which sediment of the past had been greatly dissolved.

37. Paul Ricoeur La lectura del tiempo pasado: memoria y olvido (Madrid: Universidad Autónoma de Madrid, Arrecife, 1999), 9. 


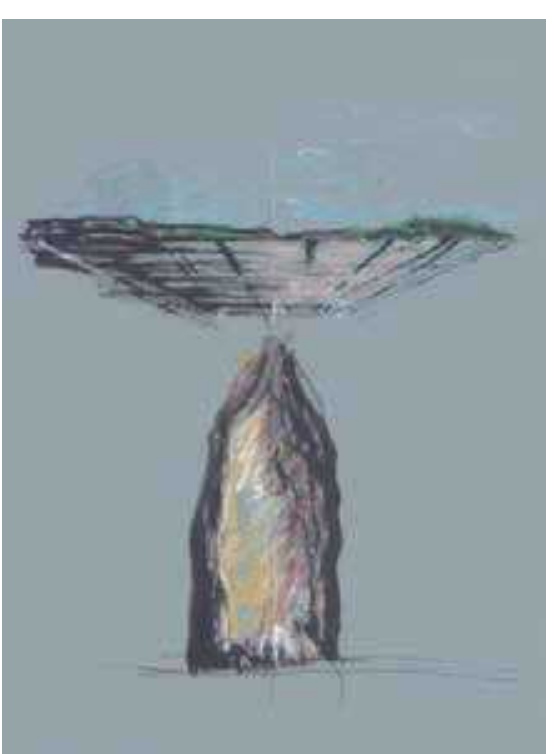

Fig 3.8 Syracuse theatre, sketch by Venezia.

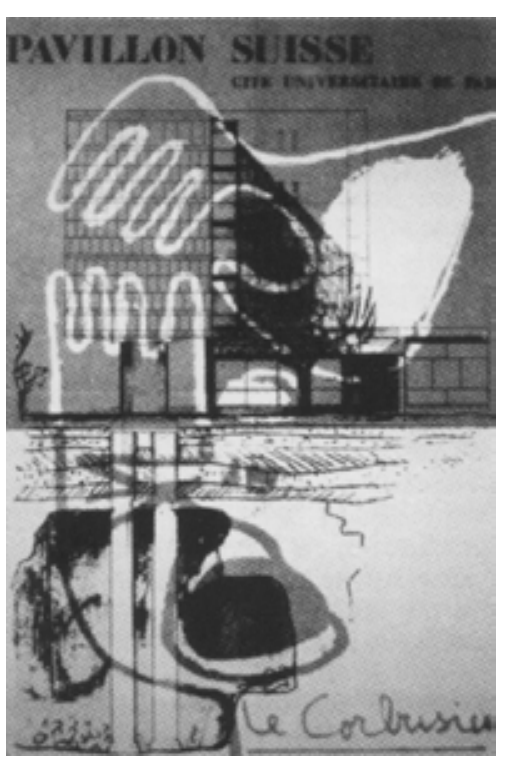

Fig 3.9. Swiss pavilion, Le Corbusier, 1930

\section{TOWARDS AN AUTHENTIC SITE}

Venezia stresses the importance for architects of viewing architecture and the ground as a whole, criticizing contemporary architecture for "having no more foundation, not based on a conceptual sediment, not based on a soil ". This regard is shown in his montage sketch in which juxtaposed Greek theatre and deep quarry in Syracuse show how architecture is implanted in the ground.(Fig3.8.) The image shares the same view with Le Corbusier, to whom Venezia constantly references, in his interpretation of the Swiss Pavilion, where a column penetrates into the earth and connects the modern building with ancient ruins. (Fig3.9.) Both of the architects are obsessed with linking the upper and underground space as a mirrored structure of construction site, and they are so much hit by the "twin cities" "138 of Naples and the tremendous ruins left by Vesuvius. Relations are established through the ground surface as irreducible interface between culture and nature. The upper world obtained by rapidly adding is formed on the basis of excavation from the invisible domain undersoil, obtained by slowly depositing. This metaphoric material supply reveals a process of inheritance, it leads to the essentia configuration of building site which has the capacity to balance constructive act and situation that exist prior to it. To achieve the subject as Venezia called "L'architettura del suolo", architecture becomes not only the product of matter displacement and testimony of temporal continuity, to which many edifices oppose today, but also the reflection of its root deep into the earth.

138. "Here we find ourselves in front of a section of Naples, a section in a sense 'Siracusana in which we can see the reality of the double city of Naples: the lower city - the thousands of cavities - and the upper city - the buildings under the sunlight. Reality that would surely hit Le Cobusier when he visited Naples."* (Note: Citation marked by "*” are translated by author.) Francesco Venezia, Che cosa è l'architettura. Lezioni, conferenze e un intervento (Milano: Mondadori Electa, 2011), 37
In Belice, the earthquake, the mass migration and the ambitious reconstruction greatly disturbed such structure of building site, in which its balanced essence has been broken by two crises: first, the fatality of the catastrophe and reconstruction resulted in removal of past images, and the second, the tendency of such profound memory faded into oblivion. Confronted with the two risks, the continuity that Venezia chased for in his projects is beyond stylish or aesthetic inheritance, aims to recover the picture of equilibrium, to reunite architecture and the earth occupied.

"The hidden forces are expressed - and therefore also place of horrors, and of earthquakes and landslides and sinking - and lush vivifying forces - exuberance in the variety of vegetation, inexhaustible wealth of flowing water." ${ }^{139 *}$

Apart from memories derived from the earth, the majestic landscape in Belice valley presents itself as sentimental terrain where pain coexists with hope. In terms of Venezia, excavating into the earth and tracing for the landscape dimension allow revealing the cultural and natural reality of the territory, from which configuration of an authentic site and the architecture are confirmed.

"Es en este paisaje que la historia reciente de Belice - el terremoto, la construcción de nuevos centros, y la transformación de sitios abandonados - se debe encontrar los

139. Francesco Venezia, Francesco Venezia: le idee e le occasioni (Milano: Mondadori Electa, 2006), 133 


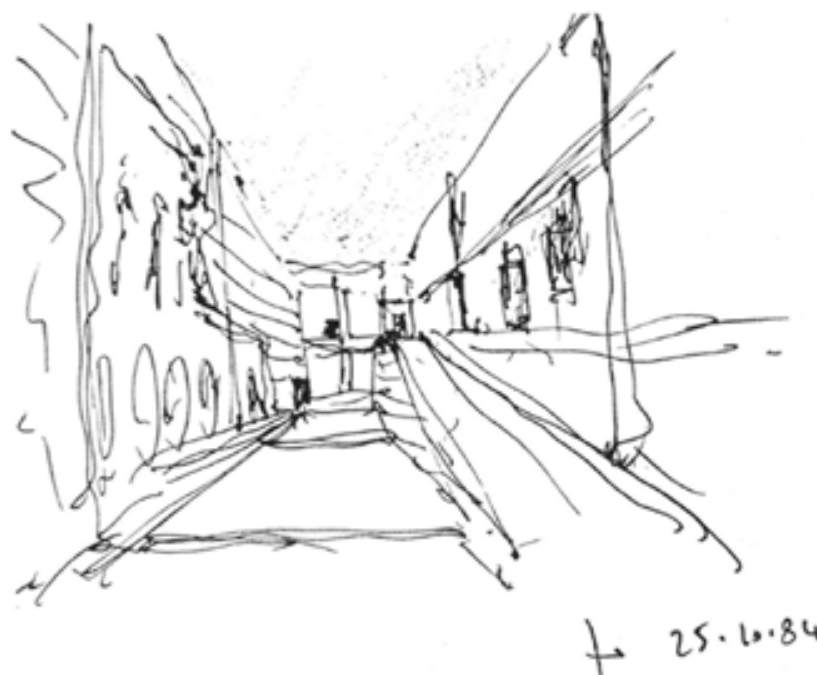

Fig 3.10. Gibellina museum ramp, Venezia.

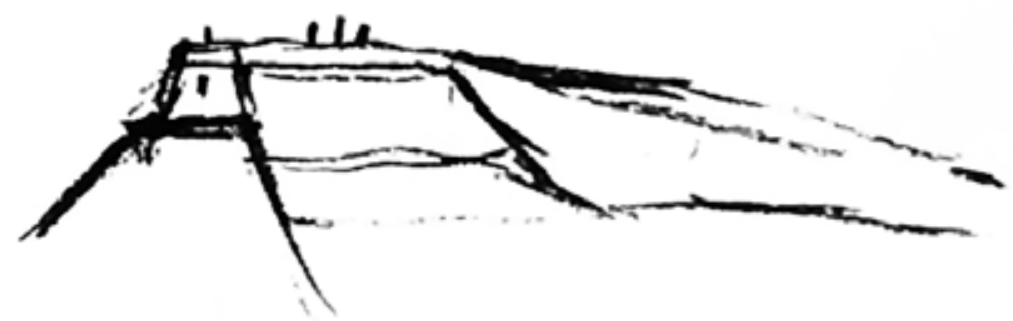

Fig 3.11. Salemi theatre sunken auditorium, Venezia.

recursos y su sentido." ${ }^{140}$

The opposing characters about history and topography in Gibellina Nuova and Salemi a new settlement without past images, and a old town built on mountain recovered from the disaster - challenged Venezia to give different strategy to manipulate the site of the museum and the theatre. He gives much importance to fit metaphors of the underground into each context while placing the wholeness of architecture and site to mediate the relation between landscape and the urban scenario. (Fig3.10, Fig3.11.)

By creating exclusive passages and making use of the preexisting one, Venezia takes people to the site and let them enter the museum and theatre. These two entryways that connect building with the city play a key role of involving people into the architectural narratives, from a variation of spatial dimension, materials, slopes and light, they contribute to progressive transmission, towards the essence of L'architettura del suolo. 


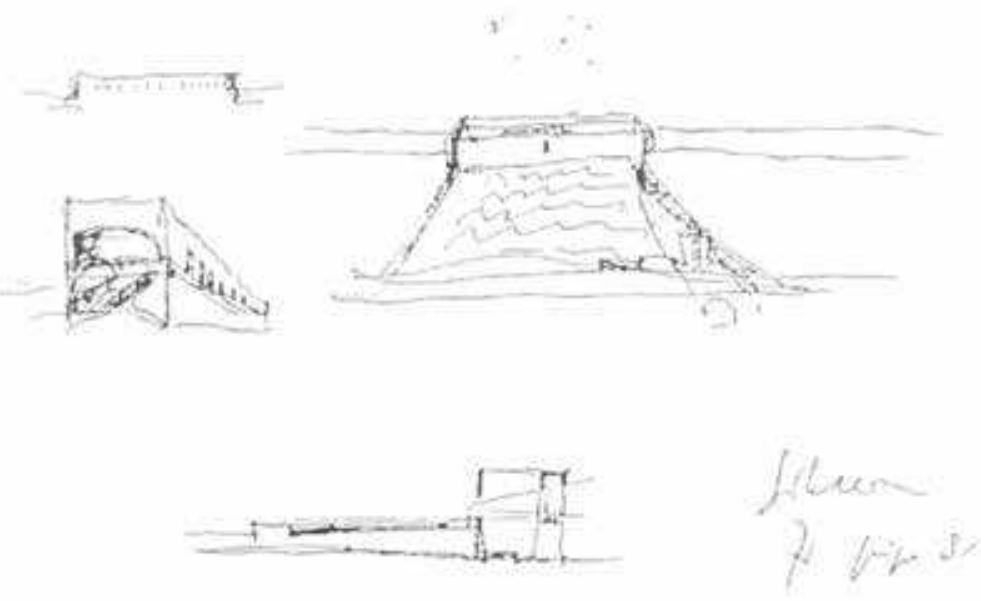

Fig 3.12. Gibellina museum and territory beyond, Venezia.

§ From the Underground

- multiple detachment

"The structure of Gibellina museum is simple, but gains a lot of strength to the fact that the building emerges as a ruin from the ground. The concrete structure washed, eroded, emerges from the wall of sandstone., ${ }^{141 *}$

The remarks of the architect suggest two main relations on which the museum is based: first, the external one that links the building as a whole with the ground, and second, the internal one that explains a dialectical connection between different parts of the building. Located on the edge of the town, the solemn appearance of Gibellina museum seems to question the rootless city about what does it really need. Instead o giving a technical manifestation or an eye-catcher landmark which were overwhelming throughout the reconstruction, Venezia looked deeply into the earth, trying to accommodate the architecture into the time and history of its territory.(Fig3.12.)

The terraced garden in front of the building based on the "continuation of the slope of the hill "142 acts as the medium that vertically separates the space, together with the ground underneath and the building facade emerges from its top, into three parts, reflecting the two relations in terms of different scales. The garden reserves, firs and foremost, the topographical character of the city and presents itself as manifesto

141. Francesco Venezia, "Temi - una conferenza a Toulouse," in Francesco Venezia: le idee e le occasioni (Milano: Mondadori Electa, 2006), 80.

142. Venezia, Francesco, 42.

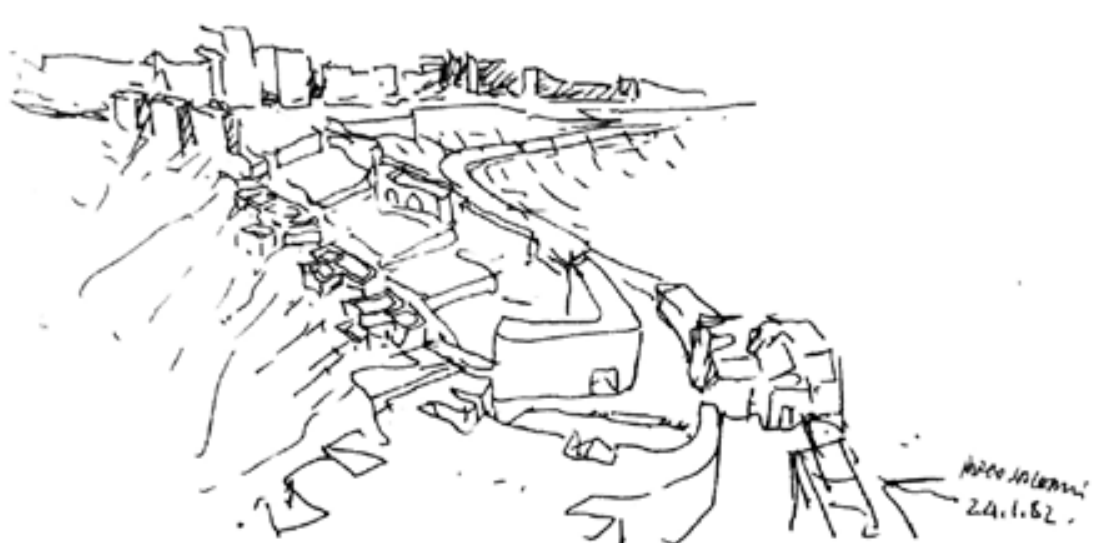

Fig 3.23. Terraces at Carmine Quarter before the theatre project, sketch by Roberto Collovà.

\section{A Theatre of transit}

the construction of cannibalism

The hybrid situation in Salemi formed by old elements and new constructions became the key character of the post-earthquake city. As Venezia insists "este ha sido siempre el esfuerzo de la arquitectura que se insiere en los centros preexistentes" ${ }^{\text {"145 }}$, the intensified dualities of this town, the new and the old, the urban and the rural, hills and plains, urged the architect to retrace the relation between the territory and city.

"The territory of Salemi ... varies at all points, and if eastward extension has almost platform, it is not so to the north and the south, where there are the mountains of the Sette-Soldi, those Poliso, the others of San Ciro, Pussellesi, Torretta etc ... It is bordered to the north with the territory of Calatafimi, Vita, to the east with the one of Santa Ninfa, Partanna, southwards with that of Castelvetrano and Mazara, to the west with that of Marsala and Trapani. With the great river, which converges various other channels of rivers crisscross the territory of Salemi, which goes to discharge into the sea of Marsala, and that of Collura, putting the mouth on the beach of Trapani “ “146*

In an article about the theatre, Venezia quoted this cartographical description of Salami to show its extraordinary topography made of rivers, ocean and mountains. Following

145. Aquiles Raventós González and Claudio Vásquez Zaldívar, Due Case, Tre Edifici Pubblici: La Arquitectura de Francesco Venezia (Santiago de Chile: ARQ, 1994), 45.

146. Francesco Saverio Baviera, Memorie istoriche su la città di Salemi connesse con dei rapidi tratti di storia siciliana (Stamp. di F. Spampinato, 1846), 203. 


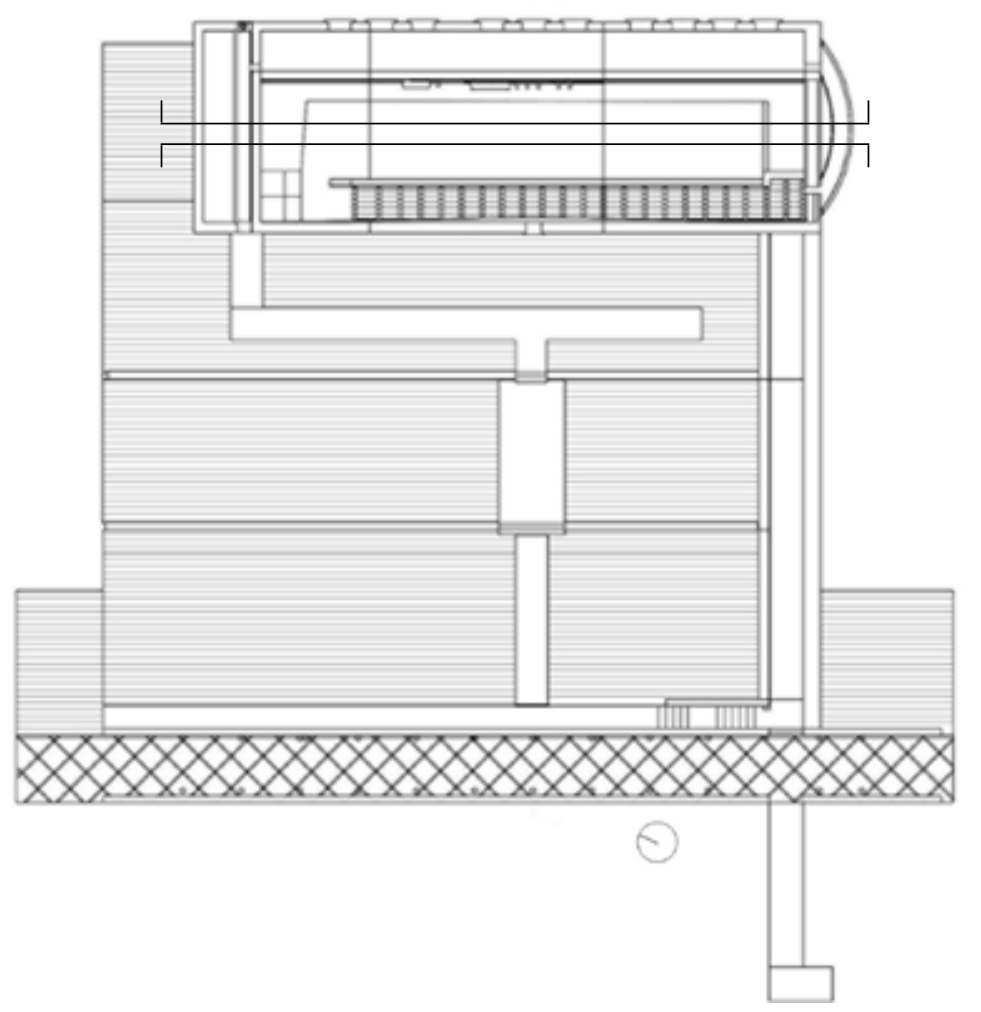

Fig 3.13. Gibellina museum plan, drawn by author

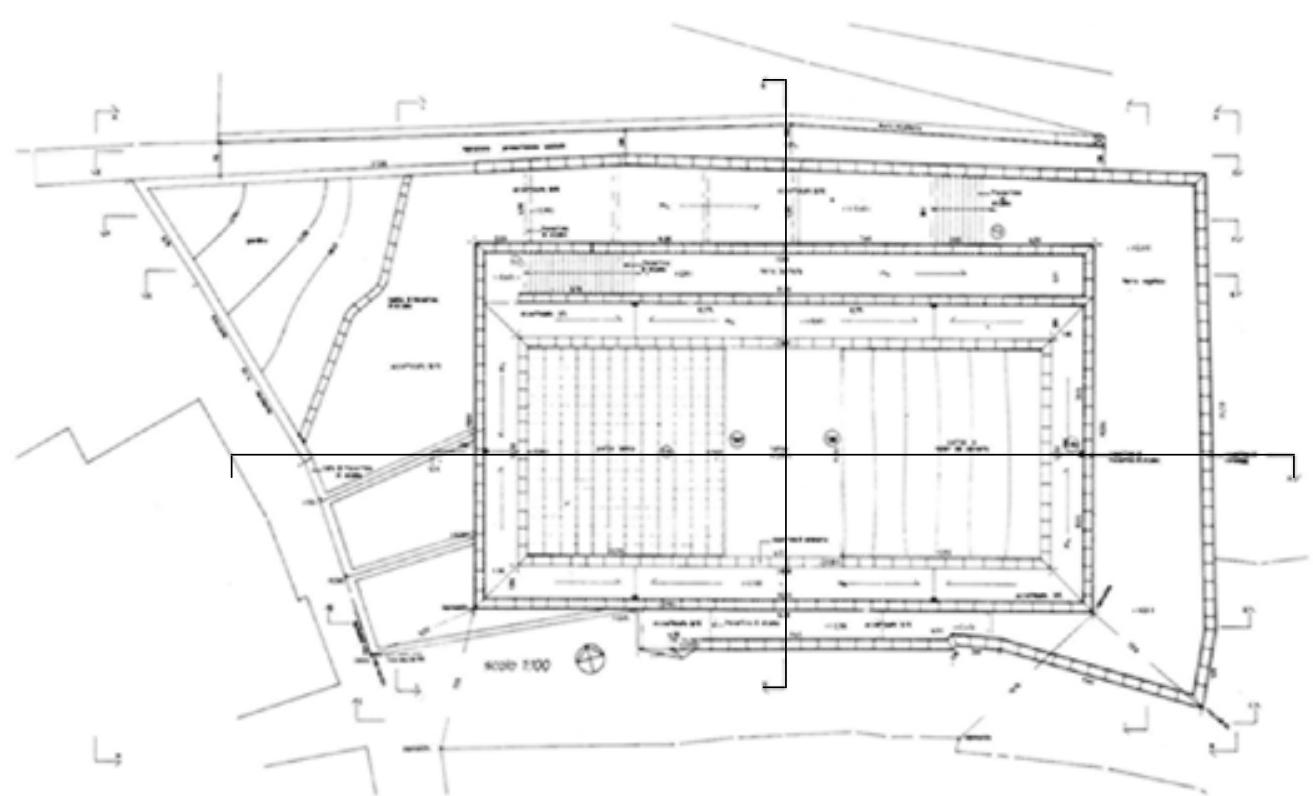

Fig 3.24. Salemi open air theatre plan.

these words, a close look is applied by Venezia on the urban fabric around the site where where "houses rooted in unequal levels ... misleading and blind streets, for which nearby places are unreachable, yet in continuous dialogue with the horizons and the path of the sun..." ${ }^{147}$ The zooming observation of Venezia between the cultural and the natural aspects of the city, as Heidegger's regards of "the culture of the world creating work and the nature of the earth", are so essential to understand the idiosyncratic character of the Carmine Quarter where the theatre is located

The Carmine Quarter on the edge of the old town was conceived as a public garden to articulate with the adjacent new settlement.(Fig3.23.) A series of controlled demolitions were implemented to transform the area into continuous terraces, of which the top plot occupied by the Church and the convent of Our Maddona del Carmine ${ }^{148}$ were cleared up for the open-air theatre. To these interrelated facts must be added the catalytic role which Venezia assigns to draw in both resurrection and innovation.

"... It consists in the construction of the first two terraces in the center area of the neighborhood: the highest is constituted as a small square, through inclined planes, is connected to the main road; the lowest covers the surface of the old basement of the church and convent of the Carmine, to form the roof decking for outdoor

147. Venezia, Francesco Venezia: le idee e le occasioni, 133.

148. Fully realized in 1555 , the church of an aisleless and six-side chapel, and the Carmine convent with a courtyard portico, which occupied the site, had undergone centuries' degradation, reformation and function changes before the final collapse prior to the 1968's earthquake. Among all, the one of the latest addressed the complex as private houses, barns and warehouses since the year of 1866 

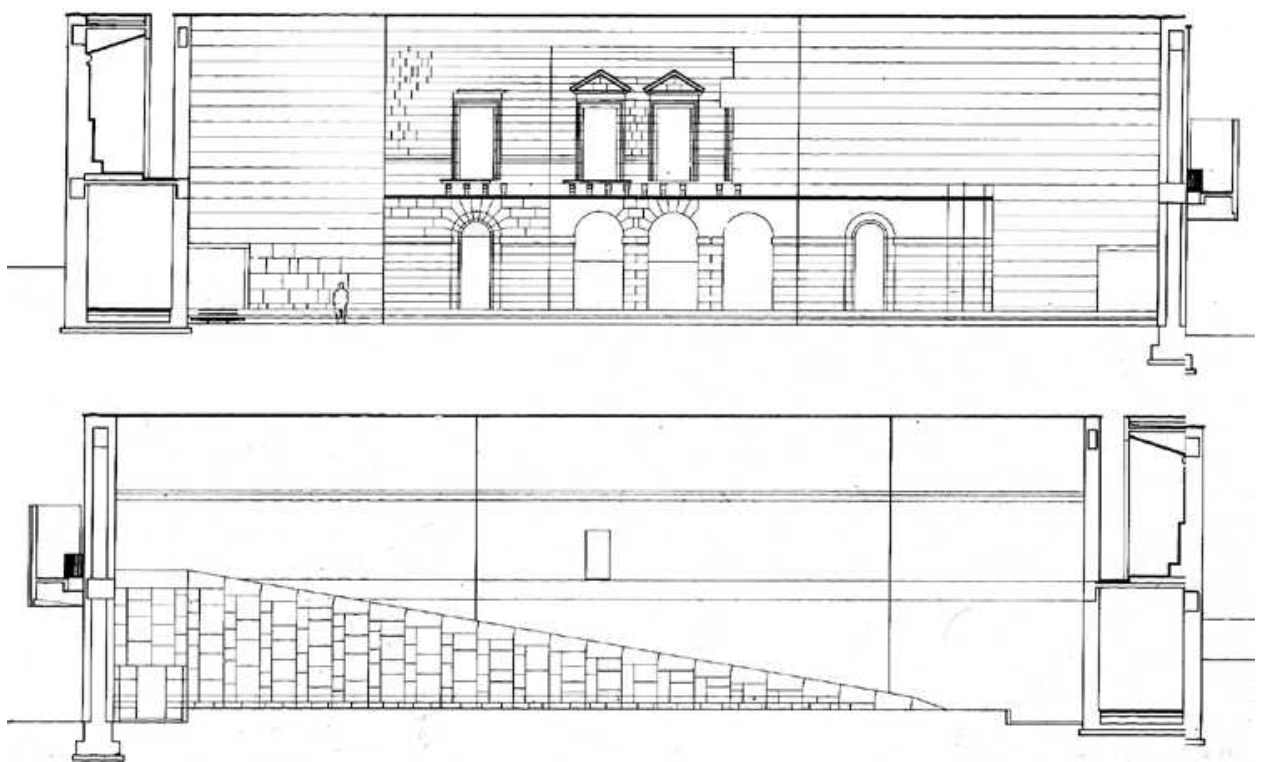

Fig 3.15. Gibellina museum long section.
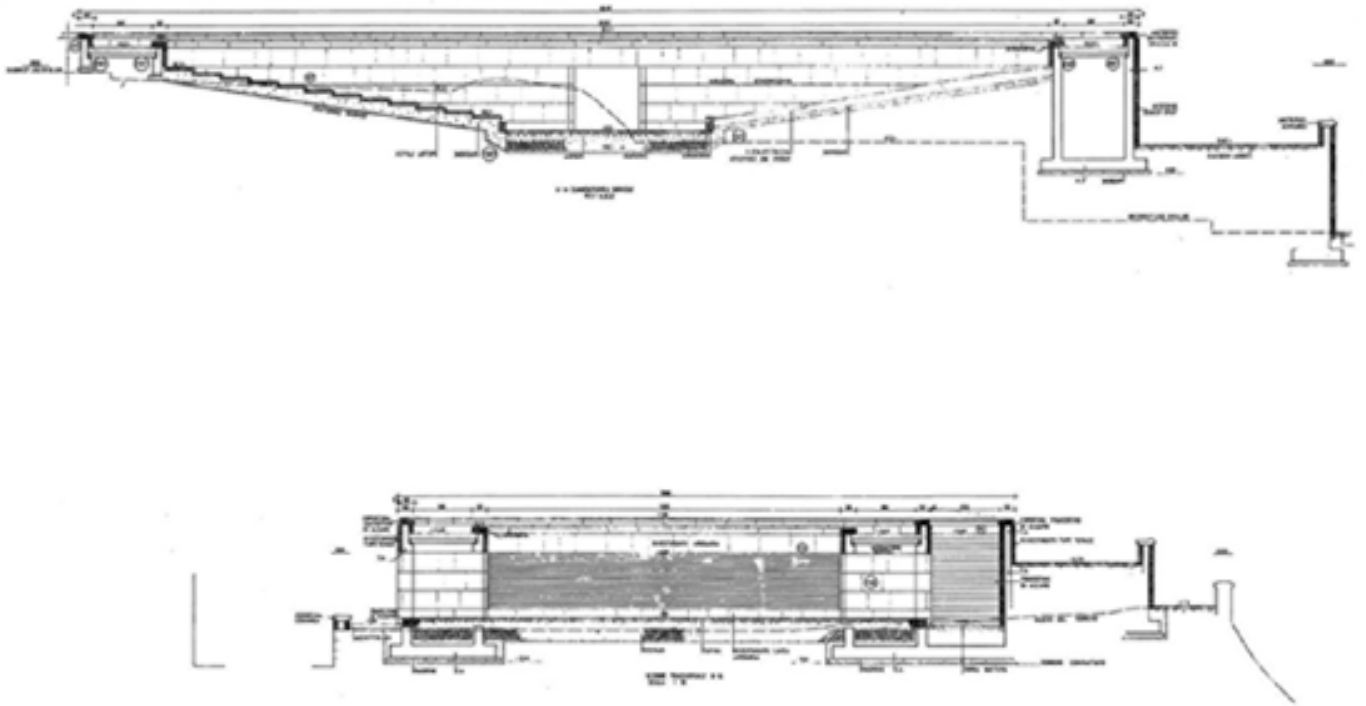

Fig 3.25. Salemi open air theatre sections drawings (dashed lines illustrate original ground) auditorium.. ${ }^{149,}$

Meanwhile the sense of continuity remains crucial to the architectural narrative, respective concerns of city roads and ruins, as well s different uses of geometry and materials highlight the separation between the top and the bottom of the theatre. The auditorium on the top devoted to a sunken space of pure geometry enclosed by the walls of travertine and sandstone, is superimposed on the elevated base which was constructed with fragments of demolished buildings and shaped according to the preexisting boundaries on site. Venezia has made fully use the terraced topography to present the central cavity as excavation into the earth without digging into the original ground surface. (Fig3.25.) The sacred place where religious ceremonies were held, now is occupied by an open facility for public activities. Manifest here is the building strategy that, as Venezia calls "Cannibalism" which inherited from the ancient Egypt, remains of the old buildings were dedicated to the formation of new forms. As a historical palimpsest of modern scheme, recycling of materials and formal variations are the key factors to present the theatre as dialectical continuum of the old convent.

The differences between the two parts of the theatre see a transmission from the bottom to the top that suggest Venezia's strategy to conceive the site and the building in terms of history and topography. The architect orgnized the orderless site as a single ground, into which the building is rooted and speaks of memory and connection to the earth. The bottom part of the theatre provides a foundation that supports the upper structure;(Fig3.26.) while on the top, the square and auditorium give a new evenness

149. Roberto Collovà and Marcella Aprile,"Francesco Venezia Open Air Theater," Divisare, June 11, 2009, https://divisare.com/projects/99508-roberto-collova-marcella-aprilefrancesco-veneziavaleria-tripoli-orazio-saluci-open-air-theater. 


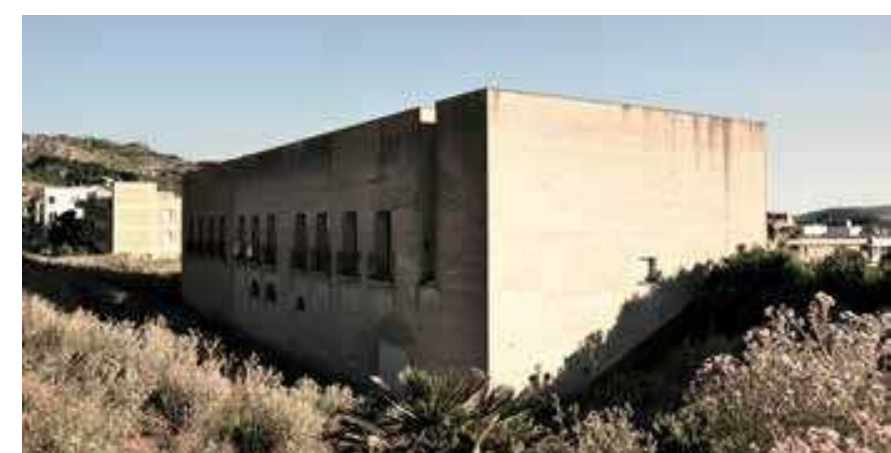

Fig 3.16. The museum back view.

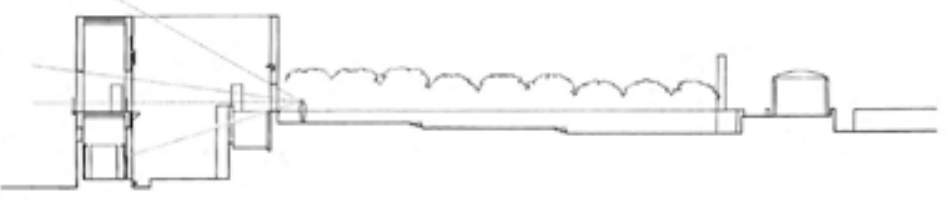

Fig 3.17. Section shows the accumulation of the exterior garden makes the interior cavity.

- into the subterranean world

Venezia conceived Gibellina museum from the "Idea of a residence, to which the exterior is remote. A whitewashed and uniform enclosure: the first shell offers no opportunities. The single access is in a marginal position: crossed the threshold, the exile is refuge. ${ }^{p 143 *}$ To achieve the idea of entering into a private circumstance from town space, the front facade of the museum is erected as a sign of inaccessibility told by the dominant window and a remarkable absence of the door. The doorway on the edge, between the terraced garden and city street, is less obvious from the distance yet becomes more significant during approximation to the building. Due to the deviation of the approach line from the building axis marked by the window, the expression of the facade varies depending on the visitor observing the whole surface or focusing on one part of the front wall.

The front garden not only reserves sufficient space for the doorway but also plays the role of reference according to which the entry journey is divided into three stages: first, a narrow path in L shape starts the itinerary by driving people from the city street into an upward way towards the building; second, a colonnade parallel to the building that breaks the continuous movement in front of the garden; and the last, a walled passage that runs next to the garden, restarting the upward route to an intensive drop to the gateway. This entry consists of a set of thresholds and slopes constantly changes bodily rhythm, establishing the ritual of movement.(Fig3.17.)

Venezia admires the Mortuary Temple of Hatshepsut as "mother of a family of building" by saying it represents its own root into the earth and manifests the people's movemen

143. Francesco Venezia, "Il rifugio," in Scritti brevi 1975-1989 (Napoli: Clean, 1990), 45.

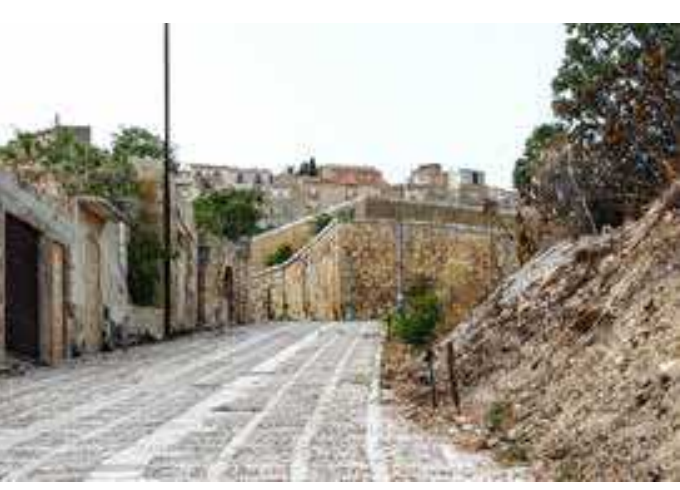

Fig 3.26. The theatre viewed from the lower position

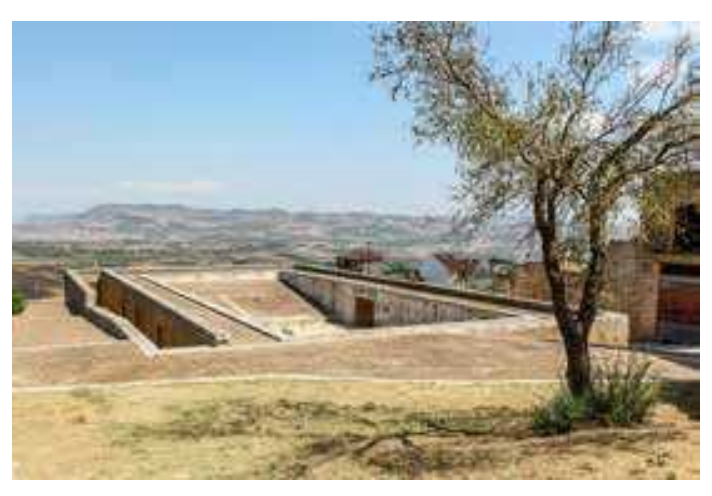

Fig 3.28. The theatre viewed from the upper position. to the surfaces, identifying the position of the ground between the hill and the field underneath.(Fig3.28.) This open-theatre presents itself as a program in search of ground, not only evoking the memory of the Carmine convent, but also integrating with the urban floor, razed buildings, and the ground, so it is able to "give shape to the emptiness of its absence." $" 150$

- confronting the horizon

The theatre's foundation raised up from the ground represents its deep root into the earth. Overlooking the countryside, the theatre act as "a camera composing the city, fragments of the ruins and the landscape by means of the horizon." ${ }^{\text {151 }}$, making the approach as an experience leaving from crowded neighborhood for the space of evenness and openness.

It is instructive to trace Venezia's manipulation of the architectural form to incorporate it into the original fabric of the Carmine Quarter and to create a program of approaching and entering the theatre. The south and east borders of the theatre was defined according to via Carmine - the main road crosses the neighborhood - as a strategy to accommodate the new project into the existing structure. (Fig. plan) The plot adjacent the road was made as an entry square, where a small garden was preserved at the corner. Though coordinated with via Carmine as a expansion of the city street, this entry area remains independent with particular pavement and becomes an interval between the urban space and the central auditorium. Beyond the east border of the theatre, restoration of an existing route has kept a narrow shortcut from the highland down to the motorway via Mazara.

150. Venezia, Francesco Venezia: le idee e le occasioni, 131

51. Venezia, Francesco, 54 


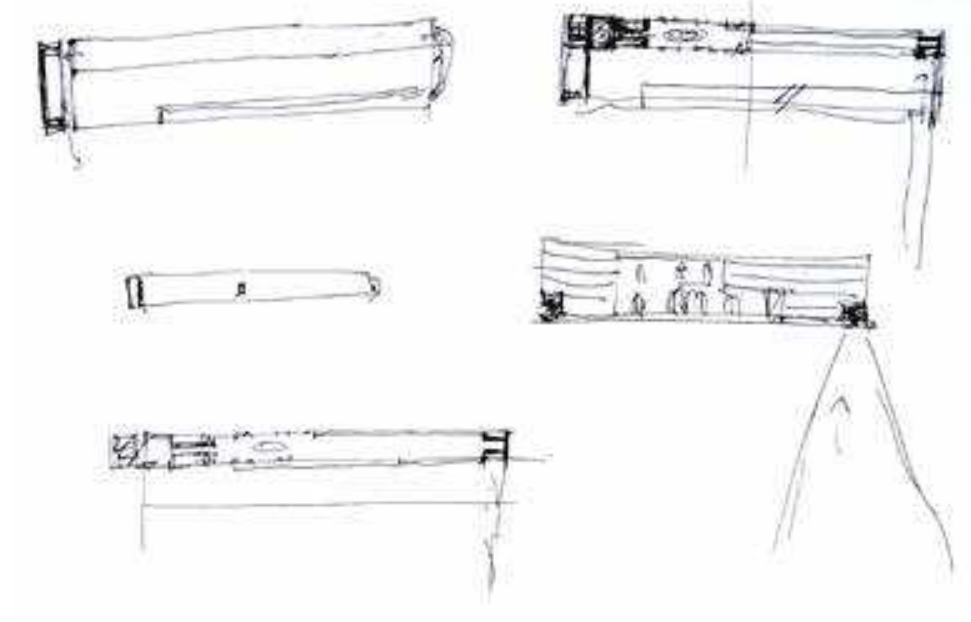

Fig 3.18. Sketch of the entryway, Venezia.

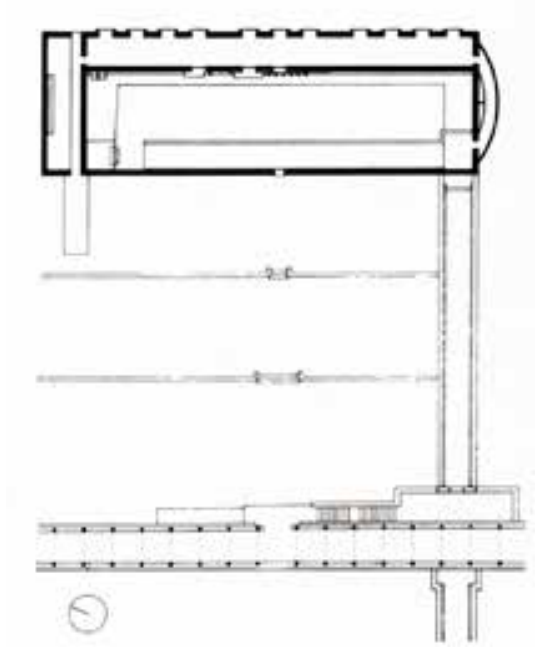

Fig3.19. Early proposal, Venezia

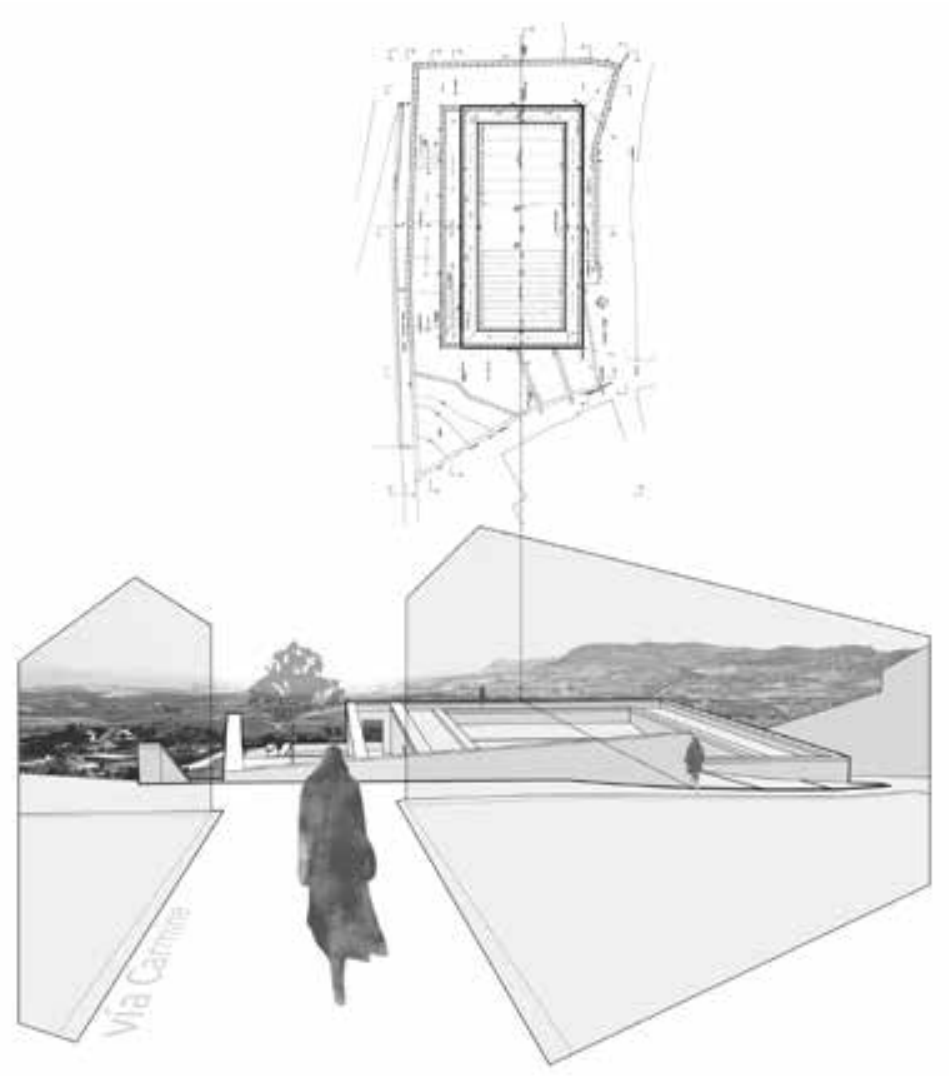

Fig 3.29. Approximation to the theatre, drawn by author.

The parapet of the small garden isolates the interior image from people who are descending from the city center. The wall terminates rightly at the axis of the sunken auditorium, whose symmetry provides measurement with which to control the majestic landscape beyond. (Fig3.29.) Visitors are given an unexpected reception by the dramatically expanded space and a dominant position to observe. The upper level of the theatre offers a platform without vertical elements since the architectural program develops beneath the floor surface. Therefore, architecture plays the role of the ground. Our body stands as the only erected figure and our eyes looking at the distant horizon from the axis of the theatre. With the attendance of people, the theatre presents itself as a coordinate system. By withdrawing architectural volume from the top floor, Venezia gives rise to the image of ground in order to establish an exclusive dialogue between the individual and the grand landscape, reminding of Le Poeme de 'Angle droit:

"The universe of our eyes rests upon a plain edged with horizon Face the sky. Let us consider the inconceivable space hitherto uncomprehended Repose supine sleep

-death

With our backs on the ground..

But I am standing straight!

Since you are erect, you are also fit for action

Erect on the terrestrial plain of things knowable you sign a pact of solidarity with nature: this is the right angle

Vertical facing the sea,

There you are on your feet." ${ }^{152}$

52. Le Corbusier, "A.3 Environment," in Le poème de l'angle droit (Bilingual edition, Stuttgart: Hatje Cantz, 2012) 


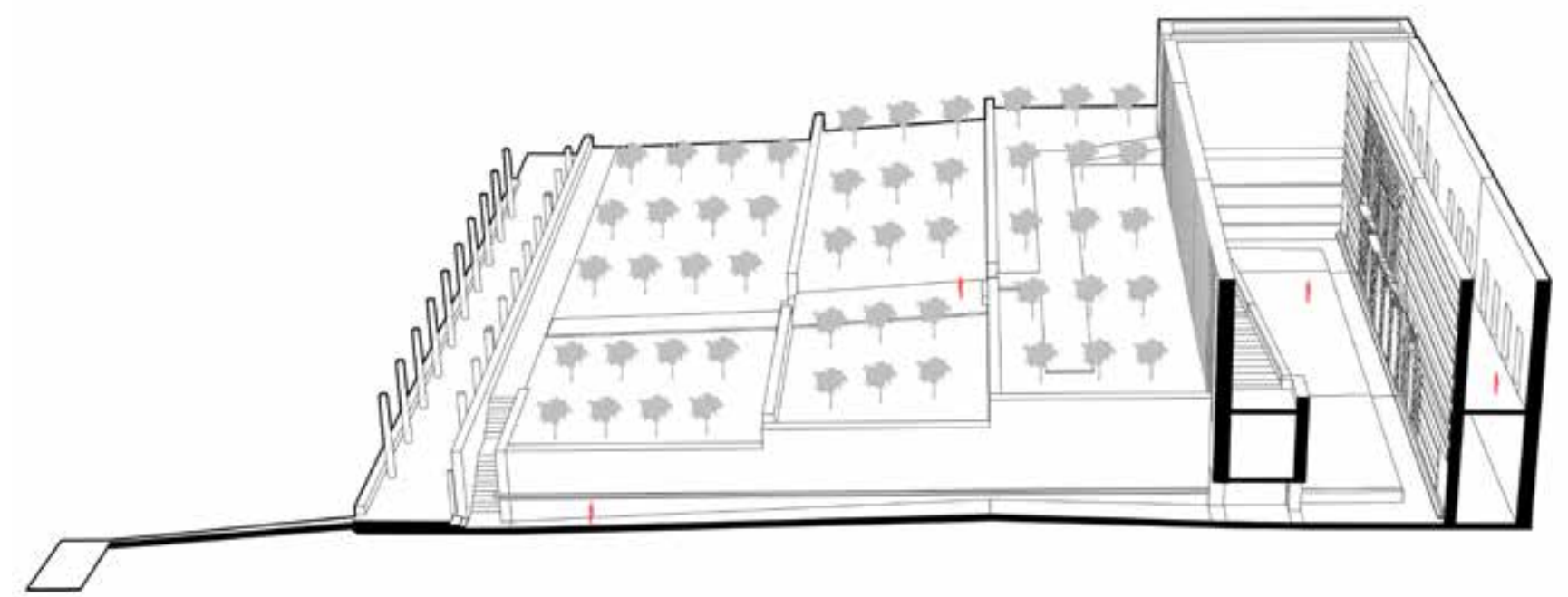

Fig3.22. Museum entryway section, drawn by author.

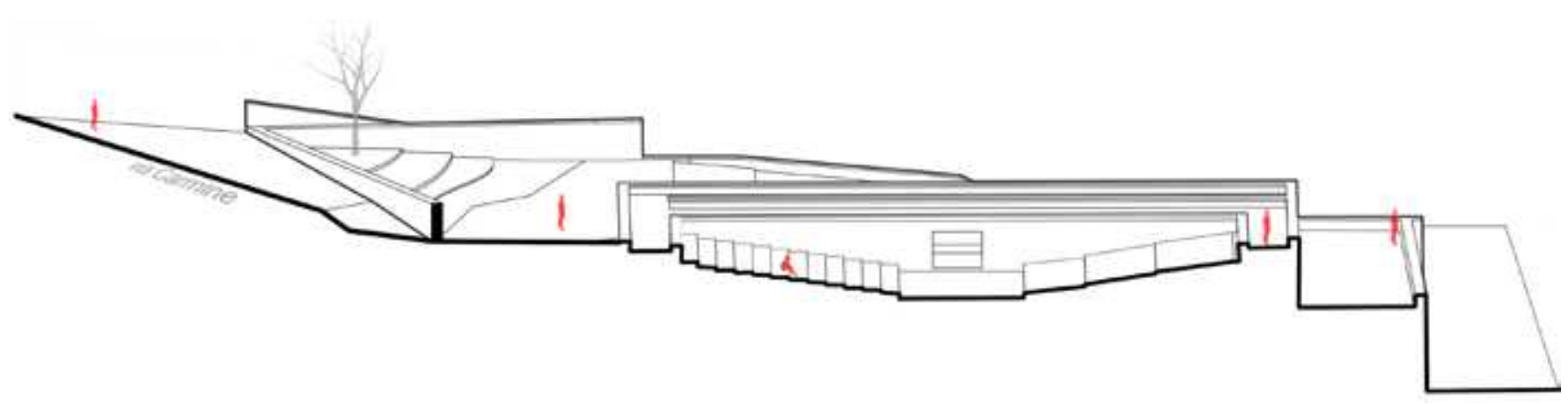

Fig 3.30. Theatre section, drawn by author
The entry route works together with the accumulation of the terraced garden to stress the cavity of the courtyard as a sunken space reopen to the visitors that " prepares the pleasure of withdrawal: one into the shells of segregation." ${ }^{144 *(F i g 3.22 .) ~ O p e n ~ t o ~ t h e ~}$ sky, the atrium creates an introspective space which involves visitors into a story told by walls: the reassembled surface of Palazzo di Lorenzo recalls the destruction of earthquake and the memory of old Gibellina; on its right side next to the vestibule, concrete cross comes out of the wall demonstrates the structure of the building, while the opposite wall made of bricks and stones in stripes draws an analogue of geological strata. These representative images of walls have formed a narrative of temporal sequence in the courtyard, which not only as a testimony of the seismic event, but also interprets the life circle of architecture as matters assembled, collapsed, and end up to the earth.
By following Corbusian notion about the standing human body that gives significance of horizons and indicates our connection with the world, Venezia develops the regards in terms of movement:

"It is essential to consider that the perception of reality is linked to the position of our eyes. Our eyes are about 1.65 meters from the ground when we are in an upright position; when we walk and move ...The horizon line has a position relative to that of our eyes. If we lower ourselves, or if we raise it, the horizon lowers or rises with us. It is therefore a decisive element in the presence of objects: our movement can make a reality arise before our eyes or, vice versa, make it set..

Venezia admires the control of relationship between bodily mobile and horizon on route to the roof of Casa Malaparte. The theatre auditorium in saddle shape realizes a similar itinerary guided by the grand view of landscape and distant horizon. (Fig3.30.) In addition, the small theatre presents itself as an architectural strategy to balance the scale of people and that of the landscape. The auditorium roof marks an orthogonal frame on the ground, providing a referential measurement according to which people are capable of contemplating their relations with the vast land and distant mountains. 


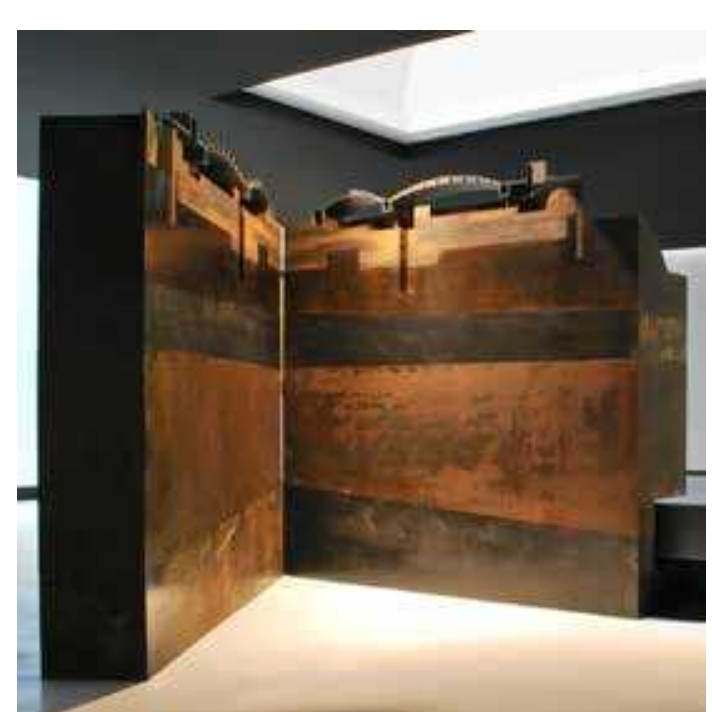

1ig 3.31. Model of Museo della Stratigrafia Storica a Toledo, Venezia, 2006-07.

$\S$ Epilogue - excavation as Method

"I remember the expression of a philosopher who is at the origin of Western culture, Heraclitus. Heraclitus seems to interpret the intent of the Egyptians to attach importance to invisible things (to what a building is invisible) when it affirms that "in-visible harmony is stronger than visible harmony. This is the secret of architecture. In the world of images, today, it is the ephemeral that prevails." ${ }^{p 54}$

As a serious adherent of the ancient Egyptian architecture, Venezia is fascinated by the invisible side of forms. From those remote works he is convinced that things work on form even when the form does not appear to the surface. In his works, excavation from existing mass that realizes an expression of a great spatial capacity under the surface becomes a representative manner to achieve this regard.

It provides another perspective to think about configuration of architecture, as Kenneth Frampton has concluded Gottfried Semper's four elements of architecture as earthwork and frame, Venezia merges the two terms into the "land architecture", giving rise to a topographical quality in architecture through an archeological manner. The model of Museo della Stratigrafia Storica a Toledo (2006-2007) gives an instructive manifesto of his insight into the visibility of architectural form as reflection of the inexhaustibility of the underground. (Fig.3.31.) The inexhaustible messages in Venezia's works, to a large extent, is realized by the architect's endeavor to weaken the boundary between earthwork and construction. This idea was implemented in his first built work Plaza Lauro. Through a delicate dialectic between passage and surface, stairs and slope constitute a soft transit from the street down to the sunken plaza. (Fig3.32.)

154. Venezia, "Temi," 77

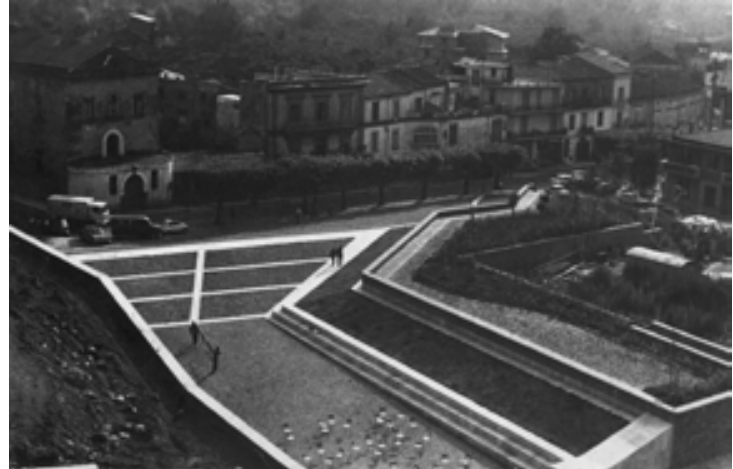

Fig 3.32. Plaza Lauro.

Apart from different forms and contextual situation, in Gibellina museum and Salem theatre, excavation becomes a representation inside an overlapped program that contain four dimensions of the territory: urban development, natural landscape, memory of seismic event and metaphor of telluric power. The similar mechanism of integration is drawn from external delimitation between elevated foundation, which permits diverse read of ruins and the ground, and the construction on the upper part, which represents the detachment. Meanwhile, the internal cavity, the courtyard and auditorium, gives wholeness to the interior as a vertical thrust into the earth.

The metaphors of the classic configuration of building site based on the connection of upper construction and the condition under the soil is realized by Venezia through his "nonviolent transformation", which creates cavity upon the ground as interpretation of excavation. By doing so, he manages to convert the banal site of merged figure-ground to a hierarchical up-down structure which not only refers to spatial dimension, but also, more importantly, works to integrate architecture and ground as one system, in which temporal and topographical continuity is thus preserved and developed.

It is essential to understand Venezia's architecture through the dialectic relation of unity and separation. Rather than being unconditionally fitted into the context, tension prevails in his works as catalyst to make people see, walk and meditate. The approaching process requires extraordinary mobility which, in order to deal with the psychologically prolonged trajectory or the sign of inaccessibility of the architectures, devoted to a certain sense of resistance of movement from the perspective of antiempathy: since convenient access would promote a simple program in architecture from which users are free to take advantage, conversely, resistance compels people to review their relation with architecture through a contextual read. Venezia designs the entry route as a path from the upper world into the subterranean domain which involves both the idiosyncrasies of the site and the experience of the body. 


\section{CRITICAL SUPERIMPOSITION}

The open-air theatre of Salemi, the museum, the small garden and the pavilion in Gibellina stand out among other built works of Venezia for revealing his use of superimposed structure to, on the one hand, commit architectures to the ground, on the other hand, cultivate the sense of tension which characterizes the space between the poles of tight establishment and tendency of collapse.

"In life we follow two different impulses. One is an impulse to abandonment, to abandon ourselves to the natural change of things. The other is an impulse to control, to control nature through geometry and measurement. ${ }^{, 155}$ *

The two impulses that suggest our attitudes on the nature indicates the fundamental quality of Venezia's architectures, which are essentially topographic. His works always treasure the natural things, especially those projects in Belice whose idea lies on reintroducing the strength of the ground into the environment of a building. The museum, the theatre and small gardens present a particular composition consists of the bottom part, in which preexisting factors of the given site are presented, and the upper part, which suggests a new construction. This manifesto of superimposition suggests Venezia's important design strategy which involves reformation of the site. Instead of a complex solution responding to the various conditions of the nature, the simple geometries applied by Venezia make the building come to the fore only when their clearly-measured volumes standing out from the locale. Nevertheless, if one gets into the architectures, those fissures, torsion and dislocation present the architecture interior

155. Venezia, "Idee e tecniche di architecttura," in Scritti, 83 as a space of inconsistency, ambiguity and irregularity, resulting from the architect's deliberate "abandonment" of the precise quality and absolute meaning in favor of the random and the unpredictable, so that the architecture could stand by itself in the face the passage of time. .

Venezia conceives architecture by the means of overlapping and isolating individual element: approach them, but do not merge them. This strategy largely enriches the space through playing with the complexity between different parts. The layered spaces of the museum, the interstices between the old facade and its back surface, the deep corridor ploughs the theatre's floor and the dislocation between its upper and lower structure, all these combinations of different structures and programs produce internal inconsistency and underline Venezia's mechanism of organizing space through ensuring the clarity of each element while leaving a wide possibility to their mutual relations. It makes his architectures as a kind of porous substance in which ambiguity and contradiction are to question the character of definiteness and correctness.

The complexity and aesthetics in Venezia's architecture come from decomposition and reorganization, recalling Palladio's words: "Beauty will result from the form and correspondence of the whole, with respect to the federal parts, of the parts with regard to each other, and of these again to the whole." ${ }^{156}$ The loose connection of elements with each other effects on the referential look of the building that relations between the 156. Andra Palladio, The Four Books of Architecture (New York: Dover Publications Inc., new edition, 2000) 1 


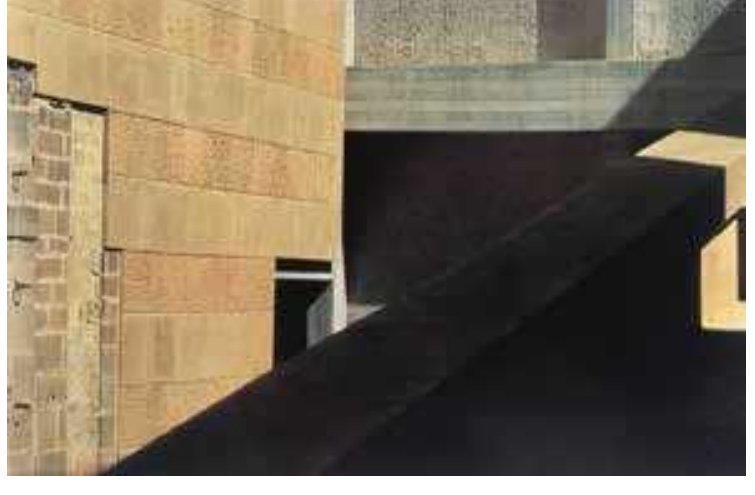

Fig 3.33 Gibellina museum.

smaller parts and the whole construction seem to be in a subtle movement. However, when observing a single element, it returns to be static and autonomous. The mobility of matters and the links between them, varied with the way of observation, simultaneously contribute to the narrative of Venezia's architecture.

As the carefully connected and superimposed elements emphasize clear delimitation of different parts of the building, circulation on the itinerary that transgresses throughout those constructional disciplines has become the only effort to balance the tendency of separation inside the architecture. In Gibellina museum, the courtyard and the twofloor gallery is connected by a circuitous route which emphasizes the alternation of interior and exterior space; the trying ascent by the ramp provides ritual experience of moving from a subterranean space to the world above the ground.(Fig.3.33.) In Salemi, the narrow staircase and the slow descent produce a diverse transmission from the upper plane connected with city street down to the historic level facing with the grand landscape.(Fig.3.34.)

"Our work as architects is to offer a certain resistance to the rapid exhaustion of the practical reasons behind the structure of a building; to evoke a concealed time that resists the apparent time of its usefulness." 157

By regarding the superimposed structure as a manner of construction and the arrangement of order of a spatio-temporal narrative, Venezia creates the hypersensitivity towards the nature of the given site and the complexity inherent in the building. Those inevitable conflicts inside the architecture where the notion of

157. Ole Bouman and Roemer Van Toorn, eds. "Architecture as evocation of concealed time," in The invisible in architecture, (Wiley, 1994), 440.

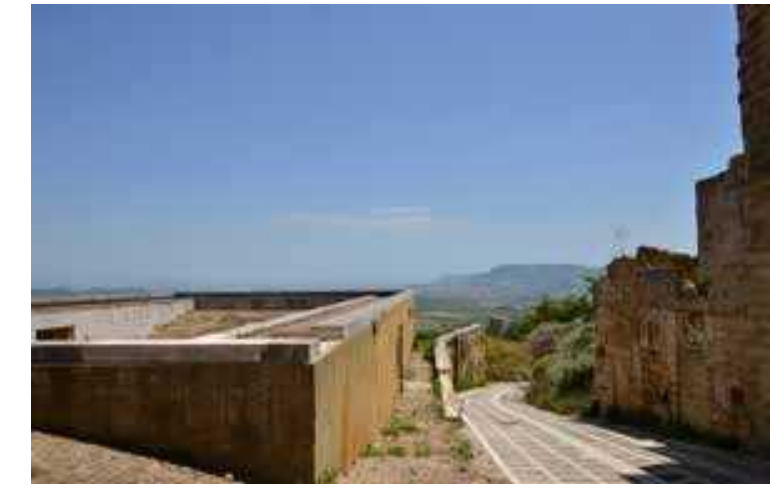

Fig 3.34. Open air theatre in Salemi.

functionalism seems to fade out, are dramatically revealed in the opposition between individual element and building's unity, between the measurable and that out of dimension, and between exhausting and wasting. These opposite factors achieve to raise a strong critique of the overwhelming certainty which degrades today's architecture as something that is subject to the maximum clarity and directness. 


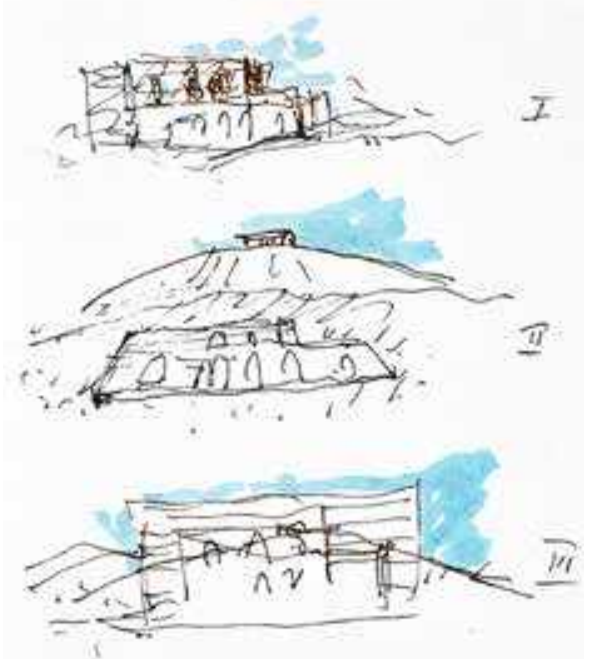

Fig 3.35. Gibellina museum sketch, Venezia.

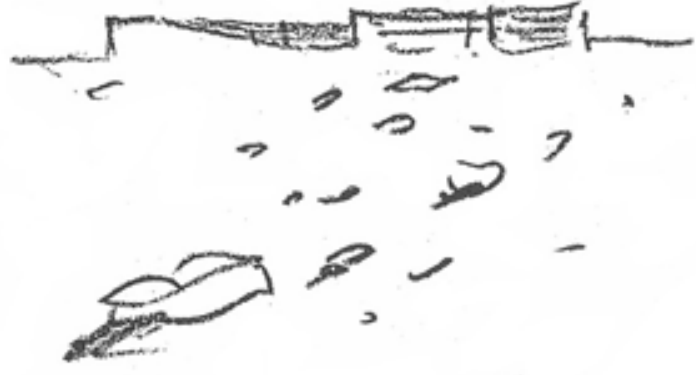

Fig 3.54. Salemi theatre sketch, Venezi
$\S$ Space for intervention: a work of montage

- delivery of views

By doing a design, Venezia always starts from a preliminary study by abstracting an initial idea. Localization and contextual conditions are not the priority in the very first phase but come afterwards to materialize the idea. When commission called for the removal of the Palazzo di Lorenzo facade, main concepts of Gibellina museum were made: "to resemble those fragments in an interior setting, to enclose the heritage in a building with a life of its own, allowing it to reveal its own particular significance as a ruin in its new setting." ${ }^{158}$ This remark explains Venezia' concept about the museum to be built in the new town as nothing more than a contingent, a building which is predetermined. What the architect has done, by formulating a new building in which old fragments are enveloped, is to reach a topographical accommodation of the memory, and more importantly, to find place for those fragments in the continuum of time. (Fig.3.35.)

The main concept and critical qualification of Gibellina museum resides on the strict recognition of limits and boundaries. Apart from the terraced garden that represent the earthwork, the building is divided into five parts interrelated with each: the front facade, the courtyard of a wall installed with historic fragments ${ }^{159}$, the two-floor gallery, the

158. Venezia, Francesco, 42

159. By explaining the reason to set the heritage inside the building against sunlight, Venezia said: "in this way the facade will retain its quality as a ruin unaltered, through this condition of belonging to the sky." Francesco Venezia, "Transfer of a fragment," Lotus International 33 (1982):74, Milan: Gruppo Editoriale Electa.

\section{The inconsistent structure}

- where those events converge

Contrary to the single and overwhelming presence of Gibellina museum, multiple read of the theatre, in terms of morphology as a standing monument or a flat ground centered by an in-laid vacuity, is available depending on the way through which to approach the site. (Fig3.54) In Salemi, Venezia made full use of topography and preexisting elements to create the theatre as prototype which shows the wide range and hybrid capacity a simply superimposed structure could reach. Its dual dispositions, achieved by raising structure and marking the ground, are symbiotically connected and revel the respective manipulation organized by the architect of the two concerns mentioned: first, the controlled evenness set up the guideline according to which the disordered condition of the site was disciplined to produce vertical hierarchy with the help of an overlapped structure; second, contour of the ruined convent was partially reserved to create a crossreferences with the theatre's layout. Distortions between old and new geometry, on the one hand, contribute the dialectics in this synthesized construction, on the other hand, formulates the itinerary throughout the theatre and makes the movement between the two levels as the alternation of the traditional and the new order.

Apparently, the complexity in the topographic and historic elements became the difficulty of this project. Nevertheless, instead of taking an overall treatment to avoid or remove those inconsistent facttors, Venezia has kept them as point of departure to formulate the two leveled structure which is essentially topographic in nature. (Fig.3.55. "It (the theatre), along with other improvement area, obtained by means of stairs and 


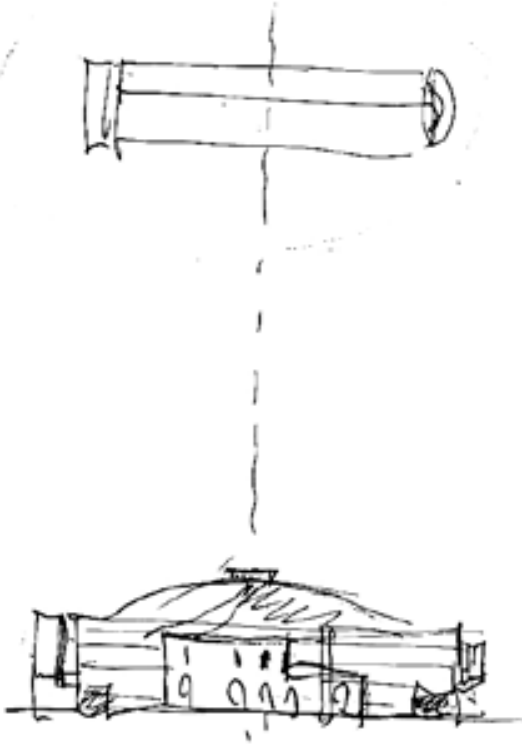

Fig 3.36. Gibellina museum and landscape, Venezi

curved bridge and the small cabin reposo serve as two wings on the lateral sides of the main building. These sequential spaces set up an orthogonal network in which each orientation would lead to an independent narrative of the space.

The meaning of this museum located on the edge of the city resides, first and foremost, on the meditation of contradictions between the urban and the rural. A significant absence of boundary in this place has resulted in an impairment loss, an impoverishmen of landscape. In order to save it from fading into a banal land without measurement, the building was conceived to provide multiple deliveries of views in order to revive the value of the landscape. A simple peasant house on the countryside opposes to the building, representing the essential character of the territory, has been selected by Venezia as counterpart of the heritage inside the building which speaks of the history of the old town.(Fig.3.36.) A set of apertures composed by the windows of the outside wall, the heritage surface in the courtyard and the back facade of the gallery, provides an axis of views from the terraced garden to the countryside by which people is capable of looking through the building's thickness and to approach, through a clear sequence set by walls, a dialogue between the monumental and the vernacular, between the past and the present.This communication dramatically juxtaposes the transparency of the building with its solid appearance thanks to Venezia's control of the scale of those apertures. Started from the same height, the front window is smaller than the other two behind. This slight but remarkable adjustment provides an important restriction to the views from the outside, ensuring it to coincide with the other windows. Therefore, what people see from the garden into the building is a simply combined image of a baroque window and a patch of landscape beyond framed as "a totally isolated landscape: a
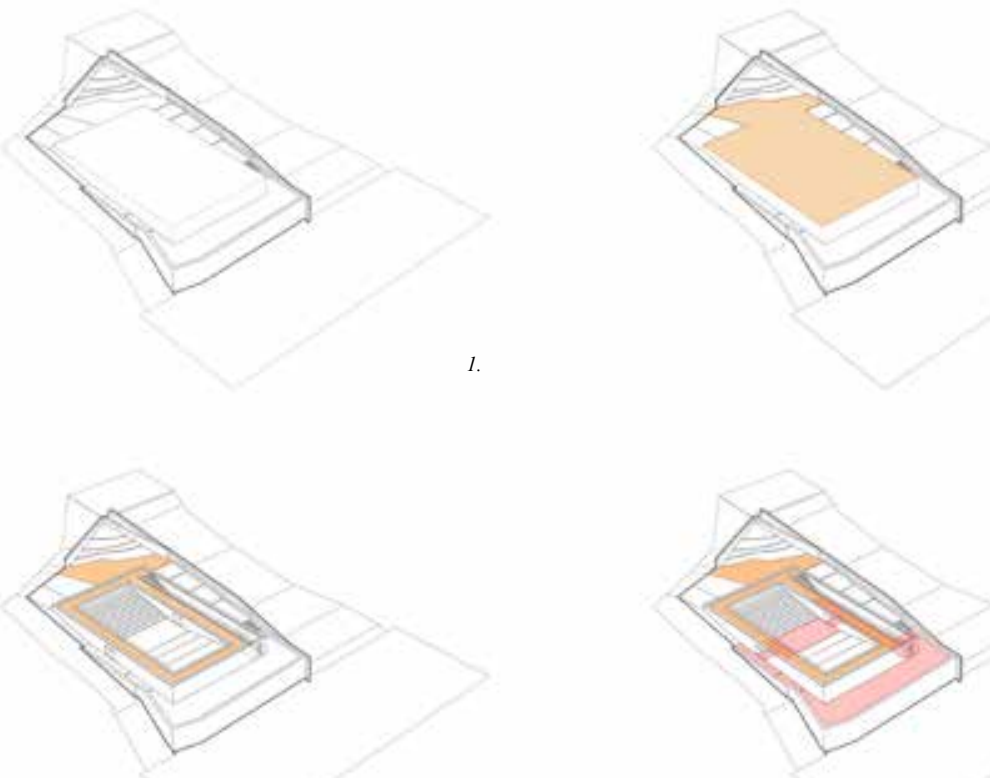

Fig 3.55. The terraced structure of the theatre with two superimposed levels: the upper level (yellow) connected with city street and the lower level (red) based on historic elements, drawn by author

embankments, acts as a link between the two levels." ${ }^{165} *$ The small square and the roof walk, respectively dedicate to the first and the last phase of the architectural promenade, compose the theatre's top plane as extension of urban street. Closely attached to each other, the incised passage, the rear terrace and the auditorium floor constitute the historic level supported by the base underneath. While the upper elements give rise to a privileged position that overlook all the architectural program, elements on the lower level are delimited from each so to acquire independence. With the help of partitions, Venezia manages to extract the spaces on the lower level from a wider surface and grant them individual spatiality by minimizing their interactions. This strategy of subdivision dissolves the unity of the historic datum and serves to deliberate sight and movement as, simultaneously, a metaphor and experience of freedom, as well as an antithesis of the static establishment seen from the upper side.

Aiming to retrieve the affirmation and protection of the site which once were established by the convent, then dissolved with disgraced transformation and finally collapsed with the building, Venezia conceived the theatre of overlapped structure to resolve, historically, the chaos of events belong to different period, and to repair, contextually, the disturbed relation with the locale.(Fig3.56.) Apart from the bunker-like base made of new materials and convent's remains that presents a combined event of secular life, religious ceremonies and the destructive event, the terraced platforms of the architecture establish a normative measurement of horizontality that enables people to face the landscape floating on the edge. From this perspective, the open-air theatre is to be regarded as exemplary for the way in which it attempts to modify in contextual terms by renewing the manner of observing. The rather abstract rationality of superimposed 

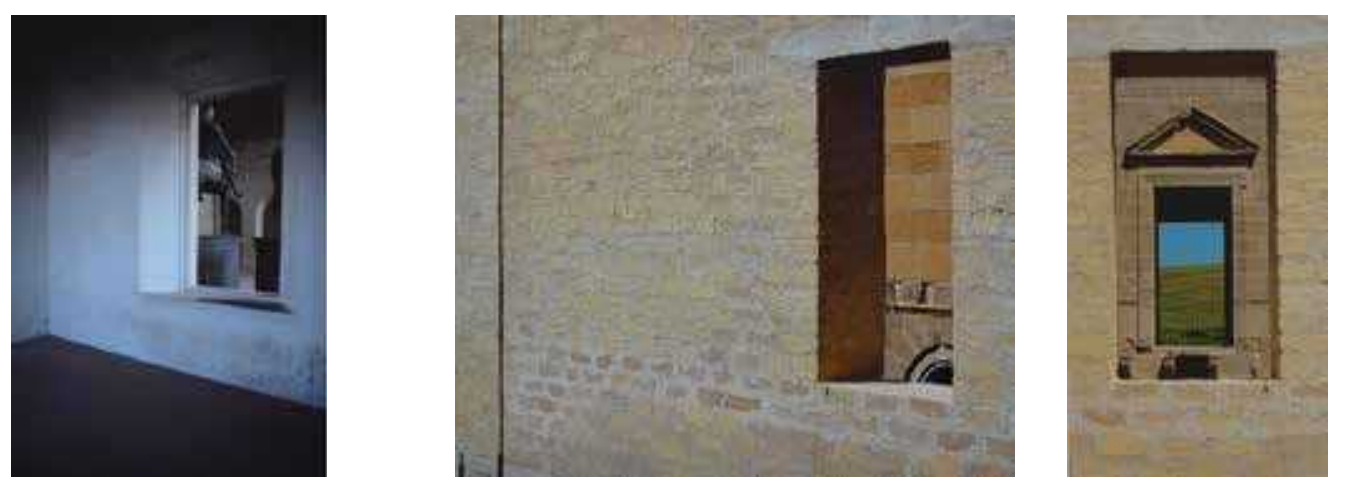

Fig 3.37. Palazzo Ducale.

Fig 3.38 Windows of Gibellina museun

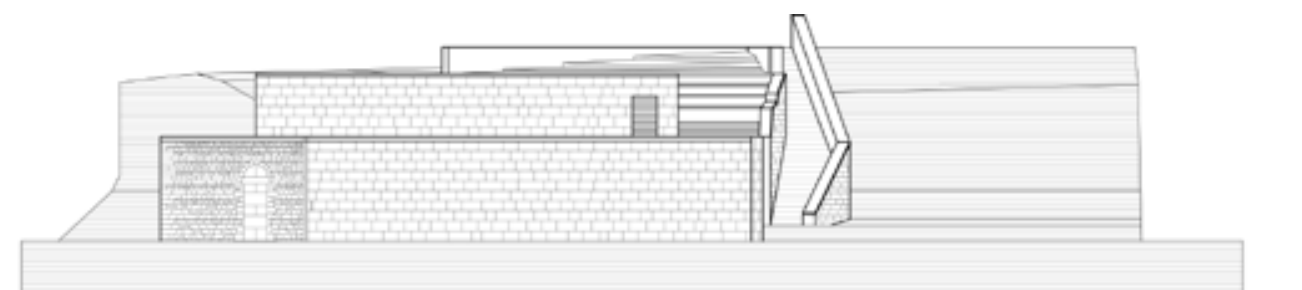

Fig 3.56. Theatre facade, drawn by autho garden of the earth, out of the earth." ${ }^{160 *}$. And by proposing this metaphorical montage, the museum comes to the fore that simultaneously recalls the memory of the past and stresses a recognition of the territory. (Fig.3.38.)

A photo of Palazzo Ducale in Sabbioneta (Fig3.37.) taken by Venezia years before the project demonstrate his inspiration to develop the idea about inaccessibility in architecture by using windows. The architect admired the "impediment to entering" allow to see but not to penetrate - of windows and applied it into the museum through the three apertures. Similar effect is realized in the same building and other works by Venezia in a more representatively constructive ways: by isolating partitions from each other, he uses the gap in-between to stress the contrast between visual connection and the detained arrival. At the same time when the play of opposing windows extends one's view, it seems to have a reverse effect on the building internal space: since the museum converts itself into the medium serving to a deliver sight through the walls, its internal capacity seems to be extremely reduced. When looking through the windows from the outside garden, people are even hardly to notice the gallery space in-between the old window and the one on the back. Venezia obviously realizes it and further works to prevent the penetrating observation from revealing the internal space. He raises the front window 2 meters from the garden ground so that people cannot lean forward to overlook the space inside.(Fig.3.39, Fig.3.40.) This purposive recession of the interiority present close distance between those elements viewed through the windows, and consequently stresses the superimposition of their temporal meanings that are al linked to the seismic event.

160. Venezia, "Il rifugio," 45.

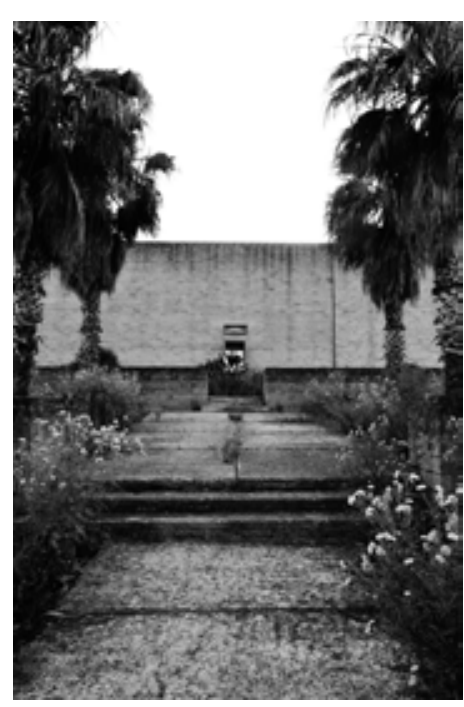

Fig 3.39 Terraced garden scheme not only gives a manifesto of temporal narrative by which the nexus between citizens and development of the city is about to be fixed, but also restores the privilege of this territory as well as its capacity to measure the nature.

- the walk provoked by distortion

As temporal disciplines are shown from the vertical order affirming the theatre as a memorial of the tragic event, a tension is arisen from the geometric scheme of the plan by the contrast between the rectangular auditorium and the irregular background. The ductile shape on the periphery serves to produce a circulation around the rigid central part and connects the entry square on the upper level with the lower terrace. This envelope scheme testifies Venezia's endeavor of creating an architectural program as a procedure to stimulate mutual accommodation of a new and pure form and the sedimentation of the territory.

The theatre periphery inherits some prominent characters from the pre-existing elements on the site: the triangular garden reserved from the original ground at the entry square and the salient corner of the terrace which was made or preserved to match the street outline. They contribute to a force that diagonally stretches the outer scheme, resulting in a deflection of the plot in rhomboid shape from the axis determined by the rectangular atrium, and disturbing relations between the two parts which, due to the stressed displacement, are driven by a subtle rotation.(Fig3.57, Fig3.58.) The deviation from the external to the internal space finally transforms the theatre into two staggered geometries which implies Venezia's abandonment of coincidence between systems. This strategy of provoking tension of movement within a single body somehow associates with the Contrapposto to describe the twist posture of human figure appeared in ancient 


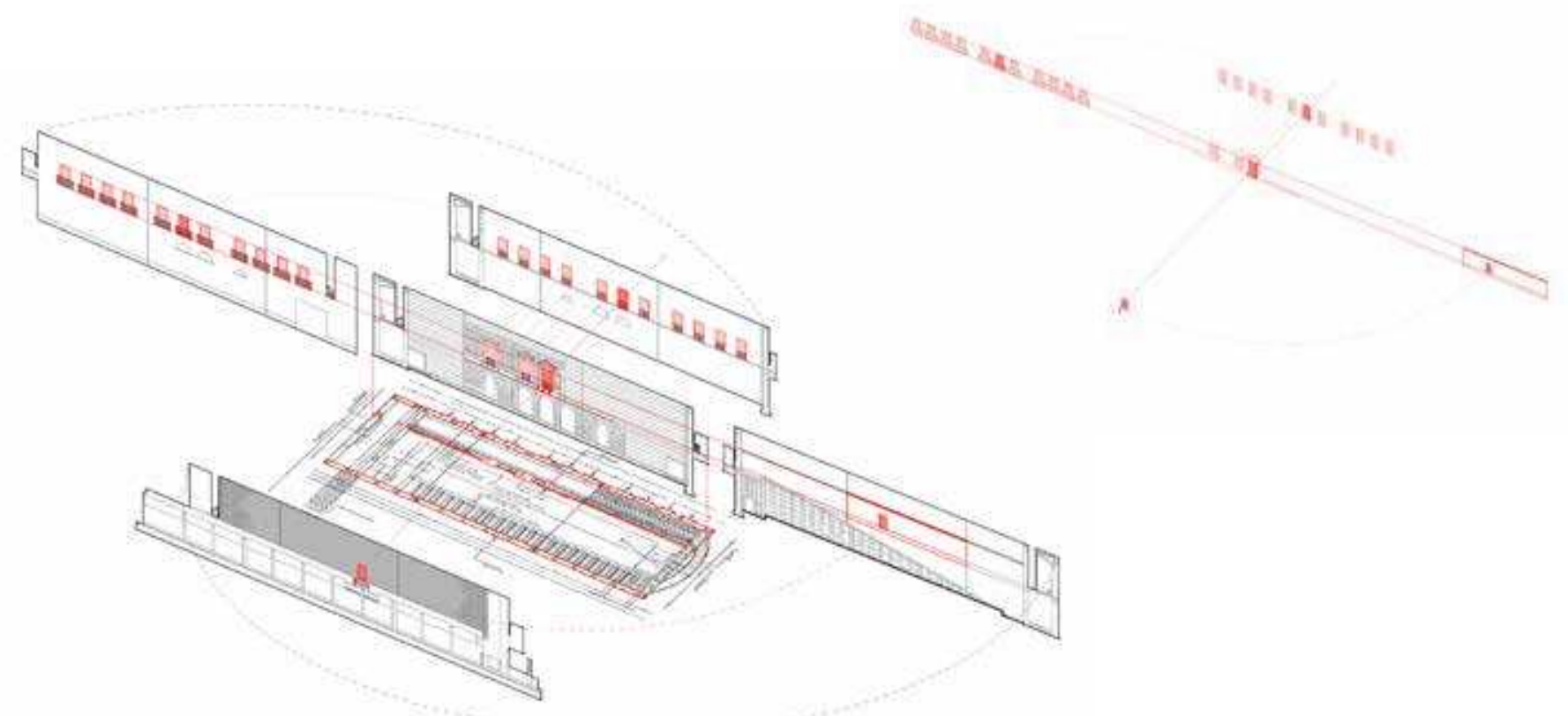

Fig 3.40. Relations of the three walls and the order formed by windows, drawn by author.

Observation through windows that challenges the presentation of the interior space alludes to Venezia's will to accentuate the duality of the museum - the richness of the internal courtyard concealed behind a brutal and austere surface - that illustrates his inspiration from Adolf Loos's use of "the best resources in its most hidden part." 16 This strategy is also achieved through the way in terms of architectural entirety. The long and pure facade of the museum, with minimized exhibition of its lateral sides, reduces its volumetric quality from the outside so that makes the construction as a thin boundary on the city edge. It coincides with Venezia's intention to revive the relations in this marginal space by consolidating the urban boundary, and successes in making the approximation process an intensive transfer of meanings from the exterior to the interio because of the impact when one discovers those overlapped messages which have been hidden.

- a hybrid frontal

Venezia also makes use of the frontal presence of the museum as manifesto of essentia complexity of the building, as well as to mediate the conflicts among different parts. Despite of being hidden from the outside, the facade Palazzo di Lorenzo as thematic element reflects its scale to the new facade through constructional elements. The left border and a vertical delimitation of the heritage surface become two prominent lines according to which the whole building is cut through. Two fissures on the museum facade not only reveal Venezia's treatment of breaking the mixed structure of reinforced concrete and stone due to a high seismic risk in the region, but also unveil three families on the surface, by which the architect suggests a "displacement between the system of

161. Raventós González, and Vásquez Zaldívar, Due Case, 28

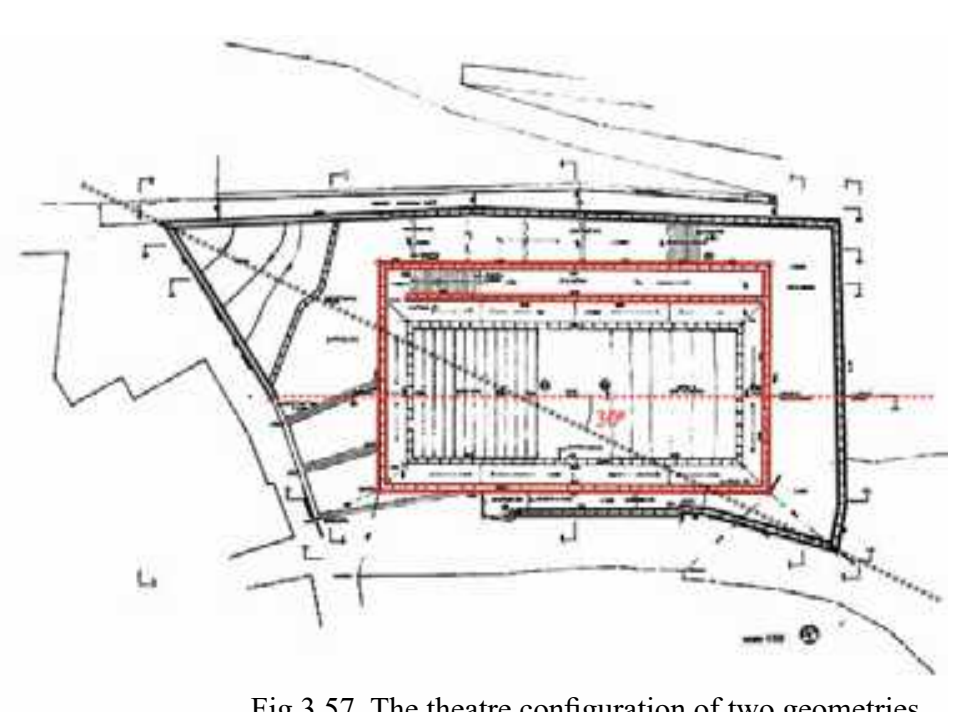

Fig 3.57. The theatrecofigut of two geometris, drawn by author based on plan drawing

Greek sculptures, but the architect further drives his inspiration to a more remote term.

"The distortion, which referring to Egyptian architecture is called the rhomboidalization of right angle, signifies beginning from a very static architecture and to put it in movement, in other words, to make it walk, to make it travel through a game of tensions." 166

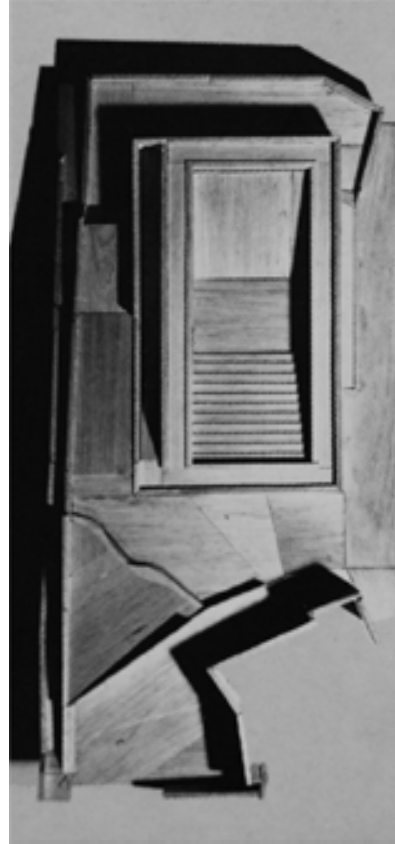

Fig 3.58. Open air theatre mode.
Rather than letting the conflicts disturb the entire architecture, through the work of metamorphosis, Venezia consolidates the relation between the two systems in order to balance the tendency of dissolution and control the inconsistency to a certain extent. He pushes the atrium to the northeast of the plot, makes the perimeter a gradually-shrinking route progressively gravitated over the central box. The terrace border which is parallel with the atrium testifies this idea: Contrary to the parapet of the garden protruding a sharp corner on the opposite, it suggests an important sign which transforms the deviation of oblique border to the accommodation with orthogonal scheme.

Geometric transformation in the plan is fundamental, but the true value of this mediation between the irregular site and pure volume achieved by Venezia lies in the developmen of spatiality that its use and possession allows move from conflicts to reconciliation and approach the confluence. As the architect insists: "In our work any innovations must be based on a solid foundation ideal constituted over a very long time. The real new can be born only from the tradition." ${ }^{167}$ his sentimental exploration explains the existence of displacement to value the opposite characters possessed by the theatre - link with the

166. Raventós, and Vásquez, Due Case, 26.

167. Venezia, "Il rapporto tra edificio e suolo," in Che cosa, 72 

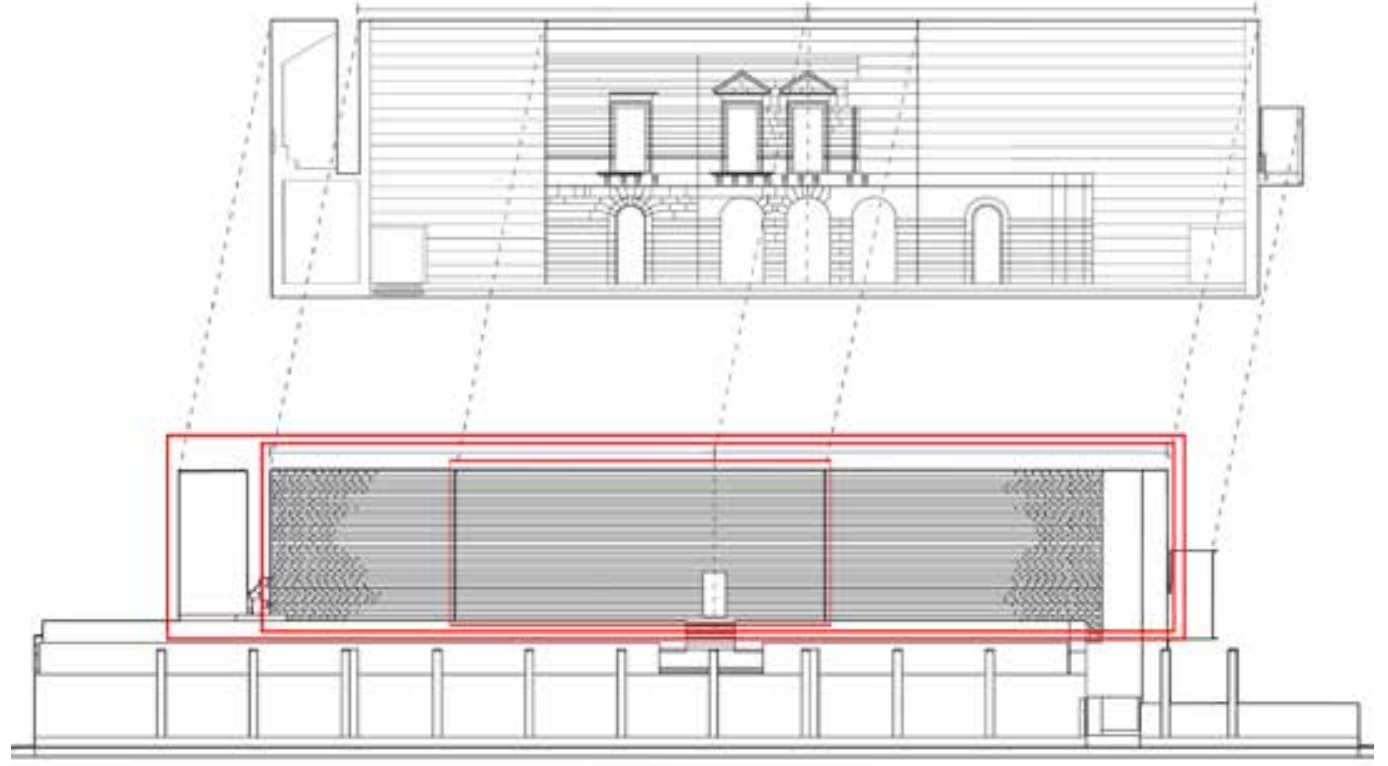

Fig 3.42. The front facade inherits order from the surface of Palazzo di Lorenzo, drawn by author.

proportional composition of the building and system of structural joints." ${ }^{162 *(F i g .3 .42 .)}$

The first family is presented by the entirety of the building facade in which a bold gap of the museum's exit on the side stands out and highlights the separation of the architectural space. The second family goes by the main part of the facade, whose symmetrical composition, centralized by the small window, offers an easy way to understand its geometry from the distance. Further reducing the scope, the third involves the window and the two fissures on both sides which partially interpret the proportion of the fragment inside. Its dissymmetry, however, intervenes the equilibrium established by the second family, granting the closer read subtle oscillations. (Fig.3.45.)

The museum facade shows potential of superimposition as a building strategy. Apart from its use of rooting the building into the earth and to combining views, it is also used to converge orders. By abstracting the old wall and making it come to the fore, Venezia creates an uncertain representation of conflicts and mutations formed when approaching different systems. Therefore, the museum's frontality is given by a synthesis which simultaneously indicates the contextual requests and the pre-determined order from other place.

Venezia's fascination of overlapping distinct systems, as manner to stimulate crossreference of the architecture, is testified by its wide application spans from general treatment to accommodate the building into the site, to the most detailed scope Fig 3.44. Fissure on old facade. relating to the manner of remounting the old remains on the new structure. Meanwhile oscillating the outside rhythm, the historic facade presents irregularities by complying

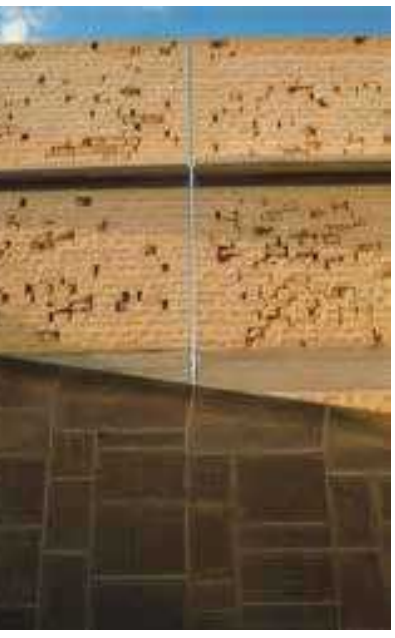

Fig 3.43. Fissure on front facade

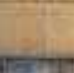

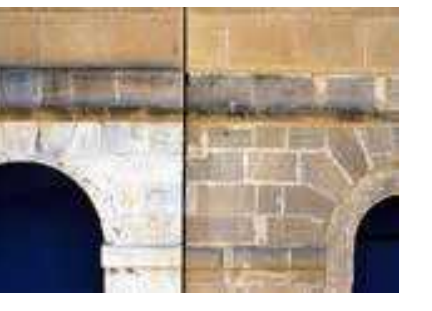

Fig 3.44. Fissure on old facade.

162. Venezia, "Temi," 80

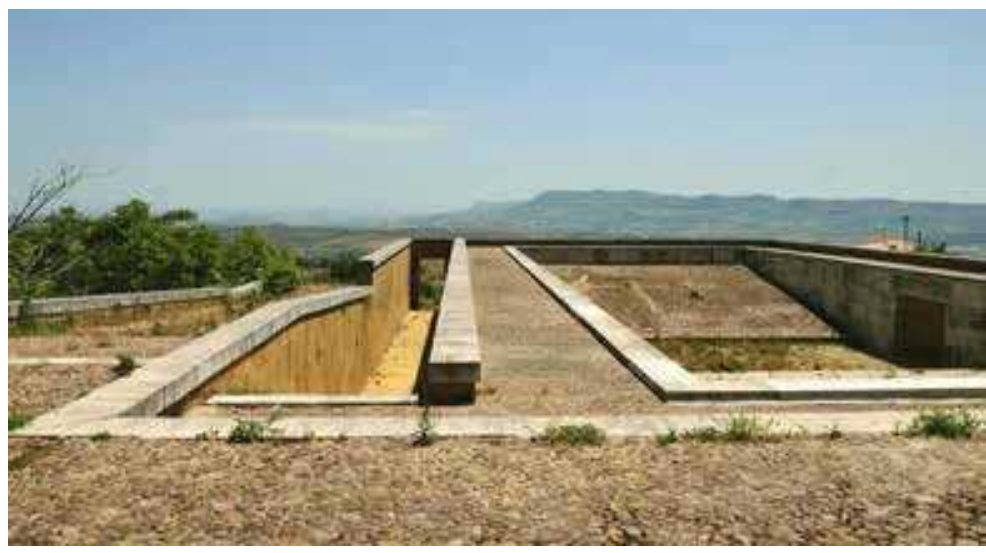

Fig 3.59. Three pathways viewed from entry square.

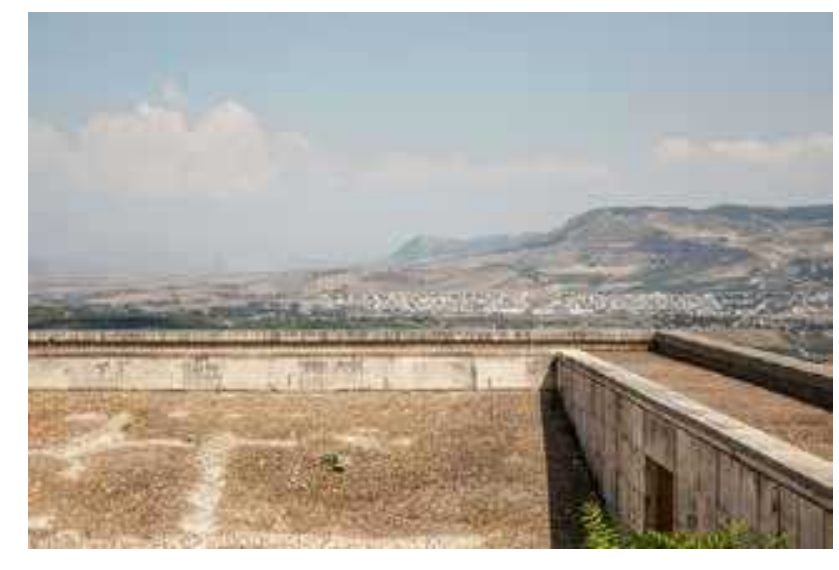

Fig 3.60. Landscape floating on the auditorium edge. given perimeter and demand of a refined form. Its overplayed structure and connection of movement provide a rational program aiming to set up disciplines in the space, which achieve the building a self-explanation that justifies the pure geometry upon old prints and retrieves the continuity between construction and its territory.

\section{- the will to connect}

Georg Simmel declaimed "the will to connection had become the Form of things." In Salemi, the superimposed structure of the theatre as materialization of the architectural promenade throughout the upper and lower level is demonstrating the will to connect with horizons. Venezia transforms the totality of its top level as a manifesto of spacing - its greatly expanded view has placed those who just came from the narrow street in a sudden confrontation with unexpected dimensions of landscape and horizons, stressing the conception of orientation and distance.(Fig.3.59, Fig3.60.) Following Heidegger's phenomenological remark: "spacing means clearing the land, opening, setting free into a free area, an opening. In so far as space spaces, space gives a free area, with which it affords the possibility of surroundings, of nearness and farness, of directions and boundaries, the possibilities of distances and magnitudes." ${ }^{\prime 168}$, here are the marks on the ground that speak the architecture in terms of a gradual revelation of landscape: the floating views on the edge of the saddle auditorium, the framed image down to the floor selected by the small door of the deep corridor, and the partially opened spectacle in front of the ramp on the lateral side.(Fig. ) It is the sequential manifestation in a

168. Martin Heidegger, Remarques sur art - sculpture - espace (Paris, Edition Payot \& Rivages, 2009), quoted in: Arnoldo Rivkin, "SPACING The post-media horizon of the work of Lacaton \&Vassal," EL croquis, no. 177/178 (2015):33. 


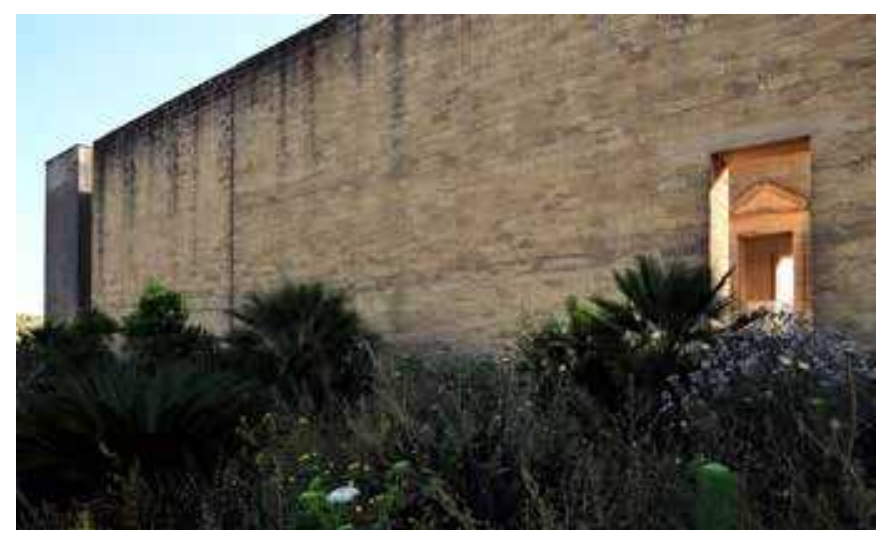

Fig 3.45. Multi-family composision of the museum facade

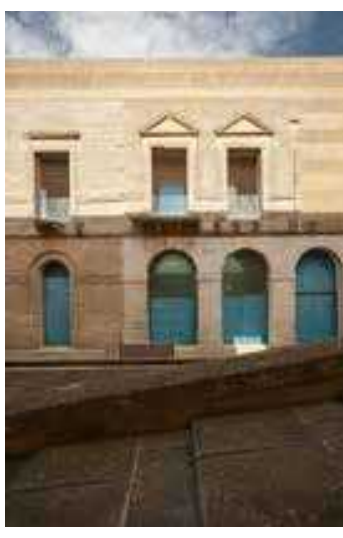

Fig. 3.46. The interior

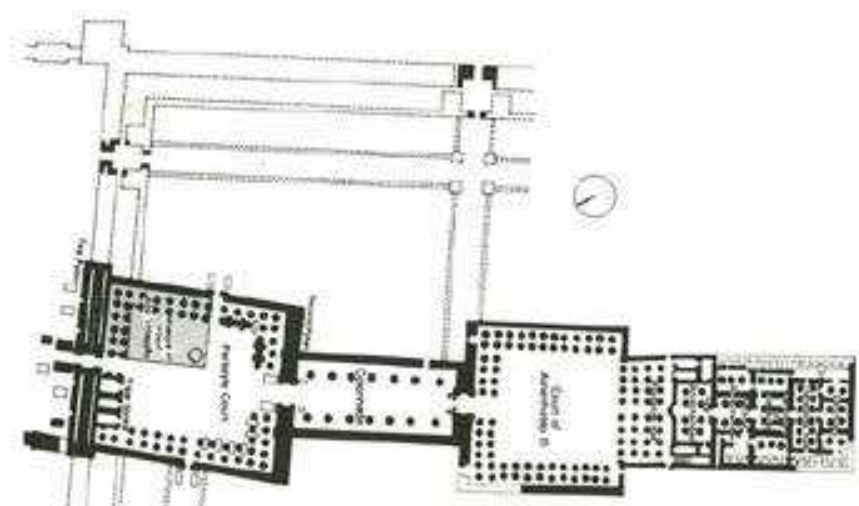

Fig 3.61. Luxor Temple, Egypt, 1100 BC-1600 BC.

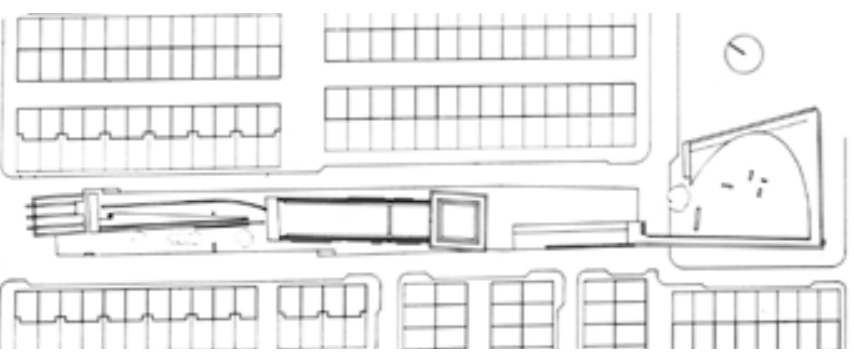

Fig 3.62. Plaza in Salaparuta, proposal, Venezia, 1986. itself with different disciplines. The unevenness of the facade, whose middle part is little higher than the rest, is faithful to the original order, presents precarious character and multiple read by playing the relations with the back wall - the elevated as overlaid layer and the embedded as part of the wall.(Fig.3.43, Fig.3.44.) Contrary to the fissures on the front wall through which light penetrates into the courtyard, interstices that delimit the remounted surface from new materials mark the surface's contour where shadow resides. Together with the broken profiles struggling to detach from the horizontal strata behind, the delicate outlines suggest an insuperable interval between the ruin and the back wall which stresses the fragility of the installed elements under the risk of collapse, indicating Venezia's manner to superimpose the two realities instead of merging them as a one. (Fig.3.46, Fig3.47.)

- movement of transgression

Venezia coincides the complexity of those elements possessed by different parts of the museum with the rhythmic movement, first and foremost, inside the courtyard. Instead of completely showing the old facade at the very first moment, the subtly elevated floor seems to refuse a casual walk up to the platform, convincing people to follow the lateral pathway that leads to gallery on the ground floor. The trench-walk between the remounted facade and the elevated floor presents itself as an external route parallel to the journey inside the gallery appears at. The oblique border at the end turns the way, then, three steps bring people up to the platform, where the ramp starts a trying ascent.

Venezia uses the old facade as not only a physical barrier between the exterior and the interior, but also a metaphorical interface between the past and the present It underscores his concerns about making the ruin convey, largely, at the level of sensibility rather than in the operational terms in the self-referential space. Since the

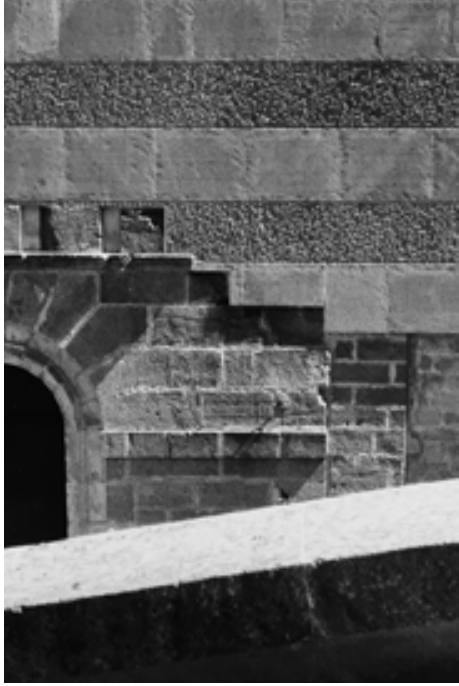

Fig 3.47. New and old materials.

downward trend that indicates a further place possess of a closer relationship with the landscape underneath the floor on which we are standing.

In spite of the atmosphere stimulating further movement, the theatre does not offer an easy approach. The sunken auditorium sees a paradox of separation and connection, either a broad pit denying crossing or a down-up move towards the edge on the other side. Venezia plays with the relation between construction and floor slope to create the qualities which are not coincident, but he also suggests a rational read of the program to unfold the concealed fact of how to use the architecture through the movement along with its itinerary. On the top level, identity of the auditorium as construction is greatly reduced as the floor rises, its protruding body from the ground gradually submerges into the earth and finally becomes part of the plain. Nevertheless, its closed and slightly elevated outline made of travertine ensures a strong boundary between the two parts. It marks on the ground a limit which does not allow to enter, consequently, it turns the way deep into the entry square where a broad descent provides an open access.

By transferring focus from the axial to the lateral, Venezia proposes an itinerary at the theatre, on which optical axes is not coincident with the way of moving through the architecture. Visitors have to reserve their will to connection and participate into the building. This strategy of movement merits a comparative analysis with his another unbuilt project during the Belice workshop - the Plaza in Salaparuta, inspired by the Luxor Temple in Egypt.(Fig3.61, Fig3.62.) In order to discipline the vast urban space, the project comes from an idea of displacement by playing with the relation among a succession of enclosed gardens and pedestrian plaza. Tension is created from dislocation of different courtyards where floor slopes and grooves provide a constant oscillation between movement direction and the axial view towards the plaza at the end. 


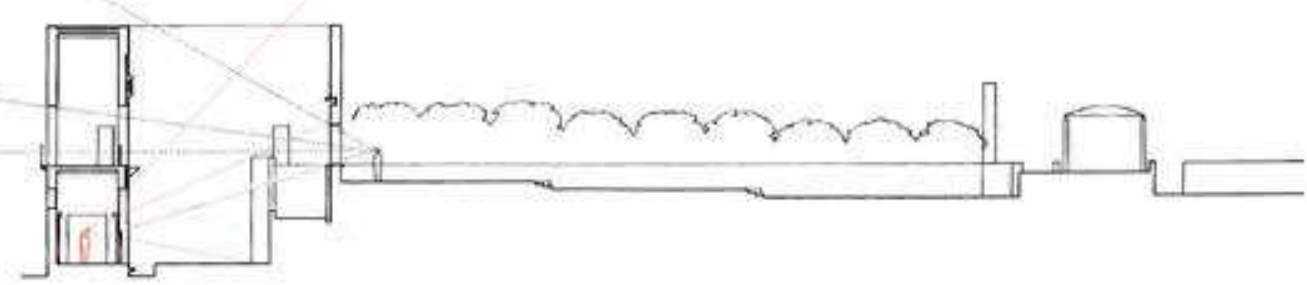

Fig 3.48. Visual analysis. redrawn by author.

gallery was left unfinished and remained closed, the architect's intention of the interio room could only be assumed by his section drawing.(Fig3.48.) The gallery creates a flashback of past experience by permitting people to penetrate through the old facade and looking out through its five openings of doors and windows. Outside, the ritua ramp and the small window above, impressively contrasted in dimension, weight and materiality, show the spectators inside the gallery an image composed of sedimentation of earth and constant alternation of light and shadow. When walking through the trenchwalk outside the gallery, a strong sense of tension derived from tactile reception prevails the movement due to its extreme closeness to the facade.(Fig.3.49.) Since the conflicts mentioned with the back wall, the remounted facade trembles and slips out of focus. By stressing the experience of uncertainty, Venezia manifests a paradoxical inscription of historic tissues into the present background.

To balance the instability generated from the facade, rigorous geometry is applied by Venezia in the courtyard layout to ensure a certain spatiality. The rectangular space of proportion 1:4 and the ramp subdividing the short side in 1:2 give a compressed scale, as the architect puts in, in order to "create a space on the scale of the San Lorenzo facade." 163 (Fig.3.50.) Neither for receiving an overall image of the heritage nor for promoting architectural promenade as much as the trench-walk, the elevated floor is set as an interval between the ramp and the facade, where the need for contemplation silences any other technical or functional consideration. Venezia defends the proportion in this central space by showing his pursuit of the measurement of human body.

"It is noted that the map of the Gibellina museum can contain exactly the outline of the human figure, coinciding the two structural joints with two salient parts of the human body: one with the navel and the solar plexus, the other with the knee." ${ }^{164 *}$

163. Venezia, Francesco, 10.

164. Venezia, "Temi," 79

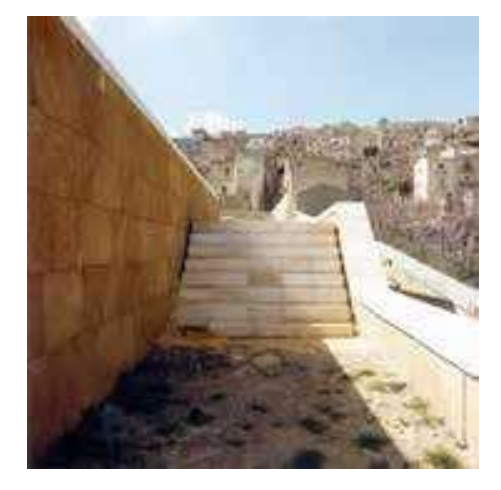

Fig 3.63. The peripheral route.

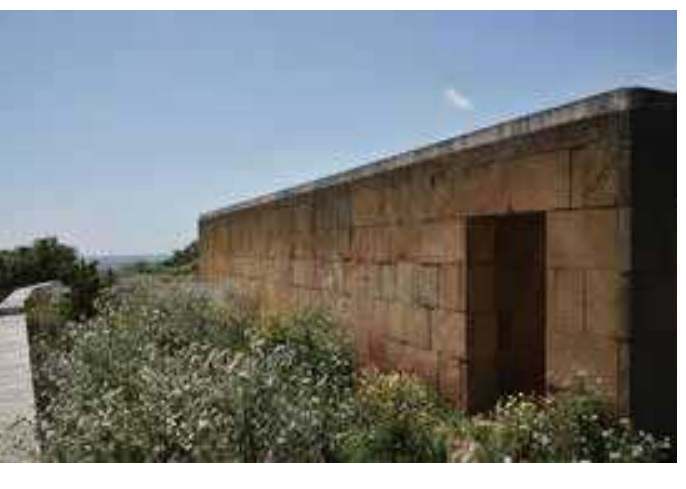

Fig 3.64 The terrace.
Fig 3.49. The trench-walk.

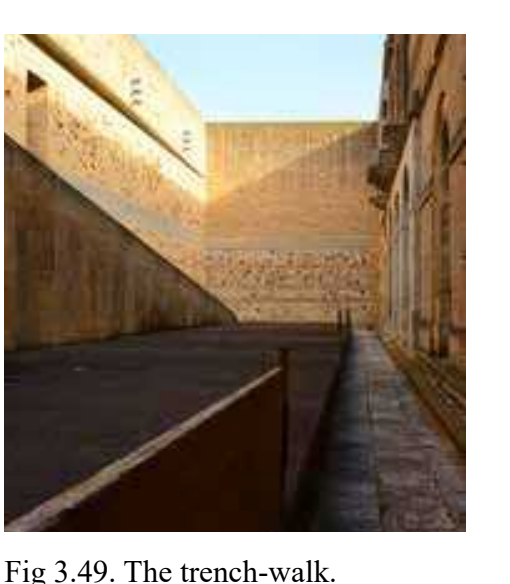

\section{西}

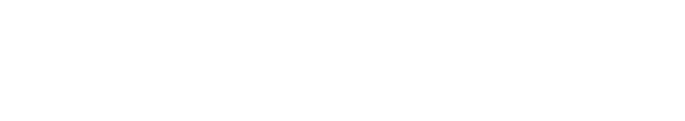

In Salemi, deviation in movement becomes a sense of being exiled from the main space - one is obliged to leave the dominated position, where the entire auditorium and a panoramic view of landscape are presented, for a peripheral route with limited connection with both the artificial and the natural space. This descending way sees a procedure of marginalization in two aspects.(Fig.3.63.) First, it accentuates an experience of outside the building by pushing people out of the boundary and removing the exhibition of interiority. The downward floor and the auditorium wall on the side separate people from the saddle place where seats and stage are placed, thus they no longer possess the predominance over the architecture and being excluded from its core domain. Second, it converts the open square into a semi-enclosed passage, so that the distance view of landscape seen from the entry square where the construction acts as geometric measurement is now replaced by a combined image of the suburb, the rural field and the natural scenery. Venezia devotes this passage on the lateral to a transmission of spatiality that forces one to distance himself/herself from the experience he/she had before, and to go into a new path towards the circumstance which is not revealed yet.

By holding the will of connection, people walk into a play between internal and external space and the act of arriving to a place, to discover that one must walk by the obstacle which separates him from the previously visualized space to arrive to the initially imagined place - the terrace on the historic level that open to the landscape. This platform on the edge sees Venezia's tendency to remove all the signs of construction - its soil floor that cultivates vegetations becomes part of the earth and the elevated auditorium is left behind - aiming to alter the way of observing as that on the upper level.(Fig.3.64.) Since artificial references and constructional measurements retreat, it is impossible to establish a version of perspective from the terrace: people are pushed to the frontier to overlook the landscape as totality with which their relationship is confined to a motionless term. It results in a particular link between spectators and the objects they are looking at that illustrates David Friedrich's paining, as professor Juan 


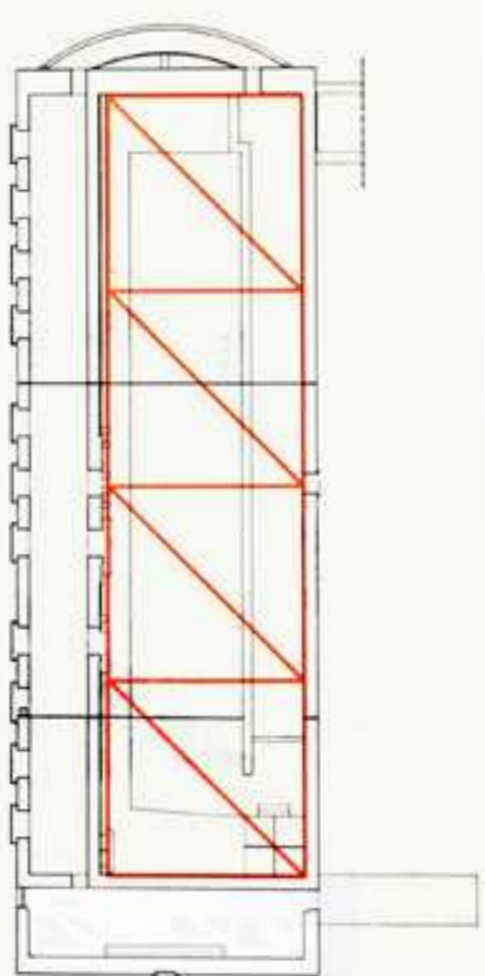

Fig 3.50. The courtyard proportion

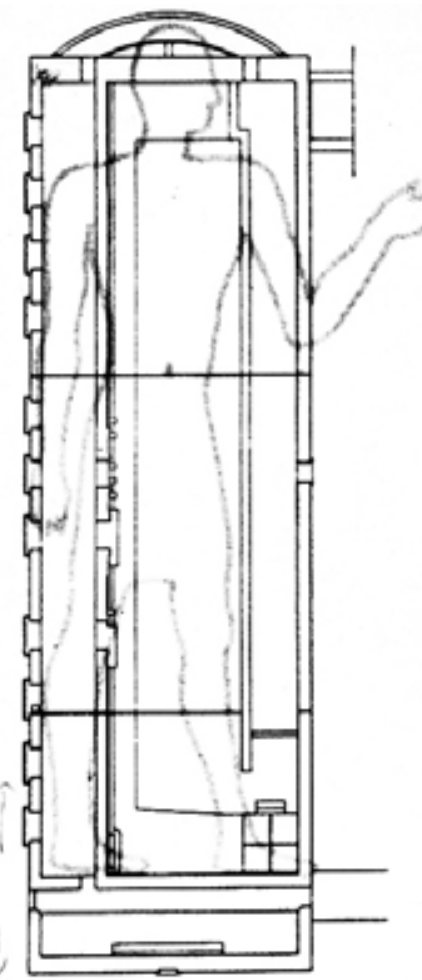

Fig 3.51. Proportion analysis, Venezia.

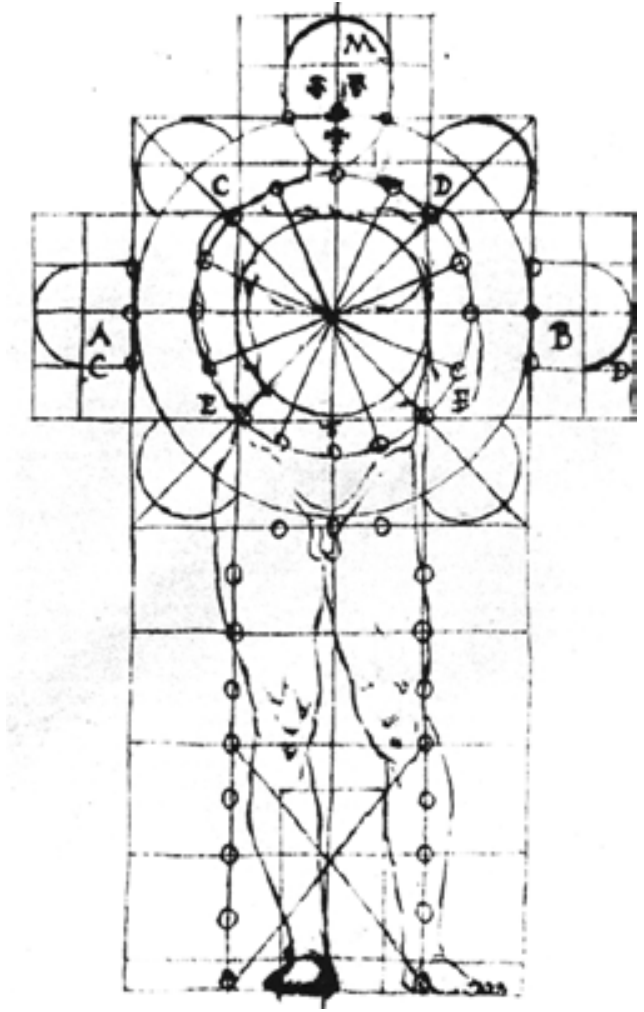

Fig 3.52. Basilica plan by Francesco di Giorgio.
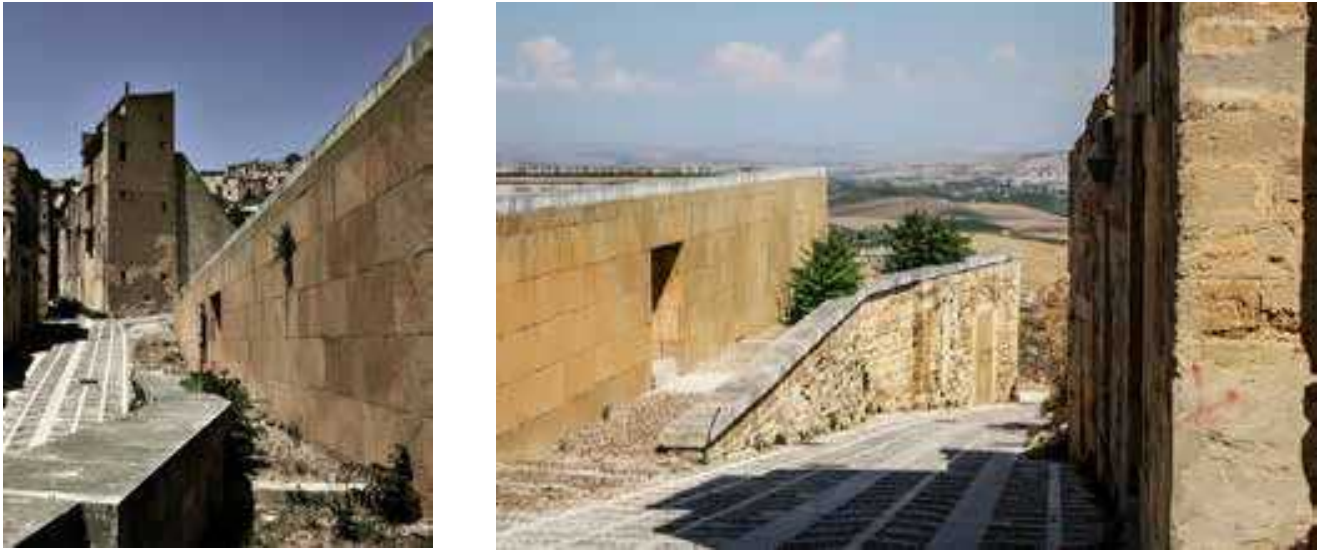

Fig 3.65. The final course of the peripheral route.
Though Venezia admitted it was a discovery after the project, the illustrated coincidence reveals the architect's visceral sensitivity of constructive harmony through classical research of having used architectural framework built by adopting human measurement. Obviously, references to those predecessors, among others, from Ancient Egyptian buildings to those Renaissance masters, Francesco di Giorgio, Leonardo da Vinci and his life-long master Le Corbusier, have been widely metabolized and are never too evident. The anthropomorphic measurement in Renaissance churches standing for the divinity is represented by Venezia, in an imperceptible manner dedicating to the metaphors in this museum as a fascinating ruin, regarding to destruction and reconstruction. (Fig3.51, Fig3.52.)

Dark lava stones unify the elevated floor and the ramp as a ground thing who has detached itself from the walls by the trench walk on one side and the recessed border on the other.(Fig.3.53.) The striking clarity in the successive layers of the ramp suggests a detained journey and its dialectic between passage and mirador, together with the short barrier revealing a risky walk close to the edge and the small door on the top Venezia postpones the complete exhibition of Palazzo di Lorenzo facade to the very last phase through an ascending way with a great enrichment of perceptions - the upward movement not only brings a surreal experience to look at the heritage, but also proposes a process of transgressing the disciplines which symbolically divide the building into the bottom and the top, referring to the subterranean world and that above the ground. In this highly sophistic arrangement of elements as if a montage of different events, Venezia organizes the circulation in the courtyard as a gradual approximation to those metaphoric messages of the temporal and the telluric, which ultimately come together in the sense of transcendence along with the ritual climb.

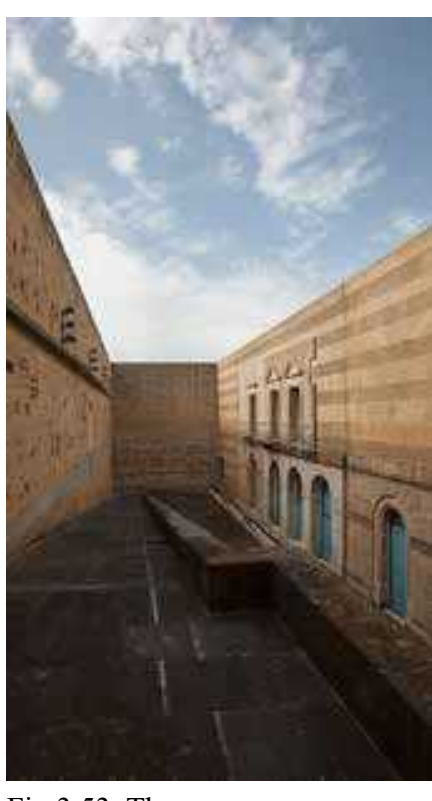

Fig 3.53. The ramp.
Miguel Hernández León called "una paisaje sin limite aparente, una lejania difusa que se extiende delante del personaje, y que, ahora, nos vuelve la espalda." ${ }^{169}$ Therefore, this terrace as it achieves a progressive approach, in short, aims to respond in this way to the will of connection.

After the terrace, a narrowed path changes the leisure walk to a hurry move back to the auditorium. Venezia proceeds to make it based on contextual consideration and measurement possessed by the theatre. In order to ensure it to be horizontal, the base wall that barriers the path passes over the auditorium door and stops at the meeting point with the declined floor, letting the rest trajectory rising without a solid border. (Fig.3.65.) This occasional termination of the structure that breaks away from the geometric scheme of the whole building could be seen as Venezia's compromise to clarify the respective order of the construction and the ground.

The task of the peripheral route and the central auditorium is not, however, to confirm claims of exclusivity in architectural discussion, but to make visible - by means of transforming, respectively, all the disagreements into constructive order rooted into the site and sequential approach to the landscape - the connection between people and the territory. In other words, the form of the architecture has integrated the topographic and emotional appeal of the ground with the logic and the meaning of the building process.

169. Juan Miguel Hernández León, Ser Paisaje (Madrid: Abada Editores, 2016), 40. 

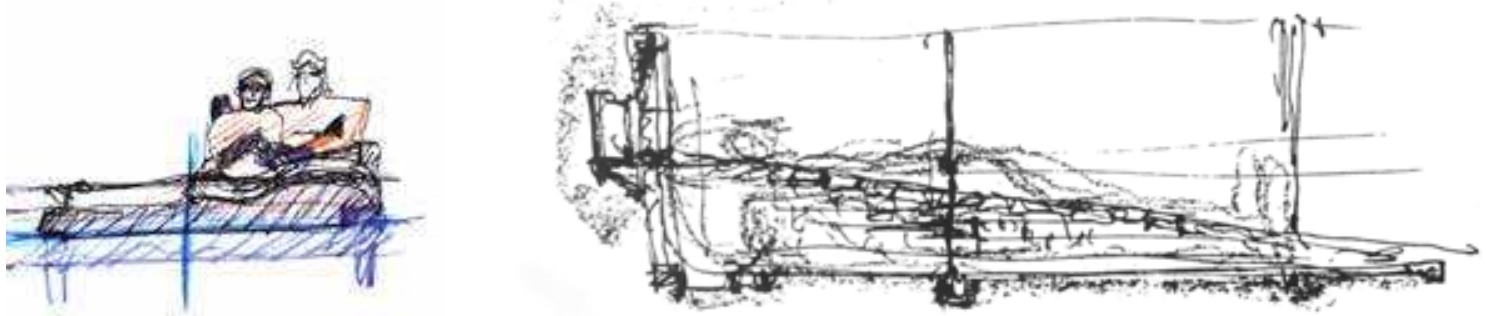

Fig 3.66. Etruscan sculpture and Gibellina museum with a lying human figure, sketches of Venezi

$\S$ Epilogue - against exhaustibility

"When I speak of harmony, I am referring to the fact that in a building a sedimentation of essentially geometric decisions is created. It is important that the different geometric systems are not coincident, for me it is of absolute importance. When the coincidence of all systems - proportional, of materials, of joints - occurs, we have the death of architecture. Architecture becomes boring, it loses the richness of its temporality. It loses its ability to unfold over time., ${ }^{, 170 *}$

Venezia's obsession with interactions of different systems presents in his building as an impulse to subdivide the space. His emphasis of the bold joints in Etruscan sculpture (Fig3.67.) or the admiration for the dual systems of Ronchamp as "a building in reinforced concrete and one in stone." revel the architect's purchase of the intrinsic monumentality in a form as fixed entirety because of gravity, and an insecure relationship of those components which are put into the tension of detachment from each other. His remarks on the richness in architecture brings a force, that architects should possess a cognition of time as historians and archaeologists have, which is, time never coincident, nor does those events happened in different moment. This idea provides critical way to fight against the varnished harmony due to the absence of temporal narrative in today's architecture. Architecture should be, and it only could be, a set of forms representing different facts.

The meaning of Venezia's works is also derived from a "fragmentary" situation, which plays the key role to demonstrate different events and to show a set of narrations about

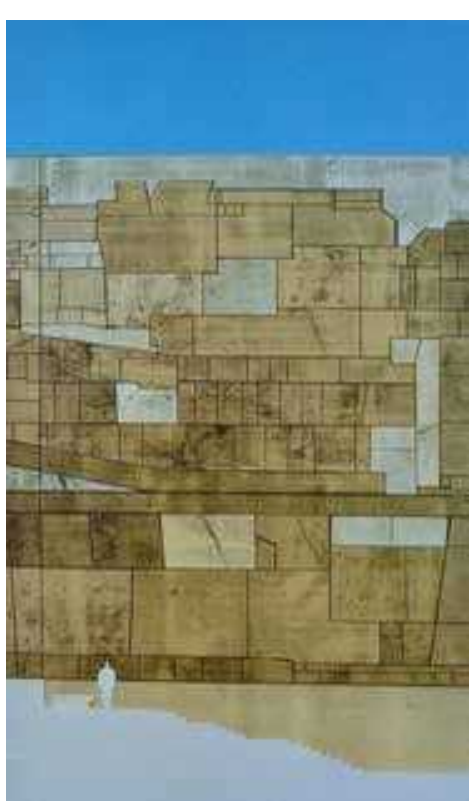
Venezia, Berlin, 1997
Fig 3.68 External wall of Neues museu

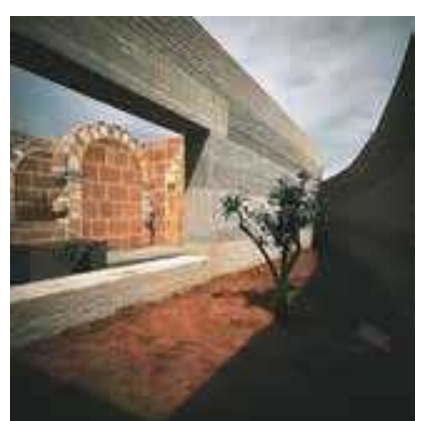

ig 3.69. Small garden in Gibelli Venezia, $1985-88$

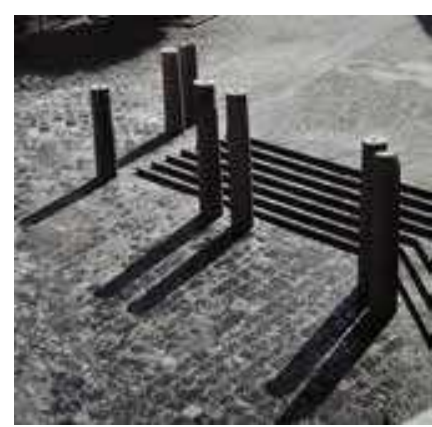

Fig 3.70. Urban Restoration in Patierno, Naples. time. The external wall of cyclopean masonry in his proposal for the amplification of the Neues museum, Berlin (1997) (Fig3.68.) reproduces the sense, in a more geometric manner, of the reassembled facade in Gibellina museum and the base wall of Salemi theatre; and just like the capitals and plinths which characterize the small garden in Gibellina (Fig3.69.), the recovered columns elevated in the urban plaza (198899) (Fig3.70.) next to the Chapel of San Pietro in Naples bring archaic tone to the contemporary city. Through the approach of communication, Venezia juxtaposes the untimely situation of old elements with the present condition. Those distortions, fissures, displacement that set their relations into loose connections to enable variations, become a conceptual effect of distancing between different realities. From this point of view, his strategy to superimposing structures is not the reason of building, but is the result of presentation of the autonomy of different elements and events in one architecture. It is this relationship established by approaching rather than merging with each other makes those historic vestiges only to be taken as referential elements, but never to be incorporated as part of Venezia's architectures. The paradoxical relation of distance between forms somehow has explained Maurice Blanchot's notes about friendship:

" the pure interval that, from me to this other who is a friend, measures all that is between us, the interruption of being that never authorizes me to use him, or my knowledge of him (were it to praise him), and that, far from preventing al communication, brings us together in the difference and sometimes the silence of 


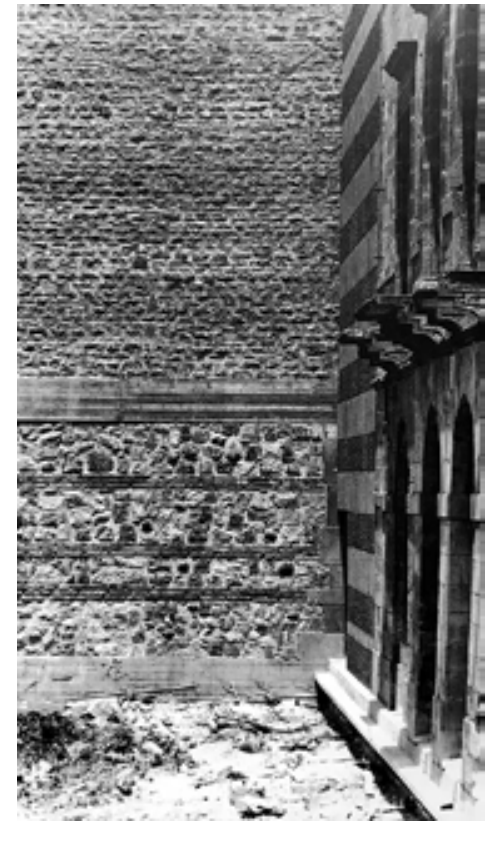

Fig 3.71. The facade connected with different materials. speech." ${ }^{171}$

Apart from the dialectical solidarity and the quality of uncertainty, tension in Venezia's works in Belice is also derived from the closeness to the ruins. Tactile perception from those old fragments turns the buildings into touchable history. As Walter Benjamin stressed the value of the feeling from fingers or skin: "For the tasks which face the human apparatus of perception at historical turning points cannot be performed solely by optical means-that is, by way of contemplation. They are mastered gradually-taking their cue from tactile reception through habit", ${ }^{172}$ those fragments on the walls and ground, supported by new structures, resonate with people's sensation as testimony of destructive event and the telluric forces which subverted the urban fabric as well as life style of this region. (Fig3.71.)

Apart from the way of arranging and suspending elements to trace for a retrospective experience, there is a recurrent paradox in his architectural promenade, between continuous itinerary and ambiguous articulations, that explains his works as subtle programs of equivocity. In fact, rather than a preset order which people must obey, Venezia conceives circulation to make people learn and make choice. This strategy in directing movement in architecture reflects a perfect equilibrium between instinct an intellect, which is quite the opposite from the method to compose the promenade totally "fit in" the building scheme.

171. Maurice Blanchot, Friendship, trans. Elizabeth Rottenberg (California: Stanford University Press, 1997), 289

172. Walter Benjamin, The Work of Art in the Age of Its Technological Reproducibility, and Other Writings on Media, trans. Edmund Jephcott (Cambridge: The Belknap Press of Harvard University Press, 2008), 40
The hidden texture of Venezia's architectures is composed through operating the overall scheme with figure-ground system and connections between the whole and parts in different levels. The divergence, deviation and a tendency of detachment from each other enable his works to escape from particular paradigm, where the constan ambiguity and contradictions seem to be activated by a dialectics of temporality, mobility, spatiality and the recurring transgression between structural and plastic elements.

Venezia's capacity to sophistically conceal geometric accuracy, spatial compactness and economy behind the narrative of uncertainty grants his architectures fascinating richness to against exhaustibility. He devotes controlled intervention of disciplines rather than some careless mixtures to achieve the multiplicity of architecture. The value of possibilities especially shows its importance and bravery in Belice. Because when confronting with the disturbed sensitivity in the trembled ground, it is neither the antiseismic constructions nor the homogeneous town spaces which speak of ideology and political slogan against the fear of earthquake risk, but is the sentimental monument enable to recall and produce, would convey perennial values. 

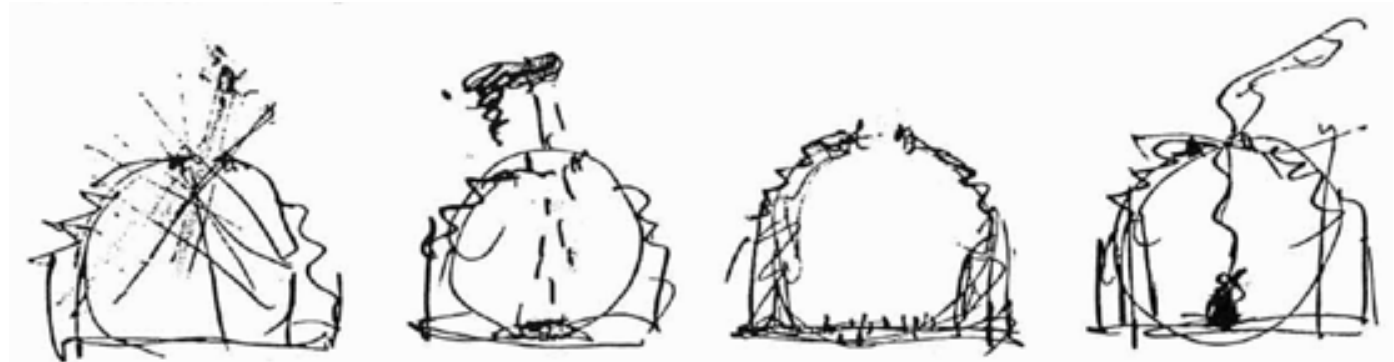

Fig 3.72. Sketch of Pantheon, Venezia

\section{IV. "IN FORMA ELICOIDALE": MOVEMENT THROUGH SENSATIONS}

"Space as a whole is concentrated in the emptiness through which the daylight and seasons, penetrating inside of the cavity, measures the rites and prayers, or the everyday facts of domestic life." ${ }^{173}$ By relating the Pantheon to the villas in Pompeii and Herculean, Venezia points out the conjunction between the sacred temple and vernacular houses resides on the penumbra within the building. (Fig3.72.) Coexistence of daily routine and the variation of natural ambient is realized in the man-made void space that, as the medium that receives, mediates between the individual and the outer world.

This archetype of space and its mythical aura is evident in Venezia's design. A similar scheme - an encompassed space open to the sky so that light, air and rains can enter into the interior - can be found in the Alcamo garden (1980), the mausoleum project in Sicily (1992) and the exhibition hall of the Neues Museum (1994). Among others, the Gibellina museum and the Salemi theatre, with their external structures that deeply roo into the ground and the internal cavity representing the subterranean condition, see a great effort made by the architect to achieve transformation and stratification in favor of a centralized layout.

Venezia compares the formation of space with the making of a clay jar. The materials superimposed on the exterior and the growing interior cavity interpret "Un tempo in forma elicoidale" (a time in helical form) - "The time that we are able to stretch

173. Francesco Venezia and Gabriele Petrusch, "Usque da infera usque ad coelum," Quaderns D'arquitectura I Urbanisme, no 166(1985): 141, Barcelona: Col-legi d'Arquitectes de Catalunya, http://www.raco.cat/index.php/QuadernsArquitecturaUrbanisme/article/view/203916/298186. between the fossil pieces, on the outside, and the newly formed pieces that accumulate inside, along the processing cycle, is the same time as the building." ${ }^{174} *$ In Venezia's architectures, the shaping procedure is represented by a uninterrupted flow that moves from the bottom to the top around the static image in the center. He seeks to design helical circulation insdie the building which in turn effects on the building shape itself. This structure of movement stays prominent from his very first work of Lauro plaza, to the radical proposal of Amsterdam Rijksmuseum (2000) in which the labyrinth buildings at the museumplein materialize a circular movement to hold a new 'treasure house' of Dutch art in the heart, and returns to a simple form in the recent Pyramid in Pompeii (2015) paying homage to Étienne-Louis Boullée. In Belice, spiral itinerary plays a key role in the narrative of territory continuity of the museum and the theatre.

Venezia attributes the inspiration to Giuseppe Terragni and his Danteum (Fig.3.73.), thinking highly of the essential idea based on movement and circularity. "In my opinion, the theme of the spiral is an important workhorse for modern architects. Terragni is a master of movement according to the spiral." ${ }^{175 *}$ What he admired most from the unbuilt monument is the coincidence of spiritual and constructive aspects with the movement as an absolute factor of form. What he admired most from the unbuilt monument is the coincidence of spiritual and constructive aspects with the movement as an absolute factor of form. As the articulation between Pantheon and vernacular

174. Venezia, "In forma elicoidale," in Scritti, 35 .

175. Venezia, "Temi," 80 

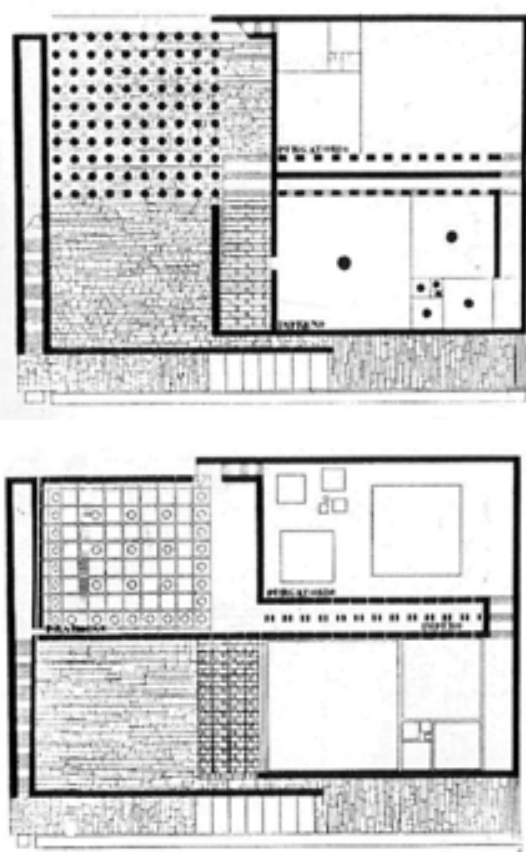

Fig 3.73. Danteum, Giuseppe Terragn 1938.

houses, it is the continuity in architectural process, as Venezia said, "a progressive transference of the structural, functional and its relation to something purely formal."176 that integrates spatial form with people's bodily movement and experience.

This conception of transference has set the basic law according to which Venezia started to conceptualize the monuments in Belice. Circuitous Itinerary is orchestrated in Gibellina museum and Salemi theatre as fundamental factor that helps to shape the buildings in a spiral form, and at the same time it equips the centralized space with extraordinary mobility on the perimeter. The meaning of a spiral route is emphasized by the movement of repeatedly passing by the same place through different levels, through which the experience is alternated between anticipation of departure and expectation of return. It is a process keeps completing a certain impression as well as a drama that evidences the partial superimposition of spatiality. In the museum and the theatre, circulation interweaves with variation of light, enclosure and scale, depending on the internal spaces that interact with each other or form an independent circumstance, and so the architectural promenade keeps altering the sense of connection and separation that plays with the spatiality of position (where) and the spatiality of situation (how) As a result, perception of a particular place could be similar to one another or become totally misfits from different levels.

Though being organized according to the similar strategy, itineraries of the two buildings see operational differences: while the museum with entry and exit provides clear orientation allowing people to get out of the architecture, the theatre structured by a circulation less rigorous was conceived to provide an endless journey.(Fig.3.74, Fig3.75.) Besides the two works, the small garden and pavilion in Gibellina that were

176. Venezia, and Petrusch, “Usque," 142

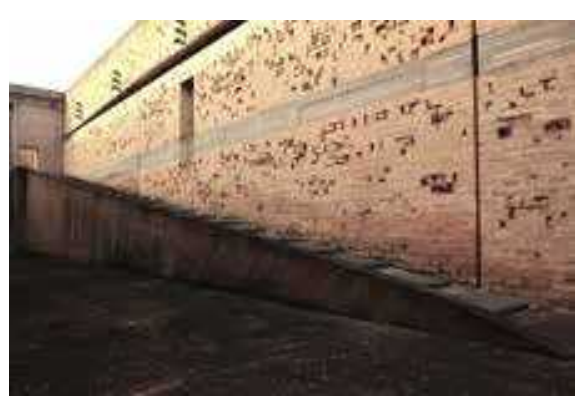

Fig 3.74. Ramp of Gibellina museum

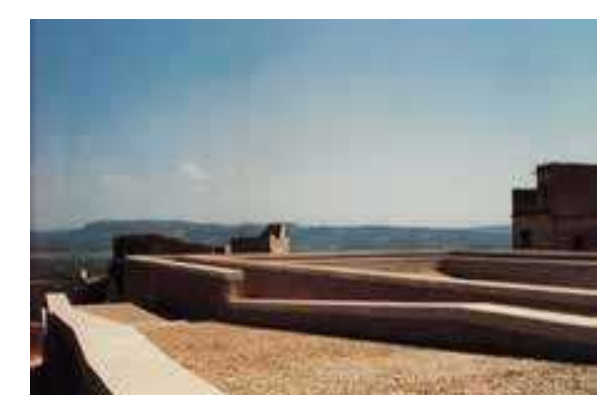

Fig 3.75. Lateral pathway of Salemi theatre.

also designed and built according to spiral form present the circulation in a smaller dimension. They will significant references to analyze Venezia's strategy to develop the movement inside an architecture through arranging the order of space and provoking visual perception. 


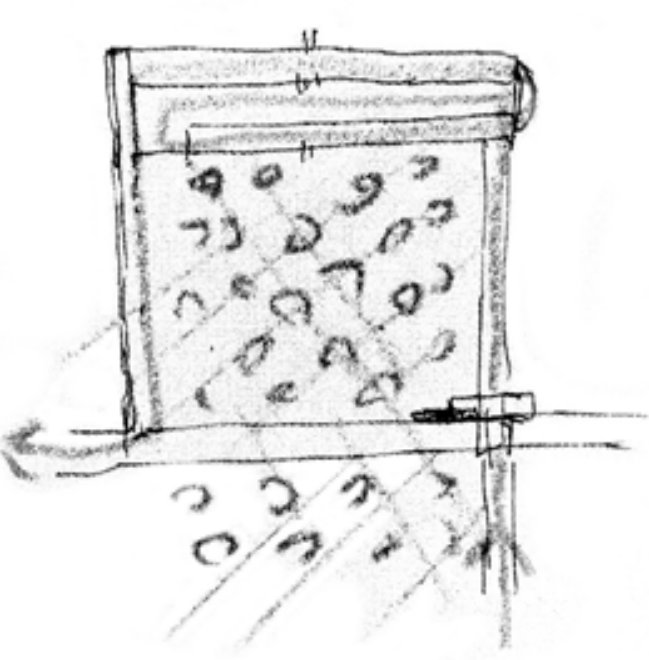

Fig 3.76. The museum route sketch, Venezia.

$\S$ A private journey

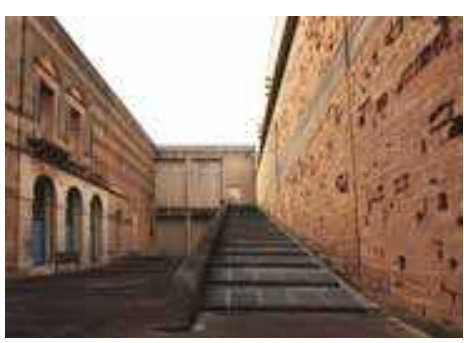

Fig. 3.77. The ramp.

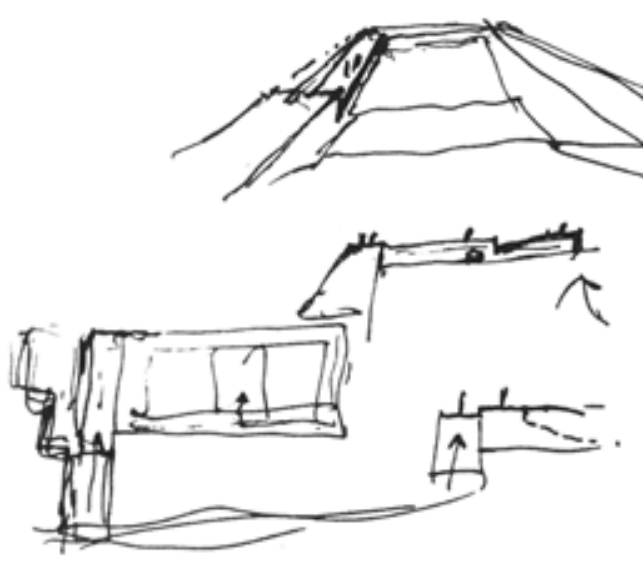

Fig 3.88. The theatre route sketch, Venezia.
Venezia integrates the helix form of Gibellina museum to the orthogonal framework. The ramp slowly rises the circulation on the ground floor up to the upper level made of three parts that are relatively independent with each other - a hanging bridge which set itself apart from the building, a long gallery with windows on both sides, and the "reposo" cabin in the end where an exit to the outside garden is placed. (Fig 3.76, Fig.3.78.)

The ramp goes up as a ritual departure from the courtyard while it is providing an extraordinary perception of the facade of Plazzo di Lorenzo that people's movemen becomes resonant with the fluidity of the old surface and its weak connection with the back wall.(Fig3.77.) Moving towards the concrete cross that comes out of the wall, the trying ascent would impress visitors with a paradoxial feeling: you have to go through a departure way in order to have a better position to observe the old facade. Venezia controls the height of the ramp to prevent people from looking to the outside through the window so as to ensure their focus on the Plazzo di Lorenzo. This ascending trajectory is regarded as a development of spatiality of situation as well as a return of spatiality of position: the small platform at the end of the ramp is rightly above the vestibule from which people entered into the courtyard, representing the circulation of a spiral structure - it ends up at the point where it started.

Being invisible from the courtyard and from the ramp, the narrow bridge hanging outside becomes a totally unexpected encounter for the visitors. It suddenly extracts
$\S$ Towards the infinite

- exchange of relationships

Movement towards the sunken auditorium of the open-air theatre in Salemi has to address double needs: on one hand, to create a rigorous and precise program in keeping with its theatrical use, on the other hand, to recapture an architectonic language, and to fulfill the commitment the site and its history have towards people, representative as they are of one of the group confronting with the territory. (Fig3.88.)

The theatre distributes a long walk to the peripheral that highlights its identity as topographical intervention to recover the position of the site towards the territory. Venezia has designed a continuous itinerary as an assembly of two reversed spiral routes - the downward one on the outside declines from the entry square to the lower floor, and the upward one goes into the auditorium, climbs up the stairway and returns to the top. (Fig3.89.)

Enter through the short doorway of a rigid geometry, people who have turned their back to the majestic landscape on the narrow pathway on the terrace, now, are conducted into the interior space by the passage on the bottom that bisects the auditorium.(Fig3.90.) Symmetry of this wrapped space is achieved by slopes on both sides - the stage in cobblestones and the steps of lava stones used as seats and stairway - which rise from the bottom, giving the in-between route a strong sense of immersion, suggesting the arrival at a subterranean space after all the circuitous passages on the upper side. (Fig3.91.) 


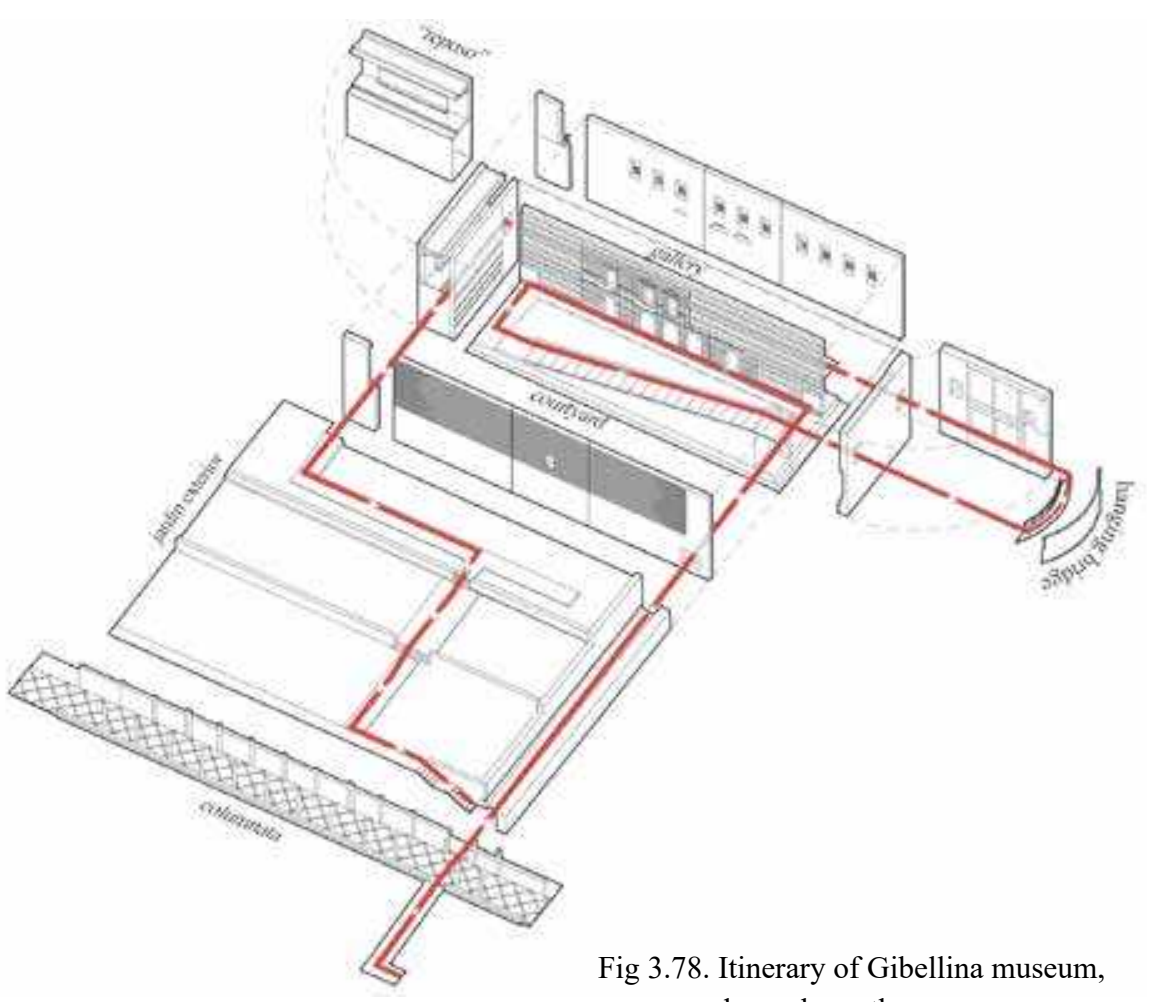

drawn by author

people from the ritual walk, cuts off their connection with the thematic narrative and absorbs them into an exiled circumstance. A bold interval between its floor in curved shape and the external wall of the museum illustrates the bridge as a floating space which not only disengaged from the building but also far above the ground. The beam underneath which bisects the passage, as the only joint element that indicates the architecture's symmetry. Venezia also relates this exiled structure to human body: "the external hanging passage in turn coincides with the skullcap: there is an analogy between the anatomical shape of the skull box and this passage." ${ }^{177 *}$

The curved-concrete shell elevates a solid enclosure. Fissures at the end are not for looking out but to emphasis Venezia's idea of detaching this bridge from the building. (Fig3.80.) This is a space without event. It has been pushed out of yet has no communication with the space outside, it connects the courtyard with the gallery yet does not reveal the place it leads to - people do not know where they are going to. Venezia privileges the pathway as secret passage in which one is capable of feeling the vibration from the cantilever floor and hearing resonance of his own paces. The intensively changed spatiality and removal of communication confirm claims of exclusivity in private walk, in which a feeling of lost is provoked because both situation and position of spatiality become uncertain. To achieve the idea of "un giro salir, entrar de nuevo." 178 Venezia creates an extraordinary program of reorientation - which is operated intensively and quietly aiming to subvert the movement and experience that provisionally break away from the spatio-temporal narrative of the building.

177.Venezia, “Temi ” 79

178. Hidalgo, "Francesco," 51.

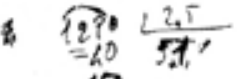
in

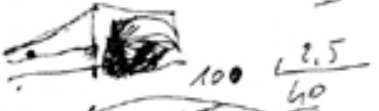
te oltivin

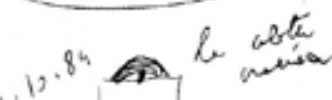
7 in

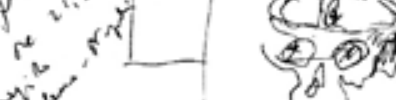

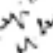

Fig 3.79. Sketch of hanging bridge,

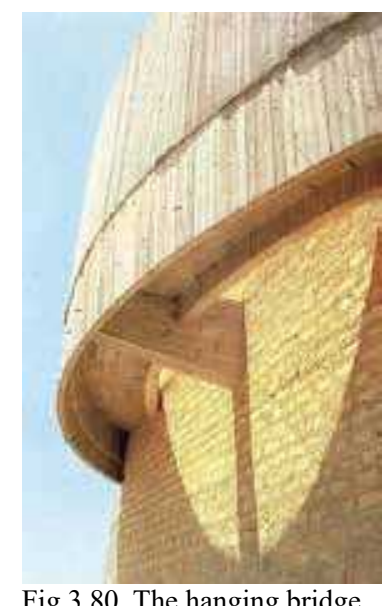

Fig 3.80. The hanging bridge,

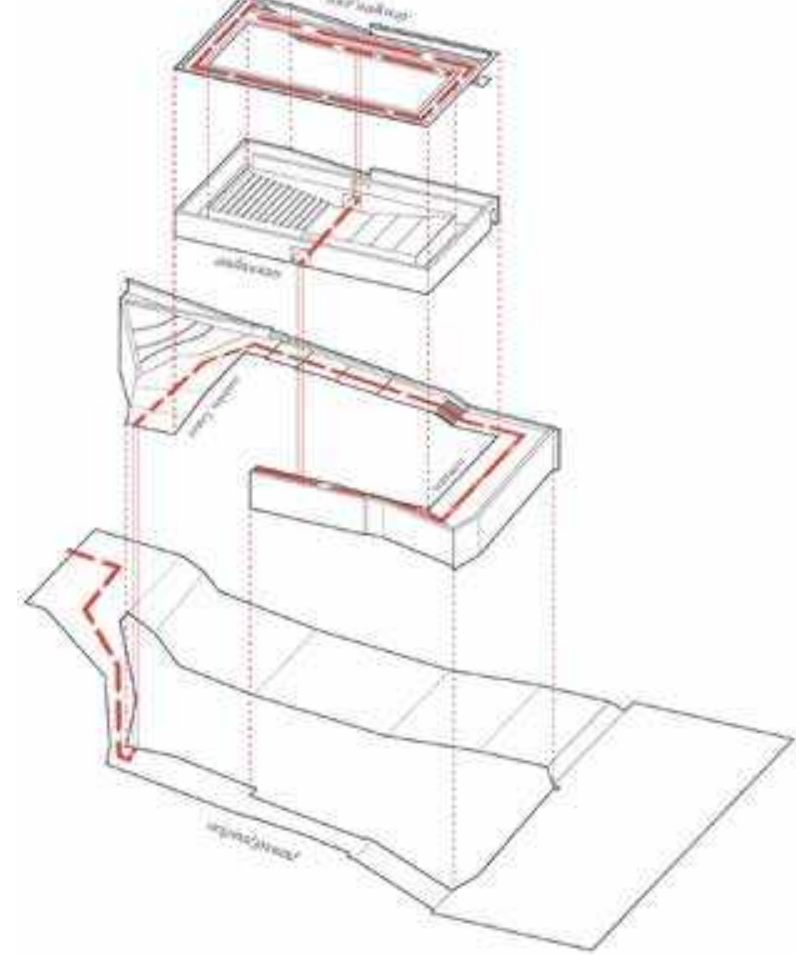

Fig 3.89. Itinerary of Salemi theatre, drawn by autho

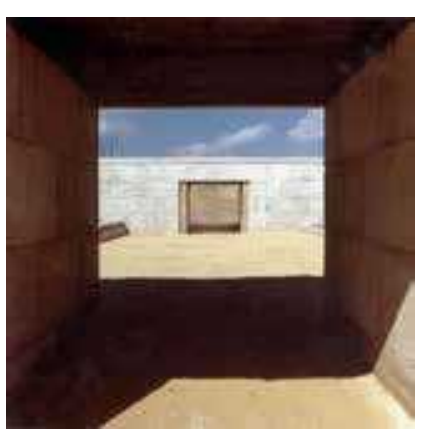

Fig 3.90. The auditorium doorway.

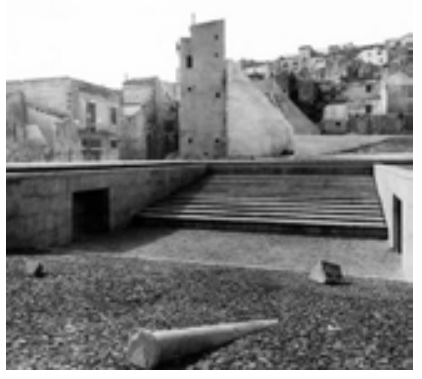

Fig 3.91. The sunken auditorium.

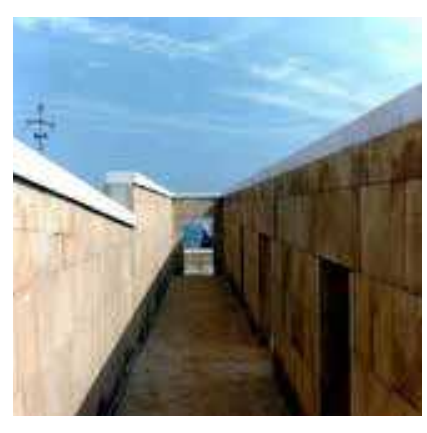

Fig 3.92. The corridor.
The decision to retrieve the convent ruins of columns and lay down them on the stage as work of scenography has materialized a disordered condition caused by seismic damage. The spiral form that structures the theatre enables people to read the ruins from different levels so as to have distinct experiences. When standing on the entry square, a symbolic mage of equilibrium is presented by the landscape floating on the theatre edge and those fragments beneath seen as still life that represent stable image of topographical sediment. Positions of spectators and the stage are, then, dramatically exchanged during the following trajectory on the periphery of the auditorium, making the next encounter of the two over a tension that the fragments above on the slope threaten to roll down, which eventually become precarious figures over this symmetric space.

In the passage adjacent to the auditorium, the restricted dimension and strictly orthogonal composition of high walls on both sides reinstate a calm space. (Fig3.92.) The deep route with restrooms on the side takes a series of conditions as point of departure: the topography, with a stairway that offers an intense ascent to the roof from the historic level, the opposite door with a selected view, gives the way back to the terrace; the minimized connection with the outer world that accentuates the feeling of immersion and lost. This transit stands out from the rest passages of theatre, which were conceived as routes to bring visitors to the open view, for its expression of narrowness and depth. By pushing this corridor out of the auditorium to conceal the link between the upper and lower levels behind the main space, Venezia manages to endow it with individual character and as a consequence, to dissolve an overall narrative. The narrow passage becomes an exiled space that forces people to go out of the core place and again to approach the superior ground. 


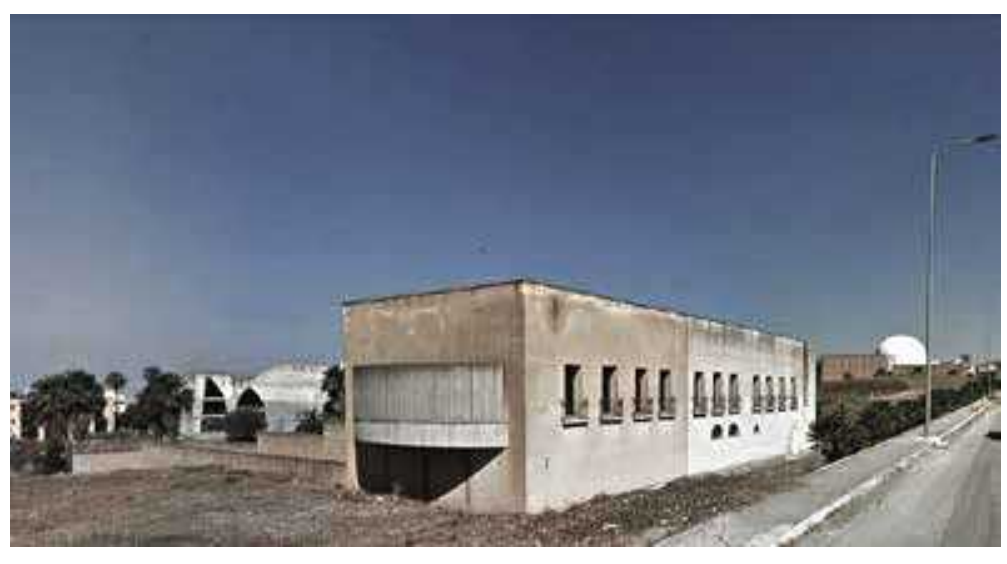

Fig 3.80. Gallery from the outside.

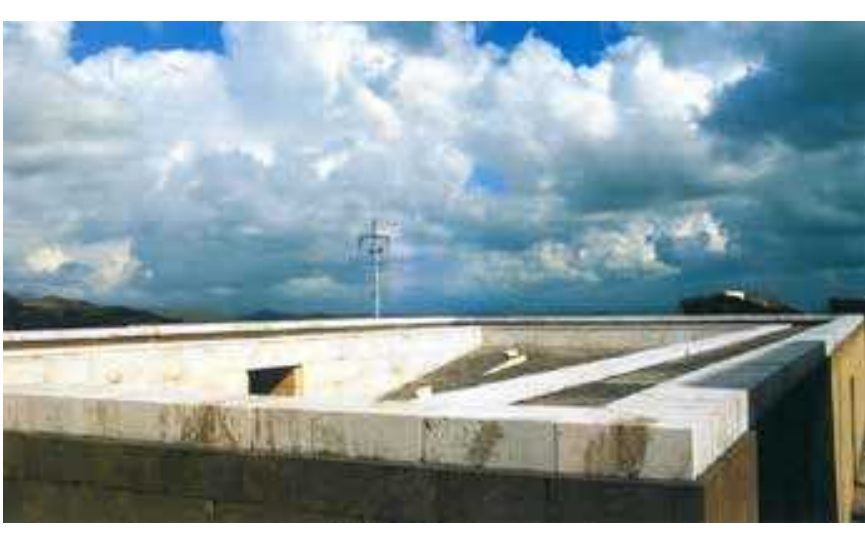

Fig 3.94. Roof walkway
The shielded passage returns to the building through the door open to the gallery on the second floor. Venezia was intended to reproduce the Mannerist sense in this interio space - "as could be the corridors of the 16th century, and these people were used to walk, talk, admire, perhaps an ancient bust, sometimes these galleries were then decorated with sculptures..." ${ }^{\text {179* } ~-~ a n d ~ a c c o m m o d a t e ~ i t ~ i n t o ~ t h e ~ m u s e u m ~ u s e .(F i g 3.81 .) ~}$ Thanks to the unfinished condition, the empty space clearly reveals the two main issues which Venezia addressed in this long corridor: to combine and interact views toward the courtyard on the one side and the landscape on the other, to establish a dialogue with the reposo at the end, illustrated by the partially revealed bench and a beam of light reflected on the wall. The first task is achieved by the play of opposing windows. The new windows to the rural side partly correspond to and continue the rhythm of those old windows on the inner façade, through which people can overlook the courtyard. The slightly dropped floor of the balcony give rise to the limit between the interior space and the exterior. (Fig3.82.) This subtle change on ground has its Islamic origin and is used by Venezia to create a rhythmic movement. By placing people in the middle position, the deep corridor presents itself as a shelter to show the representative images: the ruin and extraordinary movement resides on the sunken courtyard, the coolness and serenity in the dim gallery, and the vivid landscape of Sicilian territory.

- "reposo"

The bold separation between the gallery and the reposo breaks resting cabin from the main body of the building the connection, meanwhile, gives visitors an open view to the outside world. At the end of the architectural journey, Venezia creates an exclusive

179. Bebdetta Rodehiero, "interview with Venezia," in Permanenza e trasformazione in architettura. Gibellina e Salemi: città usate (Ph.D diss., Universitat Politècnica de Catalunya, 2008), 32.

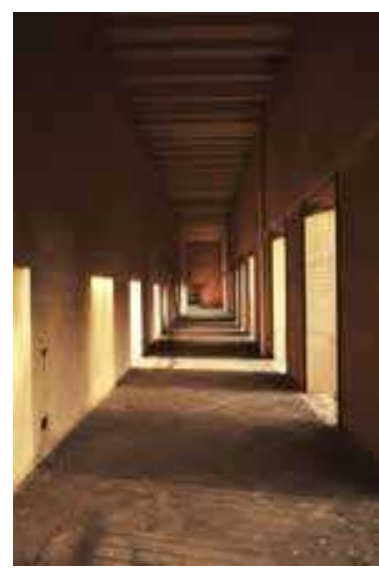

Fig 3.81. Gallery interior

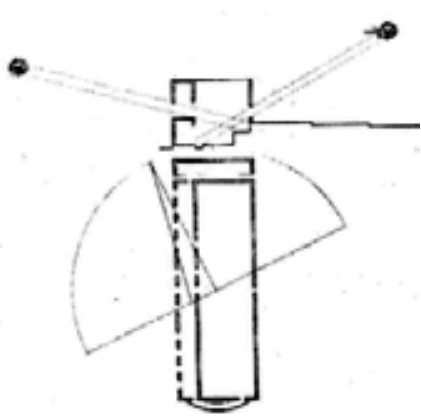

Fig 3.82. Analysis of sunlight, Venezia.

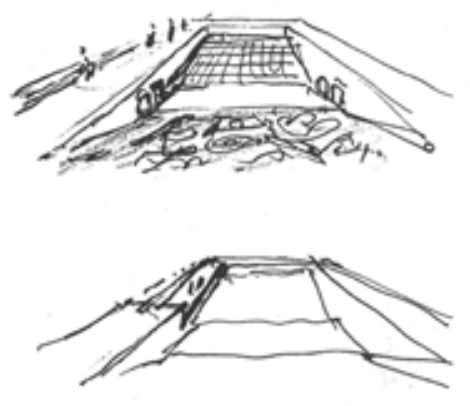

Fig 3.93. Sketch by Venezia. the loop

Venezia privileges the walkway on the roof to make it crown the whole structure and to be the last phase of the architectural promenade.(Fig3.93, Fig3.94.) It rises people to a position of all-seeing, not only the landscape and the town, but also a complete read of the theatre from the square to the sunken auditorium and the terrace at the edge. The panoramic views combine historic and topographic meanings with the help of a presentation of the pathway in simple geometry on the top being superimposed on the symbolic sediment underneath inside the auditorium, which definitely evokes the overlapped structure of the Swiss Pavilion admired by Venezia, ruins undersoil is getting in touch with the construction above the ground "in the gesture of two hands clasping, two worlds unusually put in contact: a mysterious world of earth and a solar world, dominated by geometry." ${ }^{183 *}$

Apart from the capacity of convergence, the loop route grants the theatre a supreme quality of time by its implication of an infinite movement. The strategy to use annulus form to materialize an endless circle evokes the pedestrian work made by Dimitris Pikionis at the Acropolis and the opposite Filopappou hill, in which rings on the both ends of the uphill pathways combine human action with the landscape and the grand monuments. Though Venezia talks little about the theatre's circulation, the roof passage could be regarded as his own development of the prototype of the Danteum. It tries to fulfill the task of continuing or keeping the movement after arriving at the most spiritual point on the top.(Fig3.95.) That is, in order to be capable of establishing dialogue with the natural landscape, with the melancholic ruins and the sediment inside

183. Venezia, "Teatri e Antri," in Scritti, 89. 

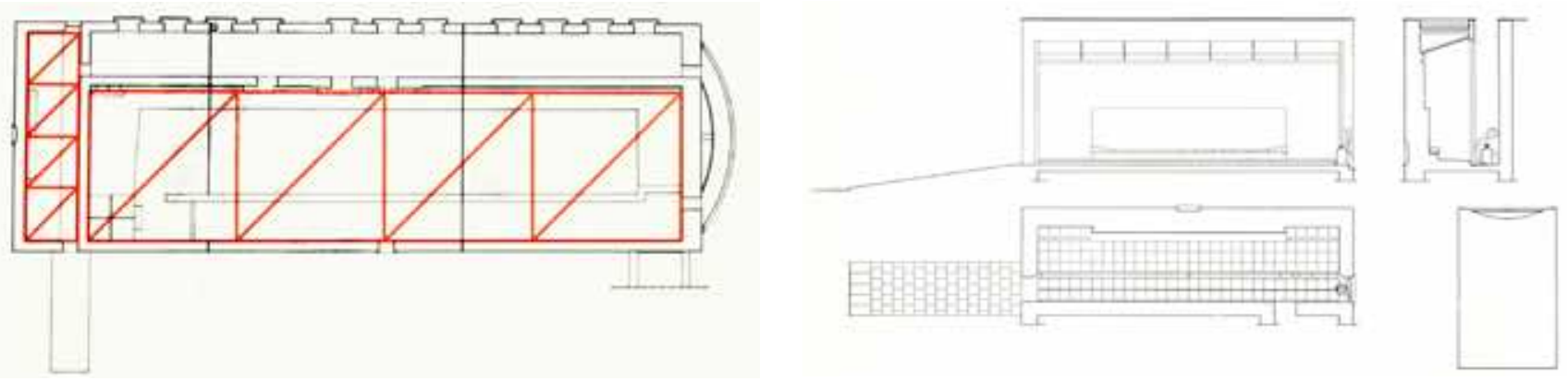

Fig 3.84. Proportion of Gibellina museum.
Fig 3.83. Plan and elevation of repose.

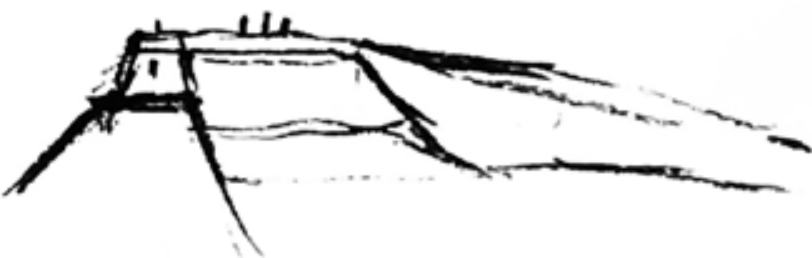

Fig 3.95. Roof sketch, Venezia. lounge that combines mobility and stability for an individual to sit and take rest. (Fig3.83.)The wide interval captures breezes and grants sunlight a pure and restricted contour. This recurrent form of roof in Venezia's works, allowing extraordinary rhythm of light and shadow, has its classical origin in Hubert Robert's temple and Boullée's Royal library ${ }^{180}$ Contrary to the pliable character of natural elements, an almost surreal archaism of silence is given by the cylindrical support over which extends the awning and the long bench beneath, recalling ancient Egyptian forms, and finally peaks at the serpent sculpture in-between the break - a snake in the cave.(Fig3.85.) The mythological Python, coiling around the cylinder and sipping from the basin, the image drawn by Friedrich Nietzsche in his Thus Spoke Zarathustra, gives "the most symbolic vision of architecture: the idea of a cavity, of a cave, as a "matrix" of architecture, and the idea of a snake as an eternal return." ${ }^{181,}$

By articulating those metaphoric elements in this space of limited dimension, Venezia devotes the reposo to an interface between the natural and the artificial, between the present and the past, to reconcile the relation with the terrain that the building as city boundary possesses, and the melancholic history of destruction it records as a ruin. The reposo is made remote and alone. It seems to be an independent architecture within the museum, as Venezia admires the separation of Ronchamp between the roof and the body underneath. The independency of the cabin is emphasized by its the proportion of 1:4, (Fig3.84.) which presents a similar spatiality of the courtyard in a smaller scale. (Fig.) This treatment of scale and dimension may give the visitor a feeling of Déjà vu, and also efficiently reduces the people's awareness about the reorientation from the long side of the building the short side.

180. In the projects of Museo della Stratigrafia Storica a Toledo and the Exhibition center of Pompeii to introduce natural light to the archeological site.(2001-02)

181. Venezia "Idee e tecniche di architettura," in Scritti, 85.

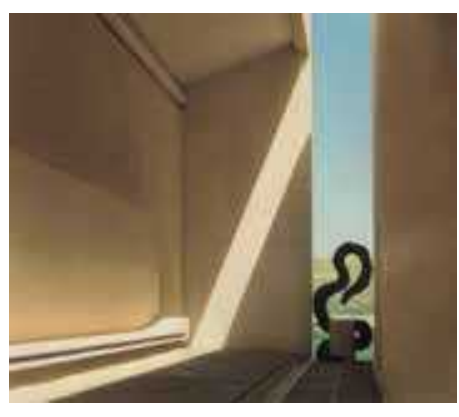

Fig 3.85. The reposo. the earth, people must detach themselves from instant terms, and the space has to be clear of functional appeals. From this perspective, the infinite journey and all the other metaphors this small theatre provides do speak of spiritual meanings of transcendence, which bridges the individual with the world, affirming the essence of theatre as Frances Amelia Yates's said:

"Pretende que todas las cosas que la mente humana puede concebir y que, sin embargo, no puede ver materialmente, tras haber sido archivadas mediante diligente meditación, queden de manifiesto mediante signos corporales de tal manera que ... sea posible, de un golpe de vista, el percibir todo aquello que está escondido en lo más profundo de la mente humana. Y pensando en esta su condición material es por lo que le llamó Teatro".

\section{the circulation that withdraws}

The up and down circulation of the theatre illustrates a particular itinerary - one must walk by the main space of the building to reach the area beyond before turning around and getting back into the said space. Venezia has applied this organization of movement into a roofless pavilion in Gibellina to show its capacity in the project of smaller dimension.(Fig3.96 ) In order to meet with the street corner, Venezia breaks the project into two parts: a square walled building subtly elevated from the ground and an open plaza contoured by parapets. The external circulation which passes by the building and connects with the plaza marks a continuous procedure to involve people into the site. The small plot in fan shape gently withdraws the internal circulation by its curved outline, determining an itinerary in helix form by turning the way back towards 184. Frances Amelia Yates, El arte de la memoria (Siruela, 2005), 155 


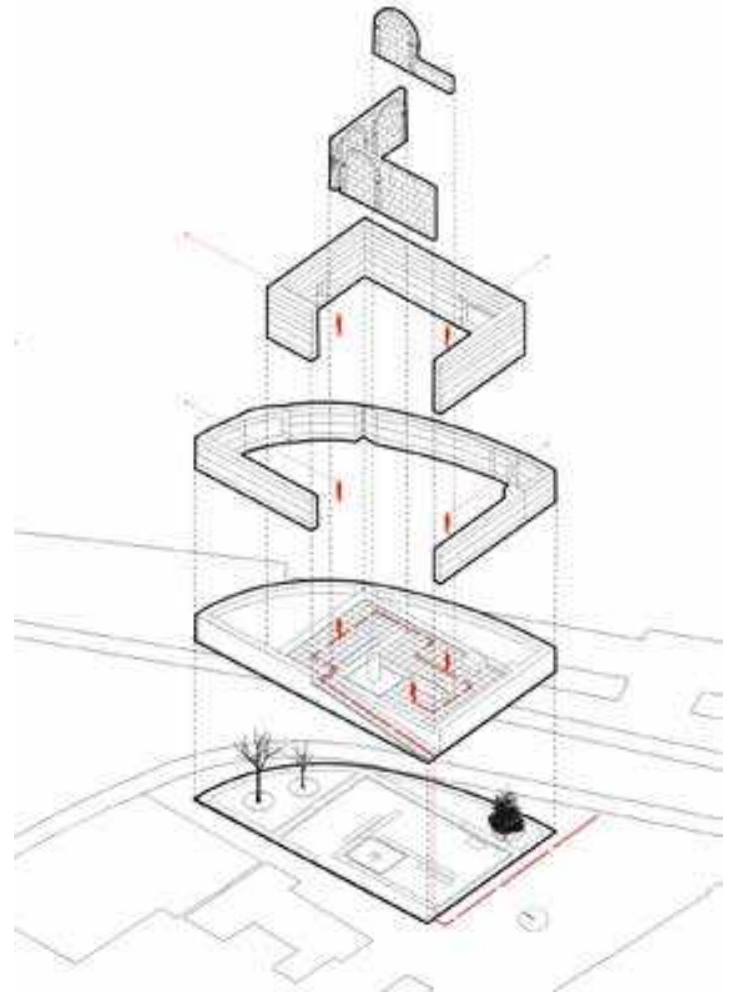

Fig 3.86. Itinerary of small garden, drawn by author.

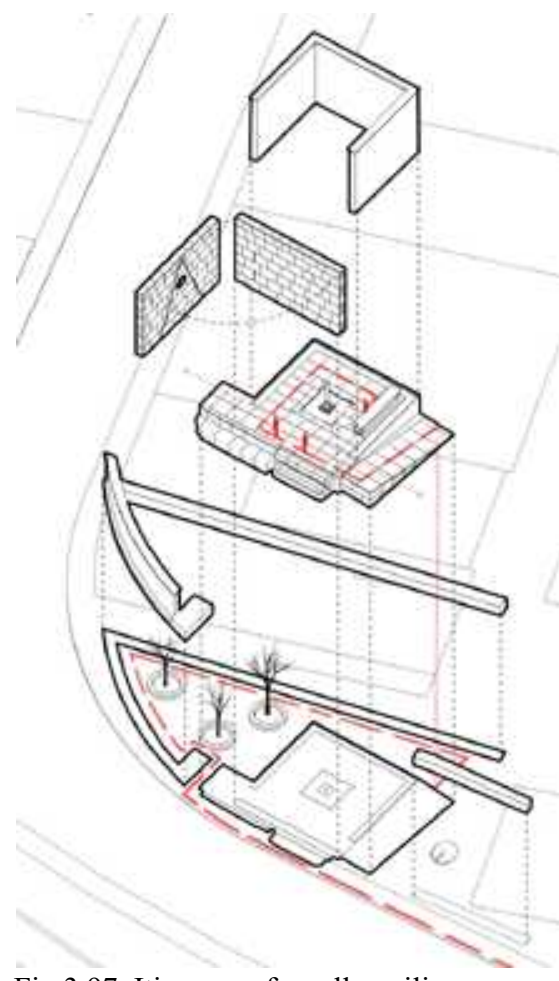

Fig 3.97. Itinerary of small pavilio drawn by autho

\section{- a garden of isolation}

The museum's narrative is achieved through a series of events, which are relatively independent with each other thanks to Venezia's control of regulatory layout that ensures spatial autonomy and individuality through a continuous itinerary. The similar attempt has been used in the small garden of Gibellina. Located at the street corner, the garden presents itself as a solid structure without an easy accessibility. The curved wall directs people to pass by the windows from which the interior richness is revealed, and to reach the back of the building where a narrow ramp gives access. (Fig3.87.) The garden was conceived as a two-shell structure of which the inner one, a square for walk has been subdivided, according to golden section and spiral composition, into three parts whose connections with each other have been minimized.(Fig3.86.) As in the museum, Venezia complies the theory of Alberti in this small garden, which is, maintaining the same proportion throughout one building. This geometric law gives the layout of his works the classical eurythmia. ${ }^{182}$ Two small gardens, which cannot be entered, are placed at the corner to isolate spectators from the urban space, leaving a narrow delivery of views through the exterior and interior windows which mark visual axis in a right angle. The garden's journey is an analogue of the ritual itinerary of spiral circulation inside the Danteum. At the heart space amidst silence, a cylinder rising from the basin, it gives rise to the narration as told in other works designed by Venezia in Belice - the fragility as the result of the earthquake and a strong continuity of life from the earth.

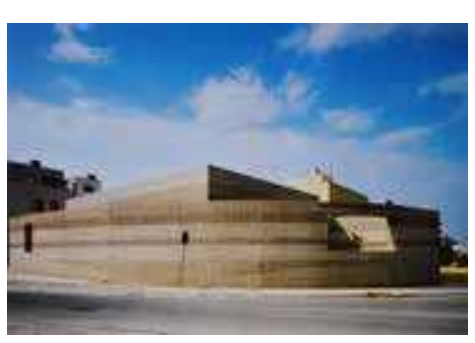

Fig 3.87. Small garden in Gibellina.

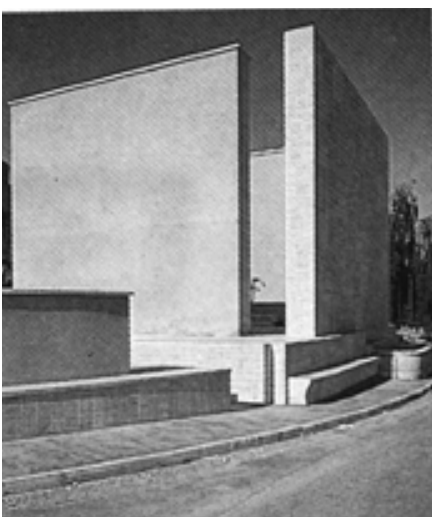

Fig 3.96. The pavillion. the building through the long side until to a short ramp which leads to the interior. (Fig3.97.)

The language of emptiness and silence in the square room is retaken by a sensual materiality of the floor, and the independent wall on the street side made of travertine, and the other three walls treated with plaster finish. Connection and separation contribute simultaneously the spatiality here - gaps between the two sets of walls promote a restrained communication with the outside, and the bench deep inside permits a private circumstance for contemplation. The central crack on the floor evokes the impluvium in Roman house, as well as suggests the seismic event. Together with the elevated sculpture, they establish a dialogue with the inscriptions of sun and light on the wall, rendering the space with a mythical aura. As Venezia said "In Sicily there is a very strong memory, very strong. so putting together memory and coolness seemed to me a result, I think, really excellent." ${ }^{, 185}$ *, by creating a world of shadow and light, water and vegetation, the square terminates the spiral flow and combines retrospective atmosphere with physical comfort. As all the works done by Venezia, the pavilion ceases to be a pure mental place, since it always possesses a strong link with the territory and must be nourished by the nature and culture in the historicity of time. 
$\S$ Epilogue - monument for walk: from the solitary to the collective

"The function of a path is to be a skeleton. And as a skeleton it must be concealed from the grace of life." 186*

The display of fragility in those ruins at the core place in Venezia's architectures endows the spiral movement throughout the space with sentimental characters. Those remains of fragments are, as Georg Simmel said, "of the fact that things come from nature and return to nature" 187 , manifest the life cycle of every construction, contributing to the internal wreckage concealed from the external protection. Tensions between the new and the old, between construction and destruction produce particular instability that characterizes his buildings as well as promotes a stronger storytelling. In Venezia's works of Belice, though everything is linked to specific narrative, the internal relations are not tightly fixed that permit elements to have their own autonomy with respect to the circumstances. Venezia is obsessed with the itinerary in Villa Giulia, the centra courtyard that organizes circulation obstructs visual so that sometimes arriving to, via a concealed transmission, the previously visualized place becomes unpredictable Dislocation between visibility and trajectory of movement greatly enrich the whole sequence that serves " to ambulate, to appear, to look out and look in." $188 *$ This value of continuous ambiguity between enclosed space and external space is seen from 186. Venezia, "Idee," 85.

187. Georg Simmel, "Two Essays: The Handle, and The Ruin," in Hudson Review. 11:3 (Autumn, the-Ruin.

188. Rodehiero, "Interview," 32
Venezia's buildings and peaks in the hanging bridge and reposo of the museum, as well as in the auditorium and terrace of the theatre. They manage to achieve a journey with the rhythm created by oscillations between going out and returning, that movement becomes Venezia's accomplice in establishing the inconsistency which makes his edifices as symbol of divergence.

In the museum and the theatre, Venezia has developed the architectural promenade which not only makes the manner of seeing, but also conducts our perception to understand the different characters of the two buildings submitted to respective circumstances and demands.

One would have a strong feeling that Gibellina museum was conceived as an introspective program based on individual experience. Due to the banality of the new town, by minimizing the communication with the outside space and preserving the most valuable encounter with the rural to the final phase, Venezia contributes the main space and the most important exhibition to the sunken courtyard. The remounted facade transforms the museum into a ruin, a fossilized substance to establish dialogue with the living ones. As the architect dedicates the building of despoliation to "indecipherability on the one hand, structuring on the other hand"189, universal language in the space is replaced by individual read. Dimension of the trench-walk and the hanging bridge is minimized as if they were to accentuate personal perception of tactile feeling from the fragment facade and vibration from the hanging bridge floor, not to mention the delicate

189. Venezia, "Transfer," 74 


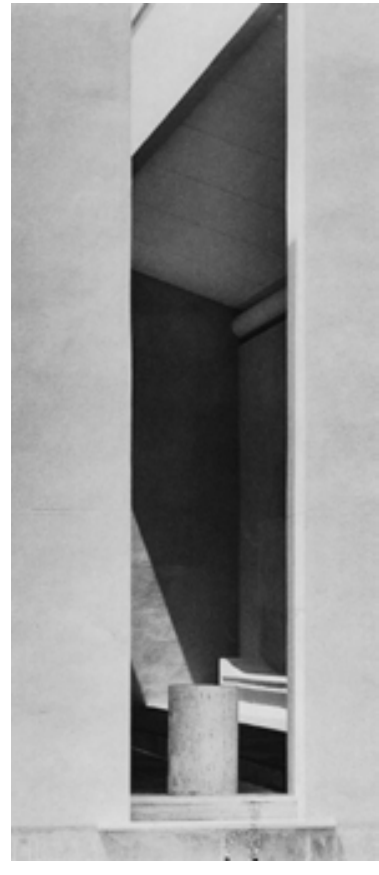

Fig 3.98. The reposo.

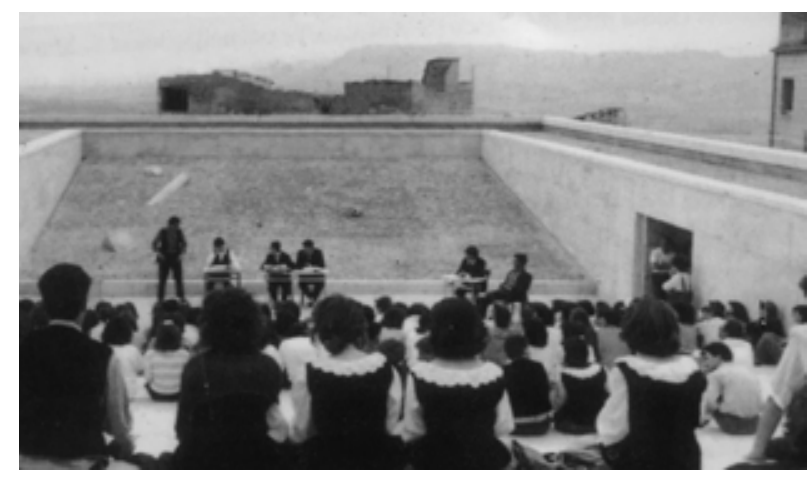

Fig 3.99. Performance in the auditorium. lines of light and landscape brought by fissures on the wall only to be captured by those focused eyes.

Wholly gathered into itself, Gibellina museum with its restrained power ensures privacy of movement in order to produce and protect all the experiences which cannot be shared with others. It seems to be an irony that such inherent exclusiveness in a building for public use. However, Venezia affirms its essence as a solemn monument dedicated to commemoration - it is hard to imagine a crowd of people flooding into the reposo, talking and laughing - that being hospitable will definitely disgrace its meaning of this building generated from serenity and sensitive emotions.(Fig.3.98.)

Opposite character is derived from the Salemi theatre since it addresses the need of a much bigger scale - to recover the collective identity of the city communities and their relation with the territory. Therefore, public participation is essential in this program. Rather than delving into the subtlest of one's feeling, the terraced structure place people in the confrontation with landscape and horizons so as to amplify their perception. The geometrical matrix of the theatre provides support for the takeover of the site as well as the means to create a mediation between the existing things and the predominant elements. The reverence of the theatre for the topography and its transformation sets itself the task of promoting communication. The evenness and openness it gives to the plot facilitate the access and bounds the townscape with the vast scenery; the double-spiral circulation that connects different levels and links the external terrace to the internal auditorium is capable of generating greater interaction among citizens or between actors and audience. Upon the ruins of old convent and church, this little theatre revives the marginal plot of the town by restoring its value as an embodiment of social activities of the community.(Fig3.99.) What is left after all this is the contradictory impression of the space created in the two buildings that, on different levels, manipulates people's participation and stimulates experiences that range from the solitary to the collective. In so far as they are accessible memorials, of great significance for discovery or recovery the meaning of territory, it would help the museum and the theatre to be full in keeping with the desire of history and the land alike to make the building a continued one.

The modernity of that movement as an absolutely architectonic form was developed by the masters from Giuseppe Terragni to Le Corbusier. In Belice, Venezia makes this concept sentimentally related to the memory of seismic event, the idiosyncrasy of the territory. In this term, he defines an essential but original language, capable of producing pathways being skeleton as signs of authentic lyricism with a sure sense of architecture, and as well affirms the necessity to provide it with flesh and blood. 


\section{CONCLUTION - MELANCHOLY, RETROSPECTION AND PERMANENCE}

When talking about the idea of locus in the sense of a singular place and event, Aldo Rossi approaches the historic context and city monument with Maurice Halbwachs's ${ }^{190}$ indication regarding the formulation of collective memory towards the inherent characters in a space: "When a group is introduced into a part of space, it transforms it to its image, but at the same time, it yields and adapts itself to certain material things which resist it. It encloses itself in the framework that it has constructed. The image of the exterior environment and the stable relationships that it maintains with it pass into the realm of the idea that it has of itself. " $" 191$ Apart from the images that contribute to the routine of developing relatively static structure, those "extraordinary events are also fitted within this spatial framework, because they occasion in the group a more intense awareness of its past and present, the bonds attaching it to physical locale gaining greater clarity in the very moment of their destruction." 192

The significance of Venezia's works in Belice resides on the reflection of the particular time that the seismic event became an extraordinary event that detached the fixed images from the ground. By applying the remains of ruined buildings in the new architectural process, the museum and the theatre, as well as the pavilion and the small garden seek to work with the memory of the catastrophe. They represent a dramatic

190. Maurice Halbwachs (1877-1945), French philosopher and sociologist who is known for his development on the issue of collective memory.

191. Maurice Halbwachs and Coser Lewis A., On collective memory (University of Chicago Press, 1992), 134

192. Ibid continuity with the old buildings in the new place, and the all those remounted fragments contribute powerful signs that fight against and stand out from the oblivious reality in the reconstructed towns.

Venezia's strategy to create monuments in memory of the earthquake, through materialization of the hidden power insides the earth, comes from reorganization of the site in favor of articulation. This intervention and implementation enable the inhabitants to recapture image of the past by understanding how they are physically preserved.

"We must work so that every public building, every residential district, every single unit comes to light with criteria worthy of the historical heritage that it integrates." ${ }^{193 *}$

Venezia's search of an architectonic continuity is first achieved by a personal cognition of history to treat the past facts as neither untouchable elements nor prototype of archaism. He subtly disturbs the disciplines of materials so to explore another meaning of old fragments from the new building, and vice versa. This idea has essentially detached Venezia's philosophy and practices from any trend of architectural design. The charm within his buildings is distinguished by, first and foremost, the resistance to functionalism and effectiveness. Ritual characters prevail over practical appeals in the space, and through this "olvido funcional", as Venezia comments on the roof of Casa

193. Francesco Venezia, Terremoto e ricostruzione. Parola a Francesco Venezia (September 5 ,

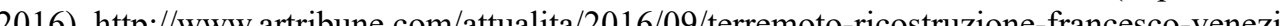


Malaparte, architecture participates into the establishment of framework of the site, so that it acquires greater connection with the circumstance from which it is generated.

The quality of continuum in his architecture is also derived from, in a more poetic way, his obsession with the Greco-Roman world and Ancient Egypt. This retrospective look gives him with a classic and melancholic view towards architecture and ruins, whose monumentality is deeply rooted into the continuity of an architecture's afterlife:

"The only possibility for classism today is that it is bound to a melancholic view of reality, to a strong sense of change, of something being broken. Melancholy is the contemplation of an order which is returning to its previous nature...ruins are so fascinating because they show us how a building grows up, how architecture forms. In Hadrian's Villa in Tivoli you can read, like an anatomic diagram, all the Roman of structure..."194

Venezia's pursuit of pre-texts in the history of architecture enables him to have wider possibilities to create form, just like his understanding of the essence of Modernity is the "LIBERTY" to develop strategy in order to adapt to the circumstance.

"The modern architect, should be a person immune, who can fall back on with the same tranquillity and the same plenitude of his own work, the extremely current or the extremely archaic forms, because FORM is independent of the contingent facts." 195

194. William JR Curtis, Modern architecture since 1900 (London: Phaidon, 1996), 627.

195. Raventós, and Vásquez, Due Case, 46.
This idea stays prominent in his works in Belice. A quality of nostalgia and an anonymous character, are derived from the hybrid-forms of new geometry and old remains. The representation of continuity of territory, of history, and of architectural process has created a constructional system in which the order of natural things is transformed into an important part of the architecture.

By rooting architecture and stressing the quality of detachment, Venezia shows an exemplary way to resolve the predicament of time which today's architecture is facing. It probably answers the question raised by Kenneth Frampton: "How then should we begin to reclaim the 'ground' within which architecture might be reconstructed as a critical and creative discipline?" ${ }^{196}$ As Venezia is in finding for architecture a specific base of its own, he is not so much interested in linguistic exploration or artistic interpretation. His buildings that deeply dwell into the earth, relating themselves to " algo como un sello, algo que sella, que se pone sobre el lugar.",197, that have contributed permitting an analogical interpretation of Daedalus' labyrinth. In order to confine (in some sense respect to) the natural restlessness within the deep space, both the architects have marked on the ground through excavation and construction.(Fig3.100.)

Unfortunately, what we see today in Belice are nothing more than declining facts. The unfinished construction and outmigration leave the towns conceived to be tourist resorts in great depression. Those ambitious buildings which are living in an ironical harmony with the desolate reality seem to be the work of prophecy that they were

96. Kenneth Brian Frampton, "In search of Ground," in The invisible in architecture, eds. Bouman, and Toorn, 195.

197. Hidalgo, "Francesco," 47 


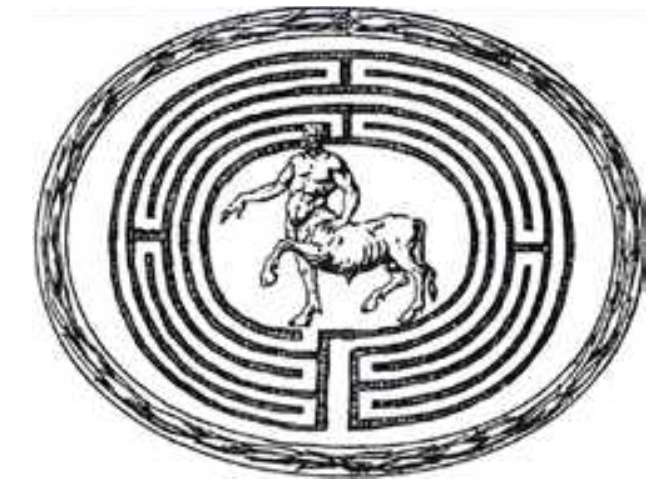

Fig 3.100. The labyrinth of Daedalus. Maffei, 1709 .

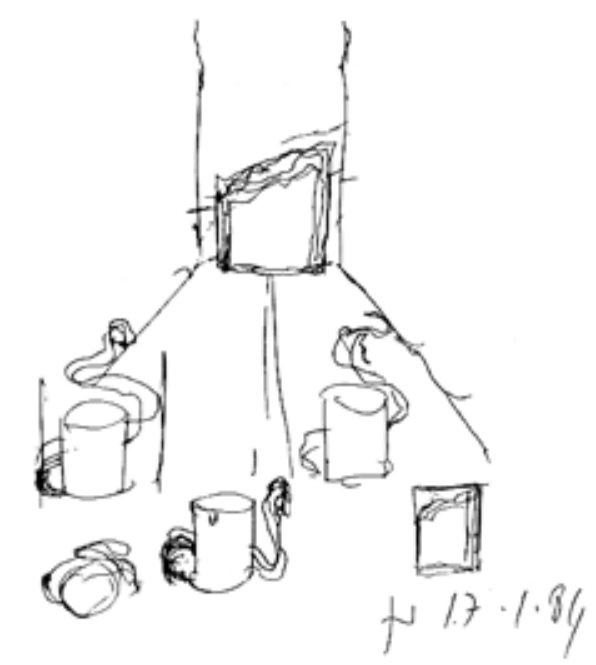

Fig 3.101. Sketch of the reposo, Francesco Venezia, 1984

made for compensating the towns to be abandoned again. Nevertheless, it is curious that Venezia's monuments, though in dilapidated conditions, stand out from the depressed reality. They become extraordinary ruins staying still in restoring an environment permitting balanced communities. The inexhaustible energy inside these works somehow reminds of Charles Correa's words when talking with John Hejduk, that al the great architecture "has underneath its plane of calmness, monsters." In this sense, the monuments in Gibellina and Salemi seem to present themselves as the serpent sculpture in the reposo - a monster in the cave.(Fig3.101.) Through his nonviolent transformation, Venezia has created new extraordinary event against the ephemeral to achieve the main aspiration that architecture should have: that of long-lasting. 
Chapter IV .

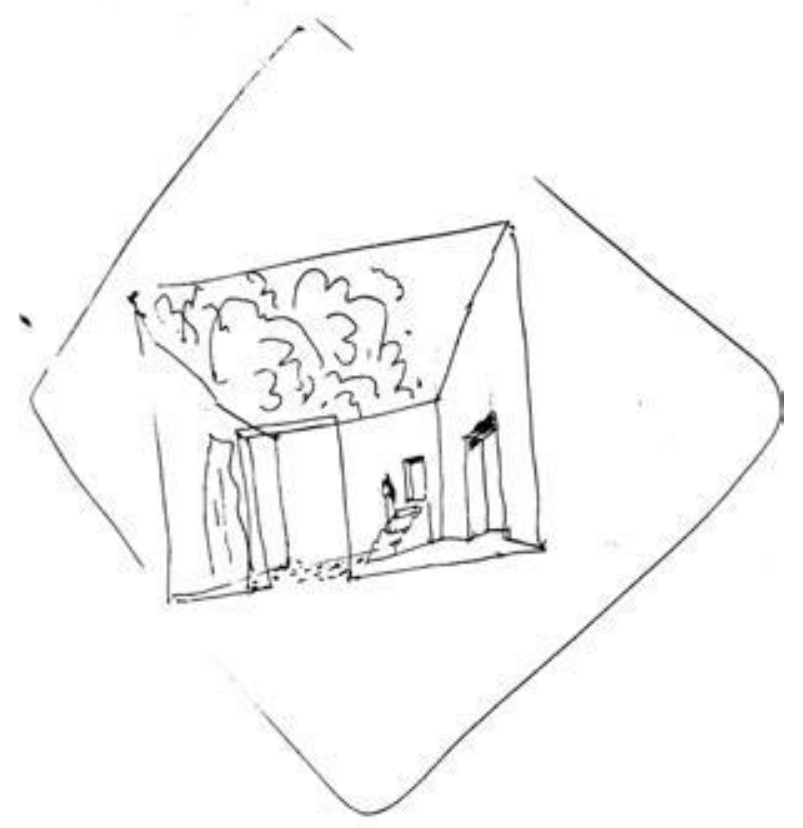

THE PROVISIONAL VISUALIZATION

Alvaro Siza, ephemeral images on the paths in Santiago de Compostela and Porto 

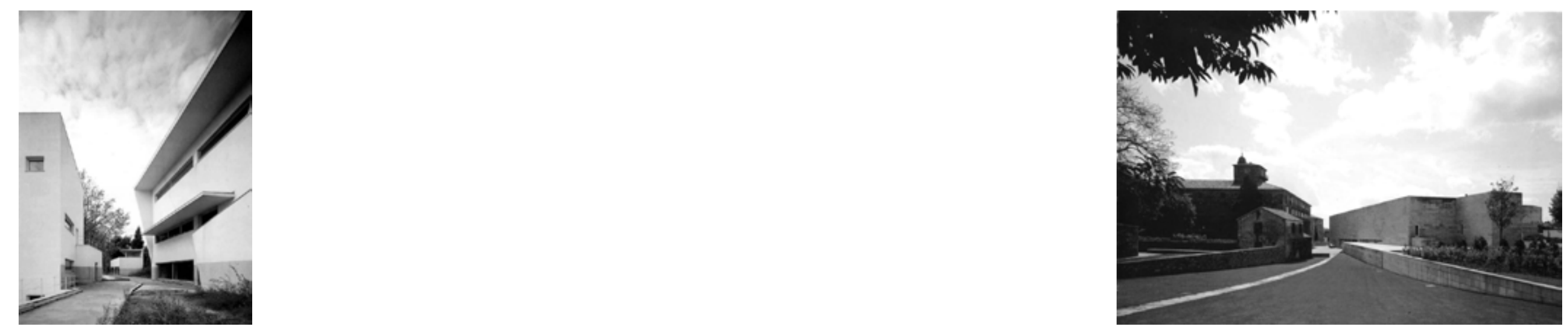


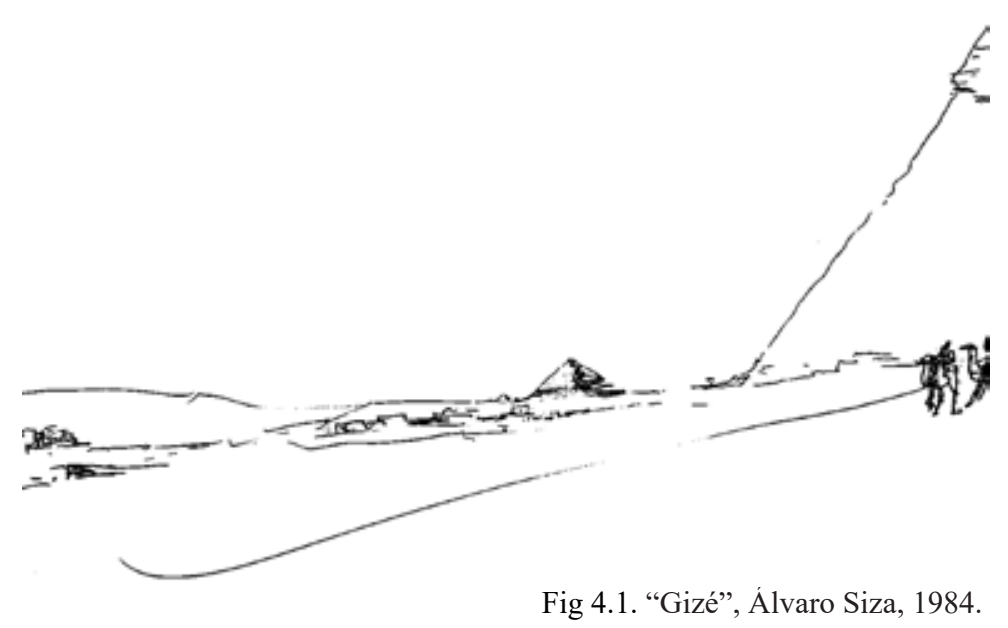

\section{THE SIGHT INSIDE THE OTHER: SKETCH AND ARCHITECTURE}

We perceive in a non-mediated way. That which we learned reappears dissolved amongst the lines which we later draw. ${ }^{198}$

For an understanding of Siza's working method, studying his drawings seems to be an effective way. It is crucial to delineate the different focuses of the architect from those free lines in his travel sketches, portraits and analytical drawings. They represent Siza's changing points of view and the way of seeing which indicate his intention to involve the real world into the pictured one. By capturing the visible and giving the elements representative figures with his painter's intuitive eyes, Siza deals with relations between sites, projects and human figure by using his architect's analytical ability so as to create spatial metaphor in those sketches. Those opposed expressions in sketches, derived from his altering views from one to the other, have been reserved and developed during his design process, leading to fundamental characters of his architectures.

$\S$. The stratification of representation

- the site

In Siza's sketches it is always hard to find the importance of paper. Sometimes, lines stop before reaching to the edge, leaving the rest part in blank; but more often, objects are abruptly interrupted by the paper borders as if they keep moving freely out of the

198. Álvaro Siza and Kenneth Frampton, Esquissos de viagem $=$ Travel sketches (Porto: Porto Documentos de Arquitectura, 1988), 15

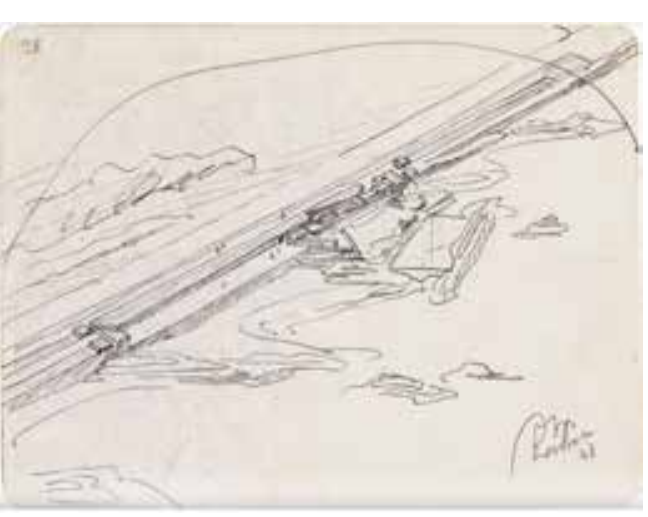

Fig 4.2. Leça Swimming Pools sketch, Álvaro Siza.

limits (Fig 4.1.) Apart from those travel sketches showing landscape of large scale, this implication of an expanding circumstance was apparent in his study sketches of the very first projects, the Boa Nova Tea House (1958-63) and Leç Swimming Pools (1966). Solid geometries superimposed on the free landscape may suggest that the primary task of both projects lies on how to accommodate constructions to the various and natural form of the sites along the coast line. (Fig4.2.) While obvious distinctions between the finite volumes and outstretched lines claim an abstracted indifference between the building and the site, the zig-zag route towards the tea house and the protruding pools seen as delaminated extension from the lineal boardwalk, however, imply a deliberate development on morphology by which Siza had taken topographic conditions to calibrate architectural forms.

The precocious capacity that Siza had shown in the early works of controlling the contact between the particularities of terrain and the building anticipates his insight to capture and to make use of the dialectic relationship of architecture and its physicalsocial and historical context in the later period. The social housing complex settled in urban fabric commissioned by SAAL (Serviço de Apoio Ambulatório Local) from the 70s, the Faculty of Architecture in Porto (1987-1994) and the Galician Centre of Contemporary art in Santiago de Compostela (CGAC) (1988-1993) that coexist with old structures, and his continuous practice of small houses constructed on irregular plots, to name a few, give demonstration the interactions less continuous with the sites as 


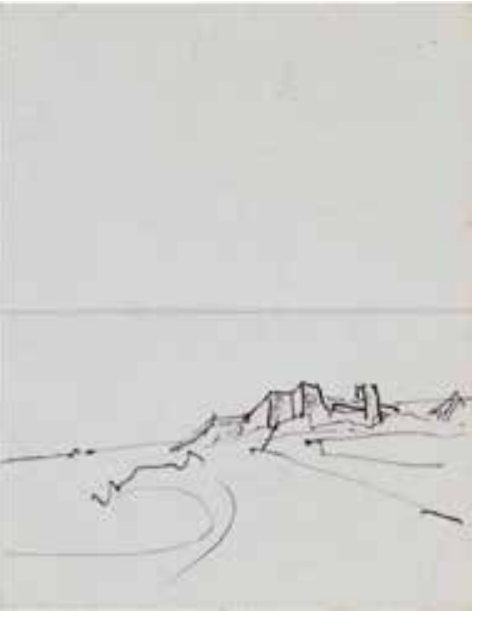

Fig 4.3. Boa Nova Tea House sketch, Álvaro Siza.

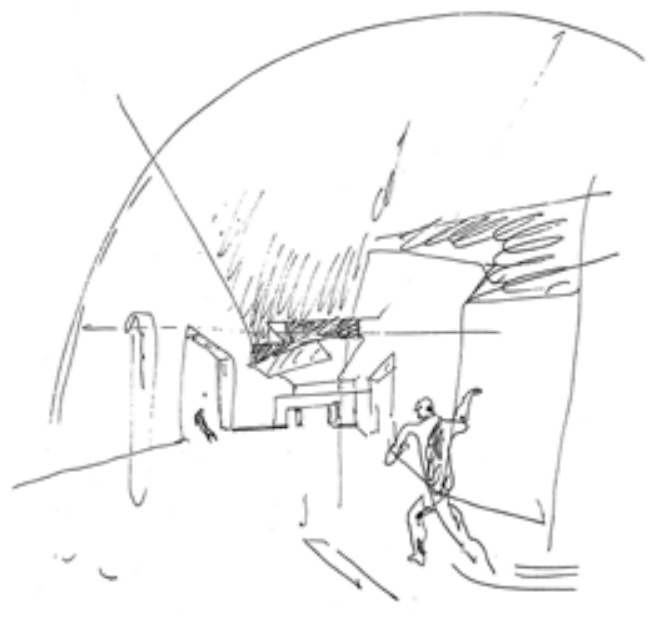

Fig 4.4. Cargaleiro foundation headquarters (1991-51), Álvaro Siza.

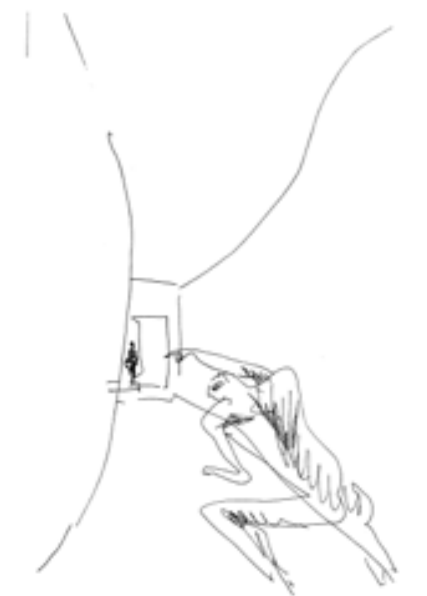

Fig 4.5. Vision for madrid exhibition (1992), Álvaro Siza. buildings achieve a high degree of formal autonomy. This figurative resistance set up by the those relatively rational geometries and plain materials, in some respects amplifies a temporal delimitation in Siza's projects between architectures submitted to human reformulation and the invariant terrain suggesting an alien monumental ground as "archeology or historicity where the past — that is, the existing site or its representation -remains alien to us." ${ }^{199}$. Nevertheless, geometry of development in these projects revealing their random adaption to the contextual accidents - the bending volumes occupying the street corners to fill the gaps, or property walls and old structures are used as points of departure of new projects (Fig. ) - is to be found when someine is getting into the setting. As Siza said: "In my first works I began by looking at the site, then making classifications [...] today I take everything into account as what interests me is reality." ${ }^{200}$ In his practices of dialectic contextualism, what does Siza search for is more a strategy of form through syntactical deliberation than merely imitative patterns with the aim of creating the very specific and latent resonance between architecture and site. In this respect it reminds of a story told by Siza: it was 1956 when Fernando Távora visited the site of the Boa Nova Tea House before leaving for his global tour, while looking at the various landscape of North Atlantic Ocean and the rocky coast, the maestro said to young Siza by standing his side - the fwho was going to be in charge of this project— "it must be here."(Fig4.3.)

99. Robert A. Levit, "Language, sites and types: a consideration of the work of Álvaro Siza," The Journal of Architecture 1, no. 3 (1996): 239

200. Álvaro Siza, "Entretien avec Alvaro Siza ," interview by Laurent Beaudouin and Christine Rousselot, September 08, 1977. Article, Architecture, Mouvement, Continuite (AMC), no. 44 (February 1978):33-41.

\section{architecture}

Siza's panoramic vision in those drawings that mediates the relation between the main figure and its environs is dramatically altered in the sketches framed by individual's perspective which always hint at an architectural promenade: "I need to be able to imagine the sequence of space from the atrium, into the room, with the view out of the window." ${ }^{201}$ In these occasions, he endeavors to soften the separation between the scenes and viewers by association with an opposed movement: inwards, the loose configuration in the end suggests a further development towards the deep, and outwards, an oncoming force triggered by the unfinished condition is absorb the audience.(Fig.4.4, Fig4.5, Fig4.6.)Such juxtaposition of perspective distance and intimate proximity makes the pictured elements approach us, invade and occupy where we are, but simultaneously leak to the hole in the depth, creating a sense of continuity as if during a stroll which would "allow our eyes to move like a bellows." 202

Siza's drawings provoke viewers to move in order to see, it gives rise to the irreducible relationship between the visible the invisible. John Berger indicates the importance of relating the two terms as reflection of space and time:

Lo visible implica un ojo. Es la materia de la relación entre lo visto y el que lo ve. Sin embargo, el observador, cuando es un humano, es consciente de lo que no ve ni verá nunca su ojo debido al tiempo y la distancia. Lo visible lo incluye (porque ve) y, al

201. William Curtis, "A conversation with Alvaro Siza," El Croquis 13, no. 68/69 (1994): 242.

202. Josep Quetglas, "Respiración de la mirada," conference text in June of 1994 accessed May 15, 2018, http://www.arranz.net/web.arch-mag.com/quet/02s.html. 


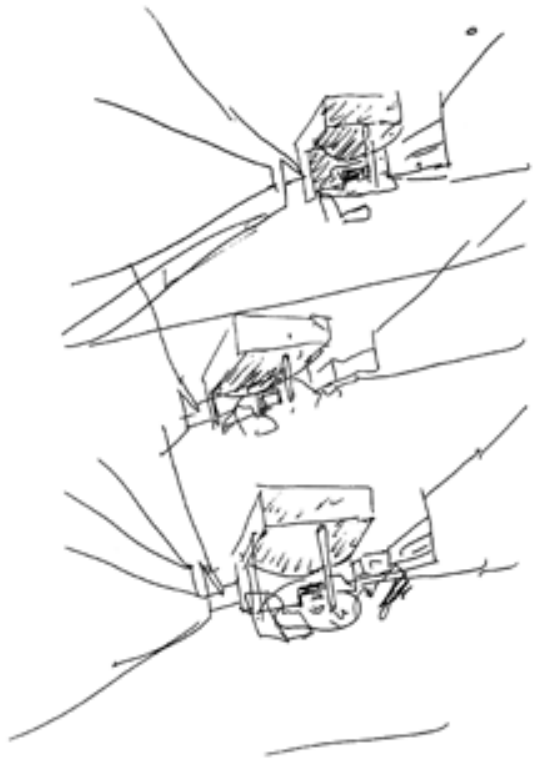

Fig 4.6. Casa Vieira De Castro(1984-1997),

living room sketch, Álvaro Siza.

mismo tiempo, lo excluye (porque no es omnipresente). Para él, lo visible consiste en lo visto, que, aun cuando sea amenazante, confirma su existencia, y lo no visto, que desafía esa existencia. ${ }^{203}$

Perspective from a casual angle against ordinary axial representation and distortion of objects on the margins which Siza represents in sketches imply an architectural promenade made up by a succession of unique points of view, creating metaphoric images of speed of movement and the flow of time. (Fig.4.6.)The resultant spatial fluidity and continuity work to anchor our experience in the tension between the existent things and the risk of disappearance of what we are looking at. The implicated movement places viewers in an uninterrupted stream of perception guided by the sequence of captured elements, as if stimulating their will to pass through the space.

\section{the human figure}

Apart from the temporal delimitation between buildings and sites, layered composition is further developed in Siza's project drawings as in one way or another the human figure is always inscribed in.(Fig.4.7, Fig4.8, Fig4.9.) These personalities seen as interpretation a priori of his unbuilt works should be distinguished from those in his travel sketches which represent the real scenes. Rather than being fully involved in the spatial fluidity, these outstanding characters who are enamored in their own events dancing men in their "naked primal state" occupy the foreground and flying angel takes social houses under his wings - remains alien to the buildings behind and the backdrop of mountains, rivers and urban fabric. Siza insists on the protagonist role of human in

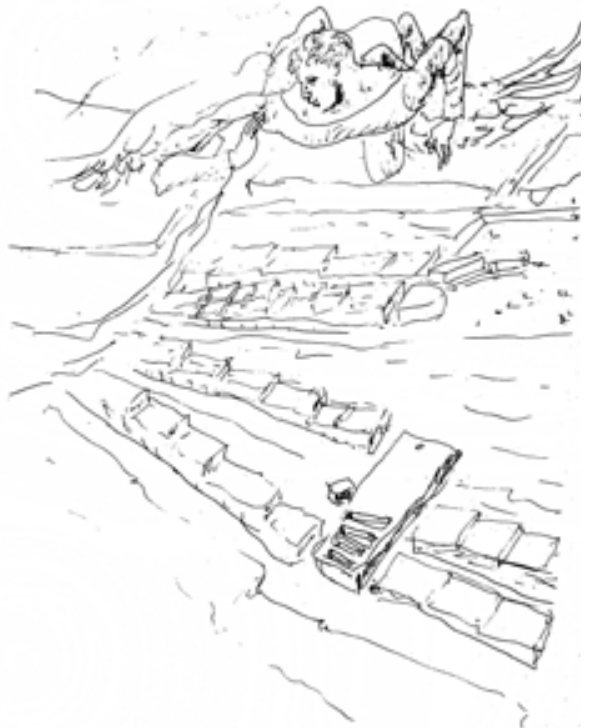

Fig 4.7. Quinta da Malagueira and angel, Álvaro Siza.

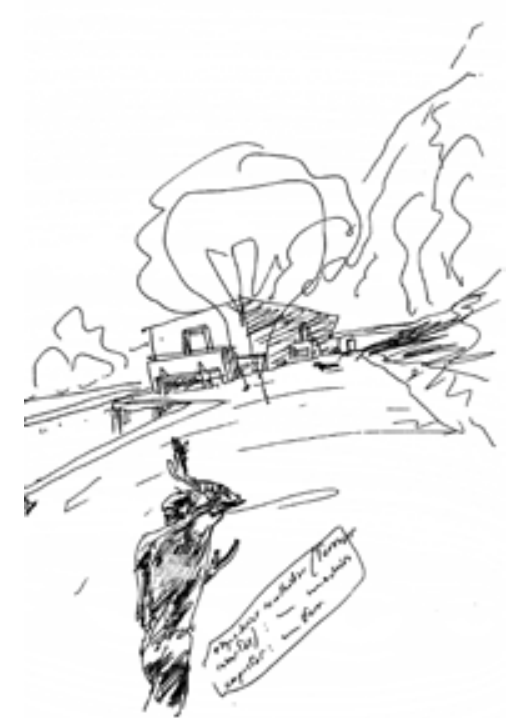

Fig 4.8. Casa Vieira De Castro(1984-1997) perspective, Álvaro Siza. architectures, and so does he carry out this belief in drawings as manner of conceiving by which viewers are confronted with, once again, a subdivision of the dichotomy realized by the ground and the constructions.

What Siza sought to demonstrate here is not a vivid phenomenon rendered by the users of , the architecture to be built, but oppositions between the human impulsethe momentary character of their moving bodies and fleeting gestures- and the topographical and constructional frameworks as preset structure. ${ }^{204}$ It is the estrangement hovered between architectures and human figures against the unity of language that endows Siza's drawings with Piranesian remoteness.

The figurative images of human body have been developed from those expressive personalities to recurrent figures of the painter's hands and legs that imply the author in the unmarked foreground. (Fig.4.11, Fig4.12, Fig4.13.) These partial self-portraits self-reflexive, on the other, yet to confirm the author identity from those anonymous fragments. on the one hand, anchor the sketches to the author's own eyes that makes the drawings

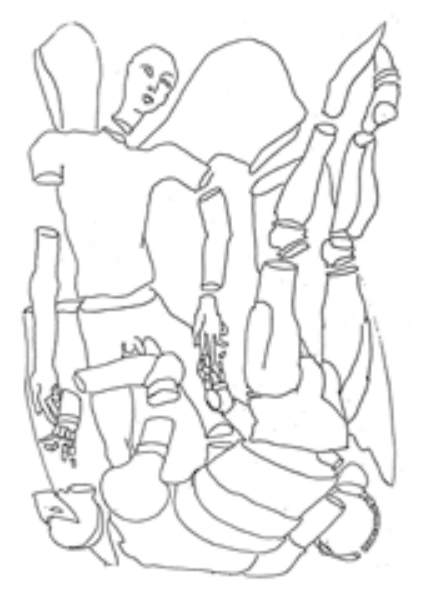

Fig 4.9.Sketch of human figure, Álvaro Siza, [n.d.]
204. In fact from Siza's own statement we see fewer obsessions with the affinity between human characters and pictured architecture. than taking them as measuring instrument. It is the then building I am designing The human figure brings there an important help in finding the scale. I do it as a need to try to control the scale." Francisco Granero Martin " "Conversando Con Álvaro Siza El dibujo como liberación del espíritu." EGA Expresión Gráfica Arquitectónica 1, n 20(Sep. 2012):62, https://polipapers.upv.es/index.php/EGA/article/view/1404. 


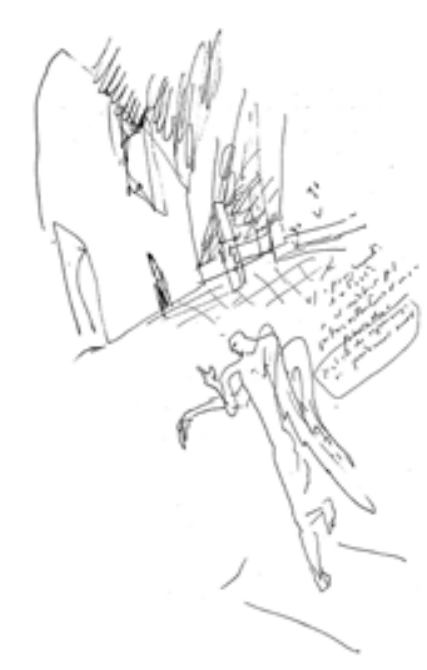

Fig 4.10. Santa Maria church and angel, Álvaro Siza, [n.d.]

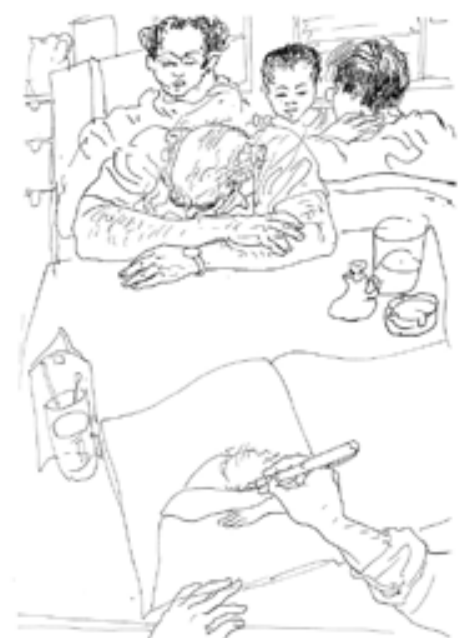

Fig 4.11. Fernando Távora taking nap, Álvaro Siza, [n.d.]

"When we read the word 'I' without knowing who wrote it, it is perhaps not meaningless, but it is at least estranged from its normal meanings." ${ }^{205}$

Characterized by the subtle estrangement and proximity, Siza's sketches provoke empathy that asks the audience to be at the author's own side at this moment, as if they were looking at themselves from their interior space. As a mystical bond between the painter and spectators, the hands and legs withdraw the painter's privilege of seeing and creating, and give it to the viewers so that the author becomes a random audience. This would be understood as the process of "externalization", which, in Freudia psychology, refers to the intention by which an individual will project his or her interna characteristics onto the outside world, "particularly onto other people". ${ }^{206}$ Walter Benjamin uses this psychological term to interpret the mechanism of seeing:

"If the theory is correct that feeling is not located in the head, that we sentiently experience a window, a cloud, a tree not in our brains but, rather, in the place where we see it, then we are, looking at our beloved, too, outside ourselves."207

205. Edmund Husserl, "Logical Investigations," in Esquissos, 7.

206. Joseph Sandler, Projection, identification, projective identification (London: Karnac Books,

207. Walter Benjamin, "To the public: Please protect and preserve these new plantings," in OneWay Street and Other Writings, trans. Edmund Jephcott and Kinsley Shorter (London: NLB, $1979), 52$.

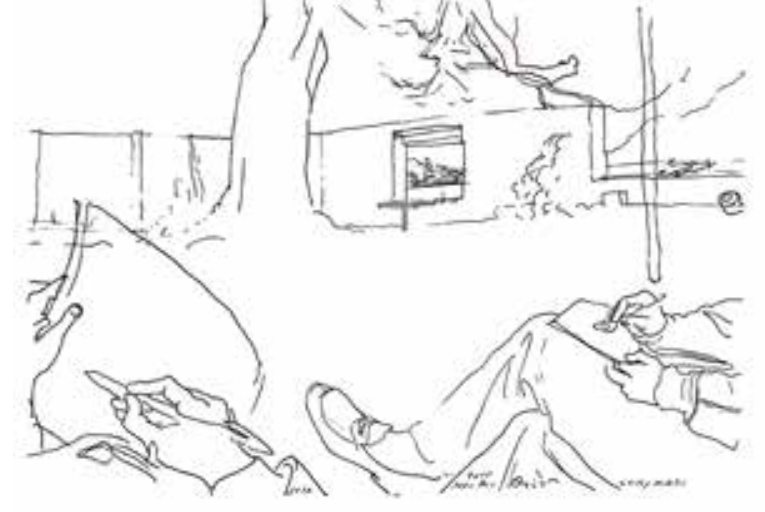

Fig 4.12. Villa Le Lac sketch, Álvaro Siza, 1981.

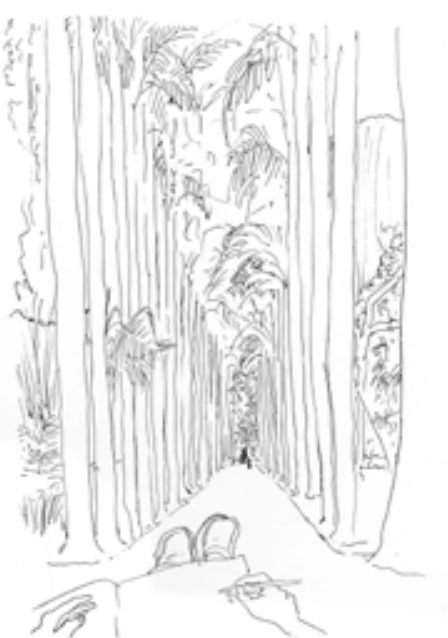

Fig 4.13. Rio de Janeiro, Botanic Garden, Alvaro Siza, 1982
Though Siza denies any volunteer behind the auto-reflection ${ }^{208}$, the implied anonymity and accessibility enable spectators to have a direct involvement in the pictured space, the hands and legs become synoptic links between individual person and the objects they are looking at. Siza acknowledges the fact of the "others", which refers to according to Jacques Derrida ${ }^{209}$, the inexhaustible and available source of motives and securities to approach the reality in observation, and in this respect Siza liberates himself to see and to draw outside himself. By inviting "the irreducible singularity of the other" to his creative process Siza obtains the essential ideas of making architecture based on an individual's perception, as he says: "I need to be able to walk as a visitor, the owner, or a child who visits the future building." 210

\section{- the mirror}

The emphasized continuity between the sketches and the real world, and the exchangeable position between those who see (the spectator and the author) make Siza's drawings understood as experiences that are set in motion by the presence of an audience. In the meantime, this process is affected by the latent mirror-like effect which 208 Siza insists that he pictures the hands unconsciously, which differs from the hands appear in some drawings of Andrea Palladio. He says: "This occurred a first time, I do not know when, as I was drawing an urban landscape. Spontaneously I put my hands on the drawing.", and the only reason is "to face some aspects of the drawing, to draw attention to it." Granero Martín, "Conversando," 61.

209. "La palabra 'real' [...] significa la irreductible singularidad del otro en tanto abre un mundo [...]" Jacques Derrida, "Espectografías," in "Los Dibujos De Álvaro Siza: Anotaciones "Nuno Higinio Pereira Teixeira Da Cunha, (Ph.D diss, Universidad Complutense de Madrid, Facultad de Filosofía, Departamento de filosofía IV, 2007), 57.

210. Curtis, “A conversation,” 242. 


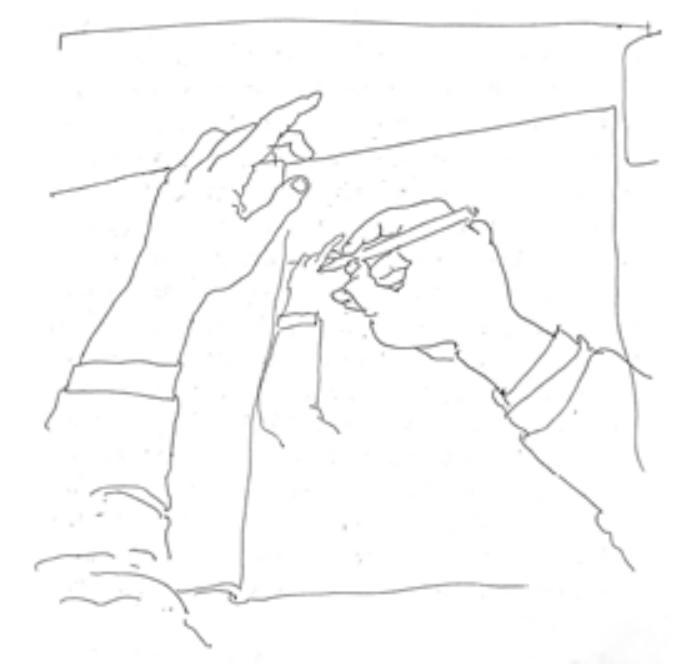

Fig 4.14. Sketching hands, Álvaro Siza, [n.d.]

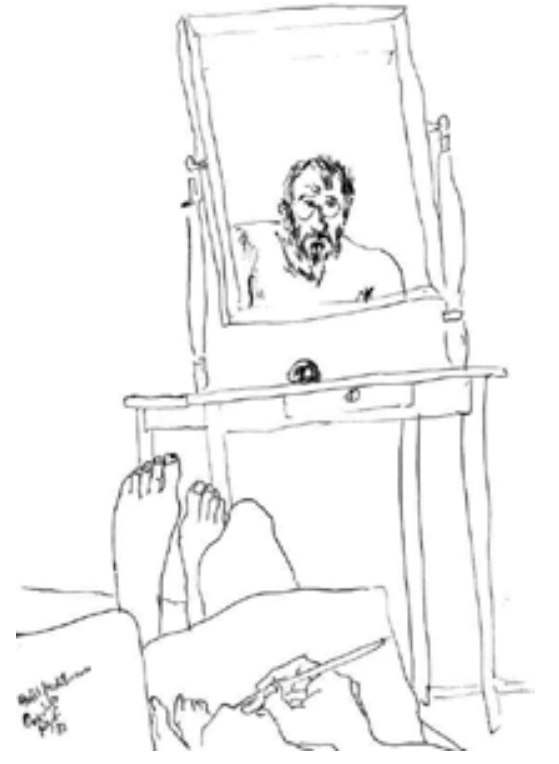

Fig 4.15. Self-portrait, Álvaro Siza, 1982.

\section{$\S$ Epilogue - a fragile invitation}

Georges Did-Huberman indicates the split in the act of seeing: "Ineluctable, sin embargo, es la escisión que separa en nosotros lo que veos de lo que nos mira. Por lo tanto, habría que volver a partir de esa paradoja en la que el acto de ver sólo se despliiega al abrirse en dos. Ineluctable paradoja." ${ }^{212}$ Similar split appears in Siza's drawings and is conveyed through a layered representation of time. The site, alien and invariant, represents the topographic datum upon which architectural promenade structures a quantitative process. The two groups contribute to the setting that keep attracting our eyes. Whilst the overlaid human figures or the sketching hands in constantly changing states, whose momentary and anonymous character suspend themselves in the intermediate position between the pictured world and the real one, "inventing one to oscillate back and forth between the subject and the object." This move would end up with a subject-situation correlation that realize endows the imaginary figures and architectures with the right of looking back to the audience.

The trichotomy in Siza's drawings relates to the Greek terms referring differen modalities of time - Aion, Chronos and Kairos - and creates a game of seeing which invites and rejects at the same time. Tension and disequilibrium from oscillations serve Siza's search of a specific instant by introducing time and motion as key elements in spatial perception. A sense of non-repeatability leads to the crisis of connection by which the audience are in a fragile relationship with the represented world: It shows us how much there is, but simultaneously moves it away from us. We will be no longer part of the world we are looking at because we are losing the continuity with it.

212. Georges Didi-Huberman, Lo que vemos, lo que nos mira, trans. Horacio Pons (Buenos Aires: Manantial, 2010),13. 


\section{$\S$. Two works}

Opposites in Siza's drawings is seen as a guideline for the search of the reality which the architect sought to touch in architectural works. Delimitation between architecture and site as discipline avoids the ground from being transformed into the figurative element, so as the building obtains its own character through a relative detachment from the environs. However, when turning to the pathways in his projects as track overlaid on the natural base, one may notice how the changing character of a rhythmic movement depends upon the interaction with the ground.

William J.R.Curtis considers Siza's invention as procedures that materialize and configure images to find links between inherited concepts, which recalls Freud's analysis of dream, is subject to "the process of transforming the thoughts into pictures preference is unmistakably given to such as permit this putting together, this condensation. It is as though a force were at work which was submitting the material to compression and concentration $[\ldots] " .{ }^{213}$

To relate those free images with each other, Siza has always considered architectural promenade as essential touchstone. This Corbusian notion of constantly changing experience plays an essential role in Siza's works as pathways that converge distance, turnings, ascent, descent and material pavement work equally and together with those unexpected ruptures, protruding volumes or curved surfaces of buildings, making up a successive series of events that keep attracting and orienting our eyes. Meanwhile, oscillations sensed from the moment when one is in the occasional contact between the exterior space and the interior, or is facing the facades as varying physiognomy, make visitors enmeshed in the tangle of observation. It gives rise to the expression of a specific moment which serves fundamentally, as Siza puts in, the thought of realizing contingency:

213. Curtis, "Notes on invention," El Croquis, no.68/69, 249.
"Each of my designs seeks to capture, with the utmost rigour, a single moment of fleeting image, in all its nuance. To the extent to which one manages to capture that fleeting quality of reality, the design will emerge more or less clearly, and the more precise it is the more vulnerable it will be." ${ }^{214}$

The expression of something in motion works closely with the immediate and the fragmentary aspects in Siza's architectures, but this does not mean to dissolve the wholeness of the project. Conceptual orders are always introduced to consolidate the entire composition, wherein those momentary facts in architectures, as Moneo observes, are sculpted and organized in sequence so as to create "a continuous allusion to the constant change that gives rise to temporal succession." 215

Siza's strategy of achieving varying experiences in his design through architectural itinerary would assume a progressive compression - it works simultaneously on topographical, constructional and corporal aspects - that keeps concentrating one' eyes on the trace of the delicate and changing facts orchestrated along the pathways inside and outside the buildings. As movement becomes the key element to understand this metabolic process, this is why it would be relevant to give a reflection upon Siza's architecture with two comparable works realized during the same period yet with different strategies: the Faculty of Architecture in Porto (Faculdade de Arquitectura da Universidade do Porto, 1987-1994) and the Park of San Domingos de Bonaval (199094) affiliated to the Galician Centre of Contemporary art in Santiago de Compostela. Itineraries of both projects achieve a high level of integrating new buildings, vestiges, 214. Álvaro Siza, “On my work,”in Esquissos de viagem, Frampton, 71.

15. Rafael Moneo, Theoretical Anxiety and Design Strategies in the Work of Eight Contemporary Architects (Cambridge: The MIT Press, 2004), 203. 


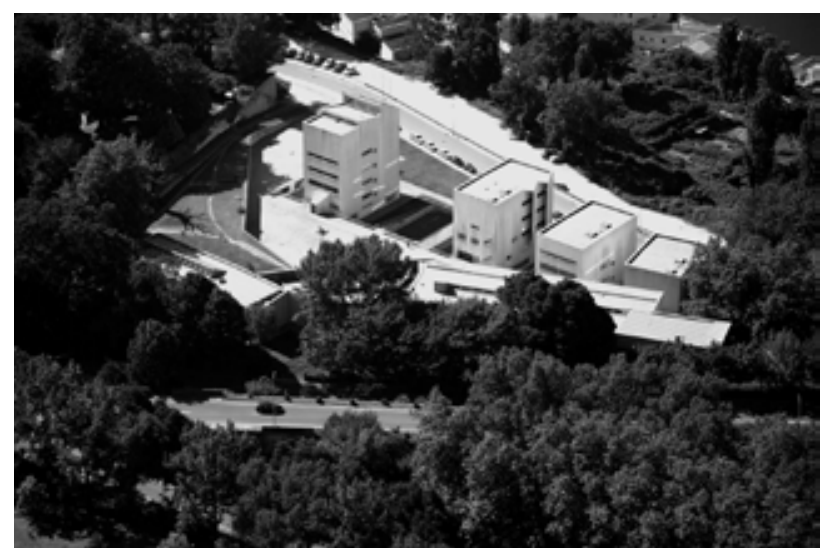

Fig 4.16. Porto School of Architecture (1987-1994).

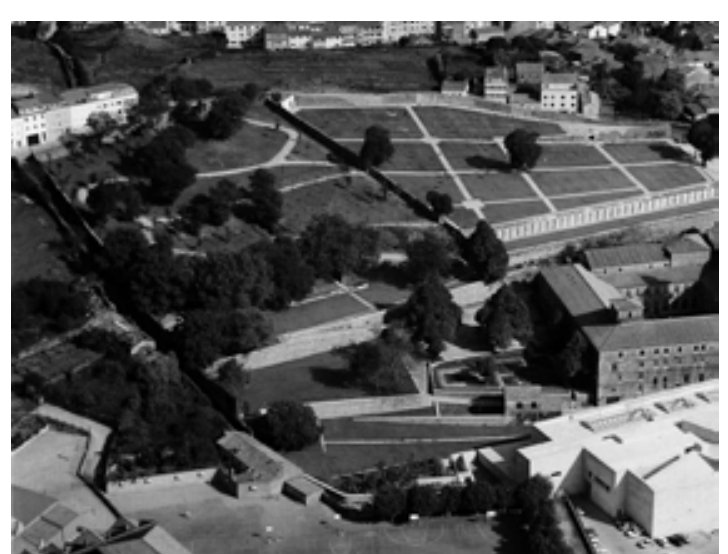

Fig 4.17. Park of San Domingos de Bonaval (1990-1994). landscape and urban views throughout the trajectory, while promoting instant pulses of one's perception so that he or her would stay and enjoy a precise moment.

$\cdot i$

As indicates his aphorism "architect don't invent anything, they transform reality", topographic conditions and preexisting elements on the both sites were regarded by Siza as point of departure. The particular hierarchy from preset structures - the two courts reserved for the school in Porto, an elevated and enclosed parterre calibrated to Quinta da Póvoa villa and the adjacent triangular site on the lower level, and the trichotomy of the site in Galicia of barren orchard, the oak groves (A Carballeira), and abandoned cemetery - provided Siza with resources and limits to rediscover the archeological qualities, and to establish respective transmissions of phenomenon and physical space (Fig4.16.) Parallel to the approach towards his insight into the contextual elements and transformation adapt to the respective functional uses and constructional requirements, it is essential to argue that how an indifferent character is preserved as a resistance to formulate a remote monumentality in sites that validates the relationship of the terrain with the buildings and events overlaid.

The primary issue is followed by a question that initiates respective study about the composition of the two itineraries, with respect to their orchestration of "fleeting images". That is, to what extent architectures participate into and how they act in their (architectural) promenade. This paradoxical term establishes a transversal theme in the two projects whose itineraries play the key element to articulate the whole setting through divergent strategies. In Porto, circulations throughout the upper and lowe precincts are strongly defined by buildings, whilst in Santiago de Compostela, the zigzag route that penetrates into the historic terrain is developed according to a progressive detachment from architectural control of the museum and the old convent which have configured the park entryway.(Fig4.17.) In this respect, it would be more difficult to answer the question in terms of the former case than of the latter one since the school's itinerary has a higher degree of integration of the exterior pathways and the interior circulation of those studio buildings. However, a sight of polarization is needed to make distinction. That is to say, when focusing on the itineraries that structure and compile the narration of the entire place, architectures is the more a background that accompanies than a space that contains. Rather than the interior organization of the architectures, though it is occasionally criss-crossed with the exterior space so as to provoke oscillations, it is the volumetric expressions of the buildings, together with the topological relations and the geometrization of passages, that contribute to those "fleeting images" which interrupt, syncopate, connect and distract our views, so as to structure a constantly changing stream of our perceptions as we move through the place.

$\cdot$ ii

The conditional accommodation to sites and the succession of momentary images in the school and civic park suggest a tendency that offsets the metaphor of historical heaviness and reminiscent melancholy which ought to be given by the past vestiges. This fact endows the two projects, as reflection upon Siza's works, with an unorthodox metaphor of rituality and monumentality. However, far from betraying memory and history as basis of his design, Siza has established in his architectures a debate of temporality as a result of the transformation of the vestige as a figurative image into the 
image per se. This deflection gives another possibility of observation of images which, according to Georges Didi-Huberman that the action of "seeing" is always connected with the feeling of "lose", works closely with the non-repeatability of our movement. As a result, Siza has successfully stressed and reconstructed the "aura" in those past images through this paradoxical process, and has accommodated it into our walking experience as a collection of fleeing events. 
II. CONFIGURE ANOTHER REALITY

When talking about the "logic of the place", Josep Muntañola affirms the dichotomy of conceptual movement and figurative forms which balances the meaning.

"La lógica del lugar nos expresa en su propia estructura la dialéctica entre razón e historia, por ello la lógica de representar lugares siempre ha comportado un equilibrio entre experiencia y racionalozación. El lugar, como límite, es más que nunca un balance rítmico entre razón e historia; ya que, el tiempo depositado en espacio, o sea el lugar, siempre refleja en su misma estructura el equilibrio existente entre un aumento de movilidad atrás y adelante en el tiempo (razón), y un alejamiento progresivo del lugar originario (historia). Acuerdo febril entre movilidad conceptual y forma figurativa (entre movimiento y reposo, diría Spinoza), la lógica del lugar marca siempre la medida bajo la cual la humanidad es capaz de representarse a sí misma. Y así empezamos a estar muy cerca del corazón de la arquitectura como lugar para vivir." ${ }^{21}$

Through establishing a suspended structure which legitimates human activities between reason and history, the author indicates a certain remoteness of place. This notion aiming at spatio-temporal equilibrium is represented in the relation that Siza has established between his projects and the plot where they are located. In his works, physical and conceptual fractures appear as recurrent feature that are constantly questioning the absolute presentation of the continuity between architectures and land.

The renovation of Chiesa Madre and Piazza Alicia in the historic center of Salem (1991-1998) (Fig.4.18, Fig4.19.) is one of the best samples to see the Siza's capacit to achieve, through a strange, personal process of purifying reality, a balance among

216. Josep Muntañola Thornberg, La arquitectura como lugar: Aspectos preliminares de una epistemología de la arquitectura (Barcelona: Edicions de la Universidad Politécnica de Cataluña, epistemologia 1996 .

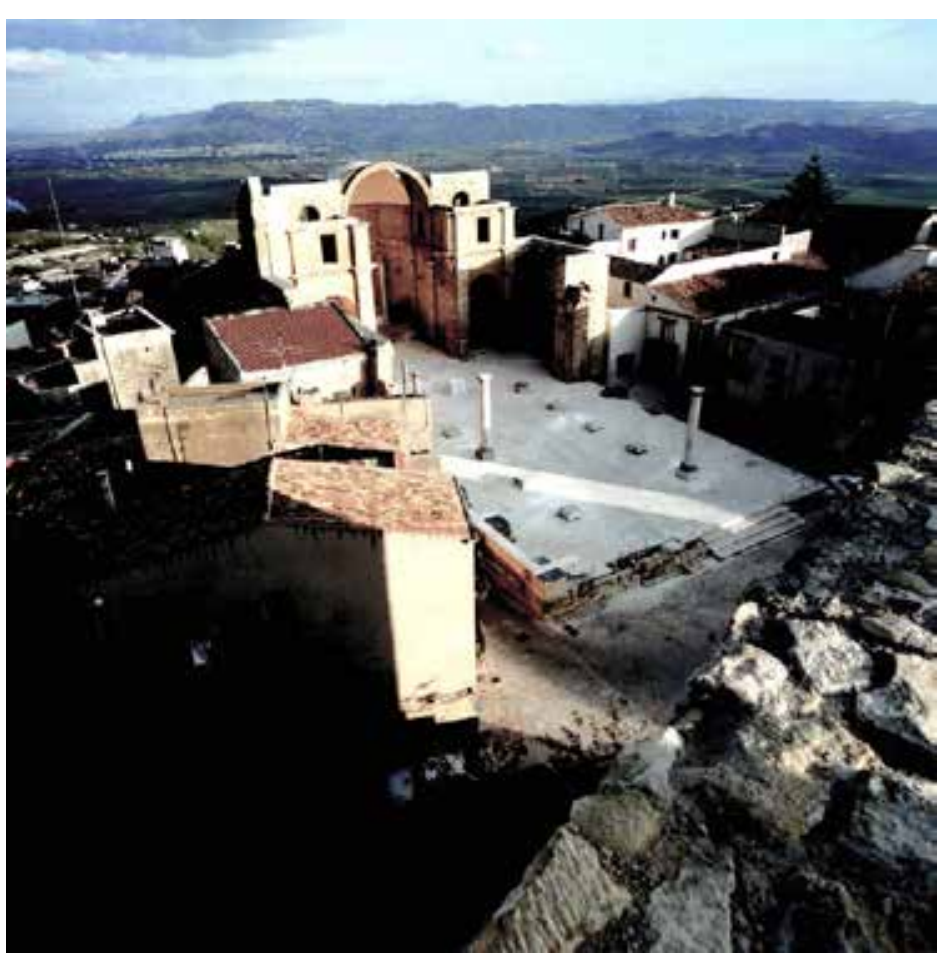

Fig 4.18. Redevelopment of Chiesa Madre and Piazza Alicia, Salemi (1991- 1998), Álvaro Siza and Roberto Collovà

historical vestiges, topographical conditions and the autonomy of new constructions. Contrary to the retrospective expression which Francesco Venezia established in the open-air theatre by recalling metaphors of the subterranean world, Siza has made less articulation between the ruins and the land since he did not place emphasis on the volumetric and material continuity, but on the system of different levels and geometry of the floors in order to shape the emptiness. New floorings were introduced to redefine the ground of the destroyed church, disconnecting old fragments from the original surface. In addition, the Piazza Alicia on the lower level is distinguished by the oppositions of renovated scheme, shaped by dislocated rectangular, and the continuous outline of the neighborhood. The inconsistency of materials and geometries lead to spatial and temporal separations, which seem to create a typological alienation among the rescued columns and the church apse by giving them formal independency. This renovation can be seen as a celebration of instability and discontinuity, with which Siza has created extraordinary and exceptional reality in the place that intensify the tension in a balanced structure with the sphere of old facts.

Siza is always aware of the conflicts in the place, as he puts in: "a site is valid for what it is, and for what it could be or wants to be - sometimes these are opposing things, but they are never unrelated.", and the order that projects give to the site is the "bringing together of opposites." ${ }^{217}$ His attitude of accepting contradictions, because of "all that exists is important and one cannot exclude anything from this reality.", ${ }^{218}$ recalls Fernando Távora's remarks - "to include everything and exclude nothing". Rather than uniting different elements, diverse disciplines and oppositions are well preserved in Siza's projects as opportunities to create counterpart to the existing. This strategy based

217. Siza, "On my work," 71.

218. Siza , "Entretien ," 40. 


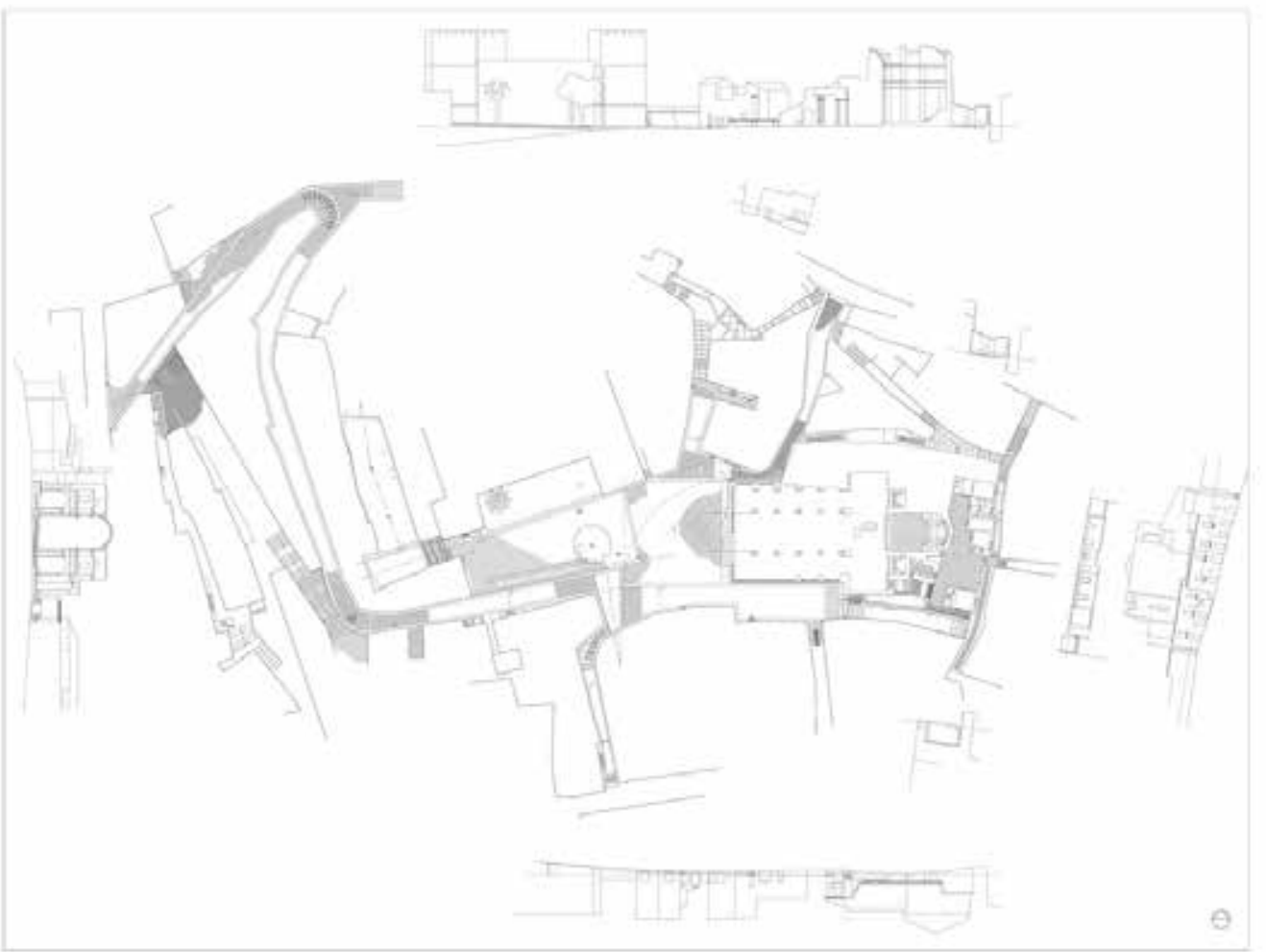

Fig 4.19. Redevelopment plan for Salemi historic center.

on conceptual division makes his projects as manifestation of two worlds. Architectures and new scheme are not produced from the ground, but are carefully imposed on the preset base as responses to its demands, and the awareness of the delimitation becomes typical experience in his works.

To be sure, Siza never neglects references and origins in the place. He defends them, rather than creating apparent connection between buildings and ground, through addressing the contextual needs. In the Faculty of architecture in Porto and Bonaval Garden in Santiago de Compostela, we will see its application on a larger scale in the projects of building complex and cultural landscape. And from the entryways of the two works, we start to understand the architect's mechanism of transforming a series of abstract and perceptible episodes into the transmission between the old and the new realities. 


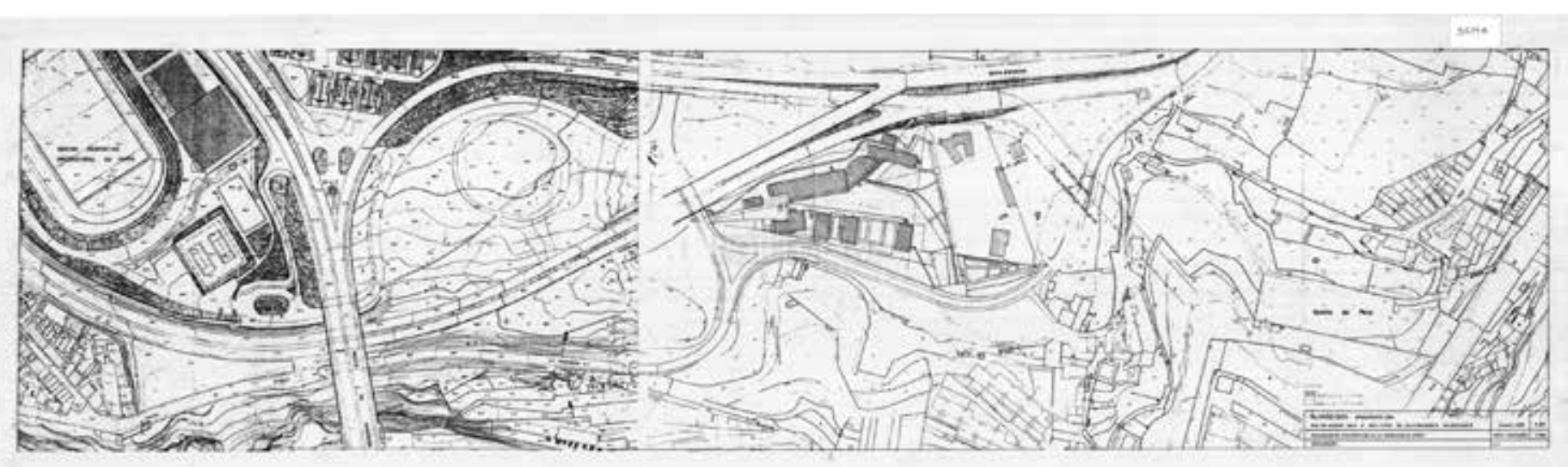

Fig 4.20. Site plan of Faculty of architecture of Porto University.

$\S$ Critical combination

- the Paradoxical Syncretism

Adjacent to the access of Arrábida bridge, the trapezoidal plot occupied by the new Faculty of architecture overlooking the estuary of Douro River is a combination of urban textures and agricultural traces. The vertical images structured by the river bank, the terraced land ${ }^{219}$ occupied by traditional houses and modern buildings on the top indicate the development of the city of Porto. (Fig4.20.)

Terrain unevenness gave the place natural separations that anticipated Siza's respective strategy to manipulate the site and to implement the project. On the west side, a raised courtyard of Quinta da Póvoa, outlined by solid boundary, had been preserved for the first stage work. (Fig4.21.) Under the premise of conserving existing walls, old edifices and gardens, Siza was commissioned to reform the protagonist villa and to design a provisional atelier.

Siza made use of the masonry to protect this upper plot from the outside world. Topographic indifference here as essential character enables him to consolidate original relations and to develop an introspective organization by featuring old traces and 219. Siza has indicated the value of topographic terraces in site, "In Porto, as you know, the organization in terraces on both banks of the Douro River continues upstream, and it is When those terraces reached the city they were converted many times as containing wanks gardens. But this traditional structure of terraces and platforms is nowadays being attacked violently due to the strong real esta presures. In fact, the teraces of the Faculty of Architecture are the last ones in the city of Porto." (RODRÍGUEZ, 2015:257)

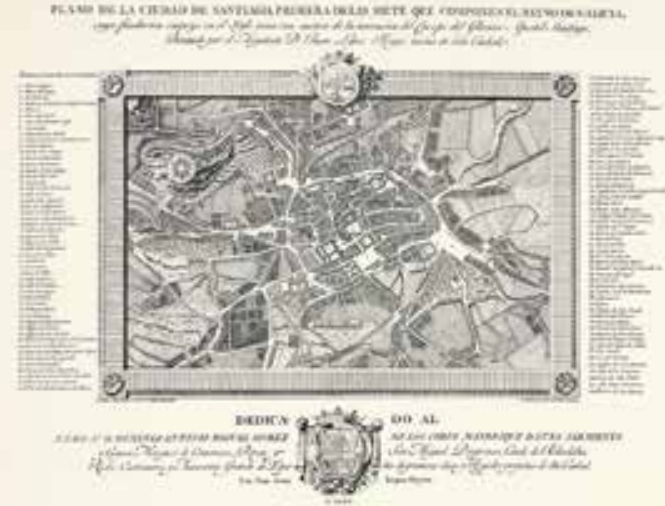

Fig 4.54. Plan of Santiago de Compostela, 1796

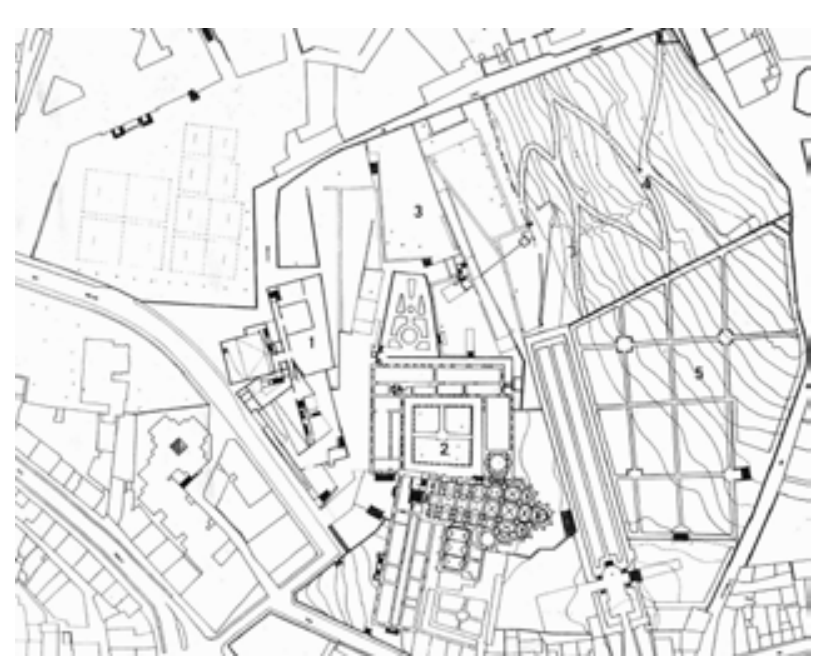

Fig 4 55. Plan of the Bonaval garden of Santiago de Compostela.
Rediscovery of the order

Reconsidering the limits

The rehabilitation of the Bonaval garden demonstrate a capacity to make the meeting of opposites at the margin of historic center of Santiago de Compostela -on the one hand the natural landscape and existing elements from the abandoned land, on the other the artifice of construction and enclosed space for exhibition of contemporary art. Idea of this project was based on the essential points with respect to the city, landscape and history: to reconcile the conflicts between the old orchard, grove and cemetery and convert them into a civic park, to recall the historical memory of the city through the pre-existing elements, and to promote dialogue between the old convent and the contemporary museum through the new access of the garden. (Fig4.54, Fig4.55.)

Thanks to a map of 18 th century which provides a precise information of the original plan of this precinct, the architect and the team were able to trace the foundations of the old organization related to the convent, not only the existing structures upon the ground, but also those walls, pathways and irrigation channels buried under the ground. Knowing it is pointless and impossible to recover the image of this multi-use land as it was before, Siza focused on the preservation of its organizational structure through partially reconstructing those excavated elements, as the manner to change this conventual yard into a public garden.

Two drawings made by the architect with integrated information suggest different perspectives to rediscover the site in terms of the new project. The situation plan, shows only few structures remained on the ground, puts emphasis on the topographical 

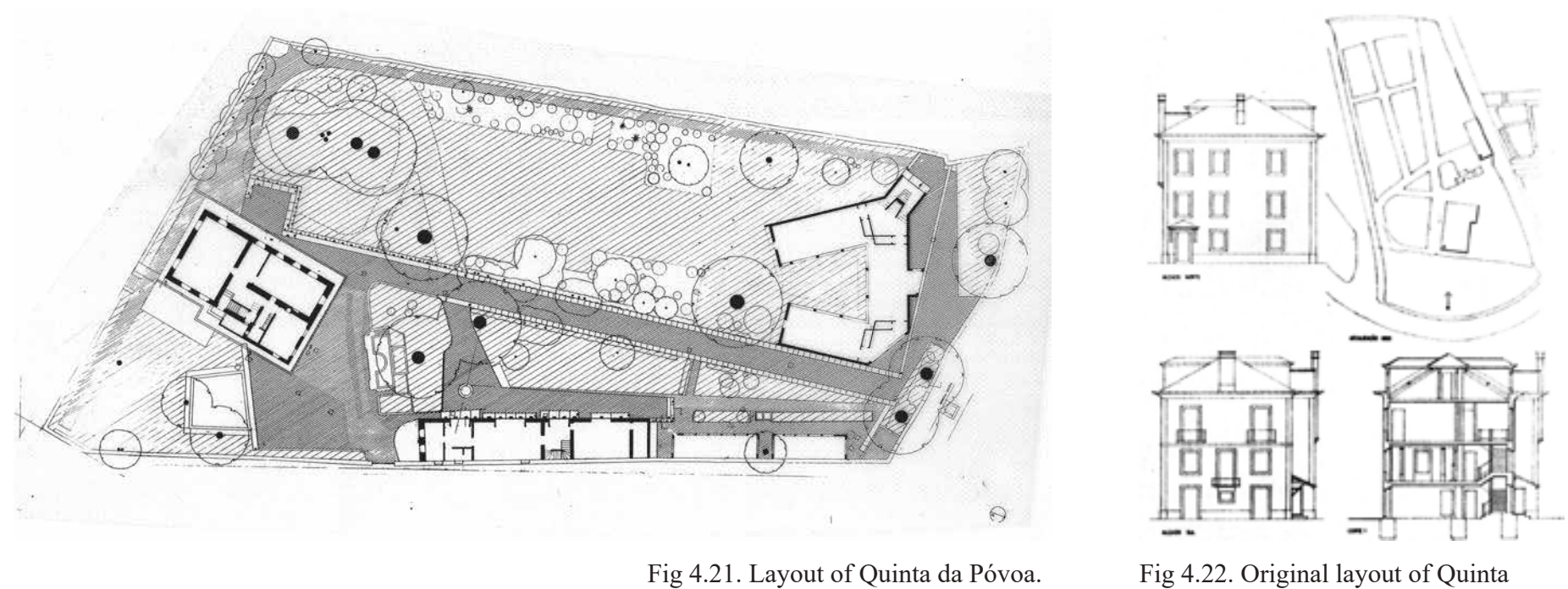

Fig 4.21. Layout of Quinta da Póvoa.

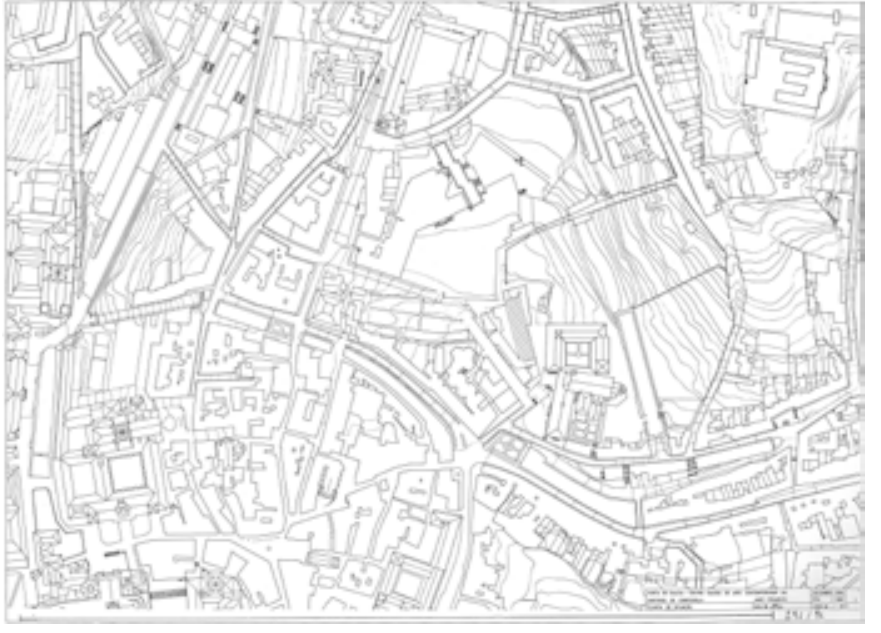

Fig 4.56. Situation plan, 1988.

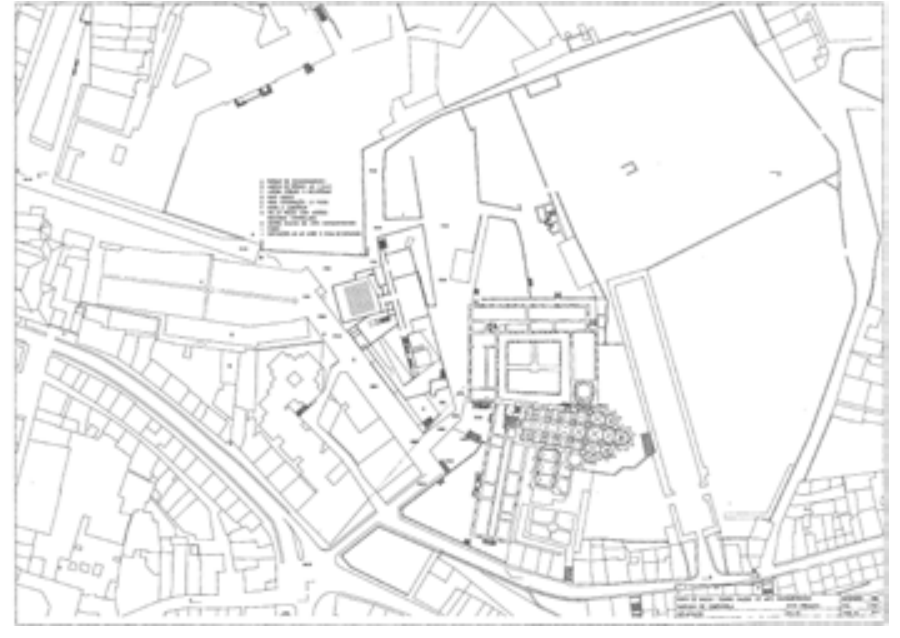

Fig 4.57. Implementation plan, 1988 da Póvoa.

calibrating new scheme to the heritage house painted in pink (la casa Cor de Rosa). (Fig4.22.) Rediscovering the spatial structure was carried out parallel to the construction of Carlos Ramos Pavilion, the free-standing atelier at the far end. Siza's first proposals for the studio, a simply lineal volume (Fig4.23.) sited next to the old villa manifest the prototype - a ledge-divided building with a full-height colonnade - of the side building of Portugal Pavilion for Expo '98 and the wings of Setúbal teacher's training school (1986-1993). This outstanding structure yet gives less respect to the preexisting elements may reflect the architect's initial idea to lend a certain importance to this first building of FAUP. Several months later, the revised project of a U-shape structure with an open patio represents the author's strategy to include contextual facts into the pavilion. In addition, its relocation at the margin of the site even contributes to balance between a compound of self-sufficiency and the connections with future constructions.

The bended shape of two wings aligned with the garden edges and the other points to the villa's corner, and a cut-off corner as a consequence to protect the root of the tree nearby, manifests the geometrization of the pavilion based on an attentive reading of the existing reality. Nevertheless, its white facades stay indifferent to the surrounding elements and the luminous interior establishes proxemic relations among studios place emphasis on the inconsistency between the new and the old buildings.

Transformation of the garden also suggests Siza's dialectical strategy to avoid a unified program. Neither the original criss-crossed scheme in favor of accessibility nor his early proposal of triangular shape whose sharp tip highlights the building's orientation towards the house was approved (Fig4.24.). The Carlos Ramos pavilion is located at the end of a continuous garden, where a big tree in front of the patio manages to interrupts face-to-face communication with the old house.

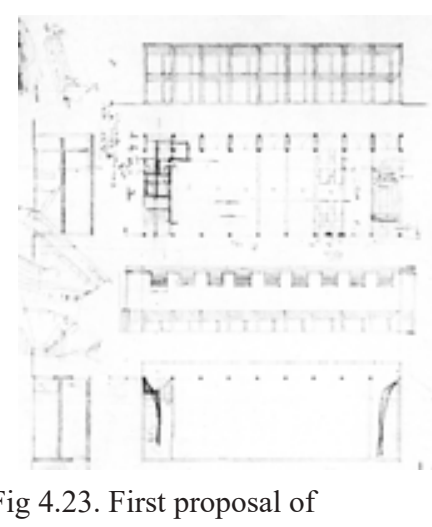

Carlos Ramos Pavilion, 1985

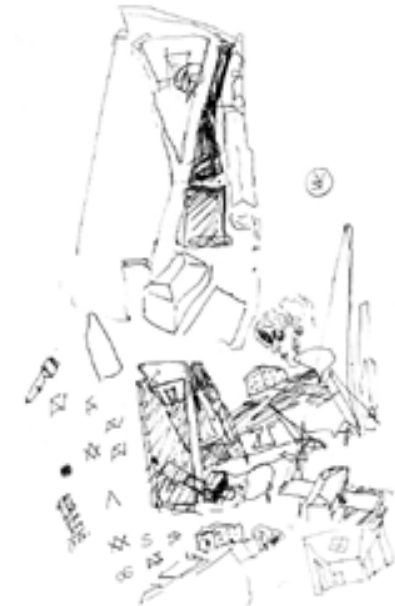

Fig 4.24 Proposal of Quinta da Póvoa garden, 1987. features of this steep ground. (Fig4.56.) The implementation plan (Fig4.57.), on the other hand, ignores terrain unevenness and reveals exclusively the architect's strategies of selecting those old elements, as indicators of memory, to produce the garden scheme. By remounting walls to configure limits and to control visual perceptions, a structure of three platforms accompanied by a circular trajectory is defined. From the orchard on the bottom, visitors go up to the oak grove on the top, then turn to the open place recovered from old cemetery and a narrow patio of niche walls before descending to the yard behind church's apse where there is a way back to the start point.

As the significant elements that consolidate boundaries and convert the inclined site into a serial of platforms, those walls rebuilt in granite, as reflections of the city's constructional history, have made a group of limits that controls views and movement. Holding the idea to reproduce the old system led by vertical trajectories, Siza takes the slopes in different areas as reference to define the height of these wall, in order to achieve "the ascension along a path of ramps and stairs in a zig-zag way going across distinct platforms". ${ }^{226}$

The garden is thus conditioned by the conflicts and alternations between the vertical and the horizontal. The zig-sag boundaries of solid walls that introduce rigid measurement to the ground recalls Richard Serra's land art, the "Shift". (Fig4.58.) Both of the architect and the artist convert constructions into interventions in the territory and impose geometrical sequence on the natural surfaces to generate individual order, which manifests the idea of displacement. In the garden, the play of the continual process of the walls and their abrupt interruptions and reconnections have shown Siza's strategy of
Fig 4.58. “Shift”, Richard Serra, $(1970-1972$
226. Juan Rodríguez and Carlos Seoane, Siza X Siza (Barcelona: Fundación Caja de Arquitectos, 2015), 342 


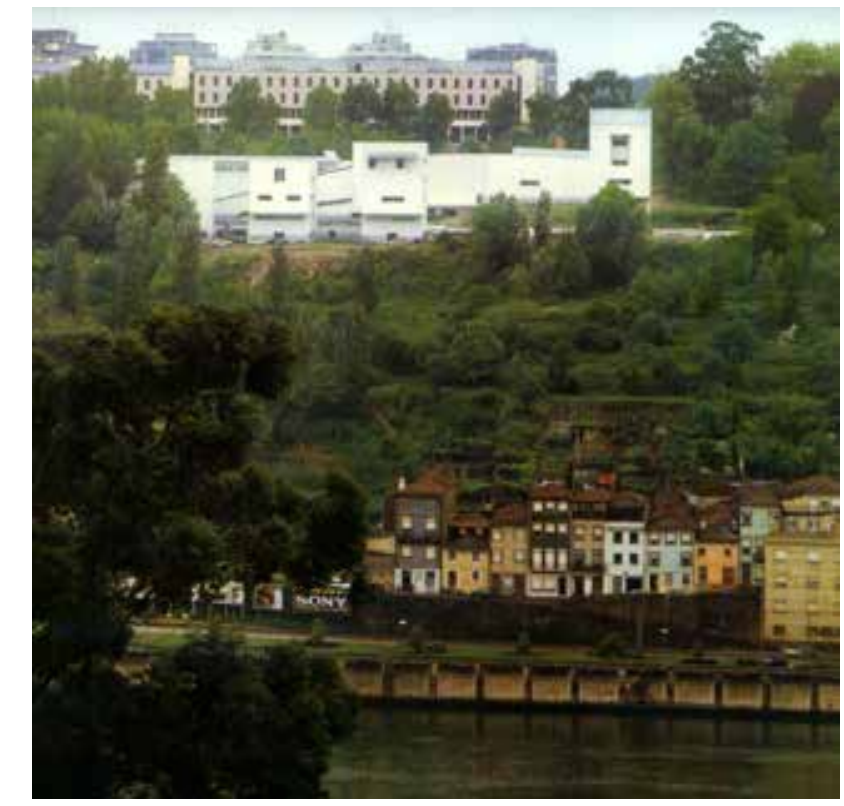

Fig 4.25. View of the bank.

These distancing operations endow the Carlos Ramos pavilion with the sense of articulation and dislocation at the same time. The using of preexisting orders to detain circulation and visibility manifests Siza's personal attitude towards spatial and temporal continuity. Being set as a fracture, this free-standing studio is thus suspended between the geometric patterns of the site and its original layout, managing to break the selfsufficient setting.

- accidental simultaneity

Though Siza had schemed the whole faculty during the first work despite of the unclear location of the new campus, work of the second stage consists of a complex of studio buildings, administrations, exhibition hall, library and services had suffered huge alternations along the years to establish relations with the location and the adjacent layout of Quinta da Póvoa. The triangle platform on the north-south slope between the upper motorway and the lower panoramic road, with outstanding visibility and accessibility, privileges the new buildings on the river bank to mark a key entry to the city.

Siza started the project with a single building of multiple functions. Proposal of a fanshape block with continuous facade possesses a softer relation with the site. (Fig4.26.) Later, it became a square cube. Apart from the retrospective sense that relates this new building with Nasoni's Episcopal Palace in the city center, the unified body defines circulation around the patio, the column matrix accommodates the rigorous volume to the inclined, and the open space underneath, recall the Convent La Tourette.(Fig4.27.) Though several adjustments were made by the architect to reorganize the orthogonal geometry, relations between the plot and this massive structure remain so harsh that one
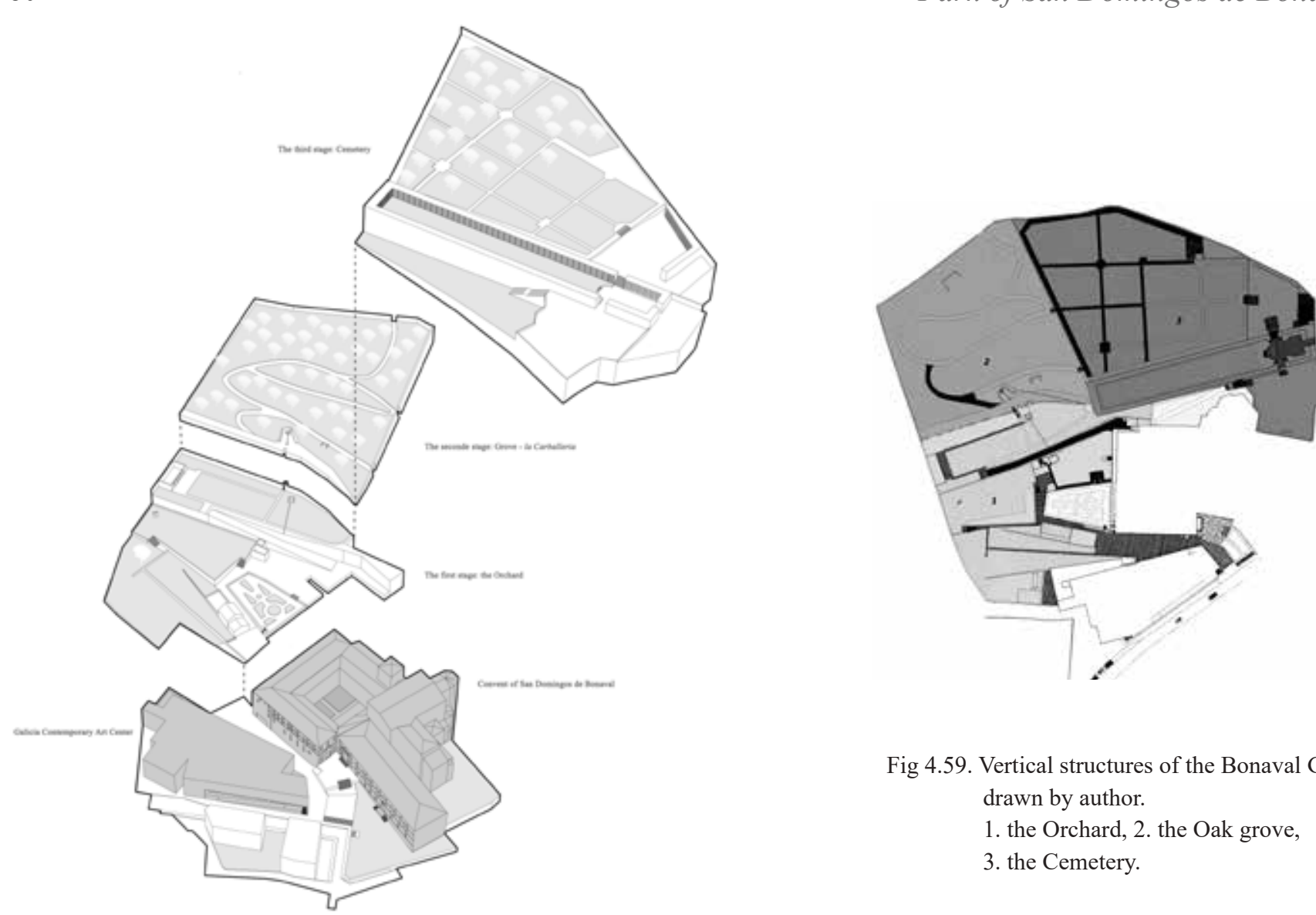

Fig 4.59. Vertical structures of the Bonaval Garden, drawn by author. 1. the Orchard, 2. the Oak grove, 3. the Cemetery.

resorting to the presence of the boundaries for references of itinerary

When passing through the pathways along the walls to reach the upper platforms, visitors become aware of the place from its conditions of frontiers and of transit. The constructive elements, precisely controlled in their dimension and position, subdivide the precinct, while determining a topological and a visual field. Displacement is realized by the directional lines through a succession of screens, whose vertical penetration in the ground indicates the slope of the land, while their upper edges indicate visual horizons for the perception of the territory.(Fig4.59.)

In the Bonaval garden, transit was sought by delineating a geometry on the base of an archeological map, while at the same time providing the observer with the feeling of ascension through zig-zag extension of the routes, affirming the basic idea of rediscovering the place. In this sense, Siza's work represents Muntañola's notion of the balance of the logic of place. The forces derived from the redefinition of those historic elements manage to break the indetermination of the landscape and is interpreted as a rational instrument that reveals the site. The constituent elements are linked to the ground and history to make them recognizable through direct experience and to organize the way in which they are discovered and perceived.

- configure the duality

Though the garden and museum are two separate commissions, Siza insists to develop them simultaneously. "Se entiende que el proyecto del edificio sólo es explicable desde el estudio y rehabilitación del jardín, a lo que se añade una circunstancia nueca, que es la necesidad de articular dos edificios en relación con un espacio abierto, y no sólo uno 


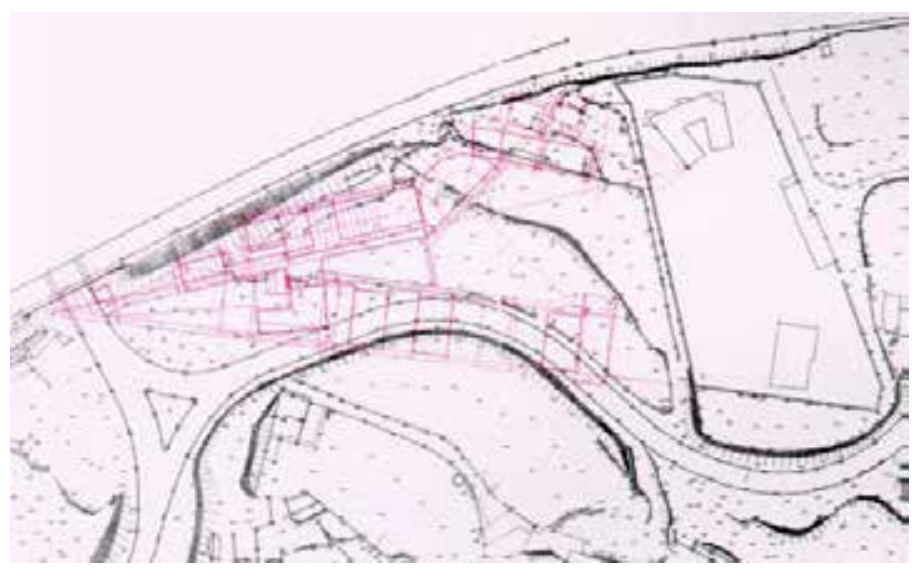

Fig 4.28. Layout of the new campus upon the original site, 1987.

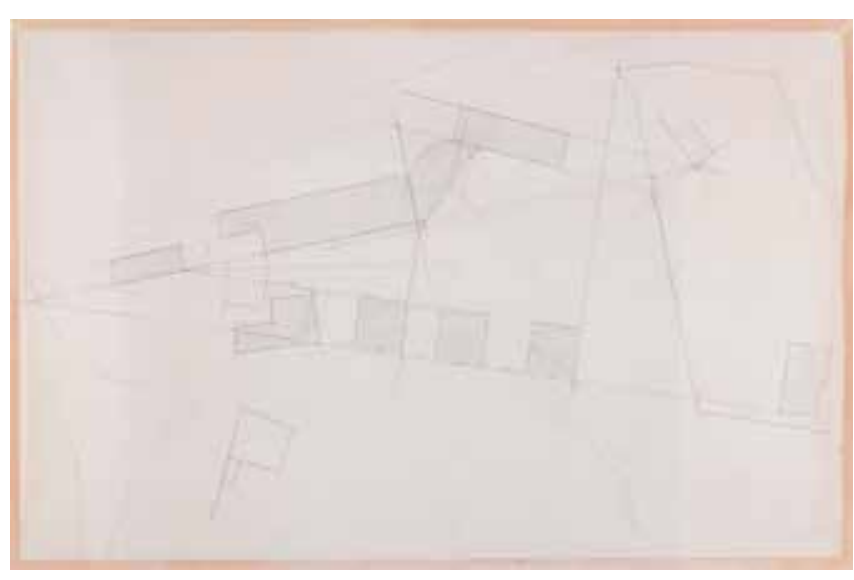

Fig 4.29. Study of layout.

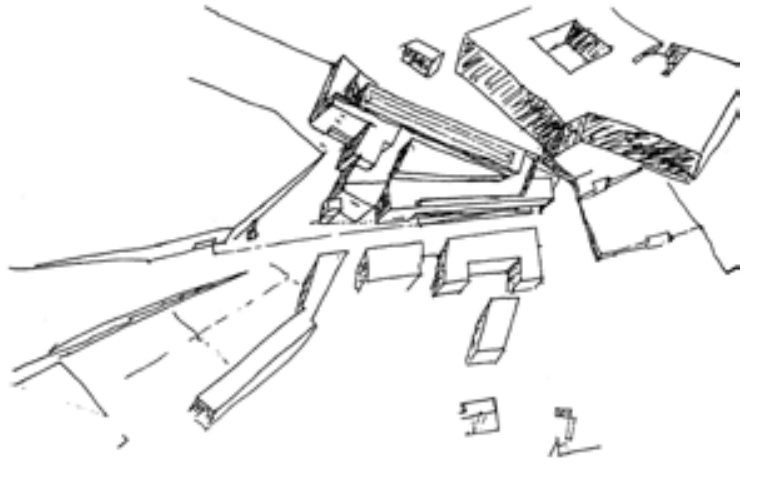

Fig 4.60 Study of C.G.A.C. layout, Siza

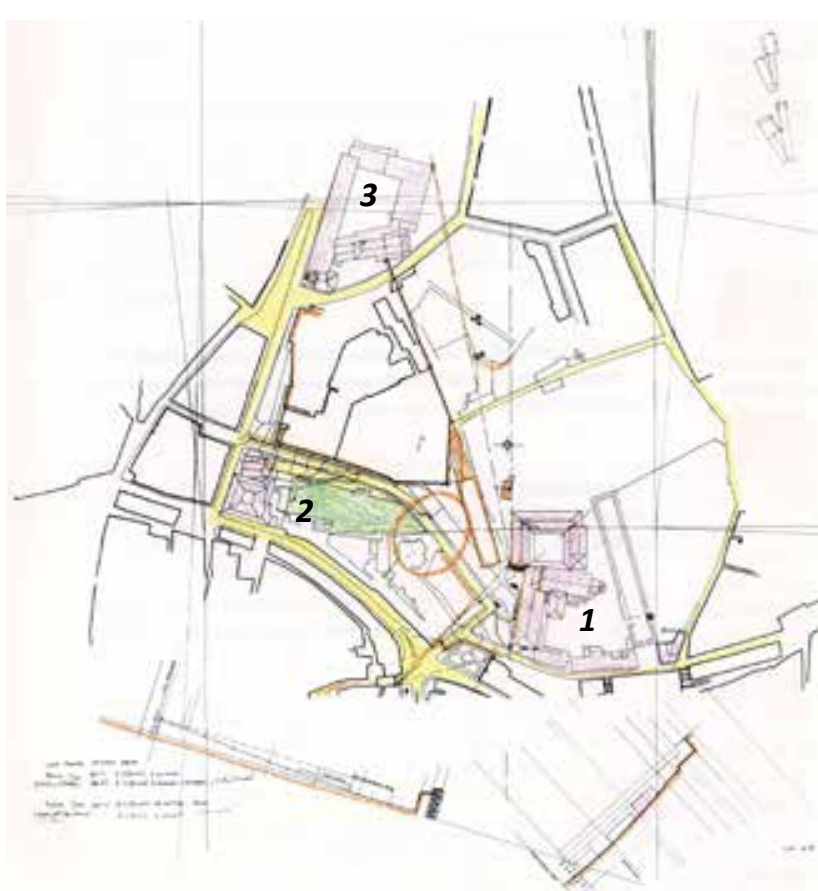

Fig 4.61. Site sketch, Siza

. Convento de Santo Domingo de Bonava 2. Hospital de San Roque

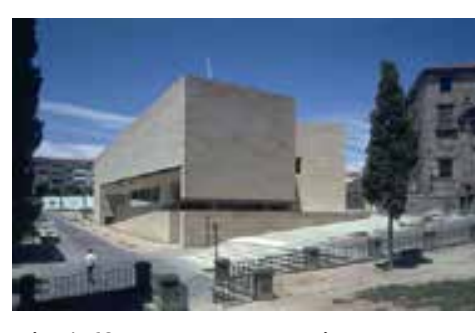

Fig 4.62. C.G.A.C exterior.

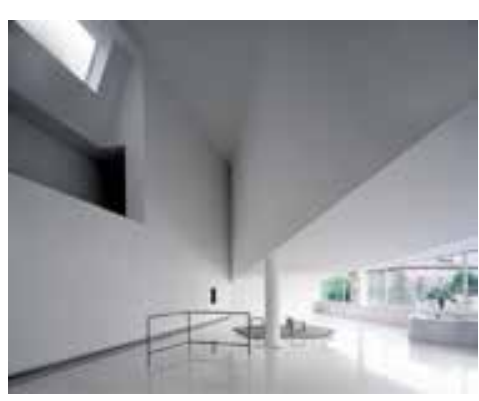

Fig 4.63. The interior reception hall.

como es más común. Al mismo tiempo. también la rehabilitación del jardín depende del concepto utilizado para el proyecto del Centro Cultural. ${ }^{, 22}$

The project of the new building begun with the architect's fighting against the request to place it a little bit set back inside the garden because of the fear of the impact of the contemporary building may have done to the Santo Domingos de Bonaval Church - a national heritage dates back to the $14^{\text {th }}$ century. (Fig4.61.) Siza finally convinced the committee to accept his proposal to set the building on the street level. (Fig4.60.) As he puts in, with regard to a new museum deserves visibility from the outer space and the equivalent value as the historic monument possesses:"un centro cultural es un edificio an fuerte en la vida de la ciudad que no puede ser sólo el anexo a un convento, a su vez transformado actualmente en sala de exposición.,228

Located at the convergence of two streets, Costa de San Domingos - the old road on the periphery of the historic center, and Rúa de Ramón del Valle Inclán - a new street of the 70s, the museum converts this area into "una zona un poco caótica".(Fig4.62. Its triangular setting, two separated wings in rectangular and a taper filling the middle gap, is highly conditioned by the composition of the garden on the one side and the alignment of the road on the other, and is suggesting relations with the heritages in this area, Hospital de San Roque on the west and Convento de Santa Clara. Inside the building, Siza does distribute the reception hall, a void space, to this middle part as if relating the interior experience with the building form. (Fig4.63.) The displacement of

227. Álvaro Siza and Isabel Aguirre, "Recuperación de los jardines del Bonaval," Arquitectos 144 (1997):34, Madrid: Consejo superior de los Colegios de Arquitectos de España.

228. Álvaro Siza, " dos museos," in Imaginar La Evidencia (Madrid: Abada Editores, 2003), 65. 


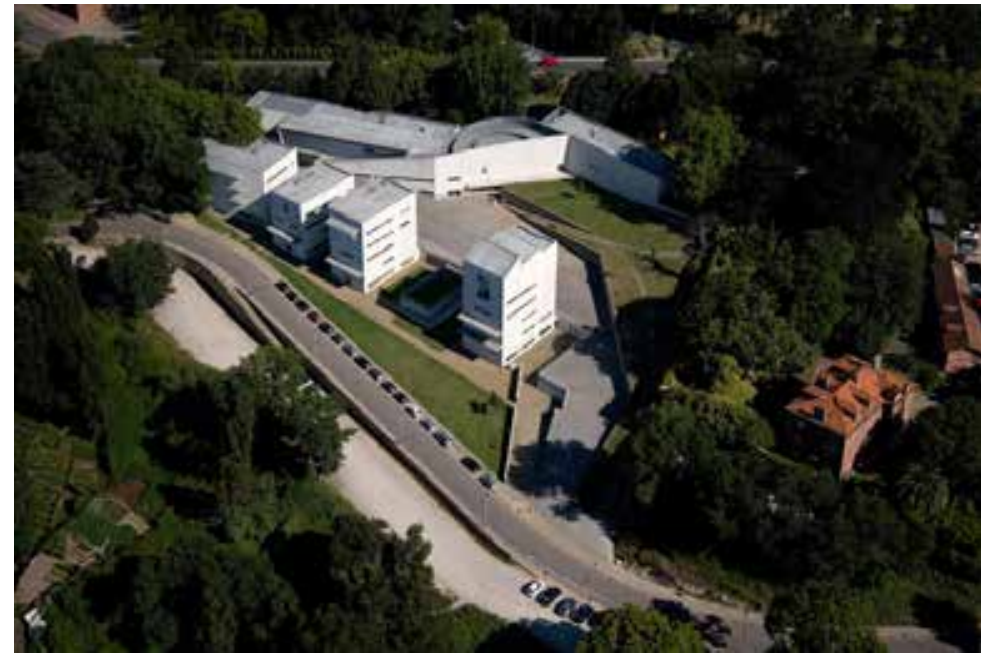

Fig 4.30. Overview of the school consists of two plots.

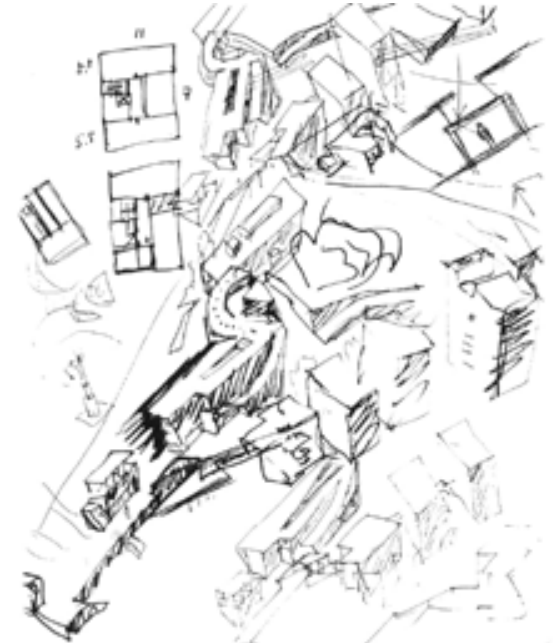

Fig 4.31. Study of layout, Siza, 1987

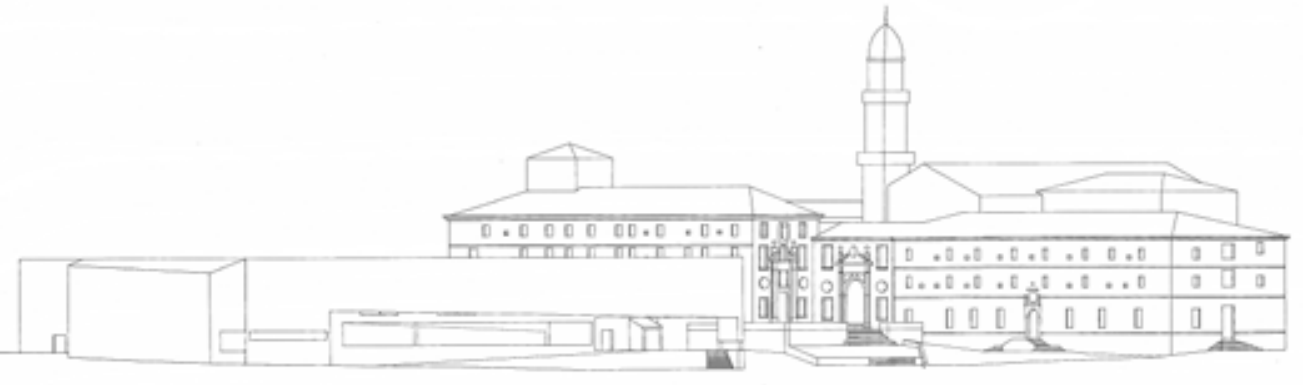

Fig 4.64. Facade along the street Rúa de Ramón del Valle Inclán.
Siza purifies the site through lines and includes topography as persistent order into the project, manifesting "architectural morphology as an emergent phenomenon."222. However, instead of lending this highly evolved system to a unified expression, Siza makes those interrelations and indicators remote and at times invisible. The highly enclosed Quinta da Póvoa remains isolated from the new campus, leaving the principle of organization to occasional encounters through porous partitions. (Fig.4.30, Fig4.31.)

The mutual relations between parts to generate the whole project, put forward by Siza suggest the concept of organic which may come from Frank Lloyd Wright, as Siza admires "the relationship between all the elements of the construction, in such a way that while and the parts mutually generated and influence each other. Syncretism rather than formal presuppositions. ${ }^{.223}$ However, Siza's strategy to hide the configurative logic, by individualizing each building as part of a complex, could be understood as the mechanism to establish continuity but at the same time to avoid the tendency to have a unified system. It serves to keep a balance between the rational way of design and the topographic and historic facts in favor of a project which is hard to conclude. (Fig4.32.) Siza formulates the final layout with his "short-sighted vision", and at the same time, the stressed plastic forces of every single building and their interactions with the adjacent ones become what feed momentary images along the approaching process and the itinerary throughout the faculty.

222. Peter Testa, "Evolutionary space. Projecting the Oporto Faculty of Architecture," in Edificio da Faculdade de Arquitectura da Universidade do Porto. Percursos do Projecto = The building of the Faculty of Architecture at Oporto University. Course of the Project, Álvaro Siza (Porto: FAUP publicą̧̃oes, 2003),70.

223. Álvaro Siza, Writings on Architecture (Milan: Skira, 1997), 96.

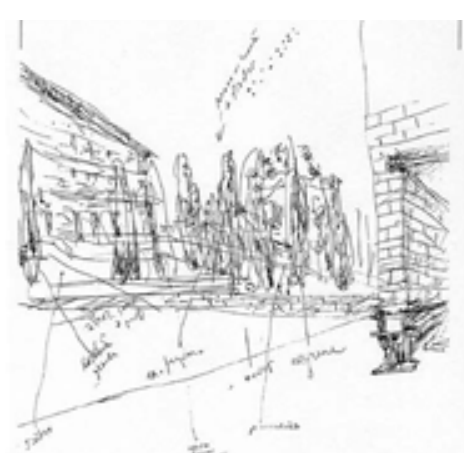

\section{Fig 4.65. Sketch of the new an}

old facades, Siza.

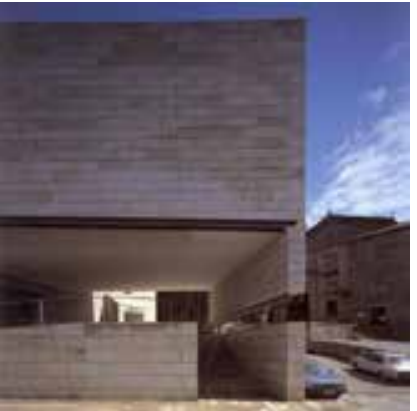

Fig 4.66. Visual connection of the new and old facades. the architectural composition is regarded as a succession of boundaries that alienate the garden from the outside streets, protecting the old land amidst frozen time.

Synthesis of the museum is also seen from constructive strategies. The building remains height similar to that of the destructed wall as if reproducing the old boundary between the street and the garden, as well as recovering a continuity with the convent behind. (Fig4.64.)A giant fracture breaks the facade on this side and reduces its dimension of the lateral facade facing to the church, giving the building a bold tectonic presence that stresses the division of meaning: the upper part in horizontal direction, suggesting an expression of indifference, is floating upon the podium made up of ramp, staircase and platform which is closely connected with the inclined ground. As the architecture of mannerism that provokes perceptions, through superposition and transparency, these two facades have drawn a great contrast between void space and material heaviness. The granite cladding and steel beams ${ }^{229}$-in Siza's words, "sólo para simular, es una mentira" ${ }^{230}$-further lead to a variety of ways to understand the architecture according to the changing of counterpoint between walls and volume. (Fig4.65.)

The application of conflicts to enrich building surfaces recalls the words of Corbusier

229. The seamless cladding at the corner of the facade, used to cover the inside structure and to provide a better resistance to the inclement weather, in a certain interpretation, also simulate massive stones. And the steel beams, rather than being structural as a load-bearing element there is a secondary structure supporting the weight- work on the visual to emphasis the edges of the wall. Colegio de Ingenieros de Caminos, Canales y Puertos, 2005), 76. 


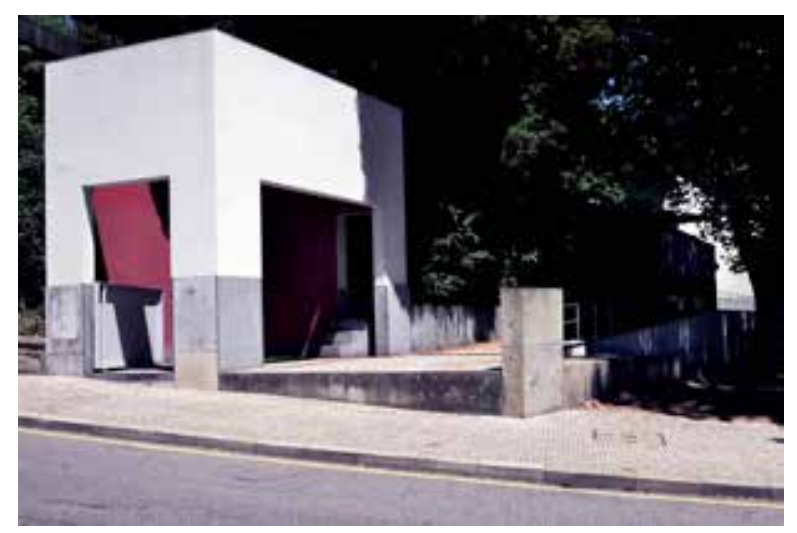

Fig 4.33. The western kiosco.

- two entryways

Partially enveloped by trees and buildings, the new campus allows people to enter through accesses at its western tip and on its south wing. The totally differen expressions that the two entrances convey, in terms of the transmission from the outside and the proxemic relations among subject and object, have anticipated the complex and intensive spatial filed composed of architectures, itineraries and landscape. Arrangement of the two accesses reveals Siza's endeavor to achieve equilibrium between the project's development and pre-existing facts through his control of articulations and fractures.

- $i$ - approach from isolation

A small roofless kiosco serves as an inconspicuous entrance at the west end under the motorway bridge. (Fig4.33.) By adding openings and removing Corbusian light cannon from previous proposals, Siza has endowed this Propylaea with open relations with the sky and surroundings. (Fig4.44.) Its trapezoidal shape and subtle deviation from the convergence point of the two wings have revealed the author's plan to minimize the tendency to have a symmetrical scheme. (Fig4.45.)

The kiosco formalized with openings defines three ground levels at the beginning of the place. The interior steps and a small aperture connect with a winding route to the service buildings behind the library. The lateral opening is adjacent to a slight ascent into the campus courtyard. This penetrating route from a narrow walk to a distended space, places emphasis on a long approach and conflicts of spatiality, manifests Siza's mechanism of composing the entering sequence in Leça swimming pool and Manue Magalhães House (1967-1970) (Fig.4.46, Fig4.47.). Beside the small platform, a ramp descending to the inferior level leads to an open patio of the cafeteria and studio building $\mathrm{E}$.

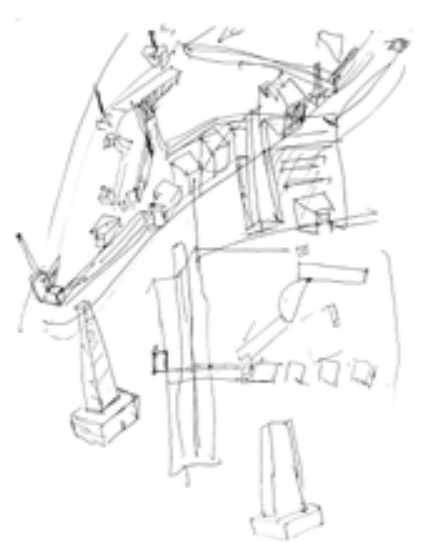

Fig 4.44. Kiosco morphology study,

1987.

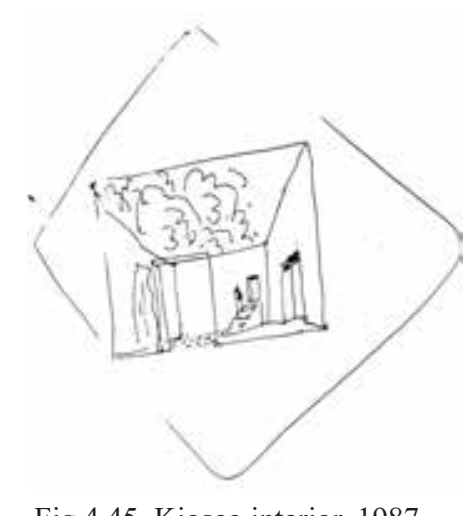

Fig 4.45. Kiosco interior, 1987.
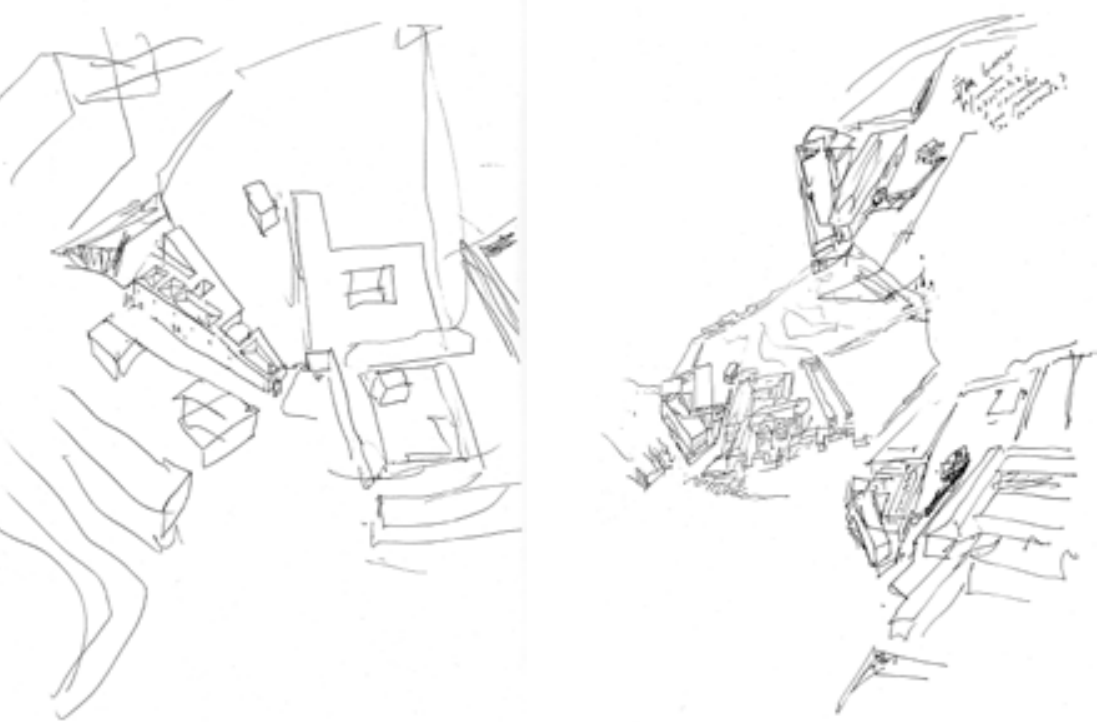

Fig 4.67. Study of layout, Siza, 1988

espacio, era necesaria una superficie de forma perfecta, después, una acentuación de su planitud, mediante algunos voladizos o algunos huecos que produjesen un movimiento delante-detrás." ${ }^{231}$ In C.G.A.C, separations on its facades become an important guidance of perception. The bold fracture on the long side that extends people's views does not only imply a forward tendency along the new street, but also reveal an inward-outward visual movement that goes through the building volume and reaches the church facade on the opposite side. (Fig4.66.) As Frampton observes: "here the spatial layering assumes a temporal dimension so that both building and enclosure are articulated in such a way as to express the passage of time. ${ }^{2023}$ Siza's museum reinforces both a physical boundary and temporal continuity on the peripheral plot of the city.(Fig4.67.)

On the general level, by positing a process of accumulation and transformation of the past realities and by giving expression of time to several dimensions, Siza manages to accommodate the architecture into this "chaotic area". He ties the scheme of the Contemporary Art Center directly to typological and morphological norms to develop the definite duality: while its interior space defines autonomous exhibition halls, its exterior organization remains suggestively to a progressive trajectory from the outer street into the Bonaval garden.

a progressive approach

Siza reorganizes the circulation at this junction area through incorporating several

231. Le Corbusier, Precisiones respecto a un estado actual de la arquitectura y del urbanismo (Barcelona: Poseidón, 1978) ,95.

232. Kenneth Frampton, Álvaro Siza: complete works (London: Phaidon, 2000), 19. 


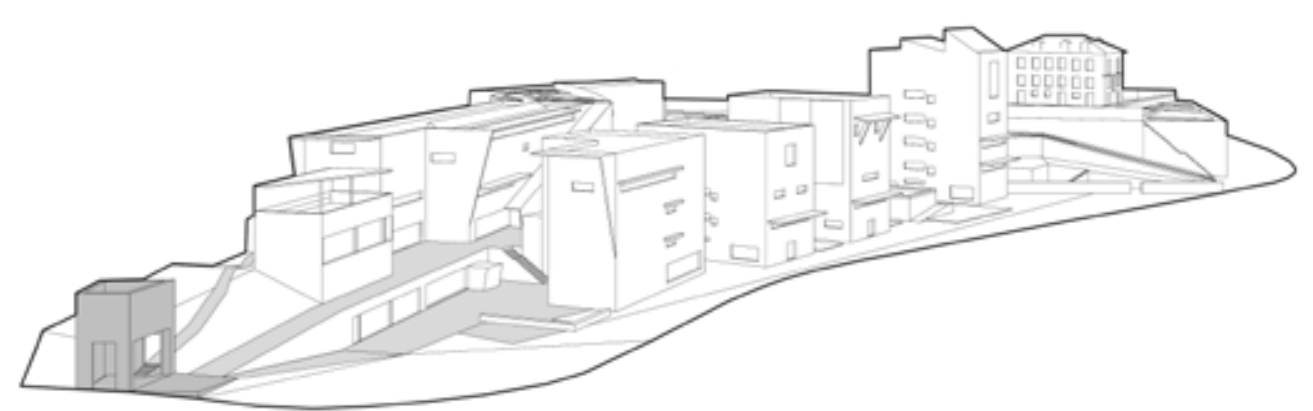

Fig 4.46. Three routes from the east entry, drawn by author.

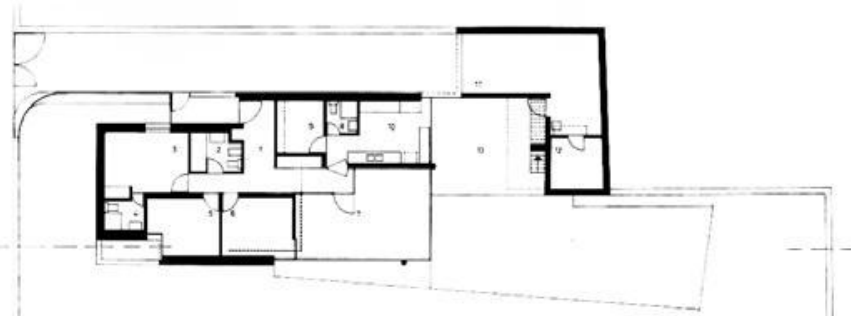

Fig 4.47 Manuel Magalhães House plan.

Complexities of this entrance derive from the contrasts between two aspects, first the programmatic organization of movement from the kiosco makes the entrance being closely articulated with the school complex and the inclined ground, second, a phenomenological approach to the isolated character and disproportional scale of the access has developed an almost surreal expression that manages to stress its remotenes to the subsequent permutation. (Fig4.48.) One may relate Siza's kiosco with the entryway of Tavora's Quinta da Conceição (1958-1960) which Siza also participated in. (Fig4.49.) The red painted walls, the austere expression of structure and materials, the staircase as metaphors of time and even transcendence give both gateways the sense of pureness. By reducing its expression of functionality, Siza enhances the introspective character of this private cabinet and protects it from the outside public events. Its austere appearance, restricted dimension and delicate light inside make the kiosco a secret place for meditation. Through anonymity, the felling of individualism and even voyeurism that visitors have experienced here would recall the recurrent painter's hands and legs in Siza's drawings. Both spatial and pictorial compositions are to privilege people, in terms of the world they are looking at, and to emphasis the existence of the subject. In this way, the paradox of an entrance that detains is told.

- $i i$ - the entry of diversion

In contrast with the metaphoric meanings that the kiosco conveys, the route and entrance on the south side provide a more descriptive manifestation of the author's strategy of how to collaborate new reality with past traces.

With open views of terraced land and Douro River on the one side, the peripheral pavement provides visitors a close relationship with the four studio towers formed by

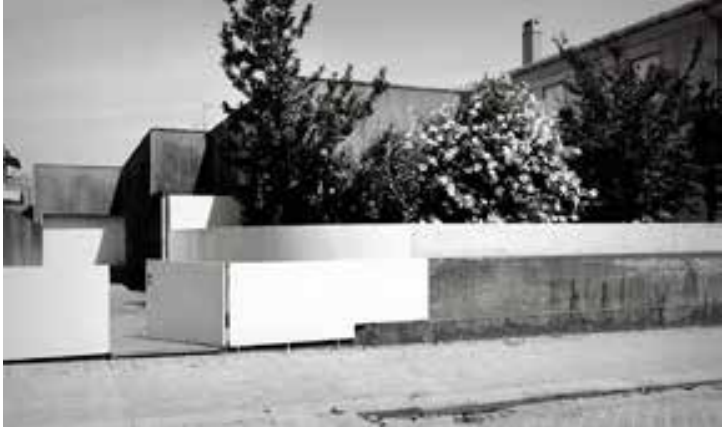

Fig 4.68. Manuel Magalhães house entry

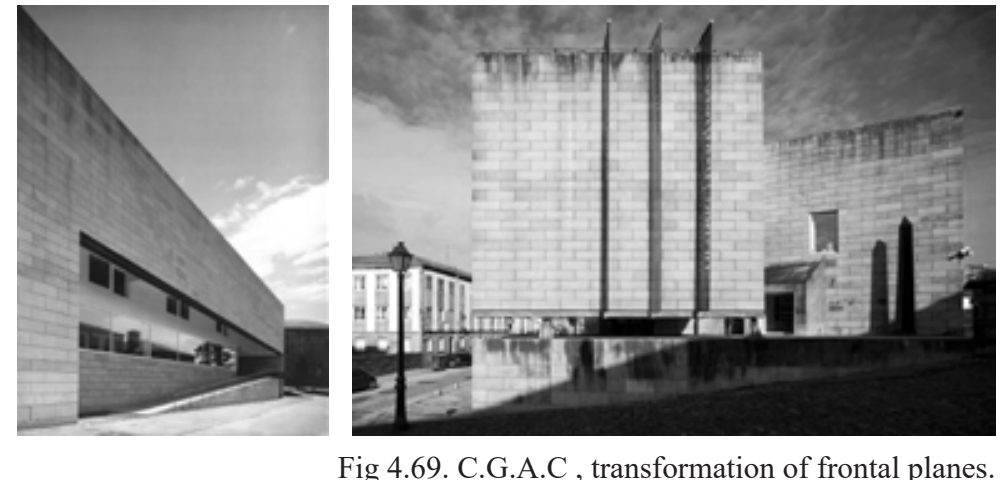

Fig 4.69. C.G.A.C, transformation of frontal planes.

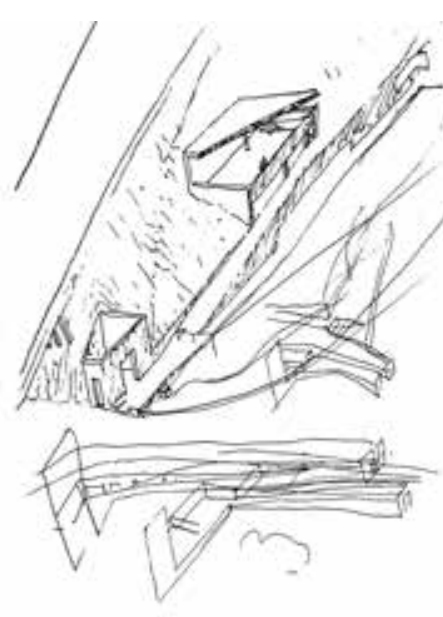

Fig 4.48. The kiosco sketch, 1987

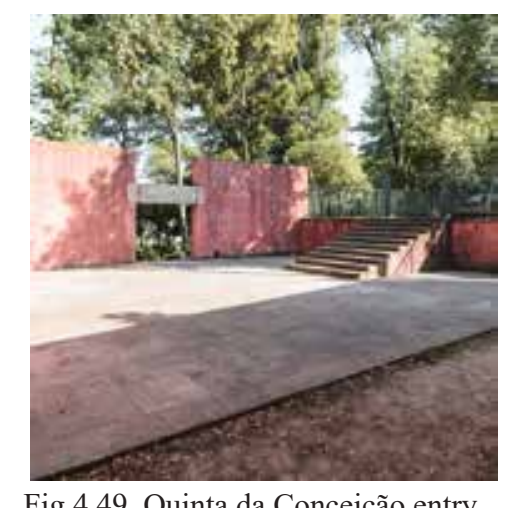

Fig 4.49. Quinta da Conceicão entry.

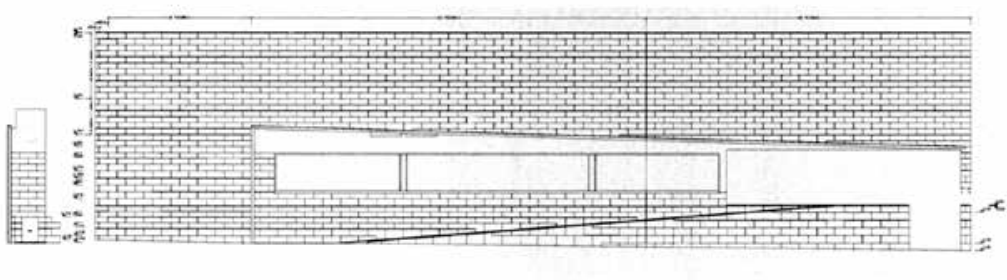

䙹

Fig 4.70. Stereotomy of detail in southwest facade.

roadways into the foreground of the museum and the church. The disciplines established by the new and old buildings reflect his intention that "disocia la arquitectura respecto a las demás artes y a la mismo vida de la ciudad", ${ }^{233}$

Entryway of the Bonaval garden begins with the museum. Here, Siza reiterates the importance of frontal character in his Manuel Magalhães house on a much bigger scale and in a more complex organization. In both works, we confront the facade along the street, and later a new frontal plane, set back or deflected, appears and shows the entry. (Fig4.68, Fig4.69.) As Moneo puts in, "everything is made frontal, even when put together in a complex scheme of lines and planes, walls and volumes." ${ }^{234}$ In one sketch, Siza depicts several figures in a variety of scales, ranging from the overall volume to constructive details, as suggestion of the visual sequence led by the transformation of the facades. The long facade that interacts between the external and internal space leads a slow movement to the rear of the street, while the short one minimizes the aperture, showing an indifferent gesture from its unitary language. (Fig4.70, Fig4.71.)

By converging the entryway of the museum with the ascension to the garden ${ }^{235}$ and steps up to the church and the convent, Siza manages to colonize and make fully use of the lot, and puts emphasis on its collective characters. With the displacement of the two oblongs of the museum and the using of geometry of slants, Siza creates a small entry plaza that defines the dialectic between the emptiness and the mass of the building.

233. Siza, "dos museos," 67.

234. Moneo, Theoretical Anxiety, 214

235. Besides this main entryway, Siza has preserved an old access to the cemetery on the garden's south side and open a small door to the grove on the east side. 


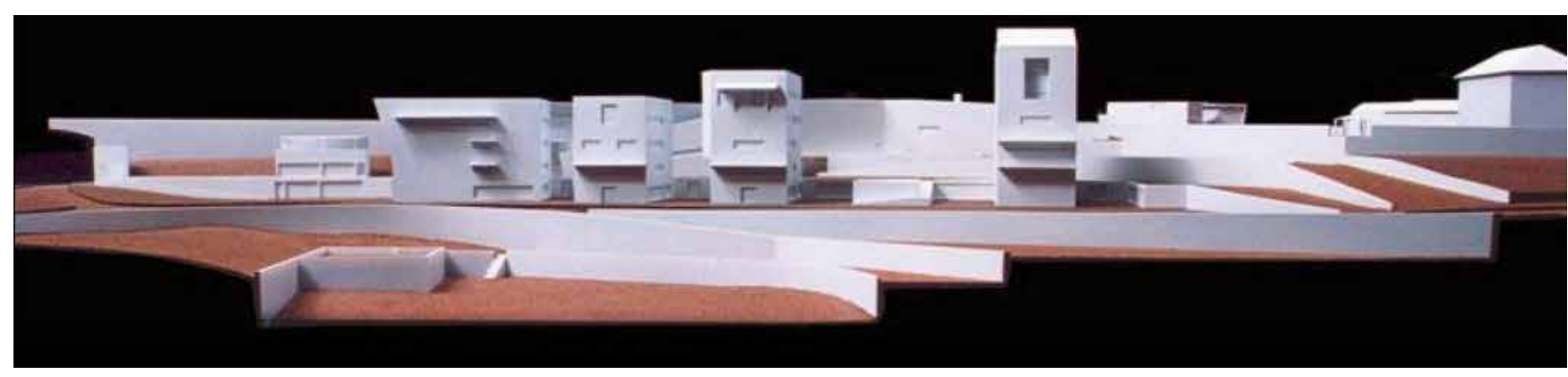

Fig 4.50. The project model. the raised campus, these towers contribute to a rhythmic sequence of solidness and openings, from which the stratification of the gallery, the raised courtyard and the north wing buildings shows Siza's operative principle of including ground unevenness into the campus levels. Despite their physical separation, the serial ateliers configured by the variation of canopies, ledges and fenestration represent an evolutionary exploration of architectural morphology as the manner to avoid repetition of the same solution. Constructional forces resulting from these outstanding elements contribute to the spatial continuity that provokes approaching process. (Fig4.51.)

At the end of the route, the dynamic spatiality of the south entry manifests a sophisticated equilibrium between the original land and the new surfaces. Siza kept the terrace in-between the upper and lower plots to retrace the previous structure of plantation in this area. By creating ramps and staircase according to the stone walls, he took spatial separation as essential inheritance from the plot to establish hierarchy and to orient the entry to four directions: the inferior peddle floor aligned with the studios, the central courtyard in gravels entered through a wide ramp, and a stone path leads to the upper platform of natural surface connected to the access of Quinta da Póvoa, beside, extra steps of masonry were added to go up a stage outside the Quinta da Póvoa.(Fig4.52) By reorienting the itinerary from a casual walk outside the long edge to complex and intensive movement through the short side, the terrace delays the appearance of the perspective of courtyard to convey the message in common with that of the small kiosco, that is, to avoid the general image of the campus in the first place. 224. Siza tried to incorporate the strong presence of the housing towers of 1960s behind into the separated atelier towers. This relation which could be observed only from the opposite bank has been interrupted by a later building between the two settings.

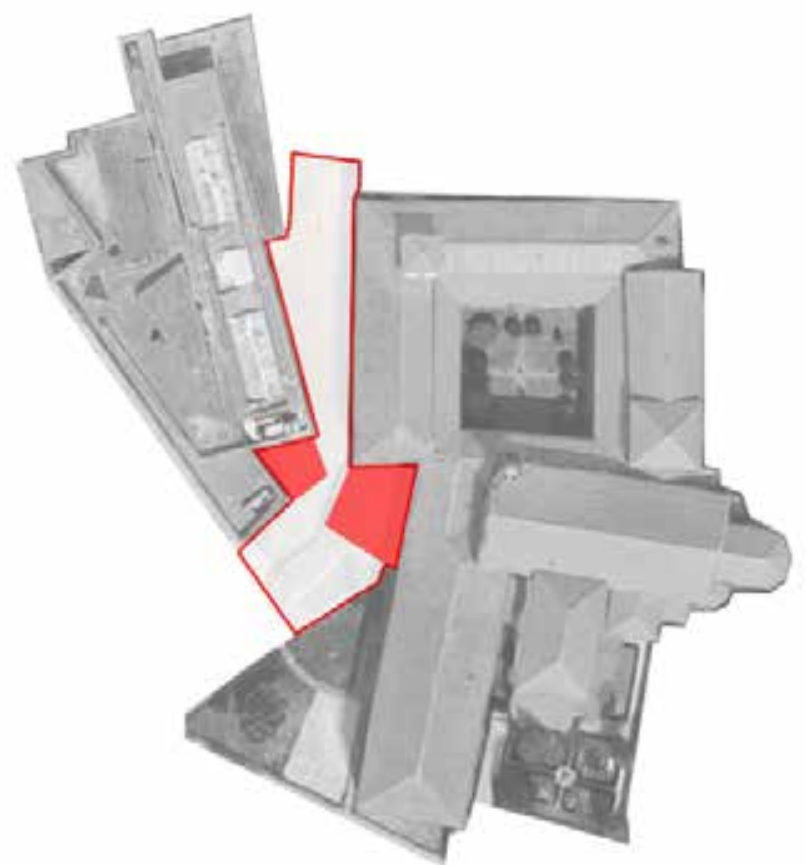

Fig 4.72. Symmetrical composition at the entry of C.G.A.C and Convent.

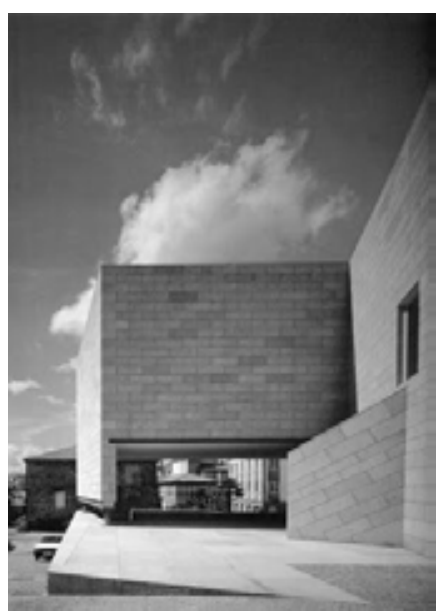

Fig 4.73. Entry of C.G.A.C.

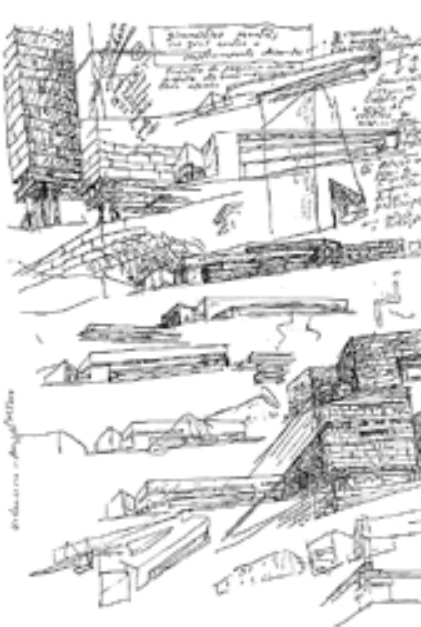

Fig 4.74. Concept sketch, Siza
(Fig4.73.) Its horizontal floor delimited from the adjacent ascending route shows the typical relation between constructions and the ground in Compostela. The volumetric twist leads to a slanted access into the museum, which subtly responds to the setting of the front terrace of the historic building complex on the opposite side. (Fig4.72.)

This concept of correspondence leads to a symmetrical system that enables Siza to extend the space before the Bonaval Garden. At the same time, this small plaza becomes convergence that brings together visitors who come from the city center, from the museum, and from the church and the convent (now is the Museo do Pobo Galego). Hence, there is a need for a break, which, in a way, dissolves the entry part of museum into small indicators with regard to the variety of relationships, between the old and the new materials, between constructions and ground, and between the seen and the unseen. The separation between wall and base, the half-roofed platform and the protruding window have intensified the fragmentary character in this area, recalling Aalto's idea of "combining several pieces of architecture in a complex ensemble." 236

After this complex space that gathers together different experiences, visitors are invited to an exclusive trajectory that goes into the garden. (Fig4.74, Fig4.75.)The long and narrow passage that gradually opens and penetrates is configured by the interplay between the northern facade of the museum, which is less tectonic and more solid than the northern one, and the austere wall of the convent ${ }^{237}$. A small house preserved next to the convent becomes a new indicator of views as well as the

236. Curtis, "A conversation," 41

237. Siza makes the new building's facades to respond to the Baroque portal of the church and the simple walls of the convent. 


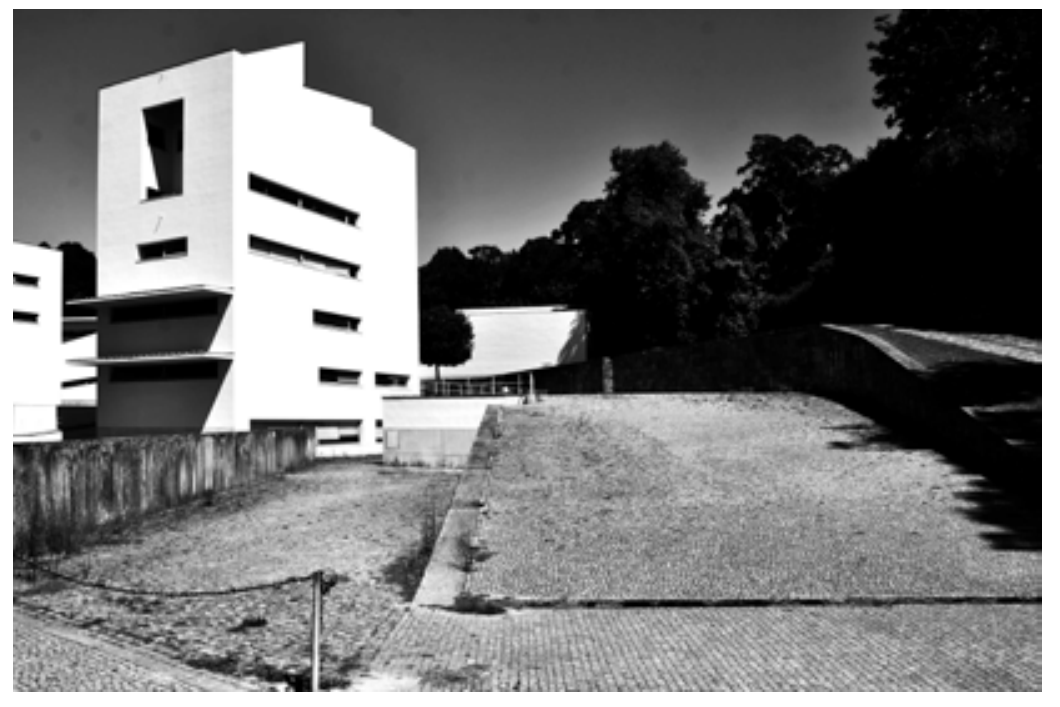

Fig 4.52. Levels of the southern entry.

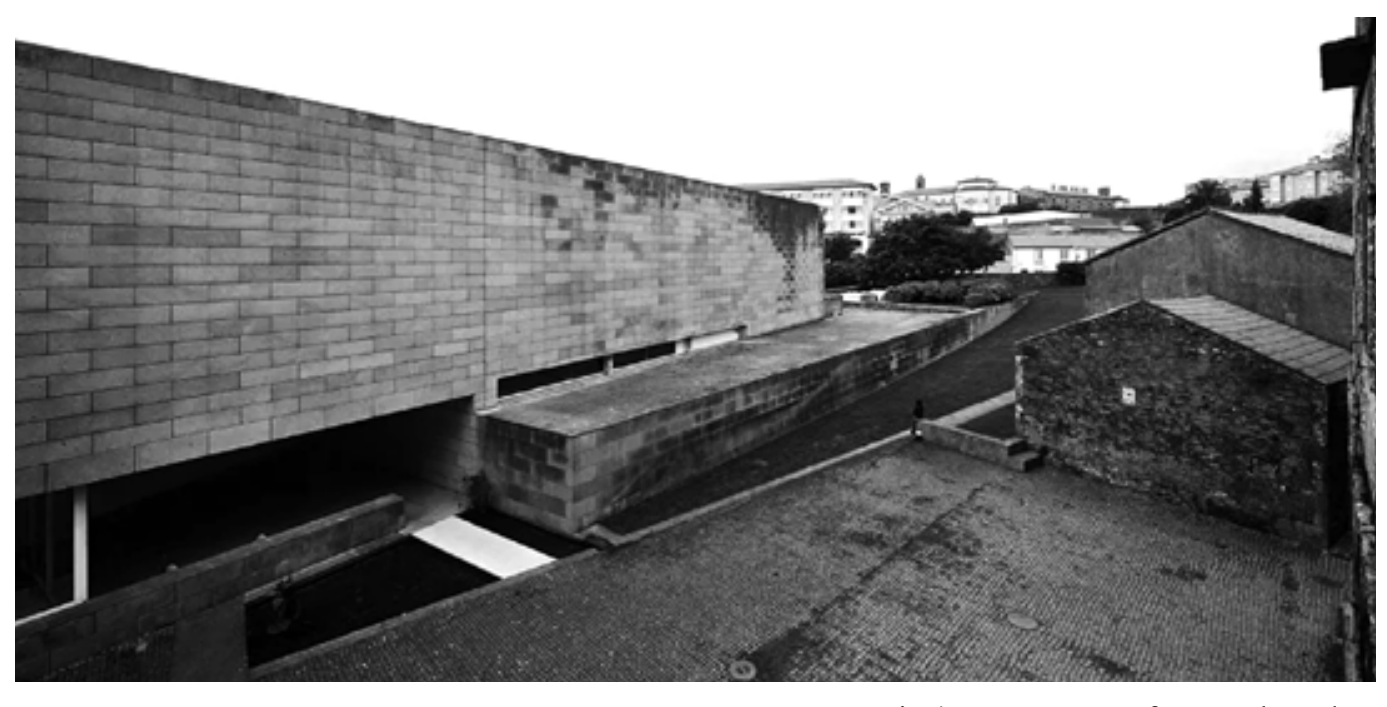

Fig 4.75. Entryway of Bonaval Garden.
In the establishment of balance to organize the two entrances made of fractures and connections through discovering the hidden realities in the place, as Adalberto Dias indicates, Siza "was able to grasp the full potential of the site, its possible construction logic and adaptability to the terrain, and understand what relationship to establish." 225

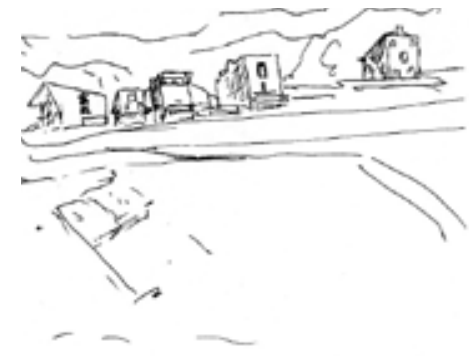

Fig 4.53. The southern towers, Siza.

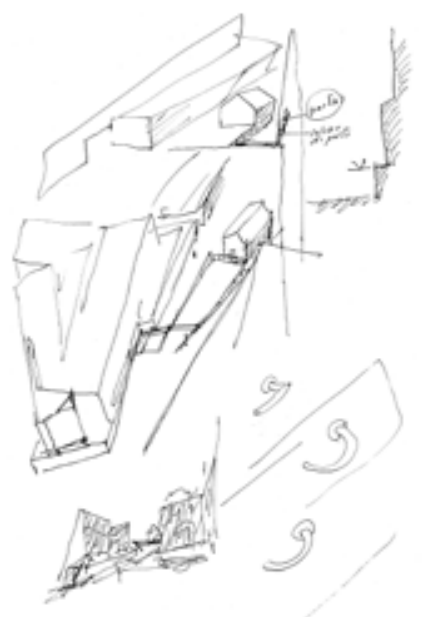

Fig 4.76. Early sketch of entryway threshold that delays the presence of deeper space. From an early sketch we can see the reversed positions of the house and its courtyard, that Siza may have considered to interrupt the unity of this entry space. (Fig4.76.) He finally abandoned the idea and divided the floor with different pavement, intensifying the contradiction between vertical boundaries of the two walls and the relief of the open place ahead. The small house creates a forked itinerary that separates the left route that goes into the orchard from the right passage that leads up to a small garden of the convent. Here Siza incorporates all of movement into the layout and volumes of architectures. By creating the division of continuity, distance and dimension, this entryway is transformed into the anticipation of the dynamics episodes that one is to experience in revived place.

In Santiago de Compostela Siza shows his mastery of scale and rediscovery of spatial order of the site. He classifies old elements in the garden and arranges them in episodes according to the topographic conditions and to the existing structures. This choreography is separated from the outside world by the bold fracture established by the Galician Centre of Contemporary Art, which incorporates the rediscovery of the place into a progressive change of spatial dimension along a continuous trajectory. The multiple characters of the architecture indicate the author's comprehensive investigation of the context. It maintains the unitary and compact volume of a single building, and at the same time, its frontal planes and the potential of interstitial spaces determine a sequence of movement and respond to the multiple needs of the neighborhoods, the topography, the history and the cultural landscape. 
$\S$ Epilogue - an attentive reading of realities

"An architectonic proposition, whose aim is to go deep into the existing transformation trends, into the clashes and strains that make up reality; a proposition that intends to be more than a passive materialization, refusing to reduce that same reality, analyzing each of its aspects, one by one; that proposition can't follow a linear evolution. Nevertheless, and for the same reason, that proposition can't be ambiguous, nor restrain itself to a disciplinary discourse, however sure it seems to be. Each design is bound to catch, with the utmost rigour, a precise moment, of flittering in all its shades..

Pieces are kept here and there, perhaps gathered by someone, leaving marks on spaces and people, melting in a process of total transformation." ${ }^{238}$

Siza's remarks combine the two seemingly contradictory attitudes towards contextuality, which, architecture, as the medium to transform, is not only to complete the perfection of a place by harmonizing with its "intrinsic genealogy" -the topography, those preexisting factors and landscape- determined by history, but also should stay clear enough to be able to avoid being subject to this overwhelming temptation. By holding this critical stance, architect is able to keep the vulnerable balance in his works between realities of the present and the past, "thus fusing both into a process of continual transformation that, while momentarily arrested, waits in its turn to be transformed." 239

Both of the Faculty of Architecture and the Bonaval Garden are constructed based on renovation of old structures to achieve reorganization of the site. Rather than imitations and physical articulations, Siza creates the relations of architectures and context through conceptual synchronization, which works to tinge these new pubic projects with 238. Álvaro Siza, Architecture and Urbanism ( $A+U$ ), no. 123(December 1980):9.

239. Frampton, Álvaro Siza, 20. dialectical and mysterious articulation with the genius loci of the sites. Besides the sense of remoteness, the strategy of promoting alienation and inconsistency between different categories contributes to the perpetual challenge to stable conditions as if encouraging visitors to capture the ephemeral images.

Organization of entryways is another key issue with regard to transmit, it reveals the very first steps of Siza's plan of a process to unfold the dynamics of the internal and the external. Siza designs according to his own perception and reaction in the space. Both of the entryways of the school and the garden, interrupted and bended by preexisting elements, and reoriented by terrain unevenness, have made up a slow and less continual procession which is highly conditioned by the control of the variation of the point of view. It seems that the experience along the approaching routes is kept closely with the author's visit to site, just like those sketches the author have made before each project. In a way, this movement calibrated on the basis of personal observation make visitors understand the constructed landscape is something less ritual but perceptible as a tangible sensation which is consolidated in a precise moment. Land and buildings which are notable for plastic characters, have taken place of the well-organized objects in drawings and work parallel to the itineraries to establish a system activated by the replacement of indicators.

Through delimiting an autonomous plot from the context while maintaining thei connections, Siza establishes the critical equilibrium in space, as Muntañola emphasized, between the reasonable configuration of the site and the facts produced by the passage of time. In this way, the entryways that make visitors be sensitive to the momentary images in order to guide them into constant interactions with the varying things and their needs, are fundamental elements that help to achieve the physical and 
psychological shift from the outside world of daily life to the setting which is opposed to stable and lasting perceptions. (Fig.4.77.)

As Siza pursuits in sketches "a permanent dialectical relationship between intuition and precise examination", ${ }^{240}$ his strategies of organizing the site and of introducing the deeper space help to realize the tension between the most direct reaction and the reason It recalls the inscription of the sculpture of the novelist Eça de Queiroz, "sobre a nudez da Verdade o manto diáfano da Fantasia (on the nakedness of truth the translucent vei of fantasy)", the coexistence of the sophisticated using of differences and the control to avoid conflicts and the fragmentary from being allowed to dominate, and the subtle equilibrium between them, contribute to the exciting characters of Siza's works.

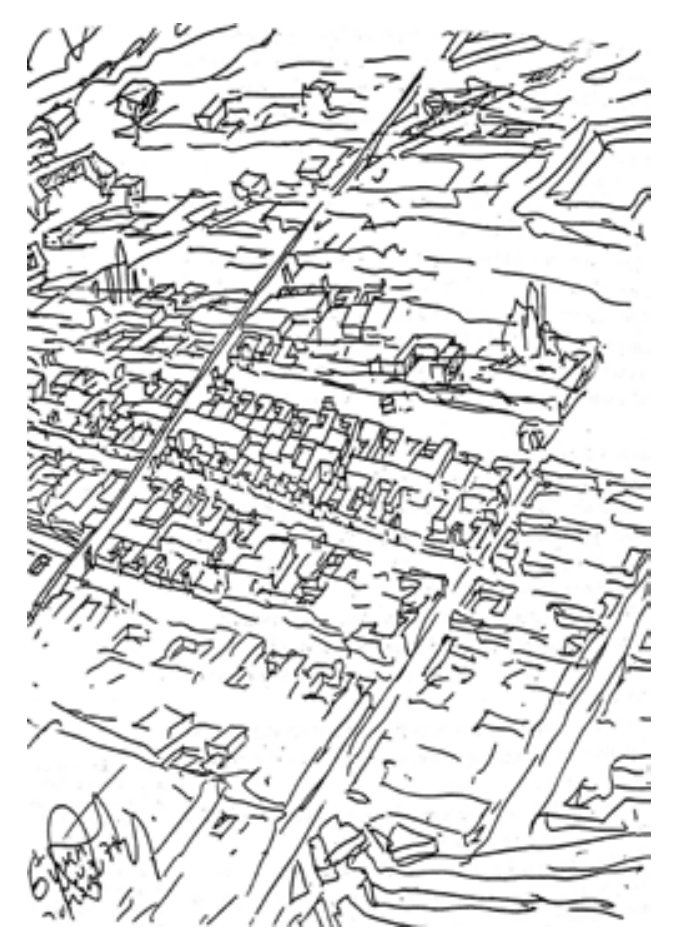

Fig 4.77. Sketch of Malagueira project, Évora, Siza 


\section{Unity of the detached}

The fractures that Siza has created on the site speak of resistance that forces us to cut ties with the outer world, and enter into the world whose spatial organization is much related to the author's own perception. By arranging directional pathways in particular angles with the other elements, or interrelating curved walls with oblique floors, Siza's architectures and landscape work show a synthesized system consists of a set of visual lines, pauses and turning points that constantly provoke instant feelings along a continual movement. With the help of geometrical rigour, Siza is able to reduce figurative language from his projects. However, at the same time he is clearly aware of the risk of over-reliance on geometry which is likely to give rise to architecture and space that are "extremely independent."

"On the one hand, I regard geometry as a form of communication between what you design and what you build; but form as the end result of a process is something different. I might have occasionally used geometry as a reference to typological models, or even as a direct reference to forms in nature, but form only arises and acquires meaning through interpretation." ${ }^{241}$

Siza's critical stance on geometry shows his idea to avoid a unitary language for the geometrical sake, which would otherwise drive architectures and its space to an absolutely diagrammatic presentation. The interpretation comes from the strategy of subdividing a general scheme into smaller components. It is intertwined and interrelating different unbalanced things. Dialectical relationships between these individual elements, and between parts and the whole work have resulted in uncertainty which is of great importance to interrupt the unitary structure and to enrich the narrative. The projecting canopies, extending benches or shrinking platforms in his buildings,

241. Álvaro Siza, El Croquis, no.140 (2008): 35. though in precise form and dimension, seem not to be the outcome of calculation but are resulted from spontaneous reflections to the various facts of the context. Through determining the rhythm of movement, alternating the space between light and shadow, and intensifying the tension between expectation and the sense of lost, these physical elements end up contributing to a matrix with regard to emotional impulses.

Siza attaches a lot importance to the itineraries. He tends to arrange elements that belong to the separated units along a specifically designed route, to make their connections, ruptures, torsions and displacement as suggestive events of encounters and discoveries. Nevertheless, his focus on the interrelations of the elements and the distribution of them in the space has made the organization of trajectory as more the method to the need than the result of an idea. This keeps Siza's works away from those of the masters as Giuseppe Terragni and Le Corbusier, and of his peer Francesco Venezia, wherein architectural itinerary often plays as the protagonist of the whole project. For Siza, "movement is just another way of organizing space, of making it legible and establishing relations." ${ }^{242}$ This idea is clearly reflected in the analytic study about the Leça Swimming Pools made by the Portugal architect and critic Pedro Viera de Almeida. For the first time Siza's work has been interpreted as a group of events taken place along the pathway through the course of time ${ }^{243}$. (Fig4.78.) The diagram illustrates the dialectical continuity of movement through the project. In the first half part, space is separated into 242. Ibid., 33.

243. The conceptual and diagrammatic approach of Pedro Viera de Almeida is developed from the notation S.E.E.P.I (Space Establishing Element Position Indicator) of the American architect and urban designer Philip Thiel, which is a method to make graphic presentation for mapping people's visual experience in the space. 


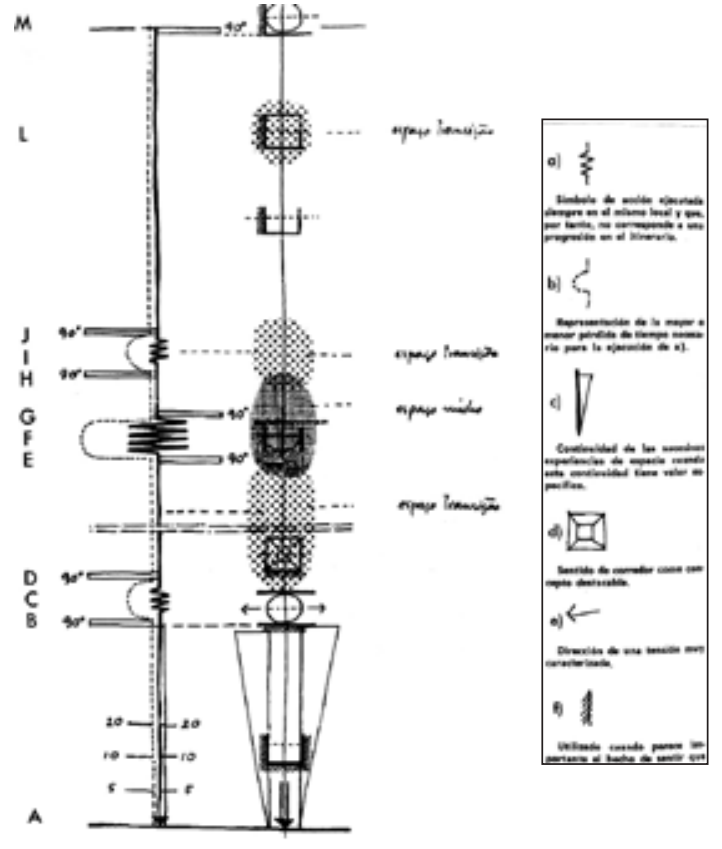

Fig 4.78. Infographic of Leça Swimming Pools itinerary, Pedro Viera de Almeida. short and narrow sectors for various activities (B-J), accumulating visitors' tension to go to the outside; while the following part provides a continuous route on the semi-exterior space (L), preparing for the encounter with the ocean. (M)

As shown in the swimming pool, itinerary in Siza's work seems to be more a reflection of what is happening in the place than an independent exploration, it is the architect's strategy to compensate for the fractures and separations in the space. While walking through the Faculty of architecture and the Bonaval garden, visitors' movement is largely conditioned by the visual perception of those constructive elements and natural things. These elements, in turn, seem to dilute the configuration of the routes, subtly distancing oneself from the presence of the evidence of the pathways. Thus, we become witnesses to a peculiar way of tackling the relationship between architectural promenade and spatial narrative that would lead to an affected interpretation of it, and, in certain cases, to an invention of pathways and imagination of movement.

$\cdot i i i$

Peter Testa has observed the distinction between the "rationalist" as Aldo Rossi, whose architecture is achieved on the basis of authoritative theoretical framework, and the "empiricist" as Siza who starts design from experience and builds on it "without ever looking back."244. This may suggest the contradictions and uncertainty that one would attain inside Siza's works. It is not difficult to discover and understand the relations that the building has established with the site, however, at the same time we are also touched by the interrelations between separated elements that reflect the instability of space and

244. Peter Testa, “The Architecture Of Alvaro Siza," (PhD diss., Massachusetts Institute of

Technology, 1984), 40. experience, which are likely to drive us into an almost lost condition, faraway in time and in place.

Such experience is not explicit, it works quickly and subtlety on a momentary impulse of personal sensation. This could be the outcome of Siza's two parallel ways of design under the pursuit of a balance between the freedom that allows "things to happen", and the control of the experience of a space. On the one hand, it is evident that the preexisting elements, the topographic and historic conditions are fundamental in his design, on the other hand, there is a tendency that the projects cease to be spurred by reality and history but become a geometric stimuli over a neutral scheme that gets a formal development going, and in this way, a "pure architecture" that Siza refers to, is thus achieved through "cutting through the constraints and by penetrating to the heart of the situation, its special atmosphere - by intuiting the particular moment." ${ }^{245}$

"Each unit emerging in space responds to different scales of perception. When Architecture closed up, the capacity of conglomeration and the measured proportion is lost. In this essence, it contains complexity and density, and gradually separates and becomes autonomous, until it is possible to say: "God is in the detail". At that moment of reading, everything which is external to it disappears, except here and there in memory, just as every perfect detail disappears, and not even a memory of it remains."

Siza's poetic words describe his ideal development of architectural narrative, that starts

245. Álvaro Siza, El Croquis, no.95 (1999):15.

246. Siza, Writings on Architecture, 33. 
from the occasion when one is touched by the rational scheme and ends up at the precise moment of intuiting the transformation of existing thing until its disappearance. As he says: "You must let things come to you naturally, in an unforced way" ${ }^{247}$, by liberating design from a set of authoritative frameworks, Siza suggests a process of reading he has been so diligently pursing, which is configured by hierarchical interpretations and activated by momentary grasp of the meanings.

While following Siza's design strategy consists of the control of geometry and transformation of movement that contribute to the expressions from the precise moment, the analysis of the Faculty of architecture and the Bonaval garden, through an inquiry into his organization of itineraries and the way perceptions change under the evolutionary dynamics of narrative, is possible to verify if he is just utilizing empirical methods or whether there is an overall guidance operating throughout the work as a whole.

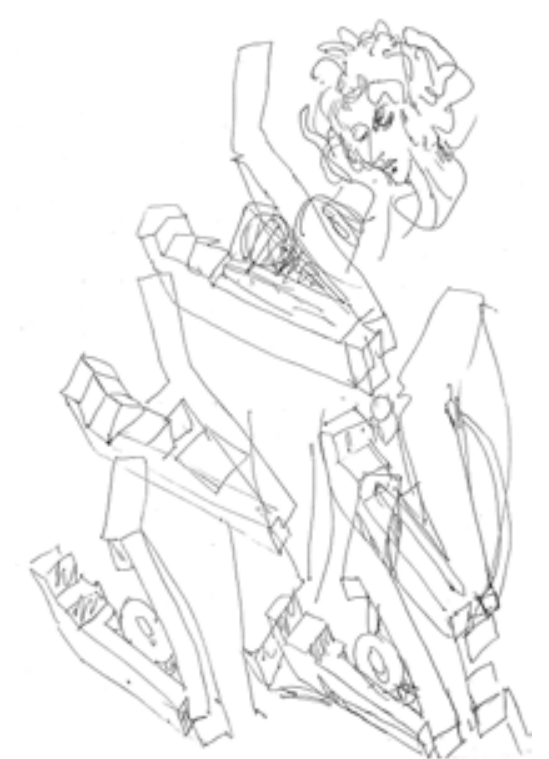

Fig 4.79. Concept sketch of C.G.A.C. Siza. 


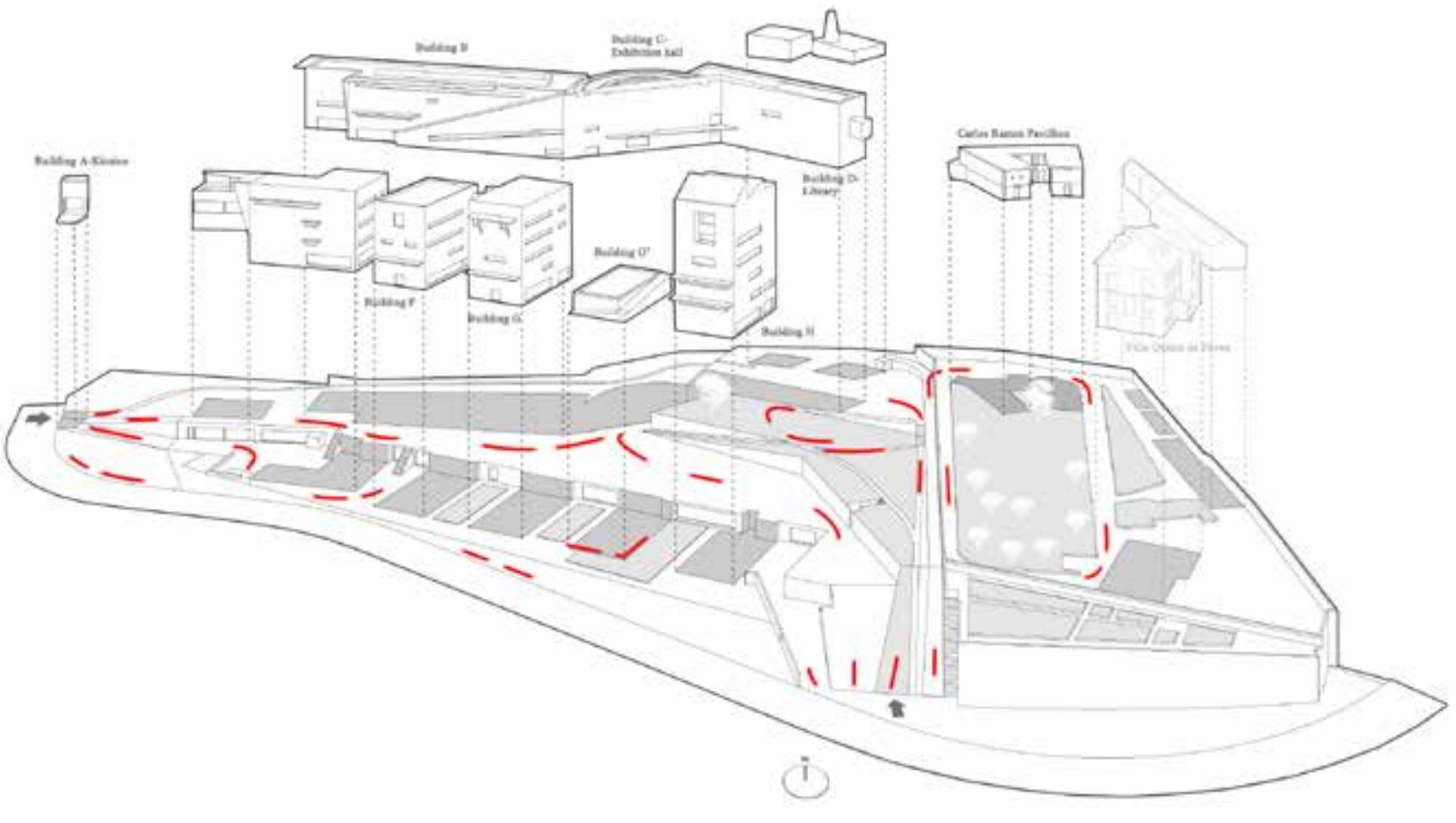

Fig 4.80. Itinerary of the Faculty of architecture, drawn by author.

\section{$\S$ The conceptual unity}

In Porto, despite of the control lines that give a conceptual solidarity to the terraced site of the Faculty of architecture, the well-separated scheme consists of the uppe and lower plots enable Siza to apply different strategies of spatial organization. Siza duplicates the U-shape paradigm of Carlos of the Ramos pavilion as the basis to configure the confluence of the new campus, and dissimulates the symmetry. (Fig.) Aside from the intensified perspective that gives rise to the spatial depth and continuity, the sophisticated joints between buildings and variations of the layout interrupt a unitary reading that leads to the presentation of a visual drama, revealing the author's consideration of the dialectical relation between the continuous and the discontinuous, as well as the intertextuality in the bidirectional circulation. (Fig.)

Early proposal of the new campus shows two straight wings that divide the trapezoid into a tapered and enclosed compound, and an unproportioned area occupied by anothe building. (Fig.) By noticing the exclusiveness in this scheme and in order to make fully use of the given area, Siza slightly twisted Building E clockwise 20 degrees, using the distortion to extend the convergence of the south and north wings, and make Building E and Building B, both in L shape, to incorporate the terrain outline into architectural geometry. This decisive change manages to break the continuity of the south edge of the complex, and as a consequence, it converts the new campus scheme into a fractal geometry of triangles - in which similar patterns recur at progressively smaller scalewherein the cafeteria, the small courtyard and the kiosco have formed a second flux at the west part after the two wings. (Fig. ) This transformation leads to a presentation of spatial division of three phases relating to the respective realities and different sequences of events: the terrace next to the south entry illustrates the unaltered topography, the

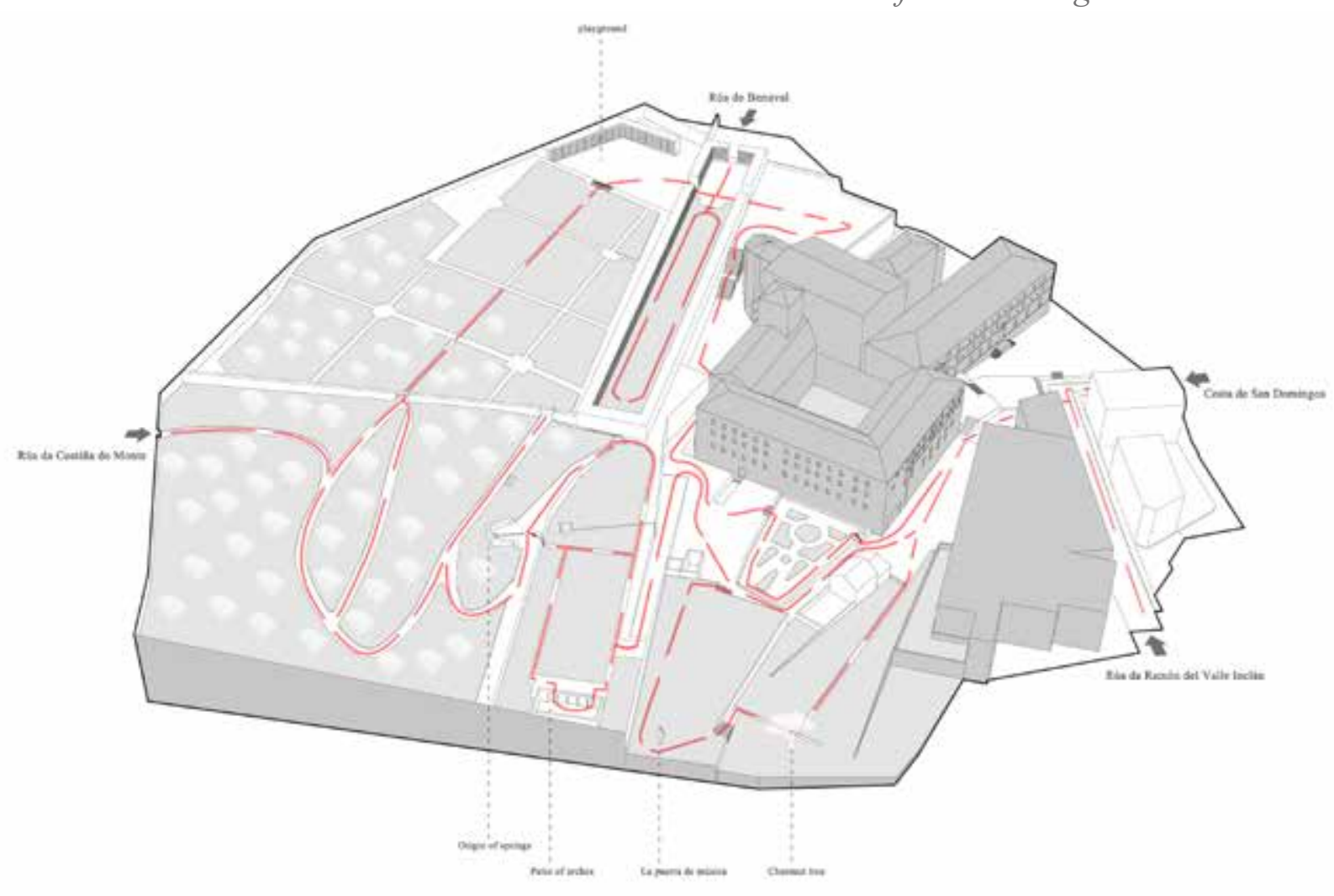

Fig 4.94. Itinerary of Bonaval Garden, drawn by author.

$\S$ Through the absence

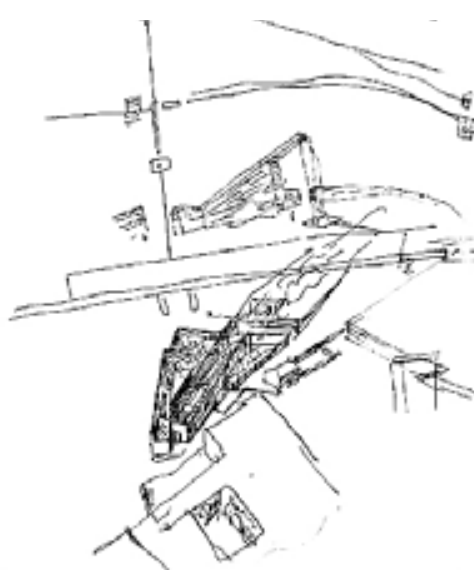

Fig 4.95. Schematic sketch of the Bonaval garden, Siza.
"When I looked at the mysterious steps and angled facades of the convent of Santo Domingo, alongside which I was commissioned to build the Santiago museum, when

I went up the terraces invaded by vegetation and contained by half-ruined walls, or when I went into the cemetery and saw from above the oak trees the roofs and the thousand towers of Santiago, I felt somewhat inhibited. I drenched my shoes, my cloths and my body. Water ran crazily everywhere ${ }^{25}$

Because of the inevitable intervention of the passage of time, Siza's idea of reorganization of Bonaval Garden to free the site from the chaos that mingles natural landscape with old constructions is closely related to his belief of the incomplete, unfinished state of the things to be transformed.

For him, "there is never anything that you can say is really concluded, in the same way that architects never finish a building. ${ }^{256}$ In the work of imposing new schemes upon an archeological site, the architect manipulates relations between those recovered structures and the ground, as if elements were scattered around the conventual site in course of time, being part of an open process that flows along a path of their own. The partially recovered boundaries and pedestrian circulations have delineated the settings and structurally separated them from each other, with a zig-zag trajectory defining the ascension.(Fig.4.94.) As shown in the sketch of the garden and the museum, steps, stone walls and other vestiges are superimposed upon the convent

255. Siza, Writings on Architecture, 128

256. Siza, El Croquis, no.140, 25. 


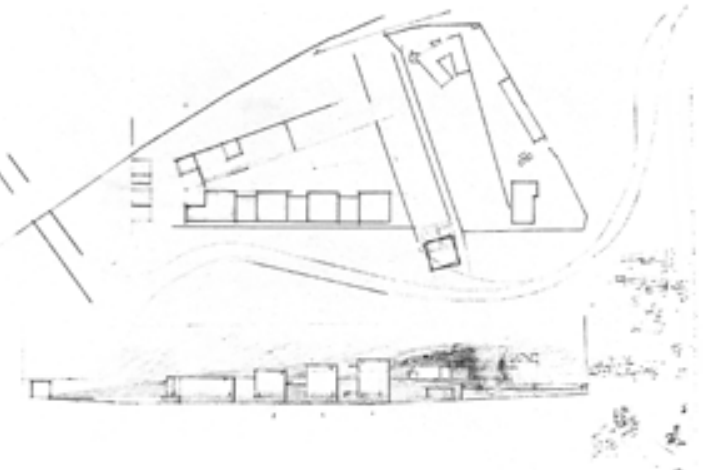

Fig 4.80. A nearly enclosed courtyard in the early proposal.

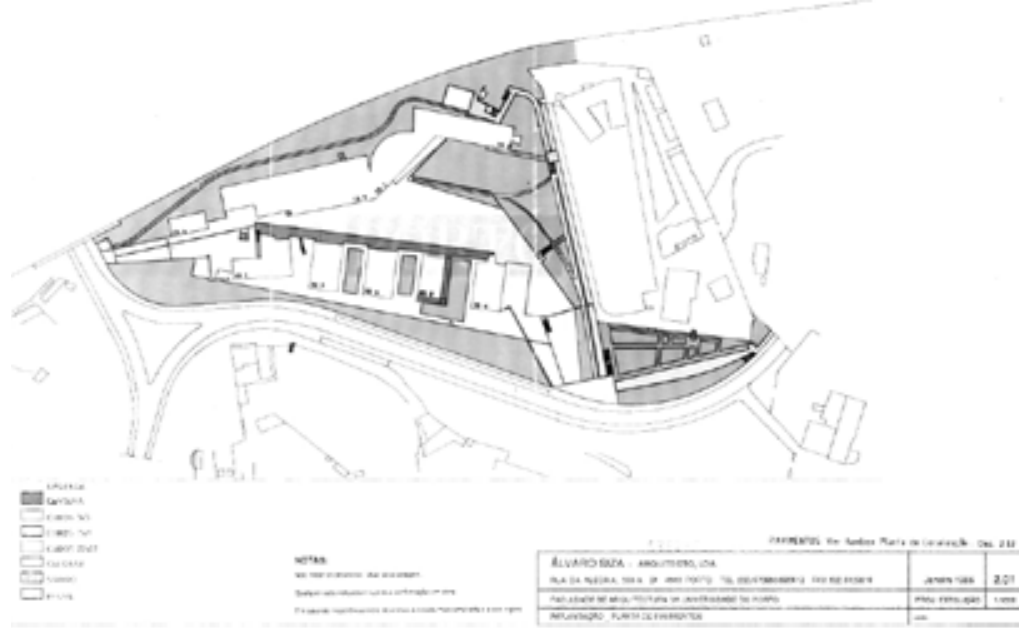

Fig 4.81. Courtyard open to the east side in the final scheme.
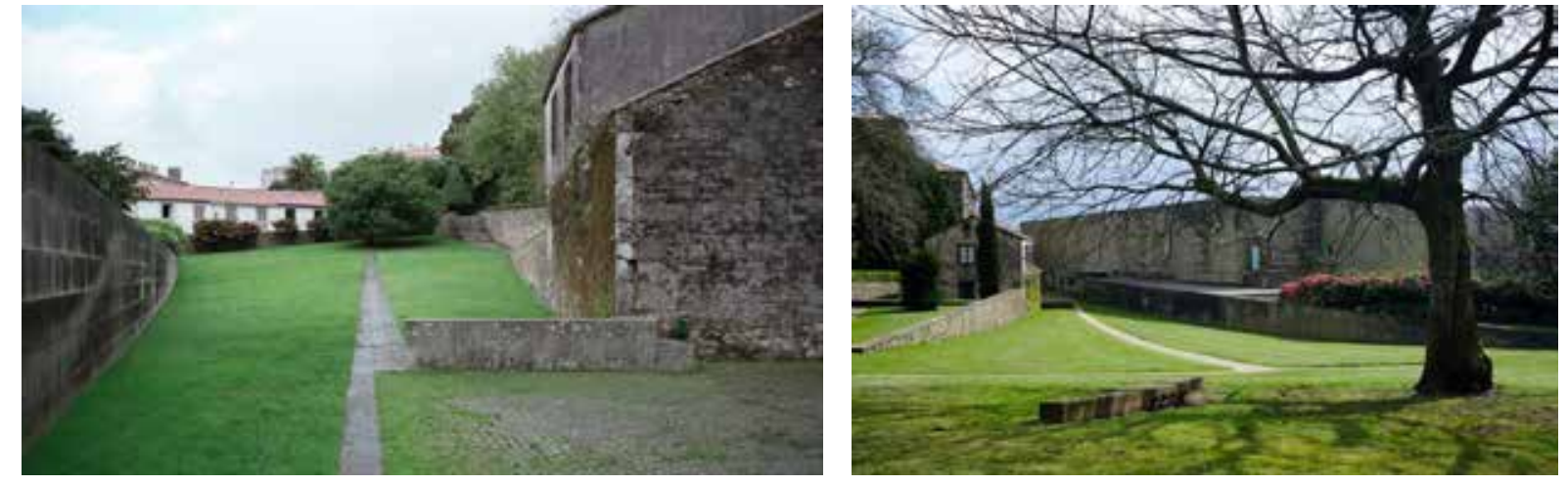

Fig 4.96. Axial route that starts orchard trajectory. introspective middle courtyard and solid wings subject to the site outlines, and the smaller compound at the end whose lack of boundaries promote communication with the outside world.

- bringing together the disparate

Visitors who enter from the kiosco will immediately confront with the density in the space. (Fig.) Siza is aware of the contradictions come from the unevenness of the ground, presenting it through the separation with which the building layers admit the uses that their diverse spaces are assigned. The cafeteria thus loses its unitary characte since the roof terrace, the dining room, and the sunken courtyard come in a stratified structure, while the passage, steps and ramp interact with each other, as if producing vertical symmetry.

The formal contradiction is transferred to the sphere of the constructional. So the terrace roof is supported by fragile pilotis, and the light panels projected from Building E and $\mathrm{B}$ are related to the solid walls. Siza uses the protruding shields to give fragmentary and plastic image to the convergence of the two wings. In addition, these outstanding elements, together with the entrances that come out of the building volumes, further shrink the aperture so that to hide the subsequent permutation of studio towers and to partially frame the terrace on the other side, giving rise to the division of the new campus between the rear space and the middle setting.

Siza tends to create a compressed space at this entry area. We perceive overlapping giving rise to numerous plastic episodes, whether shifting or encounters. The panels, walls, facades and volumes present themselves as components that are to contribute and the new building and are articulated by the water channel. (Fig4.95.) Through this montage, Siza tends to create a schematic structure in which indecency of different elements are protected, and to create a uncomplete condition wherein the existing things put emphasis on the absence of the others. Through the strategy of using the seen to recall the unseen, Siza has converted the compositional uncompletedness into dynamics of the space that keep intensifying visitors' perceptions to trace the original continuity of the site.

\section{the orchard}

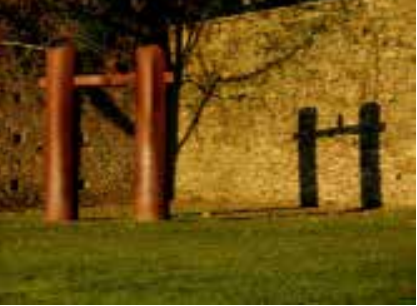

Fig 4.97. Puerta de la musica Eduardo chillid
In the final scheme of the Bonaval Garden, apart from the reconstructed boundaries, division of the three stages is clearly distinguished from the variation of itineraries which is defined according to different ideas. Architectures and preserved structures become the fundamental elements that subdivide the first stage of former orchard into three platforms. The museum and the small house form the limits that gradually open, and guide visitors to the axial route which slowly ascends towards a giant chestnut tree. (Fig4.96.) Along this penetrating way, architectural figures gradually give their importance in spatial organization to the succession of walls on the right side. At the end, a short route perpendicular to the main trace transforms the trajectory as a disproportionate cross, as if responding to the conventual yard.

The masonry steps at the side may resonate with the features found in the context, such as roadways and old walls, and actives the transmission to the upper platform through a ritual movement. (Fig. ) Contrary with the continuous itinerary that refers to the entryway from the outside world, Siza removes passage from this smaller yard, making it as a pause in the garden's ascending path. In this way, Eduardo Chillida's 


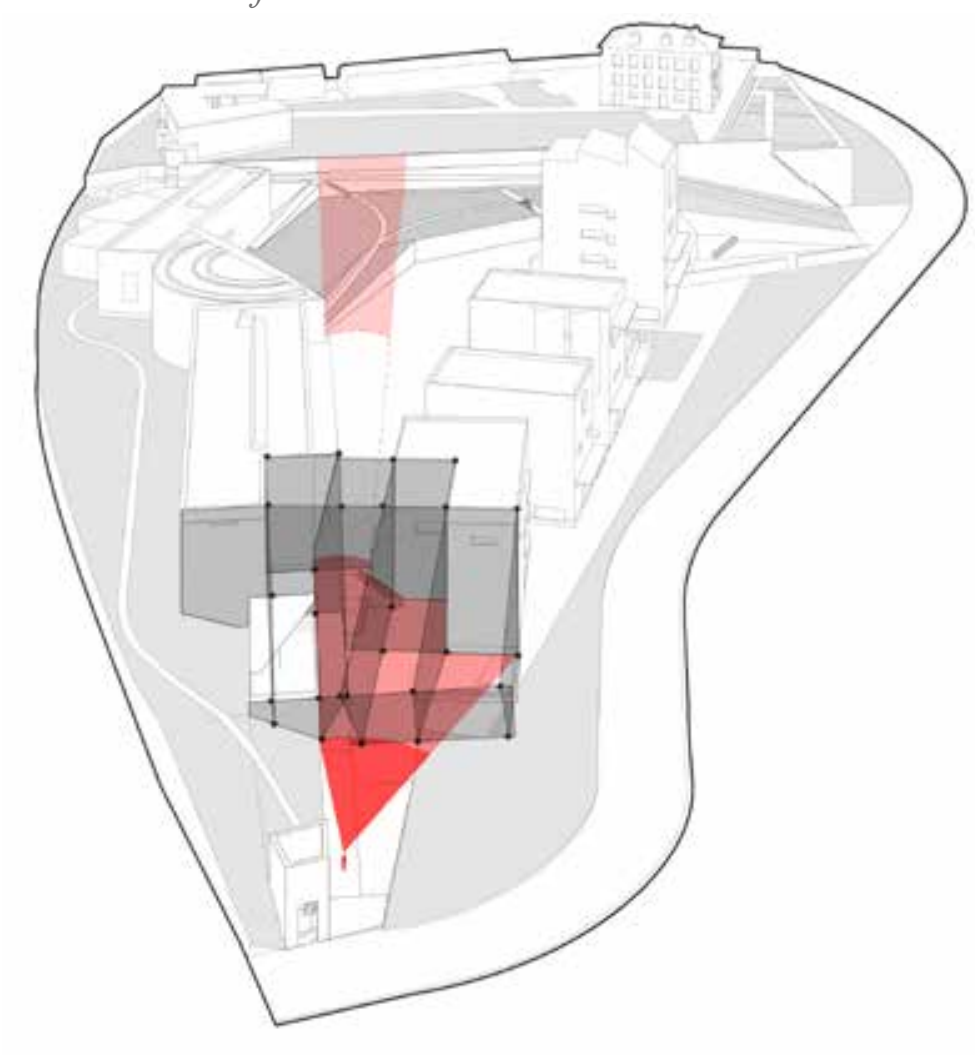

Fig 4.82. Grids in visual structure from the east side, drawn by author.

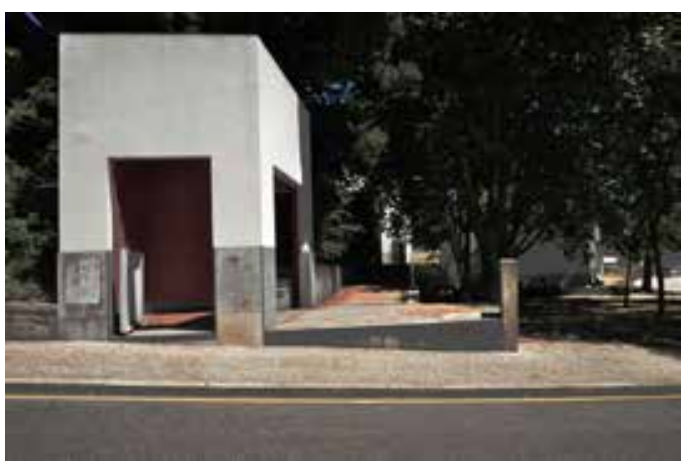

Fig 4.83. View from the east entry.

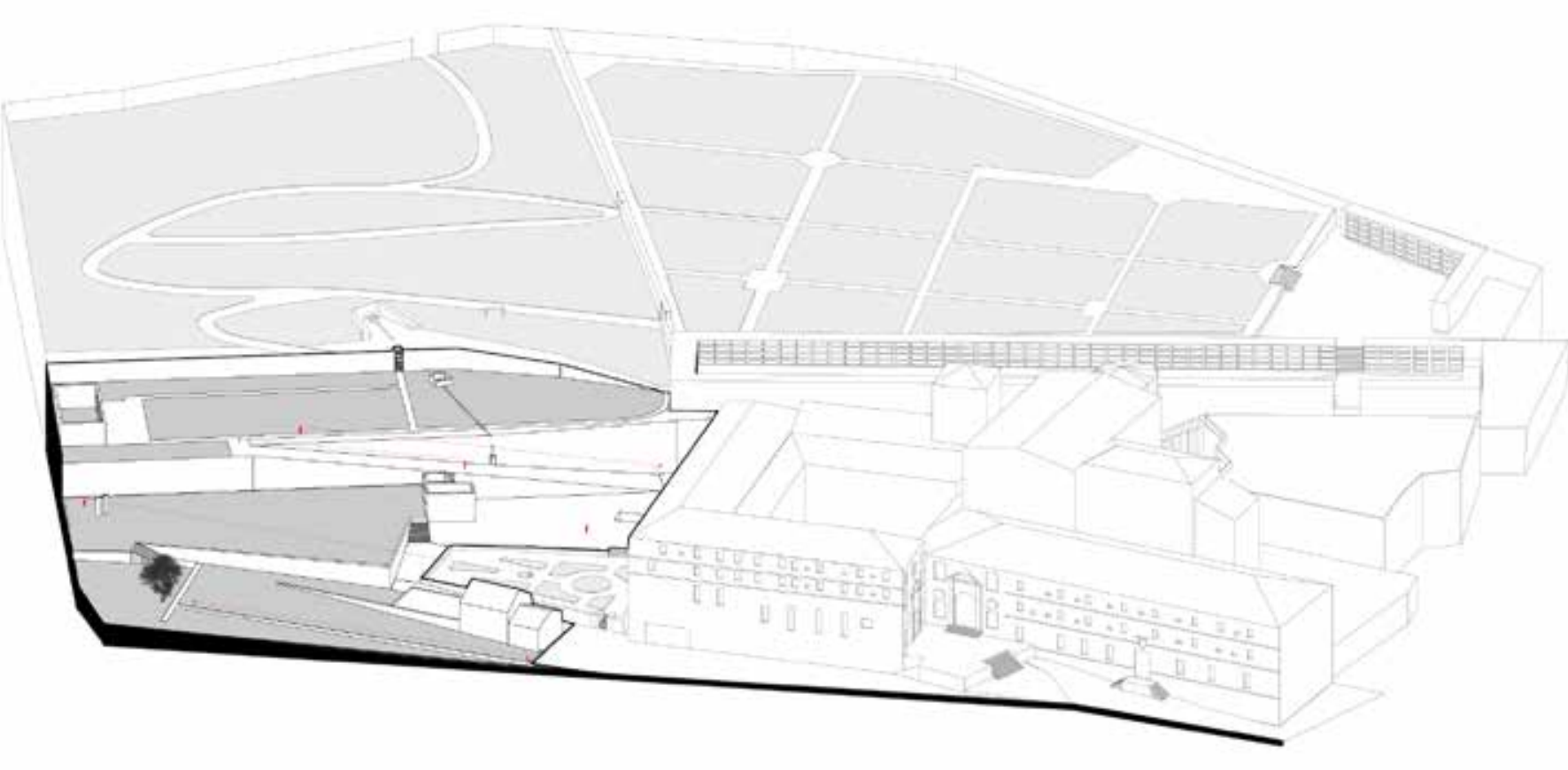

Fig 4.98. Zig-zag route on the orchard stage, drawn by author. to abstract grids, by which connection among the separated buildings and a sequence of formal development are reinforced; especially the surfaces facing to the west side become a series of determinant transverse episodes in the movement that goes deep into the space. (Fig.) These grids are activated by the subtle distortion and shifting that break the orthogonality, and get the whole process going.

Reduction of farer images and the complex organization at close range lead to oppositions of distance and density that determines our perception from the west part of the site. This can be understood in terms of Siza's strategy to resist the effort of inverse perspective from this area, otherwise it would greatly decrease the expression of spatia depth. Siza's experience from Alhambra may anticipate his manner to provoke the experience of deep space through arranging variations before a sudden release.

"In the Alhambra you pass through a sequence of open-air courts and patios, with transitions from areas of light to areas of shadow. The spaces are varying size and intensity. You may find yourself in a penumbra which suddenly allows a release, a view across the landscape. This way of multiplying space by dividing it, gives a sense of density. In the Alhambra you have the sensation of entering a 'world' which goes on and on, ever-changing. This is one of the central dimensions of architecture." ${ }^{24}$

The scheme that generates the impression of a deep space suggests Siza's concept of bringing together the disparate elements. It recalls Maurice Merleau-Ponty's notion of depth as "the dimension in which things or elements of things envelop each other, whereas width and height are the dimensions in which they are juxtaposed.", and as a spatio-temporal dimension, since "when I say that I see an object at the distance, I

248. Siza, El Croquis 13, 241

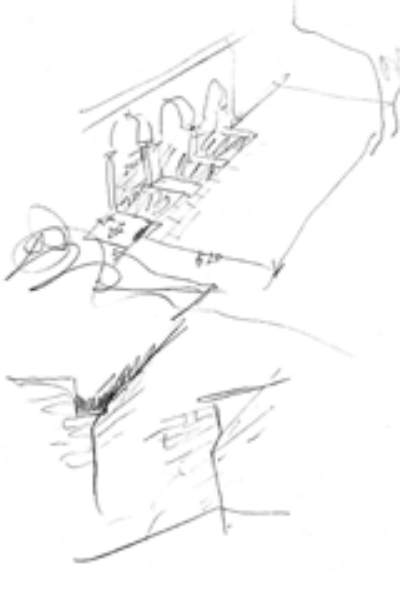

Fig 4.99. Study of the patio, Siza. sculpture "La Puerta de la Música" becomes the protagonist. The structure of 3.4 meters in height, made of weathering steel (acero cortén) and stands in oblique line at the rear end, becomes the guidance of movement which leads visitors to turn around and overlook the garden.(Fig4.97.) The framed images of the Cathedral's towers, the convent and the Contemporary Art Center permit a rediscovery of the relationships between the revived site and the city. ${ }^{257}$ The artwork also plays upon movement through indicating a point of departure which reorients the journey, so that to prevent this platform from being the place that detains visitors.

With the help of the masonry ramp that traverses this area, Siza establishes a powerful separation between the sunken yard - surrounded by ruins, springs, the convent and its small garden — and the top stage of the orchard. (Fig.4.98.) Deflection of itinerary appears again in the end of the ramp since the way is then divided into two directions. One follows the ramp course and moves to the small patio of arches on the north side, recalling the original condition of the site; (Fig4.99.) the other turns around and goes towards the south side before going up to the grove. The lineal route and slim channel have formed an orthogonal system on the ground, which relates people's movement through the zig-zag way to the flow of water according to the slope.

Under the changing density and rhythm of movement, Siza develops the orchard's trajectory from the open confrontation between constructions and the natural landscape, between the new-established and the pre-existing elements. His

257. Siza recalls that Chillida once decided to place the sculpture at the top level, but he soon anandoned the idea and relocated it at the mide position by saying to the architect: "from here one can see at the same time the towers of the Cathedral and your project [ .] it is as if one had retrieved the piece that is missing in your building and had set it here." Rodríguez and Seoane, Siza X Siza, 343. 

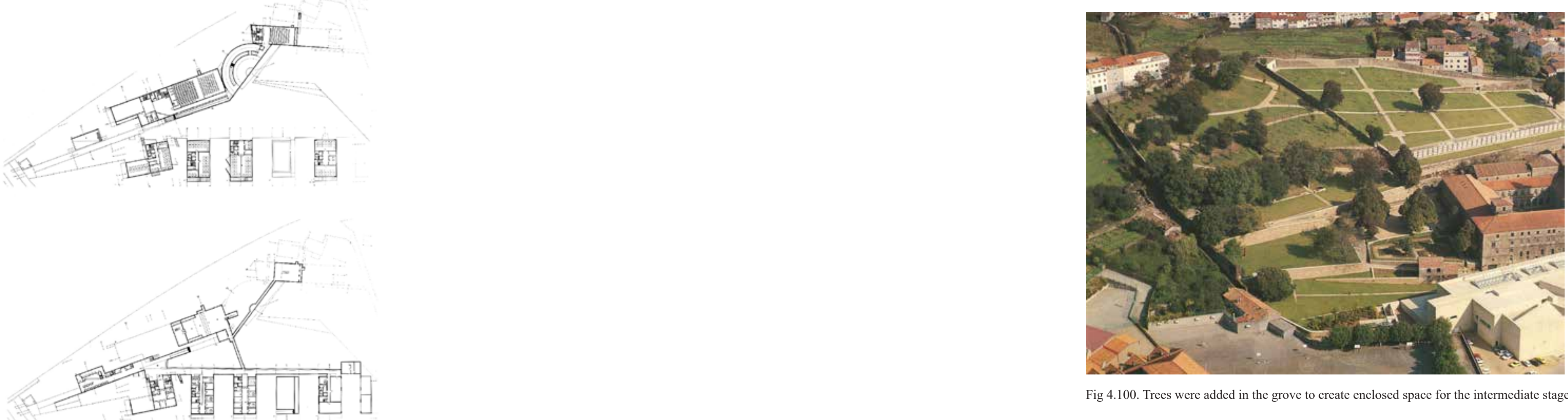

Fig 4.100. Trees were added in the grove to create enclosed space for the intermediate stage

Fig 4.84. Final plan of the first floor and the ground floor.

mean that I already hold, or that I still hold it, it is in the future or in the past as well as being in space". The highlighted correspondence between the west entry and the preexisting terrace generates a conceptually extending and lasting process, incorporating the starting place and the end point into the undeniable unity of visual structure, as wel as into an imagined trajectory through which visitors are to walk. Therefore, though we would be lured by the variety of architectural episodes from the fragmentation and ruptures, a conceptual continuity derived from our imagination ensures the presence of the sense of unity in the new campus.

\section{- the inflected responds}

Organization of the main part of the campus is another sample of Siza's capacity to transform program. (Fig.) The terrace that divides the southern entryway into layer gives visitors platforms to overlook the main space. The layout presents itself as an introspective patio whose contour is derived from topography, meanwhile buildings that wrap the territory turns over the fragmentation and complexity of the north part, an discipline the natural outline with constructive order.

The integration of geometry and natural shape of the configuration of the middle plot represents the recurrent dialectic in Siza's work as an autonomous universe, and at the same time being gravitate over the outside world. As Moneo has observed from the Beires House (1973-1976), (Fig. ) that "there are no distances to established between the natural world that is still present in the garden and the manipulated, artificial world of the construction. They are brought together by the architecture, and made one." ${ }^{249}$

249. Moneo, Theoretical Anxiety, 222

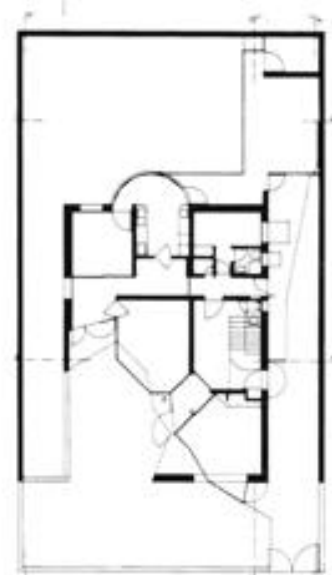

applications of oblique lines that deflect, fractures that break and turnings that reconnect in a vertical structure indicate a design based on geometries. The resulting force that controls and guides perceptions is furthered by the repetitive experience of moving towards and away from architectural complex. Contrary to the continuity through the progressive ascension, one would attain at the same time a sense of separation because of the certain distance between the main road and those outstanding elements - the tree, the sculpture and the arches — that mark the turning points of the itinerary on each level, as well as recall the original conditions of the site. The author seeks to work with the delimitation of visual perception and, at the same time, with the contradiction between continuous movement and momentary departure. By disposing these objectives "beyond reach", Siza creates a metaphor of getting over the limit of the present course in order to get close to the evidences of the history.

\section{the grove}

Contrary to the orchard's organization with rigors of geometry, the next stage "la Carballeria", a grove delineated by recovered walls, gives much importance to awareness of the natural landscape through a significant decline of constructional language and historic elements. (Fig4.100.) Siza has worked together with landscape designers on intervention in the set of pre-existing trees, the underground water and terrain unevenness, in order to transform the disordered condition of this place which had been abandoned for decades. According to Isabel Aguirre, this stage conserves few of its old oaks, and only the beginning of original paths. Spring in the grove marks the origin of the discontinuous line of water channels revived in the garden. New trees are added according to a strict trace on the organicity of the trials to control the spatial density. (Fig4.101.) 


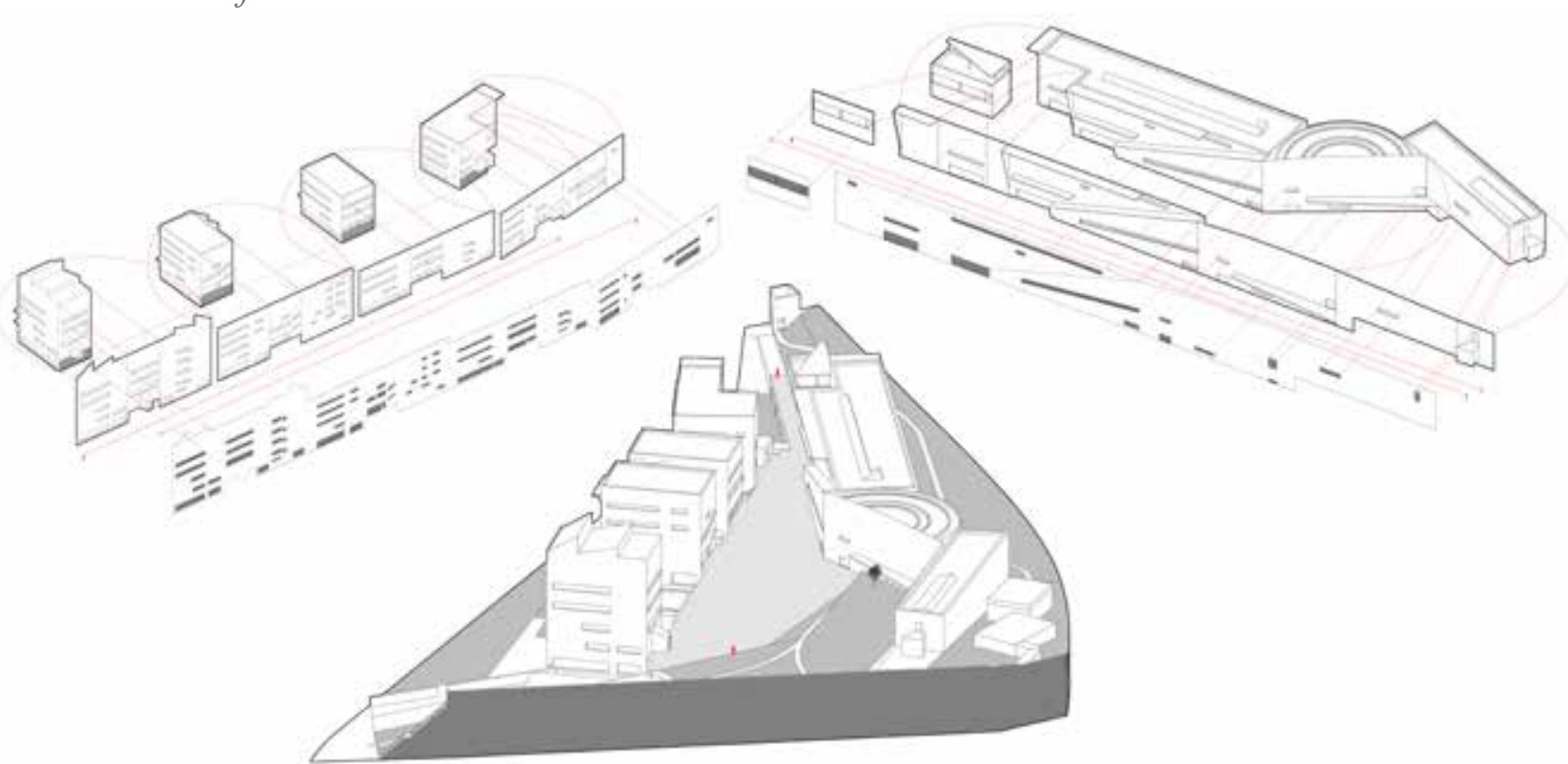

Fig 4.86. Unfolded facades of the new campus, drawn by author.
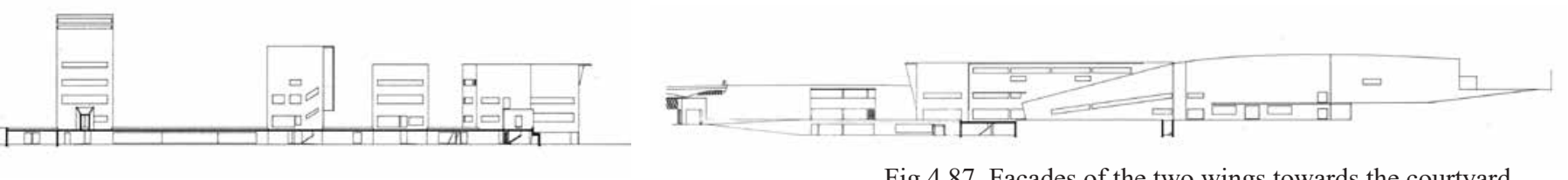

Fig 4.87. Facades of the two wings towards the courtyard.

Facades of the two wings give a direct presentation of their different uses. (Fig.) The continuous volume of the north building indicates an integral space inside, which is easier for administrative procedures, while the separated towers put emphasis on the independency of teaching space. On the south side, Siza was trying to present the value of the erosion of a volume. The alignment of ateliers stresses the potential of the broken line, that along with the movement inside the courtyard, our perceptions alternate between the unity of the interior place and the views of the exterior views through the intervals. It recalls the experience of Antonio Carlos Siza House (1976-1978). (Fig.) The courtyard becomes the core that receives images entered through the porous boundaries, and maintains at the same time the autonomy of the place and its connections with the outside world.

The architect's pursuit of a balance between continuity and discontinuity is furthered by his design of fenestrations on the south wing. The long, narrow windows at the same height of different buildings, giving suggestion of occasionally visual encounters among the various classrooms, help to incorporate the lateral facades showing the thickness of the buildings into an expression of united frontality, contributing to the fluidity of the boundary. (Fig. facades)

The inflected responds to the uneven topography, the deflection caused by the curved volume reveal connections between the Faculty of Architecture with Alvar Aalto's Institute of Technology in Otaniemi. (Fig.) Siza shows his capacity of dealing with an intensive relationship between buildings and territory on a smaller scale. The converging wings penetrate into the space, meanwhile those "diagonal gashes" and "slicing horizontals" on the facades, as what William Curtis considers as evidence that echo the "Deconstructivist fashion", however, constantly distract this tendency.

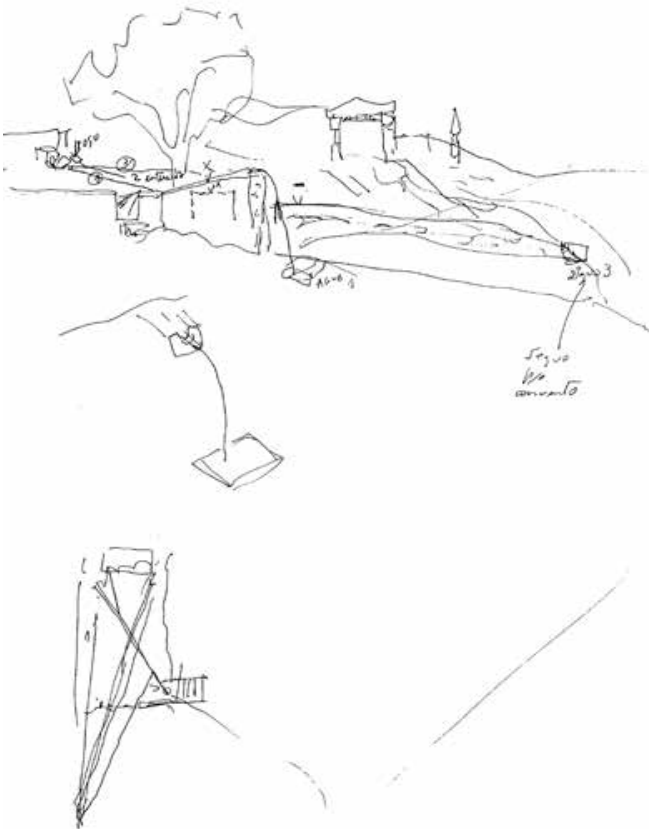

Fig 4.101. Study sketch of water channels, Siza.
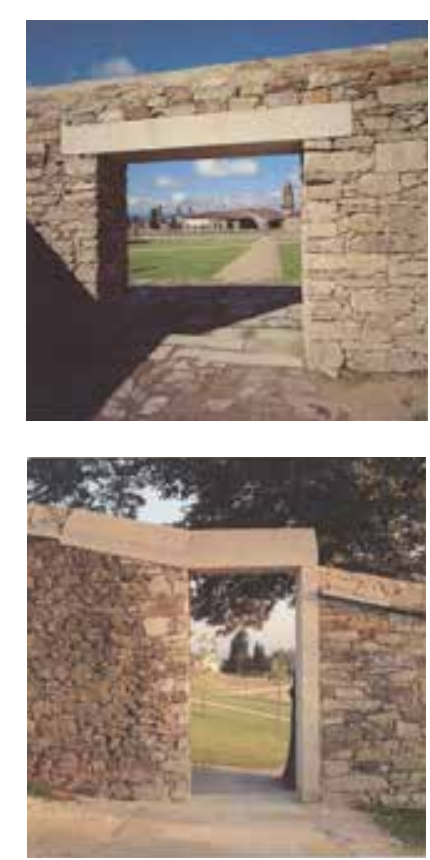

Fig 4.102. Gates connect the

Grove to the Cemetery.
All the natural elements help to create an introspective atmosphere in the grove with minimum interaction with the outside. Its trajectories, meanwhile, would have bonded the transmission to the other sectors into a lasting process of movement, not only physically, but also programmatically. The circular path in the middle, which keeps a continuous movement as if giving a casual feeling of a strolling in the small forest, orients the way to the cemetery on the south side; (Fig4.102.) meanwhile its two wings create a slow roadway along the slope, gradually ascending from the orchard to the small gate on the north boundary adjacent to the street la Rúa da Costiña da Monte. Instead of putting emphasis on the objectives that guide the walk, Siza made use of the absence of outstanding elements to realize the homogeneity of the place, and the meandering trials through the forest to promote a feeling of being lost in an anonymous plot. Visitors are not to anticipate the place where they are heading to, until the small apertures as revelation of further space capture their attention from a certain moment.

Siza has always regarded the variation of space as indispensable touchstone of the continuity: "Transformation is necessary for continuity to exist, more than necessary, I would say even inevitable." ${ }^{258}$ In fact, the grove in the intermediate stage of the tripartite division of the Bonaval garden is at its best at the level of adjusting the rhythm and experience of a movement along the programmatic itinerary. First, it represents a totally departure from the intensive movement of the orchard, as well as from its overwhelming expressions of ruins and history; second, the protected space gives rise to the feeling of momentary change when people are getting closer to the small gates. Just like the unexpected confrontation with the ocean in the Leça swimming pools after a long walk through narrow passages; or the deeply-embedded 258. Siza, El Croquis, no.140, 27. 


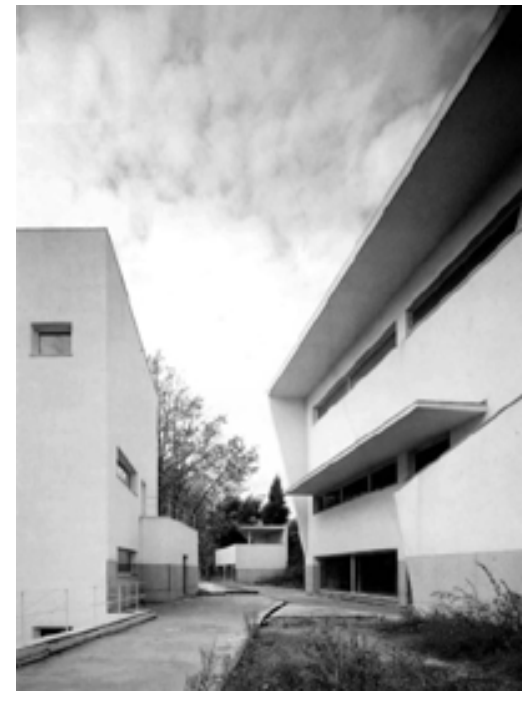

Fig 4.88. The faculty courtyar

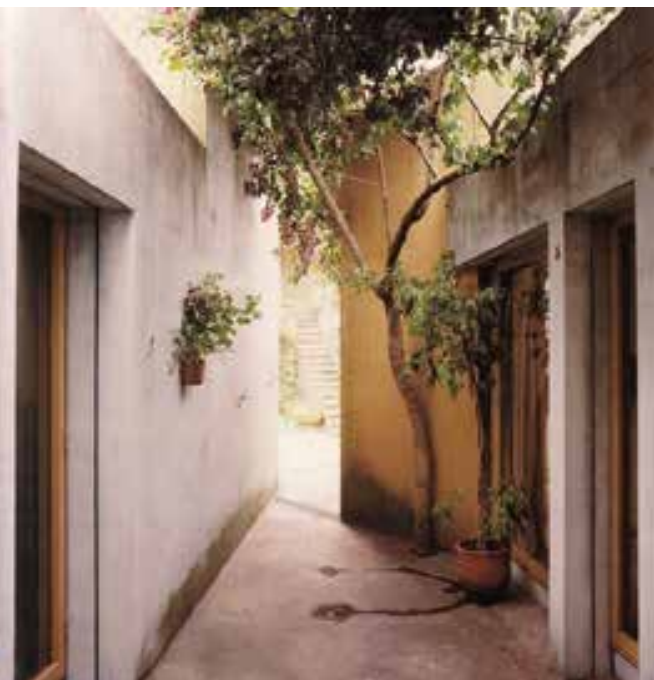

Fig 4.89. Courtyard of Antonio Carlos Siza house.

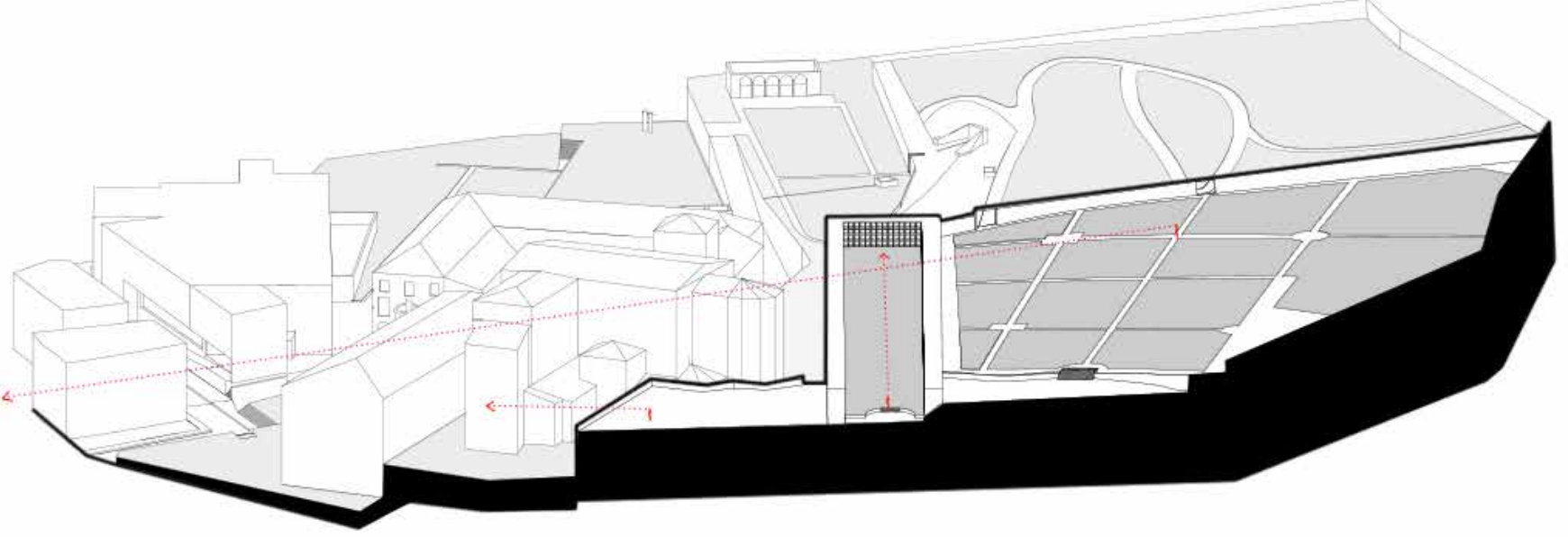

Fig 4.103. Three levels of cemetery, drawn by author.
Siza seems to entrust everything in new campus to the facades. The slim windows that slightly cut through the blank walls reconcile the volumetric contradictions of the opposing complexes, before the dialogue between the two sides ends up in an abrupt fracture, leaving uncertain story to the episode at the end.

Again, we may trace for Siza's configuration of the tapered yard's exit from Antonio Carlos Siza House. The roof of Building B that bends over to the facade seems to reproduce the slice protruded from the patio of the house. (Fig. ) These elements further shrink the aperture of the courtyard and give it delicate and attracting character. Contrary to the observation from the west side led by clear objective, it is a vacancy that constantly makes visitors perceive its presence and be curious to find what is out there. It reveals Siza's intention not to determine the specific vanishing point in steepened perspective. As what we have seen in his sketches, the distorted boundaries and looselystructured background suggesting the further space seem to attract observers and invite them to be at his position to move according to the sequence of his sight.

- until the extinction of details

For Siza, further implication of the notion of separating is the "potency" of design need to go beyond the real state of affairs into the "immunity" of some superior levels for aesthetics and perfection.

"In the perfect environment, the perfection of architecture has to be sharpened to the point of apparent irrelevance, or be detached from it, or both of these one after the other. Then the knowledge of the transformation from what it was before is erased. This is how Architecture attains completeness and liberty, the serenity of the solitude which and giant gate of the Santa Maria church of Canaveses explains, at the last moment, the rituality of the entryway to the visitors who have climbed from the patio at the bottom without knowing where the main gate is, the dramatic transfer from the dense grove to the open precinct, recovered from burial land, serves as an surprise event which is exploited to show the dynamic variations of light and shade, compressions and expansions of space.

\section{the cemetery}

Siza recovers the old cemetery by using pre-existing structures to divide it into three episodes markedly different in size and character along the descension of land: a garden on the top level provides an open platform to overlook the city skyline, a sunken yard delineated by columbarium gives an enclosed space, and an empty terrace extends to the apse of the church and a small graveyard. (Fig.4.103.)

While the walk through different stages is to a large extent driven by the progressive delivery of views to the distant Cathedral and the adjacent church, ironically, one would feel a certain distance away from the history of the cemetery itself even though its old traces are so well preserved. Siza represented the original layout of burial zones on the top through the marking of the grid pathways. Nevertheless, due to the lack of indicators, the importance of the correspondence with the origin has been greatly decreased so that the crisscross could also be interpreted as a kind of game of movement. Through the removal of "backtracking" channels, it seems that Siza was trying to detain the process of evocation in the cemetery space by separating the memories derived from these old vestiges from their physical presence. This strategy leads to an intervention more radical and dramatic in the recovery of the columbarium 

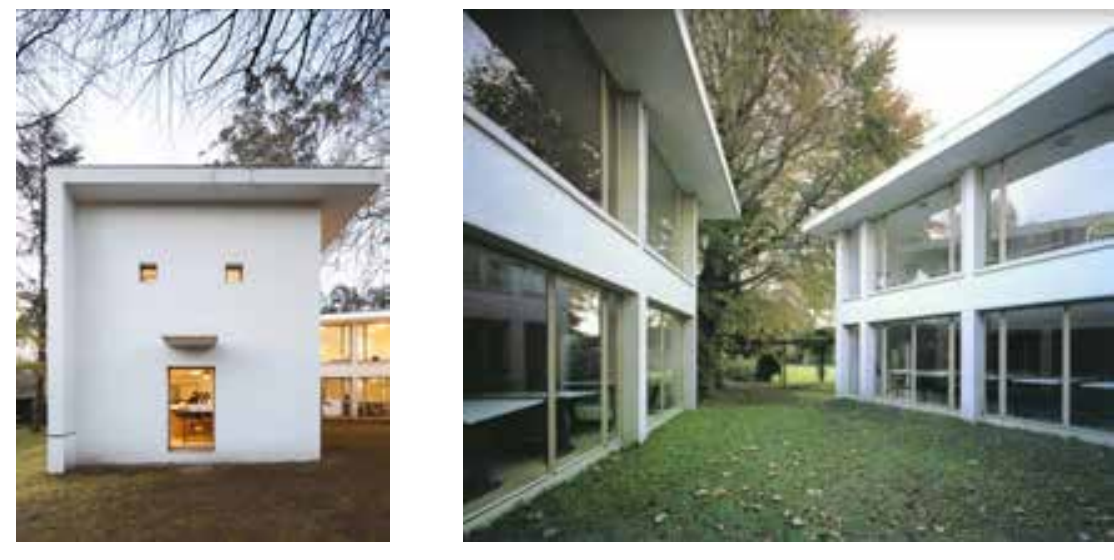

Fig 4.90. Pavilion exterior and interior are different in material and transparency.

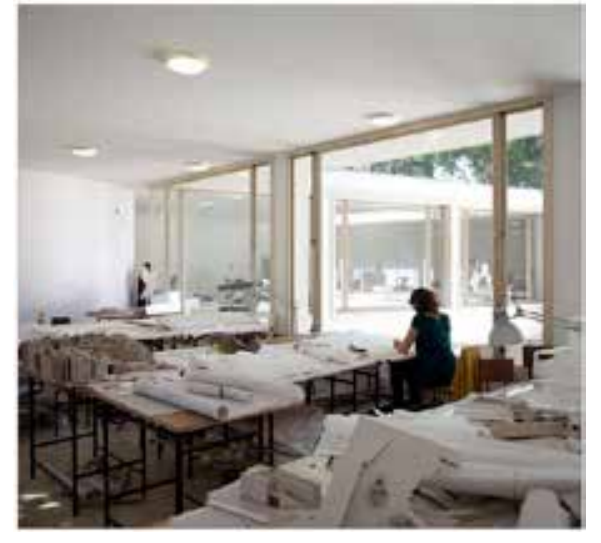

Fig 4.91 Visual interaction between classroom
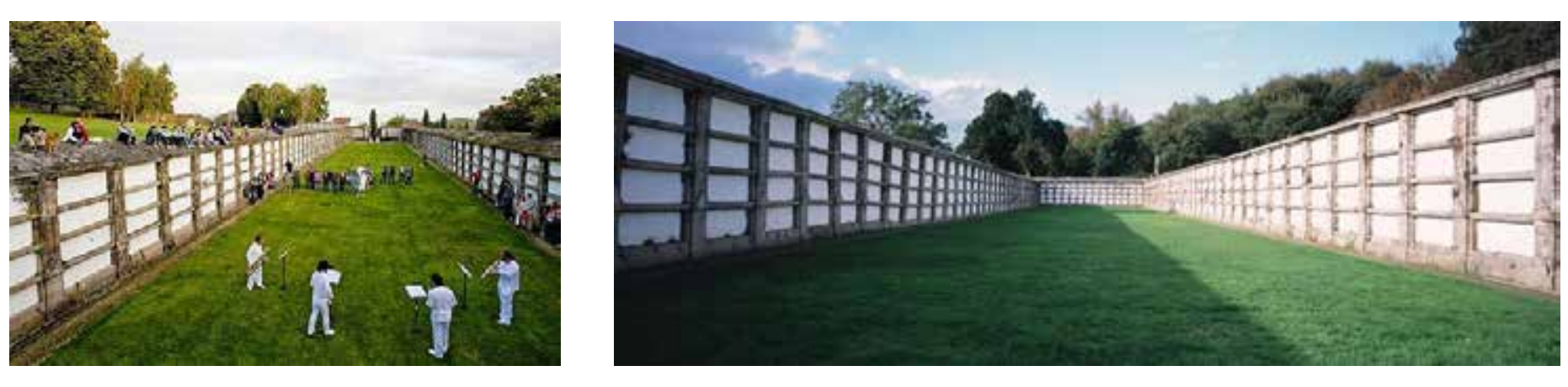

Fig 4.104. The nich yard. contains everything, outside of time and space."250

The immunity of Quinta da Póvoa enables Siza to work in such "perfect environment" for Carlos Ramos pavilion. Located at the far end and adjacent to the entry of the site, the two-floor studio keeps hiding the interior landscape as the stone wall of the precinct does. The obliquely projecting gate at the corner provides a direct access into the building, while the other circuitous route according to the pinched outline turns to the courtyard in the direction of the garden's axis. The entry direction is thus separated from the logic of the architectural form. (Fig.) Both the solid shell and the core space, enveloped by full-height windows with minimum division, complete a manifestation of a simple form made by simply constructional methods. The building has no base nor specific earthwork. The lack of apparent articulation with the ground, together with the thin and white slabs, makes the pavilion look like a carboard model which can be removed anytime.

The reduction of details in visual structure is another key issue of Carlos Ramo pavilion and as well as of the whole faculty. Siza recalls the varying observations that he has attained when strolling in Lisbon:

"A movement cadenced by a continuous and burning throbbing -expansion, contradiction- like the beating of a heart with eyes which can see a long way or can receive the protective breath of the cracked plaster walls, striped by the support, of pale transparent colors, which merge when you half-close your eyes, colors in motion, which yard. On the boundaries of this sunken space, those white-painted covers that close up the cavities which received caskets and crimination urns contribute to the repetitive patterns of the niche wall. (Fig4.104.) By counterbalancing the manifestation of the passage of time on the old walls, these blank surfaces that look like temporary elements give a message of denial of historic traces. The resulting confrontation between the temporary and the ever-lasting manages to convert the courtyard into an anonymous and simpler space, which is fundamental to free such a spatial format from its original function, as well as from the overwhelming atmosphere with regard to the death.

Siza has been very careful about the treatment of those pre-existing elements in the last stage of the garden, since the priority to transform an old cemetery into a civil park lies in the change of emotions to be released from the space ${ }^{259}$. However, reducing the mortuary air does not mean the neglect of context and references. The grids paths and niche walls become components of place for casual activities, and at the same time, without losing their character to imply memorial reality. Siza generated the ordinary and extraordinary expressions from the same object, and distributed them to various perceptional layers.

Therefore, reading of the space is thus conditioned by the stratification of cognition, that the narratives are captured by our direct and intuitive perceptions, and further unfolded with the involvement of intellectual appreciation. The lack of immediate 259. Siza has been regarded the changes of architecture and its function as reflection of the
changes of people's life. Renovation of the cemetery space has been well accepted and used changes of people's life. Renovation of the cemetery space has been well accepted and used by thities such as sill concests, exhibitions, etc. The adjocent plot with niche walls at the become children's playground. 


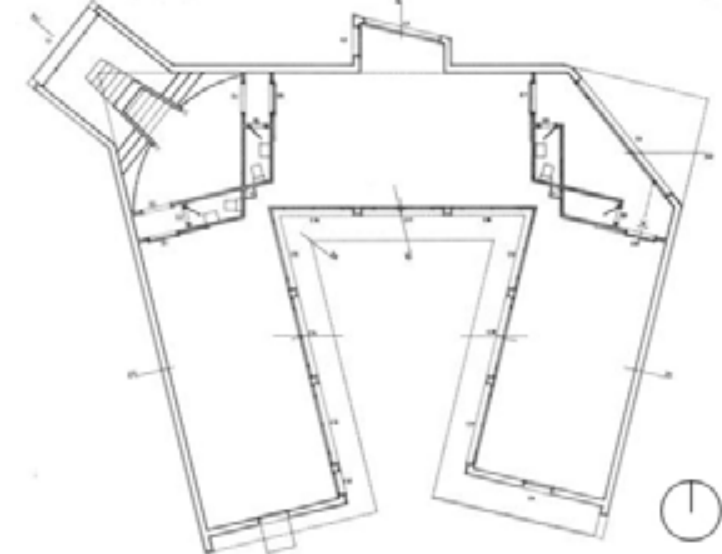

Fig 4.92. Carlos Ramos Pavilion plan

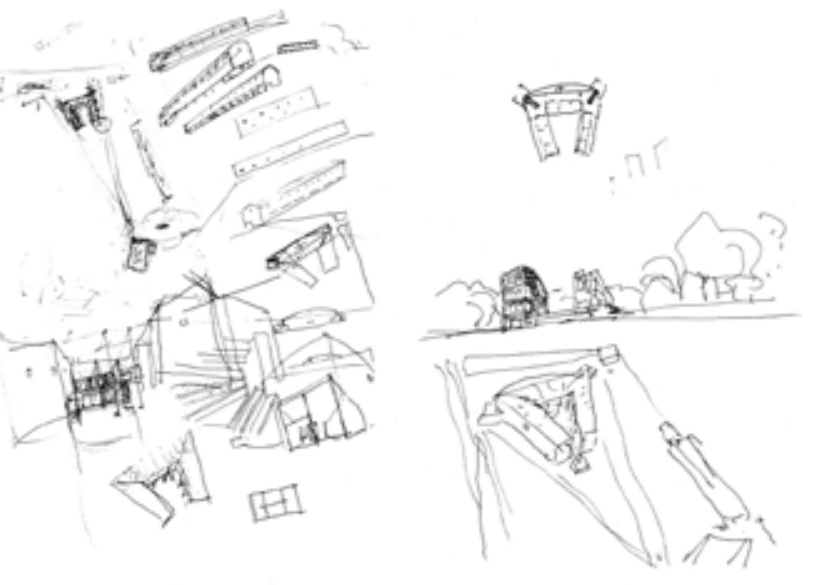

Fig 4.93. Study of Carlos Ramos Pavilion interior, 1986

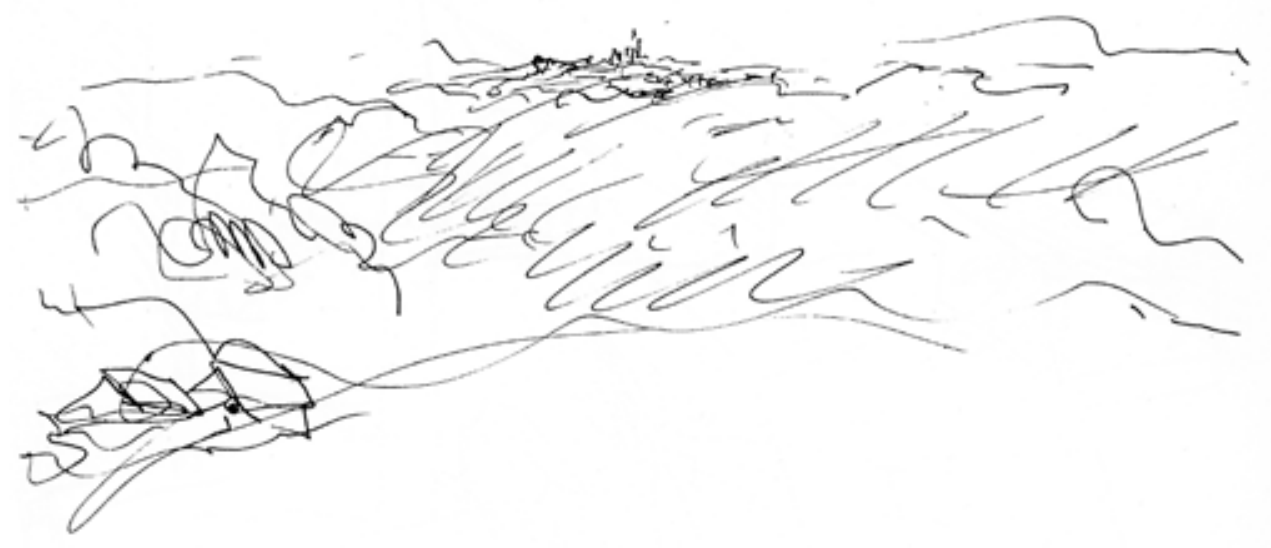

Fig 4.105. Sketch of Santiago de compostela, Siza.

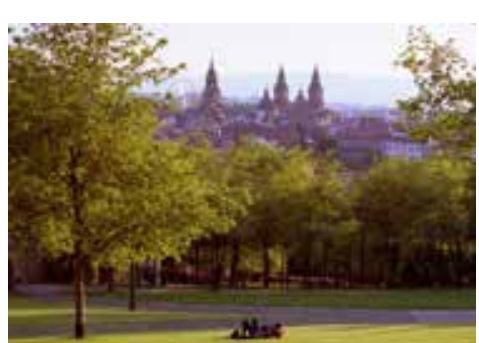

Fig 4.106. Catedral seen from the cemetery studios, or just enjoying the view from the patio, even those only figures that identify the free-standing structure, the anthropomorphic surfaces, the constant discourse of symmetry and asymmetry, and the jutting-out roof, become irrelevant. "Everything that we can consider anecdotal or accidental has vanished and given way to the strictly essential." ${ }^{252}$ However, retreat of details does not mean an eventless building, but reorientation of focuses from architectural ontology to the relations between people and the surroundings attained from the order made by the pavilion. Siza abandons the belief in doing with references, and eliminates the complementary nature of geography and history, grounding the project in the subdivision of the land itself to promote pure communications between activities in different classroom, and between people and the natural views.

The new campus of the faculty schemed in a shape of hourglass plays upon the framing and framed, and on the alternation of continuity and discontinuity. Therefore, it puts the reversal of perceptions as central feature. The spatial ambiguities and perceptual tensions that may take on a tactile aspect which is related to an individual's visua structure, wherein visitors seem to be in the search of the author. Some of the ordering

251. Siza, Writings on Architecture, 131.

252. Moneo, Theoretical Anxiety, 244 association among these layers is so important to consolidate their own disciplines, which seems to lead to a change of the way of our cognition from the continuous procedure, to a leap from one stage to another, triggering the momentary experience of the observer.

By articulating a serial experience of the discontinuous pathway of the orchard, the lost feeling in the grove and the conceptual detachment from the old character of the cemetery, Siza has kept a sense of fragmentation in the recovery of Bonaval garden as a way to control and guide perceptions, as well as to interpret the reality of this land that withstands the test of time.

"That is why the scar of history if to a certain extent enriching, and give things a different density by deleting what is not essential, what is not really solid, and that is the beauty of the ruin, because it also refers to things that can perceived through their absence although they no longer exist." ${ }^{260}$

In the fractures and emptiness of the garden there is no more than a denser and multifaceted awareness, with which visitors are able to trace for the original images according to their absence.(Fig.4.105, Fig4.106.) It gives Siza's work a great degree of freedom and the universal values, since each stage, each element is to create a unique relationship with the individual. As a result, a contemporary intervention frees the historic space from the imprisonment of its religious past and tells the present stories of a piece of city.

260. Siza, El Croquis, no.140, 23. 


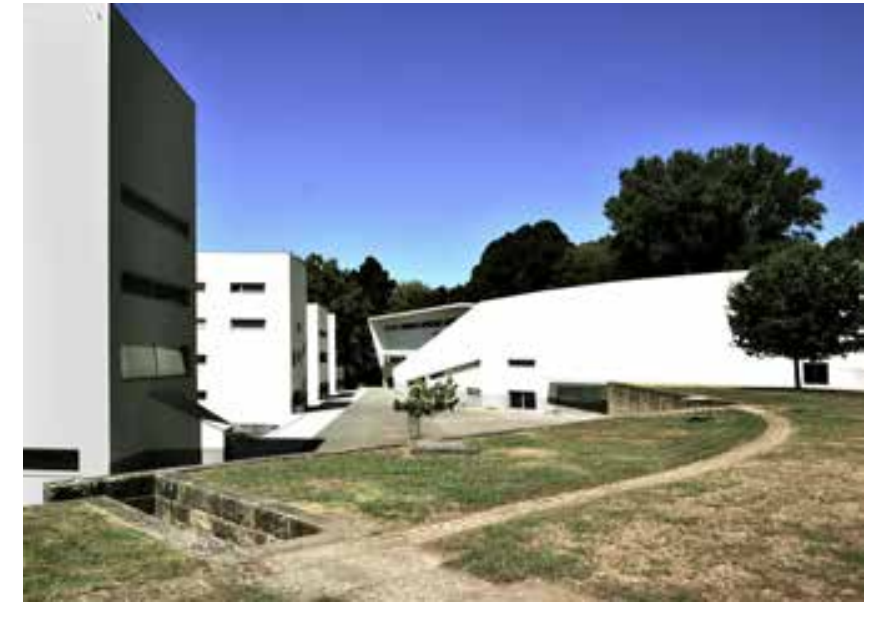

Fig 4.94. Courtyard of the new campus seen from the terrace.

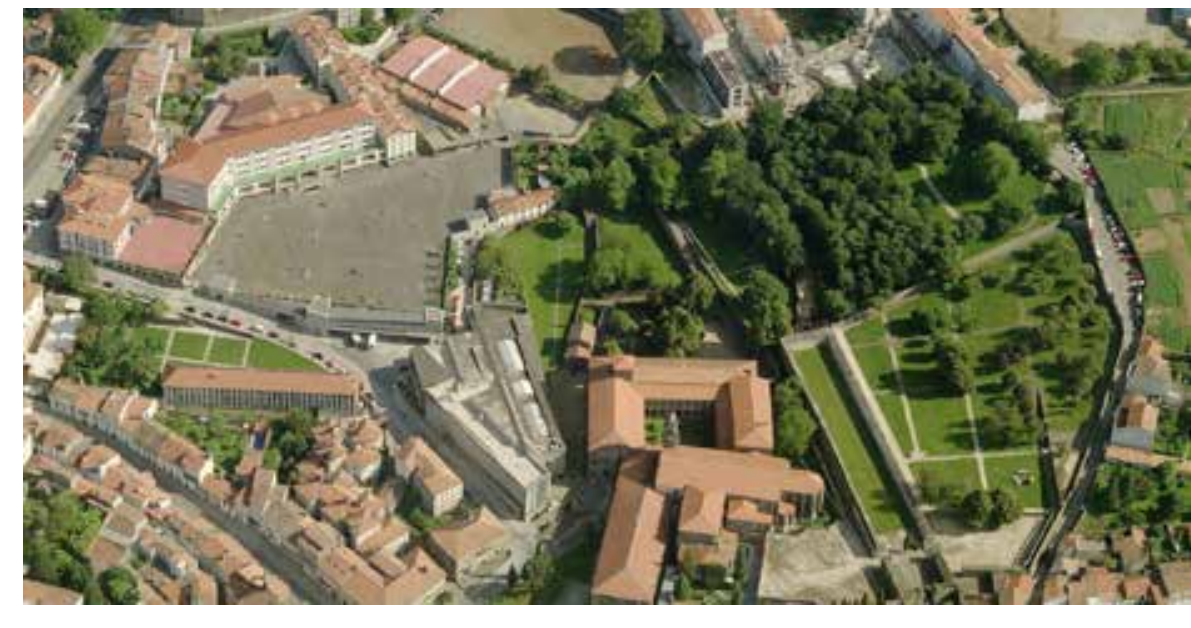

Fig 4.107. General view of the park, museum and conven

principles that Siza has applied in the space are alluded from the strategies of overlapping and encountering elements, and the lessons from Cubism of transformations between the superficial and the volumetric, showing geometric shapes from different angles at the same time. It helps to explain the particular way to observe in Siza's works, that imaginations are nested in the structure of viewed things to divine the hidden traces.

As Siza puts in that "architecture requires the perfection of the detail until the detail is dissolved." ${ }^{253}$ hierarchical reading seem to lie fundamentally in his works. The dynamics of details may attract intuitive perceptions in the first place, but at a specific moment they will give place to the schematic expressions that ask for cognitive appreciations This paradoxical remark points out the asynchrony in Siza's works to "respond to different scales of perception", and to generate a momentary balance between them. Such flexibility comes from Siza's almost instinct sensibility to make things come forth or hide behind in particular stages. It is because his personal observations possess the similar quality with all the great architects in the $20^{\text {th }}$ century, as Paul Rudolph indicated, who are "highly selective in determining which problems they want to solve." ${ }^{254}$

The dynamics of intertextuality and transformation make the Faculty of Architecture in Porto one of the best samples to show a pair of notions that lie in Siza's works - the "order of co-existents" and the "order of sequences"- which are fundamental in incorporating separated components into a conceptual unity, meanwhile making a project generate spontaneous contact with multiple realities so to prevent it from enmeshing into a unitary language.

253. Siza, Writings on Architecture, 30.

254. Rudolph, Paul. "Paul Rudolph. For Perspecta." Perspecta 7 (1961): 51, doi:10.2307/1566866. 
§ Epilogue - appreciate the accidents

"I defend the passage of time as an unrepeatable and irretrievable phenomenon, as wel as the need to display the authenticity of the material, the vitality of the things that now have no use, the energy that relates then to each other and the need for direct contact with them. This is the meaning of the passage of time." 261

Walking through a Siza work, one has to prepare for the unexpected events, since the fluidity of space is occasionally interrupted by the particular element at precise moment. Corners, ascension and descension that active immediate movement along the itinerary always lead to the confrontation with topography, ruins and urbanscape, which form greater backdrop that show the flow of time. It testifies Siza's insight into the relationship between the time of architecture and the time of history, as he puts in, "I regard every complete building as a first stone: the rest has to be done by history." ${ }^{262}$ This notion gives an inspiring perspective to look the Faculty of Architecture and the Bonaval Garden, in terms of his strategies to place the projects into different context and to make their coexistence perceptible.

In the Architecture school, topographic separation of the terraced land and the unipolar distribution of old houses enabled Siza to unveil the historic elements, as the origin of the project, through an extended trajectory. In the new campus, the conventional connection between architectures and the ground is replaced by rigid delimitations, even the pre-existing terrace loses its independency in order to become part of the geometricized layout. Despite of the conceptual unity of this space, our perception is largely driven by the immediate changes of architectural forms. This tendency can be also experienced on the upper stage. Morphological relation between the Carlos 261. Ibid., 25.

262. Ibid., 25.

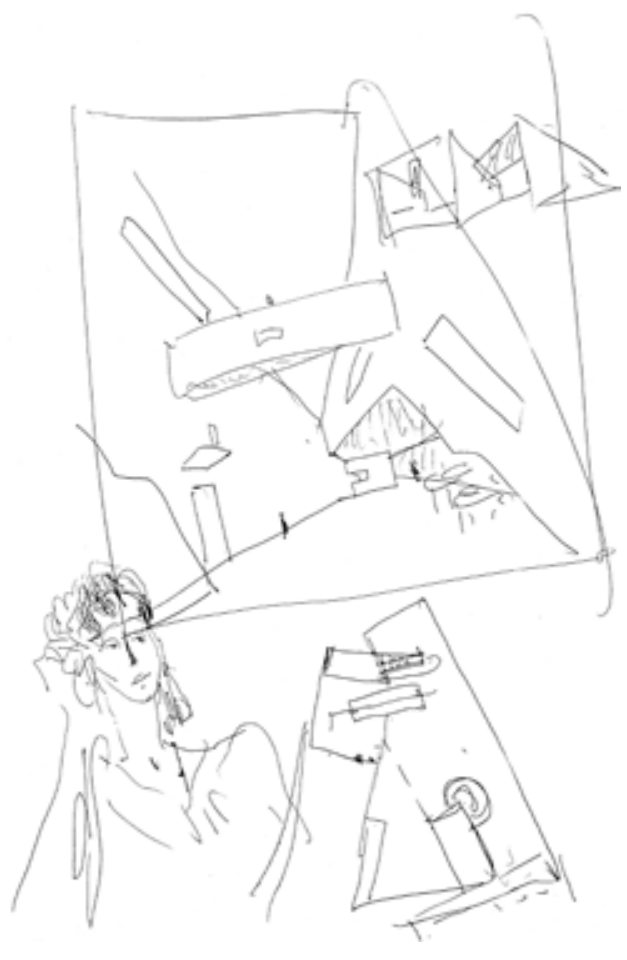

Fig 4.108. C.G.A.C interior, Siza.

Ramos pavilion and the Villa Quinta da Póvoa has been minimized, and through their reduced visual connection, the old house ends up as volumetric counterpart of the new construction. With the help of the reduction of apparently historic influences and the pursuit of the perfection of details until their disappearance, Siza creates the whole faculty as the "first stone" at the exact moment at which the site is delineated and the buildings are constructed.

In Santiago de Compostela, the strong presence of historical elements confirms a continual process which had been started long before on the site. Siza was so sensitive to this split of this preset, undeniable background and the new project that he took it as the point of departure to start the work by recruiting the old materials and conventional construction methods. His focus however was not on citing or reviving precedent types, it was on integrating those resources into a pure and effective system to establish visua structure and guide movement without falling into the trap of the rhetoric of old facts. The contemporary logic of new space and the historic identity of the site are kept by Siza as two lines that approach to each other but never meet, in order to balance the expressions of the museum and the public garden.

Despite of the differences, both works reveal a superimposed structure wherein the figure of abstract plane seems to be imposed on the unaltered ground. A mechanism of separation is thus discerned because of multiple realities are classified and organized within autonomous spheres. It helps to explain Siza's work as combination of a lasting process and opportunities to appreciate accidents, therefore, the participation of the observer in the space is fundamental. (Fig. ) It is the physical interstices and conceptual division that keep alternating one's perceptions between various levels and give rise to the movement that unleashes the dynamics of one's momentary feelings. 


\section{CONCLUTION - CONDITIONAL UN/CONTINUITY}

The unreducible opposition of unexpected encounters of fragmental episodes and an overall system which combines the discrete elements responding the condition in situ is the very heart of Siza's work. In this context, components must be differentiated from the organization of them, the former having an internal and instant value. Based on the instant perception of visitors and users, it is less subject to the author and suggest autonomous part of architecture. The latter, on the other hand, is less obvious and reveals the progressive realization of the architect's intention.

Siza is never hesitate to apply the strategy of division and subdivision to formulate space with self-explanatory parts, whose meaning is thus capable of being independent from the general structure, which presents itself as a simplified and pure establishment of a barely visible background of continuity. Apparently, the architect has turned away from an unconditional presentation of the wholeness and from the formal articulation between the components. In Siza's work, the provisional instant and intransitive event that characterize the space ostensibly weakened its relation with the ground. This detaching force is bound to give rise to a certain indifference and the visitors privilege in the architectural narration, driving his works closer to a context derived from the contemporary ideology.

In the article "Educational Journey" written in 1995, Siza indicates that "Architecture does not allow and does not accept the unexpected, the immediately and directly transposed idea." ${ }^{263}$ This remark that implies the architect's design through a continuous process, curiously, is likely to lead contradiction with the experience of spectators

263. Siza, "Educational Journey,” 30 when observing the architect's sketches or walking through the architectural spaces. There seems to be a script according to which Siza has made use of the incursions of fleeting images and unexpected episodes, as stimulus of personal actions in his space, to compose the narrative structure and intensely vary visitors' perspectives so to intervene in their perceptions. These effects contribute a set of realities that keep disturbing the quality of consistency in Siza's design.

Differences between design method and narrative effect in Siza's creation is more explicit when comparing his metamorphic sketches and those precisely-made plan drawings developed from initiative ideas. While the architect regards the instinctive impulse and desire stimulated by spatial configuration as "the hazily latent collective desire", which is the essential term that architecture should reveal, its realization must be conditioned by precise geometry involving positional relation of different elements and their volumetric interrelations. Siza regards that "Architecture means commitment transformed into radical expression, in other words, a capacity to absorb the opposite and to go beyond contradiction. ${ }^{264}$ Going beyond instead of reconciling contradiction makes a request for a proper way of coexistence of the opposite to prevent the whole program from falling into neither a group of indifferent and discrete parts, nor a homogenous condition that would only derive unified meaning. This tensed juxtaposition may also reveal the objective of Siza's work in terms of visitors and users: giving rise to new stimuli, and protecting the feeling of security in the space where people are always being accompanied. 
Composed by the distorted and dislocated pieces, the outstanding episodes in Siza's space, intensified by the force detaching them from the general structure, present themselves as self-referential forms that are far from the products of the legalization of architecture in preexisting conditions. Therefore, his architecture acquires the possibility to be no longer conditioned by the general and "passive" response of the exterior milieu: by switching the views of the whole program and giving autonomy to the parts whose relatively independent narrations will accommodate spectators, Siza always tends to create new, interior and myopic context.

Rather than letting the polarity separate the program, Siza makes use of the quality of inconsistency to achieve hybrid quality and internal vitality when designing projects. By creating perceptual limit between the two catalogues and establishing order of appearance of different components alongside designed itinerary, the architect creates hierarchy so that the general layout and the smaller parts acquire respective narration which can be experienced separately. One of the most fascinating and subtle character of Siza's space resides in the either exchangeable or exclusive identification of the two kinds of configuration in an intricate system.

In the introduction of the special issue of Architectural Design in 1993, an anthology on the application and development of Gilles Deleuze's notion of The Fold in the field of architecture, Greg Lynn regards the unreducible individuality of smaller components belonging to the overall structure an essential point in Deleuzain concept from which a particular architectural strategy can be generated.

"Intricacy is the fusion of disparate elements into continuity, the becoming whole of components that retain their status as pieces in a larger composition. Unlike simple hierarchy, subdivision, compartmentalization or modularity, intricacy involves a variation of the parts that is not reducible to the structure of the whole. ${ }^{265}$

In Mario Carpo's article "Ten Years of Folding", the Italian historian and critic declares The Fold as "a unifying figure whereby different segments and planes are joined and merge in continuous lines and volumes." ${ }^{266}$ Though architect must be cautious about the intellectual game to interpret a philosophical term into architectural language, which is likely to cuase distortion of meaning and illusion of self-satisfaction, it cannot be denied that the configurative method extracted from The Fold provides a possible way to understand the compositional mechanism of Siza's architecture in terms of the coexistence of autonomy of individual parts and continuity in the whole program.

Both Lynn and Carpo have noticed that a folded system is capable of reconciling unity with secondary individuality by presenting them from respective level. For plastic art, fold or folding suggests a dynamic process rather than a result; it works through an approximating approach rather than a definition of a intentionally-established complex condition. The subtle but irreducible borders between components and overall system, and their respective logic characterize Siza's works. Moreover, the quality of randomness on the basis of those unexpected encounters up to spectators' position and attitude gives rise to the liberty to comprehend his architectures: the mutual relation between varying expressions of constructed space and observer's instant actions establishes perceptual rules, by which visitors are guided to go in and out of enclosures

265. Greg Lynn, "Introduction," in Folding in Architecture, 2nd edition ed. Greg Lynn (New Jersey: John Wiley \& Sons, 2004), 9.

266. Mario Carpo, "Ten Years of Folding," in Folding in Architecture, 2nd edition ed. Greg Lyn (New Jersey: John Wiley \& Sons, 2004), 14 
belonging to a flow of space, experiencing coincidence between continuous movement and specific episodes. It will be seen from this that Siza proceeds project from the experience more than idea, and his works can be regarded as a configurative method as well.

The space that Siza has created is capable of occasioning for the user and spectator experiences of the abstract synesthesia of dynamic-temporal perception. Rigid geometry and pure materials are used to give his architecture clear outlines, stressing the boundary between the exterior and the interior. Siza does not regard the urbanscape, the natural scenes or the preexisting things in the site as objectives of his works, he tends to consider these elements as fragmentary interludes and transform them to conform to his architectonic language. Since the bond between visitors and the site is intentionally weakened, Siza's architecture usually presents a radical desolation, as Ignasi de SolàMorales observes, "a groundless emerging out of the singularity of an event". Therefore, people become the absolute protagonist in the space.

The discrete occurrences in Siza's project dislocate visitors' spatial and tempora experience. The orthodox experience based on the continuum between the past and the future is replaced by the "instantaneous interpretations" and its provisional significances. Solà-Morales further declares its untimely quality.

"Just as in minimalism, the syntax with which the elements of construction are laid ou in space in Siza's work is both abstract and temporary. There is no attempt to establish a procedure or to elaborate the architecture as the deconstruction of some previously existing architectonic text. The geometric dislocations, the slippings, the distortions of perpendicularity, and the incomplete anchoring of Siza's forms are the expression of an architecture produced ex novo every time. What provokes admiration or surprise in the work of the Portuguese architect is this provisional, novel quality of each project. The subtle lightness of his intention and the reduction to the minimum of the semantic resources privilege all of the syntactic content."

The incoherent configurations made by Siza give rise to the close and distant vision, and bodily movement which establish the condition of experience. Therefore, relation between visitor and architectural space is bound indissolubly with the exploitation with perceptual mechanisms of human subject. Siza creates a new architectural sensibility resonate with the condition of contemporary cultural: Architecture is freed from the obligation to manifest the system of principles, conventions, or linguistic code. There is no sense in explaining Siza's work in terms of the before and the after, it is to refer to the particular concrete conditions of each situation, obtained in precise space and time. In Siza's space, events occur in an instant and at a point. However, Siza's strategy cannot simply be interpreted as a manner to produce an ephemeral, instantaneous, fleeting architecture. What he seeks to defend is the value of places derived from the meeting of present energies, constituting the force of projective mechanisms which is able to promote and give rise to intense and creative epiphany. 
GENERAL CONCLUSION

Background and continuum in the experience as narrative 
"The true picture of the past flits by. The past can be seized only as an image which flashes up at the instant when it can be recognized and is never seen again..."

Walter Benjamin - Theses on the Philosophy of History

This book originates from and also can be regarded as the author's personal reflection on the culture and phenomenon of today's architecture. The abuse of fragmented messages and easy knowledge in favor of universal meanings constitute rapid and superficial architecture to serve and push the world of consumerism. This tendency runs away from the foundation of the discipline of architecture and promotes a progressive distancing from the appropriate and sufficient relation with the nature, with the territory and with life. Ignasi de Solà-Morales ascribes this problematic situation, first and foremost, to an alienation of place prior to architectural process

"Today's landscape hardly constitutes a background into which the architectural object might be thought of as inserting, or integrating, or diffusing itself. Powerful processes of what Gilles Deleuze has called deterritorialization situate today's architectural objects in non-places, in non-landscapes.".274

This investigation demonstrates the inevitable collusion between temporal narrative and design that pervades the works of the four architects, and gives rise to some of the most metaphoric architectural experience of the postwar period. Though in this book the architects and their works are studied in the same topic, the four monographs and eight individual cases show that it is the differences rather than similarities - although comparable concerns and attitude are recognized among the architectural, they do not contribute the main objective of this investigation - contribute to expand the panorama resulting from the task of this dissertation: explain the conception of temporal narrative in architecture, find its potential range, analyze the design strategies the architects apply to achieve the storytelling, and demonstrate the spatio-temporal experiences. The diachronic landscape of each work as well as of the eight cases as a whole, which is made of the long-term formation of site place, the constantly developed usage of the built project, and the architect's work of design and construction which is nothing more than an instant impulse of ideas and implementation, would compensate the absence of connection in today's situation.

Though the notion of time pervades in the general sense of architectural design, the works studied in this book are generated from detailed results of this grand topic The deliberately established relationship with particular historic time and event, and proactive approach to an expression of certain conception of temporality have founded a landscape of time, serving as a background that integrates architecture inserted into the territory with the actions of group of people.

This sentimental background has a frank presentation in the pathways by Pikionis and the works by Venezia in Belice. A young regime was eager to identify and legitimate itself through articulating its power to the glory and memory of ancestors in the classic period. In terms of design concept, the pathways meandering up the hills, the sophisticated pavement, and the reformation of local landscape serve an exclusive approximation to the privileged monument object. The bond between walkers and the goal up there is greatly emphasized so that all of the narratives of an itinerary towards the vestiges of history are derived from to the significance of bodily movement itself.

In the face of the dilemma as a result of the reconstruction in Belice conceived to promote oblivion, evoking recollections of the seismic event, no matter how bitter it would be, is the only way to save the territory from a crisis of identification. The building of the museum and of the theatre are applied as method to transform the site in order to create place for the event, which happened at and has been eliminated from 
the place. The old fragments collected from original location and used in the museum and the theatre surpass spatial limit and reach a deeper connection with the territory. It is also the fact the unfinished, the partial, and the cumulative in the monuments contributed an effect of detachment, that presents the buildings as capable of proposing a higher level of integration with old facts and keeping certain distance with the new reality in the cities.

In the cemeteries of Lewerentz, people come to the place of remembrance without curiosity or expectation. The narrative of time - that of the farewell to the loved ones and that of the course of life itself - is no longer an object to trace for, it becomes the reason, the meaning of individual's experience. Landscape have become objective in the contemplating walk. The individuality and completeness of the mound and the ridge present themselves as a sign of Nordic culture and funeral rites. The ceremony is thus to be understood as connection between "I" and my ancestors, between the self and the nation, between people and nature. a

As for Siza, narrative of time is not the revelation of something existing in permanence and does not come from something previously prepared, it is the production of an event. The event is grasping, the action of the visitor subject who, within the variation of flux of unexpected encounter on site, arrest the moment that most attract or impel, in order to hold on to them. It is a subjective action produces "a moment of pleasure and fragile plentitude." The order of the site and the constructed space is represented by the fleeting events. And this erratic, nomadic perception of all these events is such a characteristic feature of Siza's works that space manifests it in a subjective way.
The responsibility of all these works to create a temporal landscape and background, in which architecture can find its own place, is cultivated from the essential bond with the spirit of the age to which they belong. Articulations with specific narrative of time come from their prior task of articulating themselves to the history, the territory and groups of people. It suggest a process of "territorialization" serving as a solution to the problem raised by Solà-Morales.

If we reach an agreement that the vocation of architecture lies in its service to the exploration of pre-existing facts, then we will regard continuity as one of the essential qualities of architecture. History and topography join in the place that defines time and space.

Apart from the general landscape of time that connects the idea of the four architects, this notion of place corresponds to a continualist conception of the architectural process, and how it reflects on visitors' mind through experiencing architecture as an outsider that ends up with accommodating itself into a spatio-temporal continuum, becomes the critical line rooted in the selected works. The permanency of territory and the course of specific event are the internal explanation of the selected works, together with the immediate perception and action of an individual as subjective action, they have formed the temporal narrative of architecture. From this point of view, architect's work is to create an intermediation in order to mediate between different properties and duration of time.

Given the importance of the relationship between the observer and the work, another primary issue to consider is the way to perceive depending on the variation of the point of views of the person who travels it. The architects seek to work with the delimitation 
of visual perception and, at the same time, with the movement of the viewer. Rosalind E. Kraus' comments on the obsession of contemporary sculpture with the idea of movement - "la imagen del pasaje (del tránsito) sirve para situar tanto al espectador como al artista ante la obra y ante el mundo, en una actitud de primaria humildad a fin de encontrar la profunda reciprocidad entre ambos., ${ }^{, 275}$ - also reveal the experience of transit acquired from these architectural works, which do not suggest to be seen but to be traveled. They not only consist in contemplating the objects, but also consist in compromising and experiencing our nature in them.

The idea of transit in the eight itineraries is perceived through the reducing temporal distance between the spectator subject and the narrative of the architecture and landscape object. The permanence of an ancient civilization, the course of life itself, an event distancing from the present, and the provisional instant contribute a series of experience of a progressive approximation of the external meanings to the interna rhythm of our own body. All those things and events, organized along some continuous thread extended in the orderly succession of time, have formed a continuum that reveals how visitors are articulated with the place in the different sites.

As Pikionis, Lewerentz and Venezia seek to work with the conception of firmness and create perceptional delimitation between the objective and the subjective, Siza's work seems to be a fracture that reveals a tendency in the creation of contemporary space as a progressive reduction of effects of duration and stability. An equivocal space has emerged: there is no absolute meaning. Everything appears or disappears with human action. It is in a way that seems to give spectators more freedom in the space people gradually lose their absolute control over space. The change of the relationship between people and space affects the way how people perceive a place, which in turn will adjust the ontology of space and lead to changes in rites.

However, Siza's architecture is by no means the superficial production characterized by the defiance of time's passing. His radical admiration for the contingency and values of the short-term emerges out of the singularity of the event happened and is happening on the site, giving rise to the cultivation and maintenance of the essential of genius loci. Here, permanence and instant are much more like a continuum than two polar opposites. Therefore, the value of Siza's work lies in showing us, even in the inevitable and irreparable condition of today's landscape, the production of a continuum of place continuous to be possible, and the fact that integration and estrangement can be and must be considered as two parallel strategies to approach to the same problem.

"Whatever space and time means, place and occasion mean more. For space in the image of man is place and time in the image of man is occasion. Today space and what it should coincide with in order to become "space" -man at home with himself- are lost. Both search for the same place but cannot find it"276

As Aldo Van Eyck suggested that we are strangers in our own land, acknowledging the feelings of profound estrangement in today's world. In the face of a world of fluidity and decomposition, all of the four architects play critical roles in expanding the panorama of temporal narrative in architecture, as well as explaining our experience of the world around us, not only comes from the physical space but also from the body in its totality: spatio-temporal, mobile, knowledge, cultural, and expressive. Their works belong to the cultures that find their identity in the struggle against the passage of time,

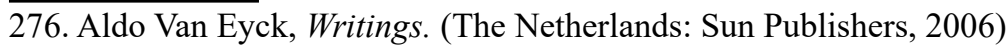


seeking to arrest time by means of ritual and memory. By affirming the relationship between human subject, the place, and occasions, the established background an continuum seek to work against the contemporary individual's experiences of loneliness and isolation. 
$-338-$

BIBLIOGRAPHY 


\section{A. General Bibliography}

\section{Books}

Alexander, Christopher. The Timeless Way of Building. Oxford University Press, 1980. Bachelard, Gaston. The poetics of space. Vol. 330. Beacon Press, 1994

Barrie, Thomas. The Sacred In-between The Mediating Role of Architecture, London: Routledge, 2010.

Barthes, Roland. A lover's discourse. Fragments. translated by Richard Howard. New York: Hill and Wang. 1978.

Benjamin, Walter. The Work of Art in the Age of Mechanical Reproduction. translated by Harry Zohn, New York: Schocken Books, 1969

Berger, John. Y nuestros rostros, mi vida, breves como fotos. [S.1.]. La Gloria Eds. 2017.

Berlanda, Tomà. Architectural Topographies: A Graphic Lexicon of how Buildings Touch the Ground. Routledge, 2014.

Bloomer, Kent and Charles Moore. Body, Memory, and Architecture. New Haven: Yale University Press, 1977.

Blanchot, Maurice. Friendship. Translated by Elizabeth Rottenberg. California: Stanford University Press, 1997.

Bouman, Ole and Roemer Toorn, Van, eds. The invisible in architecture. Academy Editions, 1994.

Buchli, Victor. An Anthropology of Architecture. reprint edition. London: Bloomsbury Publishing, 2013.

Choisy, Auguste. Histoire de l'architecture. Paris: Gauthier-Villars, 1899.

Coates, Nigel. Narrative Architecture. London: Wiley-Academy, 2012.

Corbusier, Le, Stanislaus Von. Moos, and Arthur Rüegg. Le Corbusier before Le Corbusier: Applied Arts, Architecture, Painting, Photography, 1907-1922. New Haven: Yale University Press, 2002.

Curtis, William JR. Modern architecture since 1900. London: Phaidon, 1996.

De Solà-Morales, Ignasi. Differences. Topographies of Contemporary Architecture. Cambridge: MIT Press. 1996.

Didi-Huberman, Georges. Lo que vemos, lo que nos mira. Buenos Aires: Manantial, 1997.

Fariello, Francesco. La arquitectura de los jardines: de la vdantigüedad al siglo XX. Vol. 3. Reverté, 2004.

Frampton, Kenneth. Modern Architecture: A Critical History. fourth Edition. London: Thames \& Hudson, 2007.

Gibson, James Jerome. The Senses Considered as Perceptual Systems. London: Allen \& Uwin:, 1968.

Gibson, James Jerome. The perception of the visual world. Boston: Houghton Mifflin, 1950.
Giedion, Sigfried. Space, Time and Architecture: The growth of a new tradition London: Geoffrey Cumberlege, 1949

Halbwachs, Maurice., and Coser Lewis A. On collective memory. University of Chicago Press, 1992.

Heidegger, Martin. "Building dwelling thinking." in Poetry, Language, Thought, translated by Albert Hofstadter. New York: Harper Colophon Books, 1971.

Heidegger, Martin. Bing and Time, Translated by Joan Stambaugh. New York: Harpe \& Row, 1972

Hill, Jonathan. Weathering architecture. Routledge, 2013.

Hollier, D. Against Architecture: The Writings of George Bataille. Cambridge, Mass. MIT Press, 1992.

Krinke, Rebecca. Contemporary Landscapes of Contemplation. Taylor \& Francis, 2005

Lejeune, Jean-Francois, and Michelangelo Sabatino, eds. Modern architecture and the Mediterranean: vernacular dialogues and contested Identities. Routledge, 2009.

Linazasoro, José Ignacio. La memoria del orden. Paradojas del sentido de la arquitectura moderna. Madrid: Abada Editores, 2014

Linazasoro, José Ignacio. Otras Vias: Pikionis, Lewerentz Y Van Der Laan. Buenos Aires: Nobuko, 2011.

Lindberg, David C. Theories of Vision from al-Kindi to Kepler. University of Chicago Press, 1981

Merleau-Ponty, Maurice, Phenomenology of Perception, translated by Colin Smith. London: Routledge \& Kegan Paul and Atlantic Highlands: Humanities Press, 1962.

Mitrasinovic, Miodrag, and Jilly Traganou, eds. Travel, space, architecture. Ashgate Publishing, Ltd., 2012

Mumford, Lewis. The City in History: Its Origins, Its Transformations, and Its Prospects. London: Penguin Books, 1961

Muntañola Thornberg, Josep. La arquitectura como lugar: Aspectos preliminares de una epistemología de la arquitectura. 2nd ed. Barcelona: Edicions de la Universidad una epistemología de la arquitectura.
Politécnica de Cataluña (UPC), 1996.

Norberg-Schulz, Christian. Genius Loci: Towards a Phenomenology of Architecture. New York: Rizzoli, 1996.

O'Neill, Maire. Corporeal Experience: A Haptic Way of Knowing. Journal of Architectural Education. September, 2001

Ortega y Gasset, José. Notas de andar y ver: Viajes, gentes y países. Madrid: Alianza, 1988.

Pallasmaa, Juhani. The Eyes of the Skin. Architecture and the Senses. Chichester: Wiley\&Sons Ltd, 2005.

Pollak, Michael. "Memoria, olvido, silencio. La producción social de identidades frente a situaciónes limites." Translated by Christian Gebauer, Renata Oliveira Rufino and Marlana Tello. Argentina: Ediciónes al Margen. 2006,

Psarra, Sophia. Architecture and Narrative. The Formation of Space and Cultural Meaning. New York: Routledge, 2009 
Purini, Franco. "The landscape of the city in: Seven Landscape." 12 Lotus Documen. Milan: Elect, 1989.

Rasmussen, Steen Eiler. Experiencing Architecture. Cambridge: MIT Press, 1962.

Ricoeur, Paul. La lectura del tiempo pasado: memoria y olvido. Madrid: Universidad Autónoma de Madrid, Arrecife, 1999.

Ricoeur, Paul. Time and Narrative. Chicago: University of Chicago Press, 1984.

Rossi, Aldo. Architecture of the city. translated by Diane Ghirardo and. Joan Ockman. Reprint edition. Cambridge: MIT Press, 1988.

Samuel, Flora. Le Corbusier and the Architectural Promenade. Basel: Birkhäuser, 2010. Scully, Vincent., dir. Modern architecture and other essays. Princeton University Press, 2003

T. Hall, Edward. The hidden dimension. New York: Anchor Books, eds 1969, 1990.

Tournier, Michel, Jacqueline Conte, and Rafael Conte. El árbol y el camino: Michel Tournier; Traducción de Jacqueline y Rafael Conte. Alfaguara, 1993.

Turrell, James. "Projection Pieces" James Turrell: The other horizon. Edited by Daniel Birnbaum et al. Cantz; 2nd edition, May 2, 1999.

Wittkower, Rudolf. Los Fundaments de la arquitectura en la edad del humanismo. Spanish version translated by Adolfo Gómez Cedillo. Madrid: Alianza Editorial, 1995.

Zahavi, Dan. "Inner (Time-)Consciousness." In OnTime-New Contributions to The Husserlian Phenomenology of Time, edited by D. Lohmar and I. Yamaguchi. Dordrecht: Springer, 2010.

\section{Articles}

Aalto, Alvar. "De umbral a cuarto de estar." Arquitectura: Revista del Colegio Oficial de Arquitectos de Madrid (COAM) 315 (1998): 14-19.

Aalto, Alvar. "De umbral a cuarto de estar." Arquitectura: Revista del Colegio Oficial de Arquitectos de Madrid (COAM) 315 (1998): 14-19.

Barthes, Roland, "Introduction à l'analyse structurale des récits." Communications, 8(1), (1966). 1-27, translated as "Introduction to the Structural Analysis of Narratives." New York (1977): 79-124.

Foucault, Michel, and Jay Miskowiec. "Of other spaces." Diacritics (1986): 22-27. Foucault, Michel. "The language of space." Space, knowledge and power (1964): 163.

Frampton, Kenneth. "En busca del paisaje moderno." Arquitectura 285 (1990): 52-73. Frampton, Kenneth. "Towards a Critical Regionalism: Six Points for an Architecture of Resistance." In Postmodern Culture, edited by Hal Foster. London; Pluto Press. pp.16-

Frampton, Kenneth. "Prospects for a Critical Regionalism," Perspecta 20 (1983): 147162.

García Otero, Juan Maria. "El arte en el Camino." Prensa Española General de Revistas. 1 v. (1999).

García Otero, Juan Maria. El arte en el Camino. 1 v. Prensa Española General de Revistas. 1999
Held, Richard. and Alan Hein. "Movement-Produced Stimulation in the Development of Visually Guided Behavior" "Journal of Comparative and Physiological Psychology. (1963). 56 (5): 872-876.

Holl, Steven, Juhani Pallasmaa, and Alberto Perez-Gomez. "Questions of perception phenomenology of architecture." $A+U$, Architecture and Urbanism, 1994.

Masiello, Francine. "Los sentidos y las ruinas." Iberoamericana (2001-) 8, no.30 (2008): 103-112.

Simmel, Georg. "Two Essays: The Handle, and The Ruin." Hudson Review. 11:3 Autumn, 1958):371-385. [12-08-2017]. https://zh.scribd.com/doc/80615656/GeorgSimmel-Two-Essays-the-Handle-And-the-Ruin.

\section{Doctoral Dissertation}

Guitart Vilches, Miguel. "Filtros de mirada y luz: una construcción visual del límite arquitectónico.” PhD diss., Universitad Politécnica de Madrid, 2014.

Mansilla, Luis Moreno. "Apuntes de viaje al interior del tiempo." $\mathrm{PhD}$ diss., Universitad Politécnica de Madrid, 2002.

Santa-María, Luis Martínez. "El árbol, el camino, el estanque, ante la casa." $\mathrm{PhD}$ diss. Universitad Politécnica de Madrid, 2004.

B. Specific Bibliography on Selected Architects and Projects.

\section{B.1. Bibliography on Dimitris Pikionis}

Books

Biers, William. The Archaeology of Greece. (Cornell Press: Ithaca, 1996) Frampton, Kenneth. Modern Architecture (Greek Edition). Athens: Themelio, 1987.

Doxiadis, Constantinos Apostolou. "Architectural space in ancient Greece." Cambridge: MIT Press, 1972.

Crabtree, Benjamin S. Corporeal Narratives: Architecture of Experience. Diss. University of Cincinnati, 2006

Hamilakis, Yannis. The nation and its ruins: antiquity, archaeology, and national imagination in Greece. Oxford University Press, 2007.

Brown, Keith S., and Yannis Hamilakis, eds. The usable past: Greek metahistories. Lexington Books, 2002.

Dimitris Pikionis, Architect 1887-1968: A Sentimental Topography. London: Architectural Association, 1989.

Ferlenga, Alberto. Pikionis, 1887-1968. Milan: Electa, 1999.

Metallinou, Vasilia Angelos. Regionalism and Greek architecture: the architecture of Dimitris and Suzana Antonakakis. Diss. Massachusetts Institute of Technology, 1983.

Tzonis, Alexander, Liane Lefaivre, and Bruno Stagno, eds. Tropical architecture: critical regionalism in the age of globalization. Academy Press, 2001.

Tziovas, Dimitris. Greek Modernism and Beyond. Rowman \& Littlefield Publishers, 
1997.

Zographaki, Stephania G. Neo-vernacular trends towards the recent past in Greece. Diss. Massachusetts Institute of Technology, 1986.

Hollinshead, Mary B. Shaping Ceremony: Monumental Steps and Greek Architecture.University of Wisconsin Pres, 2015.

Articles

J. Liapis, Homage to Dimitris Pikionis, Architecture in Greece Annual Review, Athens, 1969

Kehagias, Nicholas. "Paving a Greek Path to a Western Monument." accessed May 1 2015, http://www.nicholaskehagias.com/the-acropolis-pavement.

Pikionis, Agni. "On the life, Works and Thoughts of Demetrius Pikionis." $\mathrm{A}+\mathrm{U}$ architecture and urbanism, No. 192 (September, 1986): 113-120.

Bastéa, Eleni. Dimitris Pikionis and Sedad Eldem: Parallel Reflections of Vernacular and National Architecture. The Usable Past: Greek Metahistories(2002): 147.

Frampton, Kenneth. For Dimitris Pikionis. Dimitris Pikionis, Architect 1968 (1887): 6 9.

Psomopoulos, Panayis. Dimitris Pikionis: An indelible presence in modern Greece. EKISTICS-ATHENS- (1993): 253-275.

Rasmussen, Steen Eiler. Daylight in Architecture, Experiencing Architecture. MIT Press, 1964, pp. 186-7; pp. 192-214

D. Holden, Virtue and Form, Guardian, London, 22 August 1963

A.Dimitracopoulos, Dimitris Pikionis (1887-1968): Pioneer Greek Modernist, Architectural

Association Quarterly, London, January-June 1982. Article based on Diploma dissertation submitted to the Architectural Association School in 1981

Yorgos Simeoforidis, A Flavour of Modernity in Greek Architecture, International Architect, London, August 1982

A. Pikionis, On the Life, Work and Thoughts of Dimitris Pikionis, A+U, Tokyo, September, 1986

\section{Doctoral Dissertatio}

Papageorgiou, Alexandra. "Pikionis and His Work." unpublished thesis submitted to Rhode Island School of Design, Department of Architecture, December 1982.

B.1.1. Specific Bibliography on the Pedestrian intervention around the Acropolis

\section{Articles}

Sánchez, José Francisco García. "El paisaje delineado de Dimitris Pikionis: e arquitecto silencioso." $P+C$ : proyecto y ciudad: revista de temas de arquitectura 2 (2011): 105-122

E. Chlimintzas. "Pikionis Built a Way of Thinking." Forum poor architectuur, Hilversum (June, 1982).

A. C. Antoniades. "Dimitris Pikionis: His work Lies Underfoot on Athens Hill."
Landscape Architecture, Louisville (March, 1977)

Álvarez, Darío Álvarez. "El paisaje como obra de arte total: Dimitris Pikionis y e entorno de la Acrópolis." RA: revista de arquitectura 13 (2011): 37-50.

Pikionis, Agnes. "Dimitris Pikionis: 1954-1958: los trabajos de la Acrópolis= his work on the Acropolis." Quaderns d'arquitectura i urbanisme 190 (1991): 76-79.

Simeoforidis, Y. "One Of Pikionis Works In Its Context+ Transforming The Areas Around The Hills Of The Acropolis And The Philopappus." Lotus International 72 (1992): 20-22.

Loukaki, Argyro. "Whose Genius Loci?: Contrasting Interpretations of the "Sacred Rock of the Athenian Acropolis." Annals of the Association of American Geographers 87.2 (1997): 306-329.

Leontis, Artemis. "Archaeology in the Neighborhood: Views of the Ancient Agora an Other Ruins from Outside the Gate." Journal of Modern Greek Studies 27.2 (2009): $417-425$

\section{B.2. General bibliography on Sigurd Lewerentz and Cemetery}

Book

Ahlberg, Hakon, Alison Smithson, Peter Smithson and Colin St. John Wilson. Sigurd Lewerentz 1887-1975 The Dilemma of Classicism. London: Architectural Association, 1989.

Ahlin, Janne. Sigurd Lewerentz, Architect: 1885-1975. Stockholm: Byggförlaget,1987. Caldenby, Claes, Adam Caruso and Sven Lvar Lind. Two churches. Stockholm: Arkitektur Förlag AB. 1997.

Dymling, Claes and Wilfried Wang. Architect Sigurd Lewerentz Vol.I Photographs of the work. Stockholm: Byggförlaget, 1997.

Dymling, Claes and Wilfried Wang. Architect Sigurd Lewerentz Vol.II Drawings. Stockholm: Byggförlaget, 1997.

Flora, Nicola, Paolo Giardiello and Gennaro Postiglione. Sigurd Lewerentz: 1885-1975. Milan: Electa architecture, 2006.

Goodwin, Sarah Webster and Elisabeth Bronfen. Death and Representation. Maryland: Johns Hopkins University Press, 1993.

H. Whyte, William. The last landscape. Philadelphia: University of Pennsylvania Press, 2002

H.O. Andersson, Sigurd Lewerentz. En Classicismo nordico. Milan 1988.

Harlang, Christoffer. Espacios nórdicos Nordic Spaces. Barcelona: Alisaba Edicions, 2001.

Lewerentz Sigurd, Wilfried Wang and Janne Ahlin, St. Petri Church : Klippan, 196266c, Berlin: Erns Wasmuth Verlag, 2009.

López Santana, Pablo. Muerte en el bosque : fenomenología espacial comparada de tres imágenes kinetoarquitectónicas. Sevilla: Universidad de sevilla: secretariado de publicaciones, instituto universitario de arquitectura y ciencias de la construcción, 2014. 
Lopéz-Peláez, José Manuel. "La arquitectura de Gunar Asplund." Barcelona: Fundación Caja de Arquitectura, 2002.

Sigurd Lewerentz Drawing Collection 1-2. a+u Architecture and Urbanism, Tokyo, 2016.

Sigurd Lewerentz.En Swedish Architecture of the twentieth century. Ed. Ernest Benn, Londres, 1924.

Articles

"Sigurd Lewerentz." Arkitektur núm. 6, Estocolmo (1985).

Alenius, S, Björkhagen Kyrka med Rom som referens. Arkitektur núm. 6, Estocolmo 1985. Versión en español: En el Catalogo Sigurd Lewerentz de la Exposición en las Arquerías de los Nuevos Ministerios, Madrid 1987.

Alenius, Stefan. "Nel centenario di Sigurd Lewerentz." Casabella n ${ }^{\circ} 528$. (October, 1986): $42-51$.

Blundell Jones, Peter. "Sigurd Lewerentz: Church of St Peter, Klippan, 1963-66." Architectural Research Quarterly, 6 (2002): 159-173.

Campo-Ruiz, Ingrid. "From tradition to innovation: Lewerentz's designs of ritua spaces in Sweden, 1914-1966.” The Journal of Architecture 20.1 (2015): 73-91.

Campo-Ruiz, Ingrid. "Una aproximación a lo frágil: el kiosco de las flores de Sigurd Lewerentz, Diez Tesis en curso. Colección de Textos Académicos ETSAM-UPM, Ed. Mairea Libros, Madrid 2011.

Caruso, Adam. "Sigurd Lewerentz and a Material Basis for Form." OASE issue 45/46 (1997): 88-95.

Claes, Caldenby. "Basic Lewerentz. En Sigurd Lewerentz; two churches." Arkitektur Forlag (1997).

Claes, Caldenby. "El nórdico solitario: Sigurd Lewerentz." Quaderns núm. 169-170 (1986): 121-143

Constant, Caroline. "Il Cimitero Est di Malmö. La lenta scoperta del valore assolut della simplicità," Casabella no659, (Sepember, 1998): 40-44.

Jones, P. Blundell. "Revealing Details. Lewerentz at Klippan.” Spazio \& Società núm. $53(1991)$

Kacmar, Donna. "Ritual Spaces." Proceedings of the Art of Death and Dying Symposium. University of Houston (TX) Vol. 1. No. 1. (October, 2012): 25-27.

Loos, Adolf, "Architektur." in Ornamento y delito y otros escritos, 1910. translated by Lourdes Cirlot and Pau Pérez, 2nd edition, Barcelona: Gustavo Gili, 1980.

M. Brawne. "Monumental ambivalence.” Architects' Journal núm. 7, (1989).

Mansilla, Luís Moreno. "Mas alla del muro de Villa Adriana, El viaje de Lewerentz a Italia." Circo. n¹2 (1994)

Martínez Santa-María, Luís. "Un punto: el lugar de la memoria en algunos trabajos de Sigurd Lewerentz." Documents de Projectes d'Arquitectura, núm. 18 (2002): 14-19.

Torricelli, Carlotta. "La morte come passaggio. Sacro e arcaico nell'architettura di Sigurd Lewerentz." Ricerche e progetti per il territorio, la città e l'architettura. no. 4 (June 2012): 90-104
Wilson, Colin St John, and Edward Williams. "Sigurd Lewerentz," Architect's Journal. (2001).

\section{Doctoral Dissertation}

Carbonero, Marta García. "Espacio, paisaje y rito: formas de sacralización del territorio en el cementerio europeo del siglo xx." PhD diss., Universitad Politécnica de Madrid, 2011.

Fernández Elorza, Héctor. "Asplund versus Lewerentz." $\mathrm{PhD}$ diss., Universitad Politécnica de Madrid, 2014

Mansillia, Luis Moreno. "Apuentes de viaje al interior del tiempo." $\mathrm{PhD}$ diss., Universitad Politécnica de Madrid, 1998.

Petersson, Anna. "The presence of the absent. Memorials and places of ritual." Licentiate dissertation., University of Lund, 2004.

Quintanilla Chala, José Antonio. "SIGURD LEWERENTZ: 1885 1975. Una transición nórdica a la Arquitectura Moderna: Desplazamiento gradual hacia el dominio de lo táctil." PhD diss., Universitat Politècnica de Catalunya, 2004.

Santa-María, Luis Martínez. "El árbol, el camino, el estanque, ante la casa." PhD diss., Universitad Politécnica de Madrid, 2004.

\section{Exhibition}

"Lewerentz" Catálogo de Exposición, Milan 1987.

Sigurd Lewerentz, 1885-1975, Catálogo de la Exposición en Madrid del centenario de su nacimiento. Centro de Publicaciones del Ministerio de Obras Públicas y Urbanismo, Madrid 1987.

Sigurd Lewerentz, 1885-1975: The Dilemma of Classicism;[prod. to Accompany an Exhibition... of the Work of Architect Sigurd Lewerentz Held at the Architectural Association in London from 11 January to 11 February 1989]. Architectural

The Stockholm Exhibition 1930. Modernism s breakthrough in Swedish Architecture, Eva Rudberg. Ed. Stockolmia Forlag, Estocolmo, 1999.

\section{B.2.1. Specific Bibliography on Stockholm Woodland Cemetery}

Book

Constant, Caroline. The Woodland Cemetery: Toward a Spiritual Landscape: Erik Gunnar Asplund and Sigurd Lewerentz, 1915-61. Stockholm: Byggförlaget, 1994.

Johansson, Bengt OH. Tallum: Gunnar Asplund's \& Sigurd Lewerentz's Woodland Cemetery in Stockholm. Stockholm: Byggförlaget,1996.

Artículos

Cenicacelaya, Javier. "Paisaje y naturaleza en Sigurd Lewerentz." in Fabrikart (num. 7, 2011) 44-57.

Hart, Vaughan. "Sigurd Lewerentz and the'Half-Open Door." Architectural History (1996): 181-196.

Naya, Antonia María Pérez. "La muerte silenciada. Arquitectura funeraria 
contemporánea." Actas del Congreso Internacional de Arquitectura Religiosa Contemporánea. No. 2-II. 2013.

Spirn, Anne Whiston. "El lenguaje del paisaje: alfabetización, identidad, poesía y poder." Urban 5 (2013): 17-34

Treib, Marc. "Woodland-Cemetery, A Dialog Of Design And Meaning+ Illustrated Landscape By Lewerentz, Sigurd Hnd Asplund, Gunnar Sweden." Landscape Architecture 76.2 (1986): 42-49.

Crone, J. “The Woodland Cemetery.” Landscape Journal 14.2 (1995): 237-239.

\section{B.2.2. Specific Bibliography on Malmö Eastern Cemetery}

\section{Articles}

Anshelm, K. "Sigurd Lewerentz's last house." in Arkitektur no. 2, Estocolmo 1976 Mària Serrano, Magdalena. Arquitecturas sin fin. (2013).

Back Danielsson, Ing-Marie. "A rare analogy: Contemporary cremation practices." in On the Threshold. Burial Archaeology in the 21st Century. Edited by Back Danielsson, Gustin, Larsson, Myrberg and Thedéen, 2009.

Campo-Ruiz, Ingrid. “ ‘ Menos O Más? La Construcción Del Kiosco De Lewerentz En El Cementerio De Malmo/Less Or More? The Construction Of Lewerentz's Kiosk In The Malmo Cemetery." Proyecto, Progreso, Arquitectura 8 (2013): 132-147.

Campo-Ruiz, Ingrid. "Malmö Eastern Cemetery and Lewerentz's critical approach to monumentality." Studies in the History of Gardens \& Designed Landscapes. Vol. 35, no. 4 (2015): 328-344

Frediani Sarfati, Arturo. "Sigurd Lewerentz: el juego sabio, correcto y magnífico del habitante en el escenario." in DPA: Documents de Projectes d'Arquitectura (núm. 26, 2010), 43-51.

Malmö stadsteater. Estocolmo: Byggmästaren núm. 10, 1942.

Wingren, Carola. "Place-making strategies in multicultural Swedish cemeteries: the cases of 'Östra kyrkogården'in Malmö and Järva common.” Mortality 18.2 (2013): $151-172$.

\section{Doctoral Thesis}

Campo Ruiz, Ingrid. "Lewerentz en Malmo: Intersecciones entre arquitectura y paisaje." PhD diss., Universitad Politécnica de Madrid, 2015.

\section{B.3. Bibliography on Francesco Venezia}

Books:

Dal Co, Francesco, ed. Francesco Venezia e Pompei L'architettura come arte del porgere. Siracusa: LetteraVentidue Edizioni, 2015.

Francesco Venezia, Da Napoli a Venezia: 11 progetti per" Una porta per Venezia. Clean, 1992.

Francesco Venezia. Colegio Oficial de Arquitectos de Madrid, 1989
Martino, Paolo Di. Trentadue domande a Francesco Venezia. 2nd ed; Napoli: Clean,

Messina, Bruno, ed., Francesco Venezia Architetture In Sicilia 1980 - 1993. 2006. Published in conjunction with an exhibition of the name "Francesco Venezia Arquitecturas 1973-1993".

Nicolin, Pierluigi, ed. Quaderni di Lotus 2, Dopo il terremoto/After the earthquake. Milano: Electa, 1983.

Raventós González, Aquiles., and Claudio Vásquez Zaldívar. Due Case, Tre Edific Pubblici: La Arquitectura de Francesco Venezia. Santiago de Chile : ARQ, 1994.

Tafuri, Manfredo. History of Italian Architecture, 1944-1985. Translated by Jessica Levine. Cambridge: MIT Press, 1989.

Venezia, Francesco. Che cosa è l'architettura. Lezioni, conferenze e un intervento. Milano: Mondadori Electa, 2011.

Venezia, Francesco. Francesco Venezia. Introduced by Álvaro Siza. Barcelona: Editorial Gustavo Gili , S. A., 1988

Venezia, Francesco. Francesco Venezia: le idee e le occasioni. Milano: Mondadori Electa, 2006.

Venezia, Francesco. Scritti brevi 1975-1989. Napoli: Clean, 1990.

Venezia, Francesco., and José Ignacio Linazazoro, intro. Casa Malaparte. Cádiz: arquitectosdecádiz, 2001

Venezia, Francesco., and Manuel Serrano Marzo. Francesco Venezia. Madrid: Colegio Oficial de Arquitectos de Madrid, 1989. Exhibition catalog.

Articles

De la Mata, Sara. "Entrevista a Francesco Venezia." Rev. ARQUITECTURA n 281, $128-143$.

Doglioni, F. La reconstrucción de la Catedral de Venzone después del terremoto. Loggia, Arquitectura \& Restauración, 21 (2008): 76-93.

Giorgio Grassi, David Chipperfield, Francesco Venezia, Frank Gehry. "Museuminsel: la ampliación de los museos." AV: Monografías, $\mathrm{N}^{\circ}$ 50, (1994): 28-33.

Hidalgo Hermosilla, Germán. "El paisaje de la apariencia: una historia del paisaje a partir de una conferencia de John Ruskin." $D C$ : revista de crítica arquitectónica, núm. 1, (Sept. 1998).

Hidalgo, A. "Francesco Venezia: temas de arquitectura." Revista Arte Oficio, 4(4) (2012) Montaner, Josep Maria. La modernidad superada: arquitectura, arte y pensamiento del siglo XX. Gustavo Gili (1997).

Hidalgo, Aldo. "Figuras de la ruina." Revista Arte Oficio 2.2 (2012).

Hidalgo, Aldo. Observaciones sobre el espacio-vacío como anterioridad del Habitar. Revista Arte Oficio 9.9 (2012).

Venezia, Francesco. "21 febbraio 2012." Casabella, №. 814 (2012): 91

Venezia, Francesco. "La ley de la cantera: La metamorfosis y la metáfora de la piedra." Arquitectura Viva, $\mathrm{N}^{\circ} .113$ (2007): 25

Venezia, Francesco. "Progettare e 'insegnare: Designing and teaching." Domus, №. 


\section{1, (2014): 6}

\section{Research Thesi}

Morelli, Filippo. "Luce e materia, misura e natura Nell'architettura di francesco Venezia." Research thesis., Sapienza - Università di Roma, Ingegneria civile, edile e ambientale, 2013.

\section{Exhibition}

Francesco Venezia. Colegio Oficial de Arquitectos de Madrid, Madrid. Natura e Storia (1748-1943). Naples National Archaeological Museum, Naples. Pompei e l'Europa. Rapiti alla morte. I calchi, Pompeii Pyramid, Pompeii.

\section{B 3.1. Specific Bibliography on the Palazzo di Lorenzo (Gibellina Nuova Museum)}

\section{Books}

AA.VV. Gibellina utopia concreta, Federico Motta, Milano 1990

Nicolin, Pierluigi. "Gibellina: un centro storico per la città nuova." Quaderni di Lotus 2: Dopo il terremoto/After the earthquake. Milano: Electa, 1983.

Quaroni, Ludovico, et al. "Chiesa parrocchiale a Gibellina Nuova.” [s.1.]

\section{Article}

Ajroldi, Cesare. "Restauro del moderno: progetti a Gibellina." TERRITORIO (2012).

Muntañola i Thornberg, Josep, and Matías Córdoba Henríquez. Arquitectura: proyecto y uso. Edicions UPC (2003): 125-145.

Ortelli, Luca. "Architecture of walls. Francesco Venezia's Gibellina museum Architettura di muri. Il museo di Gibellina di Francesco Venezia." Lotus International 42.LCC- ARTICLE-1984-001 (1984).

Zunzunegui, Santos. "Metamorfosis de la mirada: museo y semiótica." Universitat de València, (2003):120-123.

\section{B.3.2. Specific Bibliography on the Open-air Theatre in Salemi.}

\section{Books}

Venezia, Francesco., and Mimmo Jodice. Salemi e il suo territorio. Milano: Electa, 1992

Baviera, Francesco Saverio. Memorie istoriche su la città di Salemi connesse con de rapidi tratti di storia siciliana. Stamp. di F. Spampinato, 1846.

\section{Doctoral Dissertation and}

Rodehiero, Bebdetta. "Permanenza e trasformazione in architettura. Gibellina e Salemi: città usate." Ph.D diss., Universitat Politècnica de Catalunya, 2008.
Books

Alvaro Siza Vieira, 1958-1994. el croquis N. 68/69. Madrid: 1994 Alvaro Siza: 1986-1995. Edited by Luiz Trigueiros. Lisbon: Lisboa Blau, 1995 Cianchetta Alessandra and Enrico Molteno. Álvaro Siza. Casas 1954-2004. Barcelona: Editorial Gustavo Gili, 2004.

Cruz, Valdemar. Álvaro Siza: Conversaciones con Valdemar Cruz. 2007.

Curtis, William. Álvaro Siza, Obras y proyectos. Santiago de compostela: Centro Gallego de Arte Contemporánea. 1995

Fleck, Brigitt. Alvaro Siza: Obras y Proyectos 1954-1992, Akal, Madrid, 1999. Siza, Álvaro. Imaginar la evidencia. Abada, 2003.

Frampton, Kenneth. "Poesis and transformation: The architecture of Alvaro Siza." Pierluigi Nicolin," Álvaro Siza: Poetic Profession". Rizzoli (1986): 10-23.

Frampton, Kenneth. Alvaro Siza: complete works. London: Phaidon, 2000 Frampton, Kenneth. Alvaro Siza: Obra completa, Barcelona: Gustavo Gili, 2000.

Moneo, Rafael, and Gina Cariño. Theoretical anxiety and design strategies in the work of eight contemporary architects. Cambridge: MIT Press, 2004.

Pessanha, Matilde. Siza: Lugares Sagrados - Monumentos. Porto: Campo das letras, 2003.

Rodríguez, Juan and Carlos Seoane. Siza X Siza. Barcelona: Fundación Caja de Arquitectos, 2015

Siza, Álvaro and Kenneth Frampton. Esquissos de viagem= Travel sketches. Porto: Porto Documentos de Arquitectura, 1988

Siza, Álvaro and Marc Dubois. Álvaro Siza, Inside the City. New York: Whitney Library of Design, 1998

Siza, Álvaro, 1958-2000. El Croquis.. núm. 68/69 + 95, 1985, Madrid Siza, Álvaro, and Aurora Cuito. Alvaro Siza. A. Asppan SL, 2001.

Siza, Álvaro, and Nuno Higino. Las ciudades de Álvaro Siza. Talis, 2001. Siza, Álvaro. En Blanco. núm. 1, TC Cuadernos, Valencia 2008.

Siza, Álvaro. Álvaro Siza: escrits. Edicions UPC, 1994. Siza, Álvaro. Textos. Abada, Madrid, 2014

Siza, Álvaro. City Sketches. Edited by Brigitte Fleck. Basel; Berlin; Boston: Birkhäuser, 1994.

Siza, Alvaro. Conversaciones con Valdemar Cruz. Barcelona: Editorial Gustavo Gili, 2007

Siza, Álvaro. Des mots de rien du tout: Palavras sem importância. PU Saint-Etienne, ed. 2002

Siza, Álvaro. Textos. Madrid: ABADA EDITORES, 2014

Siza, Álvaro. Writings on Architecture. Milan: Skira, 1997

Testa, Peter. The architecture of Alvaro Siza. Cambridge: MIT Press, 1984.

Vieira, Alvaro Siza, and Kenneth Frampton. Profesión poética: $=$ profissão poética Editorial Gustavo Gili, S.L.; Edición: 3. 1990 
Articles

"Entretien avec Alvaro Siza, Architecture, Mouvement, Continuite" (AMC), No. 44 (1978): 33-41

Zaera, Alejandro. Salvando las turbulencias: entrevista con Álvaro Siza. El Croquis, 68-69 (1994): 6-31

Levit, Robert A. "Language, sites and types: a consideration of the work of Álvaro Siza." The Journal of Architecture 1(3), (1996): 227-252.

Siza, Alvaro. Entrevista a Alvaro Siza. (2013).

Granero Martín, Francisco. "Conversando con Álvaro Siza. El dibujo como liberación del espíritu." EGA Expresión Gráfica Arquitectónica, n. 20 (Sep, 2012): 56-65.

Andrés, Fernado Moral. Condiciones continuas: dos apuntes sobre la obra y la ciudad de Alvaro Siza. Arte y Ciudad: Revista de Investigación 3 (2013): 799-818.

Navas, Adolfo Montejo. Entrevista a Alvaro Siza: La construcción del espacio. Lápiz. Revista internacional del arte 245 (2008): 46-63.

Waisman, Marina. El rigor poético de Álvaro Siza. Summarios 54 (1981): 206-209.

Bonastra, Quim. "Arte, arquitectura y docencia. Los espacios de libertad en el Cubo Blanco y la disciplina."Scripta Nova: revista electrónica de geografia y ciencias sociales 18 (2014)

Siza, Álvaro and Isabel Aguirre. "El mirador del horizonte: Restaurante de Santo Domingo de Bonaval, Santiago de Compostela, 1990." AV Monografias n.40 (mar 1993): 106-107.

Mota, Nelson. "Between Populism and Dogma: Álvaro Siza's Third Way." FOOTPRINT 5.1 (2011): 35-58.

\section{Doctoral dissertation}

Nuno Higino Pereira Teixeira. "Los dibujos de Álvaro Sizaanotaciones al margen." $\mathrm{PhD}$ diss., Universidad Complutense de Madrid, 2007.

Laura, Gallardo Frias. "Lugar/No-Lugar/Lugar en la Arquitectura Contemporánea." PhD diss., Universitad Politécnica de Madrid, 2012.

Peña Pereda, Felipe. "Dibujo y proyecto: del dibujo en el proceso de proyectar a través del estudio de dos obras de Alvaro Siza,el banco de Oliveira de Azemeis y el museo de Bonaval." PhD diss., Escola Tecnica Superior De Arquitectura Da Coruña, 2005

Da Cunha, Nuno Higinio Pereira Teixeira. "Los Dibujos De Álvaro Siza: Anotaciones al margen director: Julián Santos Guerrero. "PhD diss., Universidad Complutense de Madrid, 2007.

Escoda Pastor, Carmen. "El magnetismo del lugar en la arquitectura. Un análisis a través del dibujo de las diferentes estrategias de intervención en el paisaje a partir de la arquitectura del Movimiento Moderno." PhD diss., Universitat de Barcelona. Departament de Dibuix, 2007.

\section{Exhibitions}

Alvaro Siza escultura : el placer de trabajar. Fundacion ICO, Madrid, 1999

Alvaro Siza : obras y proyectos : [exposición] 24 abril-2 julio 1995, Centro Galego de Arte Contemporánea. Electa, Madrid, 1995
El chiado, Lisboa. Alvaro Siza y la estrategia de la memoria, Granada : Colegio Oficial de Arquitectos de Granada, 1994

Visiones para Madrid : cinco ideas arquitectónicas : Zaha Hadid, Mokko Heikkinem \& Markku Konomem, Hans Hollein, Alvaro Siza, Stanley Tigerman, Centro Cultural Conde Duque, 16 noviembre 1992-10 enero 1993.

\section{B.4.1. Specific Bibliography on Galicia Contemporary Art Center (CGAC)}

\section{Books}

Fernández, Xerardo Estévez. "Siza Vieira y el CGAC: Santiago de Compostela, veinte años de planeamiento y arquitectura." DC PAPERS, revista de crítica y teoría de la arquitectura 19 (2010): 57-66.

Álvaro Siza, arquitecto: Centro de Arte Contemporánea de Galicia. Xunta de Galicia, ed. 1993

Castanheira, Carlos y Pedro Llano, Alvaro Siza, Opere e Progetti, Santiago de Compostela y Milán. CGAC y Electa, 1995.

SIZA en Santiago. edited by Constructora SAN JOSE, S.A. ed. 1994

\section{Articles}

Parque de Santo Domingo de Bonaval, Santiago. Alvaro Siza e Isabel Aguirre. AV Monografías, n.51-52 (en.-abr. 1995):114-117.

Aguirre de Urcola, Isabel. "Parque de Santo Domingo de Bonaval." Cuadernos de arquitectura del paisaje, v.10 (2007): 22-36.

Tronconi, Maria Chiara. CGAC: un padiglione sul giardino $=C G A C$ : a pavilion over the garden.Lotus international, n.88 (1996): 72-91.

“Al aire libre." AV Monografias (Sept - Dic, 1999): 79-78

"Bienal de Paisaje, 1999." Barcelona Col-legi d'Arquitectes de Catalunya; Universitat Politècnica de Catalunya; Fundación Caja de Arquitectos, (2000): 207.

Isabel Aguirre, Parque de Santo Domingo de Bonaval. Cuadernos de arquitectura del paisaje, v. 10 (2007): 22-36.

Siza, Alvaro and Isabel Aguirre de Urcola. "Parque de San Domingos de Bonaval." Obradoiro: revista de arquitectura y urbanismo, n.23 (dec. 1994): 50-59

Imbrogiano, Federico, and Juan Rentero. Álvaro Siza Vieira: Desde el margen: $Y$ algunos comentarios sobre el CGAC. DC PAPERS, revista de crítica y teoría de la arquitectura 9 (2003): 73-82.

Martín, F. G. "Conversando Con Álvaro Siza. El dibujo como liberación del espíritu." EGA. Revista de expresión gráfica arquitectónica, 17(20) (2012): 56-65

\section{B.4.2. Specific Bibliography on the Porto School of Architecture}

Book

Carratalá, Luís, and Álvaro Siza. Álvaro Siza y la arquitectura universitaria. Universitat de València, 2003.

Siza, Álvaro. Edificio da Faculdade de Arquitectura da Universidade do Porto. Percursos do Projecto = The building of the Faculty of Architecture at Oporto 
University. Course of the Project. Porto: FAUP publicaçãoes, 2003

Siza, Álvaro. Edificio da Faculdade de Arquitectura da Universidade do Porto. 2003.

Caldas, Luisa, and João Rocha. A generative design system applied to Siza's school of architecture at Oporto. 2001

\section{Articles}

Araujo Fuster, Fernando. Efectos especiales en arquitectura, efectos espaciales en cine.(Un recorrido por Apocalypse Now y la Facultad de Arquitectura de Oporto). (2013): 189-201.

Siza, Alvaro. Oporto: pabellón de la Escuela de Arquitectura. Periferia: revista de arquitectura 4 (1985): 12-14

Fontana, María Pía, and Daniel de Castro. La Escuela de Oporto: teoría y práctica del proyecto. DEARQ: Revista de Arquitectura de la Universidad de los Andes 9 (2011): 152-167.

Caldas, Luisa, and João Rocha. A generative design system applied to Sizaís school of architecture at Oporto. (2001).

Testa, Peter. A Chimera In Porto, The Faculty-Of-Architecture+ Siza, Alvaro School In Portugal. Lotus International 88 (1996): 6-31.

Parque de San Domingos de Bonaval, Santiago de Compostela. Rehacer paisajes 19941999 : arquitectura del paisaje en Europa : catálogo de la $1^{\text {a }}$

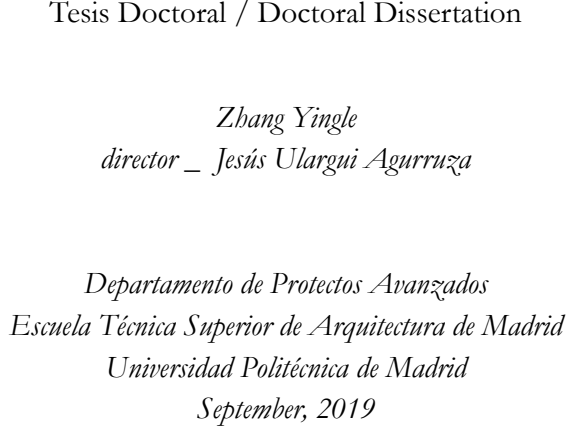

September, 2019
Saliténica de Madrid 